DOI:10.24275/uama.5813.7653

\author{
Universidad \\ Autónoma \\ Metropolitana \\ Casa abierta al tiempo Azcapotzalco

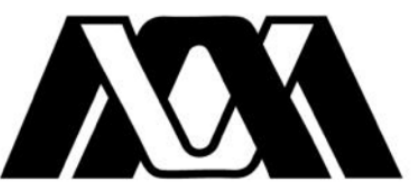 \\ DIVISIÓN DE CIENCIAS Y ARTES PARA EL DISEÑO \\ Especialización, Maestría y Doctorado en Diseño
}

\title{
NOMOLAS: GUÍAS DE USABILIDAD PARA EL DESARROLLO DE INTERFACES GRÁFICAS DE VISUALIZACIONES PARA INFORMACIÓN MÉDICA
}

\section{Mariel García Hernández}

Tesis para optar por el grado de Doctor en Diseño Posgrado en Diseño y Visualización de la Información

Miembros del Jurado:

Dr. Marco Antonio Marín Álvarez

Director de la tesis

Dra. Marcela Buitrón de la Torre

Dra. Cynthia Lizette Hurtado Espinosa

Dr. Gustavo Iván Garmendia Ramírez

Dr. Luis Carlos Herrera Gutiérrez de Velasco

Ciudad de México

julio de 2020 


\begin{abstract}
A mis padres;
por haberme impulsado

a ser eso que deseaba ser, pero sobre todo a mi papá, porque sin él nunca hubiera llegado hasta aquí.
\end{abstract}




\section{Agradecimientos}

A Ximena, por salvarme y ser mi motor en todo lo que hago; por su paciencia y amor, ya que sin éstos las noches que pase escribiendo y trabajando en esta tesis hubieran sido muy largas.

A mi papá, por quedarse con Ximena mientras yo tenía que ir a tomar clase a la ciudad de México. A Mariana, por ser como otra mamá para Ximena. A mi mamá que, aunque desde lejitos, me echaba porras y estaba pendiente a que regresara sana y salva a casa.

A Artu, por estar para mi siempre; por reírse de mis chistes sobre peleas con osos y porque antes de ser algo más, por ser mi mejor amigo.

A mi asesor, el Dr. Marco Marín Álvarez, por siempre confiar en mi y brindarme todo su apoyo.

Al Dr. Carlos Aceves González, a la Dra. Elvia González Muñoz, al Mtro. John Rey Alexander y a la Mtra. Fabiola Cortés Chávez, por haberme introducido al hermoso mundo de la ergonomía y recibirme como si fuera de la familia en Guadalajara.

Al Dr. Rodrigo Ramírez Ramírez por su apoyo durante las pruebas de usabilidad y a mi querida amiga y compañera de banca, la Mtra. Rebeca Méndez Escarza, por la compañía, los consejos y todo su apoyo con mi trabajo de investigación.

A Tommy, por ser siempre mi amigo fiel, a Alenca, por su inagotable energía, a Magenta, por su solidaria presencia hasta las 3 a.m., a Cyan y Yellow que, aunque ya no están, su amor sigue floreciendo en mi corazón.

A mis amigos, por ser mi segunda familia y estar siempre para mi mientras vivía esta aventura llamada doctorado.

A mi, por ser tan constante y enfocada en lo que me apasiona. 


\section{Resumen}

A lo largo del tiempo se han desarrollado diversos documentos y normas que establecen la forma en que las interfaces para visualizaciones de información médica deben ser diseñadas, como por ejemplo la norma ISO 9241-11 "Ergonomic requirements for office work with visual display terminal', la norma IEC TR 61997 "Guidelines for the user interfaces in multimedia equipment for general purpose use", el ISO/IEC "Information technology - user interface for mobile tools" o la norma ISO 13407 "Human-centred design processes for interactive systems", en donde se establecen lineamientos técnicos para el diseño de dichos artefactos. Sin embargo, desde el punto de vista del diseño de información y hasta la fecha de publicación de esta tesis, no han sido propuestas guías desde la usabilidad en el diseño mismo, es por eso por lo que la presente tesis doctoral tuvo como objetivo generar guías de usabilidad para el desarrollo de interfaces gráficas de visualizaciones de información médica.

El desarrollo de las guías de usabilidad propuestas en esta tesis tuvo como base investigaciones de autores como Nielsen, Frascara, Lonsdale \& Lonsdale y Cairo, quienes abordan lineamientos como el color, la estructura de la información, el texto, elementos gráficos y el usuario desde la perspectiva del diseño de información y la ergonomía cognitiva.

Las guías propuestas en esta tesis doctoral buscan que, al ser implementadas, el diseñador a cargo del desarrollo de interfaces genere artefactos usables, es decir, que sean eficientes (fáciles de leer), efectivos (fáciles de comprender) y satisfactorios (agradables estéticamente) para el usuario que interactuará con éstos. Para lograrlo se implementó una prueba de usabilidad, la cual estuvo dividida en dos fases; la primera buscaba validar la composición editorial de las guías y la segunda validar el contenido (en términos de información) de las mismas. 


\section{ÍNDICE}

\section{INTRODUCCIÓN}

$\begin{array}{ll}\text { Planteamiento del problema } & 1\end{array}$

Justificación 1

Objetivo general $\quad 3$

Objetivos particulares $\quad 4$

Hipótesis $\quad 4$

Preguntas de investigación $\quad 5$

$\begin{array}{ll}\text { Procedimiento } & 6\end{array}$

$\begin{array}{ll}\text { Resultados y aportaciones } & 7\end{array}$

\section{CAPÍTULO 1: LA VISUALIZACIÓN DE INFORMACIÓN}

1. La visualización de información $\quad 9$

1.1 Definición de información 9

$\begin{array}{ll}1.2 \text { Datos } & 11\end{array}$

1.3 Evolución de la visualización de información a través de la historia 15

1.3.1 Los primeros mapas y diagramas $(13,660 \mathrm{AC}-1375) \quad 16$

1.3.2 Teoría y la medida de la realidad $(1626-1686) \quad 22$

$\begin{array}{ll}\text { 1.3.3 Nuevas formas gráficas (1765 - 1889) } & 25\end{array}$

1.3.4 La era moderna de la visualización de Información (1901 - 2005) 29

1.4 Definiciones: la visualización de información.

1.5 La visualización de la información en el áera de la medicina 39

1.6 Figuras o técnicas de codificación en la visualización de información 43

1.6.1 Clasificaciones de técnicas de visualización de información de Alberto Cairo 44

1.6.2 Clasificaciones de técnicas de visualización de información de Ferdio 45

\section{CAPÍTULO 2: IMAGEN Y PERCEPCIÓN}

2. La imagen $\quad 50$

2.1 Percepción y percepción visual $\quad 52$

$\begin{array}{ll}2.2 \text { Variables visuales } & 61\end{array}$

$\begin{array}{ll}2.3 \text { Leyes de la Gestalt y la percepción visual } & 66\end{array}$

\section{CAPÍTULO 3: LA INTERFAZ GRÁFICA}

3. La interfaz gráfica $\quad 76$

3.1 Definición de interfaz gráfica $\quad 76$

$\begin{array}{ll}3.2 \text { Componentes de la interfaz gráfica } & 77\end{array}$

$\begin{array}{ll}\text { 3.3 Factores a considerar para el diseño de interfaces gráficas } & 86\end{array}$

CAPÍTULO 4: USABILIDAD Y ERGONOMÍA EN EL DISEÑO DE INTERFACES GRÁFICAS

4. Concepto de usabilidad $\quad 91$

4.1 Principios de usabilidad en el diseño $\quad 96$

4.2 Diseño para la usabilidad $\quad 98$

$\begin{array}{ll}4.3 \text { Ergonomía cognitiva } & 99\end{array}$ 
4.4 Métodos de evaluación de la usabilidad en las interfaces gráficas $\quad 107$

4.4.1 Métodos empíricos $\quad 111$

4.4.2 Métodos no empíricos 112

CAPÍTULO 5: NOMOLAS: GUÍAS DE USABILIDAD PARA EL DISEÑO DE INTERFACES GRÁFICAS DE SISTEMAS DE VISUALIZACIÓN DE INFORMACIÓN MÉDICA

5. NOMOLAS: Guías de usabilidad para el diseño de interfaces gráficas de sistemas de visualización de información médica $\quad 116$

5.1 Consideraciones generales $\quad 118$

$\begin{array}{ll}5.2 \text { Usuario } & 120\end{array}$

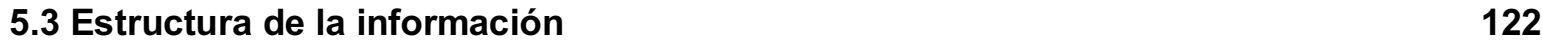

$\begin{array}{ll}5.4 \text { Texto } & 131\end{array}$

5.5 Color $\quad 148$

5.6 Elementos gráficos 156

CAPÍTULO 6: IMPLEMENTACIÓN DE LOS INSTRUMENTOS DE EVALUACIÓN

6.1 Primera etapa: evaluación de usabilidad de propuestas editoriales para las guías NOMOLAS

6.1.1 PARTE I - Lectura de la propuesta editorial y ejecución de tareas 168

6.1.2 PARTE II - Cuestionario PSSQU y Lista de Chequeo de Análisis de Tareas 171

6.1.3 PARTE III - RESULTADOS

6.1.4 Conclusión de la primera parte del método de evaluación 181

6.2 Segunda etapa: evaluación de usabilidad de información de las guías NOMOLAS 181

6.2.1 PARTE I - WORKSHOP - PRIMERA SESIÓN

6.2.2 PARTE II - WORKSHOP - SEGUNDA SESIÓN 186

6.2.3 PARTE III - RESULTADOS 188

6.2.3.1 Lista de chequeo de Análisis de Tareas (AdT) 190

6.2.3.2 Cuestionario PSSU $\quad 196$

6.2.4 Conclusión de la segunda parte del método de evaluación 200

CONCLUSIONES

Conclusiones $\quad 202$

$\begin{array}{lr}\text { Prospectiva } & 209\end{array}$

$\begin{array}{lr}\text { Bibliografía } & 212\end{array}$ 


\section{ÍNDICE DE IMÁGENES Y FIGURAS}

\section{CAPITULO 1: La visualización de información}

Imagen 1. Bloque de piedra encontrado en Abauntz, Navarra ......................... 17

Imagen 2. Mapa topográfico de una región cercana a la actual Turquía .............. 18

Imagen 3. Mapa mundial de Anaximandro ................................................... 19

Imagen 4. Primer mapa de ruta; rutas de caminos romanos ............................. 19

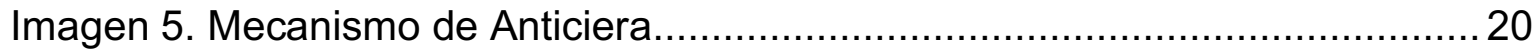

Imagen 6. Mecanismo de Ptolomeo ..................................................... 20

Imagen 7. Primera construcción gráfica; movimiento planetario..........................21

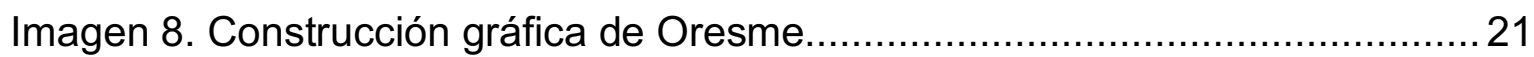

Imagen 9. Atlas mundial de Abraham Cresques.......................................... 22

Imagen 10. Secuencia visual de las manchas solares de Sheiner ...................... 23

Imagen 11. Primer mapa geomagnético de Le Nautoniers..................................24

Imagen 12. Primera representación de datos estadísticos .................................. 24

Imagen 13. Primer mapa de datos meteorológicos ........................................ 25

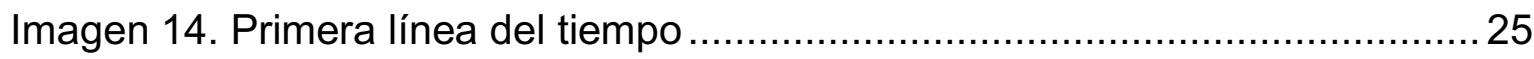

Imagen 15. Primer registro histórico de gráfico circulares, barras y series...........26

Imagen 16. Primer mapa de tiempo meteorológico …...................................... 26

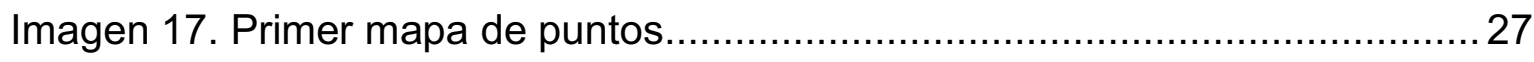

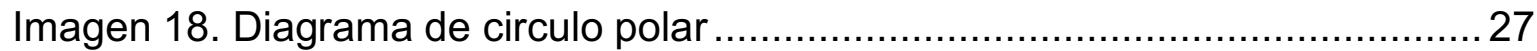

Imagen 19. Pictogramas de Mullhal.......................................................... 28

Imagen 20. Primer mapa con códigos de color.............................................. 28

Imagen 21. Primera propuesta de directivas de representaciones gráficas..........29

Imagen 22. Diagrama de Hetzprung-Rusell................................................... 30

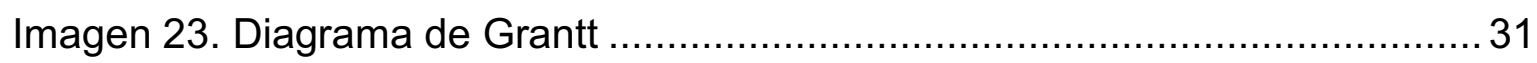

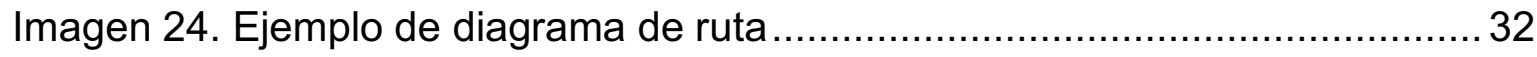

Imagen 25. Ejemplos del trabajo de ISOTYPE ................................................ 32

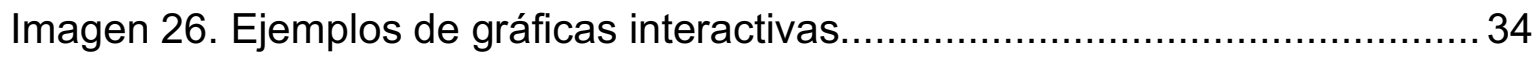

Imagen 27. Ejemplo de "moving bubble chart" ................................................. 34 
Figura 1. Relaciones entre las posturas de Ozdemir (2016), Floridi (2010) y Berin (1977) acerca del concepto de dato 15

Figura 2. Historia de la visualización de información: Los primeros mapas y diagramas ver en Anexo 1

Figura 3. Historia de la visualización de información: Teoría y medida de la realidad ver en Anexo 2

Figura 4. Historia de la visualización de información: Nuevas formas gráficas ver en Anexo 3

Figura 5. Historia de la visualización de información: La era moderna de la visualización de información ver en Anexo 4

Figura 6. Estructura de la visualización de información .43

Figura 5. Categorización de los sistemas de información.... 45

Figura 8. Métodos o categorías en la visualización de información. 48

\section{CAPITULO 2: Imagen y percepción}

Figura 1. Grado de iconicidad para la imagen fija-aislada 51

Figura 2. Percepción de información visual .56

Figura 3. Modelo del procesamiento perceptual de Colin Ware .58

Figura 4. Conjunto de números con diferentes codificaciones visuales .59

Figura 5. Características preatentivas 60

Figura 6. Variable visual: Posición. 62

Figura 7. Variable visual: Forma 63

Figura 8. Variable visual: Tamaño 63

Figura 9. Variable visual: Color 63

Figura 10. Variable visual: Tono o intensidad de color ... 64

Figura 11. Variable visual: Textura 64

Figura 12. Variable visual: Orientación. .65

Figura 13. Variables visuales. 66

Figura 14. Leyes de la Gestalt. 66

Figura 15. Ley de la Gestalt: Proximidad 68

Figura 16. Ley de la Gestalt: Proximidad. 69 


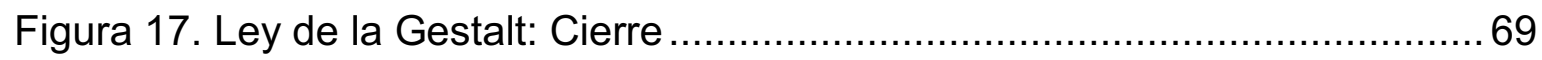

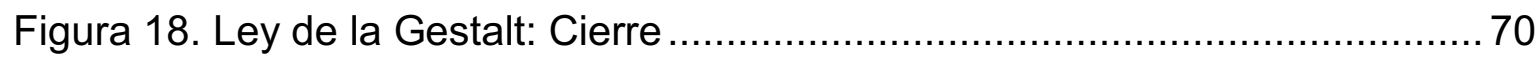

Figura 19. Ley de la Gestalt: Semejanza.................................................... 71

Figura 20. Ley de la Gestalt: Buena continuidad .......................................... 71

Figura 21. Ley de la Gestalt: Destino común .................................................. 72

Figura 22. Ley de la Gestalt: Segregación entre figura y fondo ...........................72

Figura 23. Ley de la Gestalt: Segregación entre figura y fondo .......................... 73

Figura 24. Ley de la Gestalt: Segregación entre figura y fondo ...........................74

\section{CAPITULO 3: La interfaz gráfica}

Figura 1. Elementos visuales que componen a la interfaz gráfica ......................78

Figura 2. Elementos visuales que componen a la interfaz gráfica II ...................80

Figura 3. Niveles del lenguaje en relación con la forma de presentación de

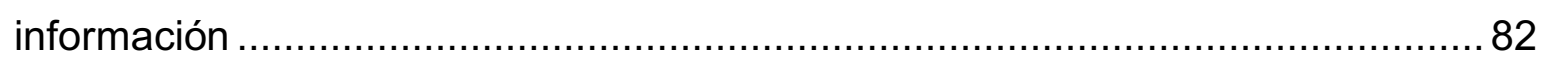

Figura 4. El usuario como ser independiente y como eje importante en la toma de

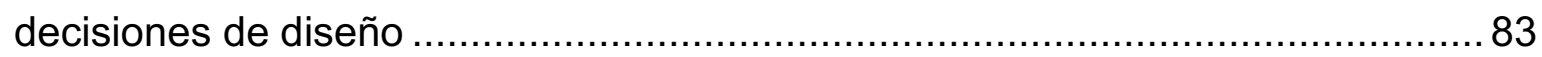

Figura 5. Elementos que constituyen a la interfaz gráfica ................................. 84

Figura 6. Elementos para el desarrollo de interfaces gráficas .............................86

Figura 7. Características de usabilidad que debe cubrir la interfaz en correlación con

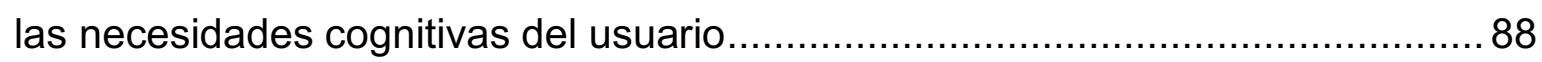

\section{CAPITULO 4: Usabilidad y ergonomía cognitiva en el diseño de interfaces gráficas}

Figura 1. Componentes de calidad que forman parte de la usabilidad de acuerdo a Nielsen .93

Figura 2. Componentes de calidad que forman parte de la usabilidad de acuerdo a

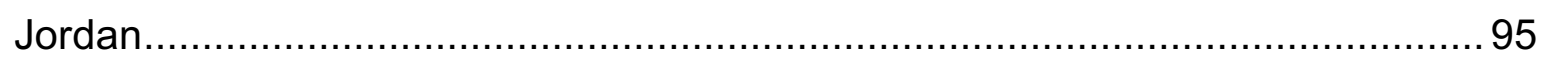

Figura 3. Principio de usabilidad en el diseño de interfaces ...............................98

Figura 4. Necesidades del usuario con respecto a soportes de información según

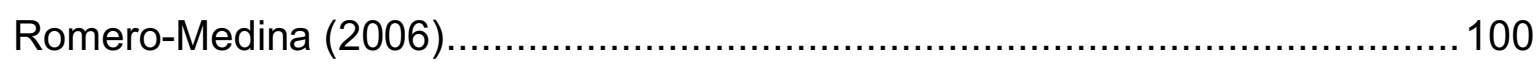


Figura 5. Marco de referencia de la ergonomía cognitiva de acuerdo a Cañas \&

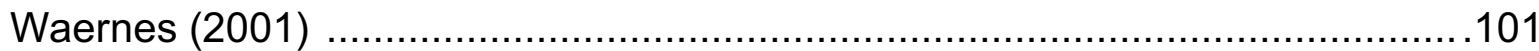

Figura 6. Modelo cognitivo general según Cañas \& Wearns ...........................102

Figura 7. Aspectos que los modelos deben considerar a la hora de explicar la

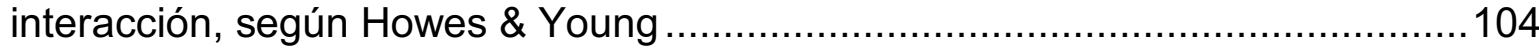

Figura 8. Parte de un plan de evaluación de usabilidad, de acuerdo a Rubin \& Chisnell 110

\section{CAPITULO 5: Guías de usabilidad para el diseño de interfaces gráficas de sistemas de visualización de información médica}

Figura 1. Puntos que abarca el presente trabajo de investigación .....................117

Figura 2. Consideraciones para definir el perfil del usuario ..............................122

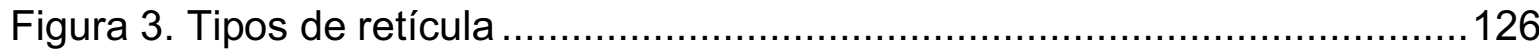

Figura 4. Tipografías recomendadas por Nielsen \& Loranger ..........................132

Figura 5. Ejemplos de tipos de letra con características inusuales.....................133

Figura 6. Espacio interlineal recomendado por Götz ......................................133

Figura 7. Ejemplo de una "viuda" en una caja de texto.....................................134

Figura 8. Ejemplo del uso de la variable "negrita" y la variable "cursiva" .............135

Figura 9. El uso de la variable "cursiva" atrasa la lectura de bloques de texto largos 135

Figura 10. El uso de la variable "negrita" en todo el texto no logra enfatizar nada del

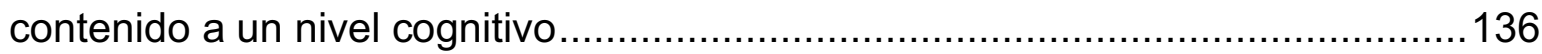

Figura 11. Ejemplo del mal uso de varias tipografías en un bloque de texto .......137

Figura 12. Ejemplo de tipografía sans serif y serif .........................................137

Figura 13. Tamaño de puntaje recomendado de acuerdo a la audiencia ............138

Figura 14. La tipografía no debe ser demasiado fina ni condensada ..................138

Figura 15. Contraste de peso tipográfico entre título, subtítulo y texto ............... 140

Figura 16. Uso de etiquetas para ayudar al usuario a identificar y distinguir información 
Figura 17. Se debe evitar el uso de etiquetas que se extiendan más allá de la tabla 142

Figura 18. Ejemplo de buen y mal contraste entre el texto y el color de fondo de la interfaz. 144

Figura 19. Ejemplos de justificaciones de contenido a partir de la cantidad del texto 144

Figura 20. Ejemplos de tamaños de interletrados mal empleados 145

Figura 21. Ejemplo de "ríos" en el texto. 145

Figura 22. Ejemplos de jerarquía tipográfica a través de fuentes serif y sans serif 147

Figura 23. Uso del color para codificación de información en dispositivos médicos, según the Human Engineering Committee of the Association for the Advancemente of Medical Instrumentation (AAMI). 149

Figura 24. Color y sus significados, según Götz 149

Figura 25. Es recomendable elegir un buen contraste entre texto, el color y el fondo 150

Figura 26. Ejemplo de fondo de color que no genera "ruido" y tiene buen contraste con demás elementos. 150 Figura 27. Nivel de legibilidad de diferentes combinaciones de colores por Nielsen

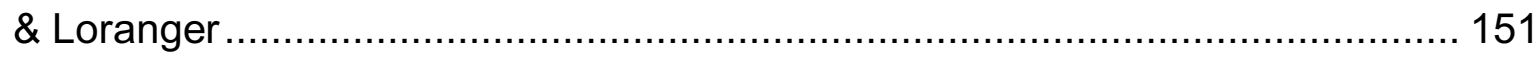

Figura 28. Ejemplo de consistencia de color entre elementos gráficos ............. 152 Figura 29. Ejemplo del mal uso del efecto de gradiente como fondo 153

Figura 30. Círculo cromático; colores complementarios, análogos y adyacentes 155

Figura 31. Uso de pictogramas para englobar connotaciones de conceptos .... 158

Figura 32. El uso de flechas y líneas crean un recorrido visual para el lector .... 159 Figura 33. Ejemplo de uso de etiquetas para hacer aclaraciones sobre elementos gráficos presentados 159

Figura 34. Ejemplo de uso de etiquetas para hacer aclaraciones sobre elementos gráficos presentados 160

Figura 35. Criterios de elección para figuras de visualización de información.... 163 
Figura 36. Métodos o categorías de codificación en la visualización de información 165

\section{CAPITULO 6: Implementación de los elementos de evaluación}

Figura 1. Etapas del método de evaluación de las guías NOMOLAS................ 167

Figura 2. Primera etapa del método de evaluación las guías NOMOLAS ......... 168

Figura 3. FASE 1: Parte I - Lectura de la propuesta editorial y ejecución de tarea 171

Figura 4. FASE 1: Parte II - Cuestionario PSSUQ y Lista de chequeo de análisis de tareas.

Figura 5. Relación entre variables e instrumentos de evaluación de la FASE 1. 174

Figura 6. Resultados. Efectiva: 1) El diseñador generó una paleta de color de cuatro colores 175

Figura 7. Resultados. Efectiva: 2) El diseñador relacionó correctamente los lineamientos de codificación de información en dispositivos médicos y los aplicó en las secciones de la gráfica de acuerdo a su significado

Figura 8. Resultados. Efectiva: 3) El diseñador estableció un buen contraste entre fondo, figura y texto 176

Figura 9. Resultados. Efectiva: 4) Veces que volvió a consultar la página el diseñador. 176

Figura 10. Resultados. Efectiva: 5) La organización de la información me fue clara

Figura 11. Resultados. Efectiva: 6) Fui capaz de completar las tareas que se me indicaron rápidamente con la información proporcionada en las guías 177 Figura 12. Resultados. Efectiva: 7) La información proporcionada por las guías fue fácil de entender 178

Figura 13. Resultados. Eficiente: 8) Tiempo en que tardó en leer la página el diseñador (segundos). 179

Figura 14. Resultados. Eficiente: 9) Tiempo en que tardó en completar la tarea el diseñador (minutos). 
Figura 15. Resultados. Satisfacción: 10) La apariencia de las guías es agradable 180

Figura 16. Resultados. Satisfacción: 11) En general, estoy satisfecho con el acomodo y presentación visual de la información 180

Figura 17. Segunda etapa del método de validación de las guías NOMOLAS... 183

Figura 18. FASE 2: Parte I - Workshop - Primera sesión................................ 186

Figura 19. FASE 2: Parte II - Workshop - Segunda sesión .............................. 187

Figura 20. FASE 2: Parte III - Lista de chequeo de análisis de tareas............... 188

Figura 21. Relación entre variables e instrumentos de evaluación de FASE 1 .. 189

Figura 22. Relación entre secciones y número de reactivos de cada sección de la lista de chequeo del Análisis de Tareas (AdT) .............................................. 191

Figura 23. Resultados de la lista de Análisis de Tareas, sección "Usuario" ....... 192 Figura 24. Resultados de la lista de Análisis de Tareas, sección "Estructura de la información" 192

Figura 25. Resultados de la lista de Análisis de Tareas, sección "Tipografía”.... 192

Figura 26. Resultados de la lista de Análisis de Tareas, sección "Color" 193

Figura 27. Resultados de la lista de Análisis de Tareas, sección "Elementos gráficos" 193

Figura 28. Tabla de resultados (puntuación) por usuario de la lista de chequeo del Análisis de Tareas (AdT) 193

Figura 29. Porcentaje del total de aciertos de los usuarios en la lista de chequeo del Análisis de Tareas (AdT) 194

Figura 30. Porcentaje del total de aciertos en cada sección de la lista de chequeo del Análisis de Tareas (AdT) por el total de los usuarios de la prueba ............... 195 Figura 31. Relación de las variables "efectividad", "eficiencia" y "satisfacción" con los reactivos del cuestionario PSSUQ 196

Figura 32. Tabla de resultados (puntuación por usuario) del cuestionario PSSUQ 197

Figura 33. Resultados de la premisa "la organización de la información proporcionada por las guías me fue clara" del cuestionario PSSUQ. 197 
Figura 34. Resultados de la premisa "Fui capaz de completar la tarea que se indicó rápidamente con la información proporcionada en las guías" del cuestionario PSSUQ 198

Figuras 35. Resultados de la premisa "La información proporcionada por las guías fue fácil de entender" del cuestionario PSSUQ. 199 Figura 36. Resultados de la premisa "La apariencia de las guías me es agradable" del cuestionario PSSUQ 199

Figura 37. Resultados de la premisa "En general, estoy satisfecho con el acomodo y presentación visual de la información" del cuestionario PSSUQ 200

\section{CONCLUSIONES}

Figura 1. Normas ISO que se analizaron en este trabajo de investigación 203 


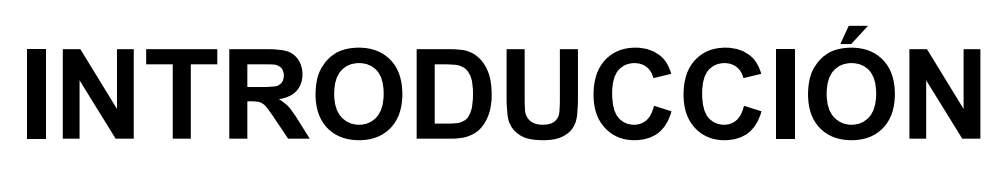




\section{Planteamiento del problema}

En este aparatado presentamos lineamientos teóricos que dan pauta a la base de esta tesis doctoral; exponemos diversos conceptos que describen la índole del quehacer de investigación.

a. Justificación

En las últimas décadas, la visualización de información, de acuerdo a lo que establece Card (1999) ha resultado ser una herramienta que ayuda al reconocimiento de estructuras, patrones, relaciones y tendencias entre un conjunto de datos, ampliando la cognición y entendimiento de dicha información. Podemos fundamentar, a partir de lo descrito con anterioridad, que la visualización de información ayuda al lector a tomar decisiones más rápidas y fáciles, a través del reconocimiento de valores y patrones visuales, como color, forma, estructura, etc. Por lo tanto, la visualización de la información puede contribuir en la toma de decisiones en cualquier rama de investigación en que se emplee.

Existe una diversa extensión de literatura que aborda el desarrollo de artefactos de visualización de información, como los ISO y demás normas internacionales, como en el diseño de pantallas de visualización, puestos de trabajo, dispositivos médicos e interfaces gráficas de usuario. Sin embargo, desde el ámbito del diseño de información, la usabilidad y la 
ergonomía cognitiva, la visualización de información no ha sido explorada del todo en el ámbito de la medicina.

Se realizó una revisión de las siguientes normas e ISO para determinar la viabilidad del problema que busca resolver la presente tesis doctoral, dichos documentos fueron los siguientes:

a) ISO 9241-11 "Ergonomic requirements for office work with visual display terminal": Esta norma contiene recomendaciones que buscan lograr la eficacia, eficiencia y satisfacción en los usuarios que interactúen con pantallas de visualización.

b) IEC TR 61997 "Guidelines for the user interfaces in multimedia equipment for general purpose use": Guías de diseño que se usan para una selección detallada de los medios de comunicación, interfaces de usuario mecánicas, gráficas y auditivas.

c) ISO/IEC "Information technology - user interface for mobile tools": Esta norma ISO contiene los requerimientos de la interface de usuario para PDA.

d) ISO 13407 "Human-centred design processes for interactive systems": Este ISO tiene como objetivo ser una guía para el desarrollo de interfaces de usuario según los requerimientos de éste. 
A partir de lo anterior, podemos establecer que el problema de investigación de esta tesis doctoral consistió en que desafortunadamente, hasta el momento en que se desarrolló la misma, no se ha abordado de manera directa el desarrollo de guías de usabilidad para diseño de interfaces gráficas que den pauta al desarrollo de sistemas de visualización de información médica desde el punto de vista del diseño de información y la ergonomía cognitiva y, por lo tanto, aseguren la usabilidad de la información que representan.

b. Objetivo general

El objetivo principal de esta tesis doctoral fue el desarrollo de una propuesta de guías de usabilidad para el diseño de interfaces gráficas de visualización de información médica.

Cuando hablamos de usabilidad, conforme a lo que plantea Nielsen (2012) nos referimos de lo fácil que es utilizar un artefacto, por otra parte, Jordan (2001) define a la usabilidad como una propiedad que engloba tres variables; eficiente (que la pieza de diseño sea rápida de leer), efectiva (que la pieza de diseño fácil de comprender) y satisfactoria (que la pieza sea agradable estéticamente).

Tomando en cuenta la postura de Jordan (2001), las guías de usabilidad que se presentan en esta tesis doctoral buscan trabajar con base a las variables previamente mencionadas. 
c. Objetivos particulares

a) Revisar normas e ISO en donde se aborde el tema de desarrollo de interfaces gráficas.

b) Hacer una compilación de lineamientos teóricos y conceptuales de autores que trabajaran la usabilidad, el diseño de información y la ergonomía cognitiva dentro del tema de diseño de interfaces gráficas y visualización de información médica para generar las guías de usabilidad.

c) Valorar el grado de usabilidad (eficiencia, efectividad y satisfacción), en relación con la composición visual (diseño) de las guías.

d) Valorar el grado de usabilidad (eficiencia, efectividad y satisfacción), en relación con el contenido (información) de las guías.

d. Hipótesis

La hipótesis que se planteó en esta tesis doctoral señala lo siguiente: a partir del desarrollo y la implementación de guías de usabilidad para el diseño de interfaces gráficas de visualización de información médica, se podrán generar artefactos ${ }^{1}$ de esta índole que sean usables (eficientes, efectivos y satisfactorios) para su usuario.

\footnotetext{
${ }^{1}$ Para Frascara (2011) cuando se habla de artefactos el autor se refiere a piezas de diseño como libros, revistas,
} folletos, infografías, material didáctico, entre otros. 
Todo esto con la finalidad de que quienes trabajen con este tipo de artefactos tengan los lineamientos teóricos y técnicos de cómo diseñar interfaces gráficas de visualización de información usables para el usuario final.

e. Preguntas de investigación

Las preguntas de investigación se dividieron en dos grupos; el primero corresponde al contenido de las guías en términos de la información y el otro a la usabilidad de dicho documento.

a) Propuestas de las guías de usabilidad

1) ¿De qué manera deben ser estructuradas las guías de usabilidad?

2) ¿Qué lineamientos conceptuales de diseño de información debe contemplar el desarrollo de esta propuesta de guías?

3) ¿Qué conceptos de usabilidad debe contener dichas guías?

4) ¿Cómo debe presentarse la información para que sea eficiente, efectiva y satisfactoria?

b) Usabilidad de las guías

1) ¿A qué nos referimos cuando hablamos usabilidad en interfaces gráficas de sistemas de visualización de información médica? 
2) ¿De qué manera se logrará que estas guías ayuden a establecer usabilidad de los artefactos de diseño a desarrollar?

3) ¿Qué tipo de instrumento se debe utilizar para poder medir el grado de usabilidad de estas guías de diseño?

\section{f. Procedimiento}

Después de haber establecido el planteamiento del problema, la justificación y los objetivos de esta tesis doctoral se determinó definir a este trabajo como una investigación exploratoria, ya que el tema que se aborda en este escrito no ha sido concluyente hasta el día de hoy, según definen a este tipo de investigaciones Hernández, et al. (2010), ya que como señala el autor, este tipo de investigaciones se realizan con el objetivo de examinar un tema o problema poco estudiado del cual se tiene muchas dudas o no se ha abordado antes. Es decir, cuando la revisión de literatura reveló que solo existen (...) ideas vagas relacionadas con el tema o bien si se desea indagar sobre temas y áreas desde nuevas perspectivas, Hernández et. Al (2010).

Así mismo, el enfoque que tuvo la presente tesis doctoral fue de carácter de enfoque mixto, ya que durante la implementación del instrumento de evaluación posteriormente descrito en el capítulo de "Estrategia de validación", se trabajó tanto con datos cuantitativos como cualitativos. 
Por último, se utilizó como método la teoría fundamentada, ya que de acuerdo a Glaser (1992), es definida como una metodología de análisis y recolección de datos a partir de teorías ya existentes, en el caso de esta tesis, se analizaron posturas como la de Bertin (1983), Prado-León \& Ávila-Chaurand (2003), Lonsdale and Lonsdale (2019), Nielsen \& Loranger (2006), Jordan (2001), entre otros estudiosos del diseño de información, la ergonomía y la usabilidad.

Posteriormente a ello, al tener un enfoque mixto, se implementó un experimento puro, el cual consistió en dos fases:

1) En la primera fase se eligió la propuesta editorial en la cual se iba a presentar las guías. Para ello se realizó una prueba de usabilidad, en la cual se utilizó la herramienta análisis de tareas, chequeo de análisis de tareas y el cuestionario PSSUQ².

2) Al tener ya la propuesta editorial de las guías de usabilidad en la cual se presentarían ante su usuario (lector), se prosiguió a dar inicio a la segunda fase. Ésta consistió en la validación de la información (contenido) de las guías de usabilidad. Las herramientas que se emplearon en esta fase fue un workshop, el

\footnotetext{
${ }^{2}$ El cuestionario PSSUQ, de acuerdo a Carlos-Gómez (2006), es un instrumento de evaluación que sirve para recoger respuesta inmediata del usuario después de una tarea en una prueba de usabilidad
} 
análisis de tareas, chequeo de análisis de tareas y el cuestionario PSSUQ.

\section{g. Resultados y aportaciones}

En esta tesis doctoral se propone un bosquejo de la historia de la visualización de información dividida en cuatro etapas; los primeros mapas y diagramas $(13,660 \mathrm{AC}-1375)$, teoría y la medida de la realidad (1626 - 1686), nuevas formas gráficas (1765 - 1889), la era moderna de la visualización de Información (1901 - 2005).

Así mismo, se presenta una taxonomía de clasificación de las figuras de visualización de información, las cuales se dividieron en las categorías de: comparación, visualización de conceptos, correlación o de patrones, distribución, datos geográficos, parte del todo, tendencia a través del tiempo, jerarquía, procesos y métodos, funcionamiento de las cosas, movimiento y flujo, rango y herramientas de referencia.

Del mismo modo, en esta tesis doctoral encontramos una taxonomía de las variables visuales dentro de la visualización de información: posición, forma, tamaño, color, valor o intensidad, textura y orientación.

Otra aportación que se hace mediante este trabajo es una propuesta de la estructura formal que debería tener una interfaz gráfica; texto, color, elementos gráficos y estructura de información. 
Así como también, se hace un recuento y clasificación de los diversos métodos de validación que se pueden emplear para conocer el grado de usabilidad de las interfaces gráficas.

De igual forma, otra valiosa aportación de esta tesis doctoral, son las guías de usabilidad para el diseño de interfaces gráficas de visualización de información médica desde la óptica de la ergonomía cognitiva, la usabilidad y el diseño de información. 


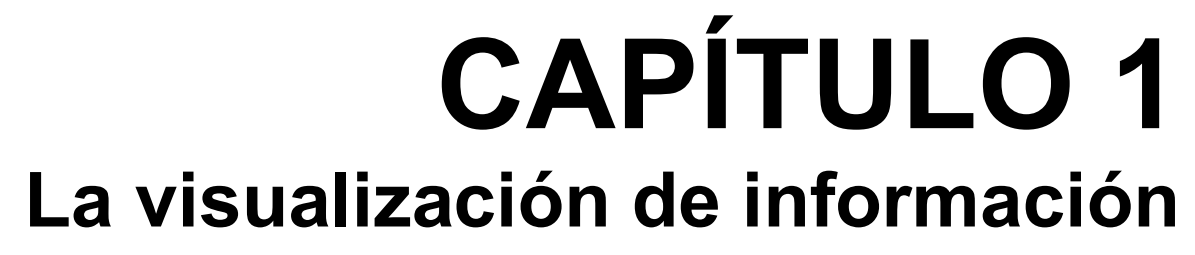




\section{La visualización de información.}

La visualización de información encuentra su quehacer en el reconocimiento de patrones y relaciones a través de representaciones gráficas. Esta disciplina toma fuerza dentro de diferentes ámbitos del ecosistema de la investigación y las ciencias; dicha herramienta busca facilitar la lectura de información y a su vez, la toma de decisiones con base a ésta.

Para iniciar con este capítulo, es importante destacar aspectos y conceptos básicos acerca de la visualización de información, para posteriormente, dar paso al desarrollo de esta tesis doctoral en sí.

\subsection{Definición de información}

De acuerdo a lo que plantea Sunik (2011:14), la información es definida como "la característica que se manifiesta en las relaciones entre ciertas entidades del mundo real". Por otra parte, Madden (2000:343), establece que cuando hablamos de información nos referimos "al hecho o circunstancia de algo que se es dicho". Otra

definición que es importante conocer es la que hace Brookes (1980) en su libro The foundations of information science, acerca de la información, en donde el autor argumenta que la información es una pequeña parte de la estructura del conocimiento que puede modificar la organización de ese mismo conocimiento. 
McCreadle y Rice (1999) plantean en el documento, Trends in analyzing access to information. Part 1: cross-disciplinary conceptualizations of access, una clasificación en cuanto a la información desde diferentes ópticas:

- Información como representación del conocimiento. Retomando la definición que hace Brookes (1980:127), "la información forma parte del conocimiento en sí. La información está almacenada dentro de éste y da forma a eso que se quiere transmitir a partir del conocimiento".

- Información como datos en el entorno. La información puede obtenerse a partir de una gama de fenómenos del propio entorno.

- Información como parte del proceso de comunicación. El tiempo y los factores sociales juegan un papel importante en el procesamiento e interpretación de la información, es aquí donde la información es interpretada a partir de la propia experiencia y creencia del receptor dentro del proceso de comunicación.

Podemos definir a la información como la base de la estructura del conocimiento, la cual es construida a partir del propio medio y entorno del cual ésta es obtenida. Esta base es interpretada y contextualizada a través de experiencias, creencias y constructos conceptuales previos de aquellos que interactúen con ésta, y transformada a su vez, en el propio conocimiento. 


\subsection{Datos}

La información, de acuerdo a lo que plantea Rowley (2007) en su libro The wisdom hierarchy: representations of the DIKW hierarchy se define en términos de datos, ya que la misma se conforma de estas pequeñas unidades de conocimiento. La información hace que los datos tengan valor y sentido, según argumenta Shannon (1948), en su libro A mathematical theory of communication, ya que estos pasan por medio de un proceso de abstracción, llamado comprensión, el cual trata de la eliminación de datos redundantes y deja aquella información tiene "sentido" y elimina la incertidumbre generada por la dispersión de dichos datos.

Los datos son definidos por Valero-Sancho, Catalá-Domínguez y Marín Ochoa (2014:489), como "representaciones referentes a atributos o variables cuantificados por las tomas de muestras y su posterior transformación alfanumérica o visual de un asunto significativo de un acontecimiento, acción o cosa". Los datos, de acuerdo con los mismos autores, "son registros codificados de observaciones de la realidad, son anotaciones convencionales sobre lo que se detecta en el estudio de los fenómenos que ocurren en ella". Ozdemir (2016) en el libro Principles of Data Science, define a los datos como un conjunto de información en formato organizado o desorganizado. Por otra parte, Weik (2000) en Computer Science and Communications Dictionary establece que los datos son una descripción que define el contenido de la información y las características de dicha información como puede ser un campo, un registro o un archivo. 
Los datos son unidades de información que representan cierta parte de alguna realidad o hecho, dichas unidades, pueden clasificarse, conforme a lo que establece Ozdemir (2016) en Principles of Data Science:

- Datos estructurados. Son datos que pueden considerarse observaciones y características. Normalmente se les puede encontrar en tablas (filas y columnas). Como ejemplo, registros científicos, tablas alfanuméricas, resultados de experimentos, etc. Este tipo de datos, de acuerdo con el autor, son más fáciles de analizar.

- Datos no estructurados. Coexisten como entidades libres que no siguen ni presentan ningún tipo de organización estándar. Un buen ejemplo de datos no estructurados pueden ser registros de cualquier servidor, publicaciones de Facebook, tweets, etc. El $90 \%$ de los datos del mundo no están estructurados, de acuerdo con el autor, por lo cual esto implica que la mayoría de la información mundial existe en un formato complicado y complejo de analizar.

- Datos cuantitativos. Esta tipología de datos puede describirse utilizando números y con procedimientos matemáticos básicos, incluida la suma. Un ejemplo de datos cuantitativos puede ser el número de clientes que frecuentan una cafetería, porcentaje de deceso anual por alguna enfermedad, etc. 
- Datos cualitativos. Este tipo de datos no pueden describirse utilizando números y matemáticas básicas. Por lo general, se piensa que estos datos se describen utilizando categorías e idiomas "naturales". Podemos ejemplificar como datos cualitativos como las emociones presentadas durante un experimento acerca de la creencia de cierto objeto, así como también, las características de ciertos arquetipos encontrados en una cultura en particular, etc.

Otra clasificación que resulta interesante mencionar es la que hace Floridi (2010), en donde el autor propone la siguiente estructura:

- Datos primarios. Los datos primarios según Floridi (2010:29), "son aquellos datos que se encuentran almacenados dentro de bases de datos que son considerados relacionales, como son por ejemplo los datos de un sistema de gestión de información".

- Datos secundarios. De acuerdo con el autor, "estos son contrarios a los datos primarios, cuando estos últimos están ausentes".

- Metadatos. Este tipo de datos "son indicaciones sobre la naturaleza de otros datos (usualmente sobre los datos primarios)", de acuerdo al autor.

- Datos operativos. Se argumenta que este tipo de datos son aquellos que están "relacionados con las operaciones de un sistema de datos en su conjunto y su desempeño". 
- Datos derivados. El autor menciona que estos datos "pueden extraerse de otros datos, siempre que se usen como fuentes indirectas en busca de patrones, pistas o evidencias que infieran sobre los datos en sí mismos.

Por su parte Bertin (1977) en el libro La graphique et le traitement graphique de l'information, sugiere dos formas fundamentales para generar una clasificación de datos: valores de datos y estructuras de datos. Una idea similar es dividir datos en entidades y relaciones.

- Entidades: Son los objetos que deseamos visualizar, los entes del interés propio. Las entidades, pueden ser las personas mismas, una raza de perros en particular, un fenómeno meteorológico, etc.

- Relaciones: Las relaciones definen las estructuras y patrones que dependen de las entidades, éstas pueden ser estructurales y físicas, como por ejemplo la forma de un edificio o de un automóvil. También estas relaciones pueden ser perceptuales, un buen ejemplo de éstas puede ser la correspondencia que hay entre una marca y sus consumidores. Las relaciones son vínculos que se proporcionan explícitamente; a veces descubrir las relaciones es el verdadero propósito de la visualización, de acuerdo a lo que establece el autor. 


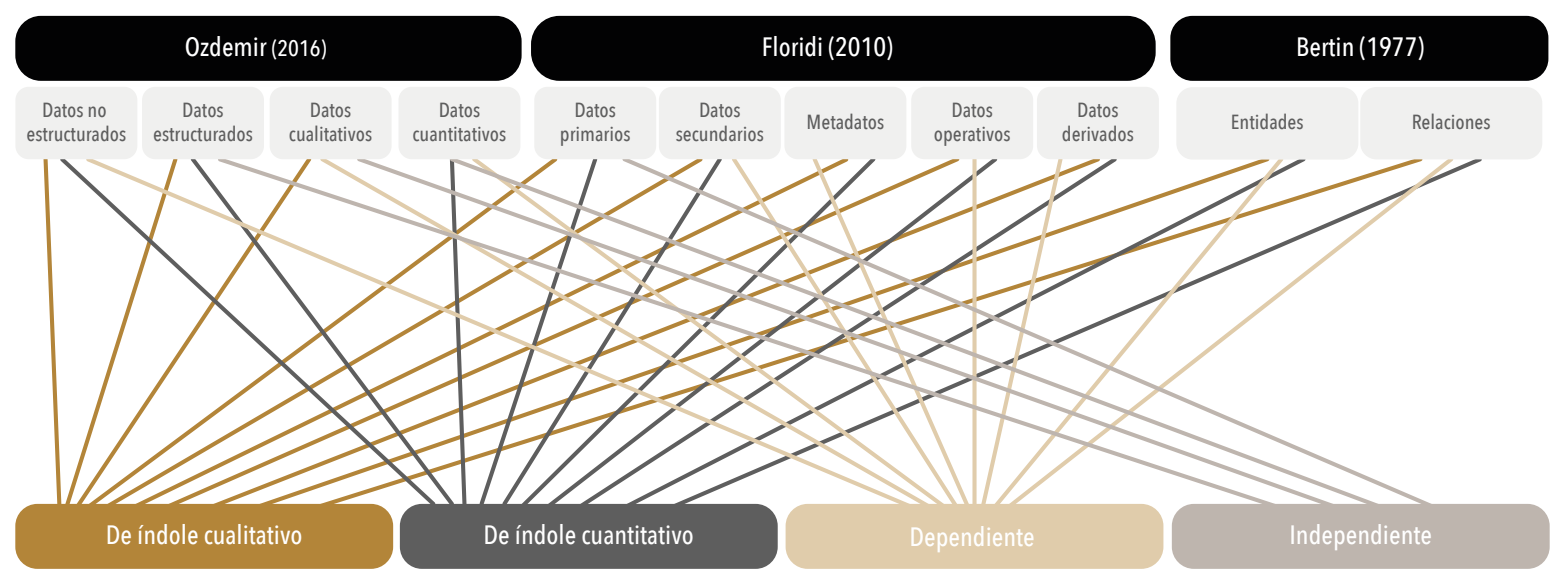

Figura 1. Relaciones entre las posturas de Ozdemir (2016), Floridi (2010) y Bertin (1977) acerca del concepto de dato. Elaborada por Mariel Garcia Hernández.

Como podemos observar, las diferentes clasificaciones previamente expuestas comparten rasgos tanto de la índole de donde parten, ya sea cualitativo o cuantitativo, así como sí son dependientes o no de otros datos. Por lo que resulta importante generar un diagrama para dar a conocer la correlación que existe en cada uno los tipos de datos propuestos por Ozdemir (2016), Floridi (2010) y Bertin (1977). Para fines de esta tesis doctoral, nos centraremos en aquellos que son de índole cualitativa y cuantitativa e independientes a cualquier otra entidad de dato.

\subsection{Evolución de la visualización de información a través de la historia.}

La constante necesidad del ser humano de comprender su entorno ha generado a lo largo del tiempo el desarrollo de diferentes herramientas que le permiten entender su realidad. A partir de esta necesidad, a lo largo de la historia, diversas herramientas de visualización de información fueron creadas. Para poder 
comprender estas herramientas, sus alcances, bondades y limitaciones es necesario conocer su historia y evolución.

En este apartado hablaremos de cuatro períodos de tiempo, los cuales responden a necesidades de información en particular y de las herramientas que el hombre fue desarrollando a partir de éstas (ver figuras 1,2,3 y 4 en la sección de Anexos). Se puede decir que la mayoría de las representaciones visuales desarrolladas en cada época histórica tuvieron necesidades diferentes de información y, por lo tanto, gráficas, por lo cual, en cada período de tiempo, el ser humano creó sus propios métodos para representar la realidad.

\subsubsection{Los primeros mapas y diagramas $(13,660 \mathrm{AC}-1375)$.}

Durante esta época, las manifestaciones visuales hacen referencia a diagramas geométricos, tablas de posiciones estelares y mapas de navegación y exploración. La mayoría de las representaciones visuales en este período de tiempo corresponden al conocimiento del propio ser humano de la naturaleza y su entorno, sin tomar como base explicaciones teóricas o científicas. A continuación, se exponen las dichas representaciones visuales en orden cronológico:

- 13,660 A.C. - Bloque de piedra en Abauntz. 
A partir a lo que plantean Utrilla et. Al. (2009), es considerado como la primera pieza de visualización de información a un bloque de piedra grabado encontrado en la cueva de Abauntz, Navarra, España. En este sistema de visualización de información donde se aprecian montañas, ríos y estanques.

Este objeto, de acuerdo a los autores, ayudó a alguna tribu o grupo de personas que vivían en alguna cueva, a tomar decisiones estratégicas de cacería, contemplando el tipo de terreno y condiciones de éste.

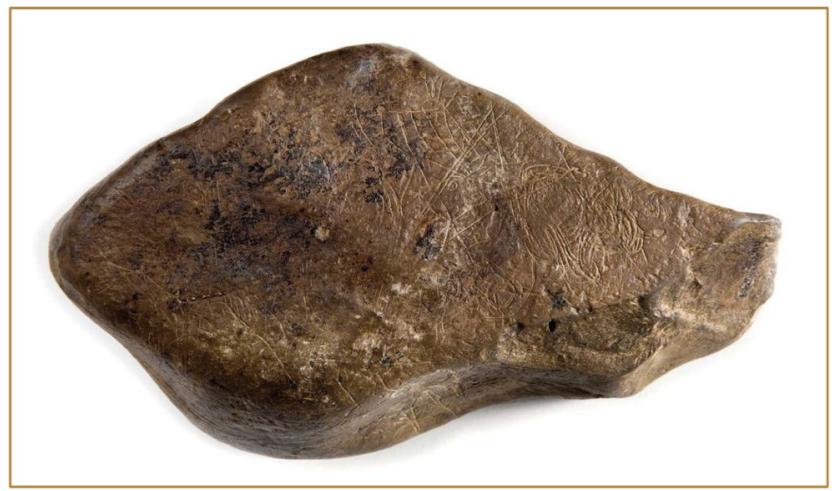

Imagen 1. Bloque de piedra encontrado en Abauntz, Navarra, España. ${ }^{3}$ Actualmente este bloque se encuentra en el Museo de Navarra, España.

- 620 A.C. - El mapa más antiguo conocido.

Esta pieza de visualización de información consiste en una tabla de arcilla, de alrededor de 7.6 c.m. x 6.8 c.m., según a lo que establece Friendly \& Denis (2009). En esta tabla de arcilla se observa un mapa topográfico de una región cercana a la actual Yorghan, Tepe.

\footnotetext{
${ }^{3}$ Ánonimo. (2017). Hallan en una cueva navarra el mapa más antiguo en Europa occidental. 7 de Julio del 2020, de 0 Minutos Editora, S.L. Tomada el 7 de Julio del 2020 del sitio: https://www.20minutos.es/noticia/492748/0/mapa/antiguo/cueva/
} 


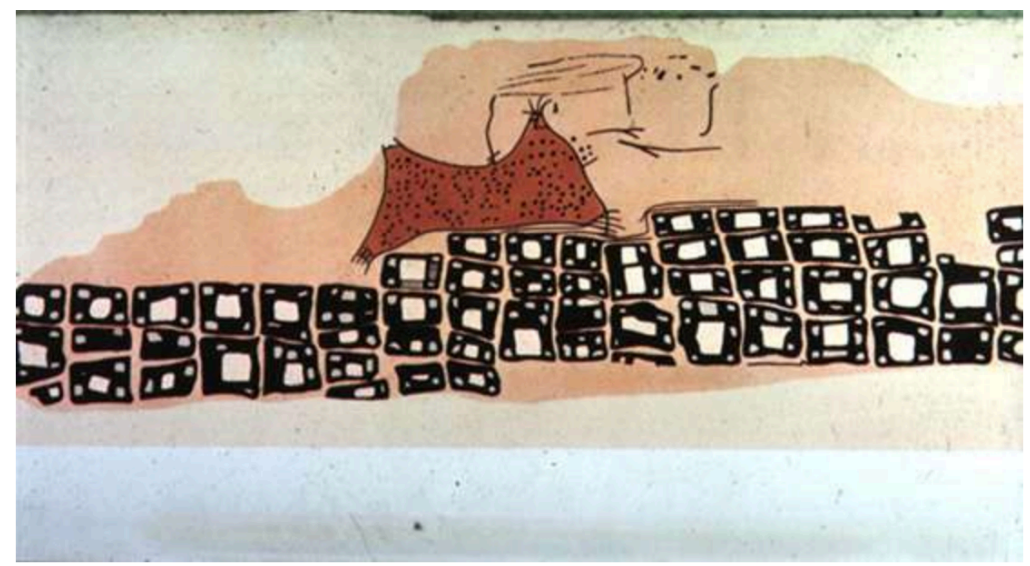

Imagen 2. Mapa topográfico de una región cercana a la actual Yorghan Tepe (actual Turquía);

el mapa más antiguo conocido. Esta pieza está alojada en el Museo Semítico de Harvard.

Tomado del sitio Milestones in the History of Thematic Cartography, Statistical Graphics, and Data Visualization por Friendly \& Denis (2009).

- 550 A.C. - El primer mapa mundial.

llustración en donde se sintetiza a Europa, Asia y África en un círculo, representado así el mundo desde una óptica cartográfica. Es atribuido al geógrafo y filósofo griego Anaximandro, según argumentan Friendly y Denis (2009).

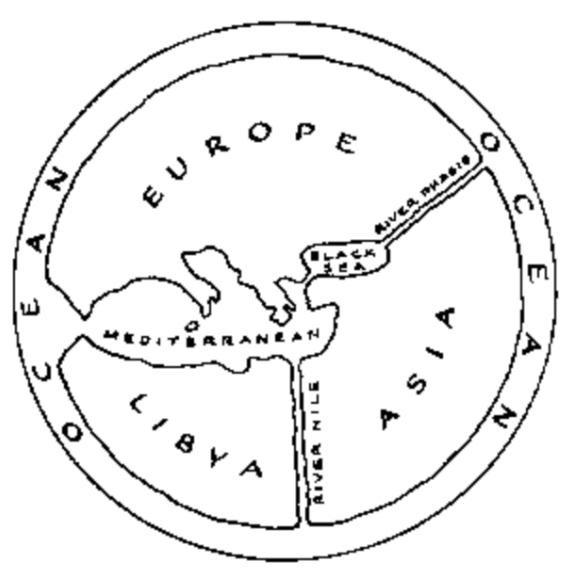

Imagen 3. Mapa mundial de Anaximandro, considerado el primer mapa mundial.

Tomado del libro An Introduction to Early Greek Philosophy de Robinson (1968). 
- 366 A.C. al 335 A.C. - El primer mapa de ruta.

Este artefacto de visualización de información consiste en la representación de los sistemas de caminos del imperio romano. Según Friendly \& Denis (2009), se utilizaron dibujos sintéticos para representar dicha información.

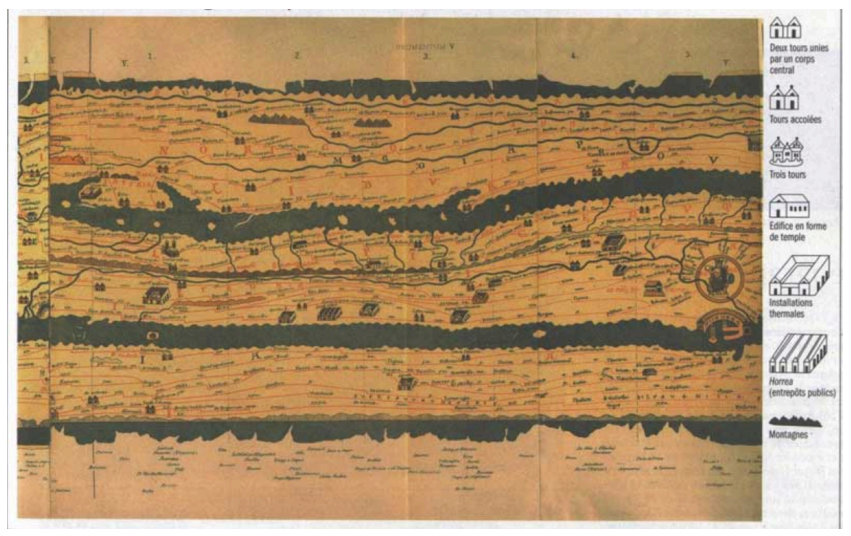

Imagen 4. Primer mapa de ruta; rutas de caminos romanos.

Tomado del sitio Milestones in the History of Thematic Cartography, Statistical Graphics, and Data Visualization por Friendly \& Denis (2009).

- 100 A.C. - Mecanismo de Anticitera.

Este artefacto está elaborado en piedra y bronce, en donde se divisaban y calculaban datos astronómicos y astrológicos que servían para predecir eclipses y eventos calendáricos.

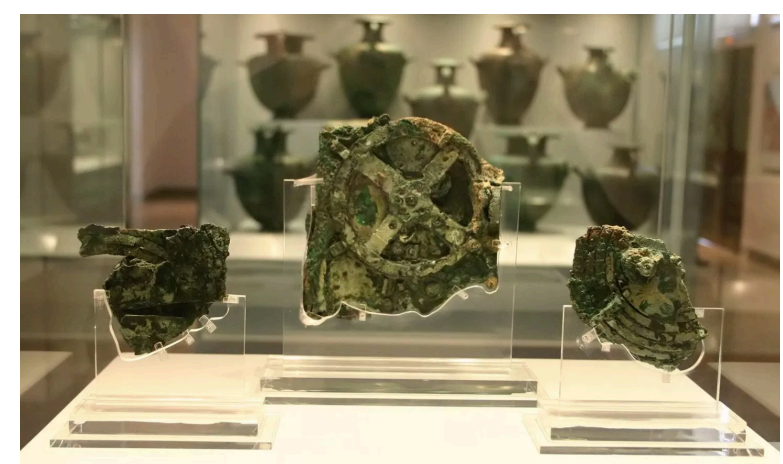

Imagen 5. Mecanismo de Anticitera, localizado en el Museo Arqueológico de Atenas.

Tomado del sitio Milestones in the History of Thematic Cartography, Statistical Graphics, and Data Visualization por Friendly \& Denis (2009). 
- 90 D.C. al 150 D.C. - Mapa de Ptolomeo.

Considerada la primera referencia gráfica dentro de la cartografía en utilizar el principio de coordenadas para su construcción, respecto a lo que argumenta Points (2017:4).

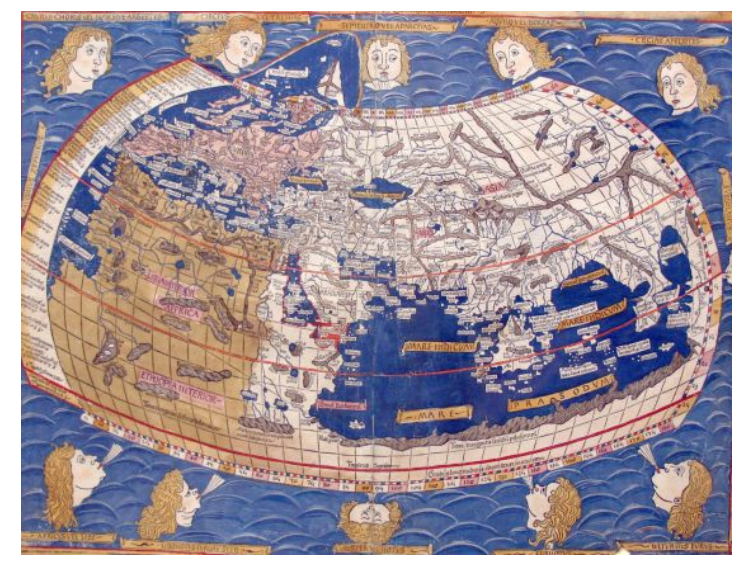

Imagen 6. Mecanismo de Ptolomeo.

Tomado del sitio Milestones in the History of Thematic Cartography, Statistical Graphics, and Data Visualization por Friendly \& Denis (2009).

- 950 D.C. - Primera construcción gráfica.

Lo que hace relevante a este gráfico es la organización en cuadricula de los elementos gráficos, ya que está permite divisar, por primera vez, de manera vertical objetos, en este caso, los planetas, según argumentan Friendly \& Denis (2009).

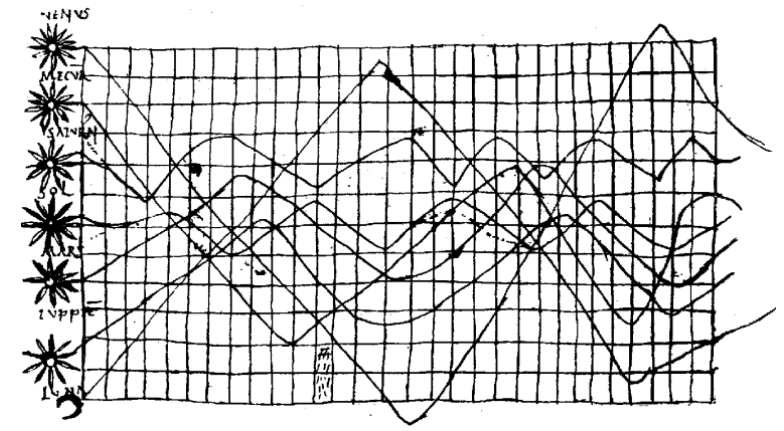

Imagen 7. Primera construcción gráfica; movimientos planetarios a través del zodíaco.

Tomado del sitio Milestones in the History of Thematic Cartography, Statistical Graphics, and Data Visualization por Friendly \& Denis (2009). 
- 1350 D.C. - Construcción gráfica de Oresme.

Nicolás Oresme (1323-1382) fue el creador de la construcción gráfica que representa datos en forma de columnas verticales a lo largo de un eje horizontal de izquierda a derecha, según plantean Friendly \& Denis (2009).

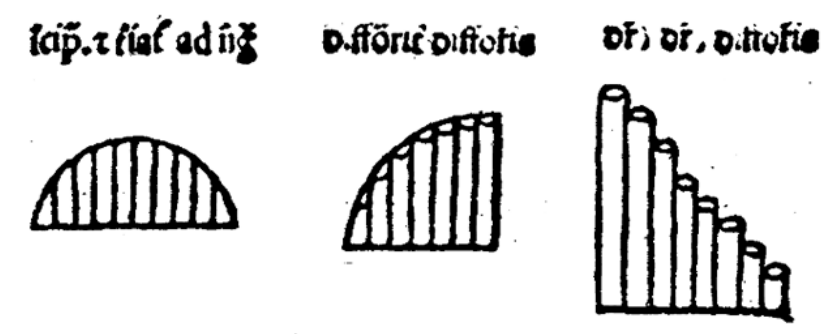

Imagen 8. Construcción gráfica de Oresme.

Tomado del sitio Milestones in the History of Thematic Cartography, Statistical Graphics, and Data Visualization por Friendly \& Denis (2009).

- 1375 - Atlas mundial de Abraham Cresques o Atlas Catalán.

Este objeto consiste en una construcción gráfica que sintetiza un gran volumen de información cosmográfica. Contiene una enorme cantidad de datos representados por un lenguaje gráfico universal, según Points (2017:4)

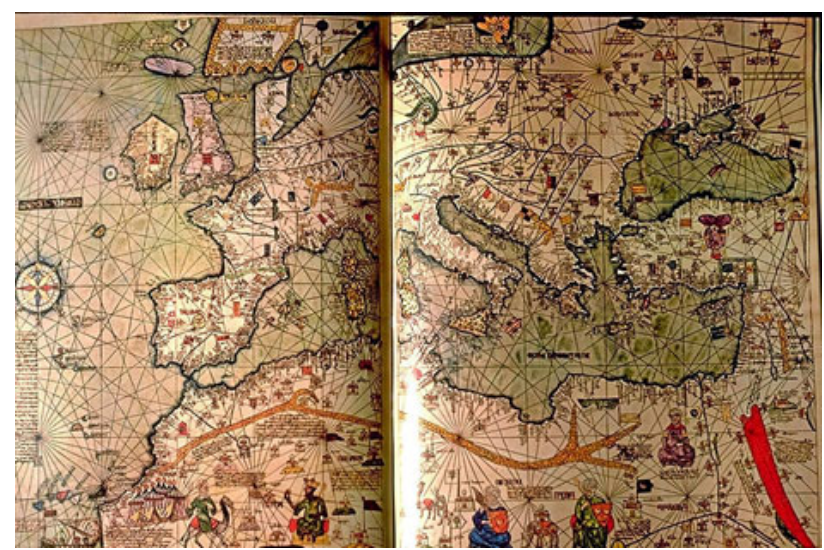

Imagen 9. Atlas Mundial de Abraham Cresques o Atlas Catalán.

Dicho documento se encuentra en la Biblioteca Nacional de Francia, es la ciudad de París.

Tomado del sitio Milestones in the History of Thematic Cartography, Statistical Graphics, and Data Visualization por Friendly \& Denis (2009). 


\subsubsection{Teoría y la medida de la realidad (1626 - 1686).}

Acorde a lo que planeta Friendly \& Denis (2009), durante este período de tiempo el ser humano se ocupó de temas relacionados con su realidad desde una óptica más teórica; la medición del tiempo, la distancia física y el espacio, la topografía, la navegación y la expansión territorial.

- 1626 - Secuencia visual de las manchas solares de Sheiner.

Según a lo que plantea Points (2017:5) esta pieza de visualización de información fue pionera en usar secuencias visuales. En este artefacto se representa los puntos solares a través de estas secuencias.

Con el paso del tiempo esta pieza se convirtió en unas de las principales herramientas contemporáneas para la visualización de información.

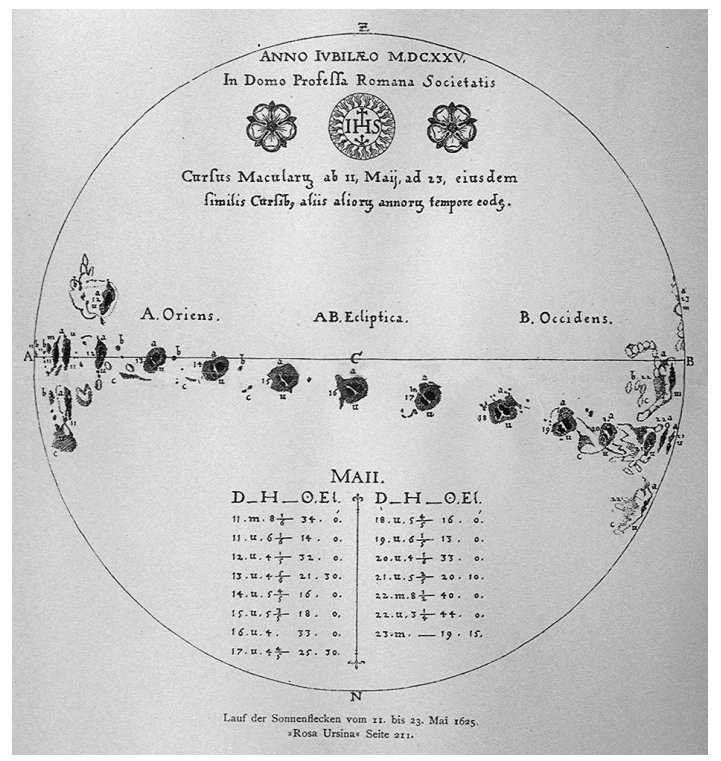

Imagen 10. Secuencia visual de las manchas solares de Sheiner.

Tomada del libro Rosa Ursina de Sheiner (1630) ${ }^{4}$.

\footnotetext{
${ }^{4}$ Scheiner, C. (1629). Rosa Ursina sive sol. S.L.
} 
- 1603 - Primer mapa geomagnético de Le Nautoniers.

Según argumentan Friendly \& Denis (2009), el mapa geomagnético de Le Nautonier fue el primer mapa en emplear isógonos. En este mapa se representa la distribución de la latitud de los meridianos a través de una tabla.

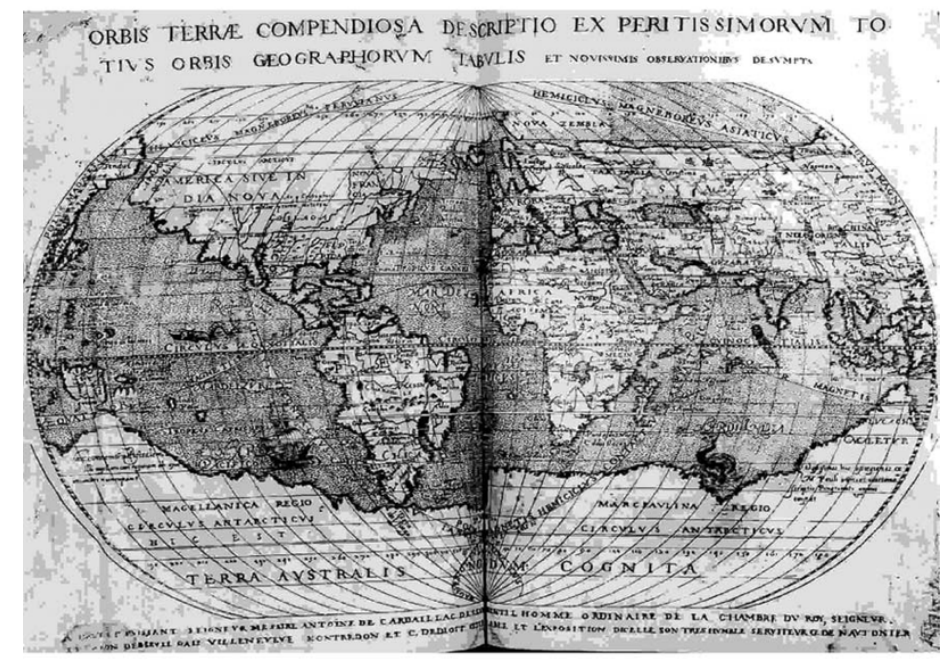

Imagen 11. Primer mapa geomagnético de Le Nautoniers.

Tomado del sitio Milestones in the History of Thematic Cartography,

Statistical Graphics, and Data Visualization por Friendly \& Denis (2009).

- 1634 - "Le Geometrie" de René Descartes.

Le Geometrie de René Descartes (1596 - 1650), es un tratado en el que se introduce por primera vez en la historial el plano cartesiano y las coordenadas, las cuales, a lo largo de la historia, pasarían a ser una herramienta importante dentro de la visualización de información.

- 1644 - Primera representación de datos estadísticos.

Según Points (2017:6), Michael F. Van Langren (1598 - 1675) desarrolló en 1644 la primera representación de datos estadísticos en donde se estudiaron 
y representaron las variaciones de la determinación de longitud entre la ciudad de Toledo y la ciudad de Roma.

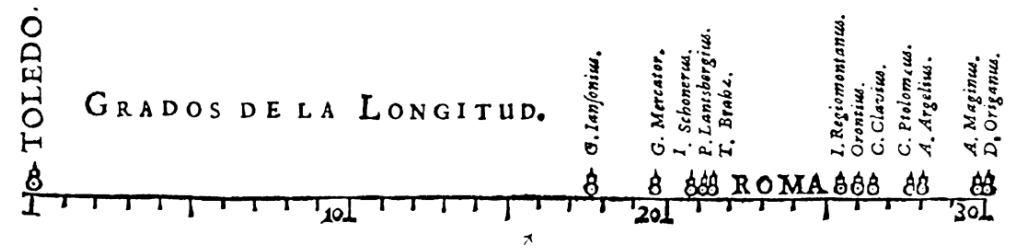

Imagen 12. Primera representación de datos estadísticos que representa las variaciones de longitud entre la ciudad de Toledo, España y Roma, Italia.

Tomada del libro La Verdadera Longitud por Mar y Tierra de van Langren (1644) 5 .

- 1686 - Primer mapa de datos meteorológicos.

Esta pieza de representa los vientos predominantes en un mapa geográfico. Este artefacto de visualización, según plantean Friendly \& Denis (2009), se le atribuye a Edmund Halley (1656 - 1742).

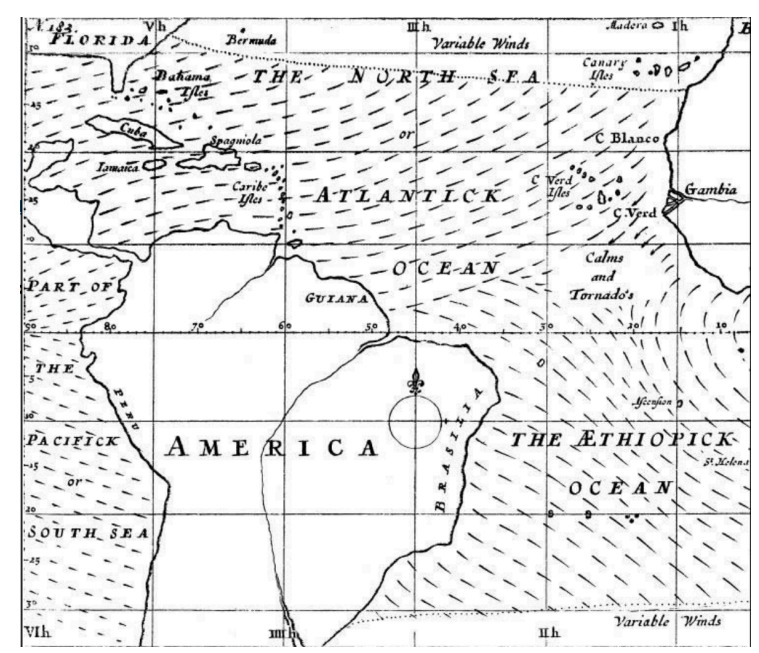

Imagen 13. Primer mapa de datos meteorológicos.

Tomado del sitio Milestones in the History of Thematic Cartography,

Statistical Graphics, and Data Visualization por Friendly \& Denis (2009).

${ }^{5}$ Langren, M. F. (1644). La verdadera Longitud por Mar y Tierra demonstrada. Madrid 


\subsubsection{Nuevas formas gráficas (1765 - 1889)}

Durante este periodo de tiempo, el ser humano comenzó a ocuparse de plantear más que una posición geográfica en un mapa, a partir de esto se dio paso al nacimiento de nuevas formas gráficas para poder presentar información más compleja. Algo importante que predominó durante este lapso en la historia de la visualización de información fue la aparición de gráficos estadísticos y mapeos temáticos. En cuanto a los gráficos estadísticos, se vio nacer a las formas modernas de visualización de información; histogramas, barras y gráficos circulares, de línea y de series de tiempo. También se crearon los mapas de alta complejidad, en donde se podían manejar temáticas y diferentes tipos de datos, así como también, se introdujo el uso del simbolismo dentro de los mismos.

- 1765 - Primera línea del tiempo.

El primer gráfico en presentar el concepto de tiempo en forma lineal fue registrado en una publicación de Joseph Priestley (1732 - 804), según proponen Friendly \& Denis (2009).

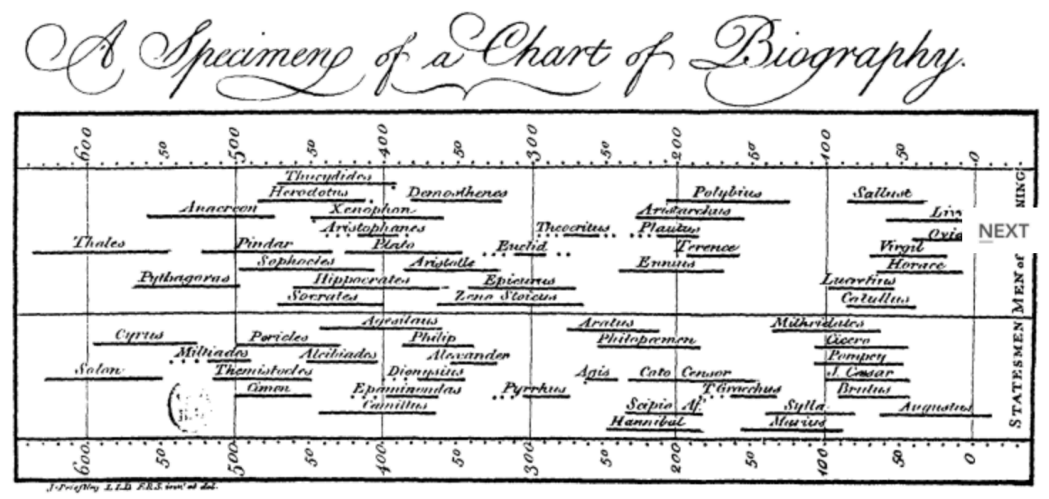

Imagen 14. Primera línea del tiempo atribuido a Priestley.

Tomado del sitio Milestones in the History of Thematic Cartography,

Statistical Graphics, and Data Visualization por Friendly \& Denis (2009). 
- 1789 - Primer registro histórico de gráfico circulares, barras y series temporales. Friendly \& Denis (2009) sostienen que William Playfair (1759 1823) ideó y desarrolló este tipo de representaciones visuales.

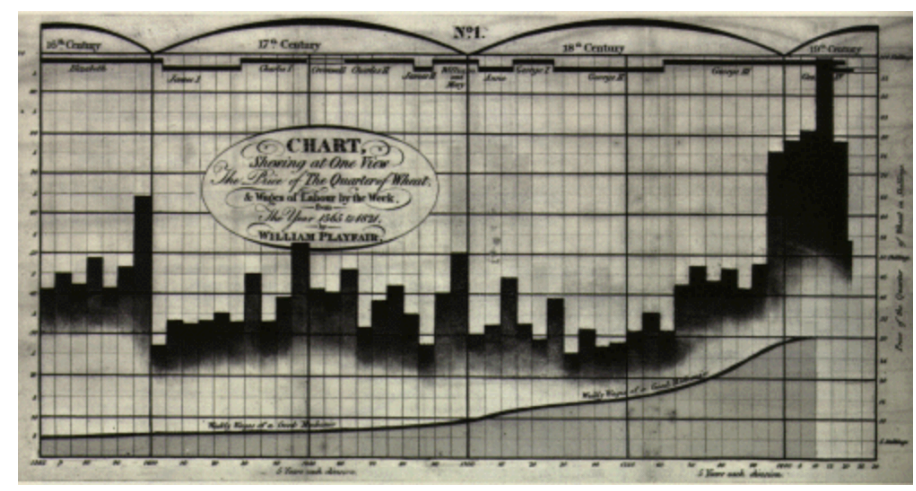

Imagen 15. Primer registro histórico de gráfico circulares, barras y series temporales.

Tomado del sitio Milestones in the History of Thematic Cartography, Statistical Graphics, and Data Visualization por Friendly \& Denis (2009).

- 1816 - Primer mapa de tiempo (meteorológico).

Creado por Mitheln Brandes (1777 - 1843) para representar datos meteorológicos de las condiciones de un territorio en particular.

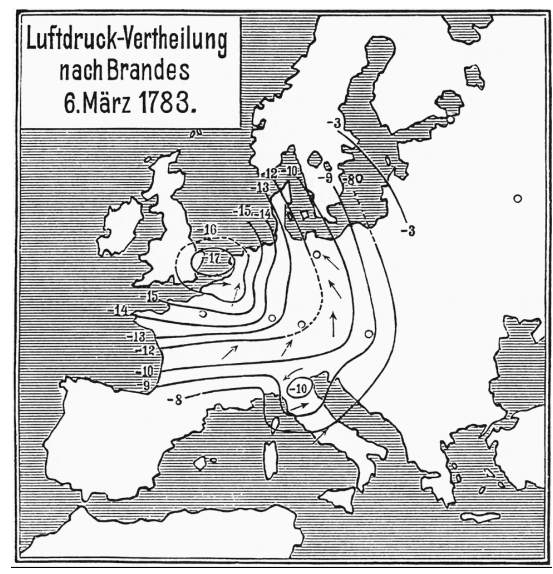

Imagen 16. Primer mapa meteorológico.

Tomado del sitio Milestones in the History of Thematic Cartography, Statistical Graphics, and Data Visualization por Friendly \& Denis (2009). 
- 1830 - Primer mapa de puntos.

Elaborado por Armand Joseph Frere de Montizon (1788 - 18??), conforme a lo que dicen Friendly \& Denis (2009), en este mapa encontramos la población de Francia representada por puntos en donde cada punto equivale a 10000 personas.

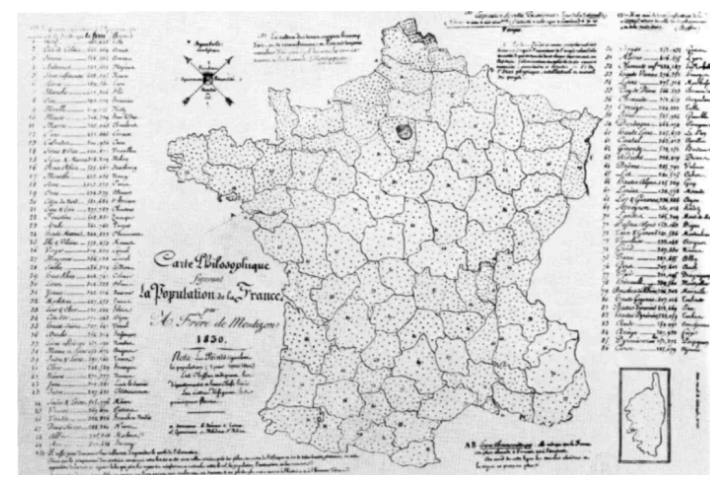

Imagen 17. Primer mapa de puntos.

Tomado del sitio Milestones in the History of Thematic Cartography,

Statistical Graphics, and Data Visualization por Friendly \& Denis (2009).

- 1856 - Creación del diagrama del círculo polar o diagrama de la rosa.

Friendly \& Denis (2009) señalan que Florence Nightingale (1820 - 1910) creó esta pieza de visualización de información para representar el número de muertes en el ejército británico durante la Guerra de Crimea.

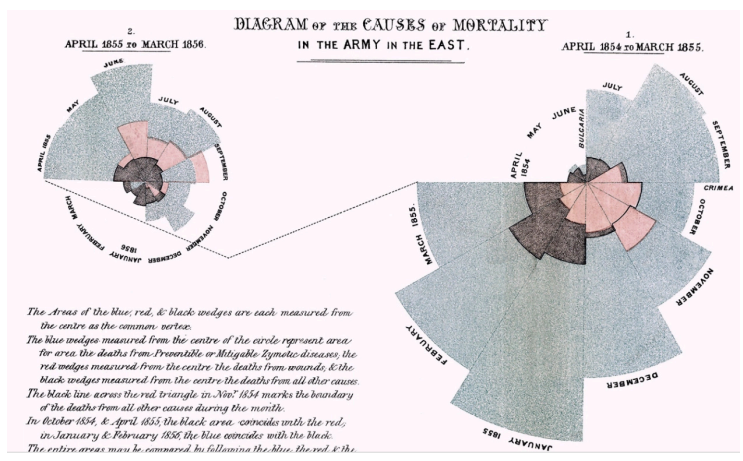

Imagen 18. Diagrama de círculo polar o diagrama de la rosa, creado por Florence Nightingale.

Tomado del sitio Milestones in the History of Thematic Cartography,

Statistical Graphics, and Data Visualization por Friendly \& Denis (2009). 
- 1884 - Pictogramas de Mullhal.

George Mullhal (1836 - 1900) inventó la estadística pictórica, de acuerdo a Friendly \& Denis (2009) en donde implementó el uso de pictogramas para representar valores estadísticos.

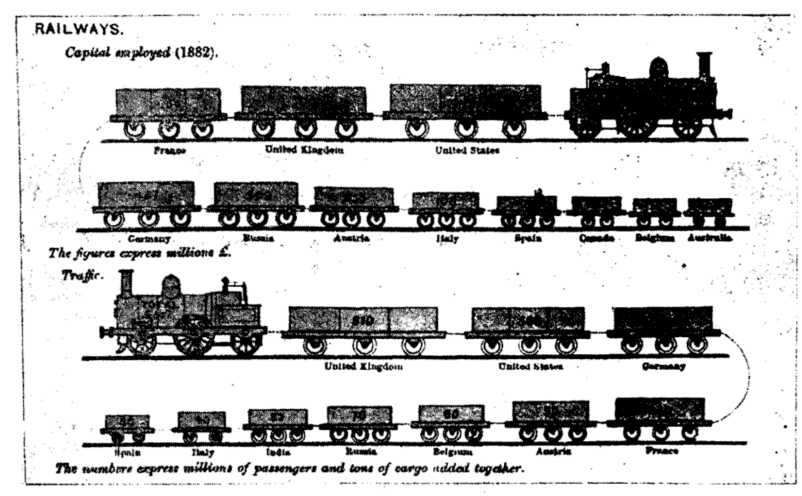

Imagen 19. Pictogramas de Mullhal.

Tomado del sitio Milestones in the History of Thematic Cartography,

Statistical Graphics, and Data Visualization por Friendly \& Denis (2009).

- 1889 - Códigos de color y mapeos.

Friendly \& Denis (2009) establecen que Charles Booth (1840 - 1916) a través de códigos de color trato de diferenciar la pobreza y riqueza en un mapa de Londres.

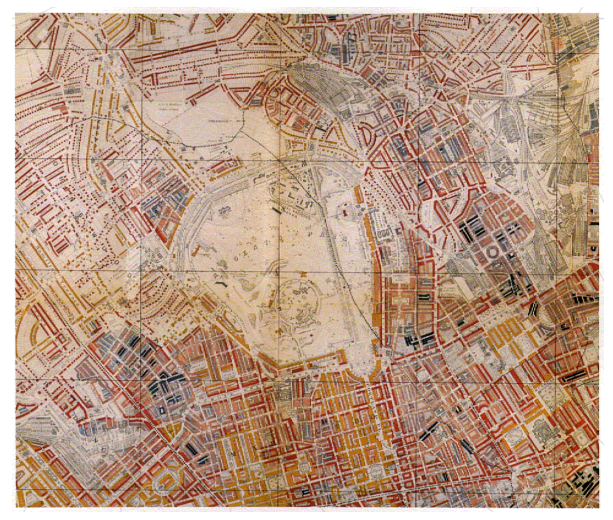

Imagen 20. Primer mapa con códigos de color.

Tomado del sitio Milestones in the History of Thematic Cartography,

Statistical Graphics, and Data Visualization por Friendly \& Denis (2009). 


\subsubsection{La era moderna de la visualización de Información (1901 - 2005).}

En este periodo de tiempo aparecieron los planteamientos teóricos que hasta la fecha establecen lineamientos de diseño de visualización de información y de datos. También, apareció un lenguaje visual abstracto icónico que concretó el uso de pictogramas, de igual manera, la tecnología fue utilizada como herramienta por la visualización de información.

- 1901 - Primera propuesta de directivas para representaciones gráficas.

El documento Propuesta para dar uniformidad en la preparación gráficos, elaborado por Cheysson \& Fontaine es considerada por Friendly \& Denis (2009), como la primera propuesta de directivas para artefactos de visualización gráfica.

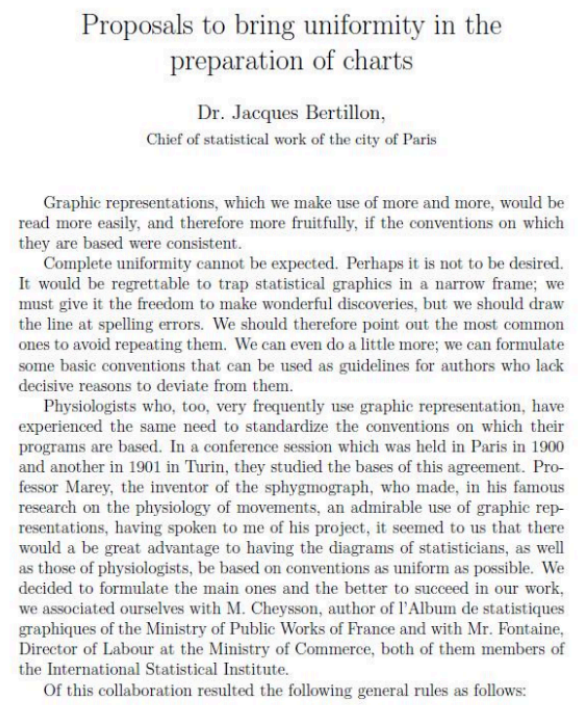

Imagen 21. Primera propuesta de directivas para representaciones gráficas

Tomado del sitio Milestones in the History of Thematic Cartography,

Statistical Graphics, and Data Visualization por Friendly \& Denis (2009). 
- 1910 - Aparición de diagramas en libros de texto.

Se comienzan a implementar el uso de estas piezas de visualización dentro de libros de textos y apuntes, conforme a Point (2017:8).

- 1913 - Diagrama de Hertzprung-Rusell.

Esta pieza de visualización fue desarrollada por los científicos Ejnar Herzprung (1873 - 1967) \& Henry N. Rusell (1877 - 1957). Este diagrama es importante para el mundo de la visualización de información, ya que fue el primero en utilizar los ejes x y y para la visualización de datos correlacionados y sus distribuciones.

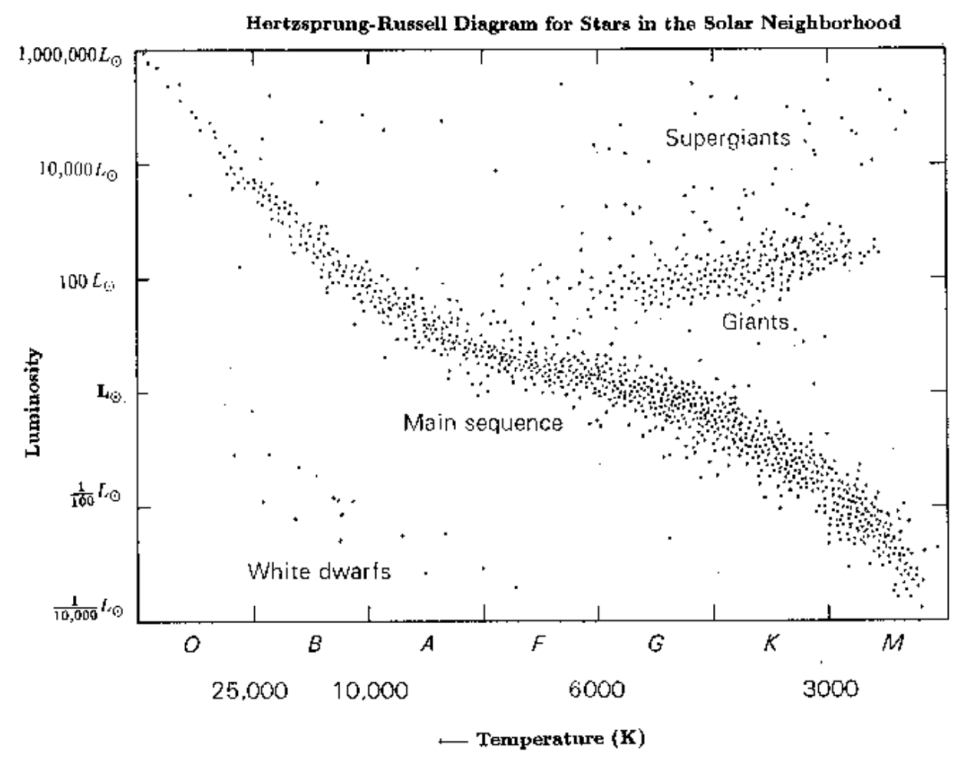

Imagen 22. Diagrama de Hertzprung-Rusel.

Tomado del sitio Milestones in the History of Thematic Cartography, Statistical Graphics, and Data Visualization por Friendly \& Denis (2009). 
- 1917 - Diagrama de Gantt.

Henry L. Grantt (1861 - 1919) desarrolló esta pieza de visualización de información que está compuesta de barras ordenadas y jerarquizadas dependiendo de las variables a ponderar en éstas.

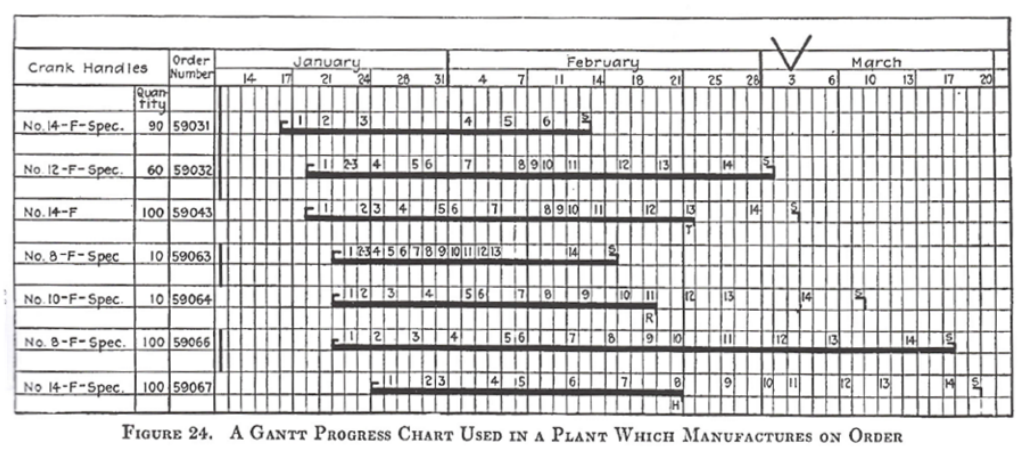

Imagen 23. Ejemplo del diagrama de Grantt.

Tomado del sitio Milestones in the History of Thematic Cartography,

Statistical Graphics, and Data Visualization por Friendly \& Denis (2009).

- 1920 - Creación del diagrama de ruta.

Sewall Wright (1889 - 1988) inventó el diagrama de ruta, el cual sirve para mostrar relaciones entre una red de variables.

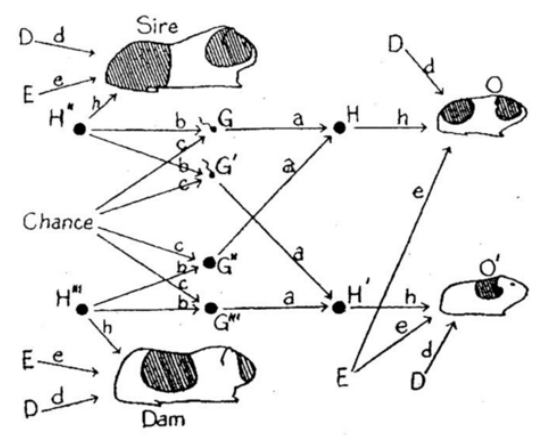

Imagen 24. Ejemplo del diagrama de ruta.

Tomado del sitio Milestones in the History of Thematic Cartography, Statistical Graphics, and Data Visualization por Friendly \& Denis (2009). 
- 1924 - ISOTYPE.

Otto Neurath (1882 - 1945) creo un sistema de representación icónica. Este sistema fue hecho para poder mostrar datos de manera más fácil de leer e interpretar, tratando de comunicar a través de un lenguaje visual abstracto conceptos universales.

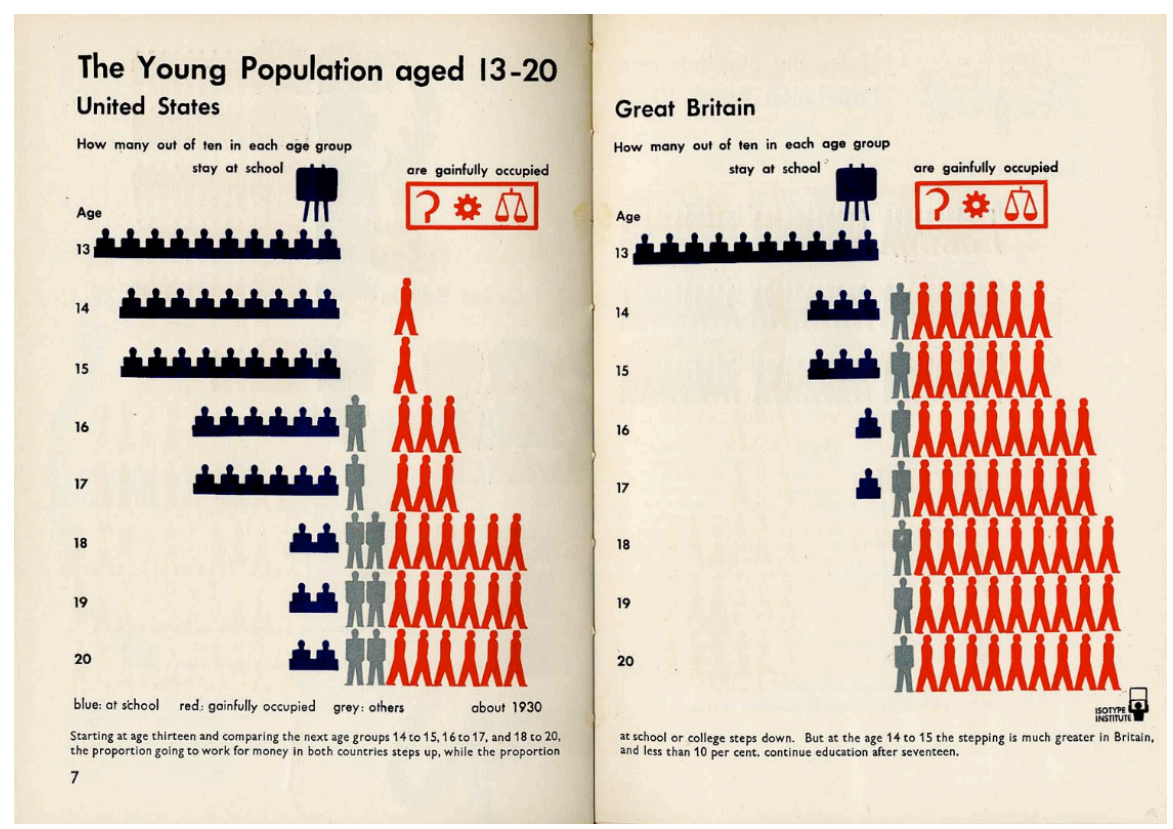

Imagen 25. Ejemplos del trabajo de ISOTYPE.

Doble página tomada del documento de Our private lives de Neurath \& Arntz (1944) 6 .

- 1962 - Libro "El futuro de análisis de datos".

John Tukey (1915 - 2000) en este documento planteó el reconocimiento del análisis de datos como una rama legitima de estadística distinta de la estadística matemática y comenzó la invención de una amplia variedad de

${ }^{6}$ Neurant. O., \& Arntz. G. (1944). Our private lives. London: America and Britain George G. Harrap \& Co. Ltd 
pantallas gráficas nuevas, simples y efectivas a comparación de las que ya existían.

- 1967 - Libro "Semiologie Graphique”

Este documento fue escrito por Jaques Bertin (1918 - 2010), el cual es considero, según Friendly \& Denis (2009), como una de las obras clásicas y más importantes de la visualización de información. Este documento señala la organización de elementos visuales y perceptuales de gráficos en correlación con las características y relaciones de datos.

- 1983 - Principios de Tufte: "The visual display of quantitative information". Edward Tufte (1942 -) es uno de los principales autores de la visualización de información actual. The visual display of quantitative information es considerado una de las obras importantes de visualización de información, ya que abarca la historia, teoría y práctica de la visualización de información.

- 1987 - Gráficas interactivas.

Richard Becker y William Cleveland desarrollaron un sistema de gráficos estadísticos interactivos sistematizados, permitiendo la vinculación y otras formas de interacción entre este sistema. 


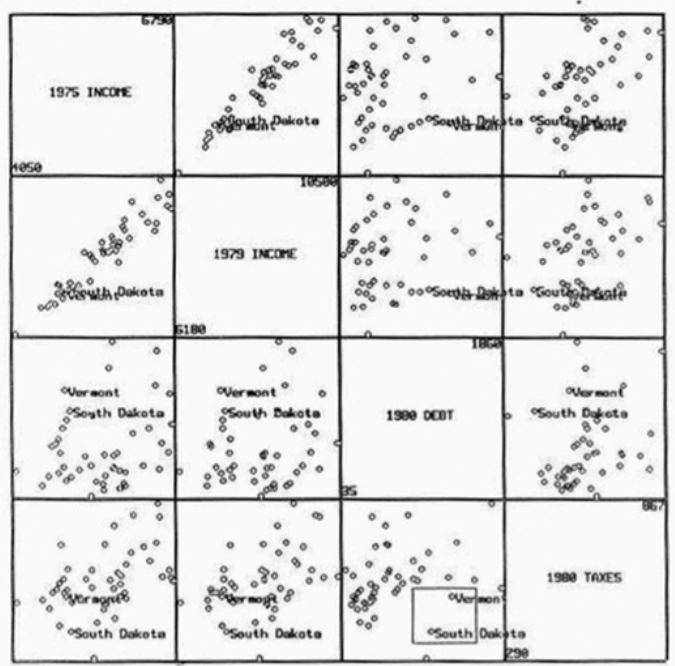

Imagen 26. Ejemplo de gráficas interactivas.

Tomado del sitio Milestones in the History of Thematic Cartography,

Statistical Graphics, and Data Visualization por Friendly \& Denis (2009).

- 2005 - Gapminder

Hans Rosling y su equipo desarrollaron este sistema de visualización de información llamada "moving bubble chart", el cual permite el análisis y representación de datos en movimiento.

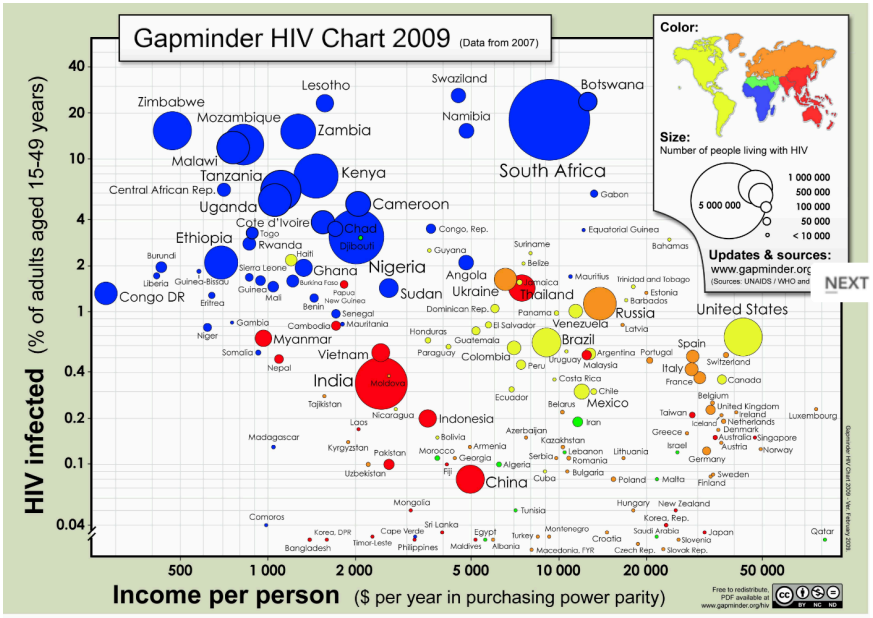

Imagen 27. Ejemplo de "moving bubble chart", creado por Hans Rosling.

Tomado del sitio Milestones in the History of Thematic Cartography,

Statistical Graphics, and Data Visualization por Friendly \& Denis (2009). 


\subsection{Definiciones: la visualización de información.}

Para comprender y abordar de mejor manera esta tesis doctoral, resulta importante hacer algunas consideraciones acerca de la visualización. Comenzaremos con algunas definiciones de este tema; de acuerdo a Card (1999) la visualización de información es el uso de representaciones visuales interactivas de datos abstractos, no físicos, para ampliar el conocimiento. Hal Varian (2009) citado por Chen (2017) establece que la visualización de información es la habilidad de convertir datos en algo entendible y que sea procesable por su lector. La visualización de información, según Fry (1997) se ocupa de hacer visible un conjunto abstracto de datos, generalmente en circunstancias en las que no existe una metáfora en el mundo físico. También este concepto es definido, según Olmeda-Gómez (2014:213), como "algo que ayuda al reconocimiento de patrones, estructuras o tendencias que ayuden a la compresión de los datos y del fenómeno que representan, ya que de otro modo sería incomprensible por su complejidad y misma magnitud".

El concepto visualización de información es definida por Pérez Montoro \& Golkhosravi (2010:4) como:

...la disciplina que se encarga de la representación visual de contenidos proposicionales mediante el uso de diagramas, gráficas y esquemas para facilitar la aprehensión, la interpretación, la transformación y la comunicación de esos contenidos a través de esas representaciones visuales.

La visualización de información ayuda al reconocimiento de estructuras, patrones, relaciones y tendencias entre un conjunto de datos, ampliando la cognición y entendimiento de dicha información. Ésta tiene dos características en particular; la primera es que busca descubrir enfoques o interpretaciones similares entre información abstracta a través de representaciones gráficas y la segunda 
característica es puede ser interpretada como una representación de datos que ayude a amplificar la cognición y el entendimiento de éstos.

La visualización de información conlleva a un proceso cognitivo que, a través del análisis y representación visual, permite al lector entenderla; es hacer simple una historia compleja y que, a través de representaciones visuales o gráficas, se pueda interpretar dicha información, la cual es contextualizada dentro de un marco conceptual en el cual, el significado es construido por el mismo lector.

Así mismo, la visualización de información provee, a través de un modelo estructurado, al usuario las pautas visuales necesarias para comprender fenómenos en particular, el cual encuentra su origen en el comportamiento de datos o ítems que presentan algún tipo de correlación entre sí, los cuales pueden compartir algún tipo de patrón, conexión o estructura en particular.

\subsection{Alcances de la visualización de información}

La visualización de información es una disciplina que puede llegar a ser bastante "flexible" para su aplicación, ya que hoy en día coexistimos en un mundo en donde somos bombardeados por información de todo tipo, convirtiéndola en una gran herramienta para la búsqueda, reconocimiento e identificación de patrones.

Shirk (2005;8), arguye que existen diferentes áreas en donde la visualización de información encuentra su quehacer: 
- Visualización de datos: Consiste en la descripción gráfica de información, esta área tiene como objetivo el proporcionar al espectador una comprensión cualitativa de los contenidos de información.

- Visualización geográfica: Esta área abarca la representación gráfica de la ubicación geográfica e información espacial.

- Visualización científica: Es la representación gráfica de la información científica. Este campo es la base de la investigación actual en la visualización de la información, y tiene la literatura más extensa asociada con esto.

- Visualización de software: Esta rama de visualización científica aborda los objetos de software (algoritmos, procesos paralelos, programas, etc.). El uso de animación por computadora y gráficos ayudan a ilustrar y representar procesos de computadora, algoritmos y programas.

Por su parte, Ponjuán Torres, $(2009 ; 164)$ señala, a comparación de Shirk (2005) tres grandes áreas o campos en donde la visualización de información interviene. Éstas están clasificadas de la siguiente manera:

- Visualización científica: Según Ponjuán Torres $(2009 ; 164)$ esta área está “destinada a comprender de manera más eficiente los fenómenos físicos a partir de grandes volúmenes de datos, generalmente parte de datos cuyas variables son intrínsecamente espaciales".

- Visualización del software: De acuerdo a idem, este campo de la visualización está "dirigida a comprender y utilizar el software con efectividad, también investiga las herramientas de visualización de programas (código 
fuente) —para mantener, comprender, perfeccionar y depurar el software— y algoritmos de animación, empleados fundamentalmente en la educación para motivar el aprendizaje".

- Visualización de información: Acorde al autor, esta área sirve "para identificar patrones, correlaciones o agrupamientos de un volumen grande de información compleja, estructurada".

Pojuán Torres $(2009 ; 164)$ valiéndose de lo que plantea Erbacher (2007) expone la necesidad un análisis de "la naturaleza interdisciplinar de la investigación sobre visualización", y éste a su vez afirmar que "se necesita la integración de aportes de dominios como:"

- Ciencia de la computación y ciencia de la información: En donde, según Erbacher (2007) "determinan la factibilidad de implementar las técnicas diseñadas, la representatividad de los parámetros de datos, la retroalimentación de otros dominios, etcétera".

- Matemáticas y estadística: ya que "aportan algoritmos vinculados con las técnicas de visualización fundamentales", conforme a idem.

- Diseño: esta disciplina es importante para la visualización de información ya que contribuye fundamentalmente en su representación gráfica y su estética visual.

- Ergonomía cognitiva: ya que, según Erbacher (2007) "ayuda en el estudio de la percepción, la identificación de reglas intrínsecas al diseño de una visualización adecuada desde la perspectiva humana". 
A su vez, Erbacher (2007), sostiene que "se requiere de expertos en los dominios, que identifiquen el tipo de visualización que se necesita, así como la presentación, exploración análisis o síntesis apropiadas". Por lo cual, podemos establecer que las bondades de la visualización de información son amplias y bastas, de tal forma en que pueden interceder en diferentes áreas dependiendo de las necesidades de comunicación de cada una de éstas.

\subsection{La visualización de información en el área de la medicina.}

Como hemos mencionado en apartados anteriores, la visualización de información es una disciplina que juega un papel muy importante en diversas áreas. Es por ello, que para fines de esta tesis doctoral, nos centraremos en hablar sobre su participación en la medicina, en donde la situaremos, según a Preim, B., \& Bartz, D. (2007), como un área especia de la visualización de información científica.

Como ya hemos observado, en el apartado de este capítulo en donde se habla sobre la evolución de la visualización de información, observamos que el hombre ha tratado explicar su realidad a lo largo del tiempo a través de dibujos e ilustraciones y diferentes técnicas de representación visual, sin embargo, el reconocimiento de esta área como parte fundamental dentro de la medicina se dio en los años ochentas, gracias a los avances tecnlógicos que comenzaron a surgir en esa época, como lo son los gráficos a computadora, los cuales permitieron el procesamiento de geometría 3D y algoritmos para darle una interpretación a tales representaciones, según plantean los mismo autores. 
La visualización de información médica tiene como objetivo la representación, la exploración y el análisis de conjuntos de datos que surgen a partir de mediciones o simulaciones de fenómenos acerca de procesos fisológicos. Sin embargo, lo más sustancial que podemos observar de la participación de la visualización en la información médica es el entendimiento de la información con la que se está trabajando, como lo establece Chittaro (2001).

Los propositos más relevantes que tiene la visualización de información dentro del área de la medicina, según Preim, B., \& Bartz, D. (2007), son los siguientes:

- Educativos. Tiene como fin generar simulaciones o acervo educativo que proporcione conocimiento a futuros especialistas en la salud acerca de algún tipo de fenómeno médico o fisologico.

- Documentales, resultado y de control. En este rubro encontramos como objetivo documentar, categorizar e interpretar información que se obtiene de etapas subsecuentes entre sí, como por ejemplo, la evolución del estado del paciente al que se está atendiendo, la forma en que el estado fisiológico responde a través del tiempo a ciertos tratamientos. También se trabaja con datos que han sido obtenidos a partir de alguna prueba clínica, además de, información que se ha sido obtenida al ingreso del paciente a la clínica o al hospital siendo cual sea la causa de su ingreso.

- De diagnóstico. Los fines de este rubro son proporcionar al paciente un diagnóstico de su estado de salud, a través de la interpretación previa de imágenes 2D o 3D, datos de resultados clínicos como niveles de glucosa en la sangre, trigliceridos, colesterol, etc., por parte del médico tratante o especialista de la salud.

- Planificación de tratamiento. Tiene como fin poder generar una estrategia de cuidados para el paciente, en donde se presenta información relevante y pertinente para el cuidado de la enfermedad a tratar. 
- Soporte intraoperatorio. El objetivo de este tópico es presentar información con relación al estado de salud del paciente desde que éste ha sido ingresado al quirofano y hasta que sale de éste, como lo es por ejemplo indicadores médicos relacionados con su condición fisologica como frecuencia cardiaca, niveles de hemoglobina, presión arterial de oxígeno, etc.

Acorde a lo que pantea Shneiderman (1996) existen siete categorías de datos con los que la visualización de información medica trabaja:

1. Datos 1D (datos lineales organizados de forma secuencial, como una lista alfabética de nombres, texto narrativo en un documento, numeraciones de ítems, etc).

2. Datos $2 \mathrm{D}$ (datos de planos o mapas que cubren alguna parte de alguna área, perímetro de alguna parte del cuerpo u órgano, fotografías de partes del cuerpo, etc).

3. Datos 3D (datos con volumen y relaciones potencialmente complejas entre sí, como moléculas, redes de tejido o masa corporal, tumores, etc).

4. Datos temporales (datos con una hora de inicio, tiempo de terminación y posibles superposiciones en una escala de tiempo, como la que se encuentra en los registros médicos).

5. Datos multidimensionales (datos con " $n$ " número de atributos que se convierten en puntos en un espacio n-dimensional ${ }^{7}$, como los registros en relación y bases de datos estadísticas, como por ejemplo, formularios y historiales clínicos que compilan tanto datos 1D, 2D y/o 3D).

\footnotetext{
${ }^{7}$ Un espacio n-dimensional corresponde a ciertos datos compilados en una sola base de datos, que combinan diferentes atributos para determinar correlaciones entre ellos.
} 
6. Datos árbol (colecciones de elementos vinculados jerárquicamente por una estructura de árbol, como directorios, puestos de trabajo, árboles de genealogía, etc).

7. Datos de red (colecciones de elementos vinculados por una estructura gráfica y conceptual; redes neuronales, entre otras).

Chittaro (2001) plantea que los datos pueden pertencer a más de una categoría en sí. Sin embargo, la separación de estos datos da pauta a que el diseñador pueda seleccionar la técnica de visualización más conveniente para la información con la que está trabajando, de la cual hablaremos a continuación.

\subsection{Figuras en los métodos o técnicas de codificación en la visualización de información}

Antes de comenzar con el siguiente apartado de este capítulo, es importante abordar la estructura de una visualización de información, ya que resulta elemental para fines de este trabajo hablar sobre ésta. Una visualización de información, según establece Cairo (2019) en el video para la Universidad Oberta de Catalunya se conforma de tres partes esenciales y que son fundamentales para la interpretación de la información que se intenta transmitir a través de ésta:

1. Estructura (Framework).

2. Codificaciones (Encoding).

3. Anotaciones (Annotations). 


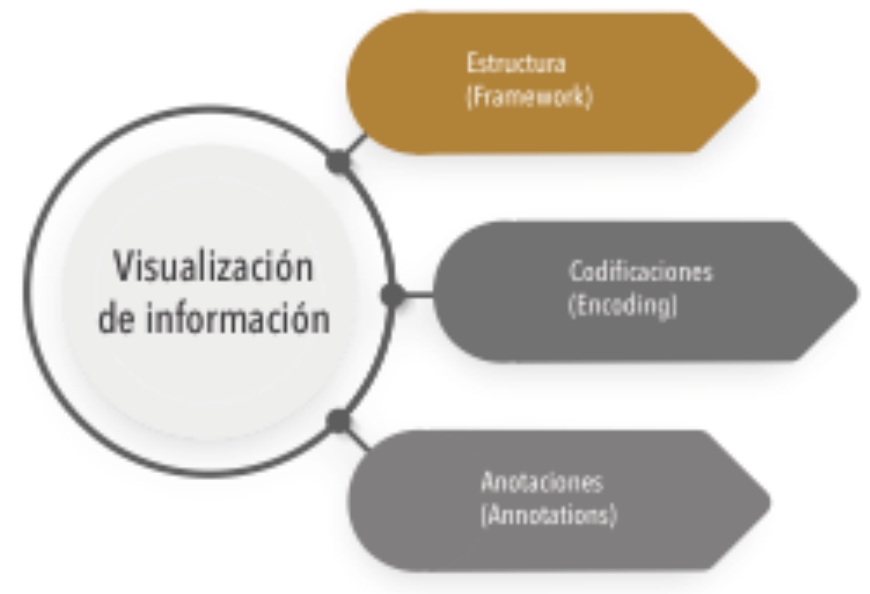

Figura 6. Estructura de la visualización de información, según Calro (2019). Elaborada por Mariel Garcia Hernández

Cairo (2019) define a la estructura como todos esos elementos gráficos que dan soporte a la visualización de información en sí, por ejemplo, títulos, figuras, texto, etc. En cuanto a las codificaciones, el autor las define como variaciones de las representaciones visuales en una visualización de información y las cuales se ven expresadas en diferentes elementos gráficos, como color, forma, longitud, grosor, áreas, ángulo, posición, etc. Por último, el autor argumenta que las anotaciones son esas ampliaciones de texto que se usan dentro de la misma visualización de información para entender el contexto de los datos.

Expuesto lo anterior, retomaremos el concepto de las codificaciones, ya que es importante para esta tesis doctoral hablar de ello, debido a que estás formarán parte de los elementos a considerar como parte de la guía de diseño que se expondrá en capítulos posteriores. Dentro de la visualización de información existen numerosos recursos de los cuales el diseñador puede auxiliarse para desarrollar el sistema de visualización de información en el que esté trabajando, a estos recursos se le 
conoce como métodos o técnicas en la visualización de información, que son parte de los elementos que anteriormente se han mencionado.

Los métodos o técnicas de en la visualización son aquellas figuras o representaciones visuales que se utilizan para expresar información a través de un elemento gráfico. Existen numerosas clasificaciones de estos métodos o técnicas, por lo cual, abordaremos a Cairo y Ferdio.

\subsubsection{Clasificaciones de los métodos o técnicas de visualización de información de Alberto Cairo}

Cairo (2019) dice que al desarrollar un sistema de visualización de información se debe de categorizar de la siguiente manera:

- Longitud.

- Posición.

- Color o intensidad.

- Área.

- Ángulo.

- Grosor.

Esta clasificación resulta bastante general, sin embargo, lo que es importante de ésta es la variación que propone dentro de sus elementos, ya que estos, de acuerdo 
al autor, encontrarán dicha variación en la correspondencia y proporcionalidad de la información que se está intentando representar a través de estos elementos.

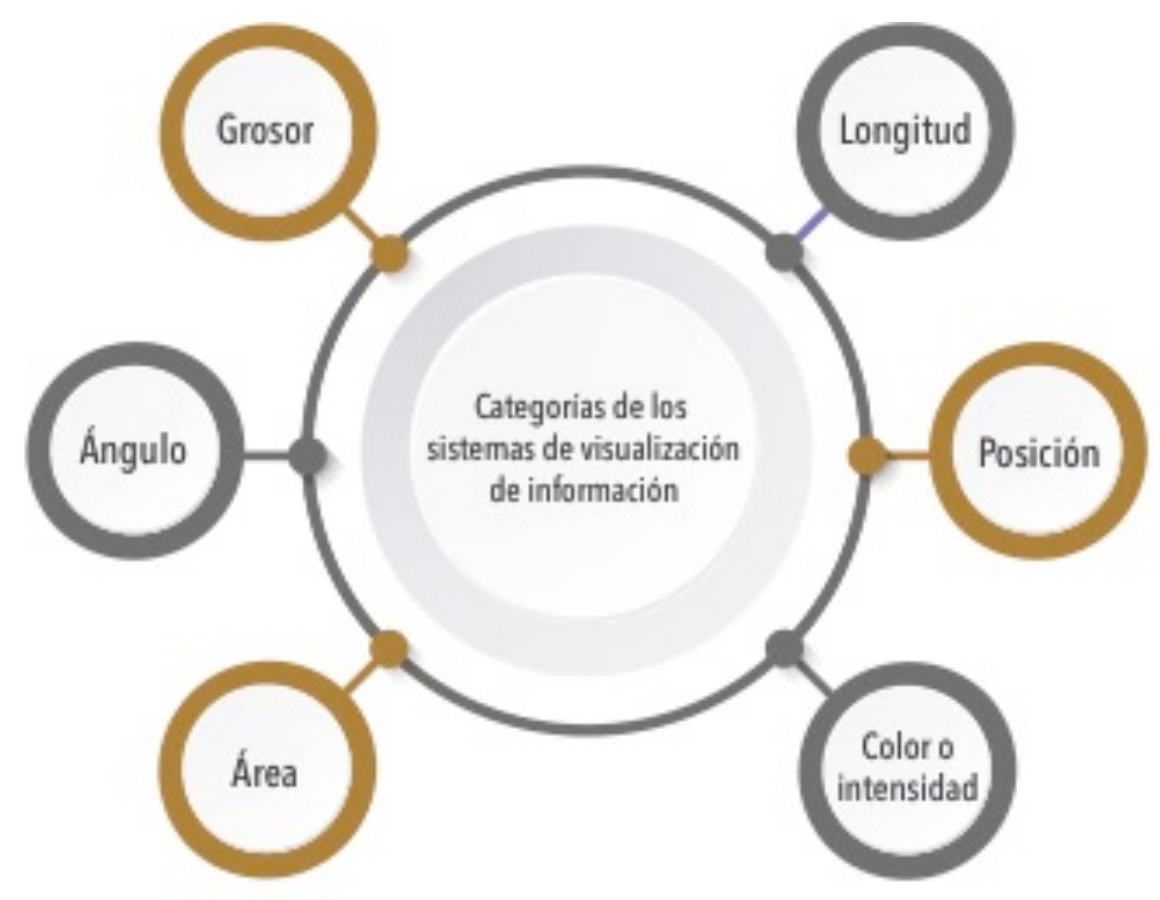

Figura 7. Categorización de los sistemas de visualización de Información según Alberto Cairo (2019). Elaborada por Mariel Garcia Hemández

\subsubsection{Clasificaciones de los métodos o técnicas de visualización de información de Ferdio}

Otra clasificación que podemos resaltar es la que hace Ferdio (2019), en donde hace un despliegue de los tipos de métodos de codificación de acuerdo a su función en relación con la información. Dicha clasificación es la siguiente: 
1. Comparación. Este método busca generar un contraste entre conjuntos de datos. A través de está técnica se busca establecer una comparación visual entre las características o atributos de dichos conjuntos de datos.

2. Visualización de conceptos. Es la representación de uno o varios conceptos a través del gráfico.

3. Correlación o de patrones. Es la proporcionalidad entre atributos o características de uno o varios datos entre sí. Se centra en revelar formas o patrones en los datos para darle significado.

4. Distribución. Esta técnica busca distribuir un dato en un lugar determinado por alguna característica o valor en especial.

5. Datos geográficos. Este método de visualización de información se encarga de representar datos que guardan relación con atributos de índole geográfica, ubicando a éstos en un lugar y espacio determinado.

6. Parte del todo. Es la representación de un conjunto de datos que forman parte de un todo.

7. Tendencia a través del tiempo. Esta técnica de visualización de información se ocupa de la representación de la evolución o perspectiva de un fenómeno a través del tiempo. 
8. Jerarquía. Este método muestra la relación de cómo las entidades se pueden clasificar y ordenar dependiendo de su grado de importancia y/o relevancia dentro de un sistema o organización.

9. Procesos y métodos. Esta técnica en la visualización de información ayuda a explicar como están hechos ciertos procesos o métodos, así como los pasos que están involucrados en éstos.

10. Funcionamiento de las cosas. Este método tiene como objetivo ilustrar el funcionamiento de algún objeto o sistema.

11. Movimiento o flujo. Herramienta que se encarga de mostrar el movimiento físico, proceso de transferencia o el flujo de conceptos abstractos a través de un gráfico o figura visual.

12. Rango. Esta técnica se encarga de la demostración de las variaciones entre los límites superiores o inferiores en una escala.

13. Herramientas de referencia. Está técnica se utiliza para localizar o buscar fácilmente puntos de datos individuales dentro de un conjunto de datos.

Después de haber presentado esta clasificación de los métodos de codificación en la visualización de información, es conveniente mencionar, que cada técnica de 
visualización abarca distintas figuras visuales que sirven el objetivo o propósito de cada uno de éstos. Estas figuras varían dependiente del tipo del objetivo de la visualización en sí y por el tipo de datos que éstas representan.

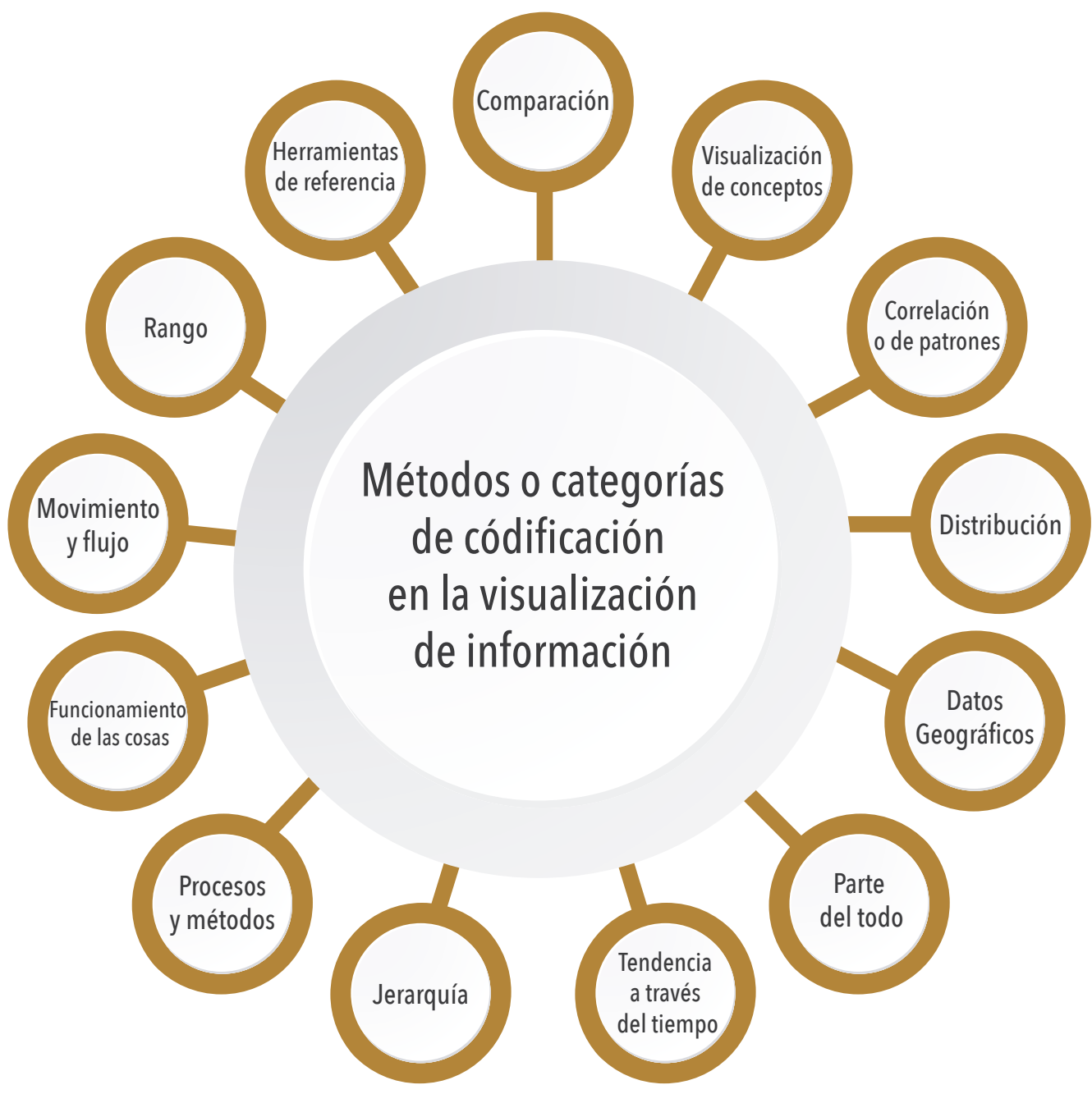

Figura 7. Métodos y categorías en la visualización de información, de acuerdo a Ferdio (2019). Elaborada por Mariel García Hernández. 
A modo de concusión del presente capítulo, la visualización de información es una es una disciplina que tiene como objetivo principal el de representar información abstracta y ordenada a través de diferentes tipos de métodos y técnicas de codificación, para que así el usuario o lector pueda tener un entendimiento más allá de lo conceptual de una serie de datos que son parte de un cierto tipo de conocimiento, el cual, es interpretado a través de sus experiencias, creencias y contexto. Dicha interpretación, ayudará a éste a tomar decisiones acerca de su realidad y poder explorar diferentes posibilidades de ésta con una certeza mayor. Así mismo, como podemos observar, la visualización de información es de suma importantancia en el área de la medicina, ya que proporciona herramientas de cognición que ayudan a identificar datos relevantes que posteriormente serán dirigidos a formar parte de diagnósticos, seguimientos de algúna enfermedad y tratamientos médicos. 


\section{CAPÍTULO 2 Imagen y percepción}




\section{La imagen}

Para abordar de una forma más integral el tema de esta investigación, debemos explorar uno de los conceptos más básicos, pero sin duda, importantes para el tema de visualización de información: la imagen. La imagen es un fenómeno cotidiano, según a lo que plantea Villafañe \& Mínguez (2002:14), es una representación icónica de la realidad. La imagen, según Villafañe (2006:31) "es un sistema de representación que tiene como objetivo explicar un conjunto de relaciones entre la agrupación homologa de ciertos elementos con otros en los que se basa". Por otra parte, Zunzunegui (2010:22) define a la imagen como "el soporte de la comunicación visual en el que se materializa un fragmento del universo perceptivo y que presenta la característica de prolongar su existencia a través del paso del tiempo". De acuerdo con Villafañe (2006:23) la imagen supone tres elementos: una selección de la realidad, un repertorio de elementos fácticos ${ }^{8}$ y la sintaxis 9 .

Generar una clasificación de la imagen podría resultar "un hecho bastante complejo ya que, al categorizarla, se correría el riesgo de reducir la naturaleza de la imagen a un aspecto parcial de la misma", conforme a lo que plantea Villafañe, (2006:39). Sin embargo, el mismo autor sugiere que la mejor forma de desarrollar una clasificación es con base al grado de correspondencia que la imagen guarda con la

\footnotetext{
${ }^{8}$ Cuando se habla de elementos fatídicos se hace referencia a hechos que son relevantes o tienen cierto grado de importancia dentro del contexto en que éstos coexisten.

${ }^{9}$ La sintaxis, de acuerdo con Dondis (1984), se refiere a la forma en que está estructurado visualmente la imagen.
} 
realidad. El nivel de realidad, según Villafañe \& Mínguez, (2002:39), es definido como un "criterio taxonómico que se basa la semejanza entre la imagen y su referente y, que se expresa a través del grado de iconicidad". Estos grados de iconicidad son definidos como "escalas de formulaciones teóricas de todos los posibles niveles de realidad, los cuales difieren fundamentalmente en dos hechos", a partir a lo que establece Villafañe (2006:39):

- El número de niveles, ya que cada uno representa un determinado valor de iconicidad o abstracción.

- Los criterios utilizados para adscribir a cada nivel el grado de iconicidad correspondiente.

La escala de iconicidad que expone Villafañe (2006:41-42) es la siguiente:

\begin{tabular}{|c|l|l|l|}
\hline GRADO & \multicolumn{1}{|c|}{ NIVEL DE REALIDAD } & \multicolumn{1}{|c|}{ CRITERIO } & \multicolumn{1}{c|}{ EJEMPLO } \\
\hline 11 & La imagen natural. & $\begin{array}{l}\text { Restablece todas las propiedades del objeto. } \\
\text { Existe identidad. }\end{array}$ & $\begin{array}{l}\text { Cualquier percepción de la realidad } \\
\text { sin más mediación que las variables } \\
\text { físicas del estímulo. }\end{array}$ \\
\hline 10 & Modelo tridimensional a escala. & $\begin{array}{l}\text { Restablece todas las propiedades del objeto. } \\
\text { Existe identificación pero no identidad. }\end{array}$ & La Venus de Milo. \\
\hline 9 & $\begin{array}{l}\text { Imágenes de registro estereos- } \\
\text { cópio. }\end{array}$ & $\begin{array}{l}\text { Restablece la forma y posición de los objetos } \\
\text { emisores de radiación presentes en el espacio. }\end{array}$ & Un holograma. \\
\hline 8 & Fotografía en color. & $\begin{array}{l}\text { Cuando el grado de definición de la imagen } \\
\text { esté equiparado al poder resolutivo } \\
\text { del ojo medio. }\end{array}$ & $\begin{array}{l}\text { Fotografía en la que un círculo de un } \\
\text { metro de diámetro situado a mil } \\
\text { metros, sea visto como un punto. }\end{array}$ \\
\hline
\end{tabular}

Figura 1. Grado de iconicidad para la imagen fija-aislada de acuerdo a Villafañe (2006).

Elaborada por Mariel García Hernández. 


\begin{tabular}{|c|c|c|c|}
\hline GRADO & NIVEL DE REALIDAD & CRITERIO & EJEMPLO \\
\hline 7 & Fotografía en blanco y negro. & Igual que el anterior. & Igual que el anterior. \\
\hline 6 & Pintura realista. & $\begin{array}{l}\text { Restablece razonablemente las relaciones } \\
\text { espaciales en un plano bidimensional. }\end{array}$ & La meninas de Velázquez. \\
\hline 5 & $\begin{array}{l}\text { Representación figurativa } \\
\text { no realista. }\end{array}$ & $\begin{array}{l}\text { Aún se produce la identificación, pero las } \\
\text { relaciones espaciales están alteradas. }\end{array}$ & $\begin{array}{l}\text { Guernica de Picasso. } \\
\text { Una caricatura de Peridis. }\end{array}$ \\
\hline 4 & Pictograma. & $\begin{array}{l}\text { Todas las características sensibles, excepto } \\
\text { la forma están abstraídsa. }\end{array}$ & Siluetas. Monigotes infantiles. \\
\hline 3 & Esquemas motivados. & $\begin{array}{l}\text { Todas las características sensibles abstraídsa. } \\
\text { Tan sólo restablecen las relaciones orgánicas. }\end{array}$ & Organigramas. Planos. \\
\hline 2 & Esquemas arbitrarios.. & $\begin{array}{l}\text { No representan características sensibñes. } \\
\text { Las relaciones de dependencia entre sus } \\
\text { elementos no siguen ningún criterio lógico. }\end{array}$ & $\begin{array}{l}\text { La señal de circuñación que indica } \\
\text { "ceda el paso". }\end{array}$ \\
\hline 1 & Representación no figurativa. & $\begin{array}{l}\text { Tienen abstraídas todas las propiedades } \\
\text { sensibles de la relación. }\end{array}$ & Una obra de Miró. \\
\hline
\end{tabular}

Figura 1. Grado de iconicidad para la imagen fija-aislada de acuerdo a Villafañe (2006) (continuación). Elaborada por Mariel García Hernández.

Después de haber revisado la postura de estos autores podemos decir que la imagen es una representación fragmentada de la realidad, sirviendo como base a la comunicación visual, en donde, dicha representación es definida a partir de la propia experiencia del espectador.

\subsection{Percepción y percepción visual.}

Partiendo del entendido de que el origen de toda imagen es la realidad, podemos decir que el espectador selecciona la "realidad" a través de la percepción. La percepción, según Smith (1975: 27) "es el significado que le damos a la información 
que recibimos por nuestros sentidos. Este significado se construye a partir de la realidad objetiva y, así como también, a partir de la forma en que la organizamos".

Otro enfoque que vale la pena abordar es el que hace Neisser (1976:7) acerca de la percepción, el autor establece que ésta "constituye el punto donde la cognición y realidad se encuentran; es la actividad cognoscitiva más elemental, a partir de la cual emergen todas las demás".

De acuerdo a lo que plantea Marín Álvarez, (2011:69) la percepción:

es un proceso cíclico, de carácter dinámico, el cual se relaciona con procesos cognitivos superiores y que avanza con el tiempo. Además, de que la percepción, es razonada como un proceso complejo y dependiente de la información que el mundo proporciona, así como de la fisiología y de las experiencias de quien percibe. Estas experiencias afectan tanto al acto perceptivo mismo, por la alteración de los esquemas perceptivos, valga la redundancia, como a otros procesos superiores, como las expectativas y las motivaciones.

Este acto perceptual cíclico, según el mismo autor, está constituido por dos periodos: el preatentivo y el de contrucción personal, En el periodo preantivo, el individuo detecta la información sensorial y la examina, mientras que, en el periodo de construcción personal, se produce por la naturaleza perceptual específica. Marín Álvarez (2011:69) arguye lo siguiente:

En el suceso perceptivo existe una constante anticipación a lo que sucederá, apoyado en la información que acaba de incorporarse a los organos sensoriales y, a manera de diversos esquemas, modelos que seleccionan la información a procesar con base a criterios extraídos de la experiencia previa, los cuales a su vez, son modificados por esa nueva experiencia 
perceptiva, y que dirigen las actividades exploratorias necesarias para obtener más información. Estos esquemas varían con cada experiencia perceptiva y determinan qué información sensorial se procesará y cuáles serán sus elementos de búsqueda para alcanzarla. Las siguientes experiencias perceptivas tendrán la influencia de las anteriores percepciones, no habiendo la posibilidad de que dos experiencias perceptuales sean exactamente iguales.

La percepción, de acuerdo a Torrades \& Pérez Sut (2008: 99) "se define por el estímulo que produce la luz que, a su vez, nos crea una sensación que es analizada e interpretada en nuestro cerebro". Siguiendo este concepto, los autores establecen el siguiente proceso de percepción:

1. Los objetos emiten o reflejan radiaciones luminosas de distinta frecuencia e intensidad que penetran en el interior del ojo a través de la pupila ${ }^{10}$.

2. La pupila se dilata o se contrae en función de las condiciones lumínicas por la acción del iris ${ }^{11}$.

3. La señal luminosa pasa por la córnea ${ }^{12}$, el cristalino y la cámara interior acuosa hasta llegar a la retina ${ }^{13}$, la parte fotosensible del ojo, dónde se

\footnotetext{
10 La pupila, según Mosby (2010) es un "orificio circular en el iris del ojo, desplazado del centro del iris ligeramente hacia el lado nasal. La pupila se sitúa por detrás de la cámara anterior del ojo y de la córnea y por delante del cristalino".

11 Ibid, establece que el iris es disco circular, contráctil, suspendido en el humor acuoso, entre la córnea y el cristalino del ojo, y perforado por una pupila circular.

12 Según Mosby (2010) la córnea es parte anterior del ojo, convexa y transparente, que supone un sexto de la capa externa del globo ocular.

${ }^{13}$ De acuerdo a Torrades \& Pérez Sut, (2008:99) la retina "es un tejido fotorreceptor que cubre la mayor parte de la superficie interior del ojo y constituye el plano sobre el que se proyectan las imágenes de forma invertida".
} 
encuentran las células ganglionares ${ }^{14}$, bipolares ${ }^{15}$ y fotorreceptoras ${ }^{16}$ (los conos y los bastoncillos, las únicas células sensibles a la luz).

4. En la retina ${ }^{17}$, los fotorreceptores (conos y bastones) transforman la luz en energía electroquímica que se transmite al cerebro a través del nervio óptico.

5. La energía electromagnética que incide sobre los conos y los bastoncillos se transforma en impulsos nerviosos que llegan hasta las células ganglionares, cuyos axones ${ }^{18}$ se unen para formar el nervio óptico en el disco óptico, llamado punto ciego porque carece de células fotorreceptoras y no es sensible a la luz.

6. Los haces nerviosos de cada ojo se encuentran en el quiasma óptico, donde parte de ellos se cruzan para ir a parar al hemisferio cerebral opuesto.

7. Las fibras que salen del lado izquierdo de ambas retinas (y que corresponden al lado derecho del campo visual) se proyectan hacia el hemisferio izquierdo, y las que salen del lado derecho de ambas retinas (y

\footnotetext{
${ }^{14}$ Mosby (2010), argumenta que las glándulas ganglionares son "células nerviosas esenciales para la visión".

15 La célula bipolar, según Ibid, es "una célula, como una neurona de la retina, con dos prolongaciones principales que se originan en el cuerpo celular".

16 Las células fotorreceptoras, son "son células que cuando se estimulan por la luz generan un impulso neural que pasa al cerebro y produce la experiencia de la visión”, de acuerdo a lo que Ibid establece.

${ }^{17}$ Para Mosby (2010), la retina es "una membrana de tejido nervioso presente en el ojo que continúa con el nervio óptico y que recibe imágenes de objetos externos y transmite los impulsos visuales al cerebro a través del nervio óptico".

18 Los axones, según Ibid, son proyecciones cilíndricas de una célula nerviosa que conducen impulsos procedentes del cuerpo celular de la neurona.
} 
que corresponden al lado izquierdo del campo visual) se proyectan hacia el hemisferio derecho.

8. Finalmente "los estímulos nerviosos, llegan a través del cuerpo geniculado adyacente del tálamo hasta la cortiza visual del cerebro, situada en el lóbulo occipital, modificando su estado fisiologico; produciéndose así el proceso de percepción visual”, conforme a lo que plantea Marín Álvarez, (2011:83).

1 Todo objeto animado o inanimado refleja luz en su superficie.

Esta luz es taptada por nuestros ajos.

2 La lus atreviesa la

tómea e ingresa hasta el cristalino por la pupila.

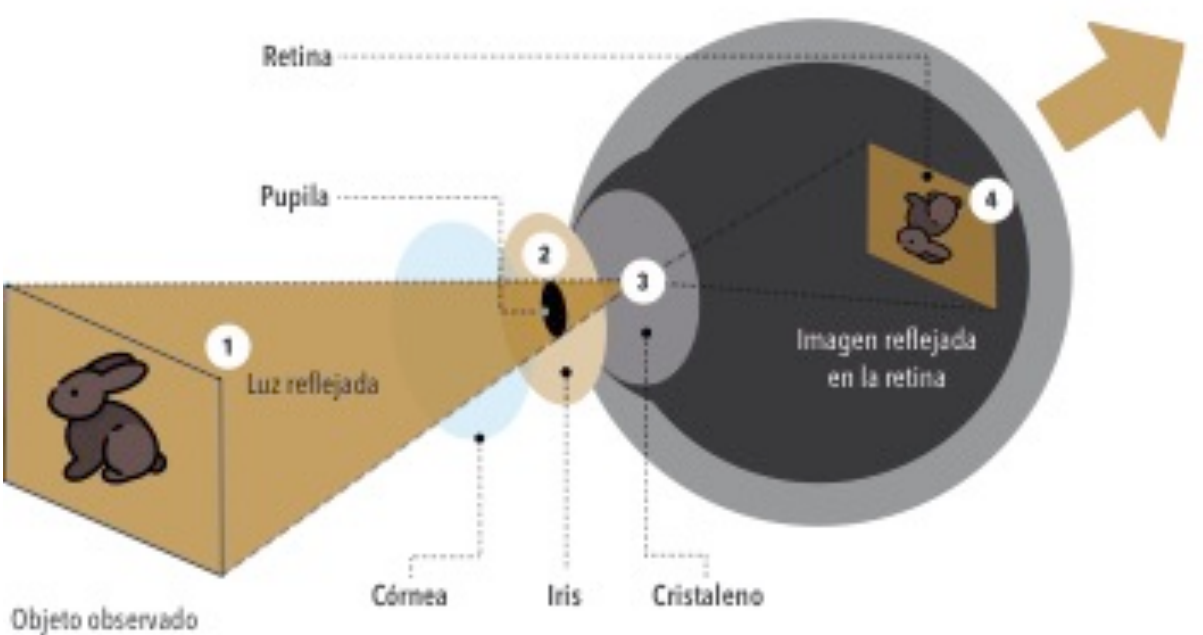

Objeto observado
Contea Iris

3 El cristaleno es un lente acuose que altera su fonta para lograr un buen enfoque.

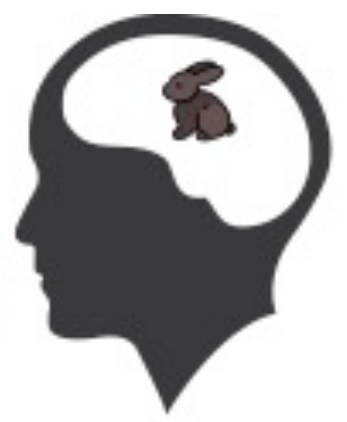

Figura 2. Percepción de información visual de acuerdo a Torrades \& Pérez Sut (2008).

Elaborado por Mariel Garcia Hemández

Podemos sostener, a partir de lo anterior, que la percepción visual es la forma en que entendemos y reconocemos el mundo a través del sentido de la vista. La percepción visual es la capacidad del cerebro para interpretar lo que ven nuestros 
ojos. Se basa en nuestra capacidad para enfocar nuestra atención de manera selectiva y de eliminar información irrelevante aludiendo de forma directa a la capacidad de recordar la información presentada visualmente y hacer de ésta algo significativo.

Para poder hacer de esta información significativa, Ware (2014:20) propone el siguiente modelo de procesamiento de información, el cual está dividido en tres fases o etapas, las cuales son:

1. Etapa 1: Procesamiento paralelo. En esta fase se extraen propiedades de bajo nivel de la escena visual. Al inicio de esta etapa, la información visual es procesada por una gran variedad de neuronas localizadas en el ojo y en el cortex visual del cerebro (como lo vimos en el apartado anterior), según el autor. Billones de neuronas trabajan en paralelo, extrayendo características de cada parte de la imagen de forma simultánea. Algunas caracterisitcas importantes de esta etapa son las siguientes:

a. Procesamiento paralelo rápido.

b. Extracción de caracteristicas visuales, como la orientación, el color, patrones de movimiento, etc.

c. Naturaleza transitoria de la información, que se guarda brevemente en un almacenamiento de grado icónico.

d. Base para la comprensión de la relevancia visual de los elementos en las pantallas. 
2. Etapa 2: Reconocimiento de patrones. En esta segunda fase del procesamiento de información visual, el autor argumenta que el campo visual, procesado en la primera etapa, es dividido en segmentos o patrones simples y propiedades visuales como el contorno, color o textura. Dentro de las caractaristicas que encontramos dentro de esta fase son las siguientes:

a. Procesamiento de información lento y selectivo.

b. Agrupación de elementos visuales similares o homologos entre sí.

3. Etapa 3: Trabajo de la memoria visual. Durante esta fase, ya que fue procesada la información y organizada en grupos de patrones, se mantiene en la memoria visual a corto plazo para forma la base del pensamiento visual.

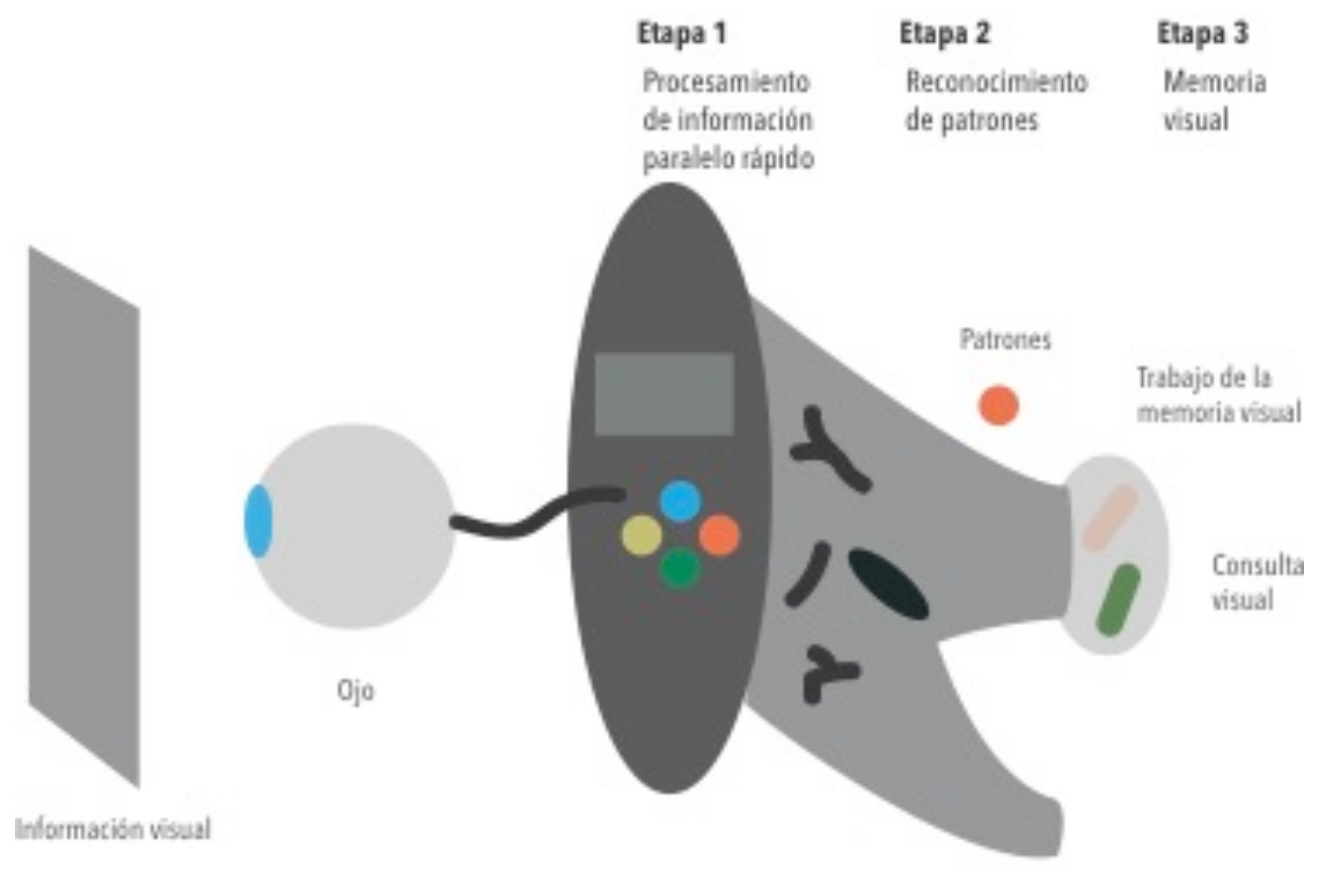

Figura 3. Modelo del procesamiento perceptual de Ware (2012).

Elaborada por Mariel Garcia Hernández 
Posteriormente, el cerebro transformará la información previamente "depurada" en información "valiosa" y "significativa". A partir de esta depuración, reconocimiento y selección, nuestro cerebro será capaz de tomar decisiones con base a la información obtenida.

Meirelles (2014: 21) arguye que existe algo a lo que llama "procesamiento preatentivo", el cual ocurre dentro de la primera fase o etapa establecida por Ware (2012), el cual tiene una duración de menos de 10 milisegundos, en donde se extrae con rapidez rasgos visuales básicos de la imagen. A éstos, la autora, las denomina como características preatentivas y de acuerdo con Meirelles (2014: 21), "son procesadas antes de la atención consciente, y es la percepción que solemos llamar de un vistazo". Siguiendo con lo que establece la autora, "los diseñadores pueden utilizar caracterísitcas pre antetivas para mejorar el descubrimiento de informacón relevante en las visualizaciones, porque estas marcas destacarán sobre las demás". A continuación, nos basaremos en el ejemplo de las cuatro imágenes númericas, las cuales muestran la misma secuencia de números propuestos por Ware, para enfatizar la relevancia de las características preantetivas en las tareas visuales. Este ejercicio consta de imaginar que se tiene que cuantificar cuántas veces aparece el número 3.

Conjunto A 24557688058465689023250 12456546378978009876567 45779808957658378585768 09086967836887869700129
Conjunto B 24557688058465689023250 12456546378978009876567 45779808957658378585768 09086967836887869700129
Conjunto C

24557688058465689023250 12456546378978009876567 45779808957658378585768 09086967836887869700129
Conjunto D 24557688058465689023250 12456546378978009876567 45779808957658378585768 09086967836887869700129 
Meirelles sostiene (2014:21), en el conjunto A de la figura anterior, se tendría que mirar detenidamente uno a uno de los números hasta encontrar el número 3 . En una de las otras cuatro imágenes, de acuerdo con la autora, "las características preatentivas, nos ayudan a realizar esta tarea con más rapidez y eficacia debido a que podemos identificar al instante el objetivo y ver sólo las marcas revelantes". Podemos observar, que gracias a las propiedades visuales del matiz de color (rojo), la intensidad o valor de color (gris/negro) y el grosor del trazo (bold) nos ayudan a realizar la tarea, porque se procesan de forma preatentiva.

Las caracteristicas preatentivas, conforme lo que sostiene Mierelles (2012:22) "pueden aumentar el rendimiento de las siguientes tareas":

1. Percepción de objetivos.

2. Descubrimiento de límites.

3. Rastreo de regiones.

4. Cálculo y estimaciones.
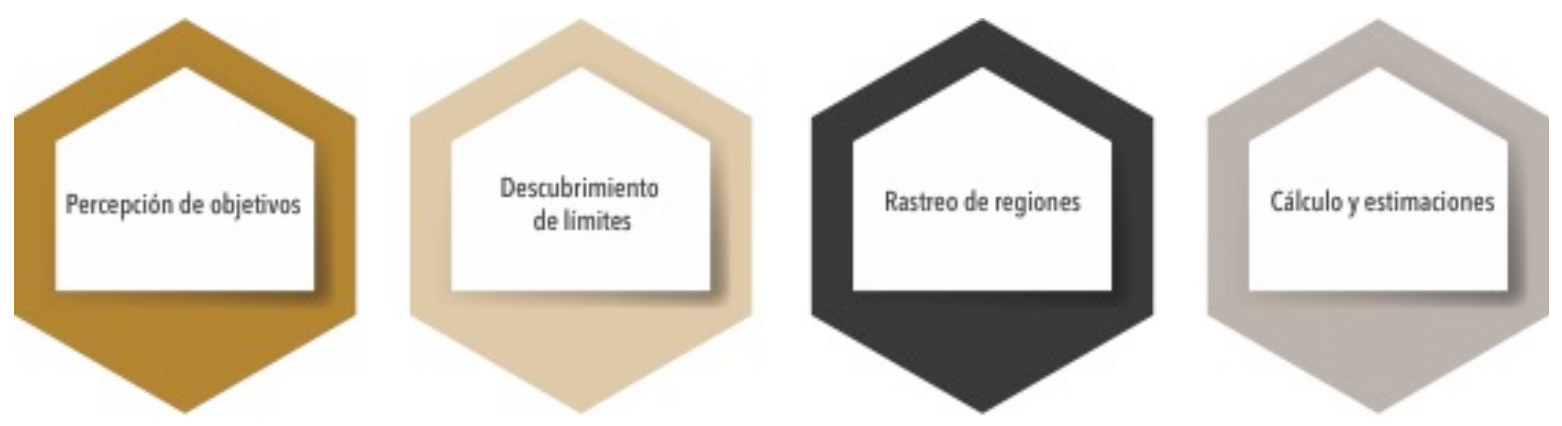

Figura 5. Caracteristicas preatentivas, de acuerdo a Mierelles (2912:22). Elaborada por Mariel Garcia Hémandez 
Como se argumenta previamente en el modelo de procesamiento de información de Ware (2012), el reconocimiento de patrones es esencial para que, la información que el ser humano recopila a través del sentido de la vista, se vuelva significativa para éste. Para que se de lugar a dicho acontecimiento, es necesario valerse de variables visuales, las cuales, según Marín Álvarez, (2011:75) "son aquellos estimulos que la percepción visual discrimina como diferentes, las cuales son esenciales para la construcción gráfica". Las variables visuales son un lenguaje destinado al ojo, se beneficia con las propiedades de ubicuidad de la percepción visual y obedece sus leyes.

\subsection{Variables visuales}

Olaya (s.f.), las variables visuales:

son los elementos básicos de la representación, son aquellos objetos geométricos de los cuales se compone ésta. Las variables visuales permiten diferenciar unos de otros y asignarles ciertas características, susceptibles a su vez de ser interpretadas junto al propio significado que el objeto pueda tener.

Las variables visuales constituyen un elemento importante dentro de visualización de información, ya que demás de ayudar al lector a detectar y reconocer patrones entre los datos expuestos, ayudan a éste a ordenar la información, atribuirles un significado y a generar juicios a partir de esto. Por lo tanto, podemos decir que es de suma relevancia hondar un poco en éstas y en su trascendencia en el proceso de percepción y, en el impacto que tienen en la lectura de cualquier tipo de sistema de visualización de información. 
Bertin (1983) definió siete variables visuales: posición, forma, tamaño, color, intensidad o valor de color, textura y orientación. Las cuales son definidas por Olaya (s.f.) de la siguiente manera:

1. Posición. Situación de localización que ocupa un símbolo en particular en el espacio. En un mapa, esto sería traducido como la posición del símbolo en algún valor de "x" o "y".

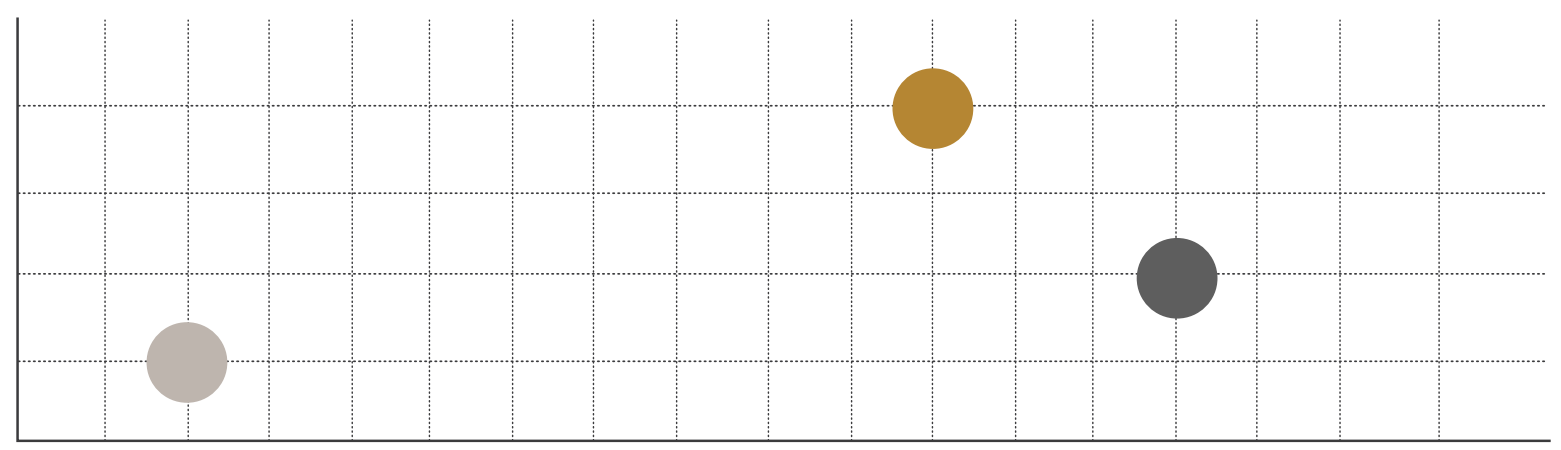

Figura 6. Variable visual: Posición

Elaborada por Mariel García Hernández

2. Forma. La forma es la figura o determinación exterior que la distingue. Ésta puede ser pictográfica ${ }^{19}$ o geométrica ${ }^{20}$. La forma viene definida por el perímetro exterior del objeto.

19 Imágenes que transmiten una idea a través de la representación de conceptos, objetos, situaciones o acciones de la realidad.

${ }^{20}$ Las figuras geométricas surgen como una idealización de las formas y estructuras observables en la naturaleza. 

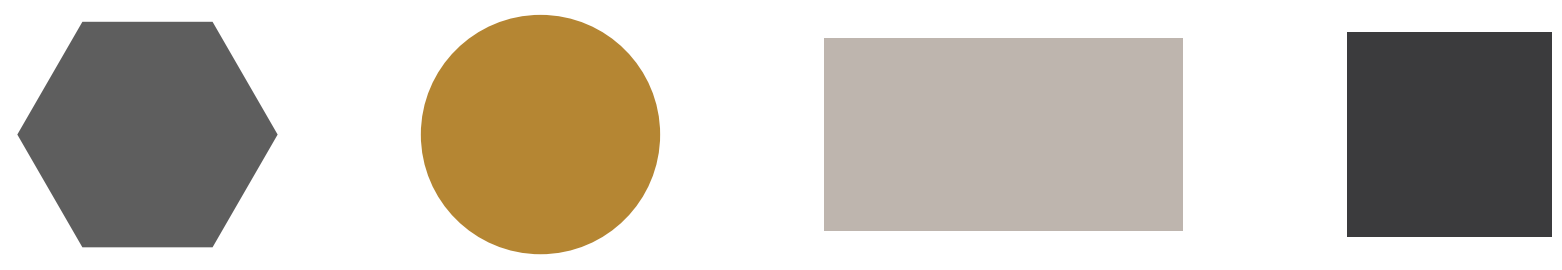

Figura 7. Variable visual: Forma.

Elaborada por Mariel García Hernández

3. Tamaño. Esta variable visual hace alusión a la proporción del objeto o del símbolo a representar. Los signos varían en tamaño en función de las dimensiones que presenta (diámetro, área, anchura, altura, etc).
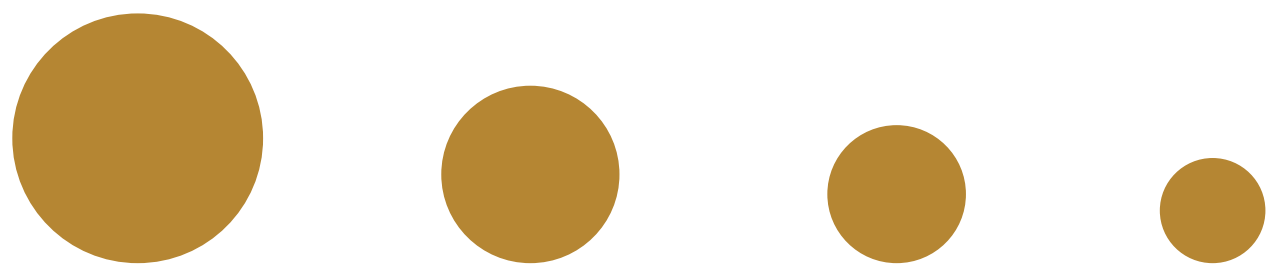

Figura 8. Variable visual: Tamaño. Elaborada por Mariel García Hernández

4. Color. Esta variable visual es de la más usada y compleja. El color responde a la longitud de onda de la luz, a esto se le llama tono, a lo cual denominamos como "rojo", "azul", "amarillo", etc.
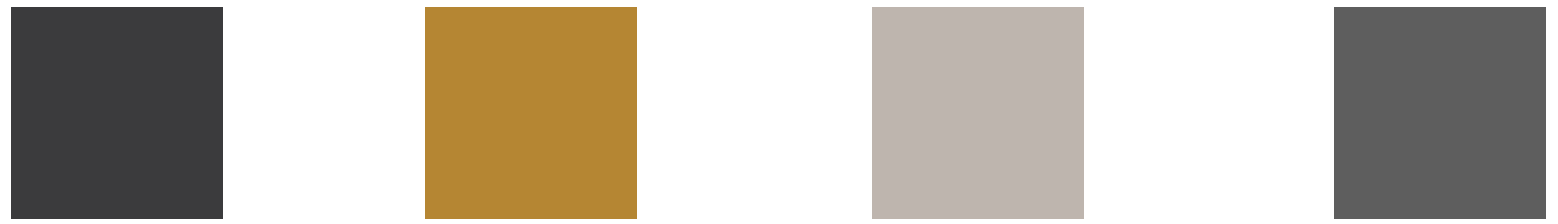

Figura 9. Variable visual: Color.

Elaborada por Mariel García Hernández 
5. Valor o intensidad de color. Hace referencia a la claridad u oscuridad de un símbolo, ya sea negro o de cualquier color. Podemos decir que esta variable hace referencia a la oscuridad relativa de un relleno.
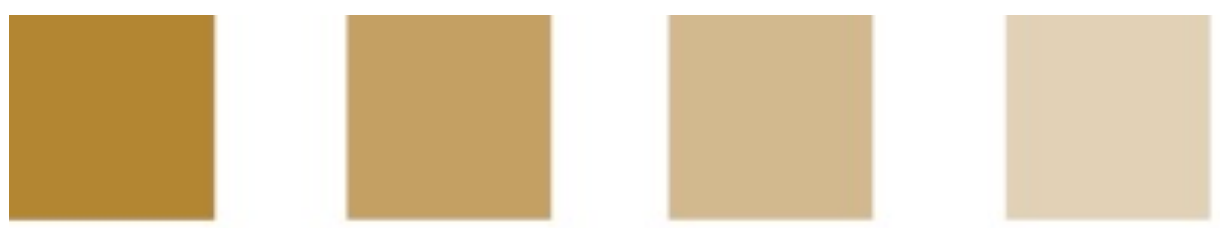

Figura 10. Variable visual: Tono o intesidad de color.

Elaborada por Mariel García Hemández

6. Textura. La textura hace referencia al relleno de un símbolo mediante algún patrón. Empleando patrones distintos se produce una diferenciación en los símbolos correspondientes. También esta variable hace referencia a la variación del espaciado de una marca en un signo.
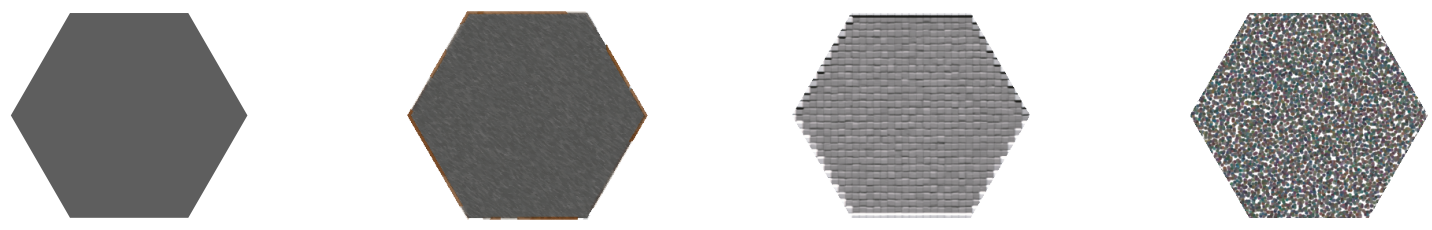

Figura 11. Variable visual: Textura. Elaborada por Mariel García Hernández 
7. Orientación. Es la variación de un símbolo al hacerle girar sobre el eje perpendicular del lienzo o soporte en donde el símbolo se encuentra.
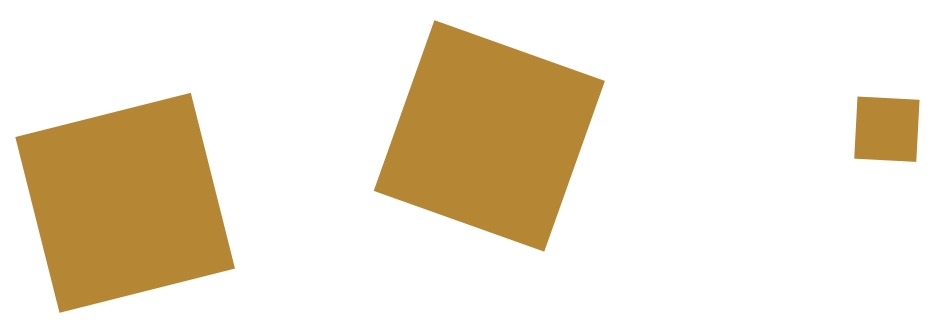

Figura 12. Variable visual: Orientación.

Elaborada por Mariel García Hérnandez

Utilizar estas variables visuales refuerza e incrementa el rendimiento de inferencia perceptiva y mejora el descubrimiento y el reconocimiento de patrones en un sistema de visualización de información.

El uso intencionado de estas variables visuales durante el procesamiento preatentivo, conforme a lo que argumenta Meirelles (2014:22), "facilita al usuario el completar tareas cognitivas que estén relacionadas con la estructuración y organización de información visual". 


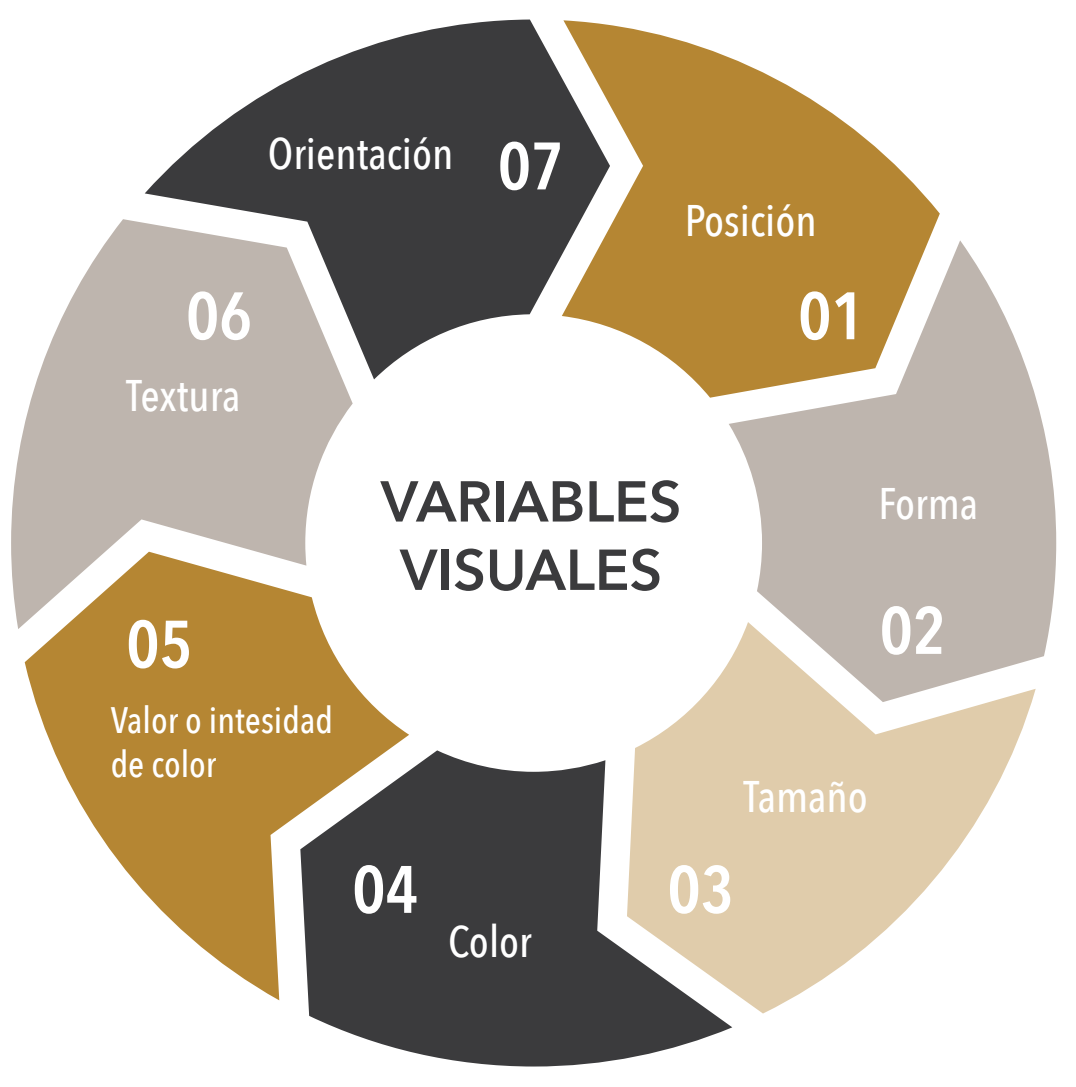

Figura 13. Variables visuales, según Olaya (s.f.)

Elaborada por Mariel García Hernández.

\subsection{Leyes de la Gestalt y la percepción visual}

Otro recurso que podemos implementar para poder ayudar al usuario a detectar y ordenar patrones en un grupo de información es el uso de las leyes de la Gestalt. Estas leyes proponen una serie de prinicipios que describen la forma en que detectamos patrones y cómo se integran las unidades inidividuales en una percepción coherente. Éstas pueden utilizarse como principios de diseño de visualizaciones de información para mejorar el descubirmiento de patrones y las inferencias perceptivas. 


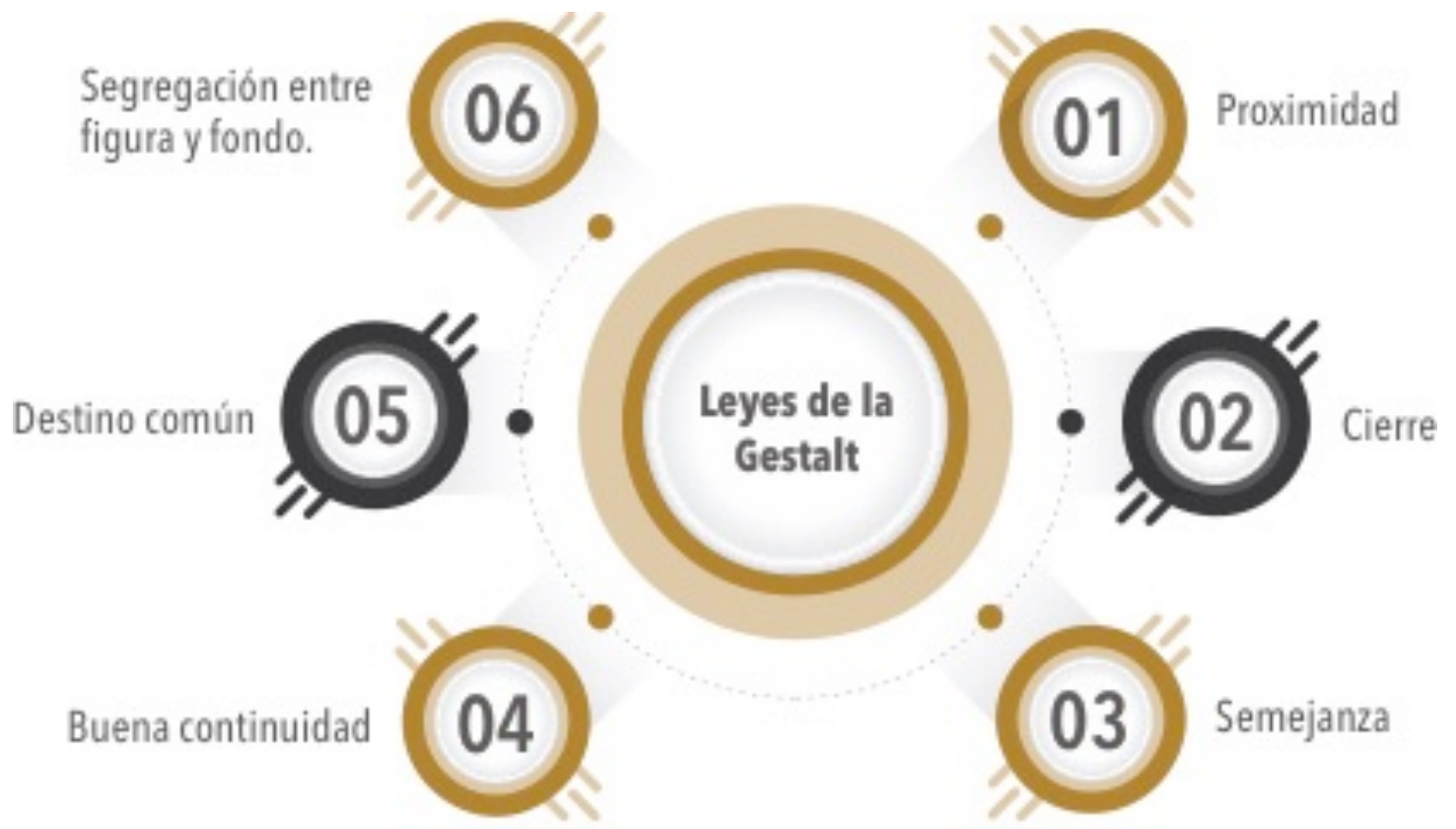

Figura 14. Leyes de la Gestalt de acuerdo a Wertherimer (1950).

Elaborada por Mariel Garcia Hernández

Las leyes de la Gestalt, para Wertherimer (1950), además de mejorar las inferencias perceptivas, facilitan los procesos de solución de problemas cognitivos. Este autor propone los siguientes mecanismos que facilitan la comprensión de estos problemas cognitivos, permitiendo que éstos se vean como un ente completo integrado y coherente:

1. Proximidad. Esta ley de la Gestalt explica" la tendencia de un grupo de elementos visuales que están cerca el uno del otro y forman una unidad perceptiva”, según explica Meirelles (2014:19). 
La proximidad, está relacionada, ya sea de forma intencional o no, con las características de ubicación y es fundamental para la asociación espacial de elementos.
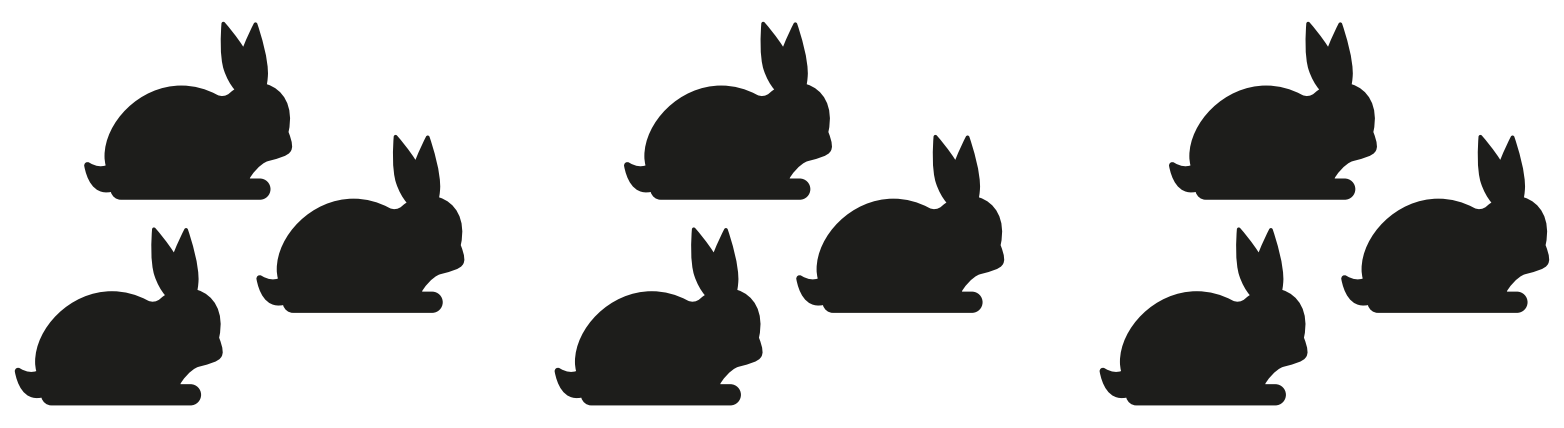

Figura 15. Ley de la Gestalt: Proximidad.
Elaborada por Mariel García Hernández

Presentamos dos imágenes conformadas por puntos ordenamos simetricamente. La diferencia entre ambas imágenes radica en que en una de ellas está a 90 grados respecto a la otra.

En la primera imagen, percibimos líneas y columnas en la otra. El espacio que encontramos entre los puntos, hace que percibamos como unidades lineales tanto en dirección horizontal como vertical.

Por lo tanto, en representaciones visuales, es de suma importancia situar cerca la información que está relacionada conceptualmente. Este principio facilita la deteccción y búsqueda de datos o infomación asociada entre sí. 


\section{0 \\ 00000000 \\ 00000000 \\ 00000000}

Figura 16. Ley de la Gestalt: Proximidad.

Elaborada por Mariel García Hernández

2. Cierre. El principio de cierre describe la tendencia de ver elementos visuales cerrados como un todo y a unir contornos. Según Meirelles (2014: 33), "incluso cuando los elementos cerrados se superponen, hay una tendencia —influenciada por el principio de la buena forma - a separar unidades y aplicar el cierre a unidades definidas".

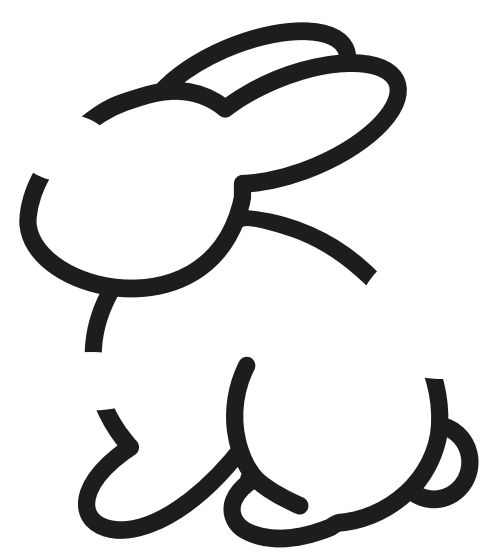

Figura 17. Ley de la Gestalt: Cierre.

Elaborada por Mariel García Hernández

Según la autora, es como si la mente "rellenara" las partes que faltan y "cerrará" el elemento visual. Este mecanismo de percepción, se polariza en 
la visualización de información, cuando por ejemplo, percibimos un diagrama de Venn y utilizamos este principio para extraer información.

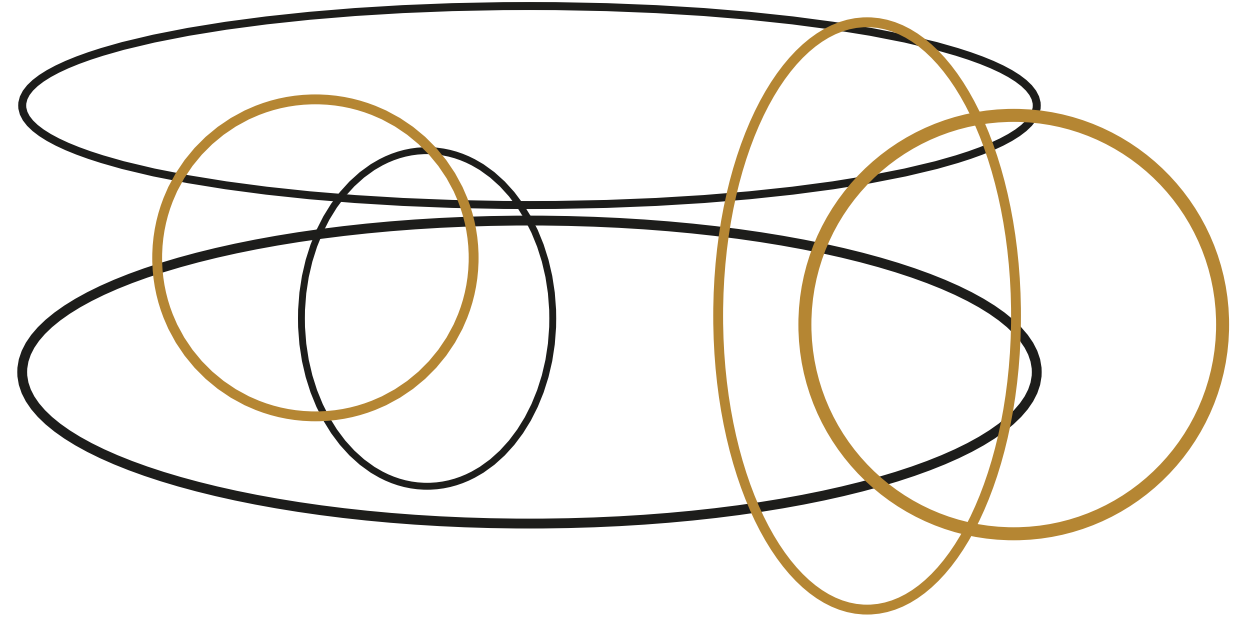

Figura 18. Ley de la Gestalt: Cierre. Elaborada por Mariel García Hernández

3. Semejanza. Este mecanismo se basa en la tendencia de agrupar elementos visuales similares en una única unidad perceptiva. Como se explicaba previamente, la mente agrupa objetos que comparten variables visuales en cómun, ya sea el color, la forma y/o la textura.

La semejanza es indispensable en la asociación por categorías. Un ejemplo de este principio en la visualización de información, es el uso de un código de color para distintas categorias, ya que esto facilita y mejora la búsqueda y comparación entre ellas. 


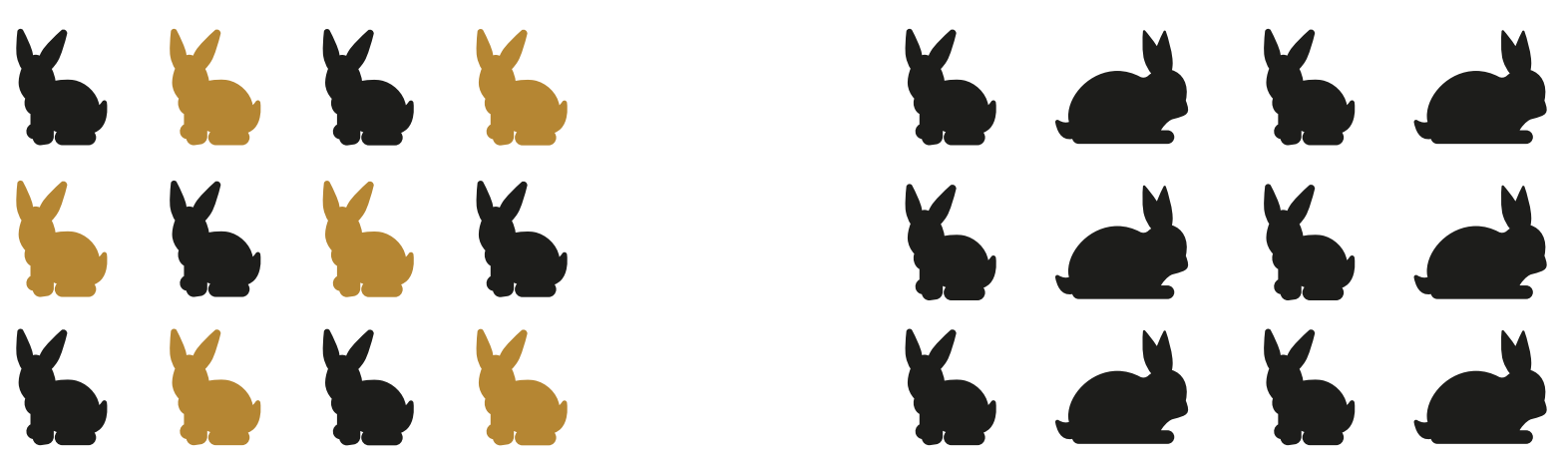

Figura 19. Ley de la Gestalt: Semejanza.

Elaborada por Mariel García Hernández

4. Buena continuidad. "Es la tendencia a construir entidades visuales a partir de elementos visuales que son fluidos y continuos, o están contectados mediante líneas rectas o curvas suaves", según Meirelles (2014:58). Podemos experimenar este principio en la visualización de información en figuras como los mapas, ya que, por ejemplo, los contornos de los estados se diferencian de las carreteras o de los ríos. Este principio tiene un rol importante en el desarrollo de redes con diversas conexiones.

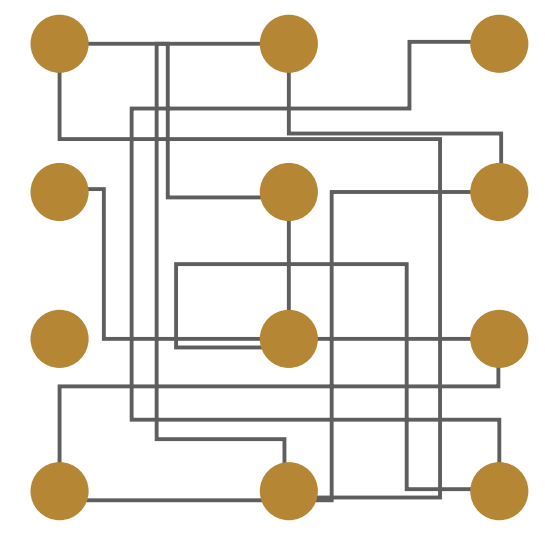

Figura 20. Ley de la Gestalt: Buena continuidad. Elaborada por Mariel García Hernández 
5. Destino común. Este mecanismo se enfoca en agrupar elementos que se mueven en la misma dirección. S e presenta un ejemplo a continuación, en donde observamos que se disintgue de mejor forma las líneas paralelas a diferencia de las líneas no paralelas.
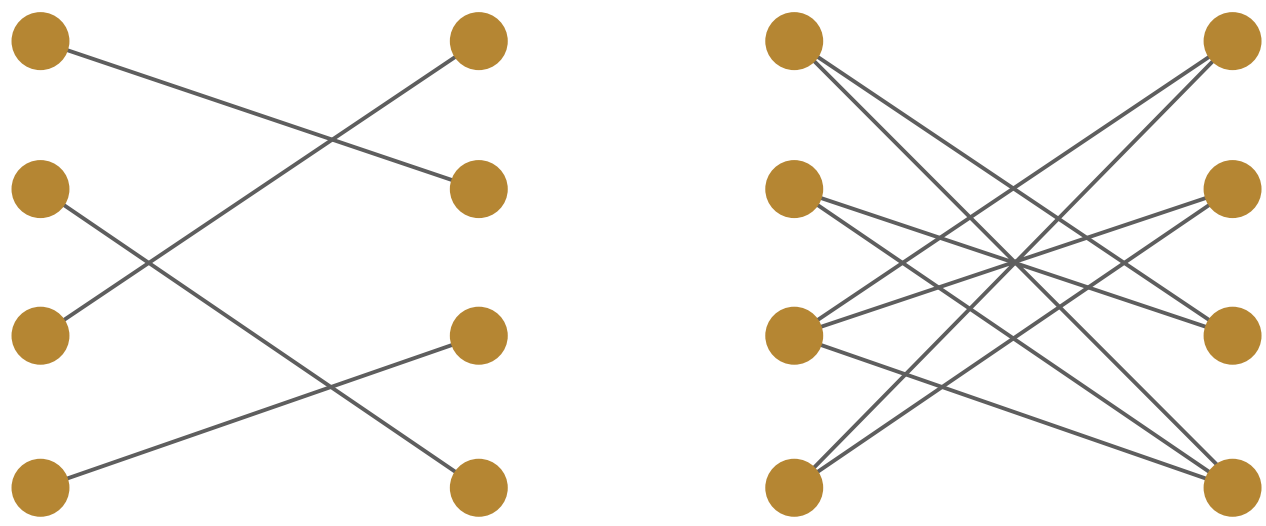

Figura 21. Ley de la Gestalt: Destino común.

Elaborada por Mariel García Hernández

6. Segregación entre figura y fondo. Este principio hace referencia a la tendencia de nuestro cerebro de organizar los elementos visuales en unidades y construir relaciones.

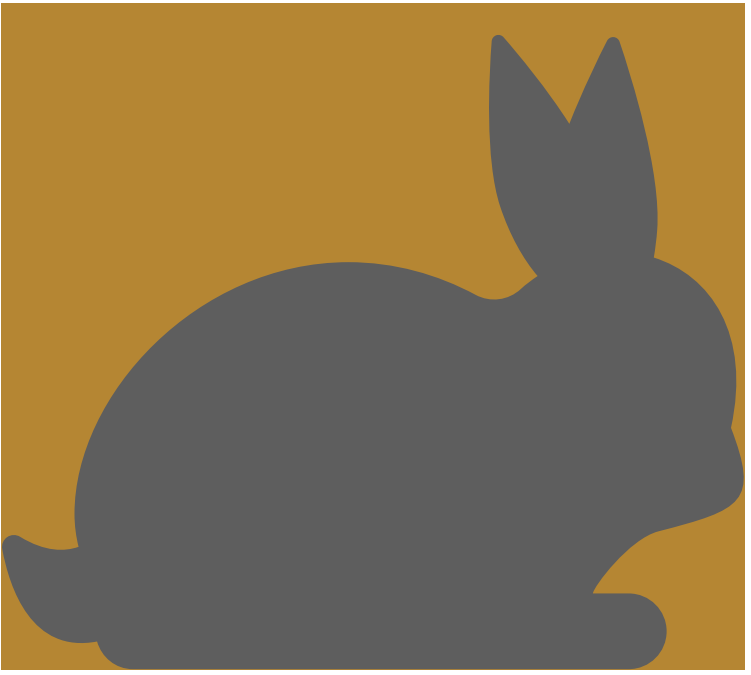

Figura 22. Ley de la Gestalt: Segregación entre figura y fondo.

Elaborada por Mariel García Hernández 
Algunos elementos, durante este proceso, se seleccionan figuras y el resto como fondo.
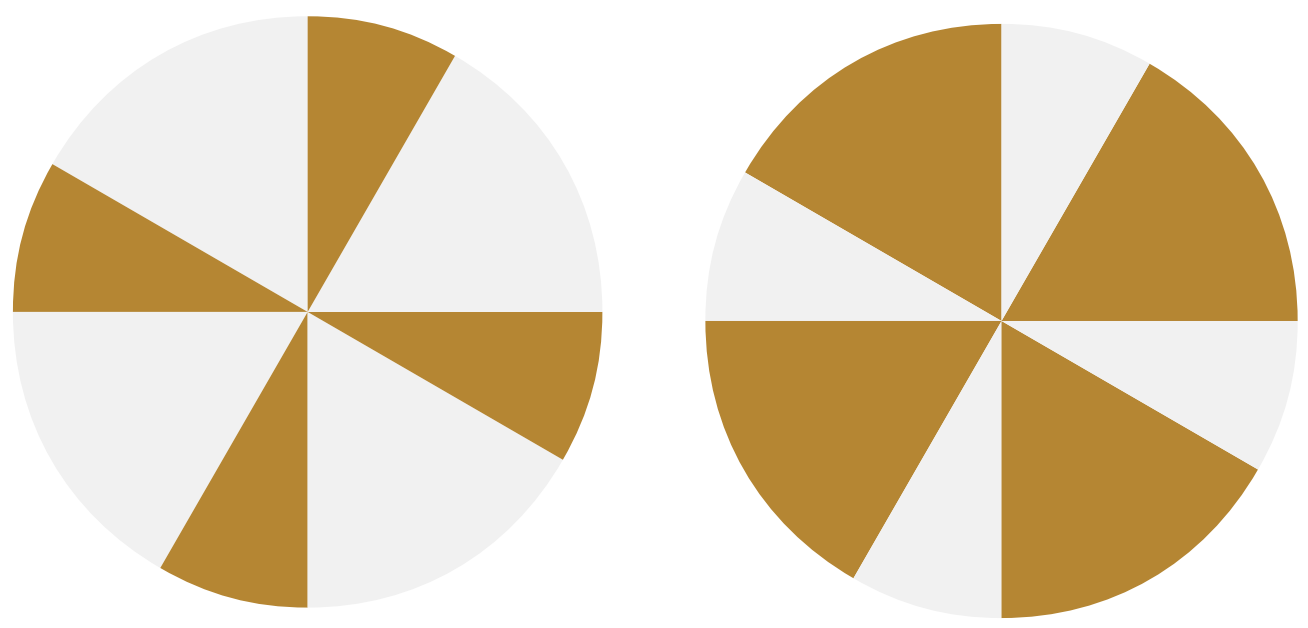

Figura 23. Ley de la Gestalt: Segregación entre figura y fondo.

Elaborada por Mariel García Hernández

La detección de límites es el factor central a la hora de percibir objetos, ya que si no se tienen estos elementos, se genera una ambigüedad y éstos se pueden percibir como reversibles. Este mecanismo de la Gestalt es un proceso dinámico, según lo describe Meirelles (2014:126), ya que "la percepción salta de una imagen posible a otra sin estabilidad".

En temas de visualización de información, existen ciertas gráficas que mejoran la segregación de figura y fondo, por ejemplo, "la variable gráfica de la escala puede influir en cómo se perciben los objetos: una forma más pequeña dentro de otra mayor será vista como la figura", según establece Meirelles (2014:126). Otra tendencia que podemos señalar, de acuerdo a la 
autora es la de "percibir las regiones inferiores en una disposición como más propensas a ser la figura que las regiones en la parte superior". Podemos ejemplificar esta premisa en la figura que a continuación se presenta, en donde a pesar de la diferencia de color, la región inferior de ésta es la que se percibe inmediatamente por el lector.
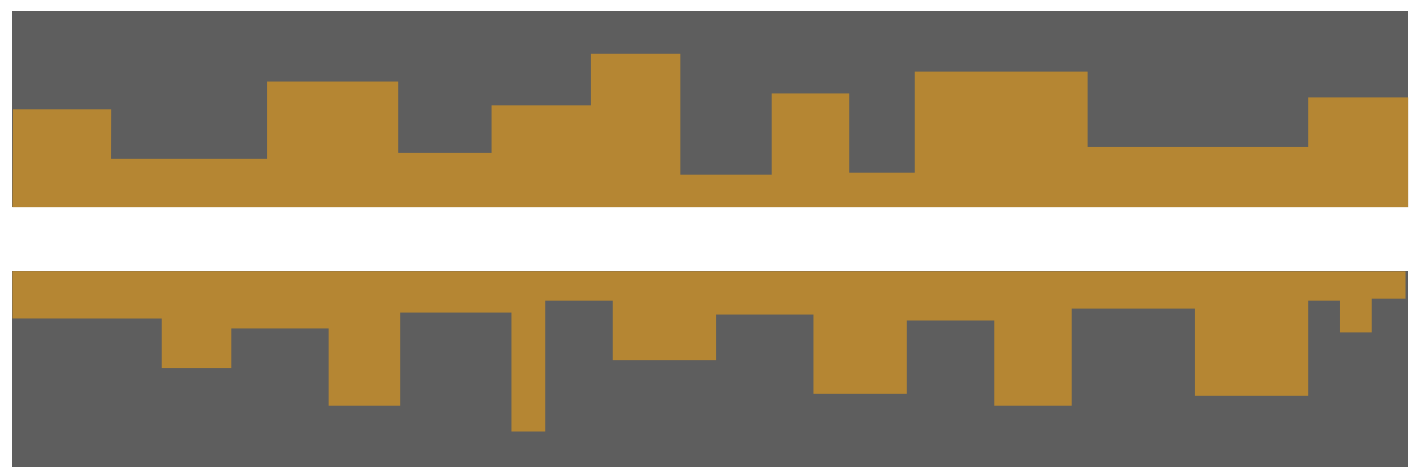

Figura 24. Ley de la Gestalt: Segregación entre figura y fondo. Elaborada por Mariel García Hernández

Los principios de la Gestalt, según Olmeda Gómez (2014: 128), se relacionan con una "posibilidad del manejo del lenguaje visual en la creación de composiciones gráficas", por lo cual, podemos inferir que dentro del campo de la visualización de información, podrían valerse como parte de la configuración del mensaje visual. Estas leyes ofrecen elementos para pensar en crear una gramática sólida de la composición visual que se busca explorar en esta investigación doctoral.

Después de haber analizado modelos de percepción visual, el procesamiento de información visual propuesto por Colin Ware, los principios visuales de la composición de la grámatica visual y sus variables visuales, nos resulta prudente 
decir que estos elementos son esenciales para la visualización de información, ya que son éstos son la base y la antesala para lo que Ware (2012:18) define como" la meta y objetivo principal de esta disciplina: la toma de decisiones a través de información significativa para el usuario".

A modo de conclusión en este capítulo, cabe mencionar que la imagen es un fragmento de la realidad que percibimos, y que ésta es traducida para su entendimiento y significación a través del proceso de percepción visual. Dicho proceso es una herramienta cognitiva, que funge como base de acción a la visualización de información, siendo el reconocimiento de patrones su objetivo principal. La percepción pasa de ser un proceso fisiológico a uno en donde se entre mezclan significados, experiencias y conceptualizaciones del lector que recibe la información visual. Ésta es la base de todo trabajo de diseño, ya que podemos definir a ésta como el punto de encuentro en donde el usuario, a través del sentido de la vista, experimenta, define y configura su realidad en términos visuales. Para lograr una significación sustancial del mensaje visual, es recomendable emplear y valerse de las diversas herramientas de configuración visual como son las variables visuales; color, forma, orientación, textura, tamaño, posición o intensidad del color, así mismo, el uso de las leyes de la Gestalt, tales como la ley de la proximidad, el cierre, la similitud, la buena continuidad, destino común y la segregación entre figura y fondo, de tal forma, para que el lector, pueda facílmente "transformar" todos esos estímulos sensoriales en información valiosa. 


\section{CAPÍTULO 3 La interfaz gráfica}




\section{La interfaz gráfica}

El producto final de esta tesis doctoral consiste en la propuesta de guías de usabilidad para el diseño de interfaces gráficas de sistemas de visualización de información médica. Dichos lineamientos tienen, como su nombre lo incluye, el objetivo de asegurar que el diseñador que tome como base estas guías, pueda asegurar la facilidad de uso y comprensión de la información que es presentada en el artefacto de diseño que está generando. Es por ello por lo que resulta importante analizar lo que es la usabilidad y la ergonomía cognitiva, ya que dichas disciplinas se encargan de asegurar esta facilidad de uso y compresión. Así como es importante hablar sobre lo que es una interfaz gráfica, ya que es el soporte en el cual el diseñador trabaja cuando se desarrollo un sistema de visualización de información.

\subsection{Definición de interfaz gráfica.}

La interfaz es un punto medular en esta tesis doctoral, ya que a partir de las guías de usabilidad se pretende desarrollar dicho artefacto de diseño, es por lo cual resulta importante definir este concepto.

Para Bonsiepe (1999), la interfaz es el satisfactor de una cierta necesidad de un usuario en especial y del entorno de éste. La interfaz, conforme a este mismo autor, existe cuando hay una interacción "real" entre el usuario, una necesidad y un objeto satisfactor de esta necesidad. Shneiderman (2005:4) define a la interfaz como "la 
membrana de comunicación entre los usuarios y el sistema por la que los diseñadores y desarrolladores de herramientas informáticas pueden hacer que la tecnología sea inteligible y sensible a las necesidades de los usuarios", por su parte, podemos señalar que la interfaz es un espacio o superficie que articula o conecta la interacción entre el ser humano (usuario) con el artefacto (lienzo) y el objetivo de una acción (aprendizaje), a partir de lo que describe. (Rodríguez Rivera, 2005)

Habiendo puntualizado en las definiciones que exponen los autores previamente mencionados, procedemos comenzar a definir el concepto de interfaz gráfica. Según Luna González (2004:4), una interfaz gráfica está compuesta por “elementos gráficos que nos ayudan a comunicarnos con un sistema o estructura". Delgado Vargas (2017:8), señala que la interfaz gráfica:

"se puede considerar como un mediador visual que facilita la comunicación fluida y clara entre un sistema y el usuario para facilitar su comprensión y uso. Ésta por lo general, se manifiesta en un entorno gráfico compuesto principalmente de imágenes y objetos para representar la información y las acciones disponibles para ejecutar".

A partir de esto podemos decir que la interfaz gráfica es un tipo de soporte que está conformado por íconos, figuras, imágenes y texto, la cual sirve como medio de comunicación e interacción entre el usuario y su necesidad cognitiva (aprendizaje).

\subsection{Componentes de la interfaz gráfica.}

La interfaz gráfica para fungir como soporte está necesariamente integrada por diversos elementos visuales. Según Luna González (2004:5), dichos componentes son los siguientes (Figura 1): 
1. Color.

2. Tipografía.

3. Imagen.

4. Composición.

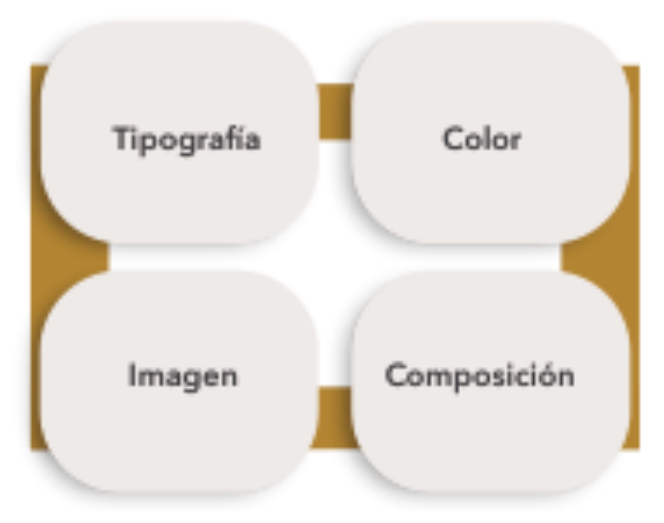

Figura 1. Elementos visuales que componen a la interfaz grafica, según Luna-González (2004:5). Elaborada por Mariel Garcia Hemández.

Para Velasco, Laureano, Mora y Herrera (2010), el color es "un elemento clave en el diseño, ya que antes de iniciar la lectura de un texto o comprender una imagen, el color ya empieza a transmitirnos un mensaje". Hemos explorado el concepto de color en capítulos anteriores y su importancia en la construcción de la imagen misma. Por otra parte, la tipografía para Prado León \& Ávila- Chaurand (2003:109) "se refiere al estilo, arreglo y apariencia de la letra". El uso y elección de un estilo tipográfico debe considerar al usuario y su situación de lectura, de tal forma en que esto, según los mismos autores no afecte la legibilidad ${ }^{21}$ y la leibilidad ${ }^{22}$ del texto.

\footnotetext{
${ }^{21}$ Según Prado-León \& Ávila-Chaurand (2003:110), desde el punto de vista de la ergonomía, la legibilidad es "es la facilidad de identificar caracteres alfanuméricos individuales".

${ }^{22}$ Prado-León \& Ávila-Chaurand (2003:110), la leibilidad se refiere a "la facilidad de comprensión de lectura, asumiendo que los caracteres individuales son legibles".
} 
En cuanto al concepto de imagen como integrante de la interfaz gráfica, Luna González (2004:6) la define como "un elemento meramente visual que se utiliza para representar objetos, sujetos o situaciones ficticias o reales, que evocan expresiones y sentimientos para transmitir un mensaje", de igual forma ,el concepto de imagen ha sido abordado en el capítulo anterior.

La composición en la interfaz gráfica puede ser entendida como el uso de un orden jerárquico en cuanto al acomodo de los diversos elementos que componen a la misma (tipografía, imagen, elementos gráficos, etc.).

Al haber puntualizado en lo anterior, podemos decir, que la composición dentro de la interfaz gráfica está ligada estrechamente con el uso de retícula. La retícula, como lo señala Andrés (2008:28), "supone una forma de presentar juntos todos los elementos de la interfaz y aportar a la maquetación orden, diferenciación, precisión y facilidad en la comprensión de la información". En el próximo capítulo, en donde presentamos propiamente las guías de usabilidad para el desarrollo de interfaces gráficas de sistemas de visualización médica, desarrollamos más a fondo el tema de la retícula y sus tipos.

Por su parte, Prado León \& Ávila Chaurand (2010) en su libro "Percepción visual II, aplicaciones para el diseño", desglozan los elementos que componen a la interfaz de la siguiente manera (Figura 2):

1. Tipografía.

2. Color. 
3. Tablas, gráficas y símbolos gráficos.

4. Semántica y sintáctica de la información.

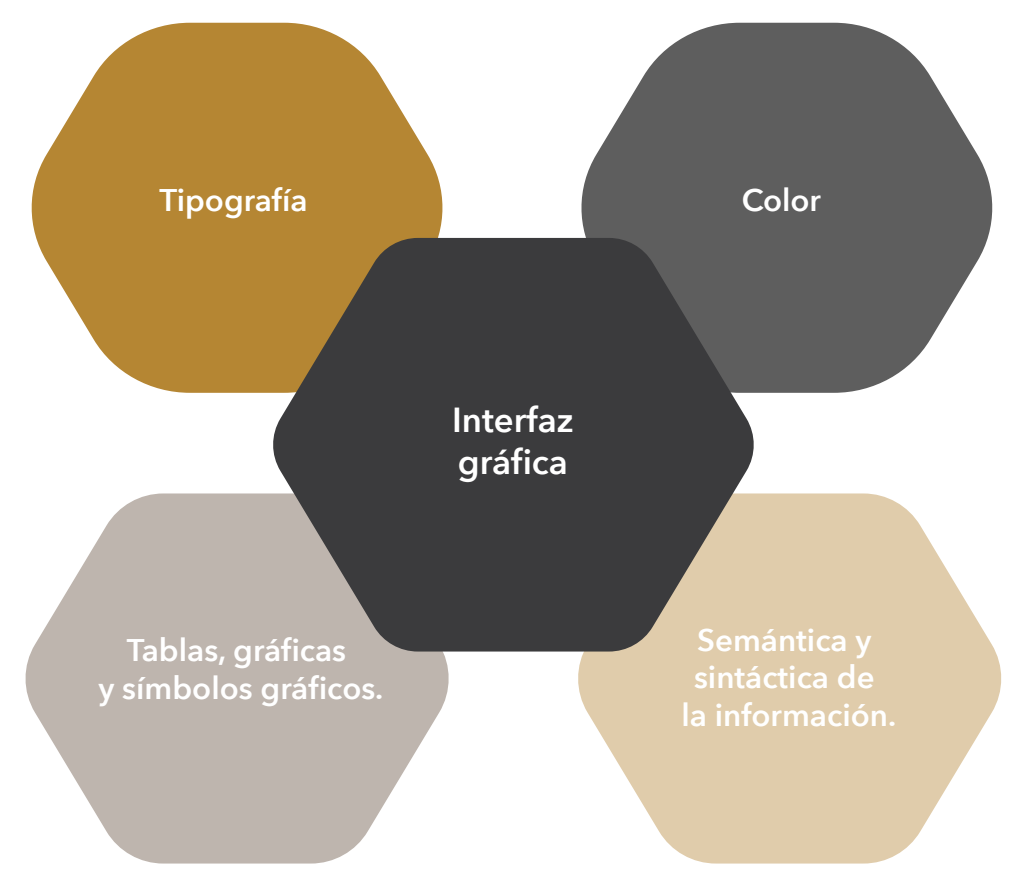

Figura 2. Elementos visuales que componen a la interfaz gráfica, según Prado-León \& Ávila-Chaurand (2010). Elaborada por Mariel García Hernández.

En cuanto a la definición de tipografía y color ya se ha abordado en párrafos anteriores, por lo cual puntualizaremos en los últimos dos elementos de esta propuesta estructural de parte de los autores. Para Prado León \& Ávila Chaurand (2003:66) cuando hablamos de tablas y gráficas, nos referimos a "herramientas para el descubrimiento de ideas", las cuales son utilizadas sobre todo en el análisis exploratorio de datos, las cuales ayudan a "identificar información relevante de un grupo de datos, así como ganar nuevos indicios o entendimiento de un problema". Idem (2010:39) define a los símbolos gráficos como "símbolos abstractos o arbitrarios sin significado obvio, lo que implica que la asociación entre el significante 
y el significado debe ser aprendida". En cuanto a la semántica y sintáctica de la información, Prado León \& Ávila Chaurand (2003:57), establecen que está relacionada con "la forma de presentación de la información". Dentro de este concepto cabe destacar los siguientes niveles (Figura 3):

1. Nivel sintáctico. El orden en que son presentadas las palabras repercutirá en facilitar la compresión del lector durante su proceso cognitivo.

2. Nivel semántico. Este nivel, en cuanto a la interfaz gráfica y su composición, se puede contextualizar como la forma en que es percibido el mensaje a través de palabras, en donde éstas proporcionan un claro significado al lector de lo que se está tratando de decir.

Según López Rodriguez (1993:459), existe un tercer nivel, al cual el autor define como pragmático. El nivel pragmático es aquel en donde "los signos deben, forzosamente, quedar comprendidos dentro de las prácticas socioculturales del receptor de la información", así mismo el autor señala que "este nivel implica los aspectos visuales y gráficos que están ligados con dichas prácticas cultuales del receptor".

Algo que afecta directamente a esta condición es la carga de la información que le es presentada al usuario, es decir, "la densidad de información", según Prado León \& Ávila Chaurand (2003:61), por lo cual, es de importante tomar en cuenta el manejo de los niveles que se han puntualizado anteriormente. Sin embargo, desde el punto de vista de la usabilidad (término lo exploraremos más adelante), resulta relevante enfatizar a un úlitmo elemento que se debe considerar como propio de la estructura 
o composición de ésta, ya que las decisiones de diseño tendrán que ser encaminadas a las necesidades cognitivas de éste; el usuario.

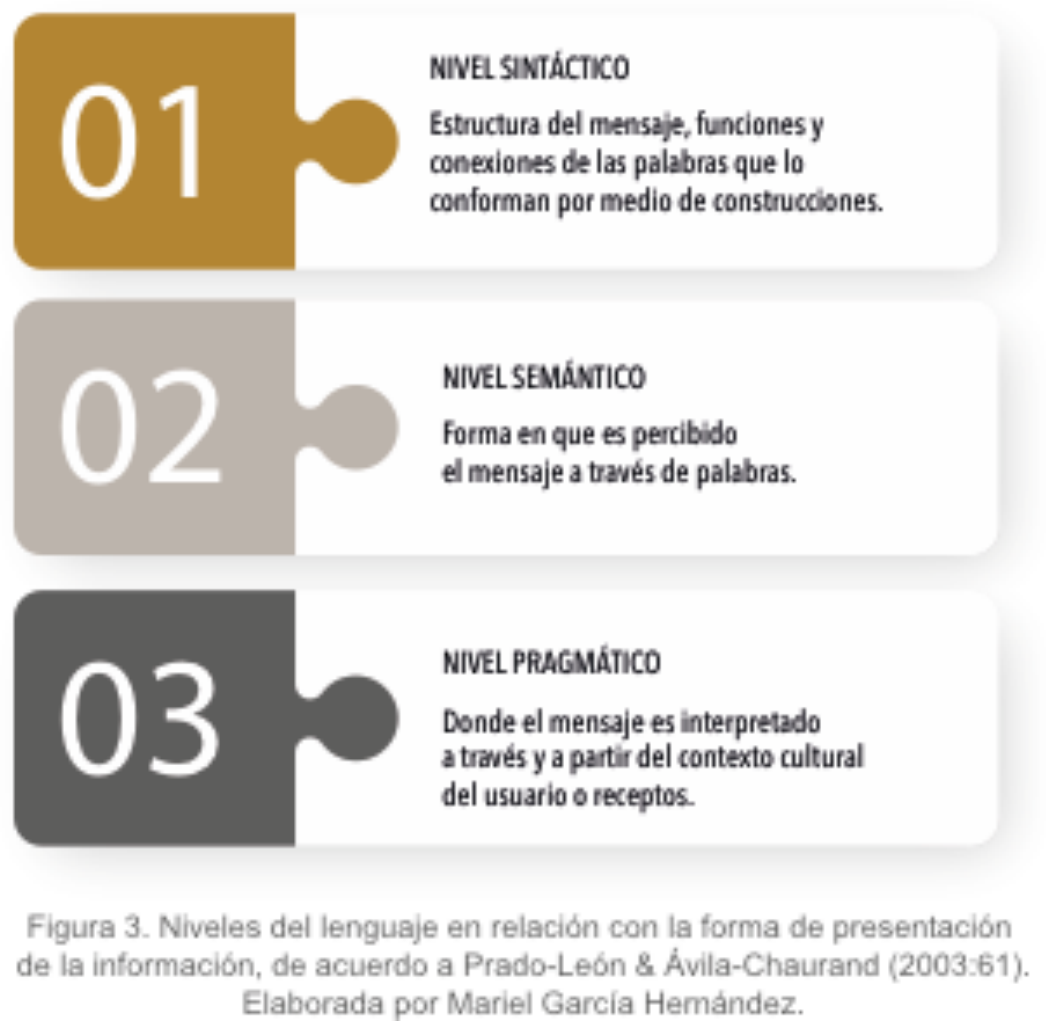

Para Frascara (2011:23), "la efectividad de la comunciación depende en gran medida de su adecuación al usuario", es decir, que todas las estretagias y consideraciones formales de diseño deben ser tomadas de acuerdo a las necesidades del usuario y por ello, el grado de efectividad se verá influenciada. El diseñador debe reconocer al usuario como un ser independiente, es decir, con una edad en especial, un determinado sexo, un nivel socioeconomico y nivel académico especifico, el cual, "tiene pensamientos, gustos, opiniones y preferencias que pueden ser ajenos al del propio diseñador", (ver Figura 4) Frascara (2011:23). Al reconocer al usuario como un ser independiente, el diseñador podrá generar 
artefactos de diseño que respondan a las necesidades particulares del usuario. Así como también, Donald Norman (1990), resalta que los productos deben responder a las necesidades, motivaciones y capacidades de los usuarios.

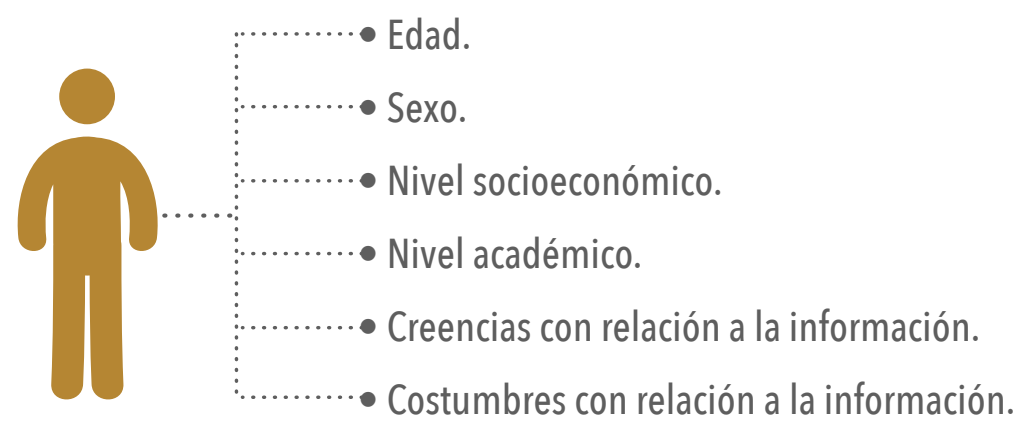

Figura 4. El usuario como ser independiente y como eje importante en la toma de decisiones de diseño según Frascara (2011).

Elaborada por Mariel García Hernández.

Después de haber presen las consideraciones anteriores, según a diversos autores sobre los elementos que constituyen el desarrollo de la interfaz gráfica, podemos establecer los items que serán considerados como puntos fundamentales del producto final de esta tesis doctoral (ver Figura 5), ya que estos ítems, como lo hemos visto, son parte escencial en la estructura y desarrollo de interfaces gráficas, ya que son puntos de partida y a la vez de sorporte para el proceso de diseño.

- Usuario.

- Color.

- Texto.

- Elementos gráficos.

- Estructura de la información. 


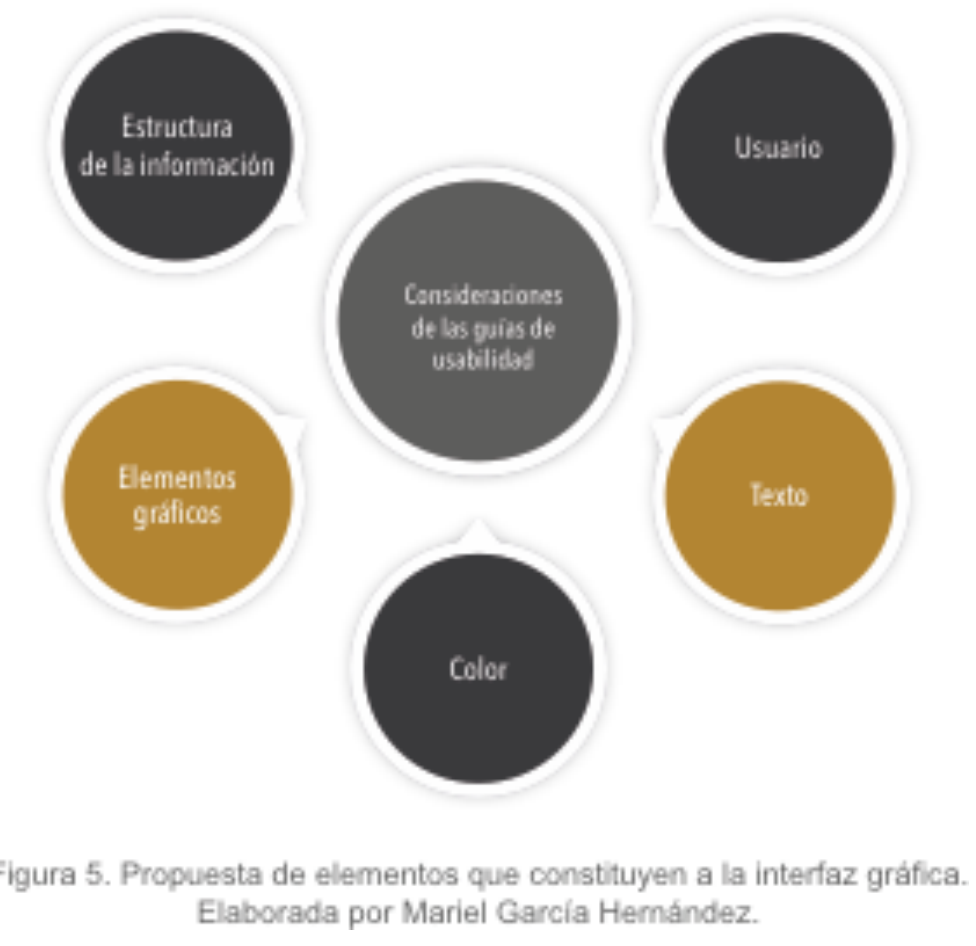

Cuando nos referimos al usuario, nos remitimos al apartado anterior como aquel que será el "consumidor" de la información con la que se trabajará. En donde, se sugiere tomar en cuenta todos los aspectos que engloban al usuario como un ser independiente considerando principalmente sus necesidades cognitivas.

Al hablar de texto, nos referimos tanto a la elección tipografíca que utilizará el diseñador para plasmar la palabra escrita, así como también, a los anchos de línea, interletrado de las cajas de texto que aparecerán en la interfaz gráfica.

De igual manera, se consideran también, la jerarquía que la propia tipografía puede establecer de una manera visual, también se pondera el uso de las variantes de 
carácter (bold, itálica, etc.) y su uso recomendado dentro del desarrollo de la interfaz gráfica.

En cuanto al item color, se hablará de contrastes entre texto, figura y fondo. Así como la elección de la paleta cromática para el desarrollo de estas interfaces. De igual forma, nos referimos a consideraciones en cuanto al uso de degradados, efectos especiales y demás variaciones del color que se pueden encontrar en este tipo de artefactos de diseño.

En el apartado de elementos gráficos se engloba el uso de diagramas, tablas, figuras de decodificación de información (enunciados previamente en el capítulo sobre la visualización de información), el uso de pictogramas, emojis o emoticons ${ }^{23}$.

Y por último, en el apartado de estructura de información, nos referimos a consideraciones de jerarquización de la propia información, desde una perspectiva visual como semántica. Así mismos, se aborda el tema del uso de retículas y sus diferentes tipos.

\footnotetext{
${ }^{23}$ Los emojjs son símbolos gráficos del tipo Unicoide, que se utilizan como para abreviar y expresar ideas o conceptos de algo en particular.
} 


\subsection{Factores a considerar para el diseño de interfaces gráficas}

Después de haber descrito los componentes que constituyen a la interfaz gráfica y así como aquellos ítems que se tomarán en consideración para el desarrollo de las guías de usabilidad para el desarrollo de interfaces gráficas de sistemas de visualización de información médica, resulta importante hablar sobre aquellos factores que se deben ponderar a la hora de desarrollar este tipo de artefactos de diseño. Según a lo que establece Rodríguez Rivera (2005), se deben considerar cinco elementos para el desarrollo de interfaces gráficas:

- Usuario.

- Análisis de tareas del usuario.

- Contenido.

- Forma de presentar el contenido.

- Navegación.

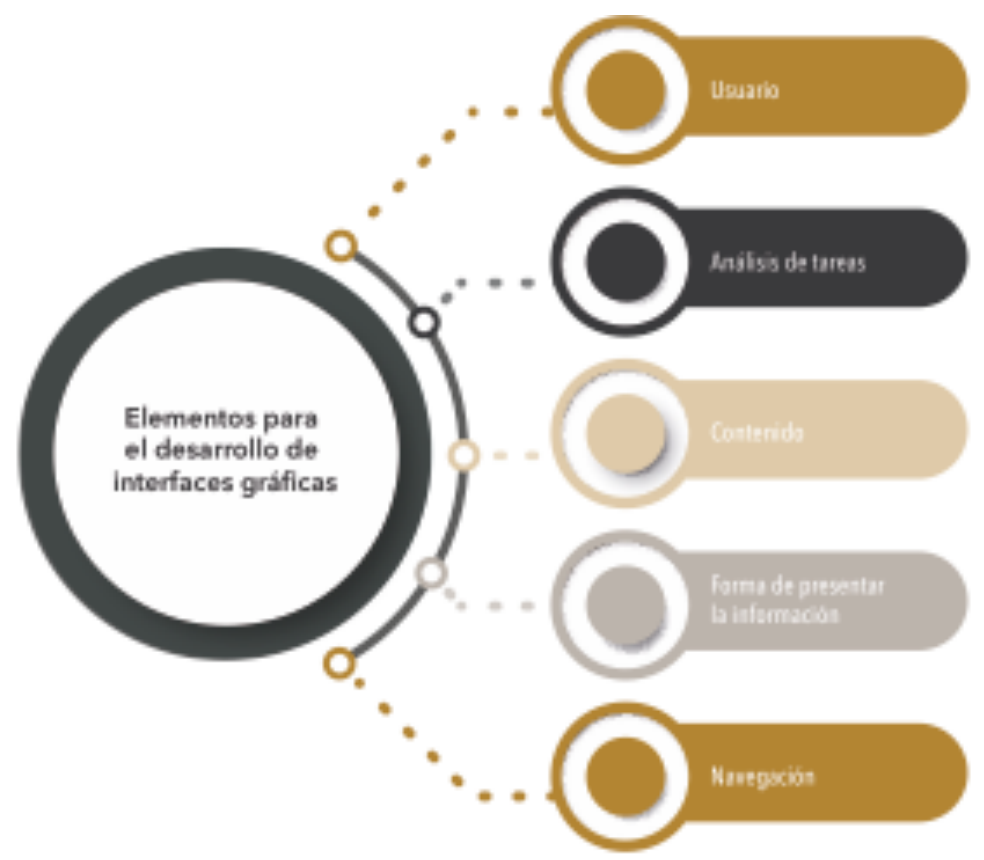

Figura 6. Elementos para el desarrollo de interfaces gráficas, de acuerdo a Rodriguez Rivera (2005). Elaborada por Mariel García Hemández. 
Como ya mencionamos en el apartado anterior, el usuario es aquel que interactuará y "consumirá" la información que se está trabajando y presentando dentro de la interfaz gráfica. Rodríguez Rivera (2005) hace énfasis en que es importante tener claro el perfil psicológico (edad, sexo, estilo de aprendizaje), demográfico (localización geográfica) y psicosocial (contexto socio-cultural, creencias y experiencias previas con respecto a la información) del usuario para poder generar un artefacto de diseño que cubra las necesidades cognitivas de éste así como, poder asegurar un buen rendimiento en la experiencia del usuario con respecto a la interfaz que se está desarrollando. Cuando hablamos de las necesidades cognitivas del usuario, necesariamente éstas están ligadas con términos de usabilidad, según Albornoz, Berón, \& Montejano (2017), conforme a estas necesidades cognitivas del usuario, la interfaz en correlación con la usabilidad, de dicho artefacto de diseño son las siguientes (ver Figura 7),:

1. Satisfactoria. Esto se refiere a que el usuario se sienta cómodo cuando interactúa (lea y navegue) con la interfaz.

2. Efectiva. Este término está ligado con el hecho de que este producto de diseño haga eso para lo que fue diseñado.

3. Eficiente. Cuando hablamos de eficiencia nos referimos al hecho de que dicho artefacto ejecute sin errores y en el tiempo esperado eso para lo que fue creado. 


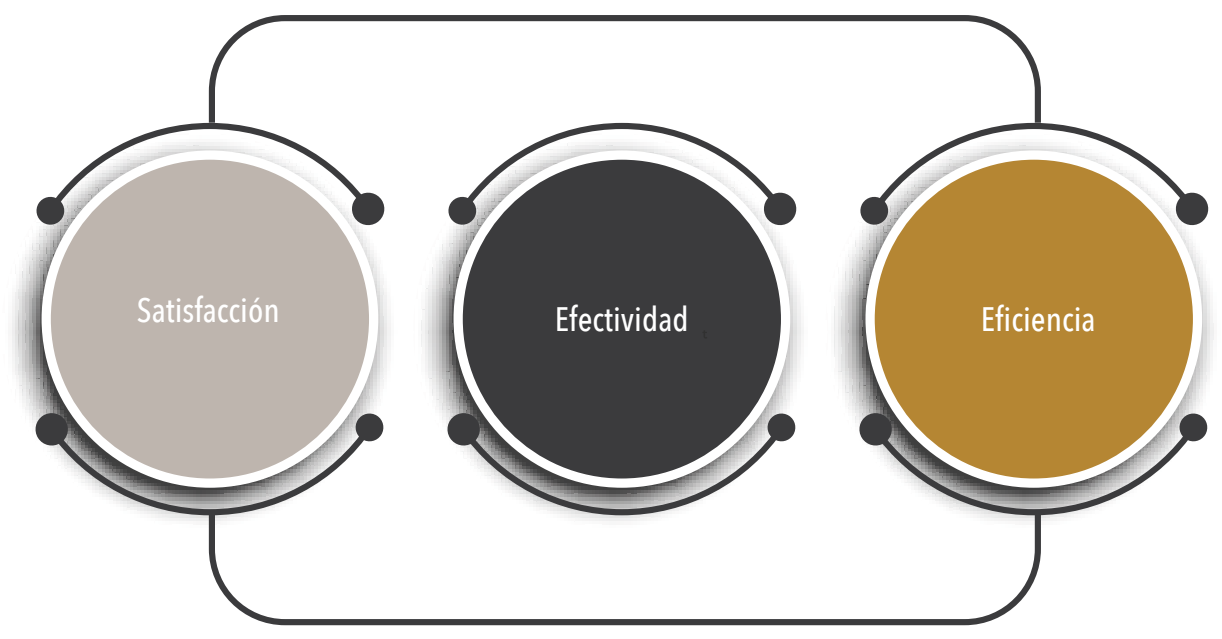

Figura 7. Carácteristicas de usabilidad que debe cubri la interfaz en correlación con las necesidades cognitivas del usuario.

Elaborada por Mariel García Hernández.

Después de haber resaltado lo anterior, el producto de esta tesis doctoral, acorde al protocolo de usabilidad descrito en el capítulo siguiente que se implementará para evaluar las guías de usabilidad, contemplaran que dichas características se cumplan por parte de dicho artefacto de diseño en correlación con las necesidades cognitivas del usuario.

En cuanto al análisis de tareas del usuario, para Preece et al. (1994), podemos definir a este concepto como un grupo o conjunto de técnicas que se encargan de estudiar como el usuario realiza una tarea en particular. Según lo que establecen Perurena Cancio \& Moragez Bergues (2013), el análisis de tareas del usuario se encarga de describir las acciones que el usuario debe realizar para completar una tarea determinada. Por su parte, para Rodríguez Rivera (2005:3), el análisis de tareas es "observar y analizar como se desempeña en las actividades cotidianas, que factores (sociales y culturales) influyen en dicho desempeño, que elementos 
apoyan o impiden cumplir las metas fijadas." Por lo cual, es importante que el diseñador defina aquellos objetivos, desde el punto de vista de información, que la interfaz debe cumplir, para posteriormente pasar a las tareas que el usuario necesita alcanzar y a su vez satisfacer desde el punto de vista de cognitivo.

El contenido, según lo definen Hassan Montero \& Núnez Peña (2005), son todos esos objetos informativos que deben ser estructurados, organizados y clasificados, éstos pueden ser texto, imagen, videos, entre otros. De acuerdo a Yang, Saladrigas Medina, \& Torres Ponjuán (2016:171), citando a Silva (2009:30) señala al contenido como "un conjunto de signos y reglas semióticas (sintácticas, pragmáticas y semánticas), cuya finalidad radica en la construcción de sentido en palabras". Este es un punto muy importante, ya que a partir de saber con qué tipo y cantidad de información se trabajará, el diseñador podrá elegir las estrategias de diseño correctas para presentar de la mejor manera dichos objetos informativos.

Cuando Rodríguez Rivera (2005:3) habla sobre la forma de presentar el contenido se refiere a "el eje del proyecto que define la forma en la que el usuario ve y accede a la información, además aclara al equipo de trabajo cómo será la navegación". La forma de presentar el contenido está ligada a la estructura y composición visual forzosamente, es decir, el uso de reticular, jerarquización de la propia información y demás decisiones de diseño como forma y color. Como se mencionaba en el párrafo anterior, el diseñador ejecutará las estrategias de diseño previamente establecidas, para reducir al mínimo el esfuerzo cognitivo de parte del usuario de la interfaz que está desarrollando. 
Por último, la navegación es definida como la forma en que el usuario encuentra y selecciona información (Vora, 2001). La navegación está relacionada con la usabilidad de la interfaz gráfica, es decir, que tan fácil es para el usuario "usar" (en esto en caso, interactuar y leer) la información que se está presentando en este artefacto de diseño. La navegación desde la óptica de la usabilidad y la ergonomía cognitiva busca "hacer fácil e intuitiva la interfaz, de tal forma que permita al usuario sentirse ubicado (...) para que pueda concentrase en el contenido y no sienta confusión o frustración respecto al artefacto de diseño", según Rodríguez Rivera (2005:4).

Por lo tanto, podemos decir que para desarrollar una interfaz gráfica es necesario considerar los elementos previamente descritos, para que ésta pueda cubrir las necesidades cognitivas del usuario al que va dirigida y ésta pueda ser satisfactoria, efectiva y eficiente para los requerimientos que éste presenta. 


\section{CAPÍTULO 4 Usabilidad y ergonomía cognitiva en el diseño de interfaces gráficas}




\section{Concepto de usabilidad}

Definir el concepto de usabilidad resulta relevante para fines de este proyecto de investigación, ya que el producto final, siendo las guías de usabilidad para el desarrollo de interfaces gráficas de sistemas de visualización de información médica, busca abordar a través de las recomendaciones contenidas en éstas, la usabilidad de dichas piezas de diseño.

Después de haber puntualizado en esta idea, procedemos a definir el concepto de usabilidad. EI ISO DIS 9241-11, establece que la usabilidad es "la medida con la que un producto es usado por determinados usuarios para conseguir objetivos específicos con efectividad, eficiencia y satisfacción en un contexto de uso concreto". Por otra parte, Nielsen (2012a), define a la usabilidad como un atributo de calidad que evalúa la facilidad del uso de las interfaces de usuario.

Vale la pena mencionar que Nielsen (2012a) establece que la usabilidad está compuesta por cinco componentes de calidad, los cuales aseguran este atributo a el artefacto de diseño con la que se está interactuando:

1. Capacidad de aprendizaje. Según el autor, este componente hace alusión a la facilidad con que el usuario puede realizar tareas básicas durante primer contacto con la pieza de diseño. 
2. Eficiencia. Este componente, conforme a lo que analiza Nielsen (2012a), está relacionado con la rapidez en que lo usuarios pueden realizar dichas tareas después de haberse familiarizado con el artefacto.

3. Fiabilidad. Nielsen (2012a), argumenta que la fiabilidad habla sobre la capacidad del usuario para recordar el uso de la pieza de diseño después de un tiempo.

4. Error. Este atributo, según el autor, trata de los márgenes de errores que puede tener el usuario durante el proceso de interacción con la pieza de diseño. Se espera un margen de error muy pequeño, que no entorpezca significativamente las tareas que el usuario tiene que realizar con el artefacto de diseño.

5. Satisfacción. Para Jordan (2001:7), este componente es el que debe predominar por encima de todos los demás cuando se busca la condición de usabilidad en una pieza de diseño. La satisfacción, según Nielsen (2012a), define el grado de que tan placentera la experiencia de interacción con dicho artefacto de diseño. 


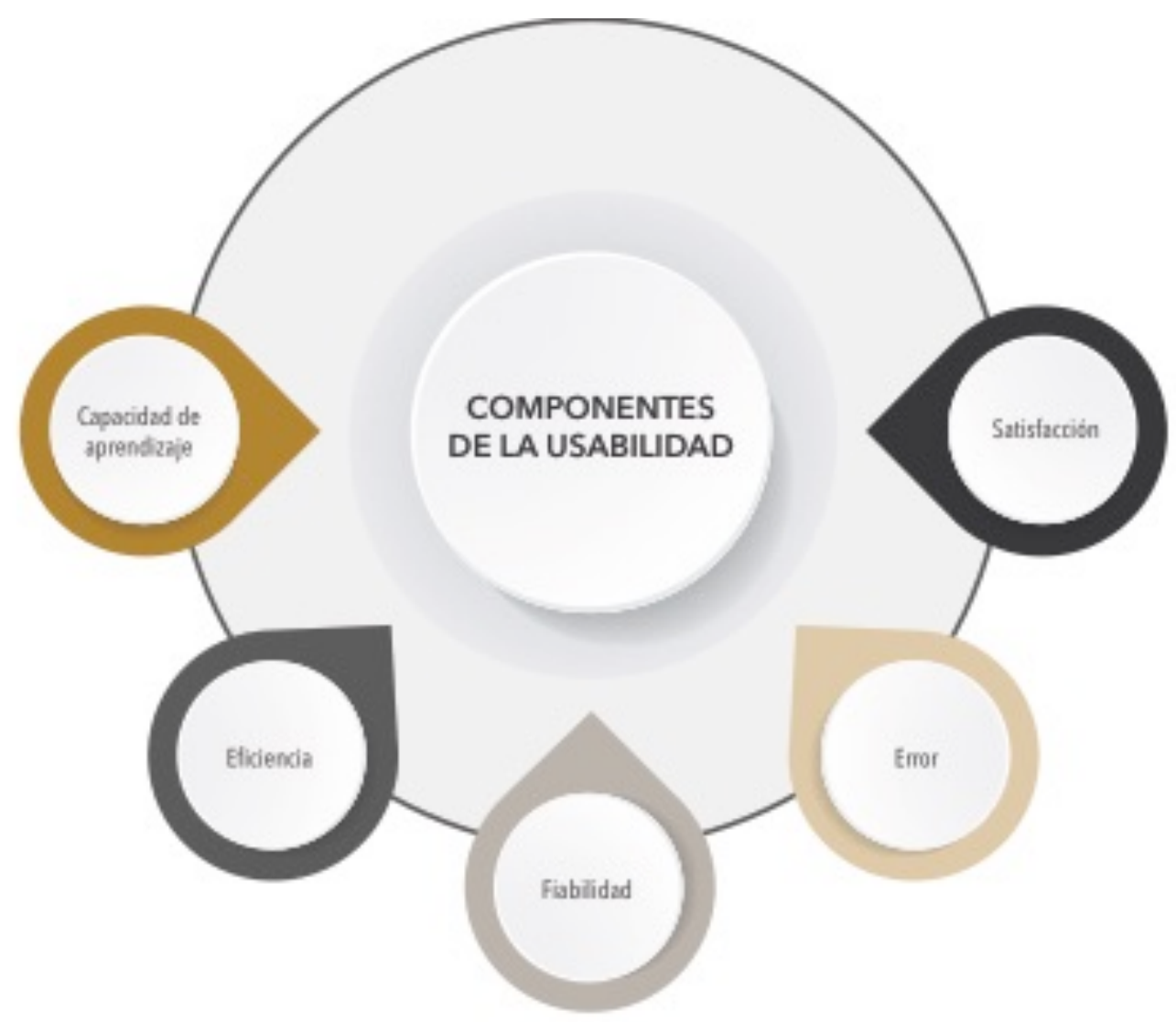

Figura 1. Componentes de calidad que forman parte de la usabilidad, de acuerdo a Nielsen (2012). Elaborada por Mariel Garcia Hernández

Por otra parte, para Jordan (2001:7), la usabilidad es una propiedad de la interacción entre un artefacto, el usuario y la tarea que éste tiene que realizar con dicho artefacto. A su vez, el autor hace un análisis de los componentes que conforman a la usabilidad:

- Capacidad de adivinar. Para Jordan (2001:12) la capacidad de adivinar se refiere a "la eficiencia, efectividad y satisfacción con la que un usuario en especial puede completar ciertas tareas relacionadas con un producto en particular durante el primer contacto con éste". 
- Capacidad de aprendizaje. Este componente hace referencia a que el usuario pueda interactuar de una manera sencilla con el producto al primer encuentro. Por otra parte, la capacidad de aprendizaje, según el autor, se refiere a la habilidad del usuario por desempeñar un nivel total de tareas después de haber completado con anterioridad dicho nivel.

- Rendimiento de la experiencia del usuario. Conforme a lo que expone Jordan (2001:14), es "el grado de eficiencia, efectividad y satisfacción con el que usuarios experimentados y relacionados con ciertos productos pueden alcanzar un objetivo o completar una tarea".

- Potencial del sistema. Este componente abarca el "nivel óptimo de eficiencia, efectividad y satisfacción con el que es posible completar tareas especificas con un producto", según Jordan (2001:15).

- Reusabilidad. Esta propiedad de la usabilidad que plantea el autor alude a la habilidad del usuario de volver a completar tareas especificas en cierto producto después de no haber interactuado con él después de un tiempo. 


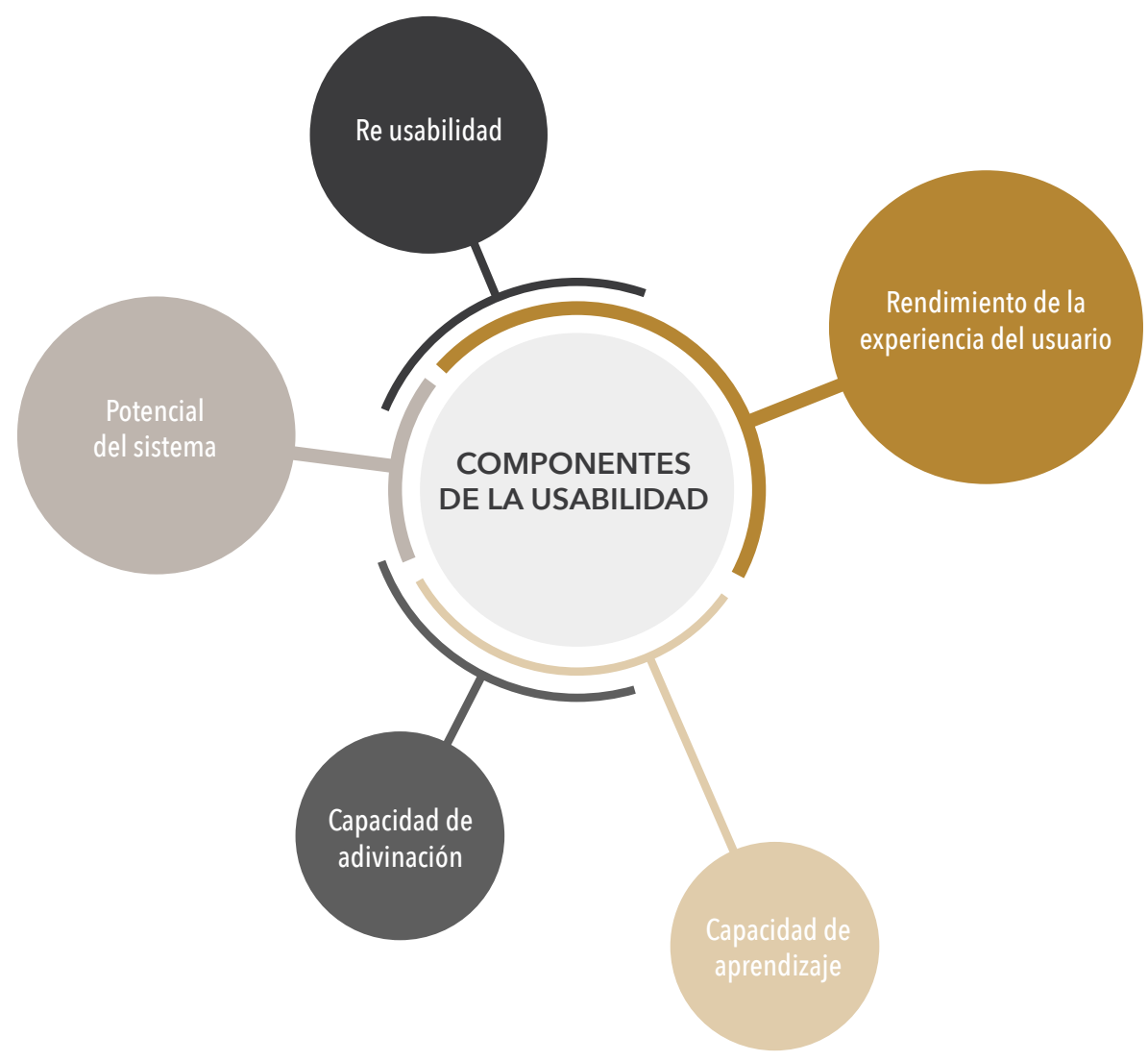

Figura 2. Componentes de calidad que forman parte de la usabilidad, de acuerdo a Jordan (2002) Elaborada por Mariel García Hernández.

Después de haber expuesto las posturas de los autores previamente mencionados podemos establecer que la usabilidad es un atributo que las piezas de diseño deben presentar, ya que, al cumplir con estos componentes de calidad, se facilita el uso, comprensión e interacción con dichas piezas. 


\subsection{Principios de usabilidad en el diseño}

Nielsen $^{24}$ (1994) indica una serie de principios heurísticos ${ }^{25}$ sobre la usabilidad en

el diseño de interfaces, los cuales, al ser cumplidos por el artefacto de diseño en sí aseguran dicho atributo.

1. Visibilidad del estado del sistema. Según el autor, este principio establece que el usuario debe estar siendo informando por parte del sistema con el que está interactuando acerca de lo que va sucediendo con dicho sistema, de una manera oportuna durante un tiempo razonable.

2. Relación entre el sistema y el mundo real. Según indica Nielsen (1994), esta premisa parte desde el hecho de que el sistema debe hablar el idioma del usuario, con palabras, frases y conceptos familiares para el usuario, utilizando un lenguaje lógico, natural y familiar para éste.

3. Control y libertad del usuario. Este parámetro, según establece el autor, alude a que los usuarios encuentren una "salida de emergencia" claramente marcada al elegir por error una función diferente con la que estaban trabajando y poder salir del estado no deseado en el que se encuentran sin tener que pasar por un diálogo extendido.

4. Consistencia y normas. Para Nielsen (1994) este principio instaura que debe existir coherencia y convencionalismos en el sistema con el que el usuario de éste esté relacionado. Los usuarios no deben tener que

\footnotetext{
24 Jakob Nielsen es uno de los máximos exponentes de la usabilidad en el ámbito web, además de que ha inventado varios métodos de usabilidad y evaluación heurística.

${ }^{25}$ Entendemos como heurístico en el campo de la usabilidad como al proceso de búsqueda desde un enfoque "paso a paso", el cual permite localizar información que se necesita para encontrar una solución o área de mejora a los posibles problemas de usabilidad que se puedan encontrar durante el desarrollo o prueba de productos de diseño.
} 
preguntarse si diferentes palabras, situaciones o acciones significan lo mismo. Este fundamento busca seguir convenciones en la plataforma.

5. Reconocimiento en lugar de recuerdo. A partir de esta premisa se establece que a través de haciendo visible los objetos, las acciones y las opciones del sistema se minimice la carga de memoria del usuario.

6. Prevención de errores. Según Nielsen (1994), cuando hablamos de la prevención de errores nos referimos a que se deben eliminar las condiciones que puedan dar pauta a que el usuario cometa omisiones, descuidos 0 cualquier acción que no le permita realizar la tarea que desea alcanzar de una manera eficiente.

7. Flexibilidad y eficiencia de uso. Conforme a lo que idem argumenta con este punto que se debe crear un sistema para usuarios con diferentes niveles de expertis y que también, éste se adapte a diferentes acciones recurrentes.

8. Diseño estético y minimalista. Este principio, conforme al autor, establece que además de desarrollar un artefacto de diseño que sea agradable de una manera visual para el usuario, debe presentar solo aquella información que se relevante para éste.

9. Ayuda y documentación. Se debe proporcionar información de apoyo a la que el usuario pueda acceder cuando tenga algún tipo de pregunta o duda respecto al sistema con el que está interactuando, según Nielsen (1994). 


\section{Ayuda a los usuarios a reconocer, diagnosticar y recuperarse de}

errores. Según con lo que establece el autor, a partir de este principio, se busca orientar a los usuarios a superar los errores que pudieron haber cometido durante la interacción con el sistema. Para ello es importante evitar diálogos de error genéricos y se recomienda usar mensajes que le muestren al usuario la causa específica del error e indicaciones de cómo solventarlo, usando un lenguaje claro y preciso.
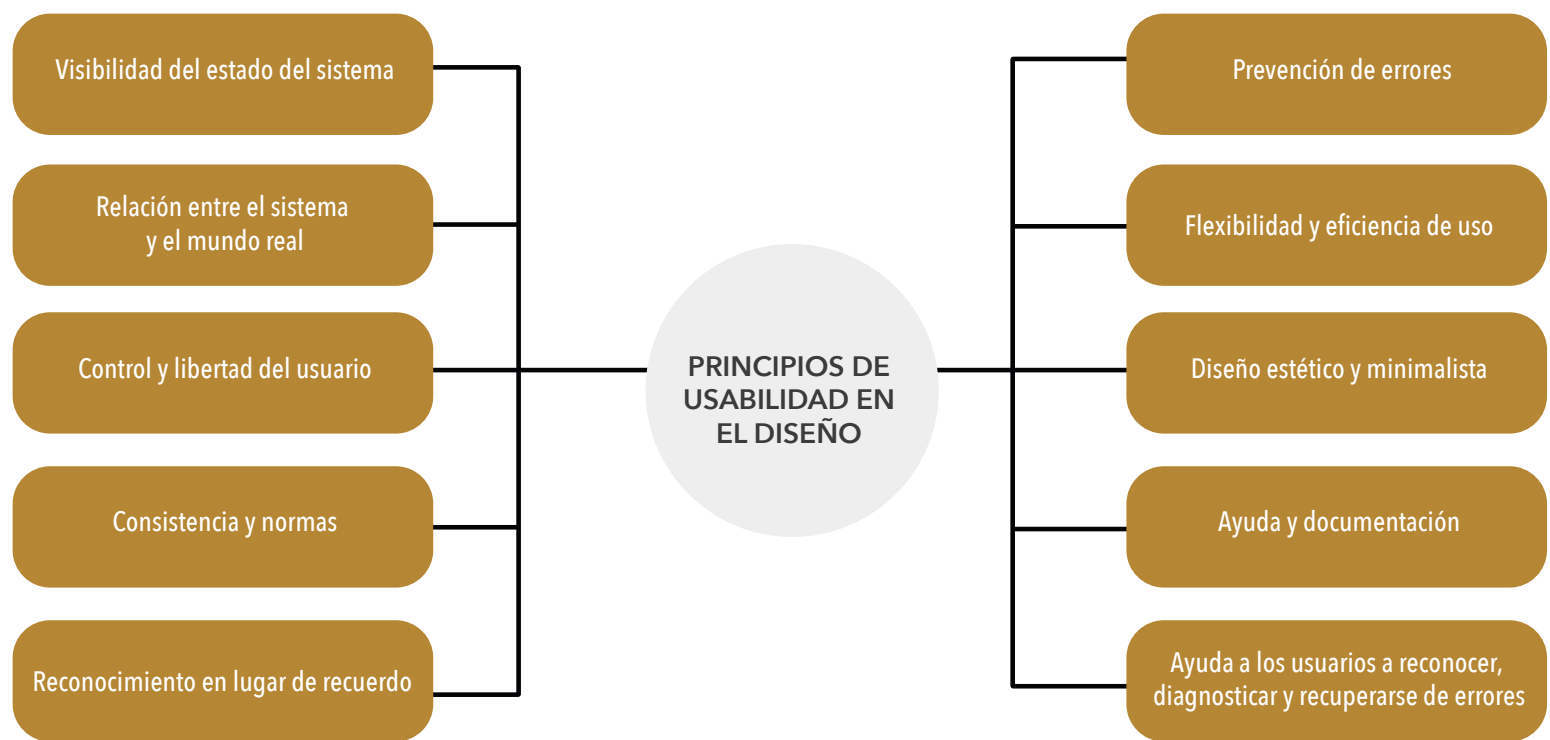

Figura 3. Principio de usabilidad en el diseño de interfaces de acuerdo a Nielsen (1994). Elaborada por Mariel García Hernández

\subsection{Diseño para la usabilidad.}

Jordan (2001) argumenta que cuando hablamos de diseño para la usabilidad nos referimos a toda decisión que está encaminada a desarrollar artefactos de diseño que toman como eje central al usuario y sus necesidades. El autor expone que el diseño para la usabilidad contempla dos rubros del usuario: 


\section{Características físicas.}

2. Características cognitivas.

El autor se refiere a características físicas a todas esas consideraciones que el diseñador debe tomar en cuenta para el desarrollo de cualquier artefacto de diseño que estén relacionadas con la morfología física del usuario; peso, estatura, edad, etc.

En cuanto a características cognitivas, Jordan (2002) establece que son aquellas que hacen referencia a las aptitudes, conocimiento, experiencias y creencias del usuario respecto al artefacto de diseño y el contexto en que interactúa con éste.

Un diseño orientado a la usabilidad tiene como propósito cubrir ambas características en correlación con el contexto de uso y requerimientos de usabilidad del producto de diseño. Sin embargo, debido al objeto de estudio de investigación nos centraremos concretamente a las características cognitivas del usuario.

\subsection{Ergonomía cognitiva}

La ergonomía cognitiva es definida por Cañas \& Wearns (2001:4), como "una disciplina científica que estudia los aspectos conductuales y cognitivos de la relación entre el hombre y los elementos físicos y sociales del ambiente, cuando esta relación está medida por el uso de artefactos". 
Por su parte, Romero Medina (2006:1), define a la ergonomía cognitiva como:

el estudio de todas las actividades humanas (capacidades y limitaciones) relacionadas con el conocimiento y el procesamiento de la información que influyen o están influidas por el diseño de máquinas y objetos que usan las personas, relacionados con procesos de trabajo y entornos con los que interactúan.

Retomando al autor anterior, éste argumenta que la ergonomía cognitiva "se centra en especificar y dar recomendaciones de adaptación al diseño de soportes de información tomando en cuanta las necesidades del usuario" éstas, según Romero Medina (2006:1), son clasificadas en tres rubros:
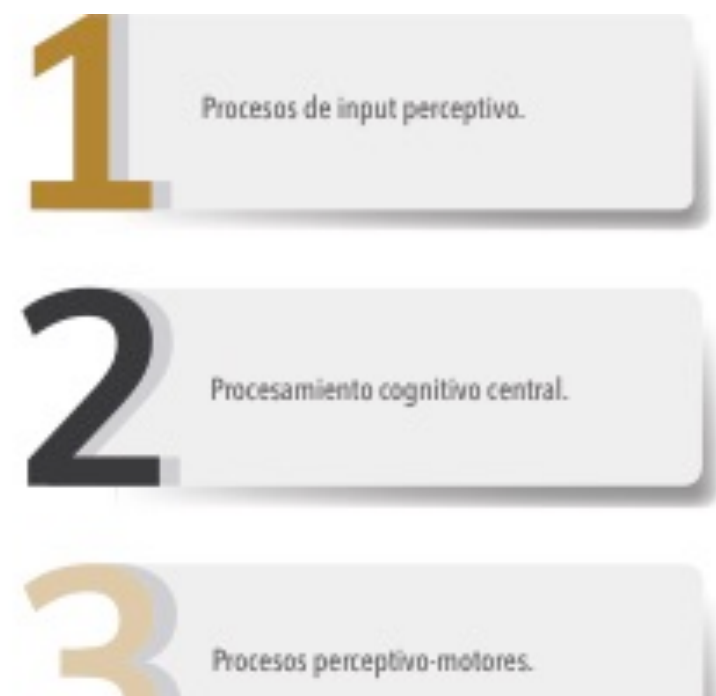

Figura 4. Necesidades del usuario con respecto a soportes de información, seguin Romero-Medina (2006). Elaborada por Mariel Garcia Hernández 
1. Procesos de input perceptivo. Estos procesos abarcan la detección, clasificación, reconocimiento de patrones dentro de la propia información.

2. Procesamiento cognitivo central. Este rubro comprende la memoria, el razonamiento y la resolución de problemas a través de la información que le es presentada al usuario.

3. Procesos perceptivo-motores. Este apartado engloba procesos más relacionados con los sistemas de respuesta y ejecución a los que el usuario puede estar expuesto.

Cañas \& Wearns (2002) hacen una propuesta de marco de referencia de la ergonomía cognitiva, en el cual se establecen niveles de alcance por la propia disciplina.

\begin{tabular}{|c|c|c|}
\hline ARTEFACTOS & NIVELES & TEMAS DE INTERÉS PARA LA ERGONOMÍA COGNITIVA \\
\hline $\begin{array}{l}\text { CMC, tal como e-mail, } \\
\text { e-conferencias, MUD }\end{array}$ & Sociocultural & Organización, historia, cultura, trabajo a distancia. \\
\hline CSCW, workflow & Cooperación & Comunicación y coordinación. \\
\hline $\begin{array}{l}\text { Sistemas basados en } \\
\text { conocimiento, sistemas } \\
\text { de apoyo en la toma } \\
\text { de decisiones indivisuales }\end{array}$ & $\begin{array}{l}\text { Procesamiento de la información } \\
\text { compleja de un individuo }\end{array}$ & $\begin{array}{l}\text { Representación, interpretación, búsqueda, modelos mentales, } \\
\text { toma de decisiones, solución de problemas. }\end{array}$ \\
\hline $\begin{array}{l}\text { Sistemas de representación } \\
\text { de datos (visuales, auditivos, } \\
\text { táctiles, etc.), sistemas de } \\
\text { output manipulación directa }\end{array}$ & $\begin{array}{l}\text { Procesamiento de la información } \\
\text { compleja de un individuo }\end{array}$ & Leyes de la Gestalt, atención, afrontamiento, lectura, comprensión. \\
\hline $\begin{array}{l}\text { Interacción motora, } \\
\text { realidad virtual }\end{array}$ & Sensorio-motor & $\begin{array}{l}\text { Diseño de instrumentos de input, feedback relacionado con el } \\
\text { input, problemas físicos, naáusea, interacción con el mundo real. }\end{array}$ \\
\hline
\end{tabular}

Figura 5. Marco de referencia de la Ergonomía cognitiva, de acuerdo a Cañas \& Waernes (2001). Elaborada por Mariel García Hernández 
Cabe resalta que en el nivel denominado como "percepción individual" se analiza la forma en que el usuario del artefacto de diseño comprende la información que le es presentada, por lo cual es donde podemos situar la presente tesis doctoral, además de que, así mismo, en este nivel se estudian artefactos de diseño tales como sistemas de presentación de datos (visuales, auditivos, táctiles, etc.), los cuales son parte fundamental del mismo, a través de lo cual nos valemos a decir, es importante considerar enfoques desde la ergonomía cognitiva para desarrollar interfaces gráficas. Para el desarrollo de interfaces Cañas \& Wears (2002:2) señalan "es fundamental utilizar como referencia el esquema de procesamiento de información tal como se entiende en la psicología cognitiva".

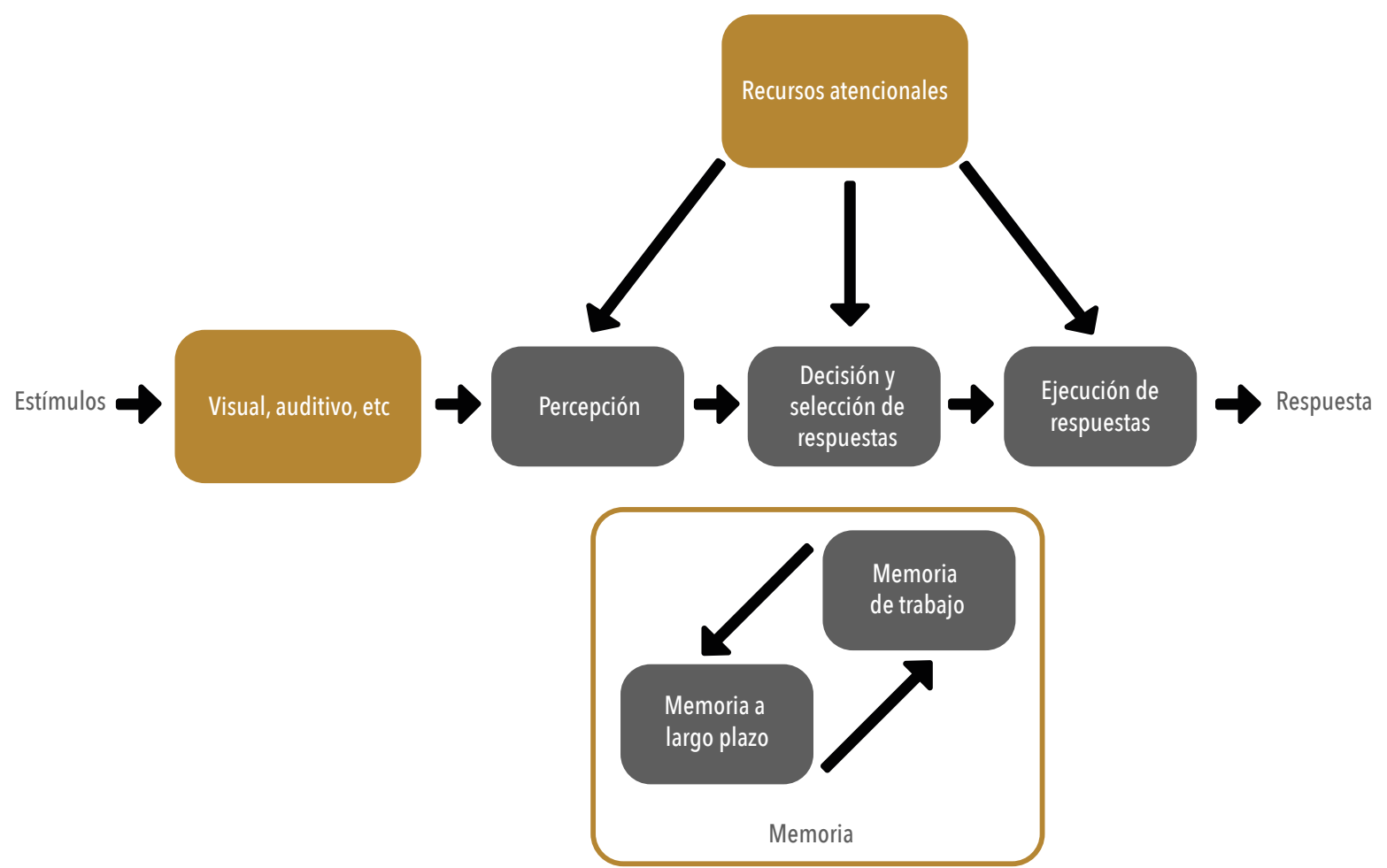

Figura 6. Modelo cognitivo general, según Cañas \& \& Wearns (2002). 
El modelo que los autores señalan dentro de su obra pertenece a Wickens (1992), en donde "el ser humano posee un sistema cognitivo compuesto por unos sistemas sensoriales encargados de extraer la información del ambiente. Esta información es analizada por los procesos perceptuales y almacenada en la memoria, para poder ser recuperada y utilizada posteriormente".

El modelo anterior, según lo que analizan Cañas \& Wearns (2002:21), se usa para tratar de explicar la interacción entre una persona y un artefacto, por esto, según los autores, "es fundamental conocer las actividades que una persona realiza". Por ello resulta importante resaltar lo que según Howes \& Young (1986) dicen en Cañas \& Wearns (2002:26), en los "aspectos que los modelos deben considerar a la hora de explicar la interacción", estas consideraciones son los siguientes:

1. Conducta. Howes \&Young (1986) mencionado por Cañas \& Wearns (2002:27), "Ios modelos deben explicar y predecir la conducta de los usuarios".

2. Conocimiento. "Para predecir la conducta de los usuarios es necesario describir cuáles son los conocimientos que éstos deben tener de la interfaz y de la interacción", señalan Howes \&Young (1986) argumentado por Cañas \& Wearns (2002:27) en su obra.

3. Representación del conocimiento. Según el autor, "el conocimiento está representado en el sistema", éste se presenta por medio de formalismos, los cuales ayudan a hacer predicciones sobre la conducta del usuario con el propio sistema. 
4. Aprendizaje. Según los autores, "los usuarios tienen que aprender el uso de la interfaz, por tanto, los modelos cognitivos han prestado mucha atención a cómo se realiza este aprendizaje".

5. Arquitecturas cognitivas. Howes \&Young (1986) argumentado por Cañas \& Wearns (2002:27) establecen que "es necesario integrar todos los aspectos anteriores en un solo modelo para almacenar el conocimiento".

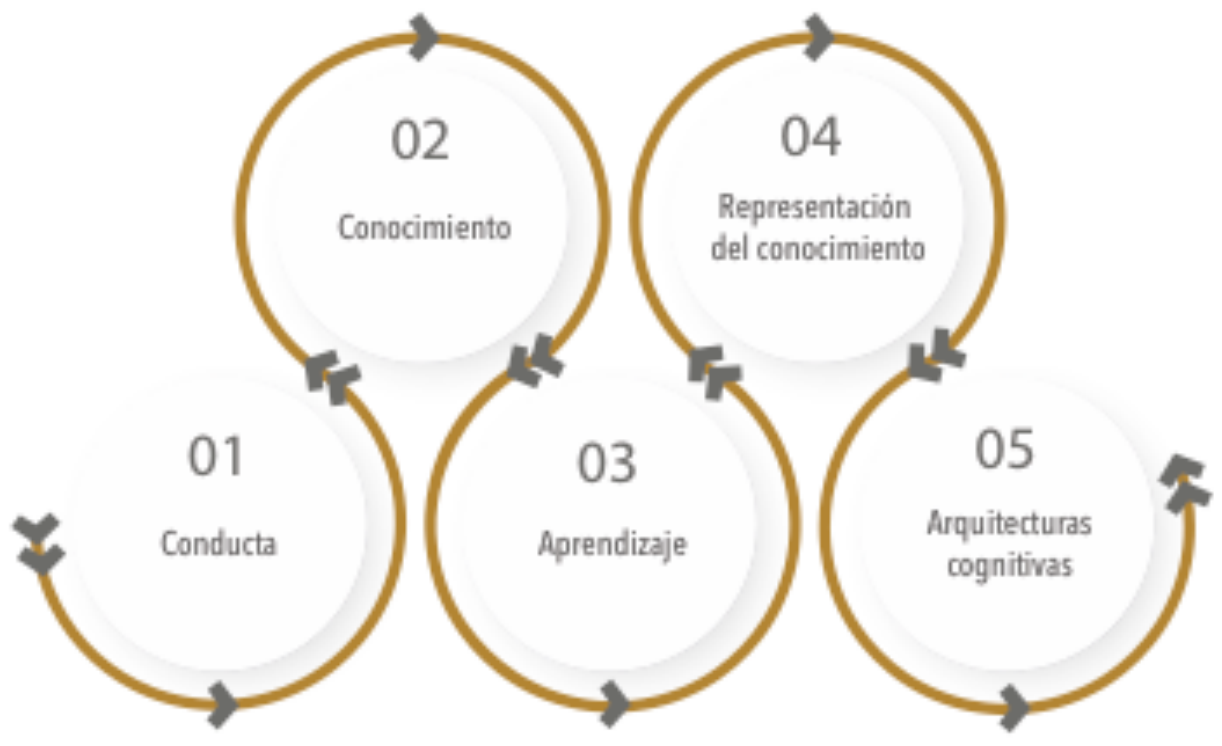

Figura 7. Aspectos que los modelos deben considerar a la hora de explicar la interacción, según Howes \& Young (1986). Elaborada por Mariel Garcia Hernandez

Retomando el modelo cognitivo general en el apartado anterior, Cañas \& Wearns (2002), señalan que este modelo "ha guiado la investigación sobre los temas centrales que se han ido planteando durante el proceso de diseño de interfaces". Así mismo, los autores proponen como temas centrales:

- Sensación. Idem exponen que a través de las interfaces gráficas los estímulos llegan al sistema cognitivo humano a través del sentido de la vista, 
por lo cual, los diseñadores deben ser "sensibles" a esta condición sensorial que se le presenta al usuario, quien codifica estímulos visuales principalmente por medio del color.

- Percepción. Para Cañas \& Wearns (2002:33), este tema dentro de los procesos cognitivos implicados en la interacción con interfaces, "es la interpretación del estimulo" que se le transmite al usuario a través de la propia composición visual del artefacto de diseño". Siguiendo lo que proponen los autores, citando a Hutchins, Hollan \& Norman (1986), existen metáforas de interacción de interfaces:

○ Conversación. En donde la interfaz "presenta un lenguaje el que el usuario y el artefacto tienen una conversación sobre un dominio del mundo que no está representado en la interfaz", Cañas \& Wearns (2002:33).

○ Modelo del mundo. "La interfaz es una representación del mundo sobre que el usuario actúa", argumentan Cañas \& Wearns (2002:33). Esta metáfora permite al usuario generar un compromiso directo con el usuario.

La premisa principal de este tema encuentra su razón de ser en que la percepción que se "construya" alrededor de la interfaz sea rápida y de una manera correcta (distancia articulatoria ${ }^{26}$ ), a través de generar relaciones cortas entre su significado y el objeto real que representa.

\footnotetext{
${ }^{26}$ Según Cañas \& Waerns (2002:33), la distancia articulatoria es "la relación entre la forma física de una expresión y el significado de dicha expresión".
} 
- Búsqueda. Cañas \& Wearns (2002) indican que el diseñador debe saber como el usuario realiza las tareas de búsqueda visual dentro de la interfaz gráfica. Los autores sugieren que la composición debe reducir el margen de error y el tiempo de búsqueda de información por parte del usuario.

- Memoria. La memoria, de acuerdo a los autores previamente mencionados, encuentra su quehacer en almacenar la información que es percibida a través de los estímulos visuales que proyecta la interfaz gráfica, para que el usuario la utilice posteriormente para alcanzar una tarea determinada. El diseñador debe, a través de la propia composición visual de la interfaz, reducir el esfuerzo cognitivo que implica el ejercicio de almacenamiento de información, el cual fue expuesto en el capítulo de "Imagen y percepción" de esta presente tesis doctoral.

Estos temas deben ser considerados a la hora de tomar decisiones de diseño relacionadas con la visualización de información. Estas estrategias son polarizadas a través de consideraciones formales de la composición visual como son el color, la tipografía, la estructura de la información presentada y los elementos gráficos. En el siguiente capítulo puntualizaremos de una manera más explicita de cómo la usabilidad y la ergonomía cognitiva son tomadas en cuenta dentro de las consideraciones formales previamente descritas.

A manera previa a una conclusión de este capítulo, según Romero Montero (2006), la ergonomía cognitiva busca favorecer la usabilidad o facilidad de uso de la interfaz gráfica a través de: 
- Reducir el esfuerzo cognitivo.

- Minimizar la taza de errores durante la lectura.

- Exigir un menor esfuerzo de aprendizaje por parte del usuario.

- Simplificar las transformaciones representacionales de la información.

- Ceñir el recuerdo de estados intermedios para la resolución de problemas.

- Mejorar el rendimiento, la productividad y eficiencia para realizar una tarea relacionada con la interfaz gráfica.

- Aumentar el confort de lectura y navegación a través de la información que es presentada en la interfaz gráfica con respecto al usuario.

\subsection{Métodos de evaluación de la usabilidad en las interfaces gráficas.}

Al haber descrito lo anterior, una pregunta importante que queremos establecer es, ¿cómo sabrá el diseñador que podrá encontrar las propiedades de la usabilidad en una interfaz gráfica? Para ello vale la pena decir que existen diferentes métodos para evaluar la usabilidad de las interfaces gráficas. Según lo que analiza Catalán Vega (2000), la evaluación de interfaces gráficas consiste en "el proceso por el que se determina el valor o la calidad de las mismas en relación a unos objetivos marcados". Por otra parte, para Rubin \& Chisnell (2008), la evaluación de usabilidad de interfaces gráficas es una herramienta de investigación en donde se involucran a personas que cumplen con ciertas características en especial para evaluar el grado de usabilidad de un producto en especifico al presentar criterios específicos. 
Rubin \& Chisnell (2008), señalan algunas de las ventajas que se pueden obtener al implementar una evaluación de usabilidad en las interfaces gráficas:

- Identifica las deficiencias de usabilidad existentes en artefactos de diseño.

- Reduce márgenes de error entre la interacción, usuario y la pieza de diseño.

- Mejora la experiencia de interacción entre el usuario y el artefacto de diseño.

- Asegura la creación de artefactos de diseño que satisfacen los requerimientos de su usuario.

- Reduce los problemas de diseño y así, la frustración que puede sentir el usuario a la hora de interactuar con éste.

Para poder implementar una evaluación de usabilidad en las interfaces gráficas se sugiere la definición de un plan de evaluación. Según Rubin \& Chisnell (2008). Según Jordan (2002), desarrollar un plan de evaluación nos ayudará a definir, entre muchas cosas, si el artefacto diseñado cumple o no con el propóstio para el que fue diseñado. Ellos señalan que un plan de evaluación de usabilidad debe contemplar los siguientes apartados:

1. Propósito y objetivos de la prueba. Jordan (2002), establece que el propósito de la evaluación nos habla sobre qué es lo que queremos llegar con la evaluación, qué es lo que pretendemos descubrir o saber.

2. Preguntas de investigación. Las preguntas de investigación ayudarán a enfocar la evaluación. Es importante que estos cuestionamientos estén planteados de una forma precisa, clara y medibles. 
3. Características de los participantes. Según Rubin \& Chisnell (2008), señalan que esta sección del plan de evaluación establece las características (edad, sexo, nivel socioeconómico, ubicación geográfica, entre otros) que el usuario del producto tiene y con base a eso, se definirá una muestra para la evaluación.

4. Método (diseño de la prueba). Este apartado es una descripción detallada de cómo llevará a cabo la evaluación con los participantes y cómo se realizará la sesión de prueba. “Debe proporcionar una descripción general de cada faceta de la prueba desde el momento en que los participantes llegan hasta el momento en que salen, con suficiente detalle para que alguien que observe la prueba sepa aproximadamente qué esperar", conforme a lo que Rubin \& Chisnell (2008:74) establecen. Más adelante, expondremos las diferentes tipos de métodos que se pueden utilizar dentro de una evaluación de usabilidad.

5. Lista de tareas. Este apartado dentro del plan de evaluación trata acerca de aquellas tareas que los participantes tienen que realiza durante la evaluación. Las tareas por realizar deben ser aquellas que tengan que ver con el propósito iniciadle la evaluación.

6. Entorno de prueba, equipo y logística. En esta sección se debe describir el ambiente en el cual se llevará acabo la prueba (natural o laboratorio), así como los materiales que se necesitan para la propia evaluación (lápices, hojas de colores o blancas, etc.). 
7. Función del moderador de la prueba. Dentro de esta sección del plan se definen los roles que las personas involucradas en la evaluación desempeñaran.

8. Datos que deben recopilarse y métricas de evaluación. Los datos que se pretende recopilar deben basarse a las preguntas de investigación que previamente se han planteado. En este apartado se debe hacer una descripción de los tipos de la información que se recopilará, así mismo, se establecerán las métricas o parámetros de evaluación del estudio mismo.

9. Contenido y presentación del documento. En esta sección del documento se plantean las secciones principales del informe de la prueba. 


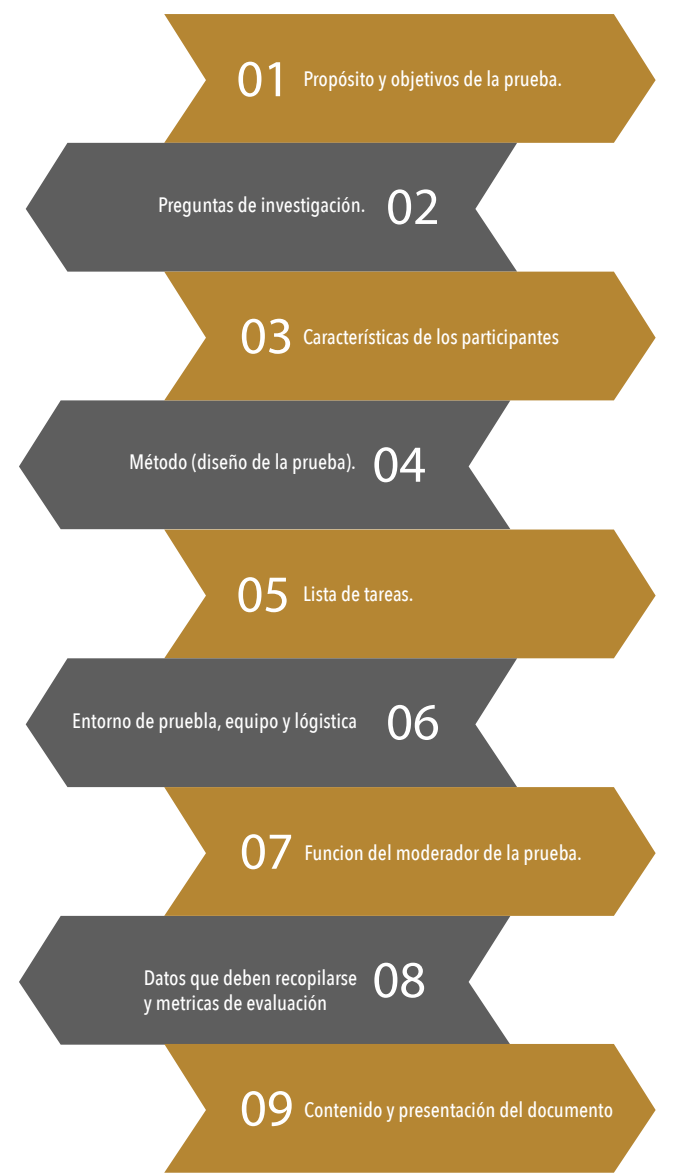

Figura 8. Parte de un plan de evaluación de usabilidad, de acuerdo a Rubin \& Chisnell (2008).

Elaborada por Mariel García Hernández 
Después de haber desarrollado el plan de evaluación y señalado sus partes, procederemos a describir las diferentes técnicas de evaluación de usabilidad que existen. Si bien es cierto que diversos autores ya han hablado sobre ello, sin embargo, se presenta dentro de esta tesis doctoral un bosquejo más amplio de las diversas formas de evaluación de usabilidad a partir de la cosmovisión de Nielsen y Jordan en particular. Para Jordan (2002), las técnicas o métodos de evaluación de usabilidad se pueden dividir en dos grandes familias; métodos empíricos y no empíricos. Estas dos grandes familias, de acuerdo al autor se subdividen de la siguiente manera:

\subsubsection{Métodos empíricos}

Molisch \& Nielsen (1990), definen a los métodos empíricos como aquellos que mediante experimentos con pruebas de usuario, con el objetivo de lograr una completa evaluación de usuario. A continuación presentamos un listado de los diferentes métodos empíricos que se pueden utilizar para medir la usabilidad:

a. Conversaciones privadas grabadas. Este método consiste en que los usuarios entren a un cuarto en donde hablan directamente a la cámara, la cual los está grabando. Se les pide que hablen sobre un tópico predefinido por el investigador.

b. Codescrubrimiento. Esta técnica consiste en que dos participantes tengan una interacción directa con el producto de diseño y descubran por su cuenta cómo funciona dicho artefacto. 
c. Grupos de enfoque (focus group). En un grupo de enfoque se reúne a varios participantes y, juntos discuten un asunto en particular. El grupo de enfoque está siendo "siempre manejado por un líder", conforme a lo que Jordan (2000:55) establece.

d. Talleres. Este procedimiento es un poco similar a la anterior, sin embargo, en un taller según Idem, es utilizado para que los asistentes discutan la creación o uso de un artefacto de diseño.

e. Protocolos de hablar en voz alta (thinking aloud protocols). Esta técnica consiste en que el usuario vaya diciendo en voz alta todo lo que piensa mientras va está interactuando con una interfaz.

f. Diarios de incidentes. Consisten en pequeños diarios que se les proporcionan a los usuarios para que vayan anotando cualquier tipo de problema que vayan teniendo con la interfaz a lo largo de su interacción con ésta.

g. Listas de verificación. El usuario hace una verificación de qué si el producto de diseño cumple o no, de acuerdo a su experiencia, a lineamientos establecidos dentro de la lista.

h. Observaciones en el campo. Este método consiste en observar al usuario en el entorno natural en el cual utilizan el artefacto de diseño.

i. Cuestionarios. Consisten en listas impresas que contienen preguntas, ya sean abiertas o cerradas, las cuales los usuarios deben de contestar.

j. Entrevistas. Esta técnica realiza una serie de preguntas de manera directa y personal al usuario. 


\subsubsection{Métodos no empíricos}

Los métodos no empíricos no requieren involucrar cabelmente la participación de usuario para poder llevarlos acabo, según planeta Casado (2018). A continuación se hace un enlistado de los métodos empíricos usados en el estudio de la usabilidad:

k. Análisis de tareas. Este método consiste en desglosar una actividad en una serie de pasos que conllevan a dicha actividad.

I. Lista de verificación de propiedades. Este tipo de listas enumera una serie de propiedades o requerimientos de diseño que, acorde a los factores humanos, asegurarán que un artefacto de diseño sea usable.

m. Valoración de expertos. Dentro de procedimiento el artefacto de diseño es evaluado por un experto en el tema.

n. Paseos cognitivos. Esta técnica se centra "en evaluar la facilidad de aprendizaje a través de prototipos del artefacto, lo que ayuda a evaluar el mismo en las etapas iniciales de desarrollo", según Lilliam, Cancio, Mercedes, \& Bergues, (2013:187).

Por su parte, Nielsen \& Landauer (1993) propone como métodos de evaluación de usabilidad los siguientes métodos:

1. Hablar en voz alta.

2. Observación.

3. Cuestionarios. 
4. Entrevistas.

5. Grupos focales.

6. Retroalimentación del usuario.

7. Medidas de rendimiento.

8. Evaluación Heurística.

Por definición, los métodos que propone Nielsen \& Landauer (1993) son similares a lo que establece Jordan (2001) más arriba, sin embargo, vale la pena definir el concepto de evaluación heurística, a grandes rasgos, consiste en una evaluación sin presencia del usuario, pero sí siguiendo los principios de usabilidad expuestos previamente en este capítulo.

La interfaz gráfica es el soporte mediante el cual se desarrollan diversos artefactos de diseño, como lo son los sistemas de visualización de información. Para desarrollar una interfaz gráfica, el diseñador debe tomar en consideración una serie de elementos; el usuario, el análisis de tareas, el contenido, la forma en que se presentará este contenido o información y la navegación que dicho usuario tendrá con la pieza de diseño. También es importante resaltar para fines de esta tesis doctoral, que la interfaz gráfica está compuesta por elementos gráficos, texto, estructura de información y el color, los cuales son elementos que se utilizaran como ítems a desarrollar propuestas en las guías de usabilidad que pretende generar esta investigación. 
Después de haber hablado sobre la usabilidad y la ergonomía en el diseño, podemos aseverar que dichas disciplinas son esenciales para la toma de decisiones al desarrollar cualquier artefacto de diseño, especialmente en la producción interfaces gráficas. La usabilidad nos va a asegurar que dichas piezas de diseño puedan usarse de una manera fácil por el usuario, y cuando hablamos por "usar" no nos limitamos al contacto físico, sino a la interacción y legibilidad del contenido que éstas nos presentan. Por su parte, la ergonomía cognitiva se va a encargar de definir la mejor manera de que dichas piezas de diseño van a "satisfacer" los requerimientos cognitivos del usuario y también, de qué manera debe ser diagramada o presentada la información de los sistemas visualización de información de tal manera en que ésta le resulte significativa al usuario de dichos sistemas. 


\section{CAPÍTULO 5}

NOMOLAS: Guías de usabilidad para el diseño de interfaces gráficas de sistemas de visualización de información médica 


\section{NOMOLAS: Guías de usabilidad para el diseño de interfaces gráficas de sistemas de visualización de información médica.}

Como se menciona en apartados anteriores, la problemática que aborda esta tesis doctoral parte del hecho de que, hasta el día de hoy, no se ha afrontado de manera directa la creación de guías de diseño para interfaces gráficas que sirvan para desarrollar sistemas de visualización de información médica.

La problemática principal de esta tesis doctoral da como resultado una propuesta de guías que permitan al diseñador desarrollar interfaces gráficas de sistemas de visualización de información médica que aseguren usabilidad ${ }^{27}$ de éstos para su usuario.

Dicha problemática tiene su origen, de acuerdo a lo que plantea Few (2004), en que la mayoría de los sistemas de visualización de información son difíciles de desarrollar de una forma clara, ya que suelen estar llenos de elementos innecesarios e irrelevantes, lo cual los hace propensos a errores y, por ende, pueden desencadenar una serie de malas decisiones respecto al conocimiento que se está intentando transmitir o proyectar a través de éstos. Las interfaces gráficas mal desarrolladas pueden crear más confusión que claridad en su usuario o lector.

\footnotetext{
${ }^{27}$ Nielsen (2012) señala que "la usabilidad es un atributo de calidad relativo a cómo algo es fácil de utilizar."
} 
El uso de tipografías ilegibles, de elementos visuales usados con un objetivo ornamental y no como un potenciador cognitivo, colores que generan mal contraste entre sí, información desordenada y mal estructurada compromete de manera grave el objetivo de comunicación de la interfaz gráfica

Las guías que se exponen a continuación como producto de esta tesis doctoral están divididas de la siguiente manera:

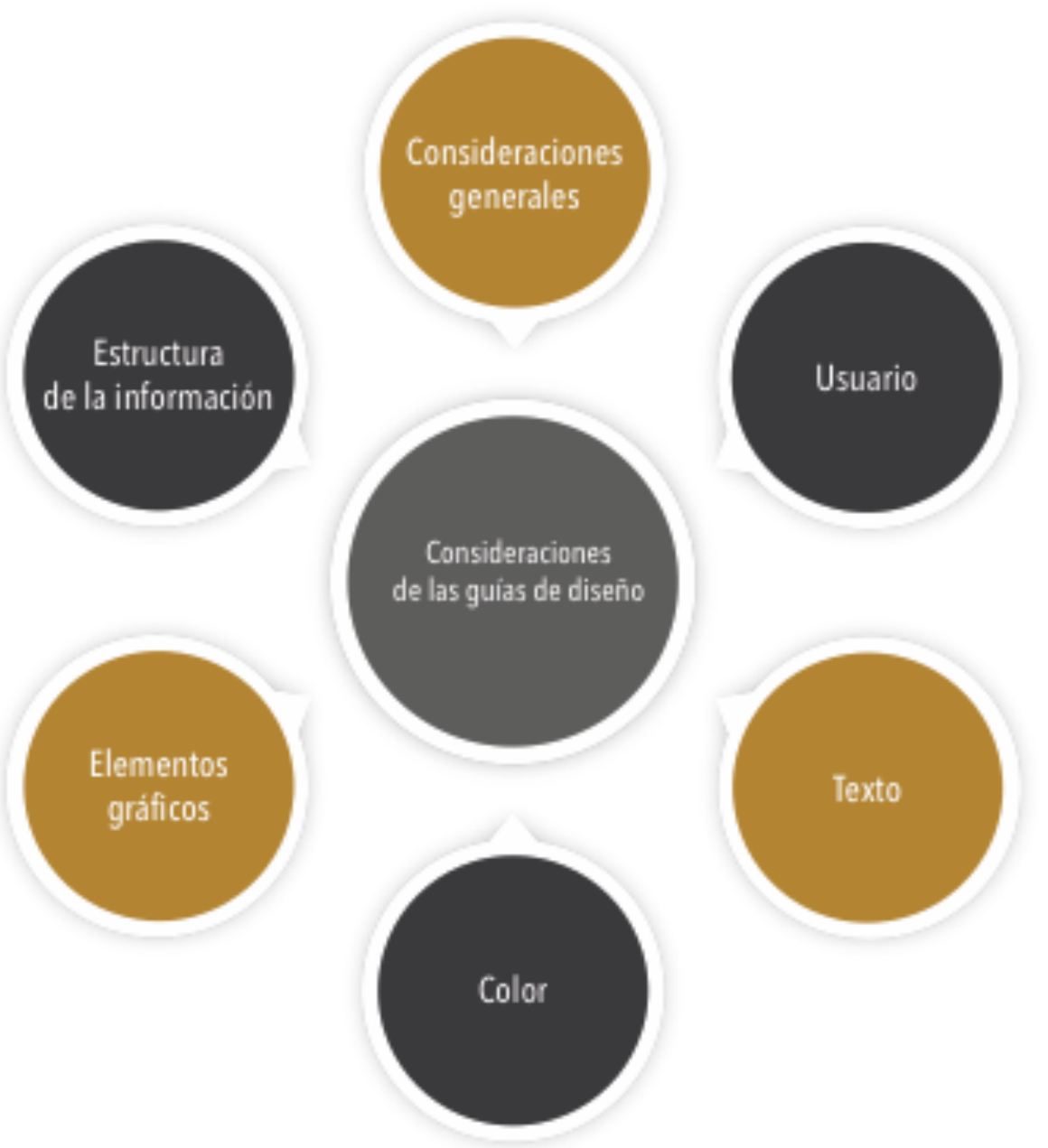

Figura 1.Secciones de las gulas de usabilidad NOMOLAS.

Elaborada por Mariel Garcia Hernández 


\subsection{Consideraciones generales}

A conituniación se presentan una serie de lineamientos generales acerca de ciertas consideraciones que el diseñador debe tomar en cuenta al trabajar con visualizaciones de información médica.

1. Agrupación de información. Cada uno de los elementos que se utilicen en la interfaz gráfica deben agruparse de manera significativa, ya que el usuario logrará su comprensión si éstos le son presentados de una manera agrupada, según a las Leyes de la Gestalt. De esta forma, el lector podrá recordar y comprender la información de una mejor manera.

2. Recordatorios o texto de apoyo. Se recomienda auxiliarse de señales visuales que ayuden al usuario a recordar la clase de información con la que están interactuando o que aporten un poco de contexto previo a dicha información.

3. Uso de elementos familiares. Es recomendable que la forma en que se visualiza la información en una interfaz gráfica se base en el conocimiento que el usuario pueda tener con respecto a los símbolos, imágenes o elementos gráficos utilizados. De esta manera, se le aporta un valor más significativo a la información y refuerza la transmisión del propio conocimiento que se está tratando de proyectar. Debe utilizarse un diseño simple y directo con una riqueza de datos, reduciendo la necesidad de inferencias, haciendo comparaciones claras y explícitas en la información de ser el caso. 
4. Uso de elementos gráficos limitados. Aunque un sistema de visualización de información tiene como fin hacer que la información que se presenta sea más accesible y rápida de interpretar para el usuario, se recomienda que el uso de elementos gráficos en cada sección de cualquier sistema de visualización sea limitado, así se evitará que el usuario haga esfuerzos cognitivos extras para determinar la razón de ser de cada uno de los elementos gráficos utilizados en el sistema. Cualquier elemento gráfico que no aporte significado o no favorezca el procesamiento y la comprensión de información debe omitirse. Deben minimizarse los patrones de distracción, colores predominantes, sombreado, 3D, cuadrículas innecesarias, etc.

5. Jerarquía. Es importante ordenar la información de modo en que ésta resulte más relevante para el objetivo de comunicación, se sugiere que vaya primero u ocupe el foco visual de la interfaz gráfica, ya que esto afectará la forma en que percibirán la información los usuarios. El objetivo es priorizar la información en orden de importancia para el usuario.

6. Consistencia. Se debe presentar de una forma coherente la información que se va a incluir en el sistema de información, ya que así el usuario la encontrará más fácil de comprender. La calidad y simplicidad de la información se debe garantizar manteniendo símbolos, colores, texto y métricas consistentes, seleccionando cuidadosamente los elementos visuales para ayudar a aclarar el significado de los datos, auxiliarse de títulos 
claros para cada sección o bloque de información y, del uso anotaciones sobre cómo interpretar la visualización.

7. Énfasis. Es muy importante generar énfasis visual en la información que sea de suma relevancia para el objetivo de comunicación de la interfaz gráfica. El diseñador se puede auxiliar desde un acomodo en la retícula que resalte dicha información hasta el uso de colores, elementos visuales o algún tipo de juego gráfico que aluda a este fin. Esto favorecerá a la memoria icónica para el procesamiento y comprensión de información que le es presentada al lector o usuario.

8. Simplicidad. El sistema de visualización de información debe presentar de una manera sencilla y accesible la información con la que se está trabajando. Es decir, que este sistema no requiera esfuerzos cognitivos grandes de parte del usuario o lector para su lectura y comprensión.

\subsection{Usuario}

El definir al usuario es necesario e indispensable para realizar cualquier tipo de proyecto de diseño, por ello se presentaman lineamientos sobre éste:

1. Frascara (2000) recomienda segmentar y definir al usuario de la siguiente manera:

i) Nivel socioeconómico: Este punto hace referencia al nivel jerárquico que ocupa el usuario de acuerdo a su bienestar económico y social. 
ii) Nivel de escolaridad o académicos: Hace referencia al grado de estudios máximo alcanzado por el usuario.

iii) Edad: Rango de tiempo que ha vivido el usuario.

iv) Sexo: Características biológicas y fisiológicas que clasifican al usuario como femenino o masculino.

v) Situación geográfica: Este punto se refiere al lugar de residencia del usuario.

vi) Situación de lectura: Hace referencia al medio por donde el usuario interactuará con la información, tomando en cuenta que puede ser a través de un medio impreso o digital.

vii) Creencias sobre la información que se le va a presentar.

viii) Usos y costumbres: Este rubro hace referencia a la manera en que se relaciona el usuario con la información que se trabajará en la interfaz gráfica. 


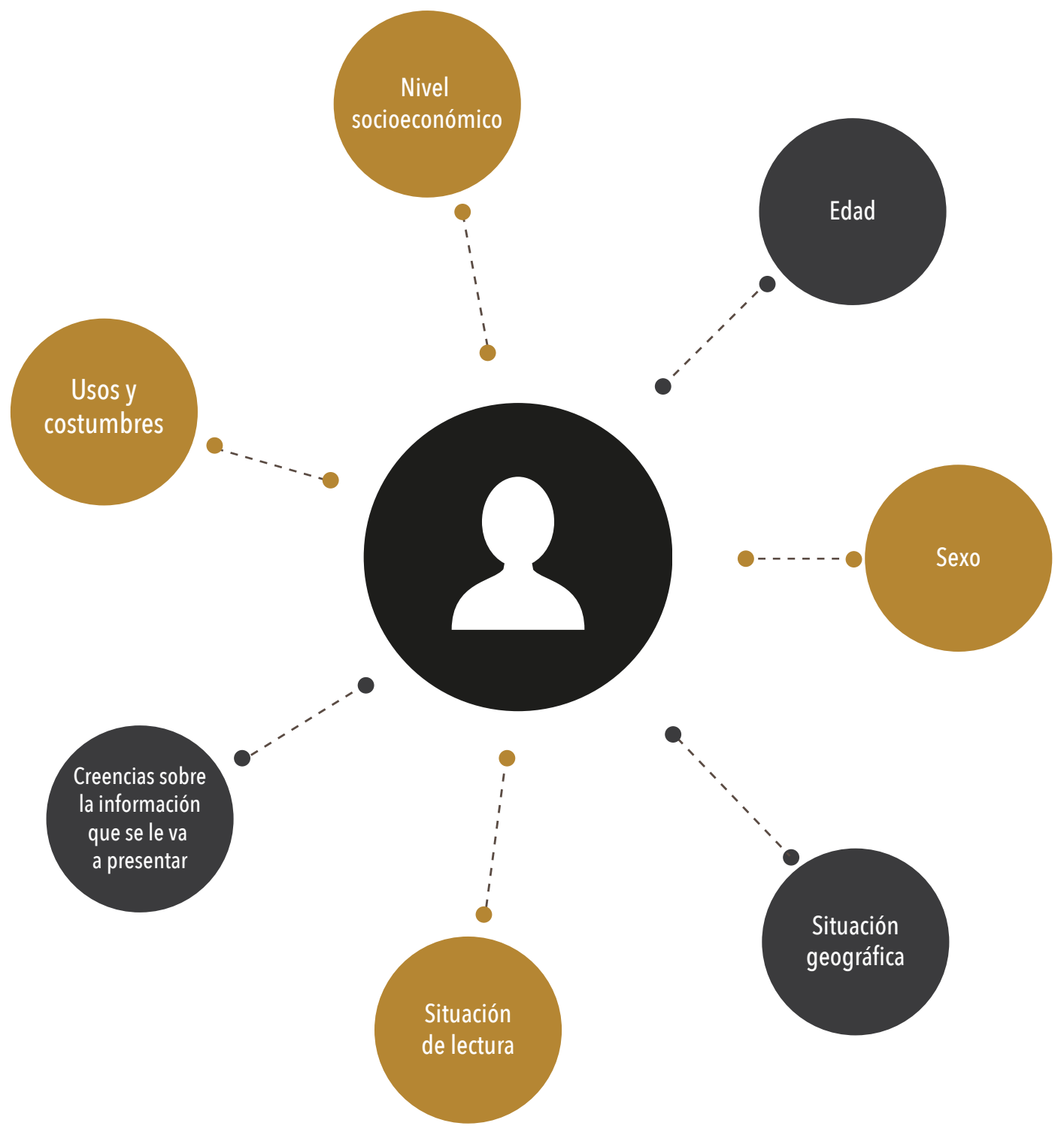

Figura 2. Consideraciones para definir el perfil del usuario.

Elaborada por Mariel García Hernández

Ya definiendo los puntos anteriores, se sugiere tener esto siempre presente a la hora de tomar decisiones de diseño. 


\subsection{Estructura de la información}

En este apartado observaremos lineamientos técnicos y teóricos acerca de cómo trabajar con datos, texto e información, buscando generar la mejor composición visual para cuidar la leibilidad y legibidad de dicha información.

1. Es primordial leer y relacionarse con la información que se va a trabajar. Sí hubiera dudas es recomendable hondar en el tema, según lo establece Cairo (2011).

2. Conforme al autor anterior, es importante que se estructure la información de una forma en que haya congruencia y secuencia entre términos y conceptos.

3. La estructura en sí de la propia información que se está trabajando en el sistema de visualización de información debe mostrar una jerarquía clara y bien planificada que ayude al lector a identificar dicho orden, acorde a lo que Lonsdale \& Lonsdale (2019a) señalan.

4. Para ayudar al usuario a procesar la información dentro de cuadros complejos, debe existir una jerarquía visual clara en la que se resalten los elementos importantes, se eliminen las distracciones y se establezca el orden visual, según Cairo (2011). 
5. Se sugiere, de acuerdo a lo que analizan Nielsen \& Loranger (2006), un diseño en el cual la navegación se haga de izquierda a derecha ${ }^{28}$ y en forma de zigzag, ya que esto responde a la forma natural en que nuestros ojos leen la información.

6. Todos los elementos gráficos que se utilizan deben apoyar a la estructuración jerárquica de información, así como también, deben ser consistentes visualmente hablando entre ellos, según argumenta Cairo (2011).

7. El texto y las imágenes que se encuentren relacionados entre sí bajo términos de concepto se recomienda que se coloquen muy juntos en términos de proximidad perceptiva (y con la ayuda de guías visuales, si corresponde) para dirigir el ojo desde el texto a las imágenes y y facilitar la integración de la información, según a lo que establecen Lonsdale \& Lonsdale (2019a).

8. Es recomendable el uso de retículas para estructurar todos los elementos que contenga el sistema de visualización de información. Las retículas más usadas en el diseño de interfaces gráficas son las siguientes:

\footnotetext{
${ }^{28}$ En Occidente, la lectura suele ser en esta orientación.
} 
a) Retícula de manuscrito. Este tipo de retícula se usa generalmente para bloques de texto largos. Está compuesta por márgenes amplios que enmarcan un rectángulo en donde se vaciará la información. Los títulos, pies y número de página se encuentran dentro de los marcadores que se localizan fuera de los márgenes.

b) Retícula de columnas. Esta retícula resulta ser bastante flexible en cuanto al acomodo de la información. El número de columnas va a depender de la cantidad de información que se esté manejando, es decir, entre más información mayor número de columnas.

c) Retícula modular. Este sistema reticular está compuesto por módulos del mismo tamaño. Se puede diagramar con base al número de módulos que se tengan sobre el lienzo, ya que a través de estos se puede crear zonas espaciales ${ }^{29}$ para insertar imágenes y texto. Entre más módulos tenga la retícula más flexible será para el acomodo de la información, sin embargo, esto aumentará el nivel de complejidad para mantener la estética de la interfaz.

d) Retícula jerarquía. Este tipo de retícula, al contrario de las anteriores, no se rige a través de módulos, columnas o márgenes. Esta retícula se adapta al contenido y no éste a

\footnotetext{
${ }^{29}$ Las zonas espaciales son agrupaciones de columnas, filas o módulos que forman un elemento
} de composición. 
ella. Este sistema reticular se establece a través de los niveles de jerarquía de la propia información.

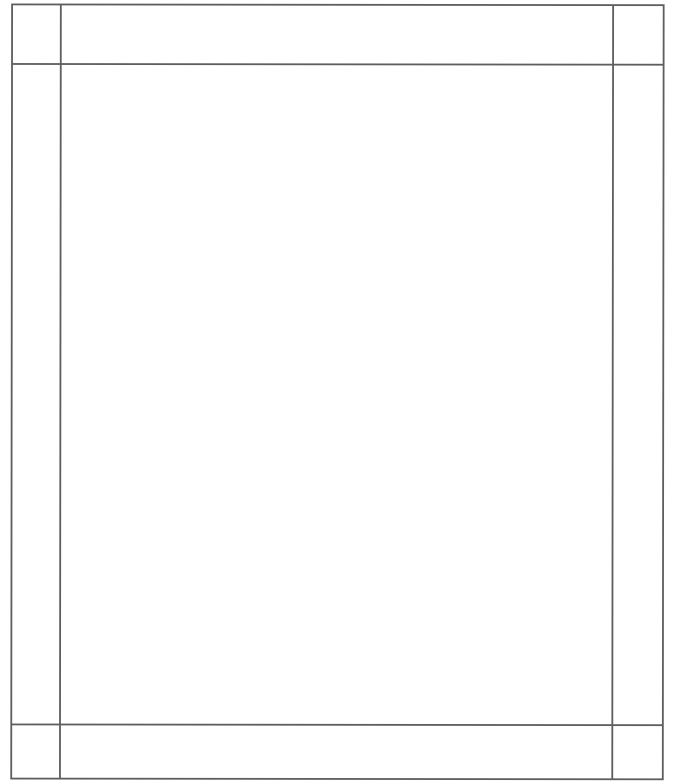

Retícula de manuscrito.

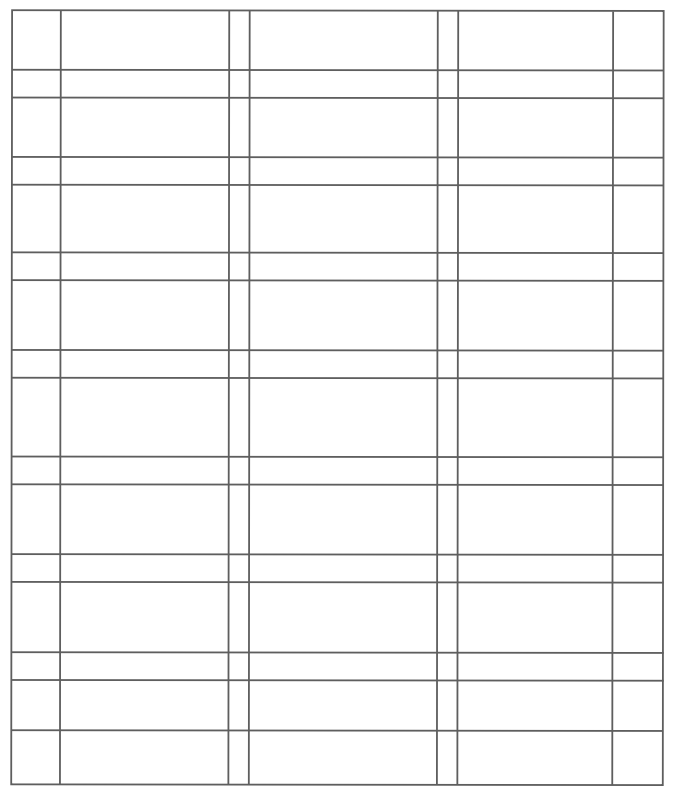

Retícula modular.

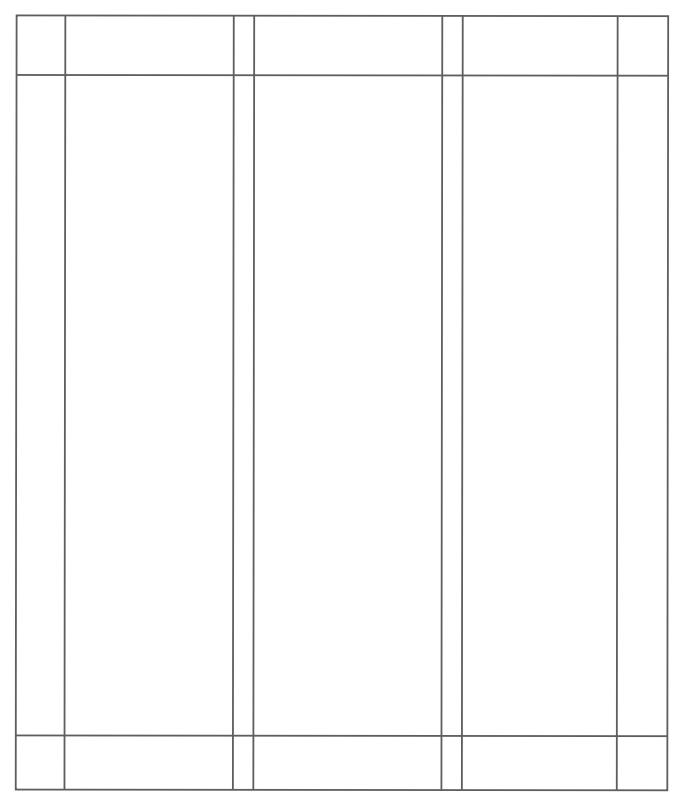

Retícula de columnas.

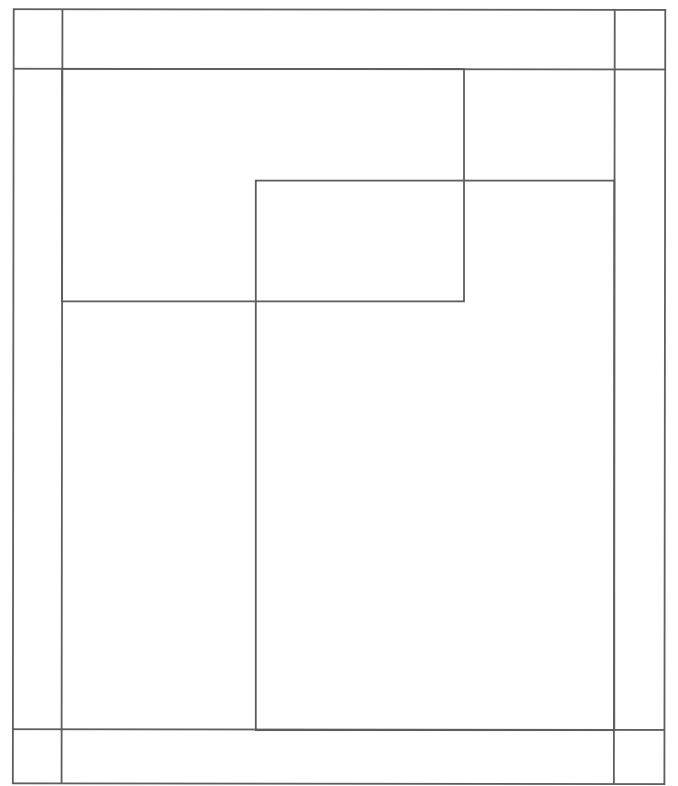

Retícula jerarquíca.

Figura 3. Tipos de retículas Elaborada por Mariel García Hernández 
9. Al ser estas guías que se enfocan en el desarrollo de sistemas de visualización médica es importante mencionar los datos médicos y sus diversas clasificaciones basándose en el caso de estudio de esta investigación que es la diabetes. Los datos médicos que se pueden trabajar respecto a esta patología son los siguientes:

a) Historial clínico. El historial clínico es un compendio de información que alude a datos de identificación y evolución del propio paciente. En éste se asienta la evolución de la patología. Dentro de este bloque de información, de acuerdo a Castro \& Gámez, (2002), se encuentran a su vez los siguientes datos:

1. Datos de identificación.

(a) Número de historia clínica.

(b) Nombre y apellido del paciente.

(c) Fecha de nacimiento del paciente.

(d) Género del paciente.

(e) Edad del paciente.

(f) Domicilio particular del paciente.

(g) Número telefónico de contacto.

(h) Peso del paciente.

(i) Altura del paciente.

(j) Signos vitales del paciente (temperatura, presión, pulso, frecuencia respiratoria, nivel de glucosa).

2. Datos relativos al centro de salud o del doctor tratante. 
(a) Nombre de la unidad o centro de salud donde ingresa el paciente.

(b) Nombre del doctor a cargo del caso clínico.

(c) Dirección de la unidad, centro de salud o doctor tratante del caso clínico.

(d) Persona facultativa a cargo del ingreso del paciente.

3. Datos referidos al proceso de ingreso.

(a) Fecha de admisión del paciente.

(b) Motivo de ingreso del paciente.

(c) Diagnóstico principal.

(d) Procedimientos quirúrgicos u obstétricos que ha tenido el paciente.

(e) Otros procedimientos significativos que haya tenido el paciente.

4. Datos referidos a antecedentes clínicos.

(a) Antecedentes familiares de enfermedades (diabetes, hipertensión, cáncer, enfermedades del corazón, etc.).

(b) Si el paciente tiene hijos y, en caso de ser afirmativo, cuáles son las edades de éstos.

(c) Historial social, tales como cuál es su trabajo, su jornada laboral, dónde vive, cuál es el ambiente emocional en el que el paciente habita. 
(d) Hábitos del paciente. Si hace ejercicio y con qué frecuencia realiza esta actividad, si fuma, se droga y toma, y la periodicidad con la que desarrolla o desarrolló estas actividades. Si se droga (o drogaba), que estupefaciente usa o usó. Patrón de sueño, a qué hora duerme y más o menos las horas que duerme sin interrupción.

(e) Alergias a medicamentos y alimentos.

5. Datos referentes a la historia de la enfermedad actual.

(a) Fecha de diagnostico de diabetes.

(b) Nombre del médico que trata actualmente la diabetes del paciente.

(c) Dirección del médico que trata actualmente la diabetes del paciente.

(d) Fecha de última revisión de parte del médico tratante por diabetes.

(e) Si el paciente está siguiendo una dieta en especial.

(f) Consumo aproximado de calorías al día.

(g) Si el paciente está tomando insulina.

(i) Unidades de insulina.

(ii) Dosis de insulina.

(iii) Hora en que se inyecta la dosis de insulina.

(h) Si el paciente ha sufrido un coma diabético, fecha de éste y frecuencia, de ser el caso. 
(i) Sí el paciente se ha realizado análisis de glucosa en la orina. En caso de ser afirmativo, mencionar las últimas dos fechas de éstos.

(j) Si el paciente ha tenido alguno de estos padecimientos:

(i) Infecciones dentales.

(ii) Trastornos en la visión.

(iii) Problemas en el corazón.

(iv)Presión alta.

(v) Problemas en los riñones o en las vías urinarias.

(vi)Alguna enfermedad recurrente o prolongada. En caso de ser afirmativo, mencionar cuál.

(k) Niveles de glucosa.

(i) En ayunas.

(ii) Después de la comida.

(iii) Antes de la cena.

(I) Si se le ha realizado un electrocardiograma. En caso de ser afirmativo, establecer la fecha.

(m)Si se le ha realizado una radiografía de tórax. En caso de ser afirmativo, indicar la fecha.

6. Datos bioquímicos relacionados con el control de la diabetes.

(a) Triglicéridos ( $\mathrm{mg} / \mathrm{dL})$.

(b) Glucosa (mg/DI). 
(c) Hemoglobina glucosilada (HbA1c).

(d) Colesterol total $(\mathrm{mg} / \mathrm{dL})$.

(e) Colesterol de alta densidad ( $\mathrm{mg} / \mathrm{dL})$.

(f) Colesterol de baja intensidad ( $\mathrm{mg} / \mathrm{dL})$.

(g) Colesterol de muy baja intensidad (mg/dL).

(h) Índice de riesgo coronario.

(i) Examen de orina.

(i) Color.

(ii) Aspecto.

(iii) Gravedad específica.

(iv) $\mathrm{Ph}$

(v) Sedimento.

(vi) Proteínas (mg/dL).

(vii) Glucosa (g/dL).

(viii) Hemoglobina.

(viv) Bilirrubina.

(vv) Cetonas.

(vvi) Urobilinogeno (mg/dL).

(vvii) Esterasa Leucocitaria (Leu/uL).

(vviii) Nitritos.

\subsection{Texto}

El uso de texto en cualquier artefacto de diseño es de suma vitalidad, ya que es éste a través del cual se transmite de manera escrita información al lector. Elegir 
la mejor estrategia tipográfica y de composición de texto es importante para la legibilidad del documento en sí y, para que la información que se está trabajando resulte significativa para su lector.

\subsubsection{Elección tipográfica}

a) Según a Nielsen \& Loranger (2006), la tipografía debe elegirse de manera apropiada para su función, es decir, para transmitir el mensaje de manera efectiva. Las fuentes tipográficas, según determina los autores son las siguientes:

\begin{tabular}{|l|l|l|}
\hline FUENTE TIPOGRÁFICA & \multicolumn{1}{c|}{ LEGIBILIDAD } & \multicolumn{1}{c|}{ CARÁCTER/TONO } \\
\hline Arial & $\begin{array}{l}\text { Es una tipografía legible. Se recomienda } \\
\text { usar en puntajes superiores a } 10 \text { puntos. }\end{array}$ & $\begin{array}{l}\text { Moderna, básica y sin adornos. Suele } \\
\text { gustar a los usuarios de todas las } \\
\text { edades. }\end{array}$ \\
Georgia & $\begin{array}{l}\text { La mejor fuente serif diseñada para la } \\
\text { lectura online. Generalmente buena en } \\
\text { tamaños de letra } 10 \text { o más. }\end{array}$ & $\begin{array}{l}\text { De aspecto tradicional, pero más } \\
\text { moderna y legible que Times New } \\
\text { Roman. }\end{array}$ \\
Times New Roman & $\begin{array}{l}\text { Tiene buen rendimiento en materiales } \\
\text { impresos, ya que en la pantalla, la legibi- } \\
\text { lidad disminuye en pequeños puntajes } \\
\text { pequeños. Se sugiere su uso a partir de } \\
12 \text { puntos. }\end{array}$ & $\begin{array}{l}\text { Es una tipografía que no es prefereri- } \\
\text { da por la mayoría de los usuarios. } \\
\text { Tiene un aspecto profesional. }\end{array}$ \\
\hline \multirow{2}{*}{ Trebuchet MS } & $\begin{array}{l}\text { Es una tipografía legible. Se recomienda } \\
\text { usar en puntajes superiores a 10 puntos. }\end{array}$ & $\begin{array}{l}\text { Tiene un aspecto moderno, sencillo y } \\
\text { vanguardista. }\end{array}$ \\
\hline Verdana & $\begin{array}{l}\text { Es la tipografía con mayor legibilidad. } \\
\text { Se recomienda usarla en cuerpo de texto. }\end{array}$ & $\begin{array}{l}\text { De aspecto simple, moderno y } \\
\text { profesional. Tiene una alta preferen } \\
\text { cia por parte del usuario. }\end{array}$ \\
\hline
\end{tabular}

Figura 4. Tipografías recomendadas por Nielsen \& Loranger (2006).

Elaborada por Mariel García Hernández.

b) El tipo de letra seleccionada deben coincidir con el tema de la información que se trabajará. 
c) No es recomendable los tipos de letra con características inusuales (Nielsen \& Loranger, 2006), ya que además de sacrificar la legibilidad del contenido, fungirán como un elemento de distracción durante el recorrido de la lectura.

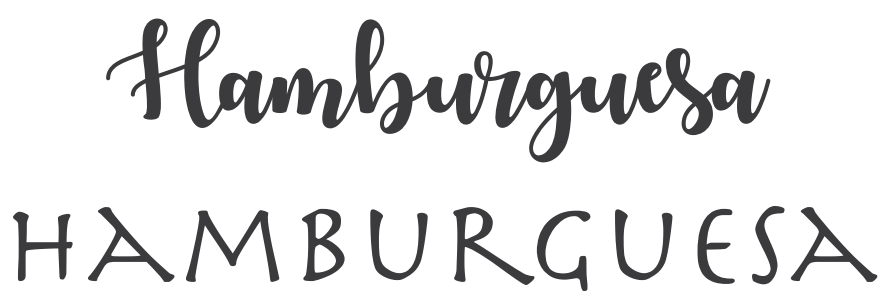

Figura 5. Ejemplos de tipos de letra con características inusuales. Elaborada por Mariel García Hernández.

d) El tamaño del tipo, el espacio interlineal y la longitud de la línea se deben coordinar y elegir juntos. De acuerdo a Herrera de Velasco \& Gutiérrez Neve (2000:160) establecen el uso de "entre 5 y 13 palabras promedio en una línea para una adecuada facilidad de lectura".

e) Según lo que sugiere Götz (1988:58), "el espacio interlineal debe ser por lo menos uno y medio más grande que la altura de $x$, es decir, 1.5".

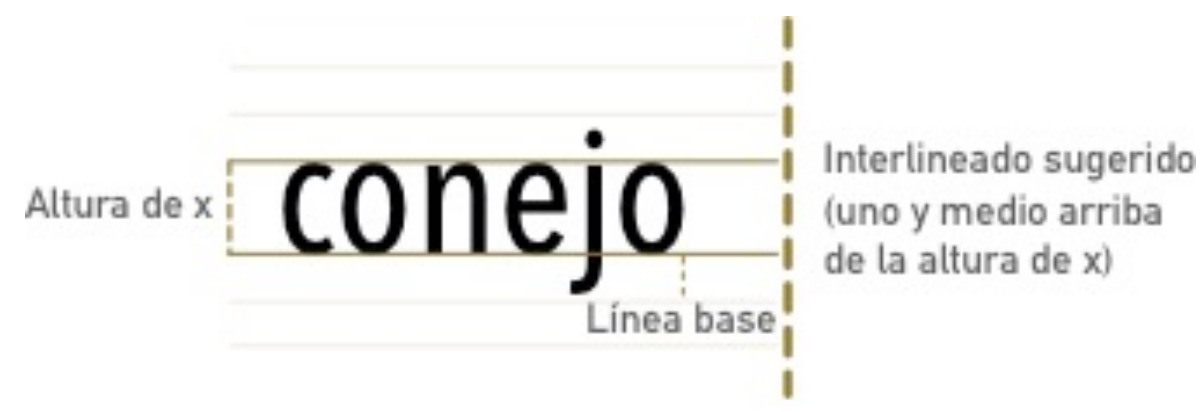

Figura 6. Espacio interlineal recomendado por Gồtz (1988:58).

Elaborada por Mariel Garcia Hernández. 
Así mismo, la autora sugiere que se le de la importancia a este elemento tipográfico, ya que interviene en la legibilidad del texto y del mismo contenido en sí.

f) Siguiendo con las recomendaciones de la autora, el ancho normal de una línea debe tener alrededor de 50 caracteres.

g) Lonsdale \& Lonsdale (2019b), hacen las siguientes recomendaciones acerca de la tipografía y su uso:

1. Debe evitarse dejar una sola palabra en un renglón dentro de una caja de texto. A esto se le llama viuda.

Lorem ipsum dolor sit amet, consectetuer adipiscing elit. Aenean commodo ligula eget dolor. Aenean massa. Cum sociis natoque penatibus pellentes.

Figura 7. Ejemplo de una "viuda" en una caja de texto. Elaborada por Mariel García Hernández.

2. En el idioma inglés, la variante "negrita" debe usarse sobre la variante "cursiva" para enfatizar el texto. La variante cursiva debe reservarse para situaciones en las que se utiliza una palabra extranjera o para títulos cortos. 
Muy lejos, más allá de las montañas de palabras, alejados de los países de las vocales y las consonantes, viven los textos simulados. Viven aislados en casas de letras, en la costa de la semántica, un gran océano de lenguas. Un riachuelo llamado Pons fluye por su pueblo y los abastece con las normas necesarias.

Figura 8. Ejemplo del uso de la variable "negrita" y la variable "cursiva". Elaborada por Mariel García Hernández.

3. La variante "negrita" se puede usar para enfatizar información, y como una técnica para engrosar los caracteres cuando estos deben imprimirse o verse en un fondo oscuro y / o de color.

\section{Se debe evitar utilizar la variante "cursiva" para grandes}

bloques de texto, ya que ésta atrasa la lectura.

Lorem ipsum dolor sit amet, consectetuer adipiscing elit. Aenean commodo ligula eget dolor. Aenean massa. Cum sociis natoque penatibus et magnis dis parturient montes, nascetur ridiculus mus. Donec quam felis, ultricies nec, pellentesque eu, pretium quis, sem. Nulla consequat massa quis enim. Donec pede justo, fringilla vel, aliquet nec, vulputate eget, arcu. In enim justo, rhoncus ut, imperdiet a, venenatis vitae, justo. Nullam dictum felis eu pede mollis tellus. Phasellus viverra nulla ut metus varius

Figura 9. El uso de la variable "cursiva" atrasa la lectura de bloques de texto largos.

Elaborada por Mariel García Hernández. 
5. Se recomienda usar la variante "negrita" para aumentar la legibilidad en un fondo de color o sombreado.

6. La variante "negrita" no debe usarse para una gran cantidad de texto porque al resaltar todo, no se enfatizará nada del contenido a un nivel cognitivo.

Lorem ipsum dolor sit amet, consectetuer adipiscing elit. Aenean commodo ligula eget dolor. Aenean massa. Cum sociis natoque penatibus et magnis dis parturient montes, nascetur ridiculus mus. Donec quam felis, ultricies nec, pellentesque eu, pretium quis, sem. Nulla consequat massa quis enim. Donec pede justo, fringilla vel, aliquet nec, vulputate eget, arcu. In enim justo, rhoncus ut, imperdiet a, venenatis vitae, justo. Nullam dictum felis eu pede mollis pretium. Integer tincidunt. Cras dapibus. Vivamus elementum semper nisi. eu, consequat vitae, eleifend ac, enim. Aliquam lorem ante in.

Figura 10. El uso de la variable "negrita" en todo el texto no logra enfatizar nada del contenido a un nivel cognitivo. Elaborada por Mariel García Hernández.

7. Se debe evitar la variante "subrayado" porque agrega bastante "ruido" y compromete la legibilidad del texto y de la información en sí.

8. No se deben usar diferentes tipos de letra para enfatizar el contenido en sí, no solo porque hace que la lectura sea más ardua, sino también porque altera la estética. 
Lorem ipsum dolor sit amet, consectetuer adipiscing elit. Aenean commodo ligula eget dolor. Aenean massa. Cum socís natoque penatíbus et magnis dis parturient montes, nascetur ridículus mus. Donec quam felis, ultricies nec, pellentesque eu, pretium quis, sem. Nulla consequat massa quis enim. Donec pede justo, fringilla vel, aliquet nec, vulputate eqet, arcu. In enim justo, rhoncus ut, imperdiet a, venenatis vitae, justo. Nullam dictum felis eu pede mollis pretium. Intezer tincidunt. Cras dapibus. Vivamus elementum semper nisi. Aenean vulputate eleifend tellus.

Figura 11. Ejemplo del mal uso de varias tipografías en un bloque de texto. Elaborada por Mariel García Hernández.

9. Según lineamientos que proponen Nielsen \& Loranger (2006) la lectura es más agradable y confortable para el usuario cuando se emplean tipografías serif ${ }^{30}$.

\section{Hamburguesa}

\section{Tipografía Serif \\ Hamburguesa}

Tipografía Sans Serif

Figura 12. Ejemplos de tipografía sans serif y serif. Elaborada por Mariel García Hernández.

${ }^{30}$ La tipografía serif es aquella que tiene pequeños remates en forma de línea en el trazo principal del carácter, según lo describe Götz (1988:56). 
10. Nielsen \& Loranger (2006) argumentan que el puntaje se debe elegir dependiendo del usuario al que la interfaz va dirigida, por lo cual se presentan las siguientes sugerencias de acuerdo al usuario:

\begin{tabular}{|l|c|}
\hline \multicolumn{1}{|c|}{ AUDIENCIA } & PUNTAJE \\
\hline Audiencia general & $10-12$ \\
Personas mayores y personas con discapacidad visual. & $12-14$ \\
Niños pequeños y otros lectores principiantes. & $12-14$ \\
Adolescentes y adultos jóvenes & $10-12$ \\
\hline
\end{tabular}

Figura 13. Tamaño de puntaje recomendado de acuerdo a la audiencia por Nielse \& Loranger (2006). Elaborada por Mariel García Hernández.

11. El puntaje mínimo recomendado para las cajas de texto es de 11 pts. y para las anotaciones 0 datos complementarios como fuentes de referencia es 8 pts., según a Lonsdale \& Londsdale (2019b).

12. La tipografía no debe ser demasiada fina o condensada en su forma, según plantean Lonsdale \& Lonsdale (2019b).

Lorem jpsum dobr st amet, consedeturer adipisang elt:Aenean com modbligulegetddorAeneanmessa Cum socis natoquepenatbuset magnisolispaturientmontesnescet midalusmusconsedetureradipisang elimodbligulaegetdblor.Lorem ipsum dolor sit amet, consectetuer adipiscing elit. Aenean com modo ligula eget dolor. Aenean massa. Cum

Figura 14. La tipografía no debe ser demasiado fina ni condensada. Elaborada por Mariel García Hernández. 
13. Los mismos autores recomiendan utilizar notas al pie para aclarar puntos en especiales del texto que se está leyendo.

\subsubsection{Títulos}

a) Los títulos deben ser uno de los elementos más dominantes en la interfaz gráfica y deben presentar rápidamente el propósito del contenido y el enfoque del mensaje.

b) El contraste entre el título, los subtítulos y el texto narrativo debe ser claro en términos de diferencias de tamaño y las características del tipo de letra.

c) De acuerdo a lo que plantea Götz, (1988:56), las tipografías sans serif son utilizadas para los títulos y subtítulos.

d) Es recomendable no usar más de tres niveles de jerarquía en cuanto a texto, el nivel de mayor jerarquía puede distinguirse usando un puntaje de letra mayor, con la variable "negritas" y centrado en el lienzo, de acuerdo a lo que argumentan Nielsen \& Loranger (2006). 
e) Lonsdale \& Lonsdale (2019b), indican que los títulos pueden estar centrados o alineados a la izquierda, mientras que los encabezados deben alinearse a la izquierda.

f) Es recomendable que los títulos puedan ser usados en la variante "negrita" o un par de puntajes más grandes que el texto principal, según los mismos autores.

\section{TíTULO}

\section{Subtítulo}

Muy lejos, más allá de las montañas de palabras, alejados de los países de las vocales y las consonantes, viven los textos simulados. Viven aislados en casas de detras, en la costa de la semántica, un gran océano de lenguas.

Figura 15. Contraste de peso tipográfico entre el título, subtítulo y el texto.

Elaborada por Mariel García Hernández.

\subsubsection{Etiquetas y leyendas}

a) Lonsdale \& Lonsdale (2019b), hacen las siguientes recomendaciones sobre el uso de etiquetas y leyendas:

(1) Las etiquetas se deben utilizar para proporcionar información detallada sobre los datos y se deben excluir si son redundantes o si el gráfico se ve desordenado. 
(2) Se sugiere que los textos de apoyo (etiquetas, leyendas, etc.) deben colocarse para ayudar al usuario a interpretar el gráfico, no para distraer o confundir.

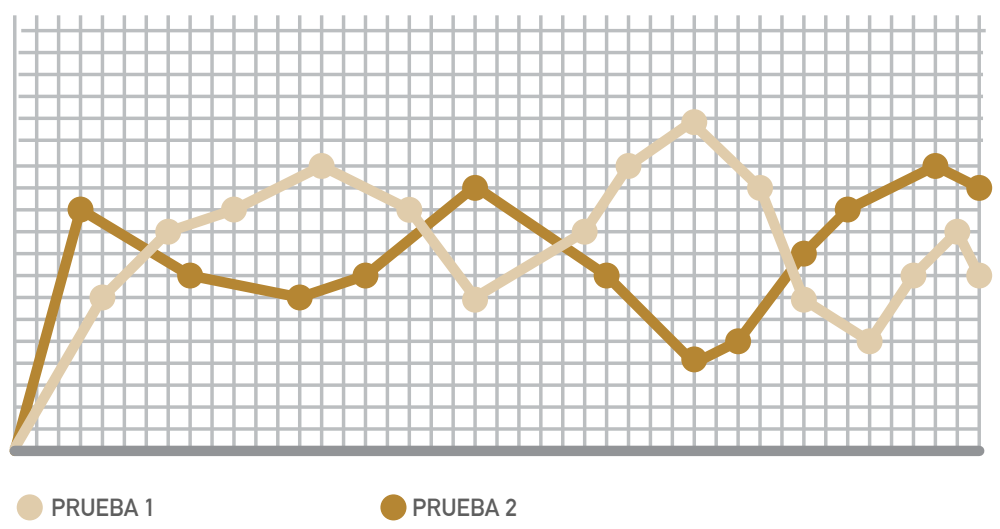

Figura 16. Uso de etiquetas para ayudar al usuario a identificar y distinguir información. Elaborada por Mariel García Hernández.

(3) Las etiquetas deben usarse con datos segmentados, con una amplia gama de datos y con áreas de datos (especialmente cuando se usa el volumen para representar el tamaño).

(4) Se recomienda evitar usar etiquetas horizontales que se extiendan más allá de la tabla. 
(5) Las etiquetas no se deben usar cuando la tarea es solo para comprender tendencias generales 0 para comparar un elemento de datos con otro.

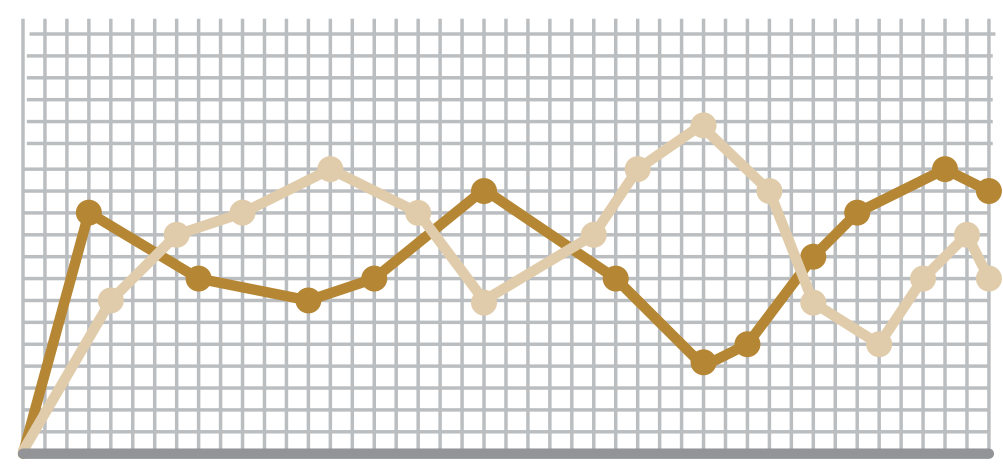

Lorem ipsum dolor sit amet, consectetuer adipiscing elit. Aenean commodo. Lorem ipsum dolor sit amet, consectetuer adipiscing elit. Aenean commodo.

Figura 17. Se debe evitar el uso de etiquetas que se extiendan más allá de la tabla. Elaborada por Mariel García Hernández.

(6) Las etiquetas deben ser concisas y se debe tener cuidado de no usar grandes bloques de texto (especialmente debajo de una línea en un gráfico).

(7) Las leyendas deben escribirse para que el cuadro se explique por sí mismo.

(8) Una buena opción es incorporar las leyendas alrededor o dentro de la tabla, de tal forma en que no parezca un ente separado de la interfaz. 
(9) Es recomendable que las leyendas tengan el mismo orden que los elementos de contenido correspondientes en el gráfico.

(10) Los símbolos auto explicativos podrían usarse en ciertos contextos en lugar de una leyenda, pero todas las abreviaturas y símbolos deben estar claramente definidos.

(11) Es conveniente utilizar verbos y adjetivos en una leyenda para sugerir o dejar claro cuál es la categoría general del mensaje que se usará en el gráfico.

(12) El utilizar una leyenda y el área de datos como conjunto ayuda al usuario a completar la tarea más rápido.

\subsubsection{Rendimiento visual del texto}

a) El texto y el color del fondo de la interfaz gráfica deben tener un buen contraste para ser legibles. Los fondos inadecuados, como los fondos de varios colores o degradados, deben evitarse para el texto. 


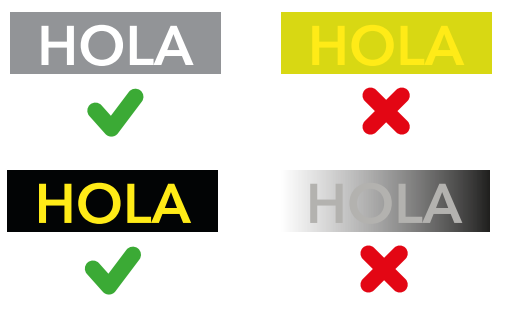

Figura 18. Ejemplos de buen y mal contraste entre el texto y el color de fondo de la interfaz.

Elaborada por Mariel García Hernández.

\section{b) Grandes cantidades de texto deben dejarse alineadas en}

lugar de centralizadas. La justificación centralizada debe

limitarse a cantidades muy pequeñas de texto o texto /

encabezados.

Lorem ipsum dolor sit amet, consectetuer adipiscing elit. Aenean commodo ligula eget dolor. Aenean massa. Cum sociis natoque penatibus et magnis dis Lorem ipsum dolor sit amet, parturient montes, nascetur ridiculus mus. Donec quam felis, ultricies nec, pellentesque eu, pretium quis, sem. Nulla consectetuer adipiscing elit. Aenean elitjadoilen cjejd com consequat massa quis enim. et magnis dis adf departurient

Grandes cantidades alineadas a la izquierda

Pequeñas cantidades de texto en justificación centralizada

Figura 19. Ejemplos de justificaciones de contenido apartir de la cantidad de texto.

Elaborada por Mariel García Hernández.

c) Se deben evitar poner todo el texto en mayúsculas, ya que compromete la leibilidad del mismo. 
d) El interletrado no debe ser demasiado ancho ni demasiado estrecho, ya que esto interrumpe el flujo normal de lectura.

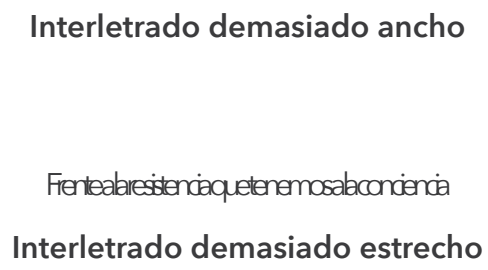

Figura 20. Ejemplos de tamaños de interletrados mal empleados. Elaborada por Mariel García Hernández.

e) El espacio interlineal debe ser aproximadamente 2 puntos más alto que el tamaño del tipo para una lectura cómoda.

f) Se deben evitar los espacios amplios entre las palabras del texto, así como también el texto totalmente justificado, ya que generan un fenómeno visual llamado "ríos", (espacios blancos verticales que parecen ríos que corren por la página) los cuales interrumpen la lectura.

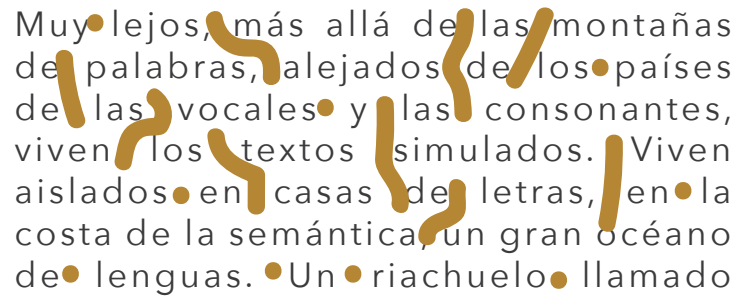

Figura 21. Ejemplo de "ríos" en el texto. Elaborada por Mariel García Hernández. 
g) Se recomienda alinear los textos al lado izquierdo y usar líneas cortas para evitar los ríos en el acomodo del texto.

h) Los párrafos largos deben indicarse con una sangría moderada de 1 a $4 \mathrm{ems}^{31}$, o separados por un espacio de una línea. Los párrafos cortos, sin embargo, no deben estar separados por un espacio de una línea.

i) Se debe crear una paleta de fuentes para establecer qué tipos de letra funcionan juntos y qué tamaños, pesos y tipos de letra se utilizarán en las diferentes partes de la interfaz gráfica.

j) Los tamaños de la tipografía deben ser apropiados para el tamaño del gráfico y el área de éste, si es que se llegan a utilizar.

k) Tanto las fuentes serif (con patín) como sans serif (sin patín) se pueden usar en combinación para crear una jerarquía visual y mantener la legibilidad. Por ejemplo, el uso de un tipo de letra sans serif para los encabezados y un tipo de letra serif para el texto del párrafo crea un

${ }^{31}$ El término ems se refiere a la medida tipográfica que equivale al puntaje del carácter. 
contraste y ayuda al usuario a navegar por los datos e identificar qué texto debe recibir atención primero.

\section{TÍTULO}

Muy lejos, más allá de las montañas de palabras, alejados de los países de las vocales y las consonantes, viven los textos simulados. Viven aislados en casas de letras, en la costa de la semántica, un gran océano de lenguas. Un riachuelo llamado Pons fluye por su pueblo y los abastece con las normas necesarias. Hablamos de un país paraiso mático en el que a uno le caen pedazos de frases asadas en la boca.

Figura 22. Ejemplo de jerarquía tipográfica a través de fuentes serif y sans serif

Elaborada por Mariel García Hernández.

I) Otra forma de crear jerarquía a través de la tipografía es utilizando diferentes pesos de una misma tipografía.

m) Es una buena opción utilizar información numérica (numeración) y textual importante en la interfaz gráfica para aumentar la precisión.

n) Los gráficos y el texto deben tener un formato consistente.

o) La tipografía no debe llamar más la atención de cualquier figura o diagrama que se encuentre en la interfaz gráfica. 
p) La variación de tamaño también se puede utilizar para enfatizar información importante y captar la atención del usuario.

q) Se sugiere que el estilo de escritura debe ser simple, independientemente de ser serif o sans serif.

r) Es recomendable usar mayúsculas y minúsculas en lugar de mayúsculas para el texto narrativo.

s) Para secuencias de palabras cortas (por ejemplo, títulos, etiquetas, palabras clave), es posible utilizar todas las mayúsculas.

\subsection{Color}

El color es una propiedad que tiene muchas caracteristicas dentro del diseño de visualización de información, ya que ésta ayuda a crear jerarquías, a reseltar información importante, entre otras cosas.

a) Wiklund (1995) en the Human Engineering Committee of the Association for the Advancement of Medical Instrumentation (AAMI) se hace las siguientes sugerencias de uso del color para codificación de información en dispositivos médicos: 


\begin{tabular}{|l|l|}
\hline \multicolumn{1}{|c|}{ COLOR } & \multicolumn{1}{|c|}{ SIGNIFICADO } \\
\hline Rojo & Prioridad alta. Advertencia. Alarma. Emergencia. Alto. Apagado. Nivel alto. \\
Amarillo & Prioridad Media. Precaución. Amenaza potencial. Nivel medio. \\
Verde & Estado normal. Inicio. Endendido. Listo. Nivel estándar. \\
\hline
\end{tabular}

Figura 23. Uso del color para codificación de información en dispositivos médicos, según the Human Engineering Committee of the Association for the Advancement of Medical Instrumentation (AAMI) (1995).

Elaborada por Mariel García Hernández.

b) Lonsdale \& Lonsdale (2019b), dicen que es conveniente usar una paleta de color que solo contemple cuatros colores.

c) Por otra parte Götz, (1988:16), propone una relación entre algunos colores y su significado.

\begin{tabular}{|l|l|}
\hline COLOR & \multicolumn{1}{|c|}{ SIGNIFICADO } \\
\hline Rojo & Activo. Poderoso. Agresivo. Fuerte. Atractivo. Dominante. Vigorazante. \\
Rosa & Cuidado. Sensible. Dulce. \\
Violeta & Místico. Sensual. Delicado. Encantadora. Solitario. Inhibido. Turbio \\
Azul & Controlado. Misterioso. Harmonioso. Frío. Profundo. Racional. Sensible. \\
Intelectual. Abstinencia. Agresivo. & Refrescante. Harmonioso. Calma. Gentíl. Cercano a la naturaleza. Conciliador. \\
Amarillo & Colorido. Extrovertido. Vivido. Lleno de alegría. Superficial. Joven. Alegre. Luz. \\
Naranja & Directo. Juguetón. Cálido. Vigoroso. Directo. Vivo. Comunicativo. Posesivo. Intímo. \\
\hline
\end{tabular}

Figura 24. Colores y sus significados, según Götz (1988:16).

Elaborada por Mariel García Hernández.

d) Para una alta legibilidad, de acuerdo a lo que establece Nielsen \& Loranger (2006) debe mantenerse un buen contraste entre el texto, el color y el fondo. 


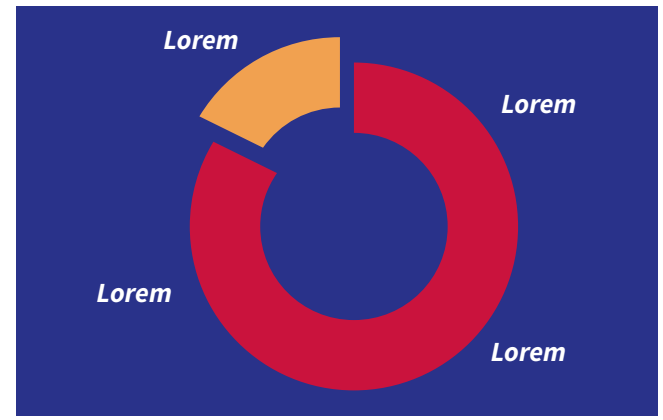

Ejemplo de buen contraste entre los elementos

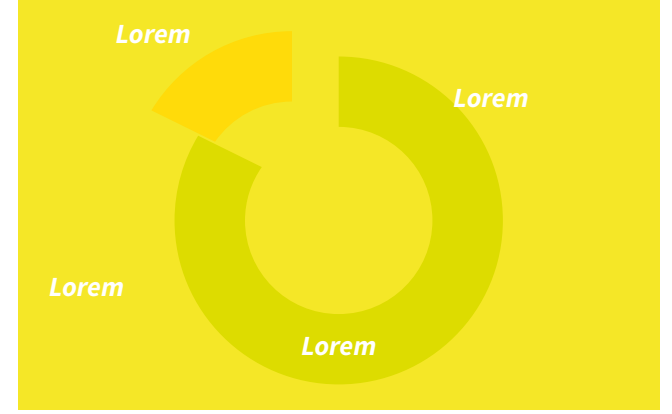

Ejemplo de mal contraste entre los elementos

Figura 25. Es recomendable elegir un buen contraste entre el texto, el color y el fondo. Elaborada por Mariel García Hernández.

e) Es muy importante usar un fondo de color que no generé "ruido visual" en contraste con el color de la tipografía y demás elementos gráficos de la interfaz gráfica. Es decir, se recomienda evitar usar colores que generen un contraste "pesado" a la vista y a la lectura, según los autores anteriores.

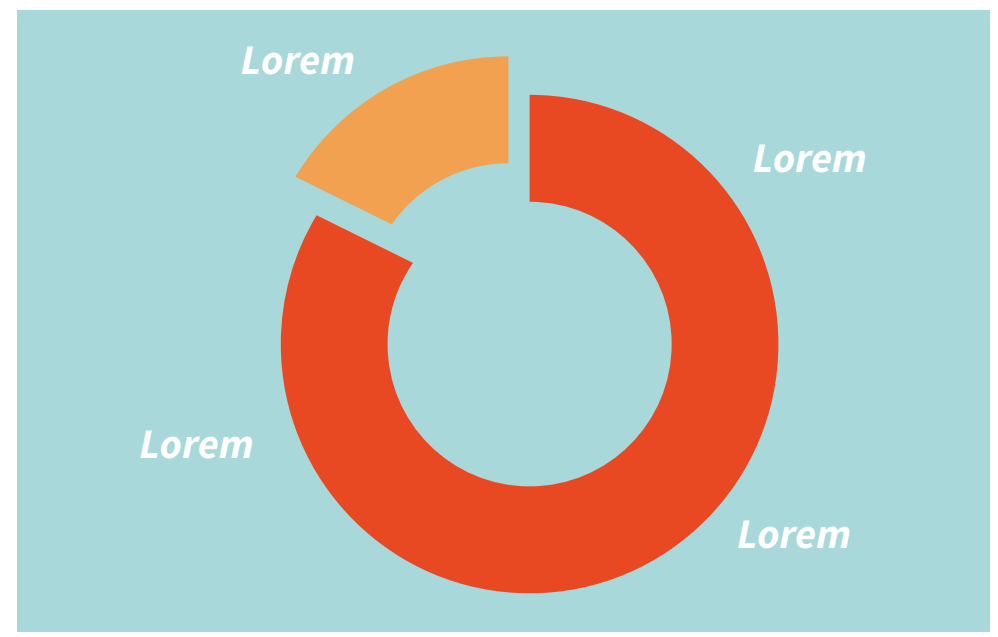

Figura 26. Ejemplo de fondo de color que no generá "ruido" y tiene buen contraste con demás elementos.

Elaborada por Mariel García Hernández. 
f) Según Nielsen \& Loranger (2006), la mejor combinación de colores para generar un buen contraste es el texto en color negro sobre fondo blanco o texto azul sobre fondo blanco.

g) Estos mismos autores establecen la siguiente relación entre el contraste del color del texto con el color fondo y el nivel de legibilidad de estos mismos elementos:

\begin{tabular}{|c|l|}
\hline COMBINACIÓN DE COLORES & \multicolumn{1}{|c|}{ NIVEL DE LEGIBILIDAD } \\
\hline Texto de color negro y fondo blanco & $\begin{array}{l}\text { Alto: Mayor valor de contraste. Diferenciación de los } \\
\text { elementos altamente perceptible. }\end{array}$ \\
\hline Texto de color azul y fondo blanco & $\begin{array}{l}\text { Alto: Mayor valor de contraste. Siempre y cuando se } \\
\text { use azul oscuro. }\end{array}$ \\
\hline Texto de color blanco y fondo gris & $\begin{array}{l}\text { Medio: Diferenciación de los elementos de un nivel } \\
\text { alto a medio, dependiendo de la saturación del gris. }\end{array}$ \\
\hline Texto de color blanco y fondo azul & $\begin{array}{l}\text { Bajo: Difícil de leer, ya que se percibe que el fondo } \\
\text { oscuro sobrepasa visualmente el texto blanco. }\end{array}$ \\
\hline Texto de color gris y fondo blanco & $\begin{array}{l}\text { Bajo: Bajo valor de contraste. Diferenciación de los } \\
\text { elementos casi inperceptible. }\end{array}$ \\
\hline Texto de color blanco y fondo gris & $\begin{array}{l}\text { Bajo: Bajo valor de contraste. Diferenciación de los } \\
\text { elementos casi inperceptible. }\end{array}$ \\
\hline Texto de color blanco y fondo azul & $\begin{array}{l}\text { Bajo: El contraste que generarlos colores hacen que la } \\
\text { lectura resulte cansada para el ojo. }\end{array}$ \\
\hline Texto de color gris y fondo blanco & $\begin{array}{l}\text { Bajo: El contraste que generarlos colores hacen que la } \\
\text { lectura resulte cansada para el ojo. }\end{array}$ \\
\hline
\end{tabular}

Figura 27. Nivel de legibilidad de diferentes combinaciones de colores por Nielsen \& Loranger (2006). Elaborada por Mariel García Hernández. 
h) El color se puede utilizar para centrar la atención del usuario y garantizar que todo el texto sea claro, legible y que se pueda leer rápidamente, de acuerdo a lo que plantean Lonsdale \& Lonsdale (2019b).

i) Según los mismos autores, el color se puede usar para ayudar a organizar fragmentos de información que compartan características en común. Por ejemplo, usar un color en especial para los títulos, otro para elementos gráficos, etc.

\section{TíTULO}

\section{Subtítulo}

Muy lejos, más allá de las montañas de palabras, alejados de los países de las vocales y las consonantes, viven los textos simulados. Viven aislados en casas de letras, en la costa de la semántica, un gran océano de lenguas. Un riachuelo llamado Pons fluye por su pueblo y los abastece con las normas necesarias. Hablamos de un país paraisomático en el que a uno le caen pedazos de frases asadas en la boca.

\section{Subtítulo}

Muy lejos, más allá de las montañas de palabras, alejados de los países de las vocales y las consonantes, viven los textos simulados. Viven aislados en casas de letras, en la costa de la semántica, un gran océano de lenguas. Un riachuelo llamado Pons fluye por su pueblo y los abastece con las normas necesarias. Hablamos de un país paraisomático en el que a uno le caen pedazos de frases asadas en la boca.

Figura 28. Ejemplo de consistencia de color en los elementos gráficos. Elaborada por Mariel García Hernández.

j) Lonsdale \& Londsdale (20019b), señalan las siguientes recomendaciones sobre color:

i) Resulta esencial usar el color para enfatizar palabras, resaltar los encabezados, señalar relaciones dentro de un documento, mostrar 
niveles jerárquicos y proporcionar estructura y organización en un documento.

ii) Se deben usar colores en contrastes claros, donde se recomienda un contraste del $70 \%$ entre un objeto y su fondo.

iii) Los colores que se usen como fondo, se sugiere que estos deben proporcionar suficiente contraste con los objetos que estén sobre éste.

iv) Se sugiere para comprobar rápidamente el contraste entre los valores, el diseño debe imprimirse en escala de grises o el monitor debe cambiarse a escala de grises. Si esto demuestra que los diferentes elementos visuales se mezclan, entonces los colores deben ajustarse para crear un buen contraste.

v) Se deben evitar los efectos de gradiente de color, ya que estos efectos dificultan la lectura del contenido de la interfaz gráfica.

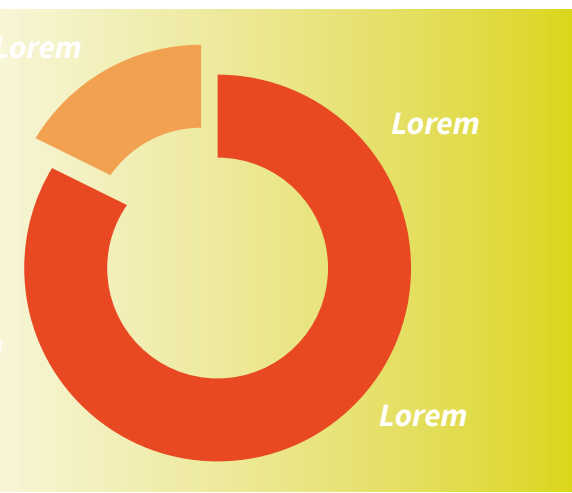

Figura 29. Ejemplo del mal uso del efecto de gradiente como fondo. Elaborada por Mariel García Hernández. 
vi) Se sugiere no utilizar los colores brillantes, altamente saturados (primarios ${ }^{32}$ ), ya que son visualmente demasiado molestos y pueden crear problemas de legibilidad.

vii) El texto coloreado, los bordes coloreados, los fondos coloreados o los patrones coloreados no se deben utilizar, a menos que con fines decorativos.

viii) Para las tareas de búsqueda e identificación, se recomienda usar una codificación de colores, ya que éstas funcionan mejor que la variación en la forma y el tamaño.

ix) Para información categórica, se deben usar colores que sean complementarios en el círculo cromático ${ }^{33}$.

x) Se recomienda para datos continuos, utilizar saturación u oscuridad de los mismos colores.

\footnotetext{
${ }^{32}$ Los colores primarios luz son rojo, verde y azul. En cuanto a los colores primarios pigmento, encontramos al cian, magenta y amarillo. cian

33 Se denomina como circulo cromático a la representación visual de seis colores luz en la descomposición de la luz visible del espectro sola sobre un círculo, de acuerdo a al siguiente orden; púrpura, rojo, amarillo, verde, azul cian y azul oscuro. Estos colores se colocan según matriz o tono de manera descendente.
} 
xi) Deben evitarse los colores adyacentes entre sí en el círculo cromático, ya que producen poco contraste cuando se usan juntos. Si se elije esta combinación, entonces su brillo debe ser lo suficientemente diferente para crear un contraste claro.

xii) Los colores deben mantenerse uniformes en todos los gráficos de todos los elementos de las interfaces gráficas.

xiii) La codificación de colores se puede utilizar en gráficos para ayudar a los usuarios a interpretar los datos.

xiv) Resulta conveniente usar colores suaves en gráficos, en lugar de los colores del adyacentes en el círculo cromático (que tienen un alto contraste).

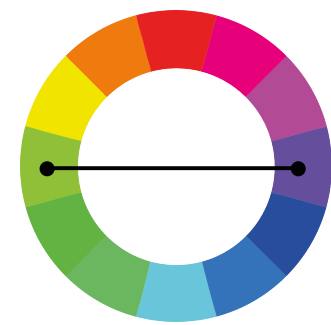

Colores complementarios

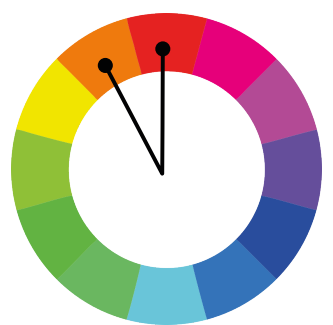

Colores análogos

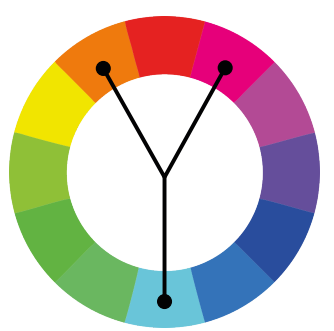

Colores adyacentes

Figura 30. Círculo cromático; colores complementarios, análogos y adyacentes. Elaborada por Mariel García Hernández.

xv) El contraste entre los colores se debe usar para la legibilidad, y diferentes valores dentro del mismo color también se pueden usar para definir capas de atención. 
xvi) No se deben usar múltiples colores para representar el mismo tipo de datos (por ejemplo, diferentes colores para cada gráfico de barras en la misma categoría).

xvii) Se recomienda usar un tono más oscuro o más claro, o un color diferente, para enfatizar un punto específico o un valor de datos dentro de la interfaz gráficas.

xviii) El gris debería usarse para información contextual y de segundo nivel, así como para elementos estructurales como las líneas de cuadrícula.

xix) El rojo no debe usarse para números positivos en un gráfico de barras, ya que está fuertemente asociado con la pérdida, pero se puede usar efectivamente para valores negativos.

\subsection{Elementos gráficos}

Los elementos gráficos son parte importante para la composición de cualquier tipo de visualización de información. Dichos elementos pueden abarcar desde fotografías, pictogramas, íconos, entre otros. A continuación exploraremos recomendaciones acerca del uso de elementos gráficos. 
a) Resulta importante definir los elementos gráficos que se utilizarán en la pieza de diseño desde el principio del proceso de diseño.

b) Dentro de una interfaz gráfica se recomienda que todos los elementos conserven un mismo estilo gráfico.

c) Todos los elementos visuales deben usarse de manera efectiva y organizarse adecuadamente dentro de la estructura del sistema de visualización de información.

d) La carga cognitiva en la interfaz gráfica que se está trabajando, de acuerdo a Lonsdale \& Lonsdale (2019) debe reducirse, se recomienda minimizar la cantidad de información que se transmite a través de gráficos, así como también se sugiere el uso de colores significativos, símbolos, líneas o barras de etiquetado directo.

e) Los elementos gráficos que se utilicen dentro de la interfaz gráfica deben aportar denotaciones relacionadas directamente con el objetivo de comunicación, conforme con lo que establecen los autores anteriores.

f) Es recomendable el uso de fotos que tengan una resolución de $300 \mathrm{dpi}^{34}$ para que estás se aprecien en sus detalles y la calidad de la imagen.

\footnotetext{
${ }^{34}$ Los dpi (dots per inch) o ppp son una unidad de medida para la resolución de imágenes. Esta unidad de medida representa los puntos que puede contener un pixel dentro de la composición de una imagen.
} 
g) Es importante implementar imágenes que tengan la misma orientación (horizontal o vertical), dependiendo de la retícula del lienzo de trabajo sobre el cual se este diagramando, de tal manera que se facilita el acomodo de los elementos que forman parte del contenido de la interfaz gráfica, de acuerdo a lo que establecen Lonsdale \& Lonsdale (2019).

h) Las imágenes que sean usadas dentro de la interfaz gráfica deben responder a términos del objetivo de comunicación y la temática de esta.

i) Wiklund (1995), sugiere utilizar pictogramas, ya que estos albergan significados universales en una imagen simple.

j) Para generar claridad, Lonsdale \& Lonsdale (2019), recomiendan usar como contenedor un círculo para el uso de pictogramas.
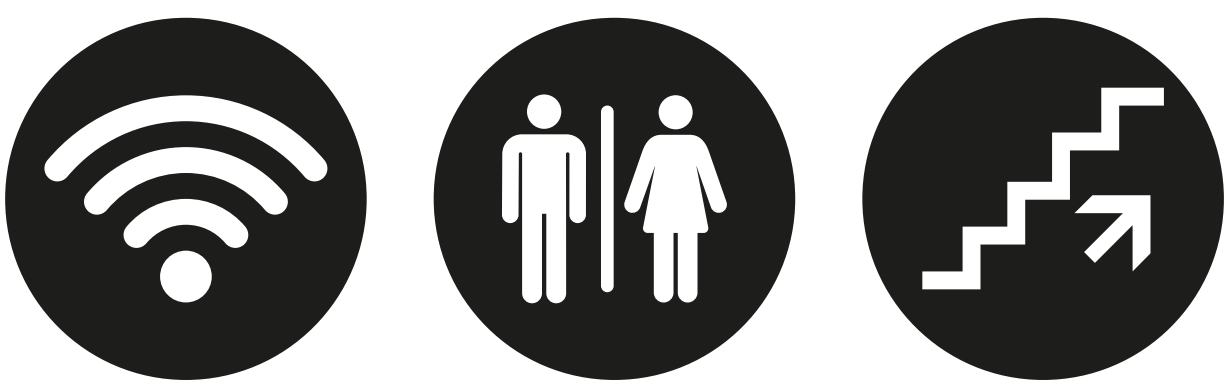

Figura 31. Uso de pictogramas para englobar connotaciones de conceptos. Elaborada por Mariel García Hernández. 
k) No es conveniente el uso de emojis ${ }^{35}$ u otro tipo de elemento gráfico que tenga un significado amplio a su interpretación, según lo plantean Krajil Novak, Smailović, Sluban, \& Mozetič (2015).

I) Lonsdale \& Lonsdale (2019), establecen que una manera efectiva de guiar al usuario a través de la lectura de la pieza de diseño es a través de flechas y líneas que puedan generar un recorrido visual.

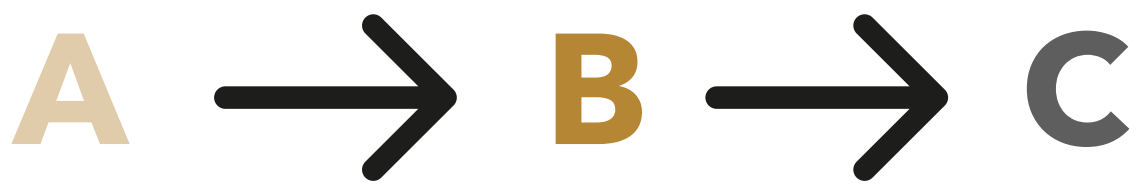

Figura 32. El uso de flechas y líenas crean un recorrido visual para el lector. Elaborada por Mariel García Hernández.

m) Resulta importante el uso de etiquetas o leyendas debajo de los elementos gráficos que necesiten algún tipo de aclaración, nota o título, establece los mismos autores.

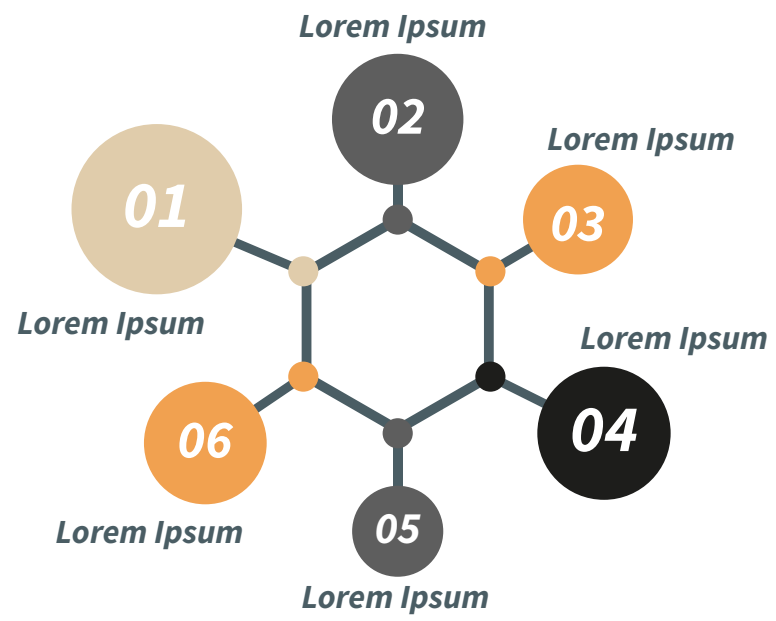

Figura 33. Ejemplo de uso de etiquetas para hacer aclaraciones sobre los elementos gráficos presentados. Elaborada por Mariel García Hernández.

\footnotetext{
${ }^{35}$ Emoji es, de acuerdo a (Rodrigues, Prada, Gaspar, Garrido, \& Lopes, 2017), "un símbolo gráfico que incluyen representaciones de expresiones faciales, conceptos abstractos, emociones, entre otros".
} 
n) Es beneficioso para el diseño de la interfaz gráfica que los elementos visuales no distraigan al usuario del contenido que se le está presentando, según señalan Nielsen \& Loranger (2006).

o) Conforme a lo que sugieren los autores anteriores, los elementos gráficos del sistema de visualización deben respetar y usar la paleta de colores con la que se está trabajando. Ya que al usar colores que no estén dentro de ésta puede generar incongruencias visuales y de contenido dentro de la interfaz gráfica.

p) Según Lonsdale \& Lonsdale (2019b) el uso de recuadros en blanco dentro de una interfaz gráfica de un sistema de visualización de información médica es recomendable para anotaciones textuales largas sobre un tópico en particular, por ejemplo, motivos de ingreso del paciente a la clínica o hospital.

q) Se sugiere, según los autores anteriores, el uso de bullets point, listas numéricas y flechas para enfatizar información que pertenezca a una misma categoría, la cual sea secuencial.

1) Manzana.

2) Pera.

3) Melón.

4) Kiwi.

5) Fresa.

Ejemplo de lista númerica
- Gato.

- Piedra.

- Muñeca.

- Contenedor.

- Mariposa.

Ejemplo de lista con bullet points

Figura 34. Ejemplo de uso de etiquetas para hacer aclaraciones sobre los elementos gráficos presentados. Elaborada por Mariel García Hernández. 
r) Los elementos que no tengan mucha relevancia dentro de la pieza de diseño, pero sigan siendo necesarios, se recomienda usar una tonalidad de gris o una opacidad de color equivalente al $40 \%$, de acuerdo a Lonsdale \& Lonsdale (2019).

s) El espacio en blanco es un buen elemento que se puede usar de manera efectiva para llamar la atención sobre el gráfico o para generar "aire" en donde hay una tensión visual por el exceso de contenido.

t) No se recomienda el uso de degradados ni texturas en las secciones que conforman a las figuras en la visualización de información, en su lugar, se sugiere el uso de plastas de colores, acorde a lo que establece Cairo (2011).

u) La relación de aspecto (altura y anchura relativas) y la densidad de datos (tamaño del gráfico) deben seleccionarse cuidadosamente para evitar una representación incorrecta de los datos, según señala Tufte (2001).

v) Sí se llegará a requerir de usar un fondo en algún tipo de figura dentro de la interfaz gráfica, se sugiere que los elementos de fondo no deben se agrupen o fusionen con los elementos de contenido, de acuerdo con Cairo (2011).

w) Se sugiere, según a lo que Tufte (2001) el uso de puntos y las líneas, ya que son una buena opción para facilitar la comparación entre valores individuales en puntos específicos en el tiempo de datos. 
x) Los elementos o información innecesarios, extraños, decorativos o irrelevantes en una figura de visualización de información deben eliminarse, mientras se mantiene el significado, de acuerdo a lo que plantea Nielsen \& Loranger (2006).

y) Es importante usar informes estadísticos, según establece Cairo (2011) a través de figuras de visualización de información en lugar de informes solo narrativos, de esta manera se reduce la carga cognitiva de la información y se mejora la usabilidad de la interfaz gráfica.

z) Es de suma importancia el uso de figuras de visualización de información para condensar datos cuantitativos y cualitativos dentro del sistema de visualización de información médica.

El criterio por seguir para la elección de las figuras de visualización de información es el siguiente:

1. ¿Qué necesita averiguar el usuario (en términos de información)?

2. ¿A qué categoría o método de codificación de información pertenece esta necesidad?

3. ¿Qué figura de visualización de información cubre esta necesidad? 


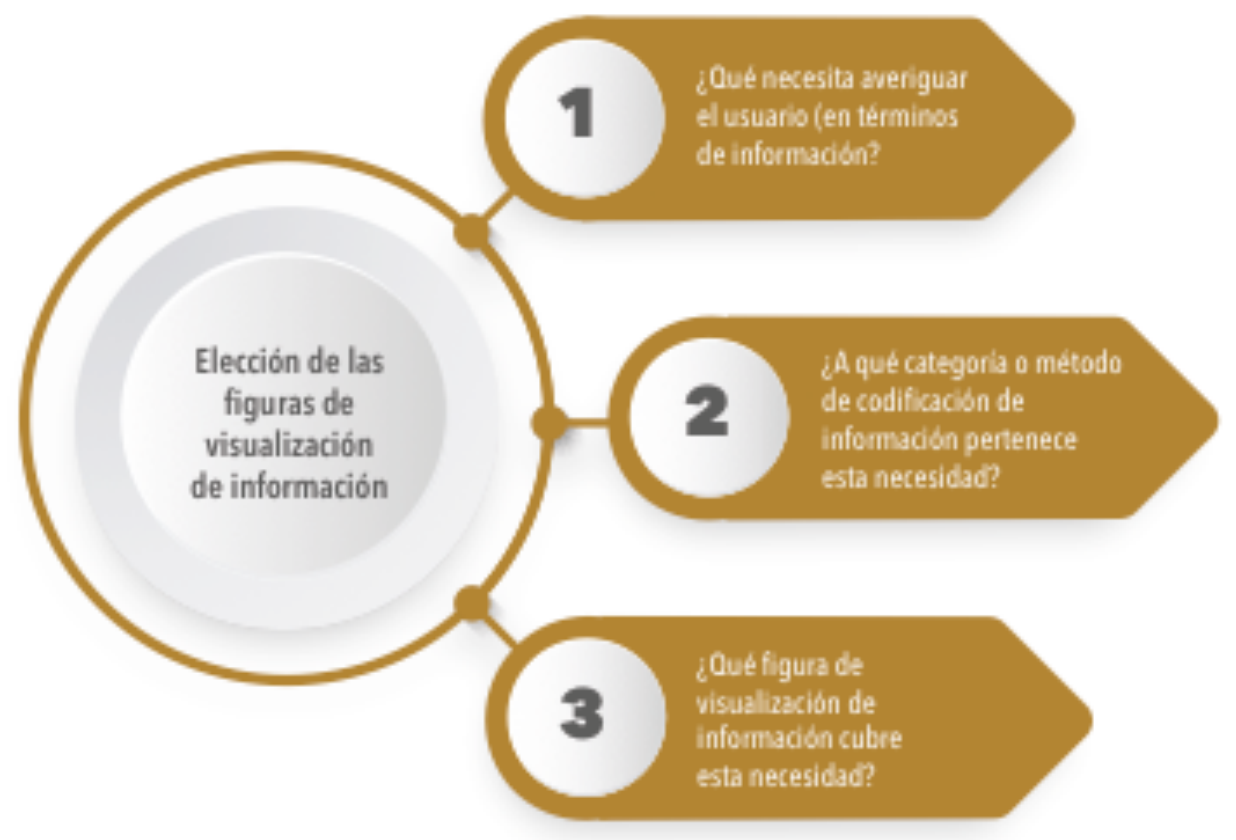

Figura 35. Criterios de elección para figuras de visualización de información. Elaborada por Mariel García Hemández.

Existen diversas categorías que se clasifican conforme a la función de la representación de la información con la que se está trabajando. Dichas categorías o métodos de codificación de información son las siguientes (Ver Anexo 2):

i) Comparación. Este método busca generar contaste entre conjuntos de datos. A través de está técnica se busca establecer una comparación visual entre las características o atributos de dichos conjuntos de datos.

ii) Visualización de conceptos. Es la representación de uno o varios conceptos a través de gráfico.

iii) Correlación o de patrones. Es la proporcionalidad entre atributos o características de uno o varios datos entre sí. Se 
centra en revelar formas o patrones en los datos para darle significado.

iv) Distribución. Esta técnica busca colocar un cierto dato en un lugar determinado por alguna característica o valor en especial.

v) Datos geográficos. Este método de visualización de información se encarga de representar datos que guardan relación con atributos de índole geográfica, ubicando a éstos en un lugar y espacio en particular.

vi) Parte del todo. Es la representación de un conjunto de datos que forman parte de un todo.

vii)Tendencia a través del tiempo. Esta técnica de visualización de información se ocupa de la representación de la evolución o perspectiva de un fenómeno a través del tiempo.

viii) Jerarquía. Este método muestra la relación de cómo las entidades se pueden clasificar y ordenar dependiendo de su grado de importancia y relevancia dentro de un sistema u organización.

ix) Procesos y métodos. Esta técnica en la visualización de información ayuda a explicar como están hechos ciertos procesos o métodos, así como los pasos que están involucrados en éstos.

x) Funcionamiento de las cosas. Este método tiene como objetivo ilustrar el funcionamiento de algún objeto o sistema. 
xi) Movimiento o flujo. Herramienta que se encarga de mostrar el movimiento físico, proceso de transferencia o el flujo de conceptos abstractos través de un gráfico o figura visual.

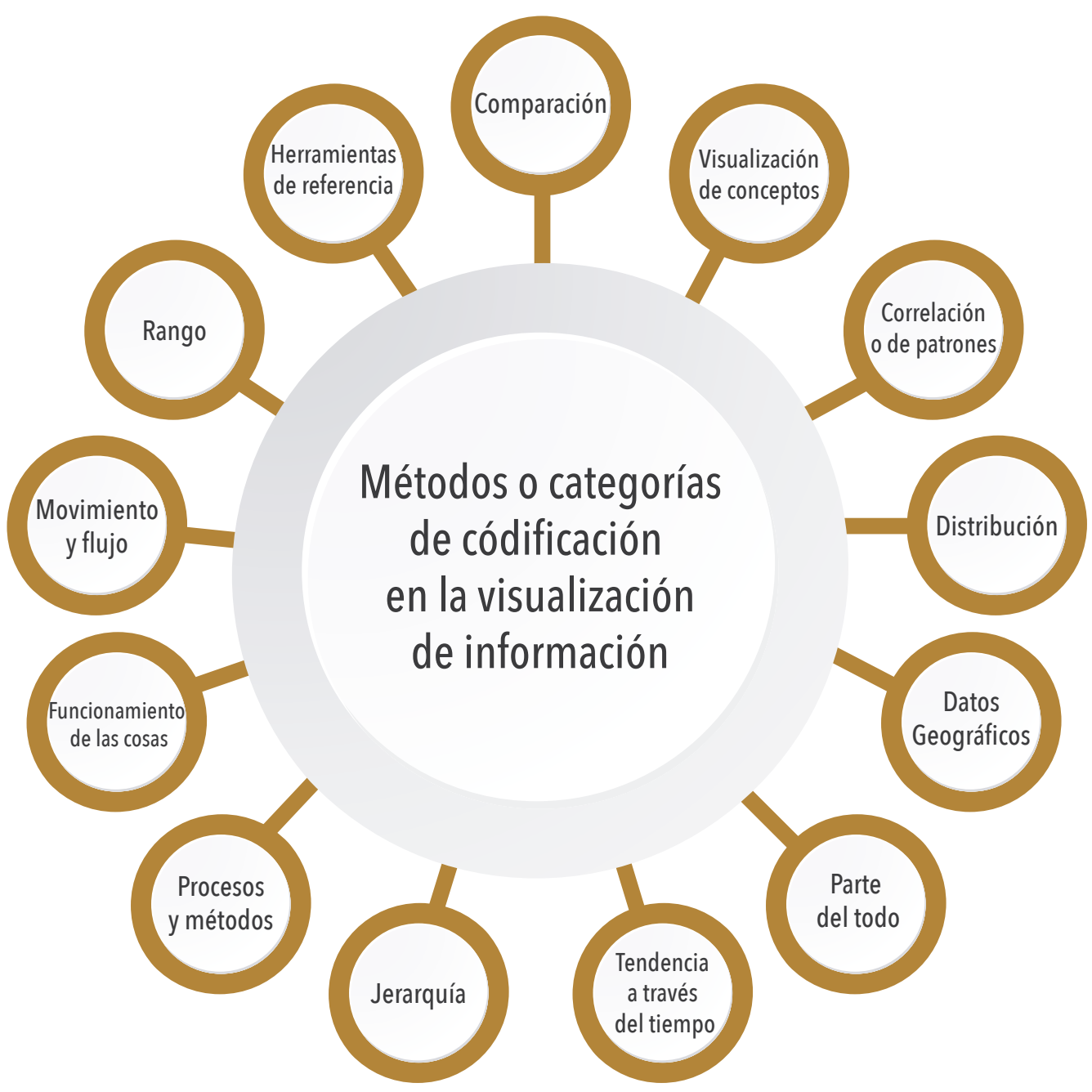

Figura 36. Métodos y categorías en la visualización de información, de acuerdo a Ferdio (2019). Elaborada por Mariel García Hernández. 


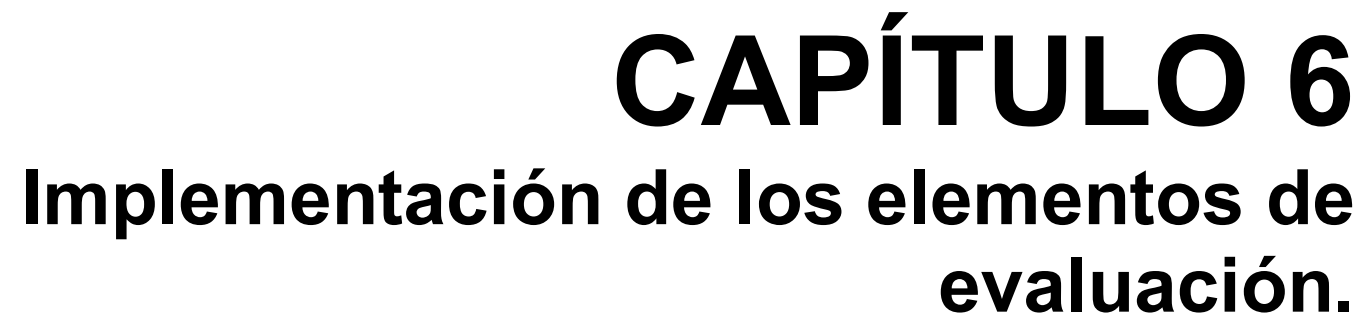




\section{Implementación de los elementos de evaluación}

Para comenzar el presente capítulo, resulta importante mencionar el objetivo de esta tesis doctoral, el cual es el desarrollo de guías de usabilidad para la creación de interfaces gráficas de visualizaciones de información médica, en donde, se busca que dichos artefactos de diseño sean usables para el usuario que interactúa con ellos. Cuando hablamos de usabilidad, retomamos la definición de Jordan (2001), en donde el autor establece que para que un artefacto de diseño sea usable, este debe ser eficiente (rápido de leer), efectivo (fácil de comprender) y satisfactorio (agradable estéticamente).

Shneiderman (1998) en su libro Designing the user interface: Strategies for effective human computer interaction, establece que la interfaz gráfica está compuesta de imagen (composición visual), concepto que podemos decir que es el "envase" y su contenido (información) concepto que sugerimos es el "producto"; es por ello que el método de evaluación a continuación presentado de las guías de usabilidad, se dividió en dos etapas; la primera evalúa la composición editorial de las guías y la segunda parte, evalúa la información que está contenida en estas guías, ya que es importante elegir la mejor composición editorial y posteriormente evaluar a la guías como un conjunto (composición editorial e información). 


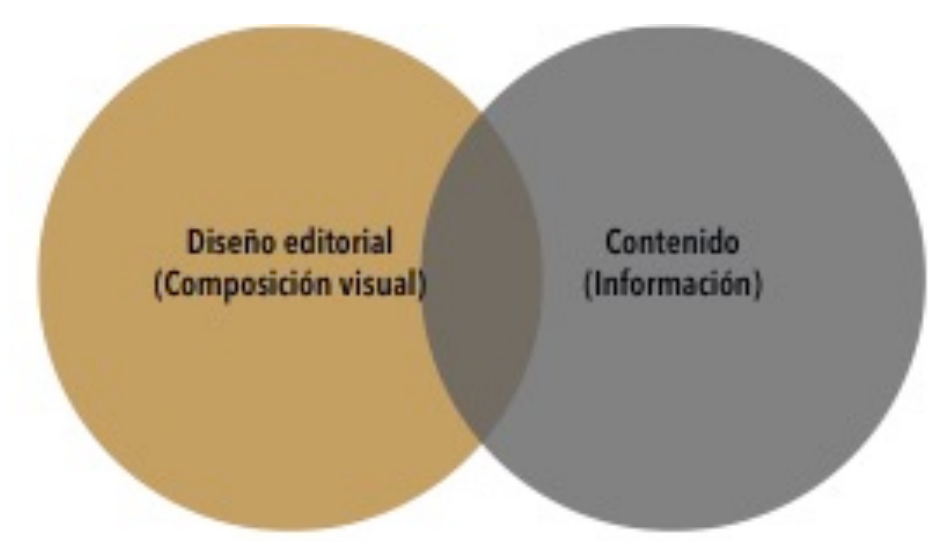

Figura 1. Etapas del método de evaluación de las guias NOMOLAS.

Elaborada por Mariel Garcia Hernández

\subsection{Primera etapa: evaluación de usabilidad de propuestas editoriales para las guías NOMOLAS}

Durante esta primera parte se evaluaron dos propuestas editoriales (la composición editorial) de las guías NOMOLAS. Los objetivos de esta primera etapa fueron los siguientes:

a) Identificar cuál de las dos propuestas editoriales es la más efectiva (en cuanto a la comprensión de la información) para el usuario (lector).

b) Identificar cuál de las dos propuestas editoriales es la más agradable para el usuario (lector).

c) Identificar cuál de las dos propuestas editoriales es la más eficiente (se lee más rápido) para el usuario (lector). 
Para el desarrollo de la evaluación de usabilidad se dividió en dos grupos la muestra total de usuario, utilizando la herramienta de Prueba A/B, la cual sirve para probar dos variables ante su usuario (ver anexos 8 y 9 ).

Se propusieron tres partes dentro de esta primera etapa; la primera que fue realizada con la exposición y lectura de una de las propuestas editoriales al participante y mediante la herramienta de Análisis de tareas (AdT) (se le pidió completar una tarea). La segunda parte se realizó utilizando la herramienta Cuestionario PSSUQ ${ }^{36}$ (ver anexo 4) y una lista de chequeo de Análisis de Tareas (ver anexo 5 y 6). En la tercera parte se hizo la recolección y análisis de los datos resultantes de los instrumentos de evaluación posteriormente descritos.

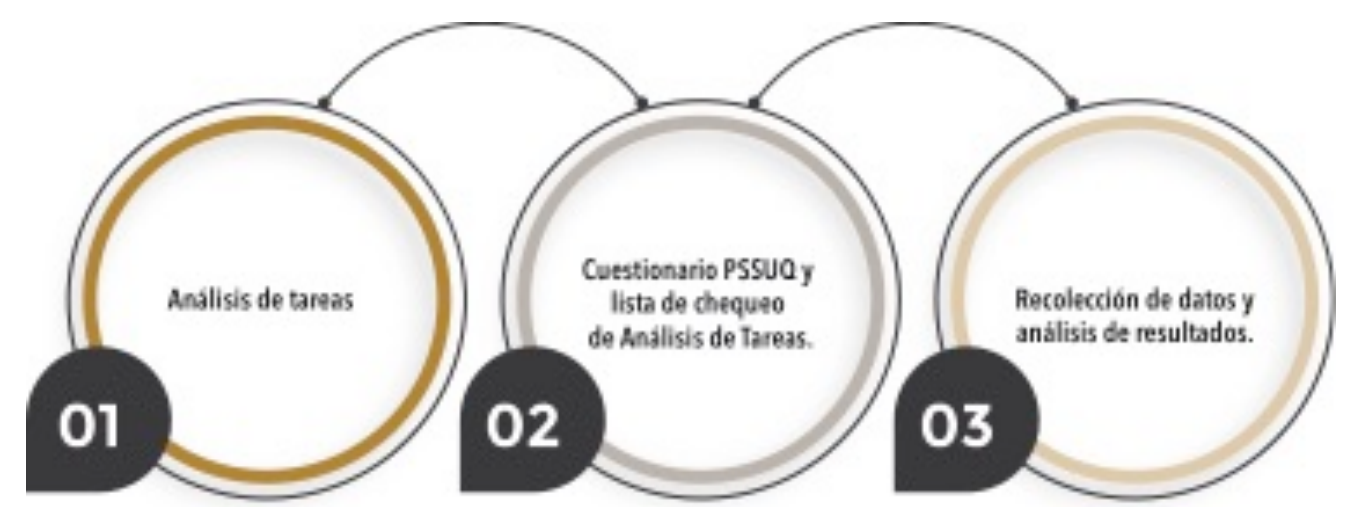

Figura 2. Primera etapa del método de evaluación de las guias NOMOLAS. Elaborada por Mariel Garcia Hernández

${ }^{36}$ El cuestionario PSSUQ es un instrumento de evaluación que sirve para recoger respuesta inmediata del usuario después de una tarea en una prueba de usabilidad, conforme a Carlos Gómez (2006). 


\subsubsection{PARTE I - Lectura de la propuesta editorial y ejecución de tareas.}

Método:

El método que se usó fue de Prueba $A / B^{37}$ y Análisis de Tareas (AdT). Esta herramienta nos ayudó a evaluar si el participante comprendió la información que se le presentó en la guía de usabilidad a partir de la ejecución de la tarea de una forma satisfactoria (la cual se evaluó con la Lista de chequeo del Análisis de Tareas posteriormente presentada en anexo 5).

Participantes:

30 usuarios. En el estudio se consideró que el participante fuera estudiante de los últimos semestres de licenciaturas en Diseño Gráfico, Diseño de Información o en

Diseño de Comunicación Gráfica, que contara con nociones intermedias o avanzadas de uso de software (Adobe Illustrator y Adobe InDesign), tipografía, uso del color, composición reticular y diseño de información. Se consideró esta muestra por dos aspectos; el primero es porque de acuerdo a Nielsen (2012) que al ser un estudio cuantitativo se sugiere una muestra entre 20 y 30 usuarios y, el segundo aspecto radica en que las guías NOMOLAS fueron desarrolladas pensandas conforme al perfil de este usuario.

Instrumentos:

\footnotetext{
${ }^{37}$ La prueba A/B es un método de comparación entre dos versiones diferentes de un elementos, de acuedo a Nielsen (2005).
} 
- 30 copias del Análisis de tareas de la actividad que se realizó con las propuestas editoriales.

- Propuestas editoriales impresas A y B.

- Archivo Adobe .Ai (Adobe Illustrator) pre cargado en computadora Mac portátil.

- Computadora Mac portátil.

- 30 copias del formatos de consentimiento informado.

Procedimiento:

Durante esta fase se le proporcionó de manera impresa una de las propuestas editoriales A o B (ver anexo 8 y 9) al usuario. Se contabilizó el tiempo de lectura de cada usuario. Después de que el usuario terminara de leer, se le pidió que colocará en su lugar la propuesta boca abajo (de tal modo que la información contenida en ésta no fuera visible).

Se le entregó al participante una hoja con la explicación de la tarea a ejecutar (ver anexo 6). Después, se le indicó de manera verbal las instrucciones para realizar la tarea. Posteriormente, se le dijo de manera explicita que podía consultar de nuevo las guías las veces que necesitara. Dependiendo el número de consultas de las guías, se fue sumando uno a uno está acción y de esta forma se midió la variable de eficiencia descrita dentro de los objetivos de la prueba. Se comenzó a cronometrar el tiempo que tarda el participante en realizar la tarea. Cuando éste 
terminó de realizar dicha acción, se le pidió que guardara el archivo en modo simple del comando "guardar".

\section{FASE 1: PARTE I - LECTURA DE LA PROPUESTA EDITORIAL Y EJECUCIÓN DE TAREAS}

\section{Prueba A/B}

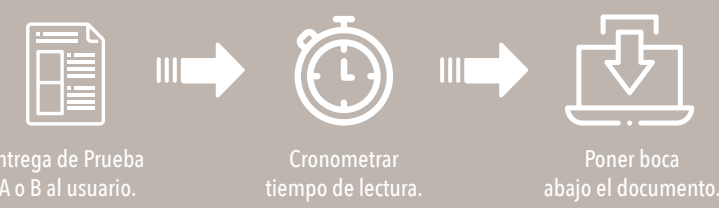

\section{Análisis de tareas}

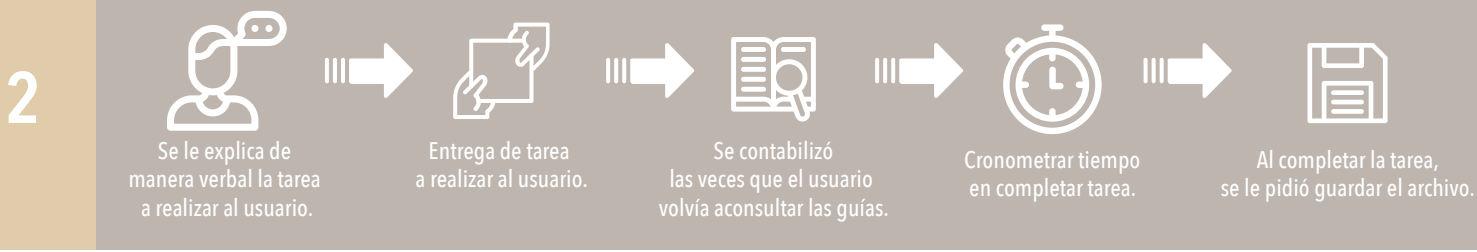

Figura 3. FASE 1: Parte I - Lectura de la propuesta editorial y ejecución de tareas.

Elaborada por Mariel García Hernández

\subsubsection{PARTE II - Cuestionario PSSQU y Lista de Chequeo de Análisis de Tareas.}

Método:

El cuestionario PSSUQ (ver anexo 4) fue implementado dentro de esta prueba para evaluar los siguientes aspectos de usabilidad y ergonomía:

a) Organización de la información.

b) Legibilidad de la información.

c) Satisfacción de la estética visual de la retícula del diseño editorial. 
El segundo método que se utilizó durante esta fase fue la Lista de Chequeo de Análisis de Tareas (AdT) (ver anexo 5). Con este método se buscó evaluar lo siguiente:

a) Eficiencia: Se midió el tiempo en que el participante leyó la página y el tiempo en que completó la tarea.

b) Eficacia: Se registró si el diseñador cubrió o no las premisas planteadas en la guía de usabilidad dentro de la tarea asignada a realizar en el AdT.

Participantes:

Los mismos participantes descritos en el apartado anterior. Instrumentos:

- 30 copias del Cuestionario PSSQU.

- Lápiceros.

- Billetes de 50 pesos mexicanos.

- 30 copias de la Lista de chequeo de Análisis de Tareas (AdT).

Procedimiento:

En esta etapa se le dio impreso el cuestionario PSSUQ y una pluma al participante. Se le dio instrucciones de manera verbal de lo que debía hacer con el cuestionario, se le dio 5 minutos para contestar dicho documento. Al terminar de contestar el cuestionario, el participante le entregó el instrumento al moderador. Al terminar la 
prueba de evaluación, al participante se le entregó un billete de 50 pesos mexicanos y se le agradeció por su participación.

FASE 1: PARTE II - CUESTIONARIO PSSQU Y LISTA DE CHEQUEO DE ANÁLISIS DE TAREAS

Cuestionario PSSUQ

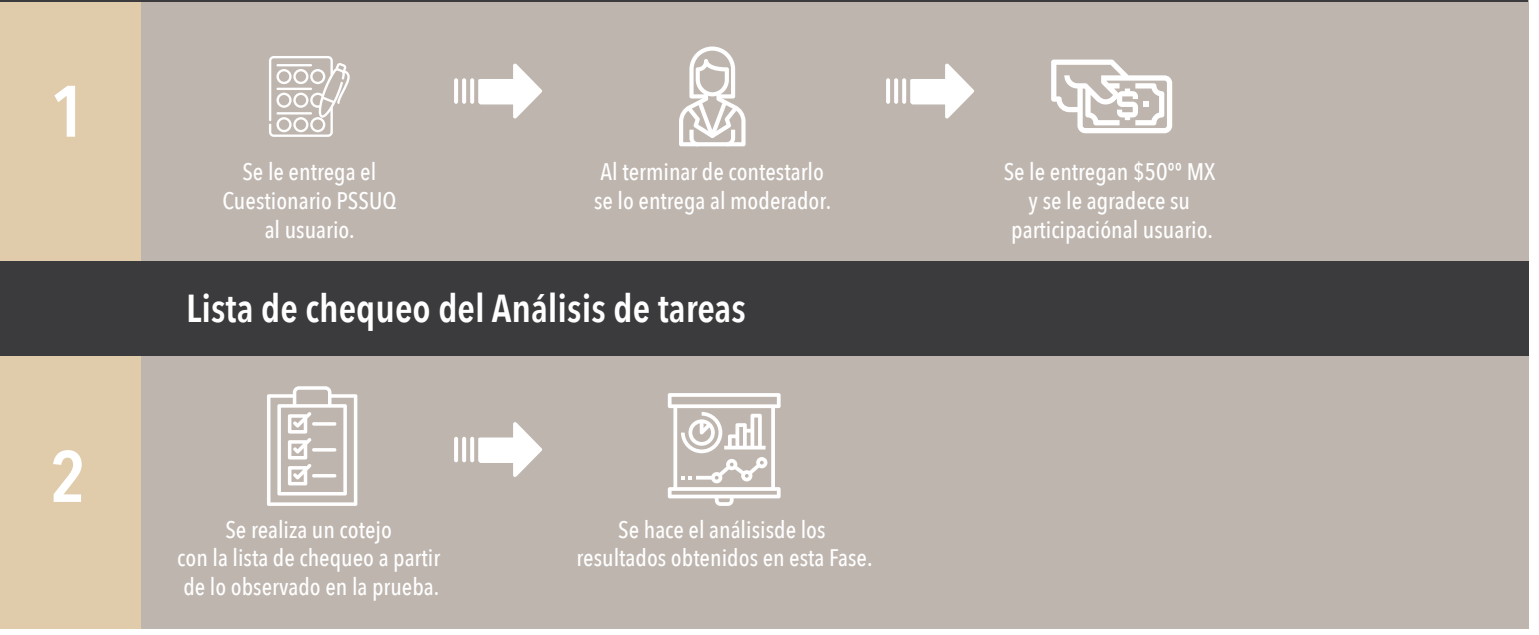

Figura 4. FASE 1: Parte II - Cuestionario PSSQU y Lista de Chequeo de Análisis de Tareas.

Elaborada por Mariel García Hernández

Duración de la prueba:

Para la ejecución de cada prueba por cada participante se estimó una duración de

10 a 15 minutos, por lo que se citó a los participantes cada 30 minutos ( 1 hora y cuarto), con la finalidad de tener un momento para acomodar el espacio entre cada una de las pruebas. 


\subsubsection{PARTE III - Resultados.}

Retomando el objetivo de la primera fase de evaluación de las guías NOMOLAS, es prudente mencionar que se buscaba evaluar la usabilidad de composición editorial de éstas.

Dicho atributo se dividió en las variables: efectividad (facilidad de comprensión), eficiencia (rapidez de lectura) y satisfacción (agradable). Estas variables fueron distribuidas y evaluadas de la siguiente manera en cada fase y método de validación de usabilidad:
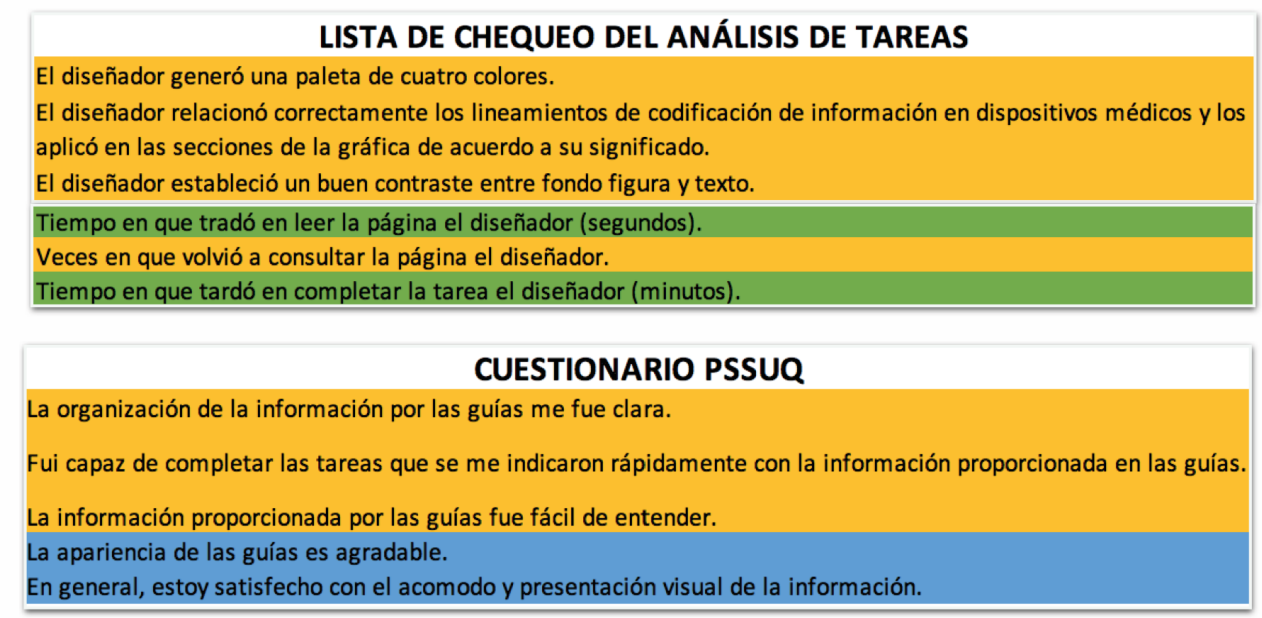

Efectividad

Eficiente

Satisfactoria

Figura 5. Relación entre varibales e instrumentos de evaluación de la FASE 1. Elaborada por Mariel García Hernández

1. Efectiva (¿Cuál de las dos propuestas editoriales es la más efectiva (en cuanto a la comprensión de la información) para el usuario (lector)?) 
RESULTADOS - VARIABLE “EFECTIVA”

¿Cuál de las dos propuestas editoriales es la más efectiva (en cuanto a la comprensión de la información) para el usuario (lector)?

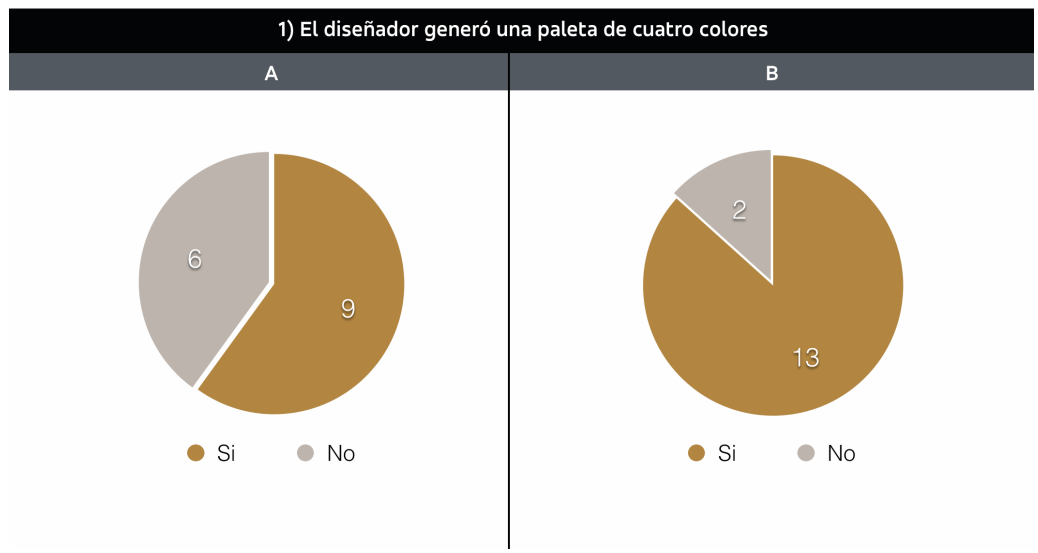

Figura 6. Efectiva: 1) El diseñador generó una paleta de cuatro colores. Elaborada por Mariel García Hernández

\section{RESULTADOS - VARIABLE “EFECTIVA”}

¿Cuál de las dos propuestas editoriales es la más efectiva (en cuanto a la comprensión de la información) para el usuario (lector)?

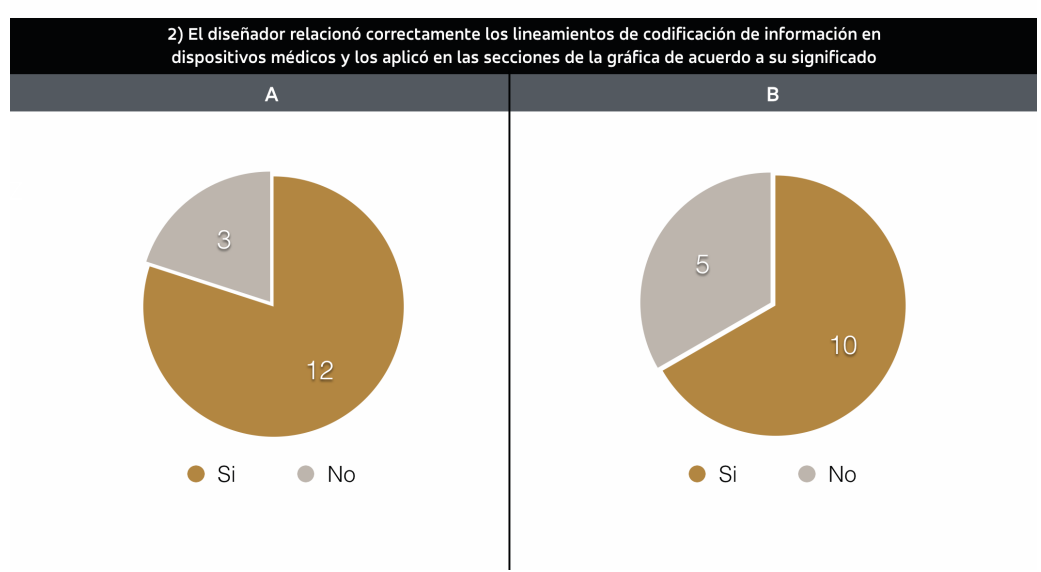

Figura 7. Efectiva: 2) El diseñador relacionó correctamente los linemientos de codificación de información en dispositivos médicos y los aplicó en las secciones de la gráfica de acuerdo a su significado.

Elaborada por Mariel García Hernández 


\section{RESULTADOS - VARIABLE "EFECTIVA"}

¿Cuál de las dos propuestas editoriales es la más efectiva (en cuanto a la comprensión de la información) para el usuario (lector)?

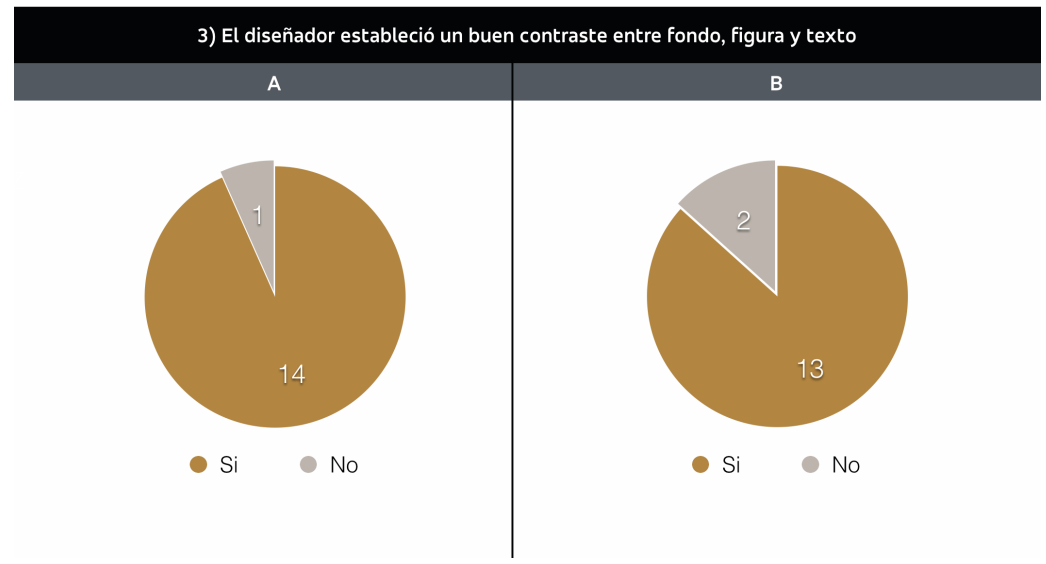

Figura 8. Efectiva: 3) El diseñador estableció un buen contraste entre fondo, figura y texto. Elaborada por Mariel García Hernández

\section{RESULTADOS - VARIABLE "EFECTIVA"}

¿Cuál de las dos propuestas editoriales es la más efectiva (en cuanto a la comprensión de la información) para el usuario (lector)?

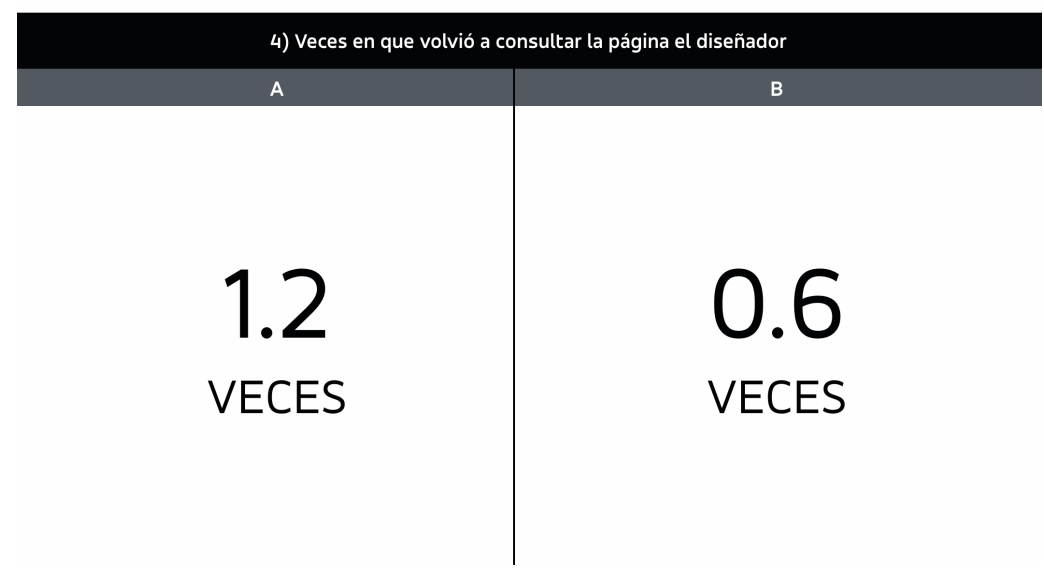

Figura 9. Efectiva: 4) Veces que volvió a consultar la página el diseñador. Elaborada por Mariel García Hernández 
RESULTADOS - VARIABLE “EFECTIVA”

¿Cuál de las dos propuestas editoriales es la más efectiva (en cuanto a la comprensión de la información) para el usuario (lector)?

\begin{tabular}{|c|c|c|c|}
\hline \multicolumn{4}{|c|}{ 5) La organización de la información me fue clara } \\
\hline \multicolumn{2}{|c|}{ A } & \multicolumn{2}{|c|}{ B } \\
\hline \multicolumn{2}{|c|}{$\begin{array}{l}\text { La organización de la } \\
\text { información me fue clara }\end{array}$} & \multicolumn{2}{|c|}{$\begin{array}{l}\text { La organización de la } \\
\text { información me fue clara }\end{array}$} \\
\hline $\begin{array}{c}1 \text { Totalmente en } \\
\text { desacuerdo }\end{array}$ & 1 & $\begin{array}{c}1 \text { Totalmente en } \\
\text { desacuerdo }\end{array}$ & 0 \\
\hline 2 & 0 & 2 & 0 \\
\hline 3 & 0 & 3 & 0 \\
\hline 4 & 0 & 4 & 0 \\
\hline 5 & 2 & 5 & 0 \\
\hline 6 & 2 & 6 & 5 \\
\hline $\begin{array}{l}7 \text { Totalmente de } \\
\text { acuerdo }\end{array}$ & 10 & $\begin{array}{c}7 \text { Totalmente de } \\
\text { acuerdo }\end{array}$ & 10 \\
\hline
\end{tabular}

Figura 10. Efectiva: 5) La organización de la información me fue clara. Elaborada por Mariel García Hernández

\section{RESULTADOS - VARIABLE “EFECTIVA”}

¿Cuál de las dos propuestas editoriales es la más efectiva (en cuanto a la comprensión de la información) para el usuario (lector)?

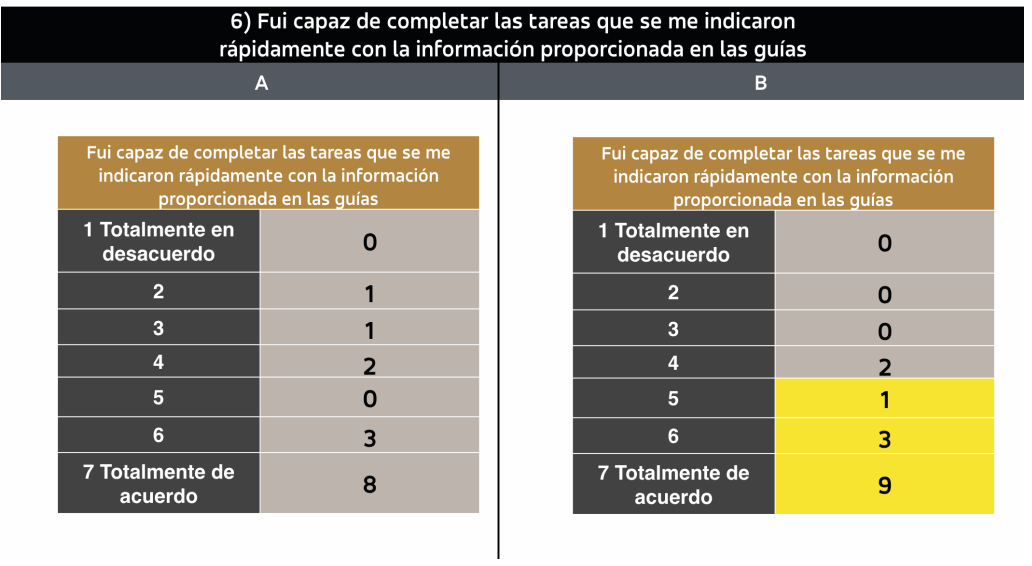

Figura 11. Efectiva: 6) Fui capaz de completar las tareas que se me indicaron rápidamente con la información proporcionada en las guías.

Elaborada por Mariel García Hernández 


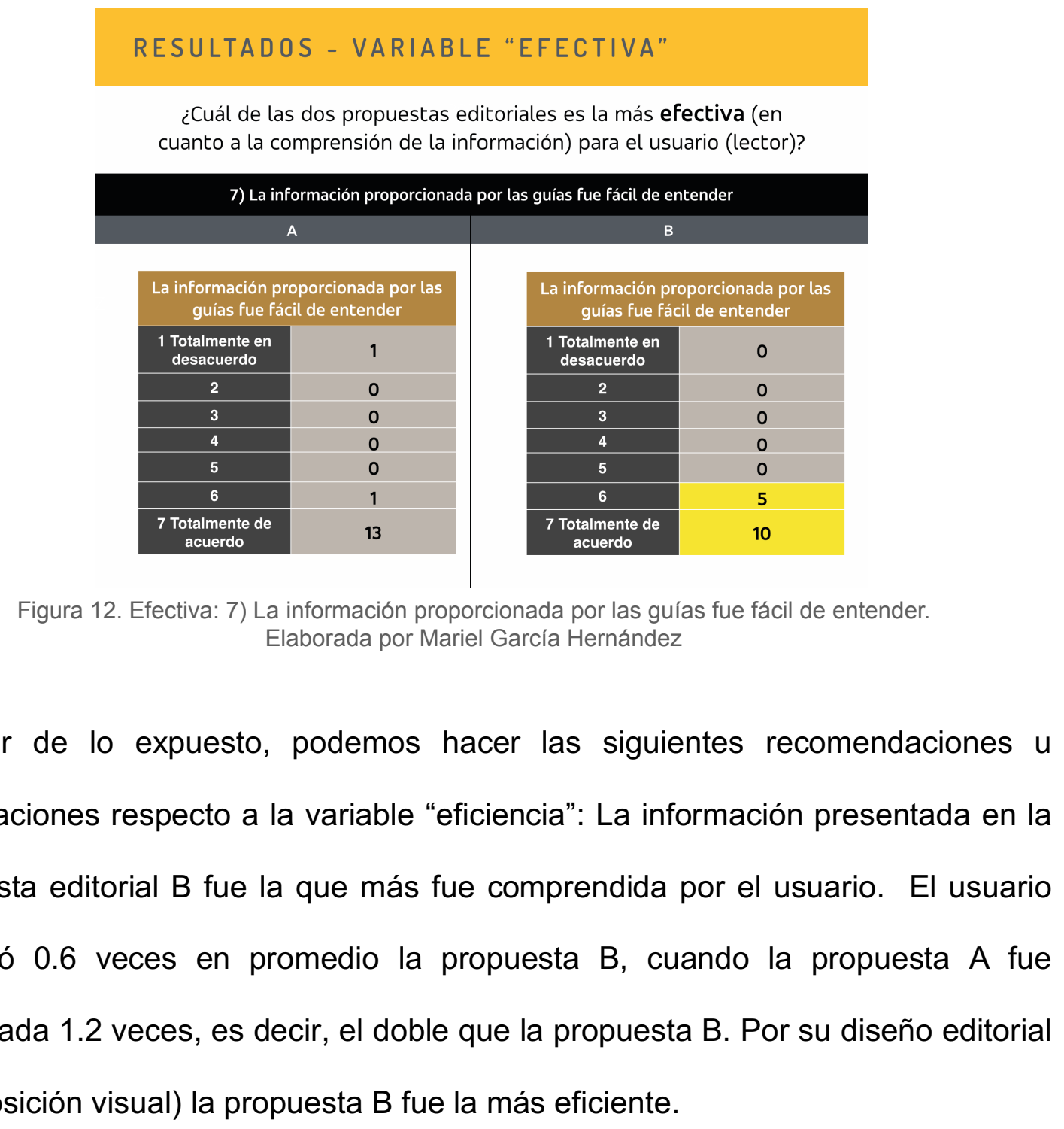

A partir de lo expuesto, podemos hacer las siguientes recomendaciones $u$ observaciones respecto a la variable "eficiencia": La información presentada en la propuesta editorial B fue la que más fue comprendida por el usuario. El usuario consultó 0.6 veces en promedio la propuesta B, cuando la propuesta A fue consultada 1.2 veces, es decir, el doble que la propuesta B. Por su diseño editorial (composición visual) la propuesta B fue la más eficiente.

2. Eficiente ¿Cuál de las dos propuestas editoriales es la más eficiente (se lee más rápido) para el usuario (lector)? 


\section{RESULTADOS - VARIABLE “EFICIENTE”}

¿Cuál de las dos propuestas editoriales es la más eficiente (se lee más rápido) para el usuario (lector)?

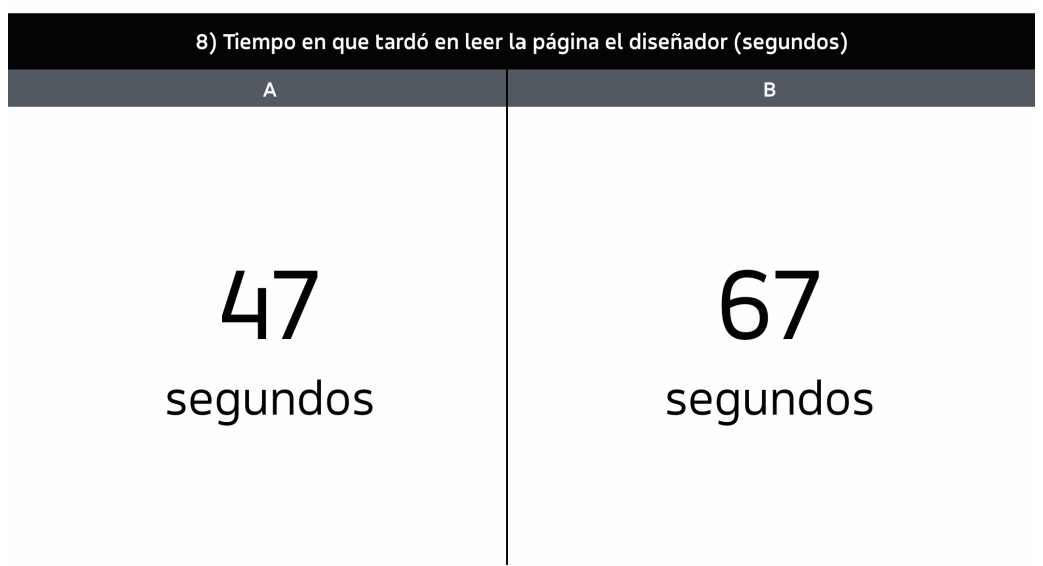

Figura 13. Eficiente: 8) Tiempo en que tardó en leer la página el diseñador (segundos). Elaborada por Mariel García Hernández

\section{RESULTADOS - VARIABLE “EFICIENTE”}

¿Cuál de las dos propuestas editoriales es la más eficiente (se lee más rápido) para el usuario (lector)?

9) Tiempo en que tardó en completar la tarea el diseñador (minutos)

A

minutos

B

\section{5}

minutos

Figura 14. Eficiente: 9) Tiempo en que tardó en completar la tarea el diseñador (minutos). Elaborada por Mariel García Hernández

En cuanto a la variable "efectividad" se hace la siguiente recomendación: a pesar de que la propuesta editorial A se lee más rápido que la propuesta B, dicha propuesta ayudó a completar más rápida la tarea asignada al usuario. 
3. Satisfacción. ¿Cuál de las dos propuestas editoriales es la más agradable para el usuario (lector)?

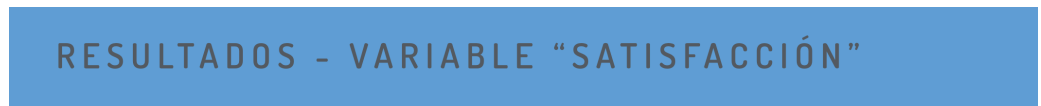

¿Cuál de las dos propuestas editoriales es la más agradable para el usuario (lector)?

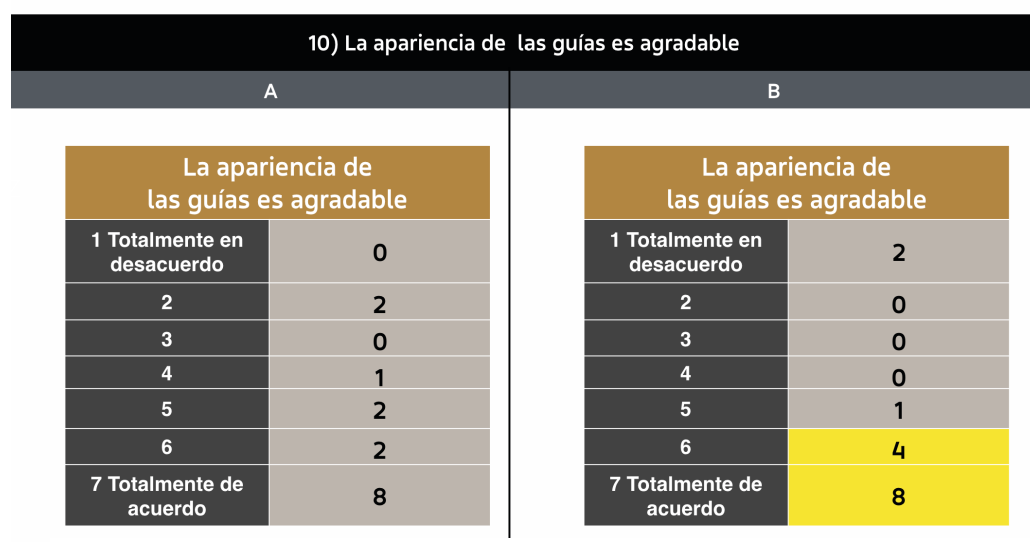

Figura 15. Satisfacción: 10) La apariencia de las guías es agradable. Elaborada por Mariel García Hernández

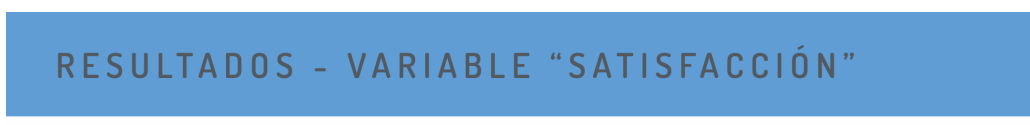

¿Cuál de las dos propuestas editoriales es

la más agradable para el usuario (lector)?

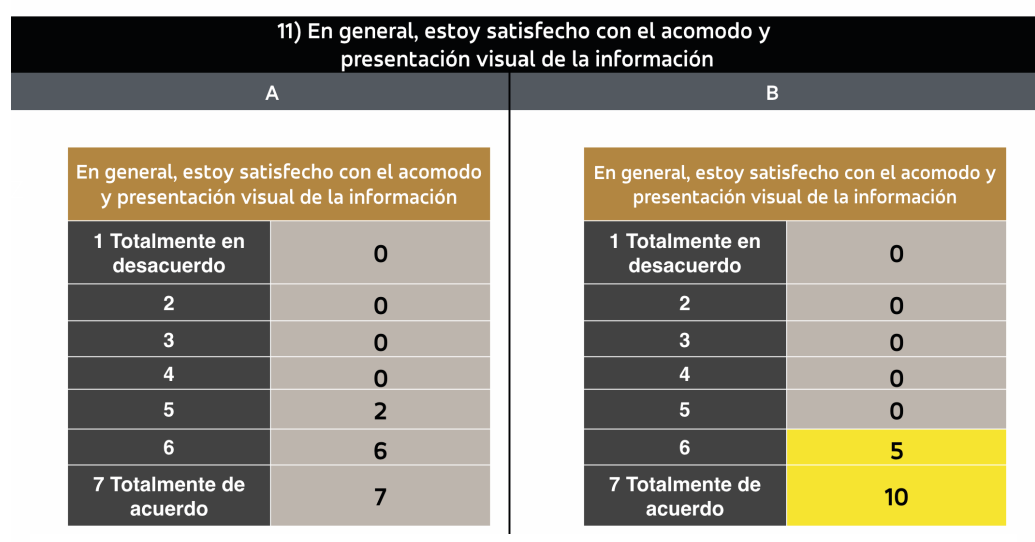

Figura 16. Satisfacción: 11) La organización de la información me fue clara. Elaborada por Mariel García Hernández

Según lo anterior, la recomendación que se puede realizar respecto a la variable "satisfacción" señala lo siguiente: la propuesta B fue la que más le agrado al usuario, 
ya que recibió el puntaje más alto en cuanto a los reactivos de satisfacción del cuestionario PSSUQ.

\subsubsection{Conclusión de la primera parte del método de evaluación}

Después de haber obtenido los resultados previamente anunciados de la primera fase de validación de las guías NOMOLAS, podemos decir que, aunque la propuesta $A$ se lee más rápido, la propuesta $B$ es la que más agradó al usuario, también es donde mejor se comprende la información, por lo tanto, la propuesta más adecuada es la $B$.

6.2 Segunda etapa: evaluación de usabilidad de información para las guías NOMOLAS

Después de haber obtenido los resultados de la primera etapa de evaluación de las guías NOMOLAS se prosiguió a vaciar la información planteada para éstas en el formato editorial con mejores resultados.

Posteriormente a esto, se dio paso a implementar la segunda y última fase del instrumento de evaluación de esta tesis doctoral.

La segunda etapa de evaluación consistió en la impartición de un workshop, en el cual se presentaron por primera vez las guías de usabilidad NOMOLAS (ver anexo 
11.9). Para ello se realizó una convocatoria a través de las redes sociales de la Universidad Popular Autónoma del Estado de Puebla ${ }^{38}$ (ver anexo 11.1), en donde se convocaba al perfil del usuario planteado en la primera fase; estudiantes de los de la carreras de Diseño gráfico y digital o a fin, de una edad entre 19 y 23 años, con conocimientos intermedios o avanzados del software Adobe Illustrator e InDesign, de igual forma, con nociones intermedias o avanzadas de uso tipográfico, diseño de información, composición y uso del color. Se usó una muestra significativa de 5 usuarios con el perfil previamente descrito, ya que de acuerdo a lo que establece Nielsen (2012) para una de usabilidad como la que plantea esta fase solo se necesita ese número de usuarios.

Durante esta segunda fase se evaluó la información (contenido) de las guías NOMOLAS. Los objetivos de esta primera etapa fueron los siguientes:

1. Identificar si la información contenida en las guías es comprendida por parte del participante (efectiva).

2. Identificar si la presentación de la información es agradable para el usuario (agradable).

3. Identificar si la información contenida en las guías se lee con facilidad (eficiente).

Este workshop se dividió en tres fases y en dos sesiones de dos horas cada una. La primera trató de una clase teórica en donde se presentaron los objetivos del

\footnotetext{
${ }^{38}$ Se eligió esta institución por su cercanía y su apertura a realizar la prueba de usabilidad.
} 
evento, conceptos teóricos y la estructura de las guías, así como la importancia de la usabilidad en el diseño y visualización de información (ver anexo 11.2).

La segunda etapa consistió en la presentación del ejercicio práctico del desarrollo de rediseño de la hoja de ingreso de un paciente con diabetes (ver anexo 11.2) con base a las guías NOMOLAS ya en su formato editorial (ver anexo 11.9), en donde se les entregará el formato Lean CANVAS de decisiones de diseño (ver anexo 11.6), el cual nos ayudó a evaluar parte del Análisis de Tareas.

La tercera etapa se le dio un cuestionario PSSQU (ver anexo 11.8) al participante para ser contestado. El cuestionario PSSQU nos ayudó a evaluar el grado de satisfacción del participante con las guías desde la óptica de la eficiencia y la estética visual de las mismas. Se realizó una lista de chequeo del Análisis de Tareas (AdT) (ver anexo 11.7) para corroborar la usabilidad de las guías a partir de las variables eficacia y eficiencia.

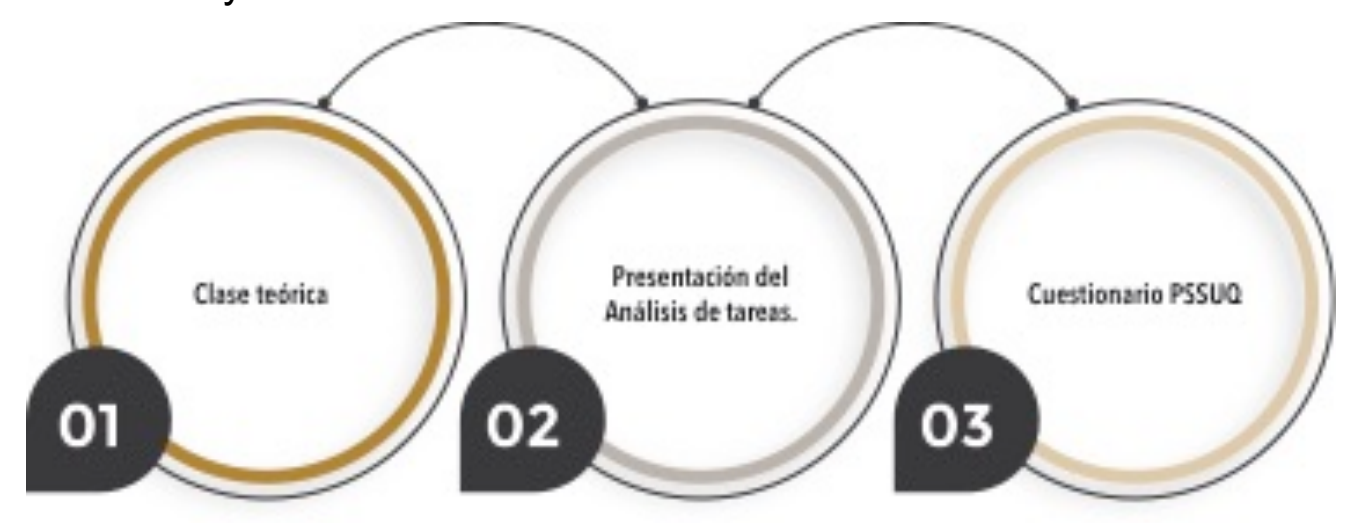

Figura 17. Segunda etapa del método de evaluación de las guias NOMOLAS. Elaborada por Mariel Garcia Hernández 


\subsubsection{PARTE I - WORKSHOP - PRIMERA SESIÓN}

Duración de la fase: Una hora y media.

\section{Método:}

El método a utilizar fue un workshop gratuito. En este workshop se les expuso a los participantes una presentación en formato Keynote (ver anexo 11.2), en donde se habló sobre el diseño de información; definiciones, tipos, malas aplicaciones e importancia de auxiliarse en otras disciplinas, así como también de la ergonomía cognitiva; definición, importancia de ésta en el diseño de información y las dos herramientas que ofrece al mismo.

Se abordó la importancia y forma de segmentación del usuario final de la pieza de diseño de información a desarrollar, así como los diferentes métodos de evaluación de usabilidad de interfaces gráficas que se pueden emplear.

Participantes:

- 5 usuarios. En el estudio se consideró que el participante fuera estudiante de las carreras de Diseño Gráfico, Diseño de Información afin, que contaran con nociones intermedias o avanzadas de uso de software (Adobe Illustrator y Adobe InDesign), tipografía, uso del color, composición reticular y diseño de información.

Instrumentos:

- Presentación Keynote. 
- Computadora Mac portatil.

- Guías NOMOLAS en formato digital.

- 5 formatos Lean Canvas de decisiones de diseño impresos.

- 5 formatos de lista de chequeo de Análisis de tareas (AdT).

- 5 cuestionarios PSSUQ impresos.

- 5 hojas de ingreso de paciente con diabetes impresos.

- Hojas blancas para bocetar.

- Lápices.

Procedimiento:

Se inició el workshop después de 10 minutos de la hora pactada por consideración y respeto a los participantes. Se expuso a los asistentes una presentación en formato Keynote/Power Point.

La presentación consideró abordar los siguientes puntos: (1) Nombre del workshop, del facilitador y de la investigación, (2) Antecedentes del trabajo de investigación (3) Objetivos del proyecto, (4) Diseño de información, (5) Usabilidad, (6) Ergonomía cognitiva, (7) Ergonomía cognitiva en el diseño de información, (8) Adaptación de artefacto-personalidad-entorno del usuario, (9) Validación del artefacto, (10) Guías de usabilidad NOMOLAS, (11) Interfaz gráfica, (12) Actividad a realizar. 


\section{FASE 2: PARTE I - WORKSHOP - PRIMERA SESIÓN}

\section{Clase teórica}
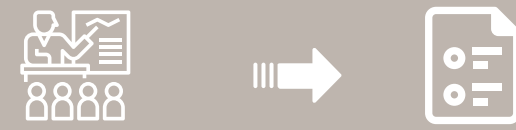

Figura 18. FASE 2: Parte I - Workshop - Primera sesión.

Elaborada por Mariel García Hernández

Al final de la exposición, se les presentó la tarea (ver anexo 11.4) a realizar y se les entregó el formato Lean CANVAS de decisiones de diseño. Además, se les envió de forma digital las guías NOMOLAS y el Lean CANVAS de decisiones de diseño. Se les pidió que comenzarán con el proceso de bocetaje. El moderador estuvo pendiente a cualquier duda que los asistentes pudieron tener.

\subsubsection{PARTE II- WORKSHOP - SEGUNDA SESIÓN}

Duración de la fase: Dos horas.

Método:

El método a implementar fue el Análisis de Tareas (AdT). La tarea a realizar fue rediseñar la hoja de ingreso de un paciente con diabetes (ver anexo 10). De igual forma, se utilizó un cuestinario PSSUQ para medir las variables previamente enunciadas en apartados previos.

Participantes:

Los mismos participantes descritos en el apartado anterior. 
Instrumentos:

Los mismos descritos en el apartado anterior.

Procedimiento:

Este fue el úlitmo día del workshop. Los participantes desarrollaron la tarea planteada en la sesión anterior. Cuando el participante terminó, se le entregó impreso el cuestionario PSSUQ y una pluma.

Se le dieron instrucciones de manera verbal de lo que debía de hacer con el cuestionario. Al terminar de contestar el cuestionario, el participante entregó el cuestionario al moderador.

\section{FASE 2: PARTE II - WORKSHOP - SEGUNDA SESIÓN}

Análisis de tareas
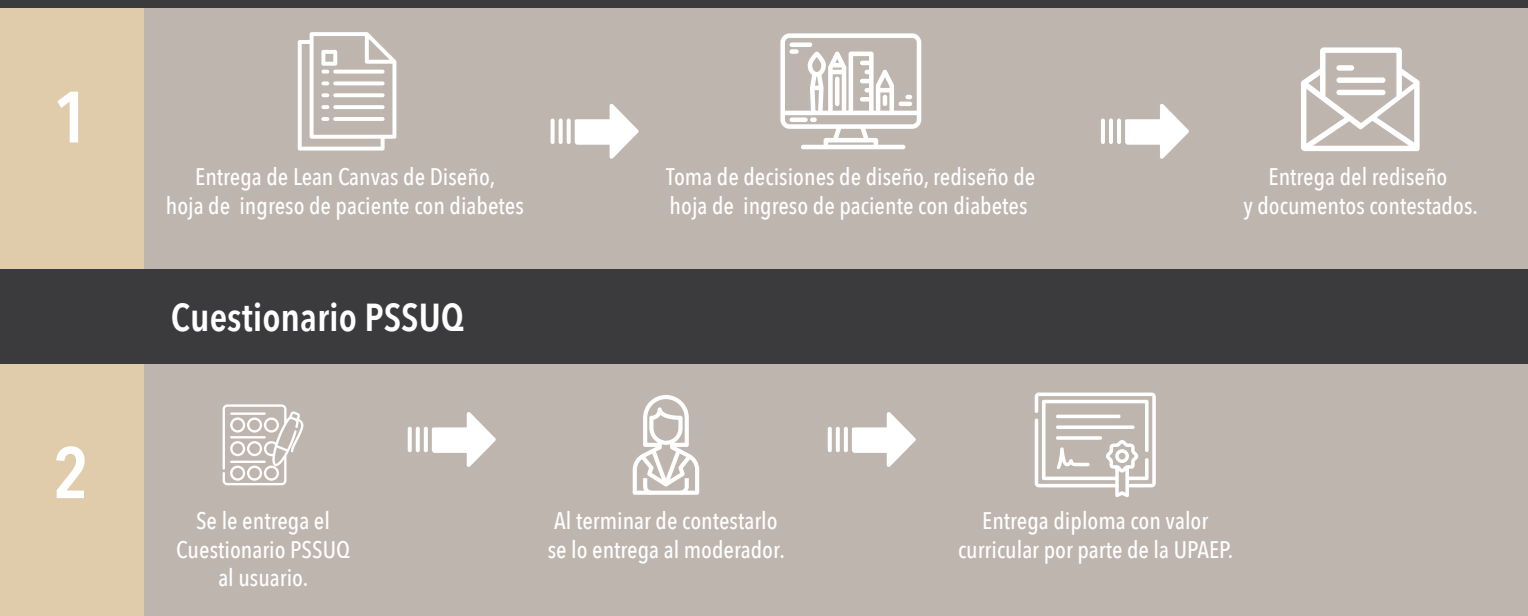

Figura 19. FASE 2: Parte II - Workshop - Segunda sesión.

Elaborada por Mariel García Hernández 


\subsubsection{PARTE III - Resultados}

Por útlimo, se hizo un vaciado de la información que se obtuvo a través de las distintas herramientas de validación de usabilidad que se implementaron en las primeras dos partes de la Fase 2.

\section{FASE 2: PARTE III - LISTA DE CHEQUEO DEL ANÁLISIS DE TAREAS}

\section{Lista de chequeo del Análisis de tareas}

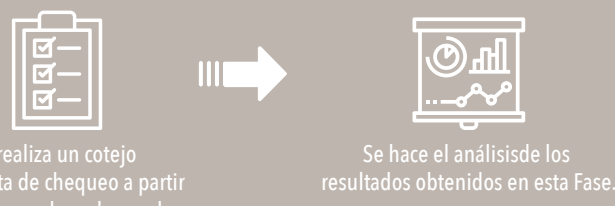

Figura 20. FASE 2: Parte III - Lista de chequeo del análisis de tareas. Elaborada por Mariel García Hernández

Para continuar con los resultados, fue importante retomar los objetivos planteados de esta segunda fase del instrumento de evaluación del presente trabajo. Los objetivos establecidos fueron:

1. Identificar si la información contenida en las guías es comprendida por parte del participante (efectiva).

2. Identificar si la presentación de la información es agradable para el usuario (agradable). 
3. Identificar si la información contenida en las guías se lee con facilidad (eficiente).

Como podemos notar, cada objetivo corresponde a una variable relacionada con el concepto de usabilidad que se plantea en apartados anteriores; efectividad, eficiencia y satisfacción (agradable).

Dichas variables se correlacionaron de la siguiente manera con los reactivos contenidos en los intrumentos de evaluación utilizados en esta segunda fase del instrumento de evaluación.

\section{INSTRUMENTOS DE EVALUACIÓN IMPLEMENTADOS EN LA FASE 2}

\begin{tabular}{|c|l|}
\hline $\begin{array}{c}\text { Lista de Chequeo del } \\
\text { Análisis de tareas (AdT) }\end{array}$ & \multicolumn{1}{c|}{ Cuestionario PSSUQ } \\
\hline \multirow{2}{*}{$\begin{array}{c}\text { Todos los reactivos de } \\
\text { la lista de Chequeo del } \\
\text { Análisis de tareas (AdT) }\end{array}$} & $\begin{array}{l}\text { 1) La organización de la información proporcionada por las guías me fue clara. } \\
\text { información proporcionada en las guías. }\end{array}$ \\
\cline { 2 - 3 } & 3) La información proporcionada por las guías fue fácil de entender. \\
\cline { 2 - 3 } & 4) La apariencia de las guías es agradable. \\
\cline { 2 - 3 } & $\begin{array}{l}\text { 5) En general estoy satisfecho con el acomodo y presentación visual } \\
\text { de la información. }\end{array}$ \\
\hline
\end{tabular}

Efectividad

Eficiente

Satisfactoria

Figura 21. Relación entre varibales e instrumentos de evaluación de la FASE 2.

Elaborada por Mariel García Hernández

Después de haber vaciado la información y analizado los resultados de ambos intrumentos de evaluación procedimos a estudiar los datos. 


\subsubsection{Lista de chequeo de Análisis de Tareas (AdT)}

La lista de chequeo de Análisis de Tareas (AdT) estaba dividida en 5 secciones; usuario, estructura de la información, tipografía, color y elementos gráficos.

Dichas secciones corresponden a lo que las Guías de Usabilidad NOMOLAS plantean como elementos a abordar cuando se trabaja con interfaces gráficas de visualización de información médica.

La sección "usuario" tenía 8 reactivos, la sección "estructura de la información" 3, la sección "tipografía" 13 , la sección "color" tenía 6 , al igual que la sección elementos gráficos. En total, la lista de chequeo de Análisis de Tareas tenía 36 reactivos en total. 


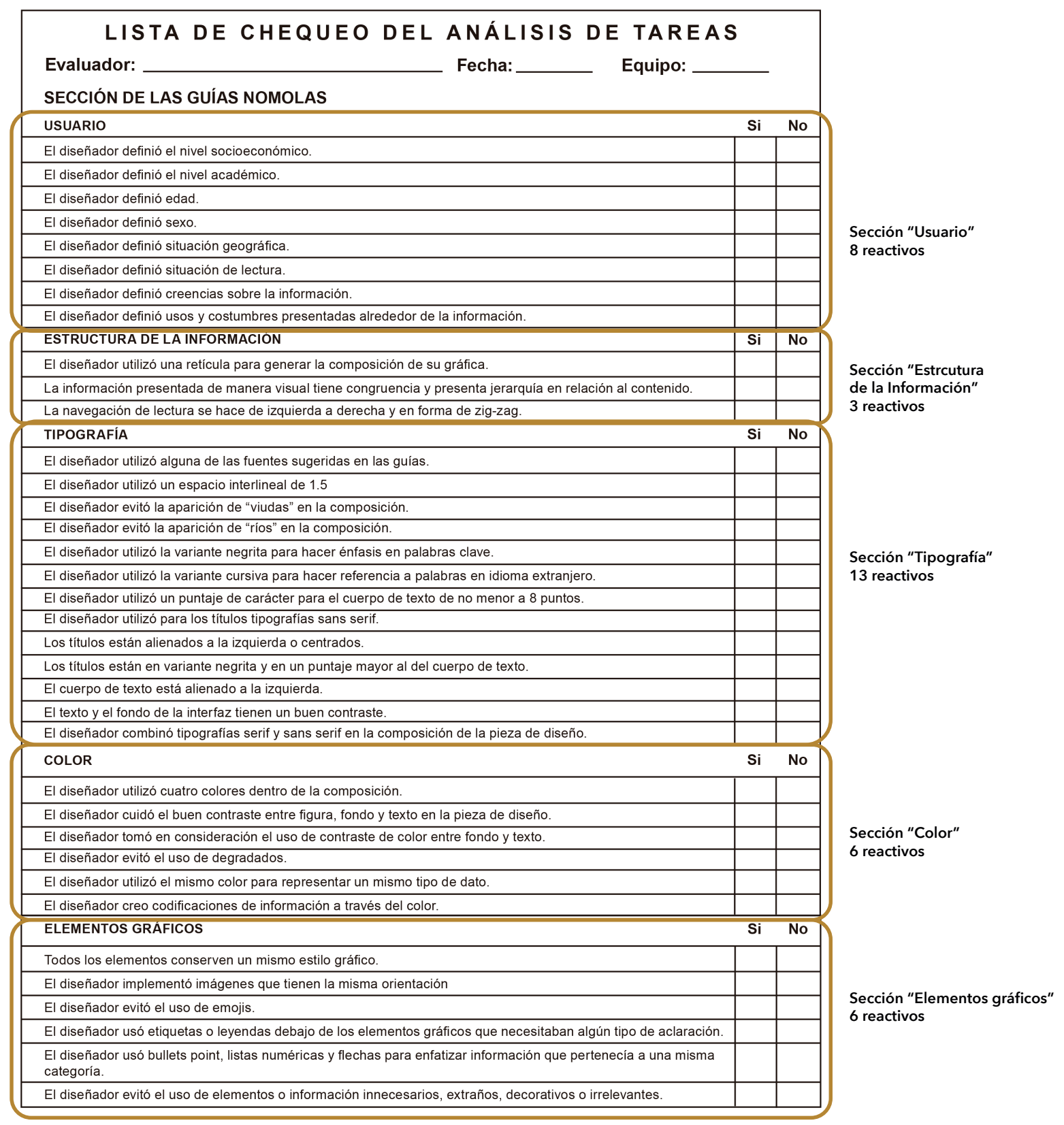

Figura 22. Relación entre secciones y número de reactivos de cada sección de la lista de chequeo del Análisis de Tareas (AdT). Elaborada por Mariel García Hernández

Después de haber implementado la prueba y haber vaciado la información que los resultados de ésta nos proporcionaron podemos observar lo siguiente. 


\begin{tabular}{|l|r|r|}
\hline USUARIO & SI & NO \\
\hline El diseñador definió el nivel socioeconómico. & 5 & 0 \\
\hline El diseñador definió el nivel académico. & 3 & 2 \\
\hline El diseñador definió edad. & 5 & 0 \\
\hline El diseñador definió sexo. & 5 & 0 \\
\hline El diseñador definió situación geográfica. & 4 & 1 \\
\hline El diseñador definió situación de lectura. & 4 & 1 \\
\hline El diseñador definió creencias sobre la información. & 4 & 1 \\
\hline El diseñador definió usos y costumbres presentadas alrededor de la información. & 4 & \\
\hline
\end{tabular}

Figura 23. Resultados de la lista de Análisis de Tareas, sección "Usuario".

Elaborada por Mariel García Hernández

\section{ESTRUCTURA DE LA INFORMACIÓN}

El diseñador utilizó una retícula para generar la composición de su gráfica.

La información presentada de manera visual tiene congruencia y presenta jerarquía en relación al contenido.

La navegación de lectura se hace de izquierda a derecha y en forma de zig-zag.

Figura 24. Resultados de la lista de Análisis de Tareas, sección "Estructura de la información”. Elaborada por Mariel García Hernández$$
\text { Elaborada por Mariel Garcia Hernández }
$$

SI

5

5

5

\section{TIPOGRAFIA}

El diseñador utilizó alguna de las fuentes sugeridas en las guías.

El diseñador utilizó un espacio interlineal de 1.5

El diseñador evitó la aparición de "viudas" en la composición.

El diseñador evitó la aparición de "ríos" en la composición.

El diseñador utilizó la variante negrita para hacer énfasis en palabras clave.

El diseñador utilizó la variante cursiva para hacer referencia a palabras en idioma extranjero.

El diseñador utilizó un puntaje de carácter para el cuerpo de texto de no menor a 8 puntos.

El diseñador utilizó para los títulos tipografías sans serif.

Los títulos están alienados a la izquierda o centrados.

Los títulos están en variante negrita y en un puntaje mayor al del cuerpo de texto.

El cuerpo de texto está alienado a la izquierda.

El texto y el fondo de la interfaz tienen un buen contraste.

El diseñador combinó tipografías serif y sans serif en la composición de la pieza de diseño.

Figura 25. Resultados de la lista de Análisis de Tareas, sección "Tipografía". Elaborada por Mariel García Hernández
SI

NO

3

5

5

5

4

2

5

5

5

3

5

5

0 


\begin{tabular}{|l|r|r|}
\hline COLOR & SI & NO \\
\hline El diseñador utilizó cuatro colores dentro de la composición. & 3 \\
\hline $\begin{array}{l}\text { El diseñador cuidó el buen contraste entre figura, fondo y texto en la pieza de } \\
\text { diseño. }\end{array}$ & 5 & 2 \\
\hline $\begin{array}{l}\text { El diseñador tomó en consideración el uso de contraste de color entre fondo y } \\
\text { texto. }\end{array}$ & 5 & 0 \\
\hline El diseñador evitó el uso de degradados. & 5 & 0 \\
\hline El diseñador utilizó el mismo color para representar un mismo tipo de dato. & 5 & 0 \\
\hline El diseñador creo codificaciones de información a través del color. & 5 & 0 \\
\hline
\end{tabular}

Figura 26. Resultados de la lista de Análisis de Tareas, sección "Color". Elaborada por Mariel García Hernández

\begin{tabular}{|l|r|r|}
\hline ELEMENTOS GRÁFICOS & SI & NO \\
\hline Todos los elementos conserven un mismo estilo gráfico. & 5 & 0 \\
\hline El diseñador implementó imágenes que tienen la misma orientación & 5 & 0 \\
\hline El diseñador evitó el uso de emojis. & 5 & 0 \\
\hline $\begin{array}{l}\text { El diseñador usó etiquetas o levendas debaio de los elementos aráficos que } \\
\text { necesitaban algún tipo de aclaración. }\end{array}$ & 4 & \\
\hline $\begin{array}{l}\text { El diseñador usó bullets point, listas numéricas y flechas para enfatizar } \\
\text { información que pertenecía a una misma categoría. }\end{array}$ & 5 & 0 \\
\hline $\begin{array}{l}\text { El diseñador evitó el uso de elementos o información innecesarios, extraños, } \\
\text { decorativos o irrelevantes. }\end{array}$ & 5 & 0 \\
\hline
\end{tabular}

Figura 27. Resultados de la lista de Análisis de Tareas, sección "Elementos gráficos".

Elaborada por Mariel García Hernández

A continuación, presentamos una tabla con la puntuación obtenida de cada uno de

los cinco usuarios que participaron en la prueba, así como la moda y el promedio:

\begin{tabular}{|c|c|c|c|c|c|c|c|c|c|}
\hline $\begin{array}{c}\text { SECCIÓN DE LAS GUÍAS } \\
\text { NOMOLAS }\end{array}$ & $\begin{array}{l}\text { PUNTOS } \\
\text { POSIBLES }\end{array}$ & U1 & U2 & U3 & U4 & U5 & $\begin{array}{l}\text { DESVIACIÓN } \\
\text { ESTÁNDAR POR } \\
\text { SECCIÓN }\end{array}$ & $\begin{array}{l}\text { POSIBLES EN TOTAL } \\
\text { POR SECCIÓN }\end{array}$ & $\begin{array}{l}\text { TOTAL POR SECCIÓN } \\
\text { SEGÚN GLOBAL DE } \\
\text { USUARIOS }\end{array}$ \\
\hline Usuario & 8 & 7 & 8 & 8 & 6 & 4 & 1.673320053 & 40 & 33 \\
\hline Tipografía & 13 & 9 & 12 & 10 & 10 & 11 & 1.140175425 & $65^{\prime}$ & 52 \\
\hline Color & 6 & 5 & 6 & 6 & 5 & 6 & 0.547722558 & $30^{\prime}$ & 28 \\
\hline Elementos gráficos & 6 & 6 & 6 & 6 & 6 & 6 & 0 & $30^{\prime}$ & 30 \\
\hline
\end{tabular}

Figura 28. Tabla de resultados (puntuación) por usuario de la lista de chequeo del Análisis de Tareas (AdT).

Elaborada por Mariel García Hernández

A partir de lo previamente planteado, proseguimos a hacer las siguientes aseveraciones respecto a los resultados de la lista de chequeo de Análisis de 
Tareas (AdT); al observar en la figura 22 podemos argumentar que el $60 \%$ de los participantes sacó un $83.33 \%$ de aciertos en la lista de chequeo de análisis de tarea y el 40\% restante sacó más del $91.66 \%$ de aciertos en el instrumento de evaluación previamente descrito.

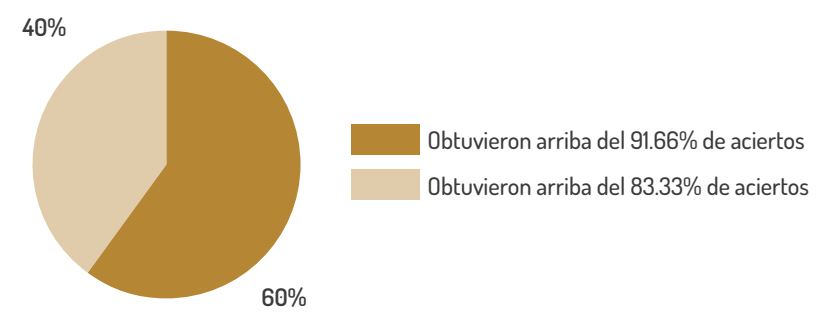

Figura 29. Porcentaje del total de aciertos de los usuarios en la lista de chequedo de Análisis de Tareas (AdT). Elaborada por Mariel García Hernández

Por lo que podemos sostener que, al mantener el número de aciertos por arriba del $83.33 \%$, el usuario de las guías NOMOLAS comprende casi en su totalidad la información presentada en éstas.

Retomando la información que se presenta en la figura 22, observamos que las secciones de "elementos gráficos" y "estructura de información" obtuvieron el $100 \%$ de aciertos por parte de todos de los usuarios participantes en la prueba, seguida con la sección de "Color", con el $93.33 \%$ en aciertos por parte del 100\% de los usuarios.

Por otra parte, la sección "tipografía", fue el apartado de la prueba con menos aciertos, teniendo un $80 \%$ de aciertos, pero aún así manteniéndose en una buena calificación. Por último, la sección "usuario" obtuvo un $82.5 \%$ de aciertos por parte de los usuarios de la prueba. 
A partir de lo que hemos observado, en la lista de Análisis de Tareas (AdT), se obtuvo un promedio de $91.066 \%$ de aciertos en el total de cada una de las secciones que conforman dicha herramienta, lo cual representa una buena calificación, haciendo evidente que los usuarios comprenden casi en su totalidad la información que las guías NOMOLAS están planteando. Por esto, podemos establecer que la información de dicho documento está siendo comprensible para su usuario, por lo que concluimos que se cumple satisfactoriamente con la variable "efectiva", la cual fue establecida dentro de los objetivos planteados de esta segunda fase del instrumento de evaluación.

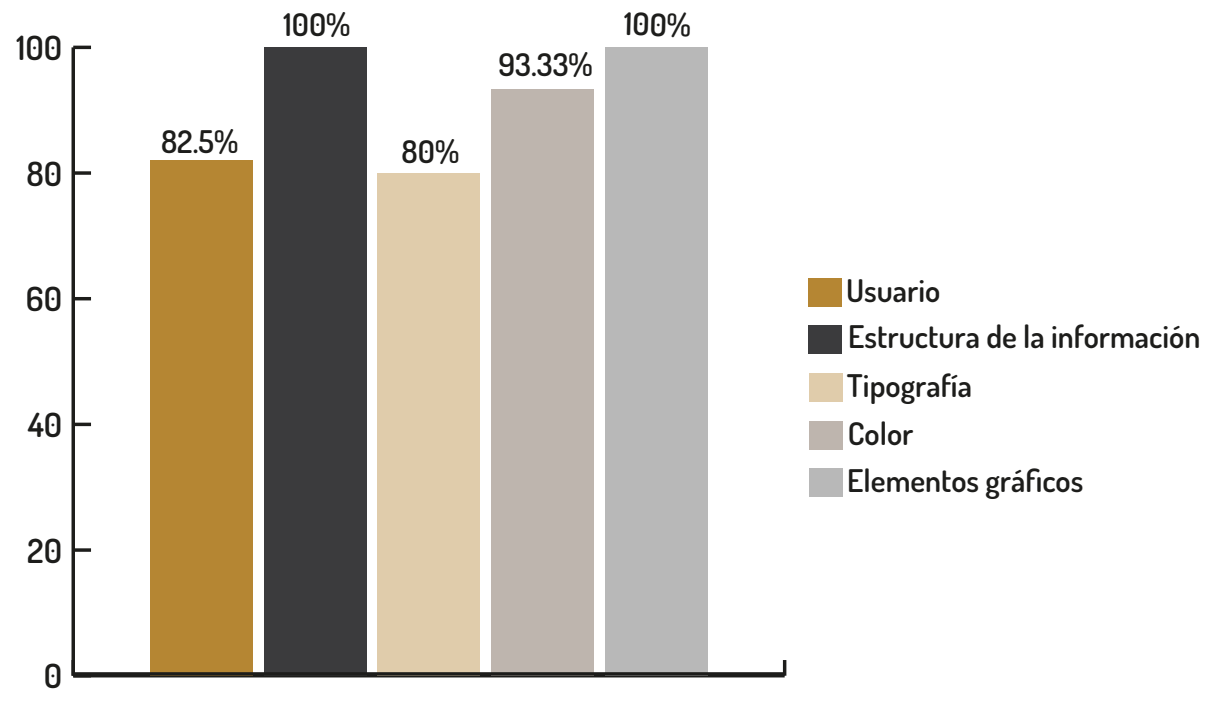

Figura 30. Porcentaje del total de aciertos en cada sección de la lista de chequeo del Análisis de Tareas (AdT) por el total de los usuario de la prueba. Elaborada por Mariel García Hernández 


\title{
6.2.3.2 Cuestionario PSSUQ
}

Este instrumento se utilizó para analizar las variables "eficiencia" y "satisfacción". Se implementó una escala de Likert en donde el valor más bajo (1) se relacionaba con la premisa "totalmente desacuerdo" y el valor más alto (7) estaba asociado con la premisa "totalmente de acuerdo".

\section{CUESTIONARIO PSSUQ}

Edad: Sexo: $M$ / $\mathbf{F}$ Licenciatura: Manejo de llustrator: Si / No

\begin{abstract}
Este cuestionario es una oportunidad para registrar tus reacciones a la guía de usabilidad. Estas respuestas nos ayudarán a entender que aspectos hay que mejorar y cuales son con los que no estás satisfechos. Para tener un mejor resultado, piensa en la tarea que se te pidió que realizaras con base a lo que las guias decían mientras contestas estas preguntas.

Instrucciones: Lea cada frase y señala qué tan de acuerdo o en desacuerdo estás y encierra en un circulo un número de la escala. Al terminar, revisaremos juntos con ustḍd el cuestionario para asegurarnos de que entendamos bien la información presentada en este cuestionario.
\end{abstract}

¡Gracias!
a) La organización de la información proporcionada por las guías me fue clara.
Totalmente en desacuerdo
2
4
45
5
Totalmente de acuerdo
1
6
7
b) Fui capaz de completar la tarea que se me indicó rápidamente con la información proporcionada en las guías.
Totalmente en desacuerdo
Totalmente de acuerdo
1
c) La información proporcionada por las guías fue fácil de entender.
Tuiailiterite uंe úesacuerúu
1
2
3
6
Totalmente de acuerdo
7

d) La apariencia de las guías es agradable.

Totaimente en desacuerdo

2

3

Totalmente de acuerdo

e) En general estoy satisfecho con el acomodo y presentación visual de la información.

Tüalimente en पंesacuerúo

3

4

5

Totalmente de acuerdo

Efectividad

Satisfacción

Figura 31. Relación de las variables "efectividad", "eficiencia" y" satisfacción" con los reactivos del cuestionario PSSUQ. Elaborada por Mariel García Hernández 
A continuación, presentamos una tabla con los resultados de los cuestionarios PSSUQ aplicados:

\begin{tabular}{|c|c|c|c|c|c|c|c|}
\hline \multicolumn{8}{|c|}{ CUESTIONARIO PSSUQ } \\
\hline & \multicolumn{5}{|l|}{$\begin{array}{l}\text { Totalmente } \\
\text { en } \\
\text { desacuerdo }\end{array}$} & \multicolumn{2}{|c|}{$\begin{array}{l}\text { Totalmente } \\
\text { de acuerdo }\end{array}$} \\
\hline & 1 & 2 & 3 & 4 & 5 & 6 & 7 \\
\hline $\begin{array}{l}\text { 1) La organización de la información } \\
\text { proporcionada por las guías me fue clara. }\end{array}$ & 0 & 0 & 0 & 0 & 0 & 1 & 4 \\
\hline $\begin{array}{l}\text { 2) Fui capaz de completar la tarea que se m } \\
\text { indicó rápidamente con la información } \\
\text { proporcionada en las guías. }\end{array}$ & 0 & 0 & 0 & 1 & 1 & 2 & 1 \\
\hline $\begin{array}{l}\text { 3) La información proporcionada por las } \\
\text { guías fue fácil de entender. }\end{array}$ & 0 & 0 & 0 & 0 & 0 & 3 & 2 \\
\hline 4) La apariencia de las guías es agradable. & 0 & 0 & 0 & 0 & 0 & 2 & 3 \\
\hline $\begin{array}{l}\text { 5) En general estoy satisfecho con el } \\
\text { acomodo y presentación visual de la } \\
\text { información. }\end{array}$ & 0 & 0 & 0 & 0 & 1 & 1 & 3 \\
\hline
\end{tabular}

Figura 32. Tabla de resultados (puntuación por usuario) del cuestionario PSSUQ. Elaborada por Mariel García Hernández

A partir de la información que observamos en la figura 26, podemos concluir lo siguiente: el $80 \%$ de los usuarios de la prueba señalan estar "totalmente de acuerdo" en que la organización de la información proporcionada por las guías les fue clara.

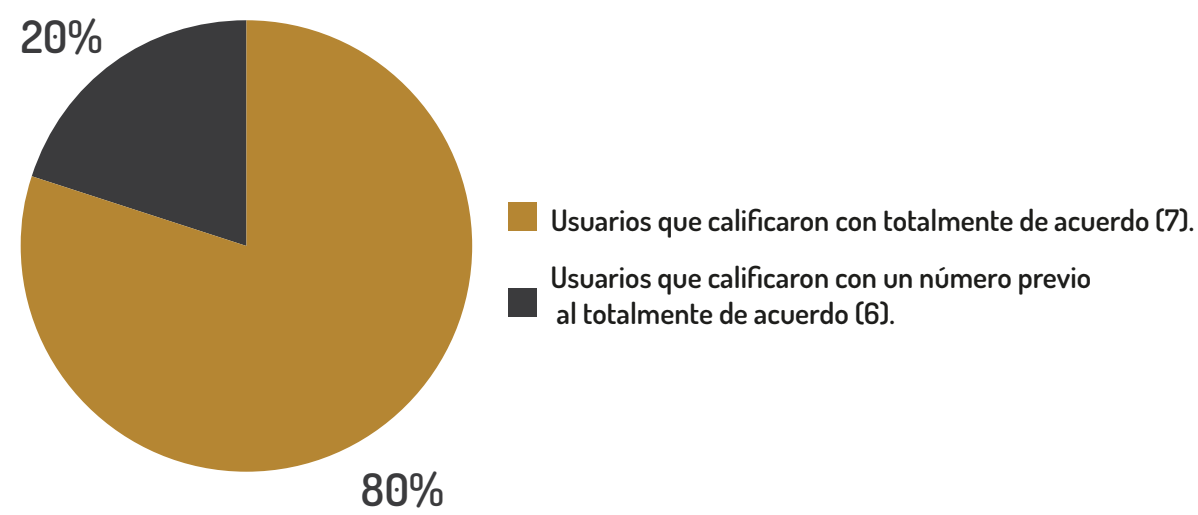

Figura 33. Resultados de la premisa "la organización de la información proporcionada por las guías me fue clara" del cuestionario PSSUQ.

Elaborada por Mariel García Hernández 
El otro $20 \%$ restante, calificó un número previo al "totalmente de acuerdo" a la premisa, por lo que podemos decir, que se percibe que este porcentaje restante de usuarios sigue estando de acuerdo con la premisa previamente señalada.

Por otra parte, se observa en los resultados de la premisa "fui capaz de completar la tarea que se me indicó rápidamente con la información proporcionada en las guías", que un $20 \%$ seleccionó estar "totalmente de acuerdo", un $40 \%$ calificó a esta premisa en un número previo al "totalmente de acuerdo".

Otro $20 \%$ indico calificar esta premisa con dos números previos al reactivo "totalmente de acuerdo" y el otro $20 \%$ restante con 3 números previos a la premisa señalada.

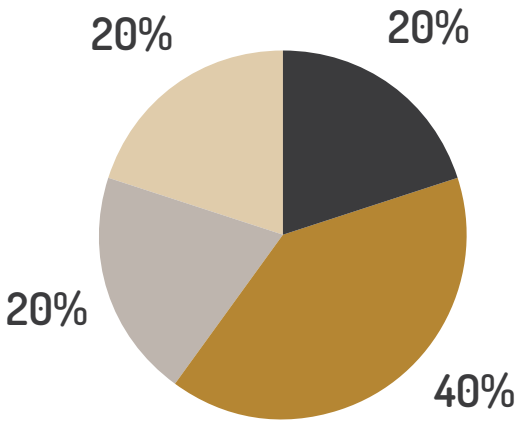

Figura 34. Resultados de la premisa "Fui capaz de completar la tarea que se me indicó rápidamente con la información proporcionada en las guías.” del cuestionario PSSUQ. Elaborada por Mariel García Hernández

En cuanto a la premisa "la información proporcionada por las guías fue fácil de entender", el $60 \%$ de los usuarios la calificaron con un número previo al reactivo 
"totalmente de acuerdo", y el $40 \%$ de los usuarios restantes con un "totalmente de acuerdo".

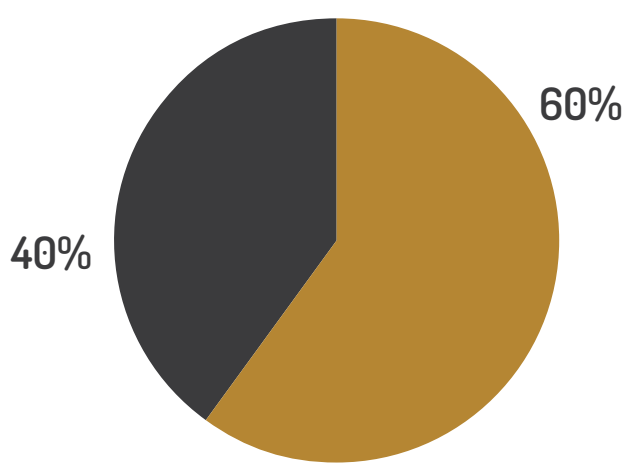

Usuarios que calificaron con totalmente de acuerdo (7).

Usuarios que calificaron con un número previo totalmente de acuerdo [6].

Figura 35. Resultados de la premisa "la información proporcionada por las guías fue fácil de entender.” del cuestionario PSSUQ.

Elaborada por Mariel García Hernández

La premisa "la apariencia de las guías me es agradable" fue calificada con un "totalmente de acuerdo" por parte del $60 \%$ de los usuario, el $40 \%$ restante calificó a etsa aseveración con un número previo al "totalmente de acuerdo".

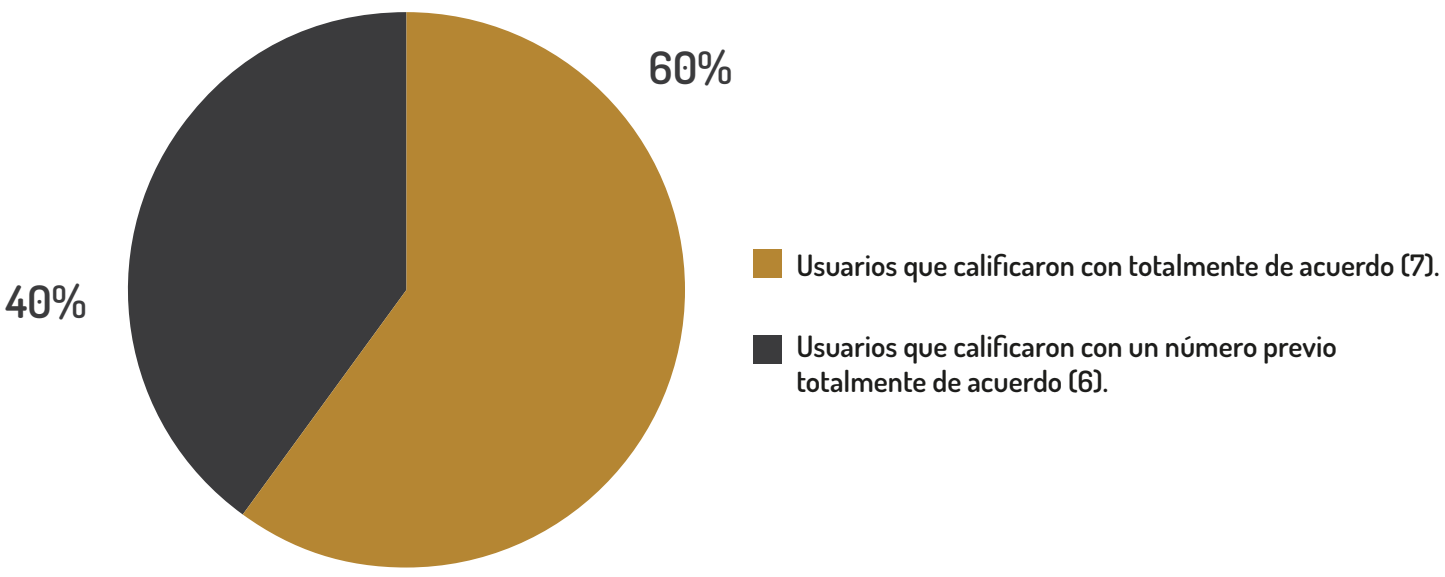

Figura 36. Resultados de la premisa "la apariencia de las guías me es agradable" del cuestionario PSSUQ. Elaborada por Mariel García Hernández 
El $60 \%$ de los usuarios calificó con un "totalmente de acuerdo" a la premisa "En general estoy satisfecho con el acomodo y presentación visual de la información". Un $20 \%$ la calificó con un número previo al "totalmente de acuerdo" y el $20 \%$ restante con dos números previos al reactivo previamente enunciado.

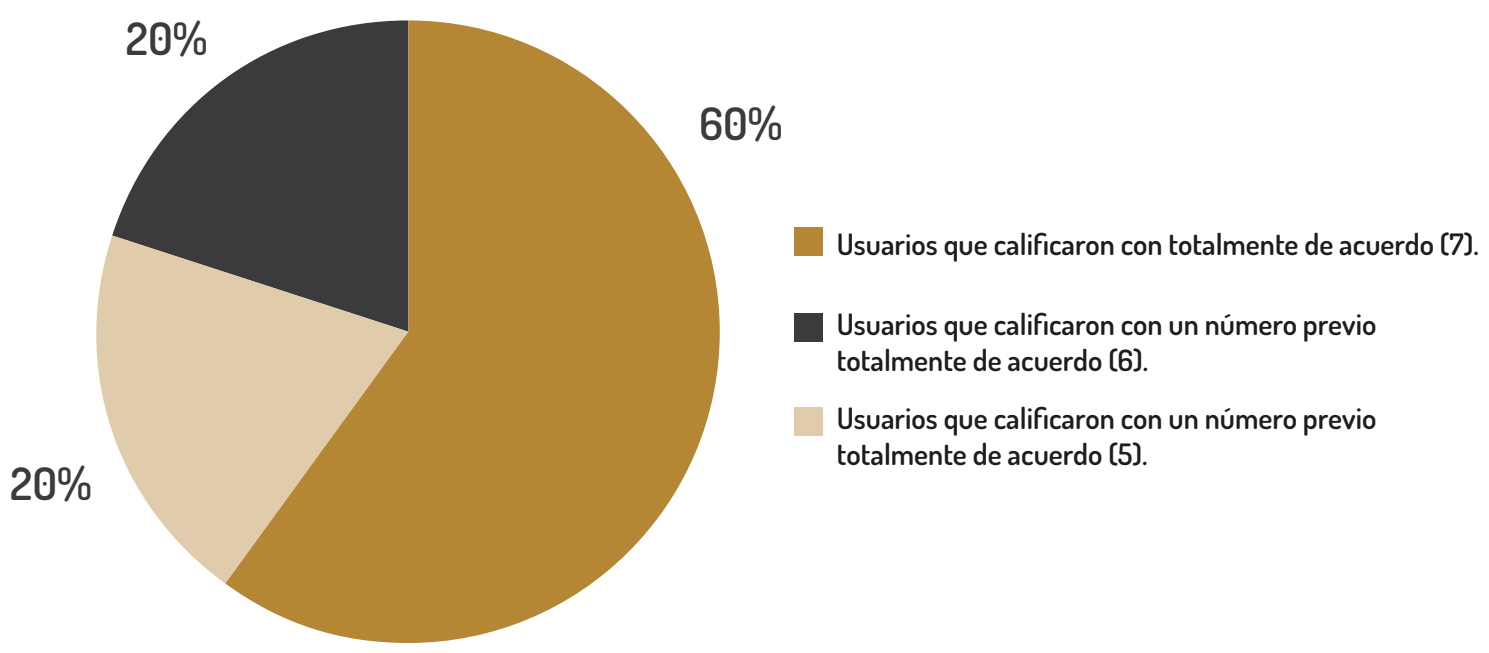

Figura 37. Resultados de la premisa "En general estoy satisfecho con el acomodo y presentación visual de la información” del cuestionario PSSUQ.

Elaborada por Mariel García Hernández

\subsubsection{Conclusión de la segunda parte del método de evaluación}

A partir de las figuras previamente mostradas, observamos que la mayoría de las premisas del cuestionario PSSUQ fueron calificadas por arriba de un número previo (6) al "totalmente de acuerdo" (7). Los usuarios están satisfechos con la organización de la información, su acomodo visual y a su vez, les es agradable (en términos de estética). Así como también, es evidente que los usuarios de esta 
prueba expresaron que la información de las Guías NOMOLAS les resultó en su gran mayoría clara y fácil de entender.

A partir de estas asevaraciones, tenemos como resultado que la información del documento evaluado fue clara (eficiente) y agrable en su presentación, cumpliendo satisfactoriamente con las variables que conforman el concepto usabilidad, y a su vez, son parte de los objetivos de esta segunda fase de evaluación. 
Conclusiones 


\section{Conclusiones}

A continuación, se presentan las conclusiones de esta tesis de investigación, así como se plantea una prospectiva que se propone a partir de los hallazgos obtenidos al concluir esta tesis doctoral.

Para comenzar este apartado, nos resulta importante retomar los objetivos de investigación, tanto el general como los particulares, expuestos previamente en la introducción de este trabajo.

Como objetivo general de este trabajo investigación, se estableció el desarrollo de guías de usabilidad para el diseño de interfaces gráficas de sistemas de visualización de información médica.

Dentro de los objetivos particulares que sustentan a éste encontramos (a) la revisión de normas ISO en donde se abordara el diseño de interfaces gráficas, así como también la recopilación de lineamientos teóricos y conceptuales de autores que trabajaran la visualización de información, la usabilidad, la ergonomía cognitiva y el diseño de información, así como también temas afines entre estas disciplinas. En cuanto al primer objetivo se revisaron las siguientes normas (Figura 1): 


\begin{tabular}{|l|l|}
\hline \multicolumn{2}{|c|}{ ANÁLISIS DE NORMAS ISO } \\
\hline \multicolumn{1}{|c|}{ Normas ISO } & \multicolumn{1}{|c|}{ Contenido } \\
\hline $\begin{array}{l}\text { ISO 9241-11 } \\
\text { "Ergonomic requiriments for office } \\
\text { work with visual display terminal" }\end{array}$ & $\begin{array}{l}\text { Recomendaciones de eficiencia, } \\
\text { efectividad y satisfacción en la } \\
\text { creación de pantalla de visualización } \\
\text { y su interacción con el usuario. }\end{array}$ \\
\hline $\begin{array}{l}\text { IEC TR 61997 } \\
\text { "Guidelines for the user interfaces } \\
\text { in multimedia equipment for } \\
\text { general purpose use" }\end{array}$ & $\begin{array}{l}\text { Guías de diseño que se usan para } \\
\text { sugerir una selección detallada de los } \\
\text { medios de comunicacion, interfaz de } \\
\text { usuario mecánicos, gráficos y auditivos. }\end{array}$ \\
\hline $\begin{array}{l}\text { ISO 13407 } \\
\text { "Human-centered design processes } \\
\text { for interactive systems" }\end{array}$ & $\begin{array}{l}\text { Directivas que tienen como objetivo } \\
\text { el desarrollo de interfaces de usuario } \\
\text { según los requerimientos de éste. }\end{array}$ \\
\hline $\begin{array}{l}\text { ISO/IEC } \\
\text { "Information technology user inter- } \\
\text { face formovile tools" }\end{array}$ & $\begin{array}{l}\text { Requerimientos de la interface de } \\
\text { usuario para PDA (Personal Digital } \\
\text { Assistant] }\end{array}$ \\
\hline
\end{tabular}

Figura 1. Normas ISO que se analizaron en este trabajo de investigación. Elaborada por Mariel García Hernández

Con esta revisión se verificó la viabilidad y factibilidad del desarrollar de las guías de usabilidad NOMOLAS, ya que al realizar el análisis del contenido de los documentos previamente enunciados nos dimos cuenta de que no existía, hasta ese momento, guías de usabilidad que abordaran el desarrollo de interfaces gráficas sistemas de visualización de información médica desde el ámbito del diseño de información y la ergonomía cognitiva.

Respecto al segundo objetivo (b), se planteó una investigación y una recopilación de diversos autores que estudian los temas de visualización de información, interfaces gráficas, usabilidad y ergonomía cognitiva. Se hizo un análisis sobre la visualización de información como lenguaje esquemático, dando como resultado un reconocimiento de patrones, a través de elementos visuales como el color, el texto, 
los elementos gráficos y su estructura visual. En este estudio hallamos que la visualización de información es un instrumento que nace a partir de la necesidad del hombre de representar y explicar su realidad. Esta herramienta ha ido evolucionando y adaptándose a las necesidades de éste, en donde dicho instrumento, conlleva un proceso cognitivo por parte de su lector, en donde, según Villafañe (2006), se lleva a acabo a través de un análisis de las representaciones visuales de ciertos elementos permite éste (al usuario) comprender la información con la que interactúa.

Continuando con nuestra investigación, indagamos en el proceso cognitivo llamado procesamiento de la percepción visual, en donde Ware (2012) dice que éste capta y recopila la realidad (imagen) que el hombre está experimentando a través del sentido de la vista. En donde se llevan acabo una serie de procesos complejos los cuales se interpretan estímulos sensoriales que son compilados a través de del ojo y es traducida en información valiosa. Dicha interpretación tiene como base una serie de características preatentivas según Meirelles (2014), de variables visuales conforme a lo que establece Bertin (1983), como el color, la forma, la textura, la posición, la orientación, entre otras, así como también, de acuerdo con Wertherimer (1950), por las leyes de la Gestalt, en donde todos estos elementos fungen como gramática visual para la compresión y el reconocimiento de la realidad, tal como lo propone Ware $(2012$

Siguiendo con nuestro estudio, se exploró el concepto de interfaz gráfica en donde podemos definirla como un soporte visual, el cual está conformado por diversos elementos; conforme a Luna González la interfaz está compuesta por color, 
tipografía, composición e imagen, por otro lado, Prado León \& Ávila Chaurand, argumentan que la interfaz gráfica está conformada por tipografía, color, tablas y gráficas , así como por la semántica y sintáctica de la información, después de haber analizado ambas posturas, nos dimos cuenta en los elementos que coincidían, y los consideramos como apartados de las guías de usabilidad NOMOLAS. Por otra parte, al hablar de diseño de información es consubstancial no hablar del perfil del usuario como base y eje rector de la estrategia misma de diseño, es por ello por lo que se analizó la postura de Frascara (2011), en donde encontramos que es de suma importancia, si estamos abordando las necesidades cognitivas del usuario, tomar como ítem de las mismas guías de usabilidad NOMOLAS a éste. Ya que al conocer y reconocer al usuario como ente independiente y con características únicas, se puede establecer un panorama más certero respecto al rendimiento de la pieza de diseño que se está desarrollando, así como de la misma estrategia y, en este caso, de las visualizaciones de información médica. A partir de lo previamente enunciado, pudimos responder las preguntas de investigación que enunciaban lo siguiente:¿Qué lineamientos conceptuales de diseño de información debe contemplar el desarrollo de esta propuesta de guías? .

Otra parte muy importante de esta tesis doctoral fueron los campos de la usabilidad y la ergonomía cognitiva. Para esto, se trabajo bajo los conceptos establecidos por Nielsen (2012) y de Jordan (2001), en donde el primer autor define a la usabilidad como la facilidad con la que se usa un objeto y por otro parte, idem dice que para que este artefacto sea usable (fácil de usar) debe cumplir con tres propiedades o características; la eficiencia, la efectividad y la satisfacción. Dichas propiedades 
fueron establecidas como las variables a ponderar en el tercer y cuarto objetivo de esta tesis doctoral. De igual forma dentro del área de la usabilidad se analizaron los componentes de la usabilidad del diseño de interfaces, en donde encontramos que dicho concepto está conformado por la capacidad de adivinar y de aprendizaje, el rendimiento de la experiencia del usuario, el potencial mismo del sistema con el que éste está interactuando y la reusabilidad del mismo sistema, según señala Jordan (2002). También se estudiaron los principios de usabilidad en el diseño de Nielsen (1994), en donde el autor establece una serie de consideraciones que al ser ejecutados conforma dicha usabilidad. Respecto a la ergonomía cognitiva, se trabajó bajo las posturas de Cañas \& Wearns (2001) y de Romero Montero (2006) y Rubin \& Chisnell (2008), en donde encontramos que la ergonomía cognitiva es inherente cuando se habla de visualización de información y usabilidad, ya que ésta establece los requerimientos cognitivos del usuario y aporta una serie de herramientas de validación de usabilidad para comprobar si el artefacto de diseño con el que se está trabajando es usable (eficiente, efectivo y satisfactorio). Después de haber analizado lo que se menciona, se pudo responder a las preguntas que planteaban lo siguiente: ¿qué conceptos de usabilidad debe contener dichas guías?, ¿cómo debe presentarse la información para que sea eficiente, efectiva y satisfactoria? y ¿a qué nos referimos cuando hablamos usabilidad en interfaces gráficas de sistemas de visualización de información médica?.

Después de haber recopilado, estudiado y analizado las posturas de estos y otros más autores en sus campos de estudio correspondiente, se prosiguió al desarrollo 
de las guías de usabilidad para el desarrollo de interfaces gráficas visualizaciones de información médica, que a su vez dio respuesta a la pregunta de investigación “¿de qué manera deben ser estructuradas las guías de usabilidad?”. Dichas guías fueron divididas en seis apartados; consideraciones generales, usuario, texto, color, elementos gráficos y estructura de la información. En la sección correspondiente a "consideraciones generales" se encuentran recomendaciones iniciales sobre composición visual para comenzar con el desarrollo del artefacto a diseñar. En apartado de "usuario" se establecen lineamientos técnicos de la segmentación del perfil de éste. En la sección de "texto" se plantean consideraciones acerca de estrategia tipográfica, como el uso de variantes, diferentes pesos tipográficos, acomodo y alineación. Por otra parte, en la sección "color" se desarrollan lineamientos técnicos del uso del color, jerarquización a través de éste, relaciones por colorimetría, entre otras estrategias del uso del color. En el apartado "elementos gráficos" se encuentran recomendaciones para la selección de esta clase de ítems; la forma en que deben ser colocados, correlaciones con su significado, etc. Por último, en el apartado de "estructura de la información" se establecen lineamientos acerca de la estructura, jerarquía y acomodo de la propia información (contenido).

El tercer y cuarto objetivo (c y d) fueron la validación de usabilidad (tomando en cuenta la definición de Jordan (2001) en donde este autor plantea que la usabilidad es una propiedad que está integrada por tres elementos; la eficiencia, es decir, que el artefacto de diseño sea rápido de leer, la efectividad, (Jordan (2001) se refiere a que la información que se plantea en éste sea comprendida por usuario ,y por último, la satisfacción, en donde el autor hace referencia a que dicho artefacto sea 
agradable estéticamente a los ojos del usuario) tanto de la composición visual de las guías y del contenido (información que se plantea en éstas), ya que según Shneiderman (1988) señala que una interfaz gráfica está compuesta tanto de la imagen (composición visual) y del contenido de ésta (información).

Para cumplir con estos objetivos (3 y 4), la estrategia de validación se dividió en dos fases; en la primera se tuvo como objetivo la prueba de usabilidad dirigida a la composición visual de las guías, en donde se utilizó el método de prueba A/B, análisis de tareas y el cuestionario PSSUQ. En dicha fase se le presentó a la mitad de la muestra una propuesta editorial $A \circ B$, en donde se media el tiempo que tardaba el usuario en leer dicha propuesta. Posteriormente, se le pidió al usuario que realizara una tarea con base a lo que había leía, cuantificando las veces que recurría al artefacto editorial para su consulta. Así mismo, se iba calificando su respuesta y comportamiento a la hora de realizar dicha tarea. Al terminar, se le entregó el cuestionario PSSUQ para evaluara su experiencia las variables previamente descritas al inicio de este apartado. A partir de los resultados obtenido de esta fase, se decidió cuál propuesta editorial era la más usable para las guías NOMOLAS y con esto se prosiguió a vaciar la información de las guías en su formato editorial. La segunda fase de la estrategia de validación consistió en conocer sí la información que se estaba presentando al usuario de las guías era usable para éste, para esto se utilizó el método de validación workshop, análisis de tareas y cuestionario PSSUQ. En esta fase se organizó un taller, en donde se convocó al usuario de las guías NOMOLAS. El taller estuvo dividió en dos días; en el primero día se le presentaron lineamientos teóricos sobre diseño de información, ergonomía cognitiva y usabilidad. En el segundo día del workshop, se le proporcionó una copia 
de las guías NOMOLAS (ya en su formato editorial) y se le indicó al usuario la actividad que iba a realizar, la cual consistía en el rediseño de la hoja de ingreso de un paciente de diabetes. Conforme a los resultados presentados después del rediseño, se calificó si el diseñador había completado u utilizado o no los lineamientos presentados en las guías NOMOLAS. Al final, de la actividad, se le indicó que contestara un cuestionario PSSUQ, en donde asistente del taller evaluó las guías de usabilidad y su rendimiento. Con lo previamente planteado, se logró responder a la pregunta de investigación "¿qué tipo de instrumento se debe utilizar para poder medir el grado de usabilidad de estas guías de diseño?".

Con la estrategia de validación de usabilidad de las guías, previamente descrita en apartados anteriores de este documento, se comprobó como positiva la hipótesis establecida en esta tesis doctoral; es decir, si a partir del desarrollo y la implementación de guías de usabilidad para el diseño de interfaces gráficas de visualización de información médica se podrían generar artefactos de esta índole que fueron usables (eficientes, efectivos y satisfactorios) para su usuario. Ya que al usar y teniendo como base guías de esta índole, que tienen como estructura lineamientos teóricos y técnicos acerca de la visualización de información, la imagen, la ergonomía cognitiva, la usabilidad y el diseño de información dan una dirección más certera al diseñador de como desarrollar artefactos de comunicación que no solo se ven bien estéticamente, sino que contienen información significativa para su usuario. 


\section{Prospectiva}

A partir de lo previamente descrito en este apartado, se planeta la siguiente prospectiva: estos hallazgos dan pauta para la publicación formal de las guías de usabilidad NOMOLAS como un documento formal, que ofrezca como base para el desarrollo de interfaces gráficas de visualización de información médica, que sea utilizada para interesados y futuros estudiosos sobre el tema como orientación técnica y teórica para el diseño de dichos artefactos. También, se hace sugiere el desarrollo de este tipo de guías de usabilidad para enfocadas en otro tipo de áreas; como sistemas de visualización para la educación, economía, etc.

De igual forma, se propone que se realicen estudios más profundos en la relación de la ergonomía cognitiva y el diseño de información con el objetivo de conocer más esta conexión y las virtudes que estas disciplinas pueden brindar, como los métodos de validación.

Así mismo, se sugiere el desarrollo de este tipo de técnicas para enfocados en la validación de interfaces gráficas, ya que se encontró que existen diversos métodos para el diseño web o diseño de productos, más son pocos lo que se adaptan a la validación de estos artefactos de diseño.

Finalmente, otra propuesta que podemos hacer es la validación del uso de estas guías llevándolo al trabajador de la salud, es decir, con base a estas guías desarrollar artefactos de información médica y que éstos sean presentados y 
evaluados por médicos y profesionales del área de la salud, para que de esta manera se de paso más cerca de la usabilidad y comprender su rendimiento, para así poder responder a la pregunta de investigación “¿de qué manera se logrará que estas guías ayuden a establecer usabilidad de los artefactos de diseño a desarrollar?". 


\section{Bibliografía}


Albornoz, M. C., Berón, M., \& Montejano, G. A. (2017). Interfaz gráfica de usuario: el usuario como protagonista del diseño. XIX Workshop de Investigadores En Ciencias de La Computación (WICC 2017, ITBA, Buenos Aires)., 570-574. http://sedici.unlp.edu.ar/handle/10915/62078

Bertin, J. (1983). Semiology of graphics: Diagrams, networks, maps. Wisconsin: University of Wisconsin Press.

Bertin, Jaques. (1977). La graphique et le traitement graphique de l'information. Flammarion, Paris.

Brokes, B. (1990). The foundations of information science. Part 1. Philosophical aspects. Journal of Information Science. 2(3-4): 125-133.

Bonsiepe, G. (1998). Del objeto a la interface: mutaciones del diseño. Infinito.

Cairo, A. (2011). The Functional Art- An Introduction to Information Graphics and Visualization. (L. G. Prado, Ed.). Madrid: Alamut.

Card, Stuart K. (1999). Readings in information visualization, using vision to think.

Stuart K.Card, Jack D. Mackinlay, Ben Shnneiderman (Eds.) Morgan Kaufmann: San Francisco.

Casado, P. (2018). Usabilidad Web. Teoría y uso. Grupo Editorial RA-MA.

Cañas, J., \& Wearns, Y. (2001). Ergonomía Cognitiva. Editorial Médica Panamericana.

Castro, I., \& Gámez, M. (2002). 2.2. Historia clínica. In M. C. G. Planas (Ed.), Farmacia Hospitalaria (Tercera Ed, pp. 295-305). Barcelona: Hospitalaria, Fundación Española de Farmacia.

Catalán Vega, M. A. (2000). Metodologías de evaluación de interfaces gráficas de usuario. EPrints in Library and Information Science, 138. Consultado el 16 de Junio del 2019 de http://eprints.rclis.org/4718/

Chen, Hsuanwei M. (2017). Information Visualization. Library Technology Reports. Abril 2017,vol.53, no. 3, p5-p 7. 
Gómez, C. (2006). Diseño Centrado en el Usuario. Universidad del Cauca.

Facultad de Ingeniería Electrónica y Telecomunicaciones Consultado el 24 de enero del 2020, http://artemisa.unicauca.edu.co/ iclaros/usabilida/chapter2.htm

Delgado-Vargas, J. (2017). El diseño universal en la interfaz gráfica de multimedia educativo. Revista Actualidades Investigatigas En Educación, 17(3), 1-19.

Díaz Nafría, J. Pérez Montoro, M. \& Salto, F. (2010). Glosario de conceptos, metaforas, teorías y problemas en torno a la información. León: Universidad de León.

Dondis, D. (1984). La Sintaxis de la imagen. Introducción al alfabeto visual, Editorial Erbacher RF. Exemplifying the inter-disciplinary nature of visualization research. $2007 . \quad$ Disponible en:

\section{http://www.computer.org/portal/web/csdl/doi/10.1109/}

IV.2007.49 [Consultado: 21 de enero de 2019].

Ferdio. (2019). Dataviz Project. Consultado del 23 de Enero del 2018 del sitio https://datavizproject.com/

Few, S. (2004). Perceptual Edge Common Mistakes in Data Presentation. Common Mistakes in Data Presentation Start with a Clear Message, 1-5. Consultado el 23 de abril del 2018 de https://moodle.chatham.edu/pluginfile.php/712404/ mod_resource/content/1/Common Mistakes in Data Presentation.pdf

Floridi, L. (2010). Information: a very short introduction, Oxford University Press: Nueva York.

Frascara, J. (2011). ¿Qué es el diseño de información? Buenos Aires: Ediciones Infinito.

Friendly, M. \& Denis, Daniel J. (2009). Milestones in the history of thematic cartography, statistical graphics, and data visualization. Consultado el 14 de junio del 2018 de http://www.datavis.ca/milestones/index.php?group=1600s

Fry, B. (1997). Organic information design (tesis de posgrado). Massachusetts Institu- 
te of Technology, Estados Unidos de Norteamérica._Consultado el 14 de mayo del 2017 de http://benfry.com/organic/thesis-0522d.pdf

Glaser, B.G. (1992). Basics of grounded theory analysis. Mill Valley, CA: Sociology Press.

Götz, V. (1988). Color \& Type for the screen. Suiza: RotoVision SA.

Hassan-Montero, Y., \& Núnez-Peña, A. (2005). Diseño de Arquitecturas de Información: Descripción y Clasificación. No Solo Usabilidad: Revista Sobre Personas, Diseño y Tecnología.

Hernández Sampieri, R., Fernández Collado, C., \& Baptista Lucio, P. (2010). Metodología de la investigación. Gustavo Gili, Barcelona

Herrera de Velasco, L., \& Gutierrez Neve Ariza, M. (2006). Selección de una tipografía para la composición de textos con base en su facilidad de lectura y sus rasgos estructurales Garamond Opti m a. MM1 Un Año de Diseñarte, 8.

International Organization for Standardization. (2015). ISO DIS 9241-11: Ergonomics of human-system interaction - Part 11: Usability: Definitions and concepts.

Jordan, P. (2001). An Introduction to Usability. London, U.K.: Taylor \& Francis Ltd.

Krajil Novak, P., Smailović, J., Sluban, B., \& Mozetič, I. (2015). Sentiment of emojis. PloS ONE, 10(12).

Langren, M. F. (1644). La verdadera Longitud por Mar y Tierra demostrada. Madrid Lonsdale and Lonsdale. (2019a). Design2Inform: Information visualisation overview [Report 01]. Gov UK.

Lonsdale and Lonsdale. (2019b). Design2Inform: Information visualisation guidelines [Report 02]. Gov UK.

López Rodríguez, J. (1993). Semiótica de la comunicación gráfica. Ciudad de México: Universidad Autónoma Metropolitana.

Luna-González, L. (2004). El Diseño De Interfaz Gráfica De Usuario Para Publicacio- 
nes Digitales. Revista Digital Universitaria, 5(7), 2-12. Tomado el 7 de Julio del 2019 del sitio http://www.revista.unam.mx/vol.5/num7/art44/art44.htm

Marín Álvarez, M. (2011). Del haluro de plata al pixel; la transmutación de la imagen. Universidad Autónoma Metropolitana.

McCreeadie, M. y Rice, R.E. (1999). Trends in analyzing access to information. Part 1: cross-disciplinary conceptualizations of access. Information Processing and Management, 35 (1). 45 - 76.

Meirelles, I. (2014). La información en el diseño. Barcelona.: Parramón Arts \& Design. Molich, R., \& Nielsen, J. (1990). Improving a human-computer dialogue. Communications of the ACM, 33(3), 338-348.

Mosby. (2010). Diccionario Mosby de Medicina, Enfermería y Ciencias de la Salud. Mycological Research (6ta ed., Vol. 106). Elsevier.

Neisser, U. (1976). Psicología cognoscitiva. México: Editorial Trillas.

Nielsen, J. (1994). 10 Usability Heuristics for User Interface Design. Nielsen Norman Group. Consultado el 15 de Junio del 2019 de https://www.nngroup.com/articles/tenusability-heuristics/

Nielsen, J. (2005). Putting A/B Testing in Its Place. Nielsen Norman Group.

Consultado el 9 de Julio del 2020 de https://www.nngroup.com/articles/puttingab-testing-in-its-place/

Nielsen, J. (2012a). Usability 101: Introduction to Usability. Nielsen Norman Group. Consultado el 5 de noviembre del 2019 de https://www.nngroup.com/articles/usabilty-101-introduction-to-usability/

Nielsen, J. (2012b). Usability 101: Introduction to Usability. Nielsen Norman Group. Consultado el 15 de junio del 2019 de https://www.nngroup.com/ articles/ quantitative-studies-how-many-users/

Nielsen, J., \& Loranger, H. (2006). Priorityzing Web Usability. California: New Riders. Nielsen, J., \& Landauer, T. (1993). A mathematical model of the finding of usability 
problems. CHI '93 Proceedings of the INTERACT '93 and CHI '93 Conference on Human Factors in Computing Systems, 206-213. https://doi.org/10.1145/169059.169166

Neurant. O., \& Arntz. G. (1944). Our private lives. London: America and Britain George G. Harrap \& Co. Ltd

Norman, D. A. (1990). The design of everyday things. New York: Doubleday.

Olaya, V. (s.f.). Sistemas de Información Geográfica. Consultado el 20 de mayo del 2018 de http://volaya.github.io/libro-sig/index.html

Olmeda-Gómez, C. (2014). Visualización de información. El profesional de la información. mayo-junio, 23, n. 3, 213-319.

Ozdemir, S. (2016). Principles of data science: learn the techniques and math you need to start making sense of your data. Birmingham, Reino Unido: Packt Publishing Consultado el 11 de Agosto del 2018 de https://bidi.uam.mx:9413/book/databases/9781785887918/2dot-types-ofdata/ch02Ivl1sec13 html?query=((definition+of+data))\#X2ludGVybmFsX0h0bW xWaWV3P3htbGIkPTk3ODE3ODU4ODc5MTgIMkZjaDAxbHZsMXNIYzA4X2h0b WwmcXVIcnk9KChkZWZpbml0aW9uJTIwb2YIMjBkYXRhKSk=

Pérez-Montoro, M. \& Golkhosravi, M (2010). Visualización de la información. Universidad de León: México.

Perurena , L. \& Moráguez, M. (2013). Usabilidad de los sitios Web, los métodos y las técnicas para la evaluación Usability of Web sites, methods and evaluation techniques. 24(2), 176-194.

Points, S. (2017). La historia de la esquemática en la visualización de datos. Visualizar Symposium. Media-Lab. Prado, Madrid, España.

Prado León, L., \& Ávila Chaurand, R. (2003). Factores ergonómicos en el diseño.

Percepción visual. Guadalajara: Universidad de Guadalajara.

Prado León, L., \& Ávila Chaurand, R. (2010). Percepción visual I. Guadalajara: Universidad de Guadalajara. 
Preim, B., \& Bartz, D. (2007). Visualization in medicine: theory, algorithms, and applications. Elsevier.

Precee, Jenny et al. (1994). Human-Computer interaction. Massachusetts: AddisonWesley.

Robinson, J. (1968). An Introduction to Early Greek Philosophy: Houghton Mifflin Company.

Rodríguez, D., Prada, M., Gaspar, R., Garrido, M. V., \& Lopes, D. (2017). Lisbon Emoji and Emoticon Database (LEED): Norms for emoji and emoticons in seven evaluative dimensions. Behavior Research Methods, 50(1), 392.

Rodríguez-Rivera, M. (2005). El Diseño de Interfaz gráfica para cursos en línea. Ciudad de México: Universidad Nacional Autónoma de México.

Romero-Medina, A. (2006). Ergonomía Cognitiva y Usabilidad. In Ergonomía. Asignatura Optativa $5^{\circ}$ Curso Licenciatura en Psicología (Vol. 2, pp. 1-20). Universidad de Mursia. Consultado el 18 de Junio del 2019 de http://www.um.es/docencia/agustinr/Tema6-0607a.pdf

Rowley, J. (2007). The wisdom hierarchy: representations of the DIKW hierarchy. Journal of Information Science. 33 (2), 163-180.

Rubin, J., \& Chisnell, D. (2008). Handbook of Usability Testing How to Plan, Design and Conduct Effective Tests (Segunda Ed). Wiley Publishing, Inc.

Scheiner, C. (1629). Rosa Ursina sive sol. S.L.

Shannon, C. (1948). A mathematical theory of communication. Bell Syst. Tech. J. 27, $379-423$

Shneiderman, B.(1996). The eyes have it: a task by data type taxonomy for information visualizations. In: Proceedings of the IEEE Symposium on Visual Languages '96. IEEE Computer Society Press: Los Alamitos

Shneiderman, B. (1998). Designing the user interface: Strategies for human-computer interaction. (Addison-Wesley, Ed.). Massachusetts: Pub Co. 
Shneiderman, B. (2005). Designing the user interface: Strategies for effective human computer interaction. In Written Communication (Cuarta Edi, Vol. 18, Issue 2). Pearson.

Shirk, G. (2005). Toward a Topography of Library Collection. In S. H. Lee (Ed.), Digital Informarion and Knowledge Managemente: New Opportunities for Research Libraries (Vol. 41, Issue 1, pp. 7-17). Taylor \& Francis Group.

Smith, F. (1975). Compression and learning: A conceptual framework for teacher. New York: Holt Rinehart and Winston.

Sunik, B. (2011). Definition of Information. BRAIN. Broad Research in Artificial Intelligence and Neuroscience, 2(4), 14-19.

Torrades, S., \& Pérez-Sut, P. (2008). Sistema visual. La percepción del mundo que nos rodea. OFFARM, 27(6), 98-102.

Torres Ponjuán, D. (2009). Aproximaciones a la visualización como disciplina científica. Revista Cubana de Información en Ciencias de la Salud (ACIMED), 20(6), 161-174.

Tufte, E. (2001). The visual display of quantitative information (Segunda Ed). Cheshiire: Graphic Press.

Universidad Oberta de Catalunya. [OUC]. (2018, Julio, 21). Visualización, percepción, diseño. Elementos de una visualización. [Archivo de video]. Consultado el 5 de mayo del 2019 https://www.youtube.com/watch?v=zJgtYMVvR48

Utrilla, P., Mazo, C., Sopena, M. C., Martínez-Bea, M., \& Domingo, R. (2009). A palaeolithic map from 13,660 calBP: engraved stone blocks from the Late Magdalenian in Abauntz Cave (Navarra, Spain). Journal of Human Evolution, 57(2), 99-111.

Valero Sancho, J. L., Catalá Domínguez, J., \& Marín Ochoa, B. E. (2014). Aproximación a una taxonomía de la visualización de datos. Revista Latina de Comunicación Social. 69, 486-507.

Velasco Santos, Perla, Laureano Cruces, Ana Lilia, Mora Torres, Marta y Herrera 
Bautista, Miguel Ángel. (octubre, 2010). Diseño de agentes pedagógicos a partir de los estilos de aprendizaje; una perspectiva a través del color. Ponencia presentada en el IV Congreso Mundial de Estilos de Aprendizaje. Tomado el 23 de Junio del 2019 del sitio http://kali.azc.uam.mx/clc/02_publicaciones/material/Dise\%C3\%B1o_de_Avata resPers pColor_10.pdf

Villafañe, J. (2006). Introducción a la teoría de la imagen. Madrid: Pirámide.

Villafañe, J., \& Mínguez, N. (2002). Principios de la teoría general de la imagen (Tercera). Madrid: Pirámide.

Vora, P. R. (2001). Internet and the world wide web. In W. Karwouski (Ed.), International encyclopedia of ergonomics and human factors. (pp. 701-704). Taylor \& Francis.

Ware, C. (2014). Information Visualization, perception for design. Estados Unidos de Norteamérica: ELSIEVER.

Weik M.H. (2000) Data Definition. Computer Science and Communications Dictionary. Springer, Boston, MA.

Wertherimer, M. (1950). Laws of organization in perceptual forms. In W. E. Ellis (Ed.), A Source Book of Gestalt Psychology (pp. 71-88). New York: The Humanities Press.

Wiklund, M. (1995). Medical Device and Equipment Design: Usability engineering and ergonomics. Florida: Taylor \& Francis Group.

Yang, Y., Saladrigas-Medina, H., \& Torres-Ponjuán, D. (2016). El proceso de la comunicación en la gestión del conocimiento. Un análisis teórico de su comportamiento a partir de dos modelos típicos. Revista Universidad y Sociedad, 8(2), 165-173.

Zunzunegui, S. (2010). Pensar la imagen (Séptima). Madrid: Cátedra. 


\section{Currículum Vitae}

Mariel García Hernández concluye sus estudios en el Doctorado en Diseño y Visualización de la Información, en la Universidad Autónoma Metropolitana Unidad Azcapotzalco, donde su línea de investigación fue la visualización de la información científica, centrándose en el área de la salud. Es Especialista en Producción Editorial y Maestra en Diseño de Información por la Universidad de las Américas Puebla y licenciada en Diseño y Producción Publicitaria por la Universidad Popular Autónoma de Puebla. Cursó el diplomado en Creación Literaria en la Escuela de Escritores SOGEM-IMACP. Ha publicado algunos cuentos en periódicos como Síntesis y algunas revistas electrónicas.

Ha trabajado como copywriter para marcas como Estrella Roja, Farmatodo, La Morena, TELCEL, y el DIF Municipal de Puebla en diversas agencias de publicidad. Ha desarrollados varios proyectos de investigación en diseño enfocado y centrado en el usuario; dentro ellos destacan temas de impacto social, como la diabetes, nutrición en edad escolar, discapacidad del lenguaje en niños, niños en situación calle y el ejercicio del voto en México. Ha publicado trabajos sobre ergonomía cognitiva, usabilidad y diseño de información en journals científicos internacionales y nacionales.

Es catedrática de tiempo parcial en la Universidad de las Américas Puebla en el departamento de Diseño de dicha universidad. Es ponente y mentora en temas empresariales de diseño y emprendimiento, imparte talleres sobre imagen corporativa, visualización de información e infografía. Fue mentora empresarial del HUB ENACTUS Tec Milenio Puebla y ha sido juez en eventos de emprendimiento en Tec de Monterrey Campus Puebla y Tec Milenio Puebla.

También es la diseñadora editorial del Journal "Studies in Gothic Fiction" para Cardiff University Press, el cual está alojado en la Universidad de Cardiff en Cardiff, Reino Unido. 


\section{Nuevas formas gráficas}

$(1765-1889)$

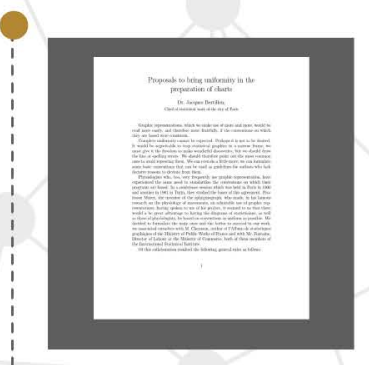

Primera línea del tiempo.

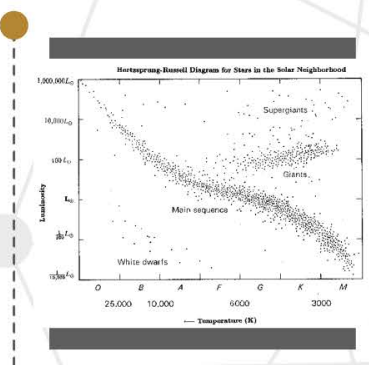

Primer mapa de tiempo (meteorológico).

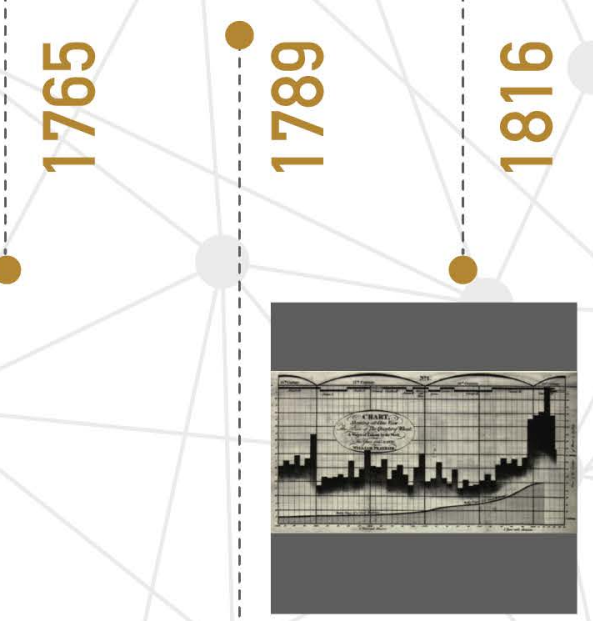

Primer registro histórico de gráfico circulares, barras

y series temporales

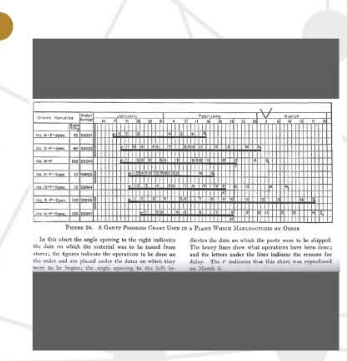

Creación del diagrama del círculo polar o diagrama de la rosa.

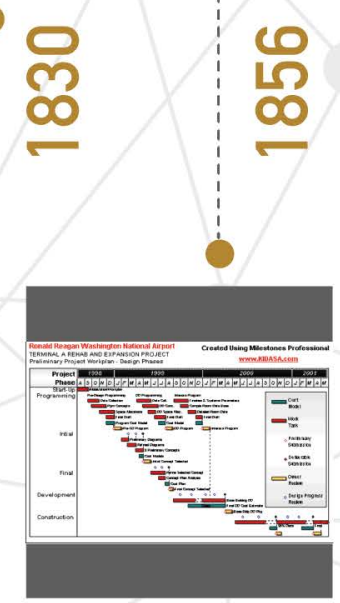

Primer mapa de puntos.

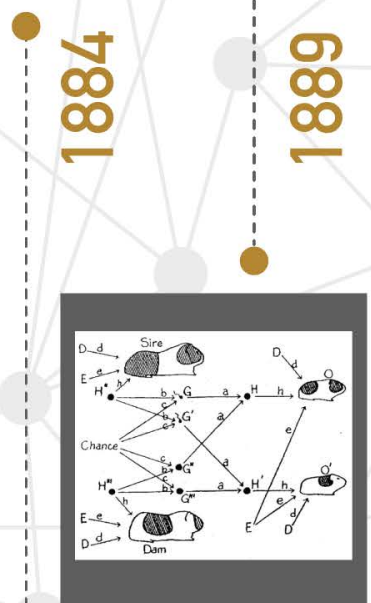

Pictogramas de Mullhal.

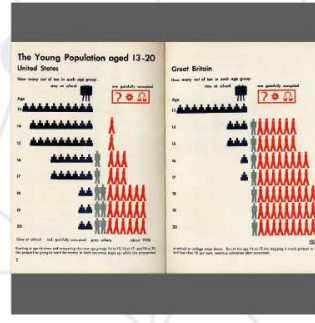

Códigos de color y mapeos.

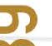

-

Figura 3. Historia de la visualización de información. Nuevas formas gráficas (1765 - 1889).

Fuente: Friendly, Michael. Denis, Daniel J. Milestones en The History of Thematic Cartography.

Statistical Graphics, and Data Visualization. York University. Canadá. 


\section{ANEXO 1. Línea del tiempo de la historia de la evolución de INFOVIS}

\section{Los primeros mapas y diagramas}

\section{(13,660 A.C. - 1375 D.C.)}

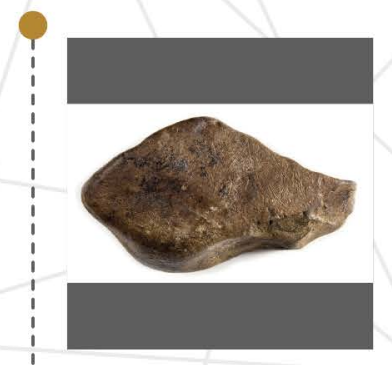

Bloque de piedra en Abauntz.

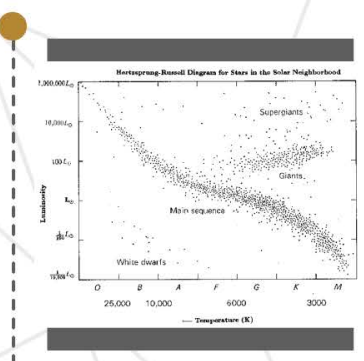

El primer mapa mundial.

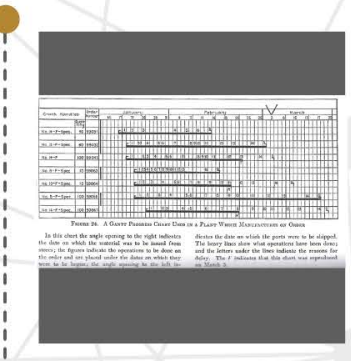

Mecanismo de Anticitera.

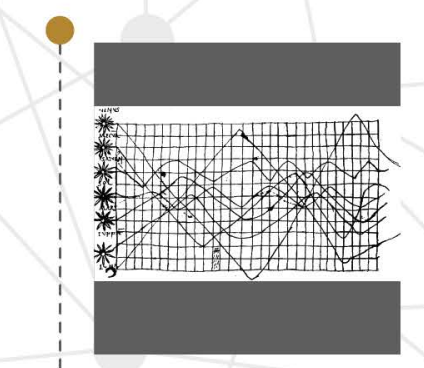

Primera construcción gráfica.

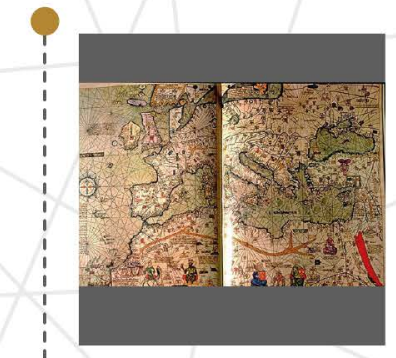

Atlas mundial de Abraham Cresques o Atlas Catalá.

0
6
6
$m$
$m$

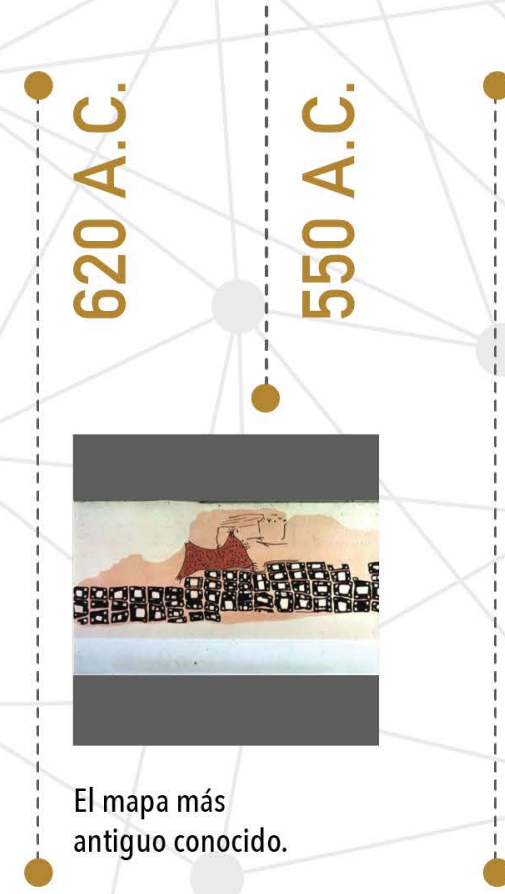

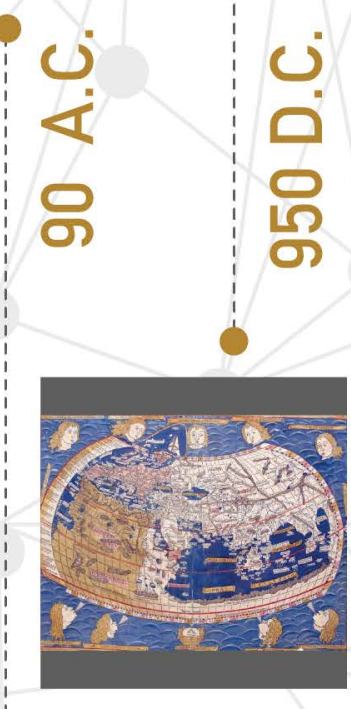

Mapa de Ptolomeo.

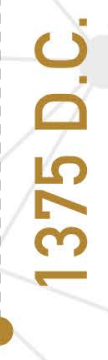

0

I

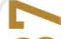

m $<$

10 m

م

m

0

西

م

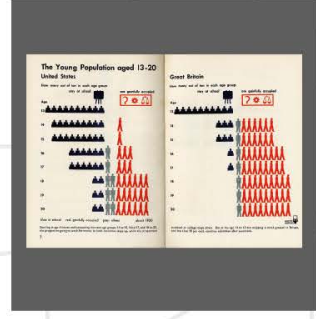

Construcción gráfica de Oresme.

Figura 1. Historia de la visualización de información.

Los primeros mapas y diagramas (13,660 A.C. - 1375 D.C).

Fuente: Friendly, Michael. Denis, Daniel J. Milestones en The History of Thematic Cartography,

Statistical Graphics, and Data Visualization. York University. Canadá. 


\section{Teoría y la medida de la realidad $(1626-1696)$}

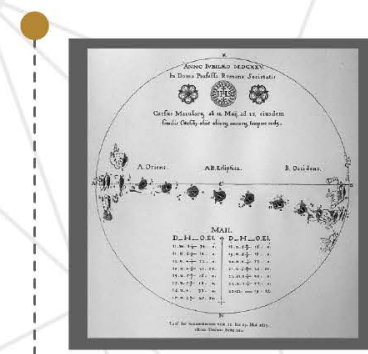

Secuencia visual de las manchas solares de Sheiner.

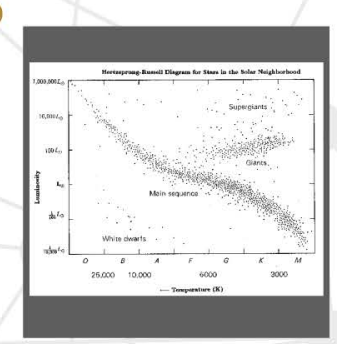

\section{"Le Geometrie"} de René Descartes.

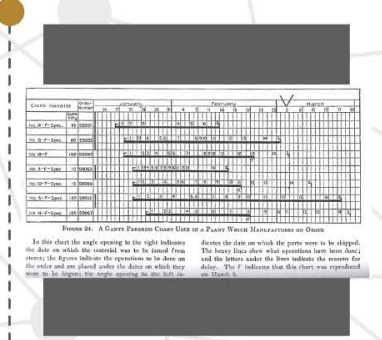

Primer mapa de datos meteorológicos.
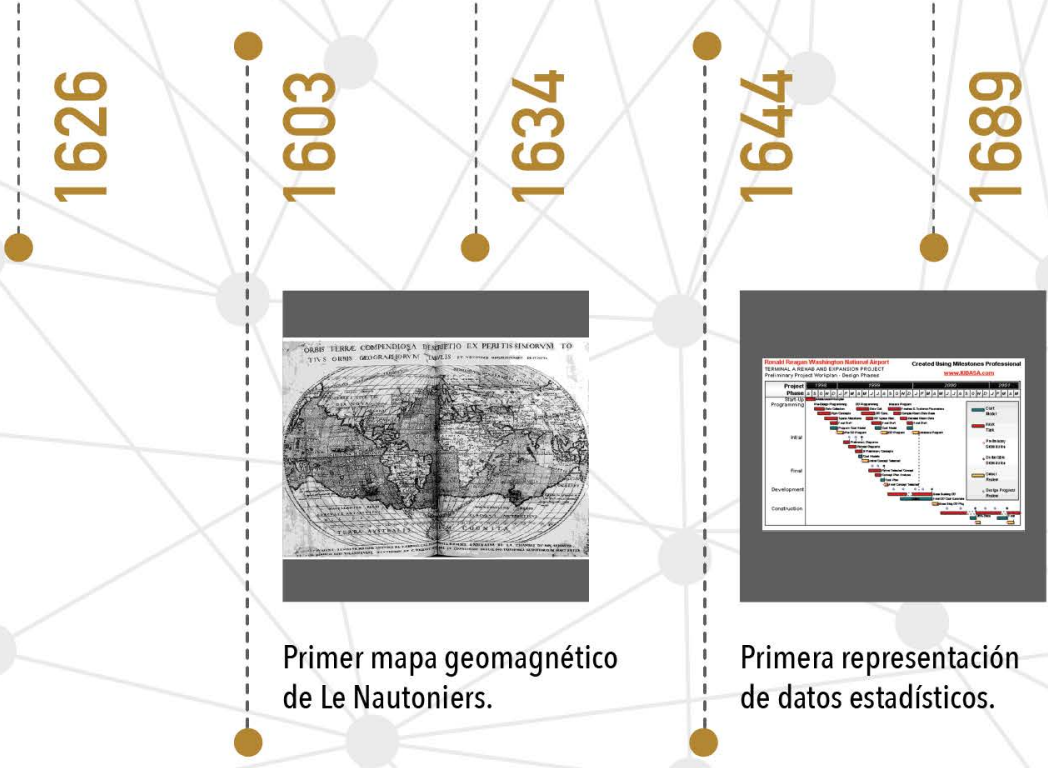

Primera representación de datos estadísticos.

Figura 2. Historia de la visualización de información.

Teoría y la medida de la realidad (1626. - 1696).

Fuente: Friendly, Michael. Denis, Daniel J. Milestones en The History of Thematic Cartography, Statistical Graphics, and Data Visualization. York University, Canadá. 


\section{Nuevas formas gráficas}

(1765 - 1889)

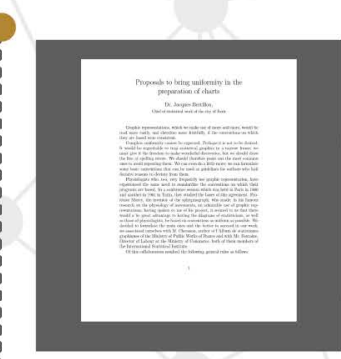

Primera línea del tiempo.

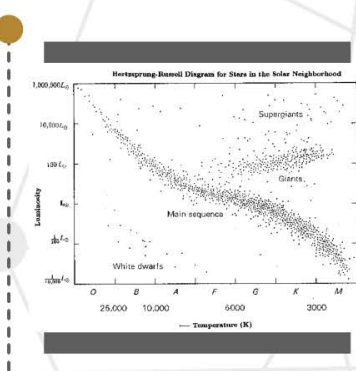

Primer mapa de tiempo (meteorológico).

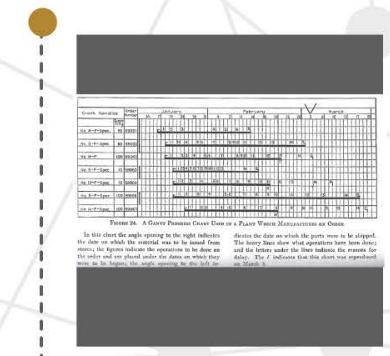

Creación del diagrama del círculo polar o diagrama de la rosa.

o

$\infty$

18

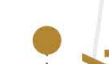

$+$

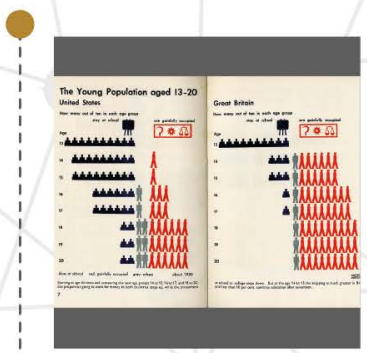

Códigos de color y mapeos.

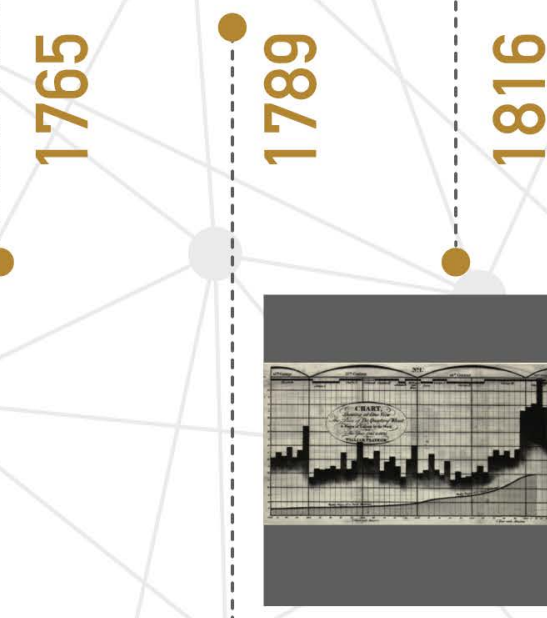

Primer registro histórico de gráfico circulares, barras

y series temporales

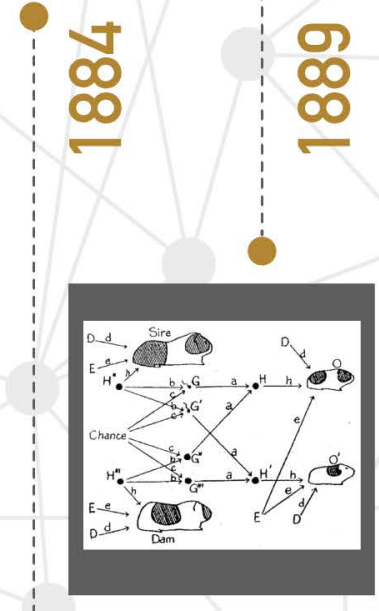

Pictogramas de Mullhal.

Primer mapa de puntos.

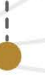

Figura 3. Historia de la visualización de información. Nuevas formas gráficas (1765 - 1889). Fuente: Friendly, Michael. Denis, Daniel J. Milestones en The History of Thematic Cartography. Statistical Graphics, and Data Visualization. York University, Canadá. 

ANEXO 2. Categorías de las figuras de visualización de información.

\section{FIGURAS DEL MÉTODO DE VISUALIZACIÓN DE CONCEPTOS}

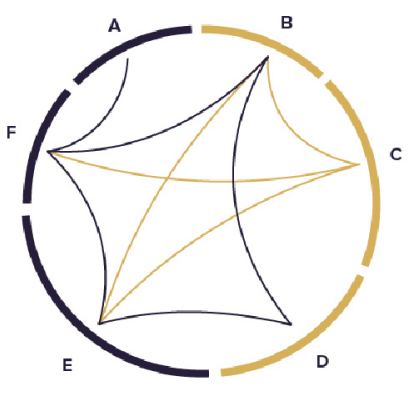

Diagrama de acorde sin cinta

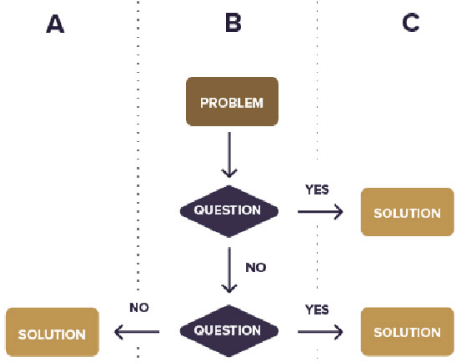

Diagrama de funciones cruzadas

\begin{tabular}{|l|l|l|l|}
\cline { 2 - 4 } \multicolumn{1}{c|}{} & $\mathbf{1}$ & $\mathbf{2}$ & $\mathbf{3}$ \\
\hline A & & & \\
\hline B & & $\bigcirc$ & \\
\hline C & 0 & & \\
\hline
\end{tabular}

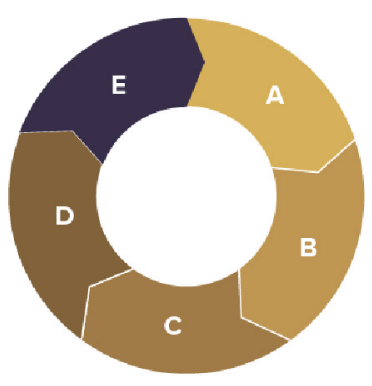

Diagrama de ciclo

A

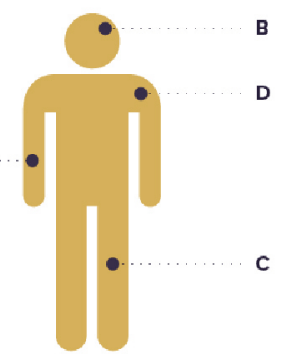

Diagrama de ilustración

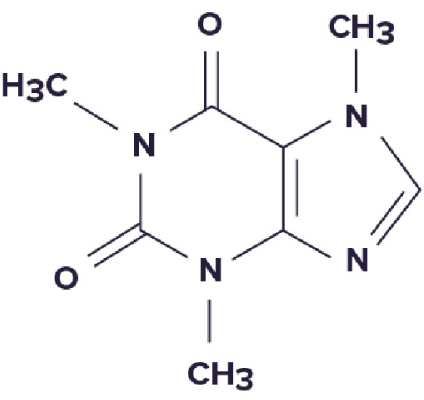

Diagrama de molécula

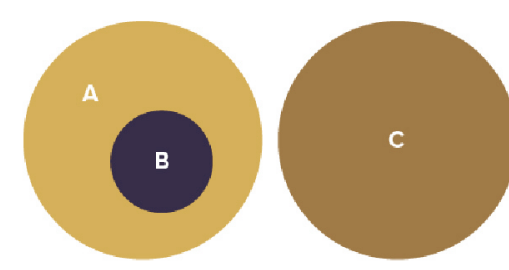

Diagrama de Euler

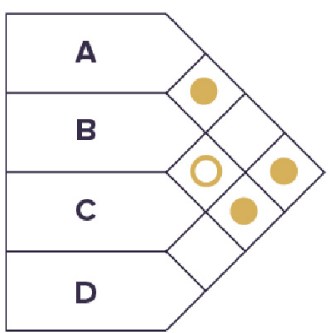

Diagrama de matriz (en forma de techo)

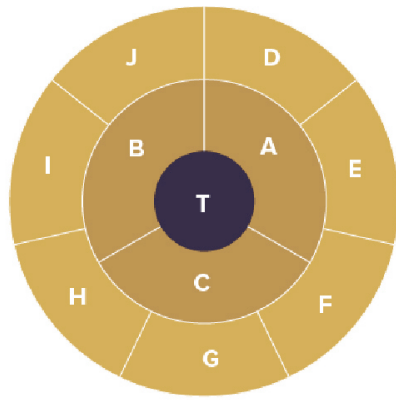

Diagrama de objetivos
A

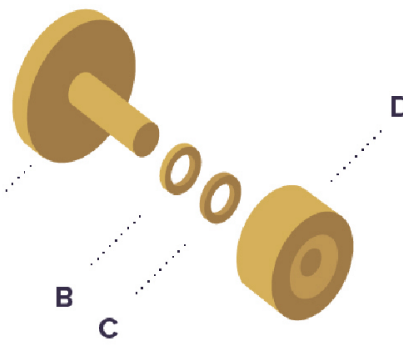

Diagrama de explicación

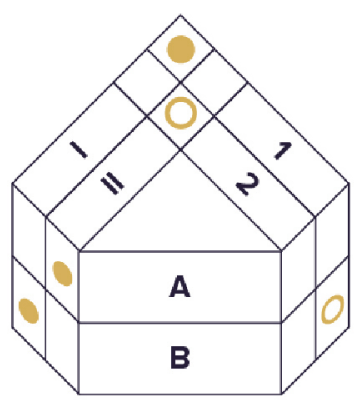

Diagrama de Matriz (En Y)

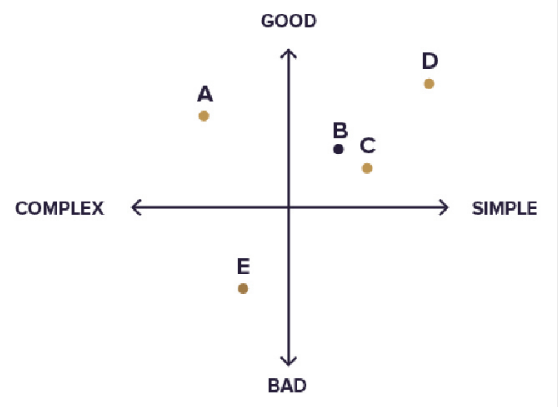

Diagrama opuesto 


\section{FIGURAS DEL MÉTODO DE VISUALIZACIÓN DE CONCEPTOS}

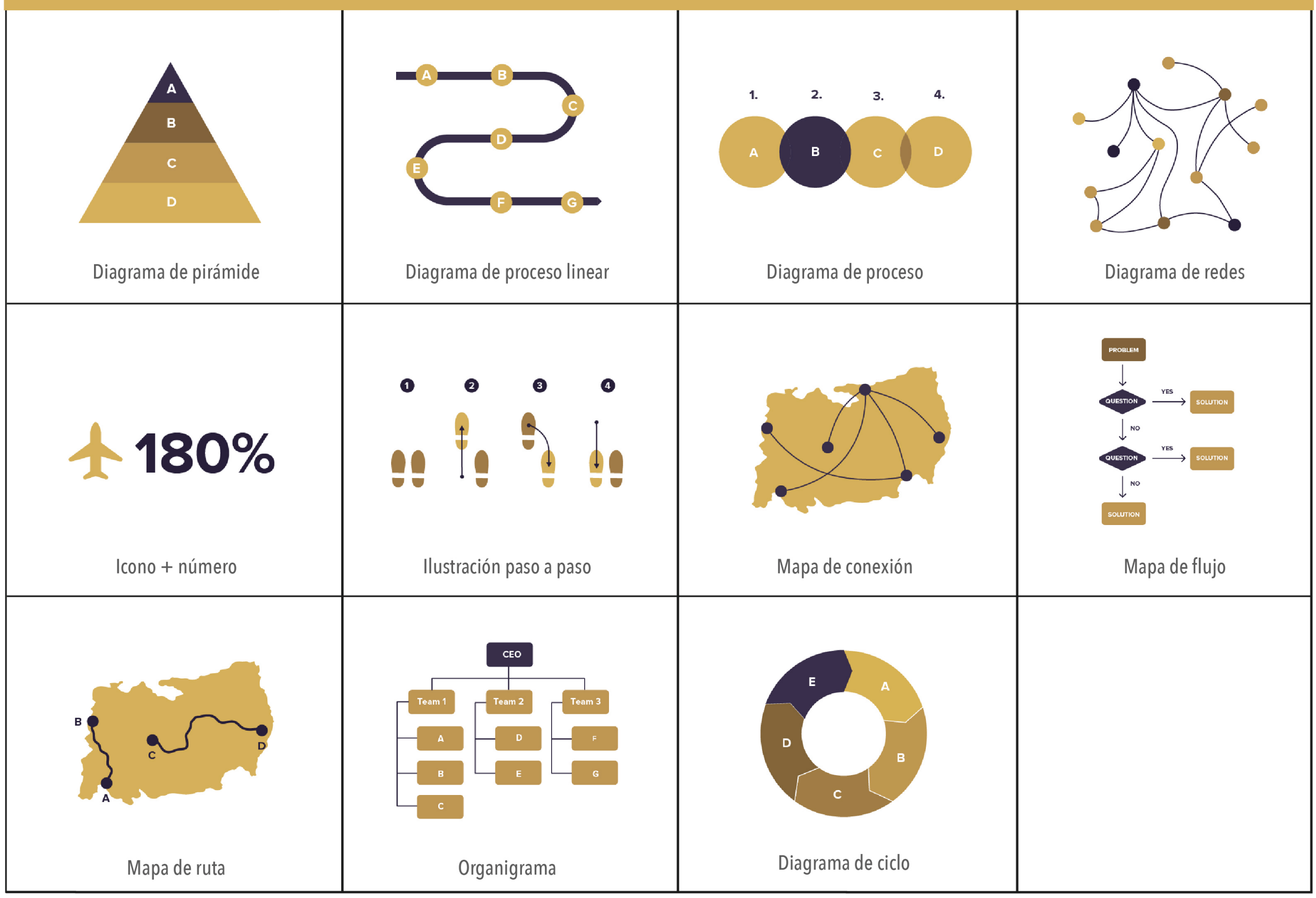




\section{FIGURAS DEL MÉTODO DE CORRELACIÓN}

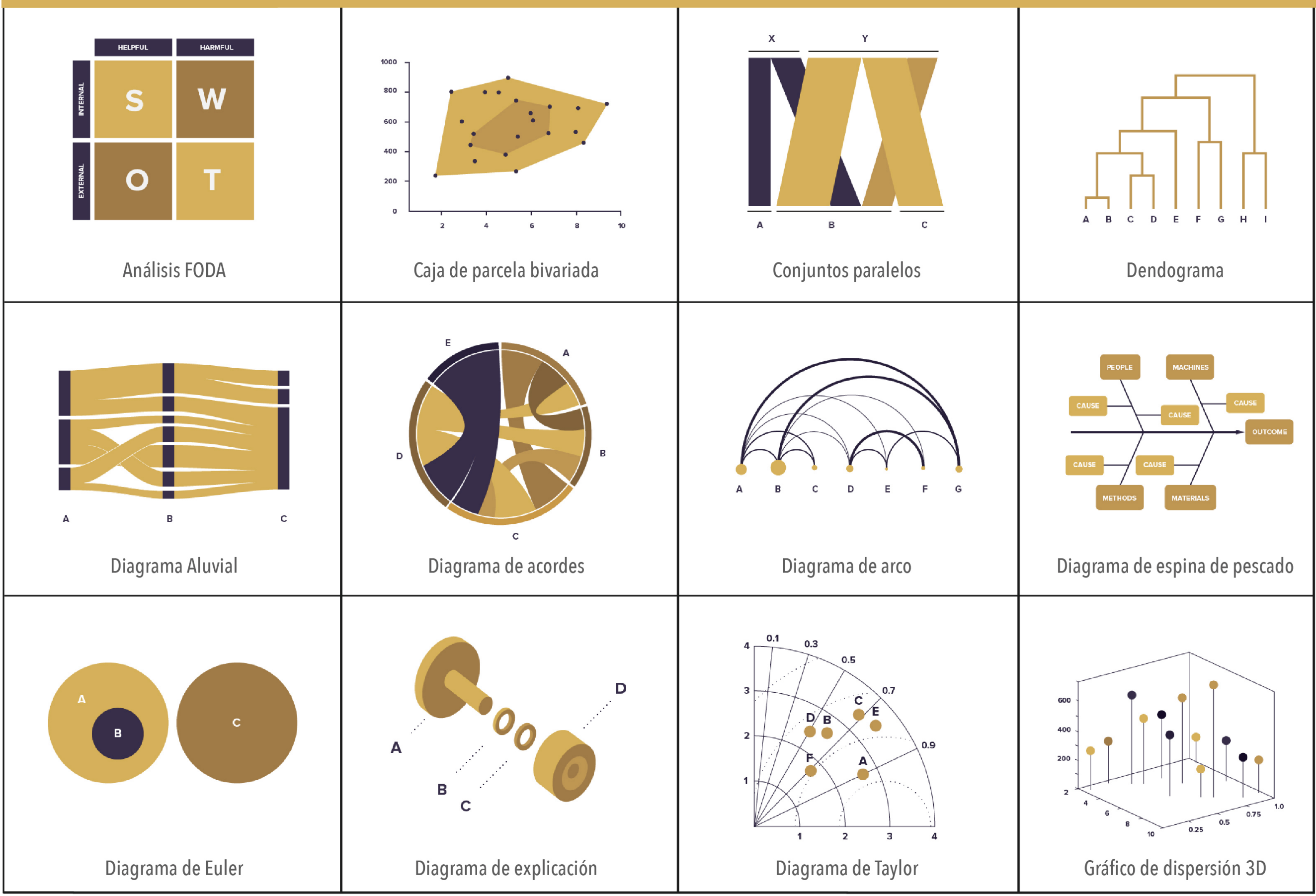




\section{FIGURAS DEL MÉTODO DE CORRELACIÓN}

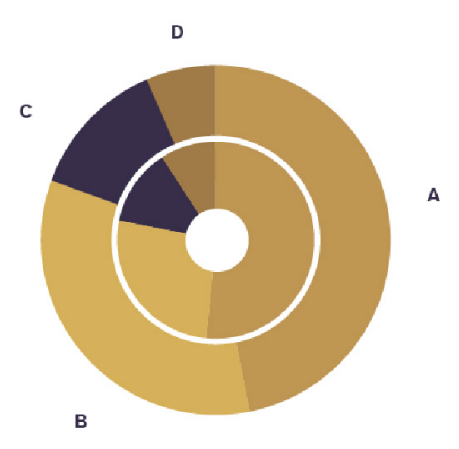

Gráfico de dona o de anillos multinivel

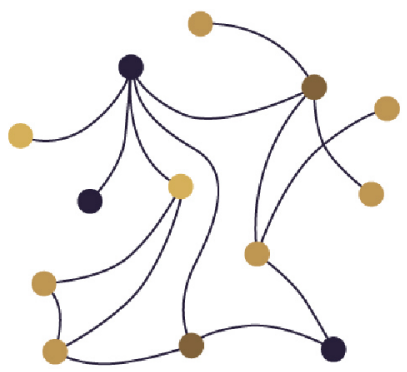

Gráfico de red

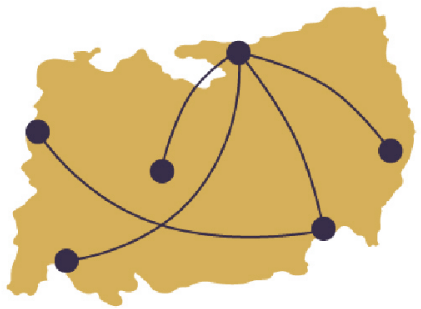

Mapa de conexión

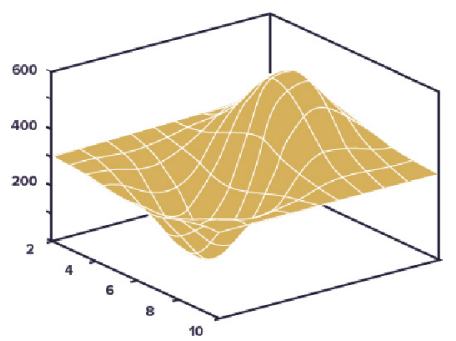

Gráfico de flujo tridimensional
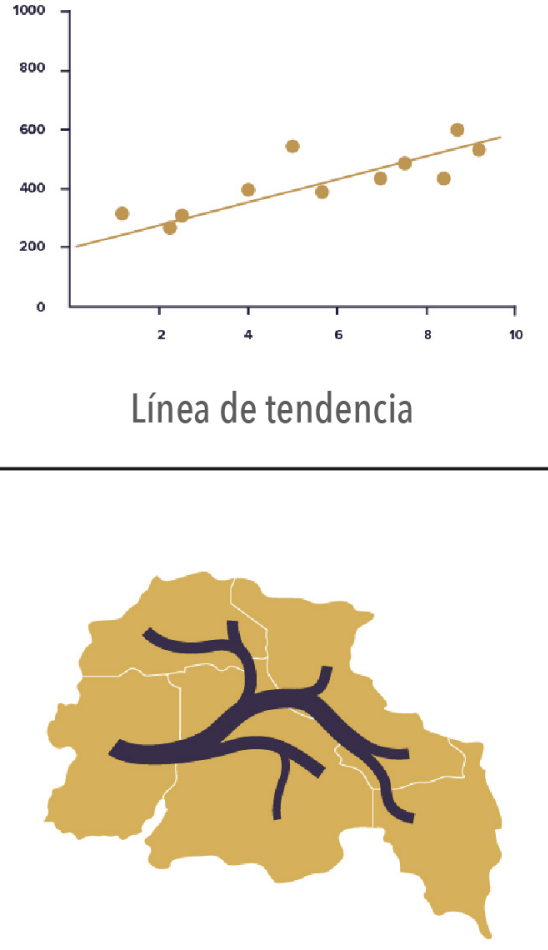

Mapa de flujo

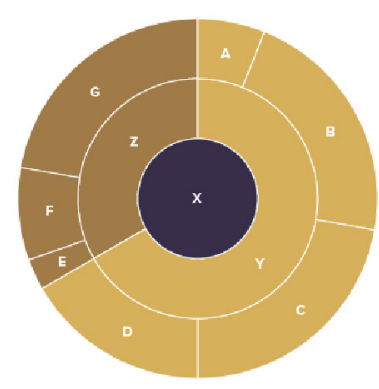

Gráfico de pastel multinivel

A B C D

Gráfico de puntos conectados

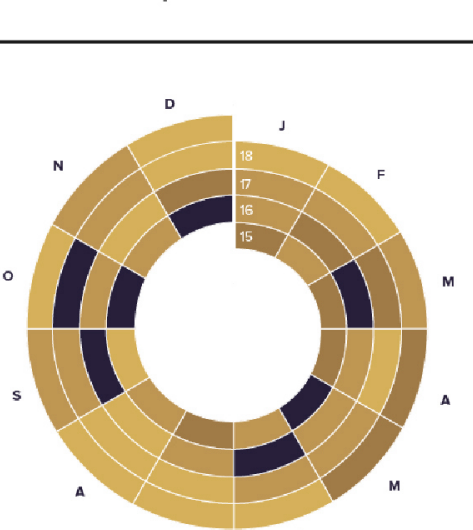

Mapa de calor en espiral

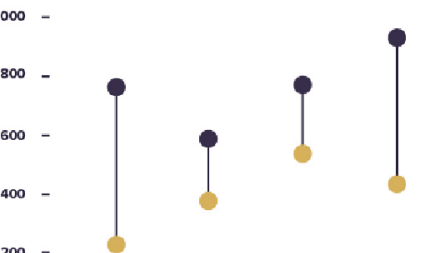

$200-$
Mapa de calor circular

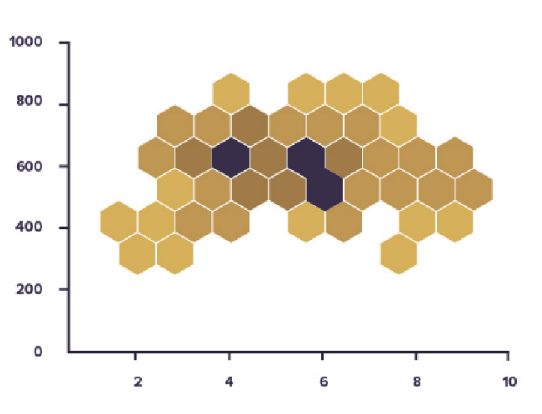

Parcela de cubo hexagonal

Red Radial 


\section{FIGURAS DEL MÉTODO DE CORRELACIÓN}

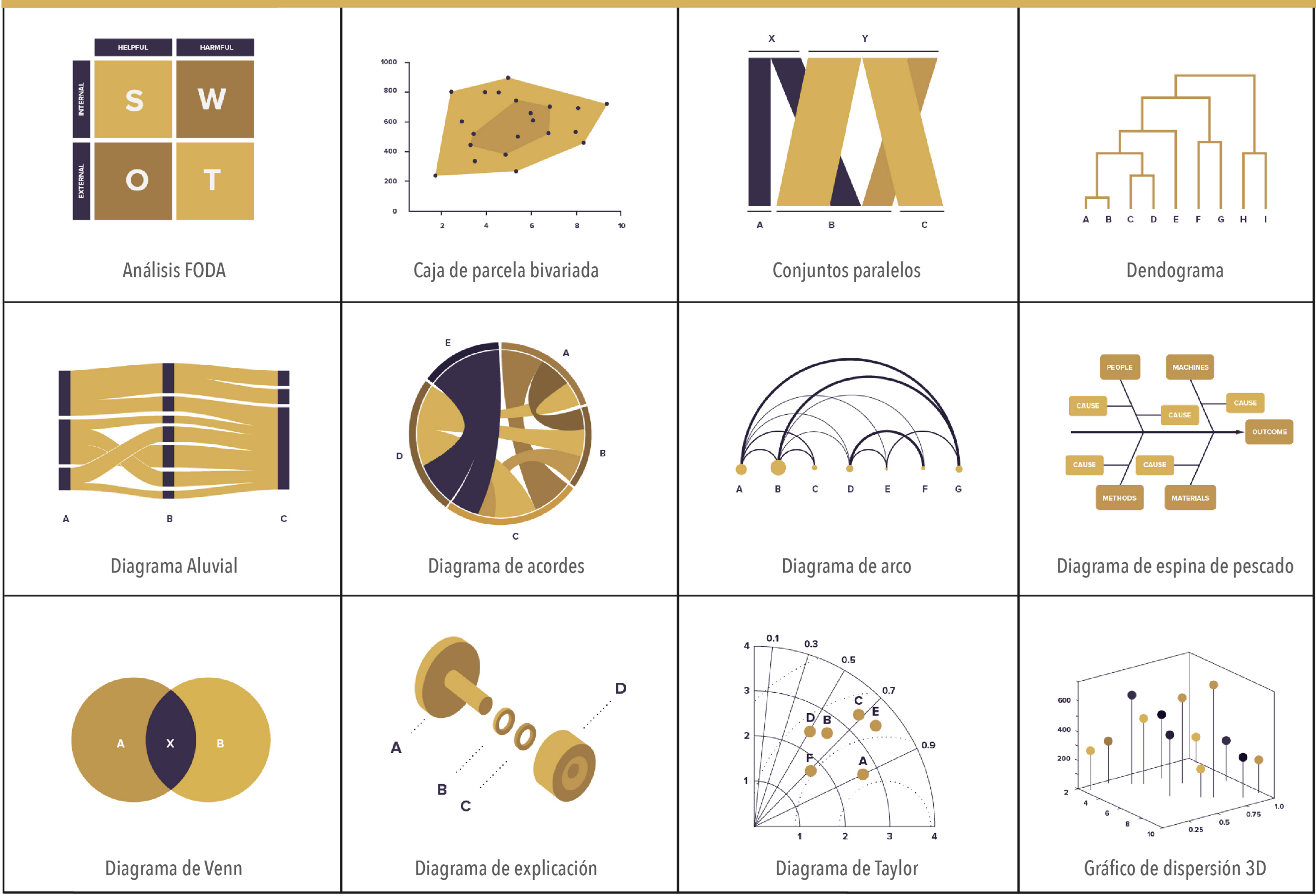




\section{FIGURAS DEL MÉTODO DE CORRELACIÓN}

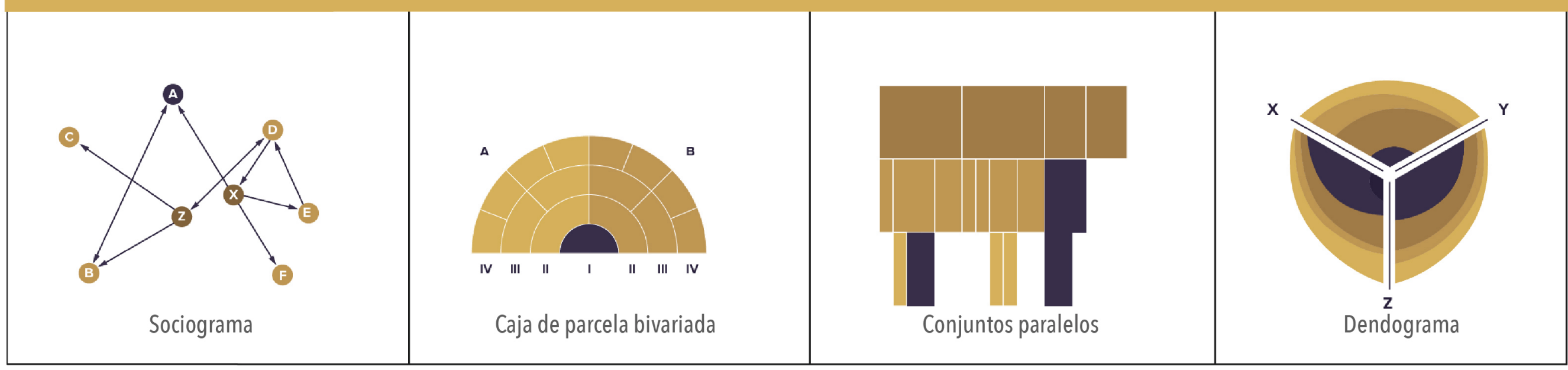




\section{FIGURAS DEL MÉTODO PARTE DEL TODO}

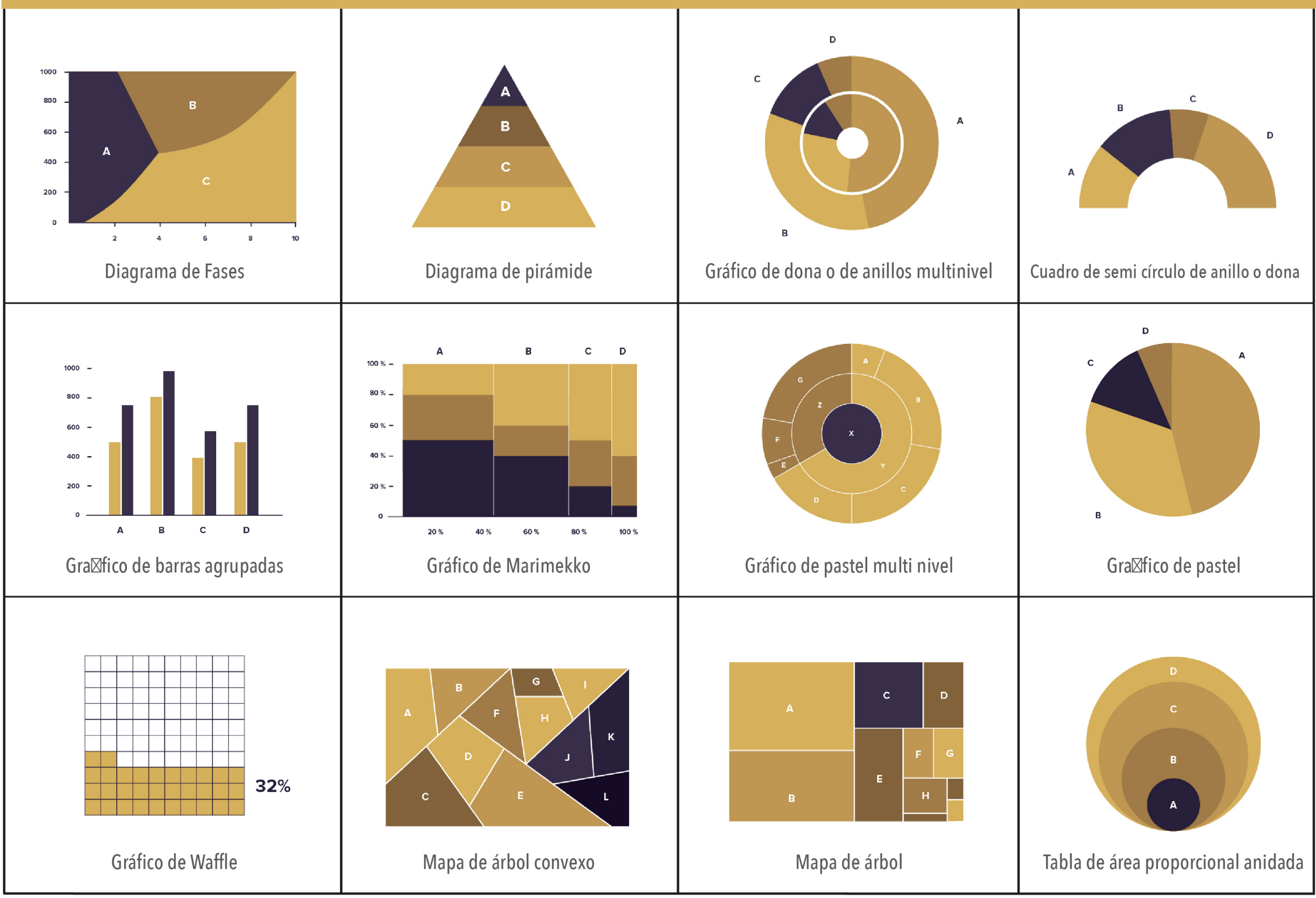




\section{FIGURAS DEL MÉTODO DE DISTRIBUCIÓN}

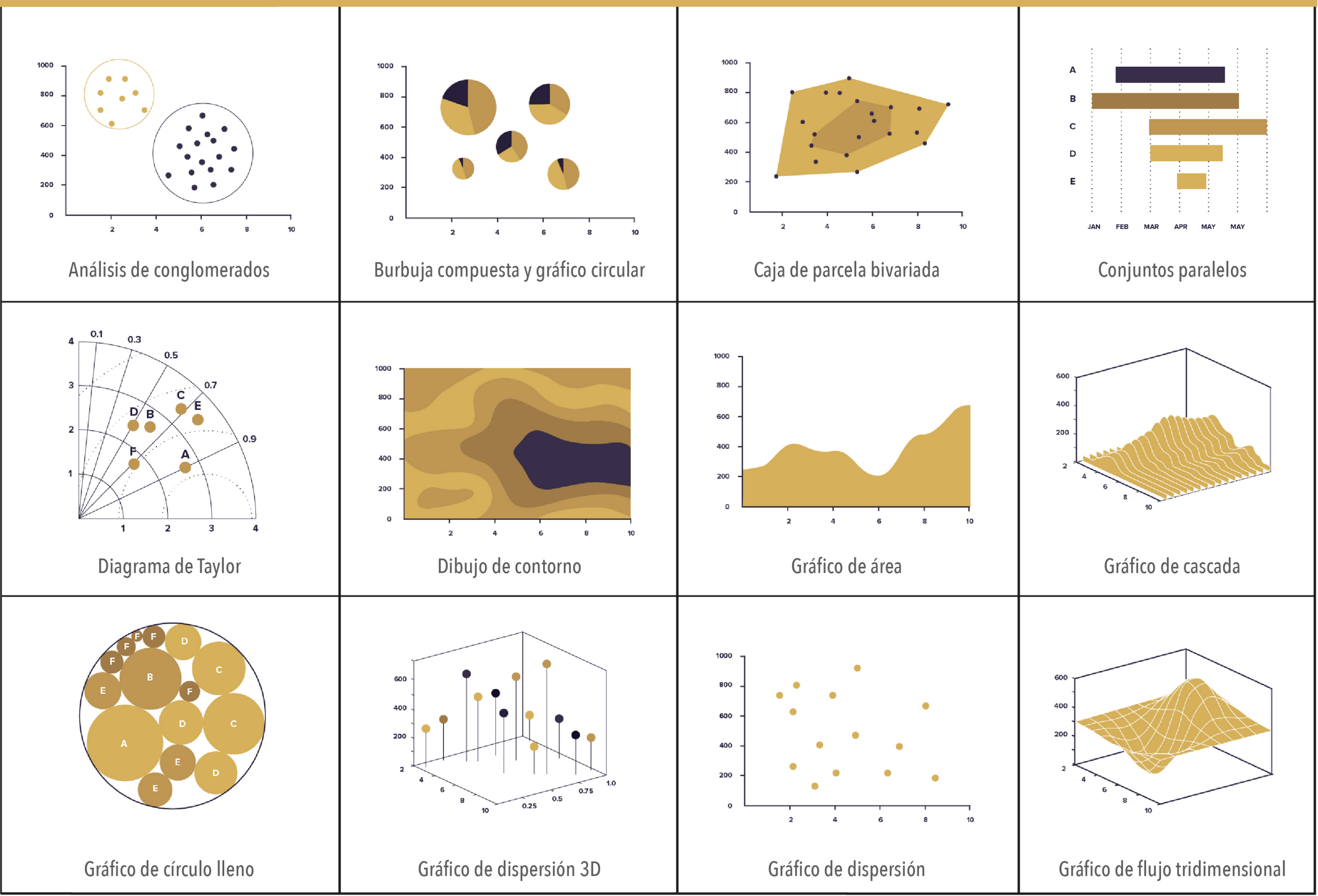




\section{FIGURAS DEL MÉTOODO DE DISTRIBUCIÓN}

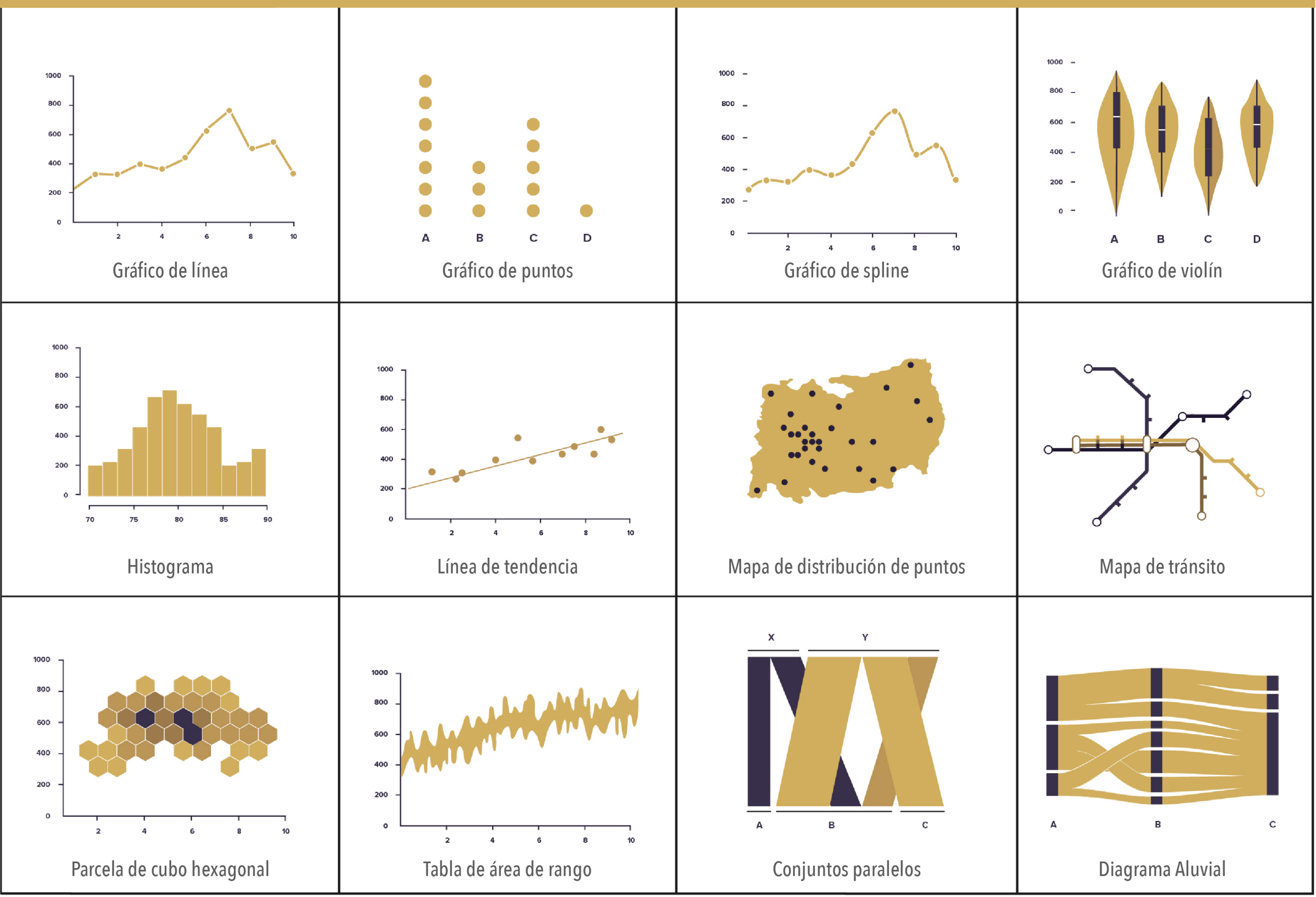




\section{FIGURAS DEL MÉTODO DE DISTRIBUCIÓN}

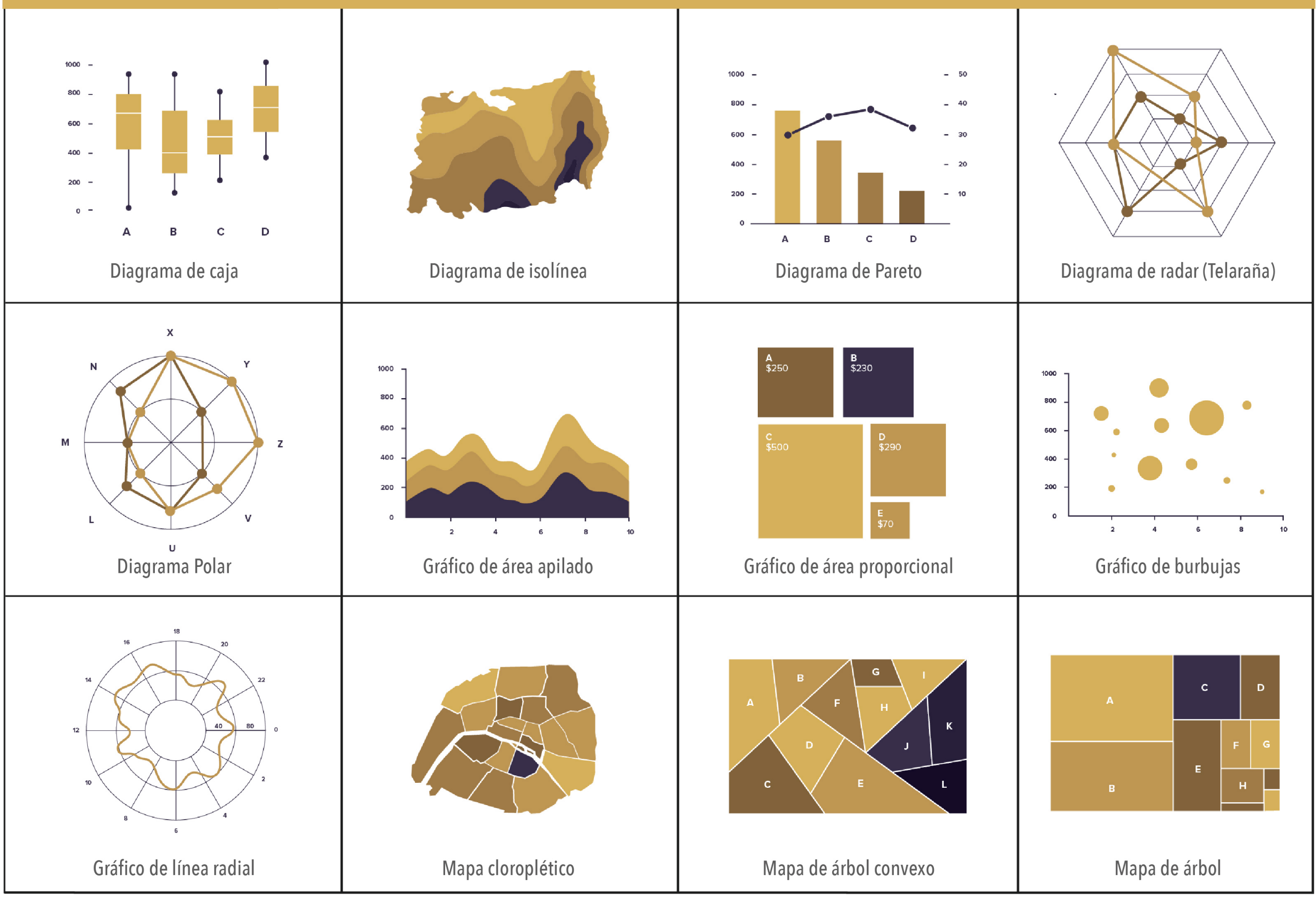




\section{FIGURAS DEL MÉTOODO DE DISTRIBUCIÓN}

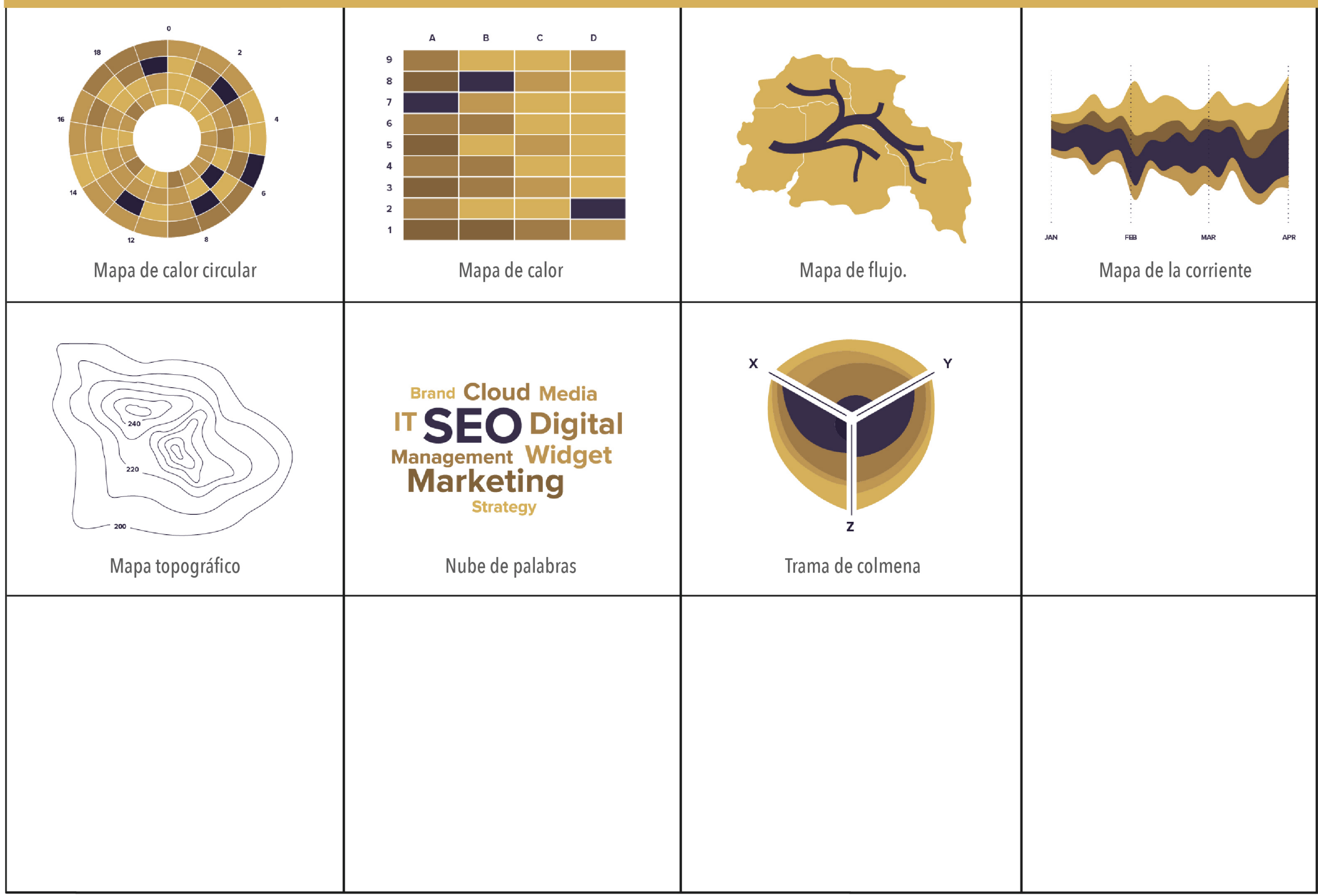




\section{FIGURAS DEL MÉTODO DE TENDENCIA A TRAVÉS DEL TIEMPO}

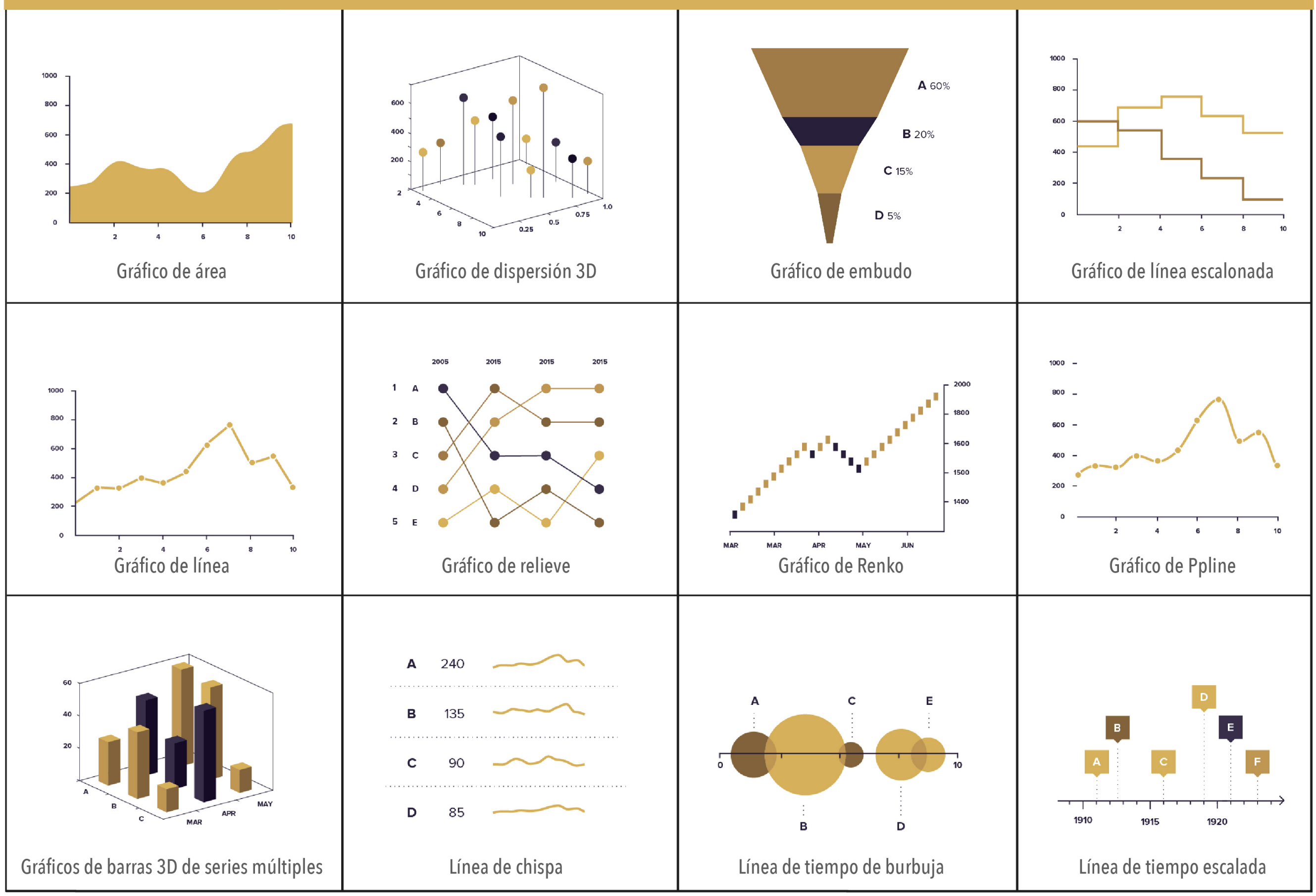




\section{FIGURAS DEL MÉTODO DE TENDENCIA A TRAVÉS DEL TIEMPO}

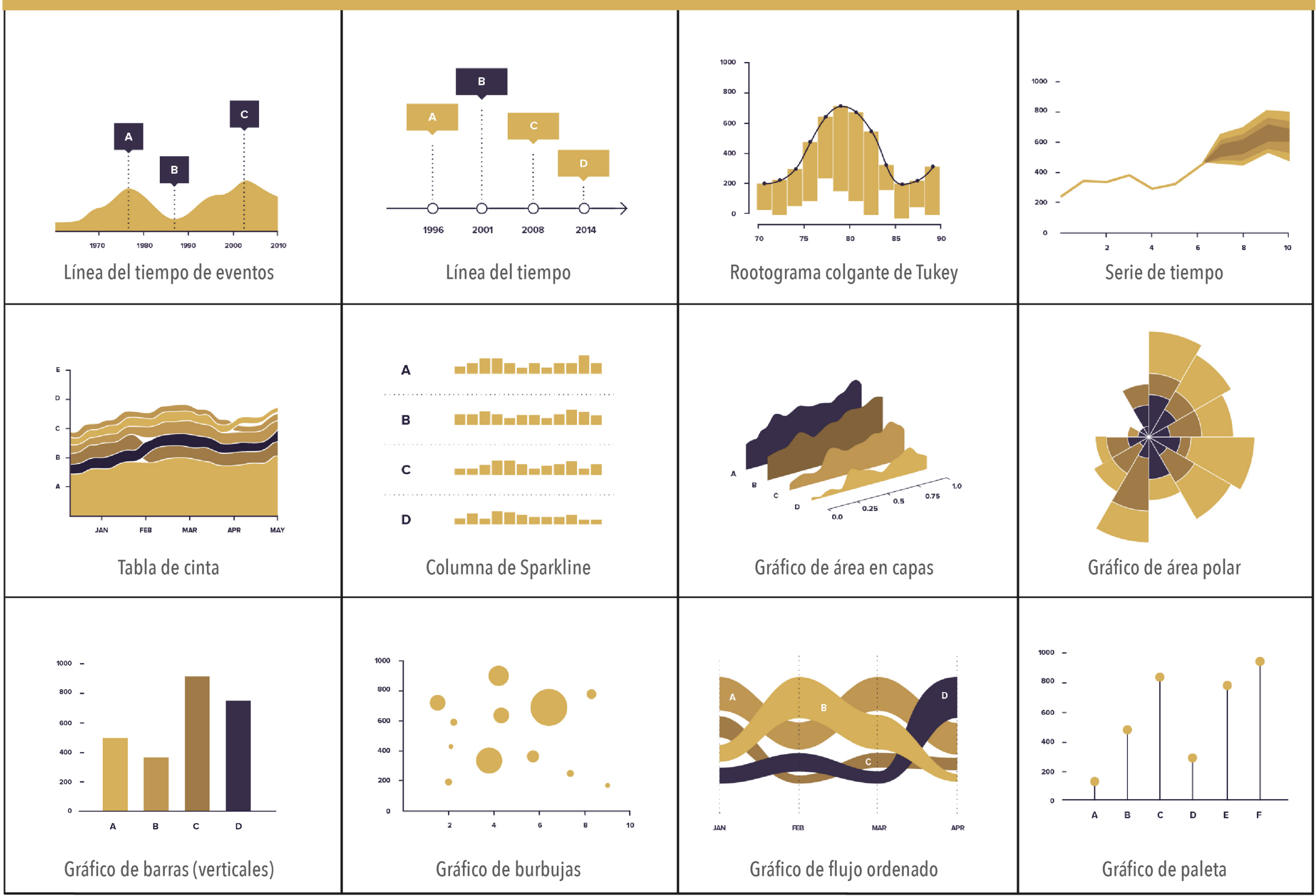




\section{FIGURAS DEL MÉTODO DE TENDENCIA A TRAVÉS DEL TIEMPO}

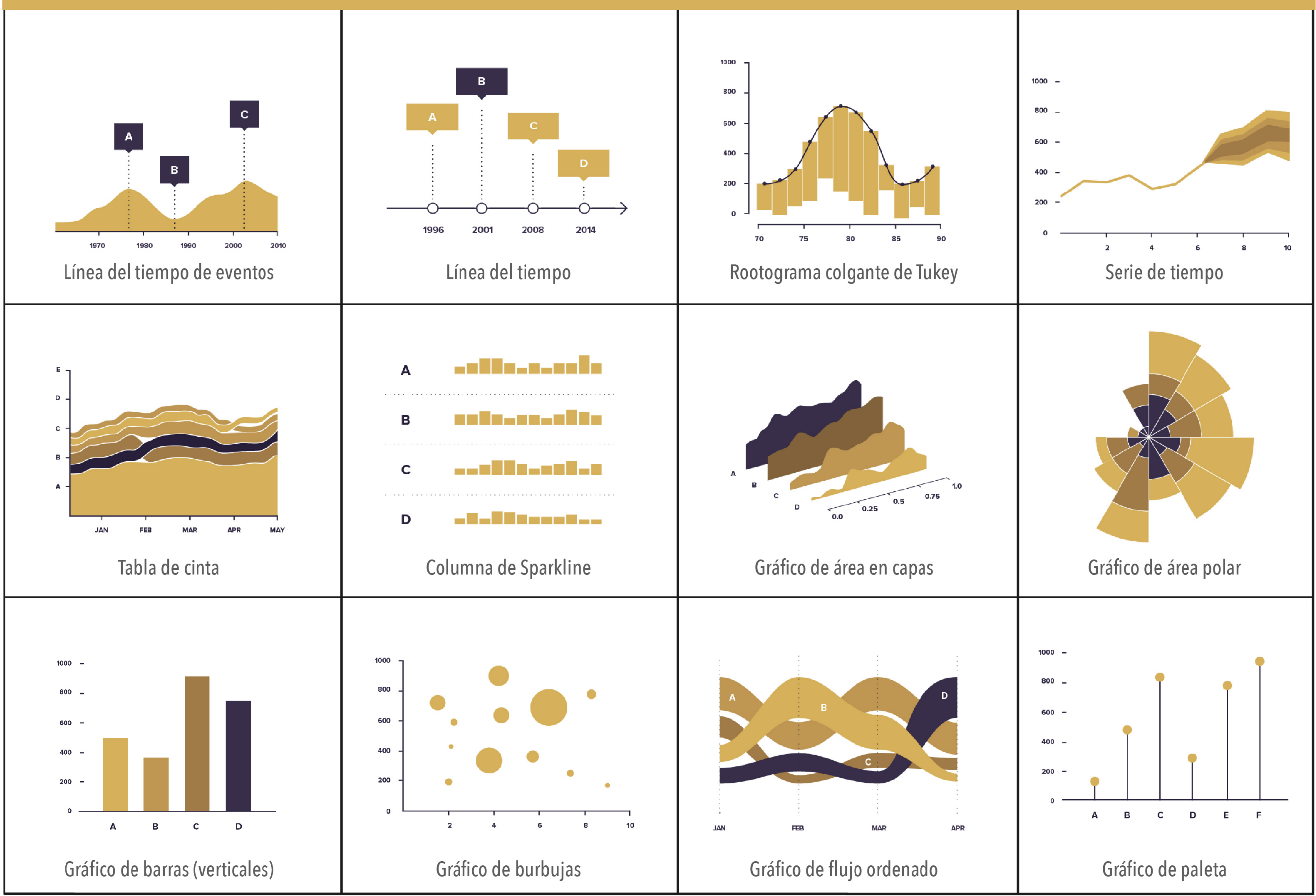




\section{FIGURAS DEL MÉTODO DE TENDENCIA A TRAVÉS DEL TIEMPO}

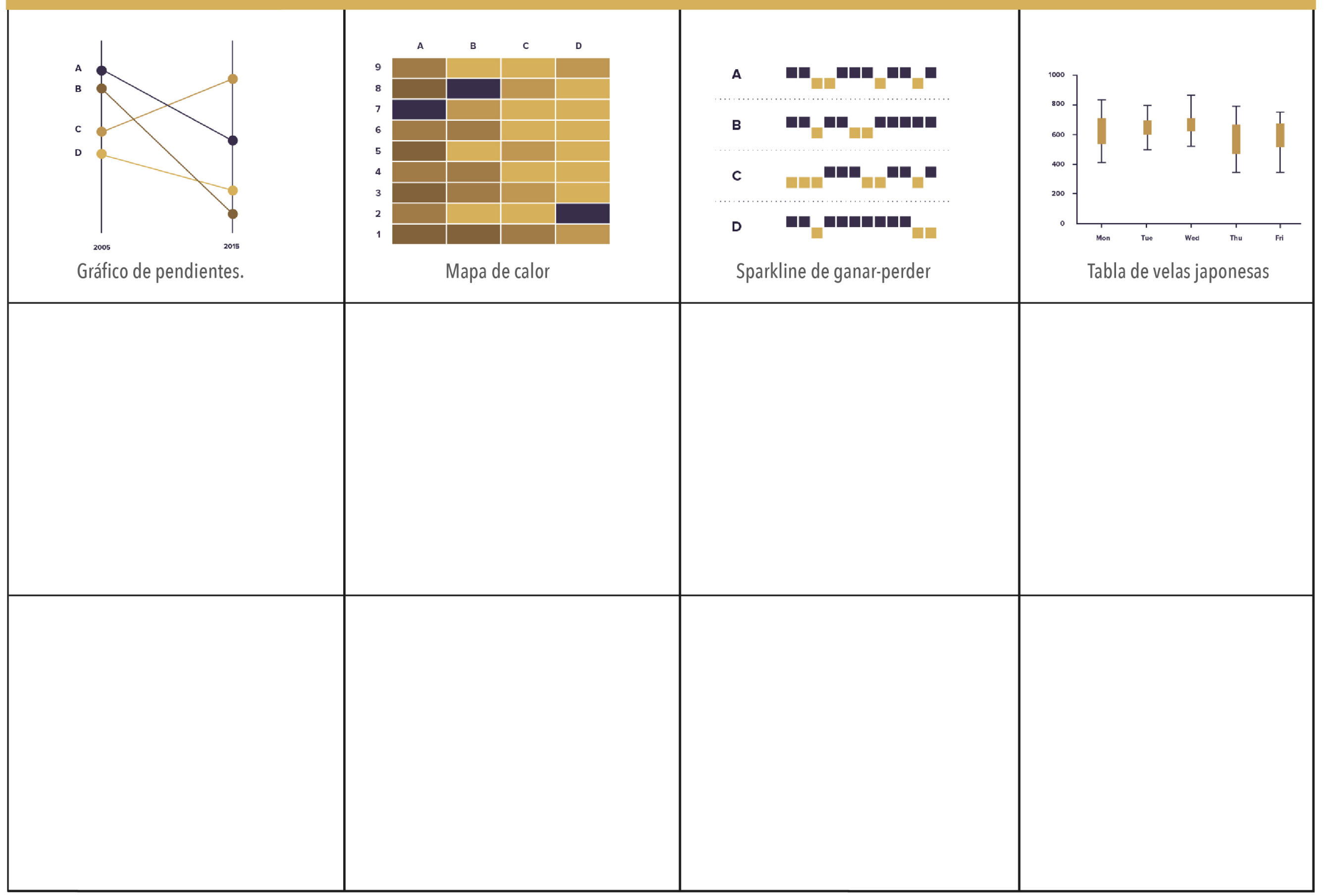




\section{FIGURAS DEL MÉTODO DE DATOS GEOGRÁFICOS}

\begin{tabular}{|l|l|l|}
\hline Mapa de pines & Gáfico de barras en un mapa \\
\hline Mapa cloroplético & Mapa de grático circular & \\
\hline
\end{tabular}




\section{FIGURAS DEL MÉTODO DE CÓMO FUNCIONAN LAS COSAS}

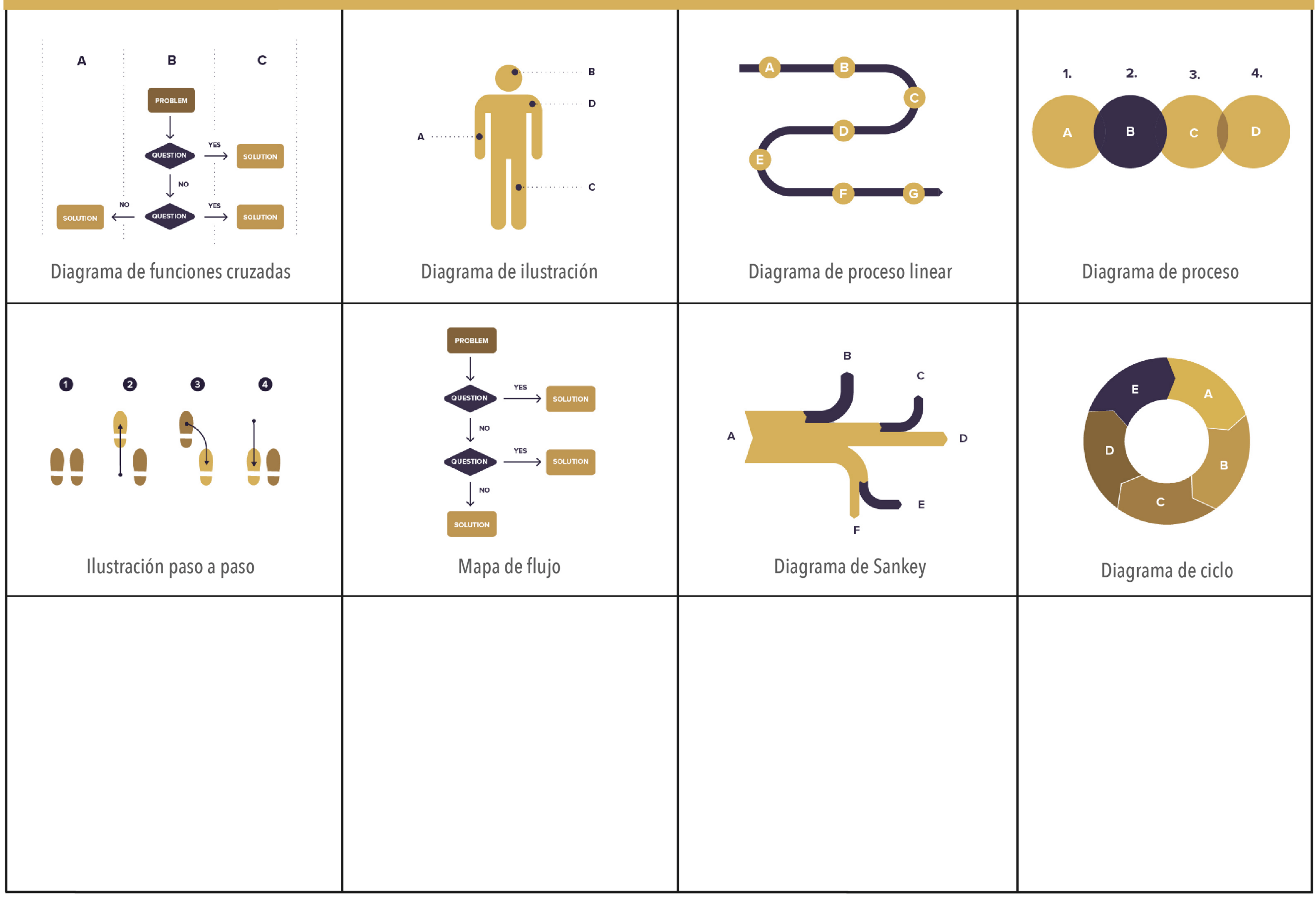




\section{FIGURAS DEL MÉTODO DE PROCESOS Y MÉTODOS}

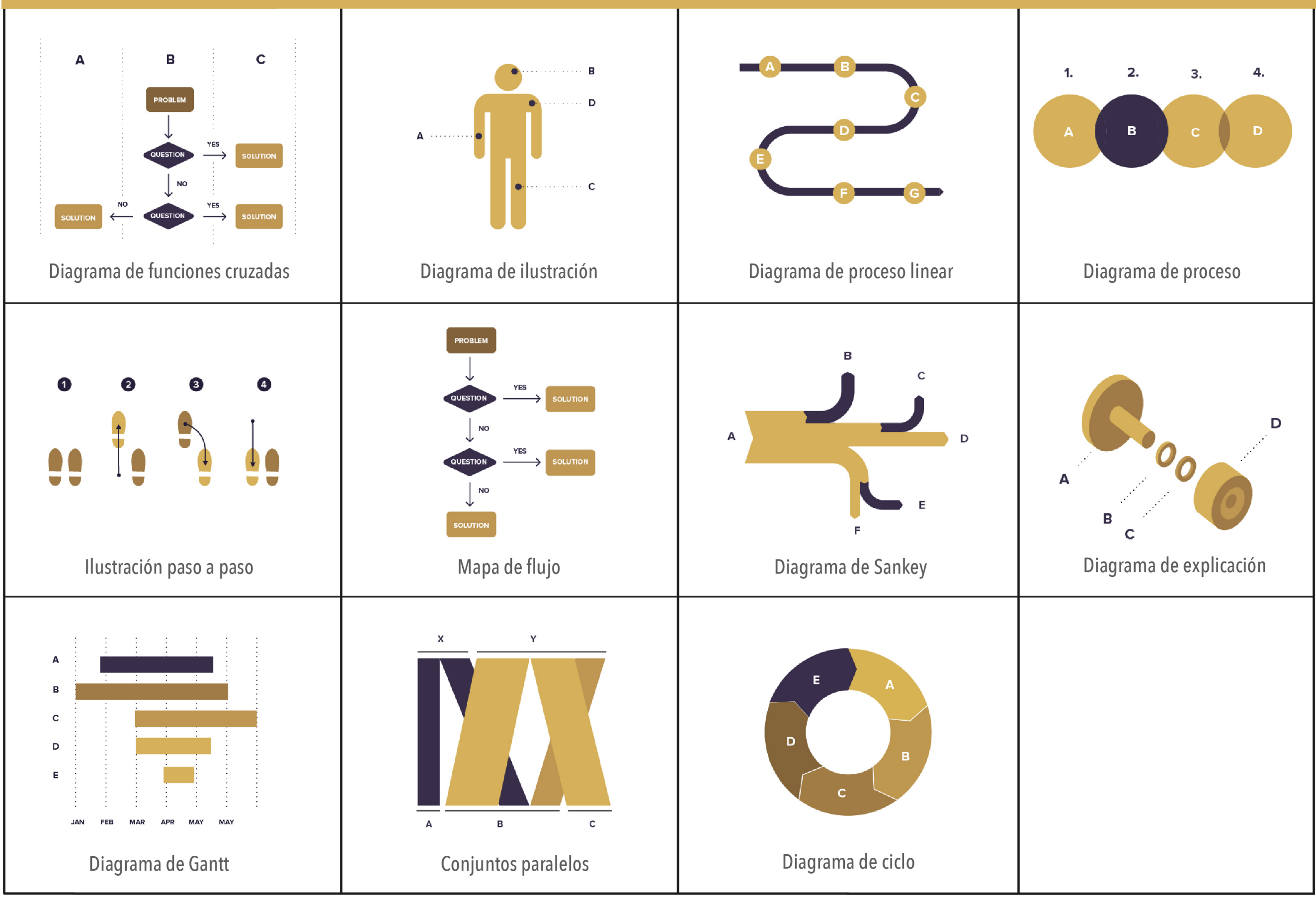




\section{FIGURAS DEL MÉTODO DE MOVIMIENTO Y FLUJO}

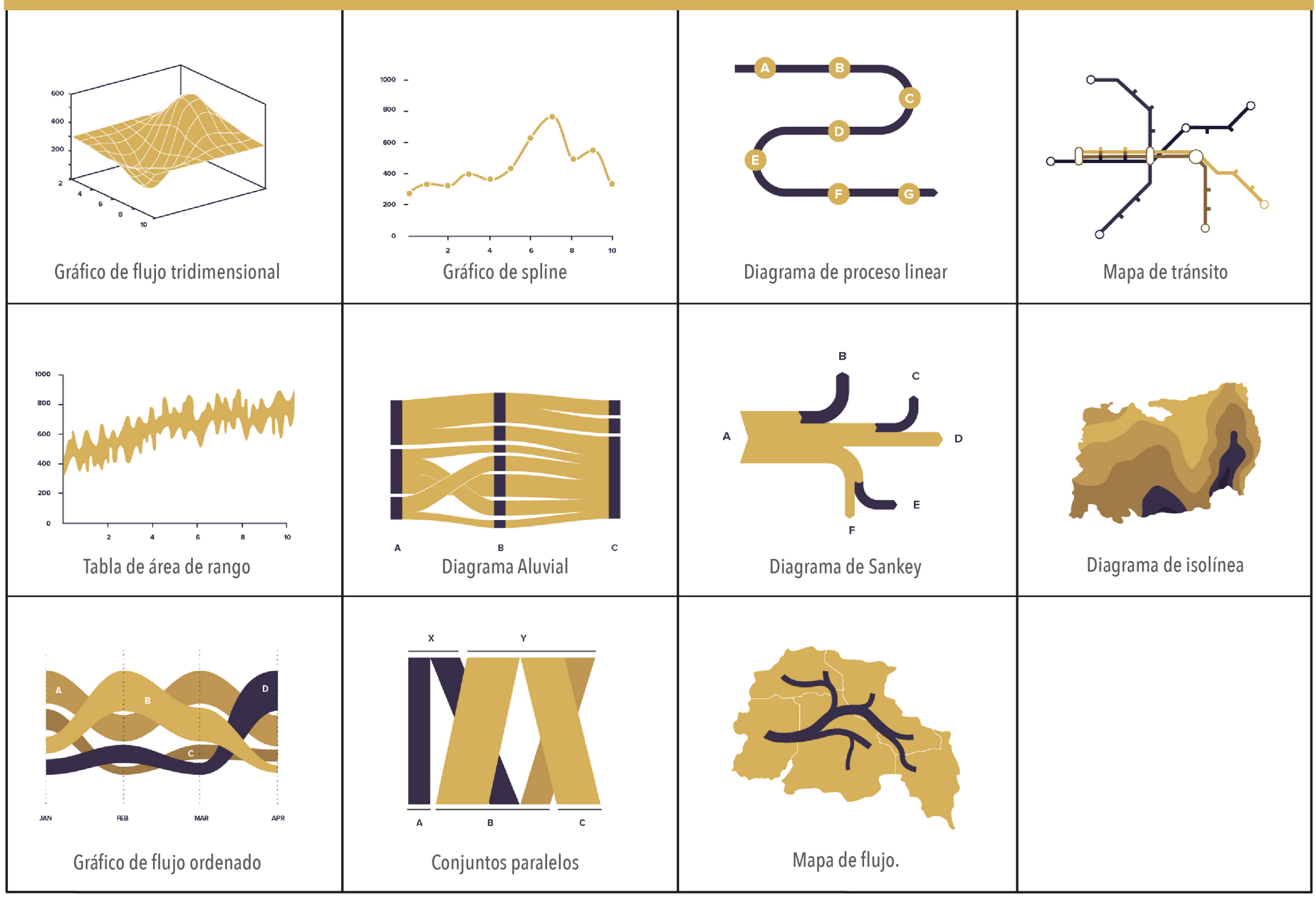




\section{FIGURAS DEL MÉTODO DE JERARQUÍA}

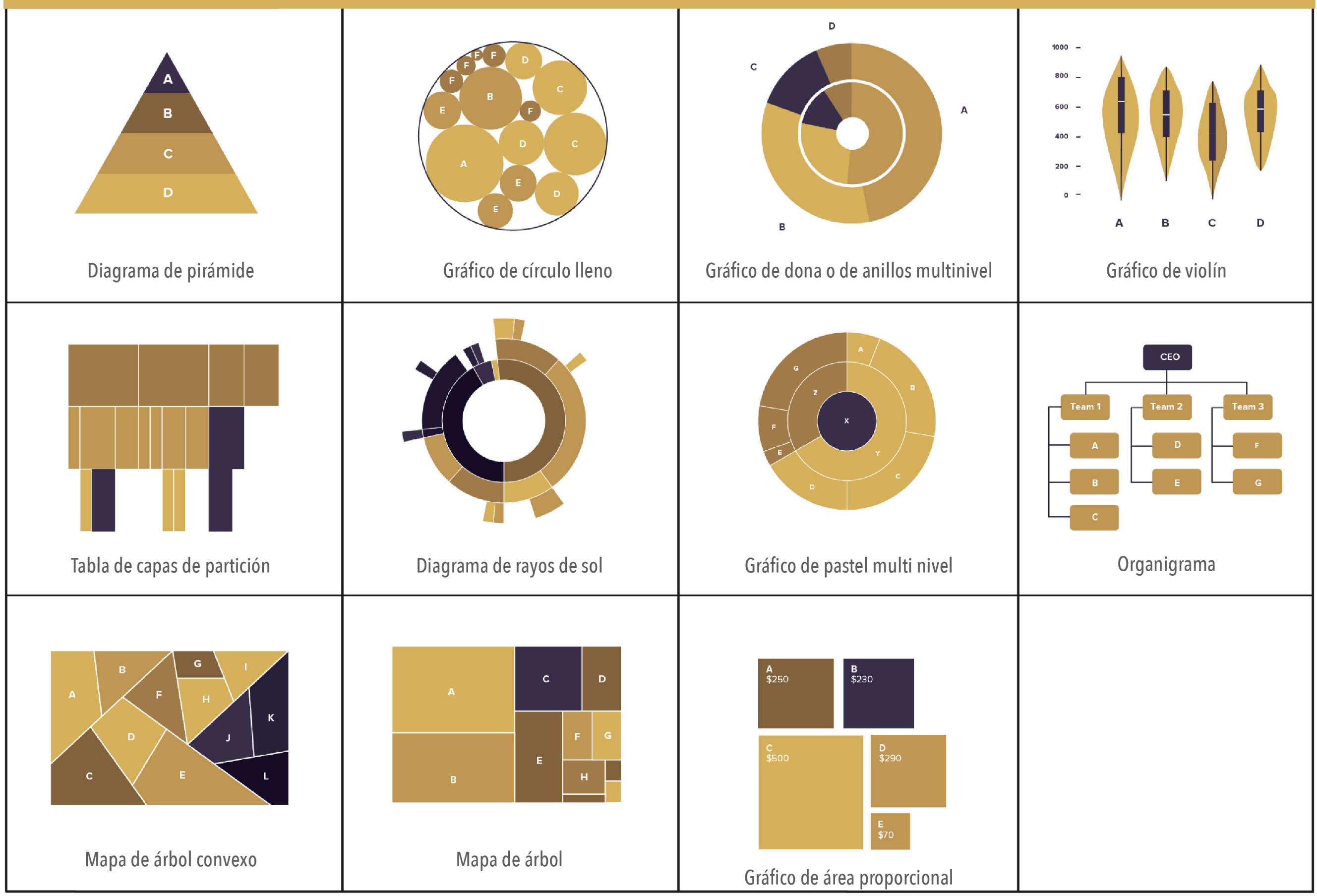




\section{FIGURAS DEL MÉTODO DE RANGO}

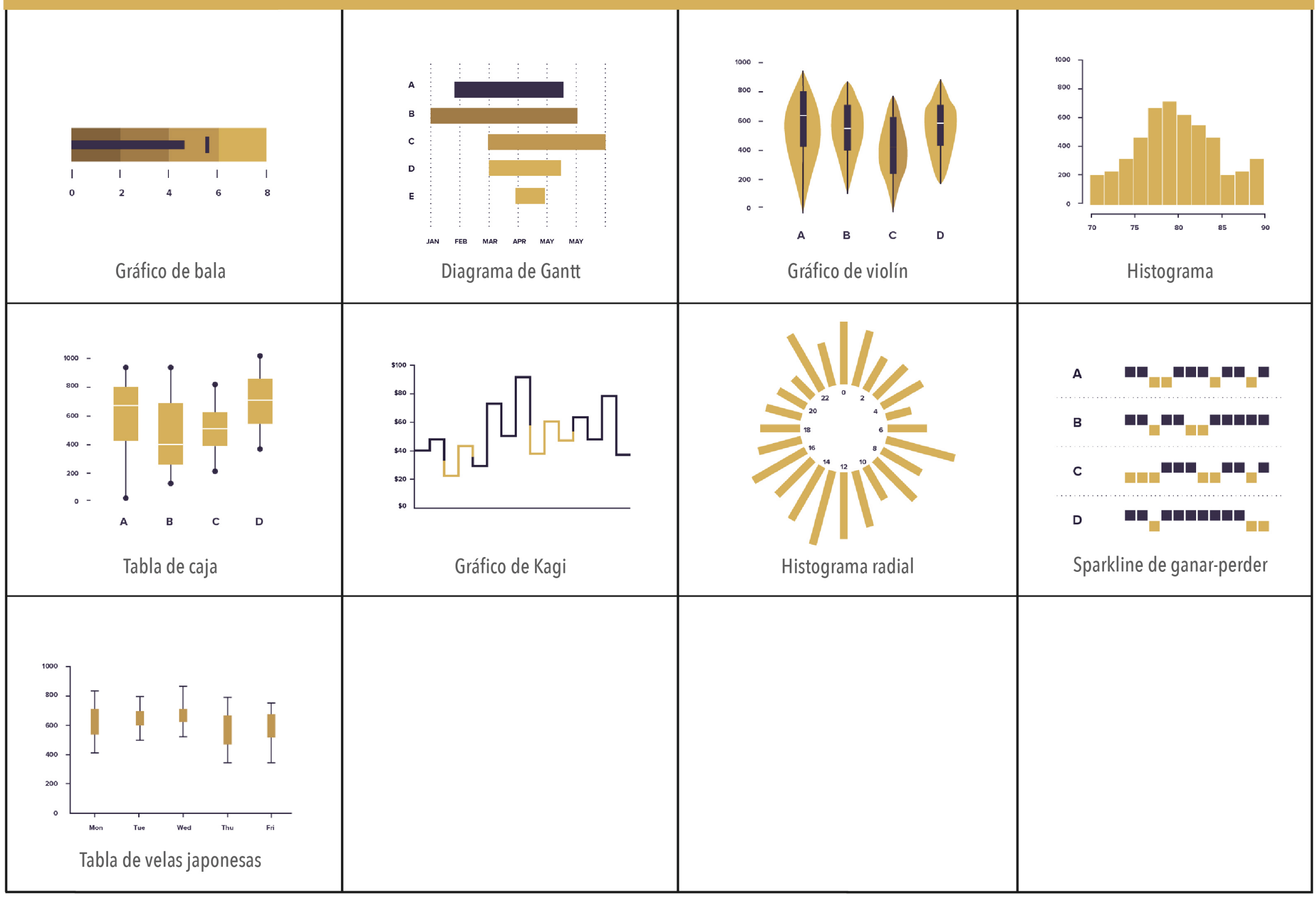




\section{FIGURAS VISUALES DEL MÉTODO DE COMPARACIÓN}

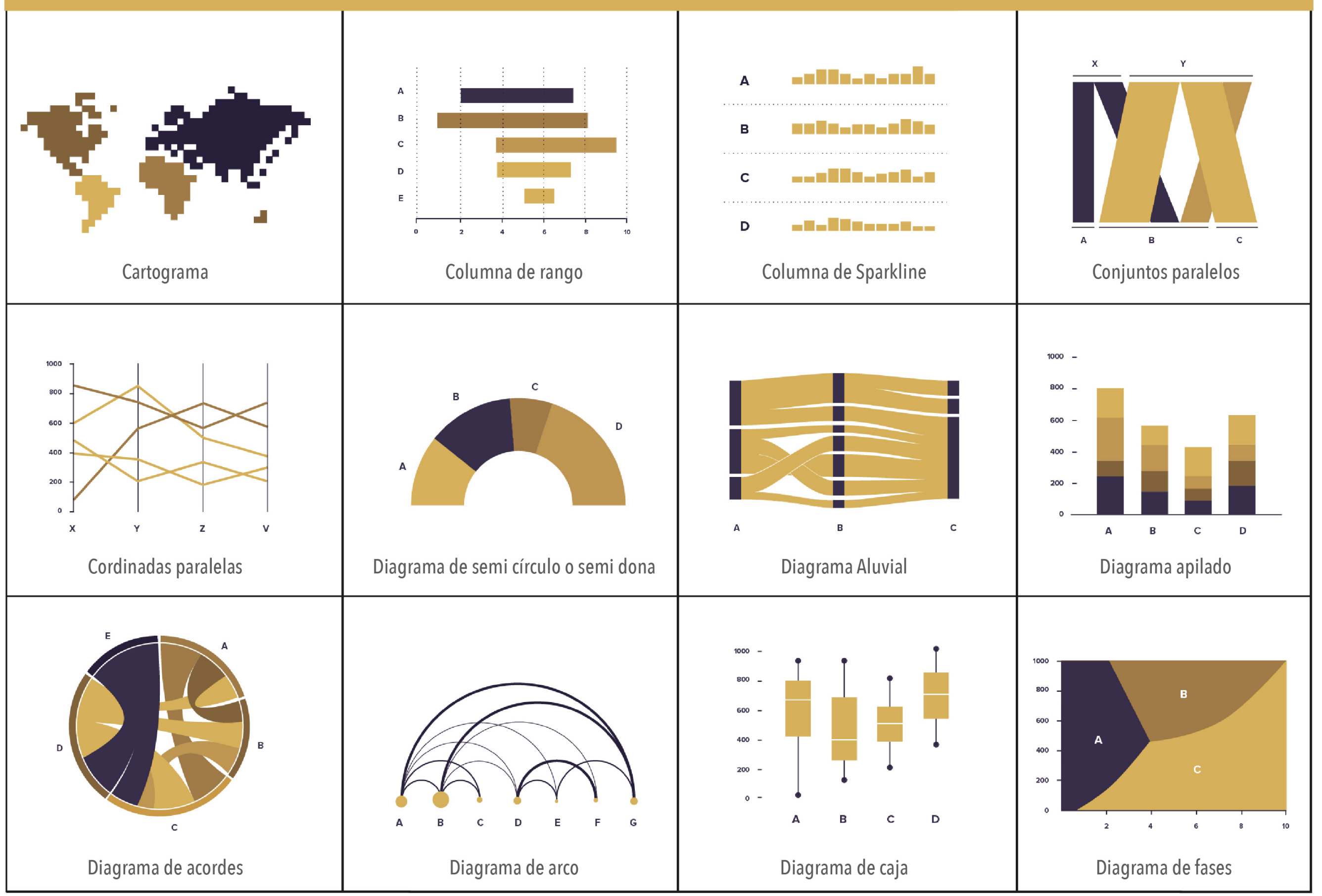




\section{FIGURAS VISUALES DEL MÉTODO DE COMPARACIÓN}

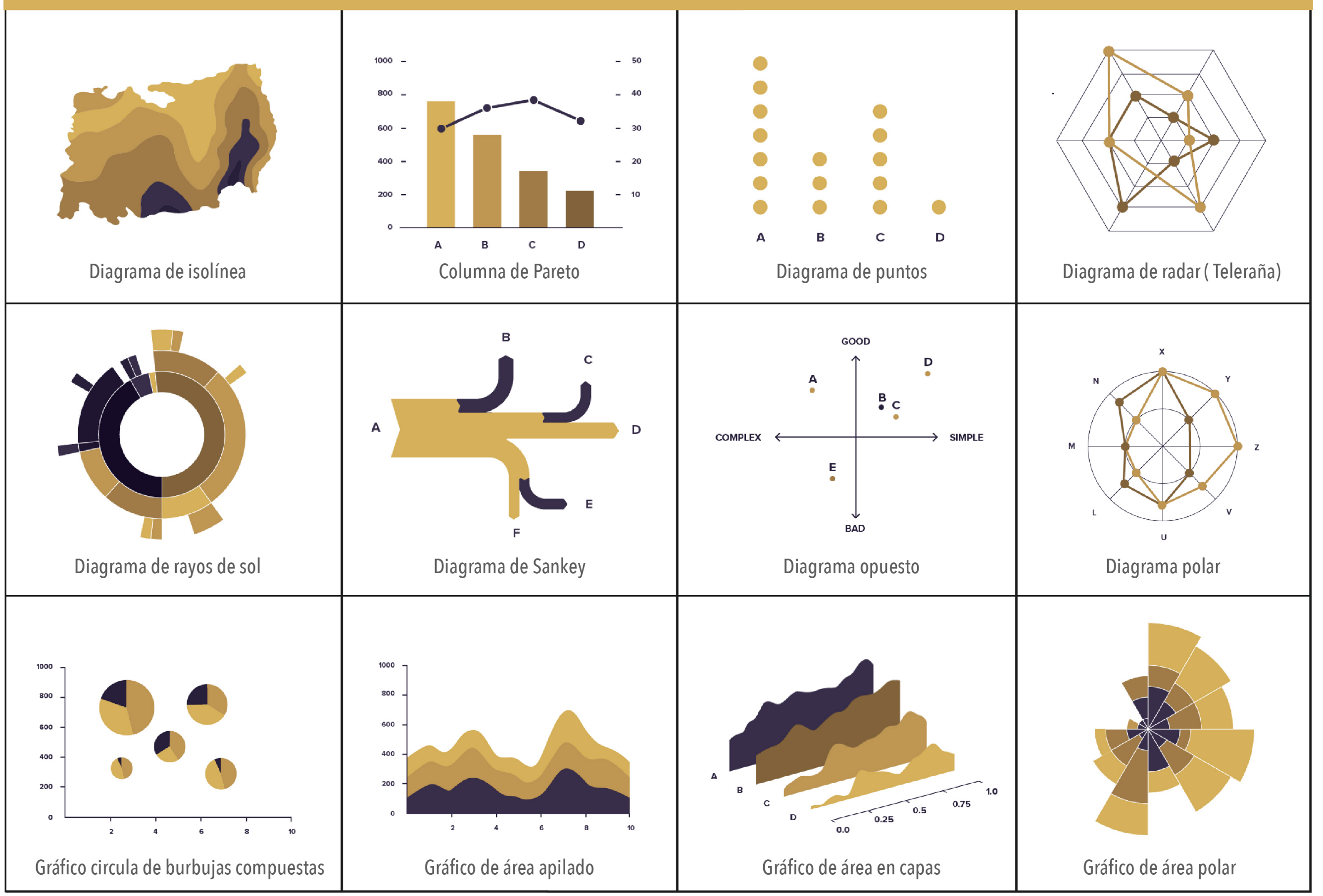




\section{FIGURAS VISUALES DEL MÉTODO DE COMPARACIÓN}

\begin{tabular}{|c|c|c|c|}
\hline Gráfico de área proporcional (círculos) & Gráfico de área proporcional (icono) & Gráfico de pendientes & 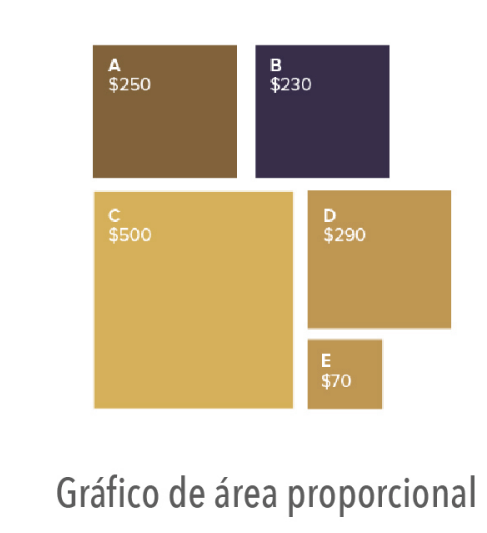 \\
\hline $\begin{array}{l}\text { A } \\
\text { Gráfico de barras (horizontal) }\end{array}$ & 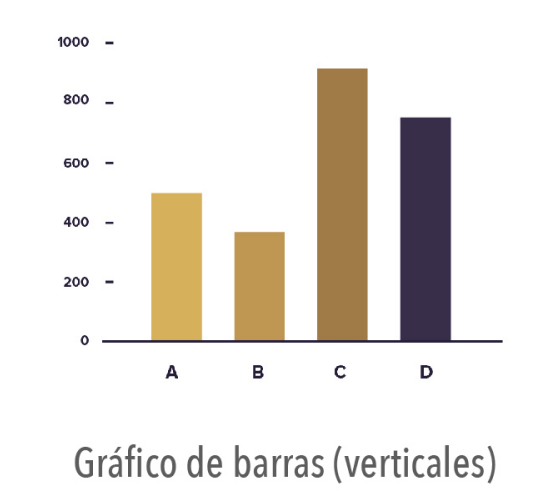 & Gráfico de barras agrupadas & Gráfico de barras curvadas \\
\hline Gráfico de barras del triángulo & Gráfico de barras en un mapa & Gráfico de barras pictorial & Gráfico de barras radiales \\
\hline
\end{tabular}




\section{FIGURAS VISUALES DEL MÉTODO DE COMPARACIÓN}

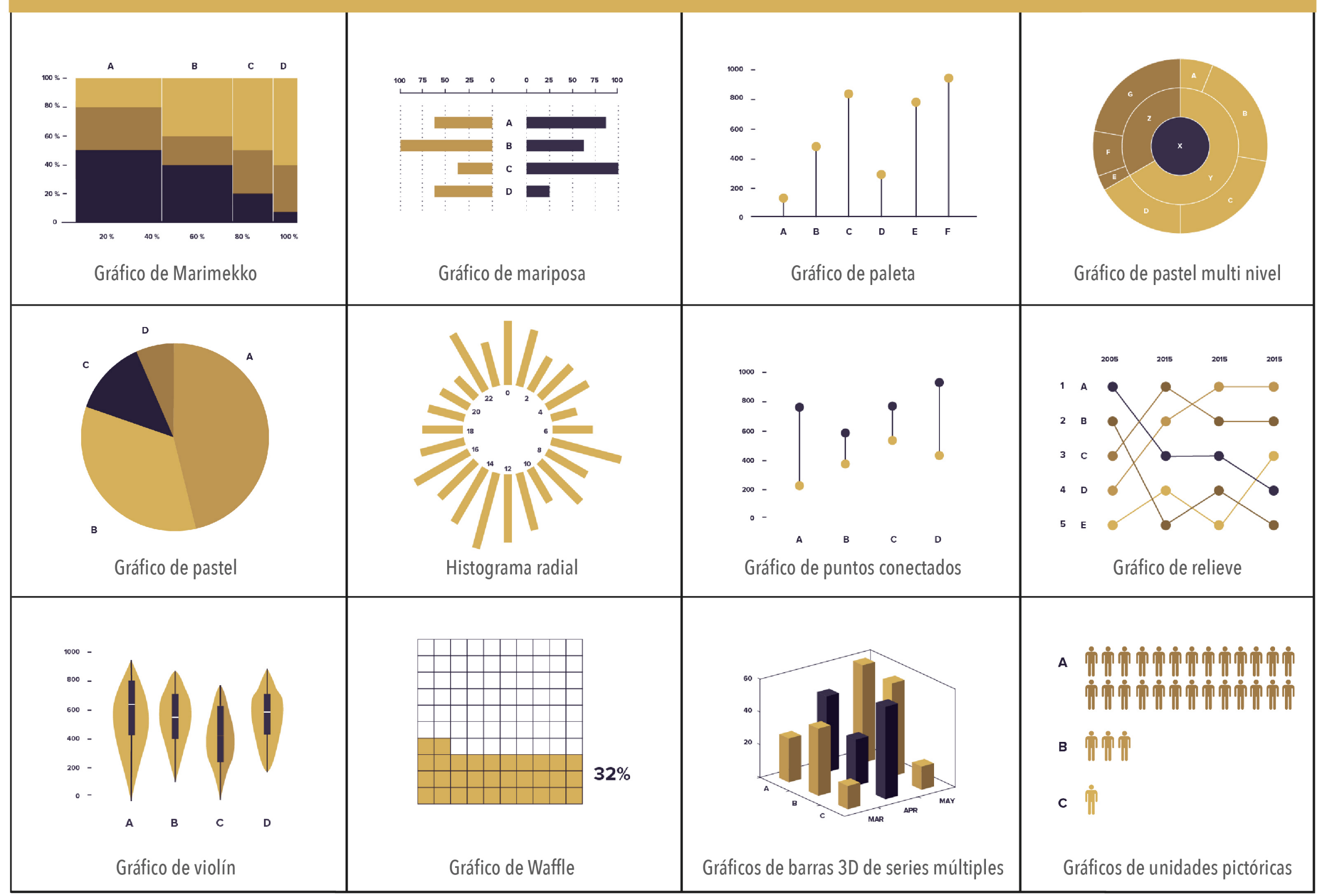




\section{FIGURAS VISUALES DEL MÉTODO DE COMPARACIÓN}

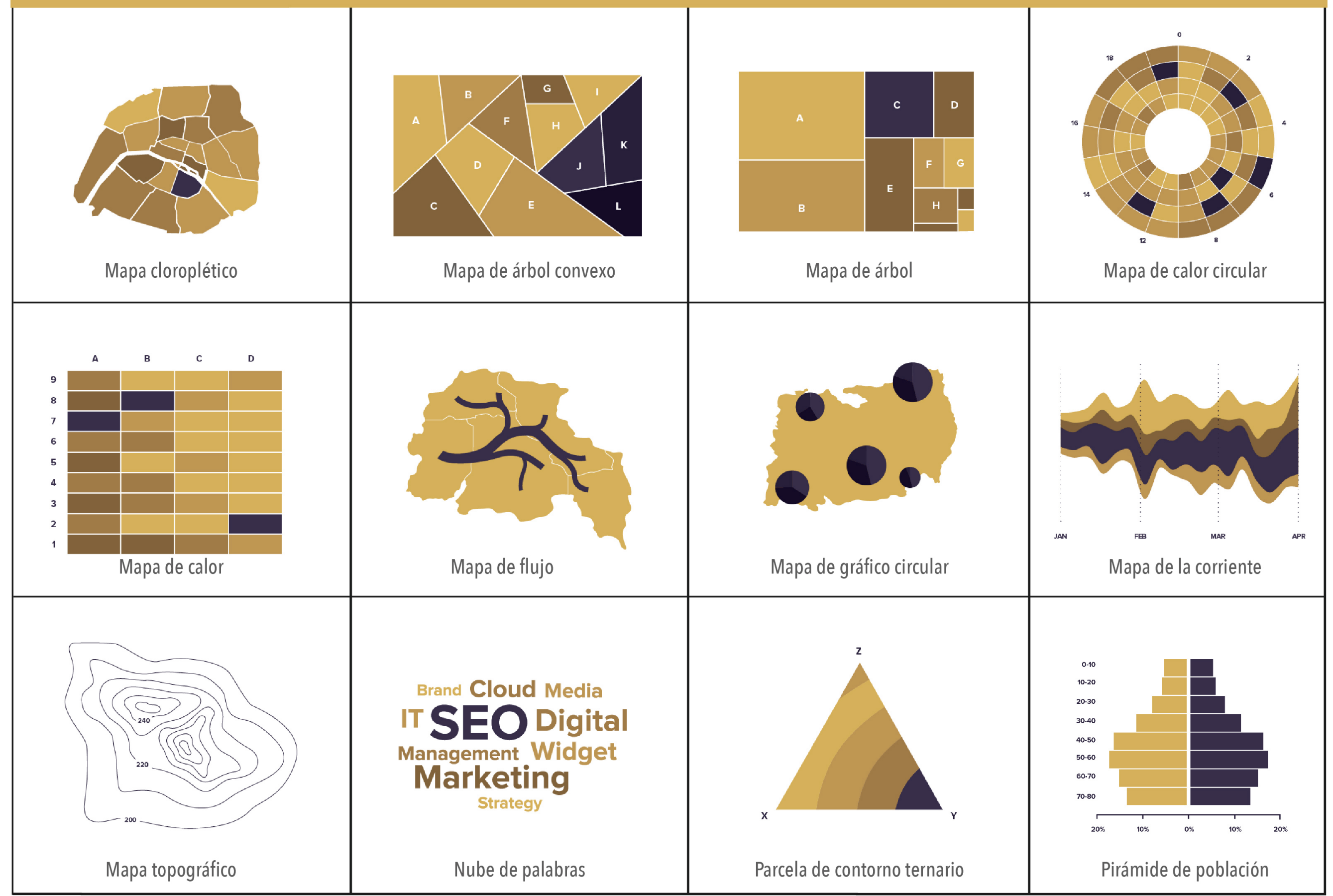




\section{FIGURAS VISUALES DEL MÉTODO DE COMPARACIÓN}

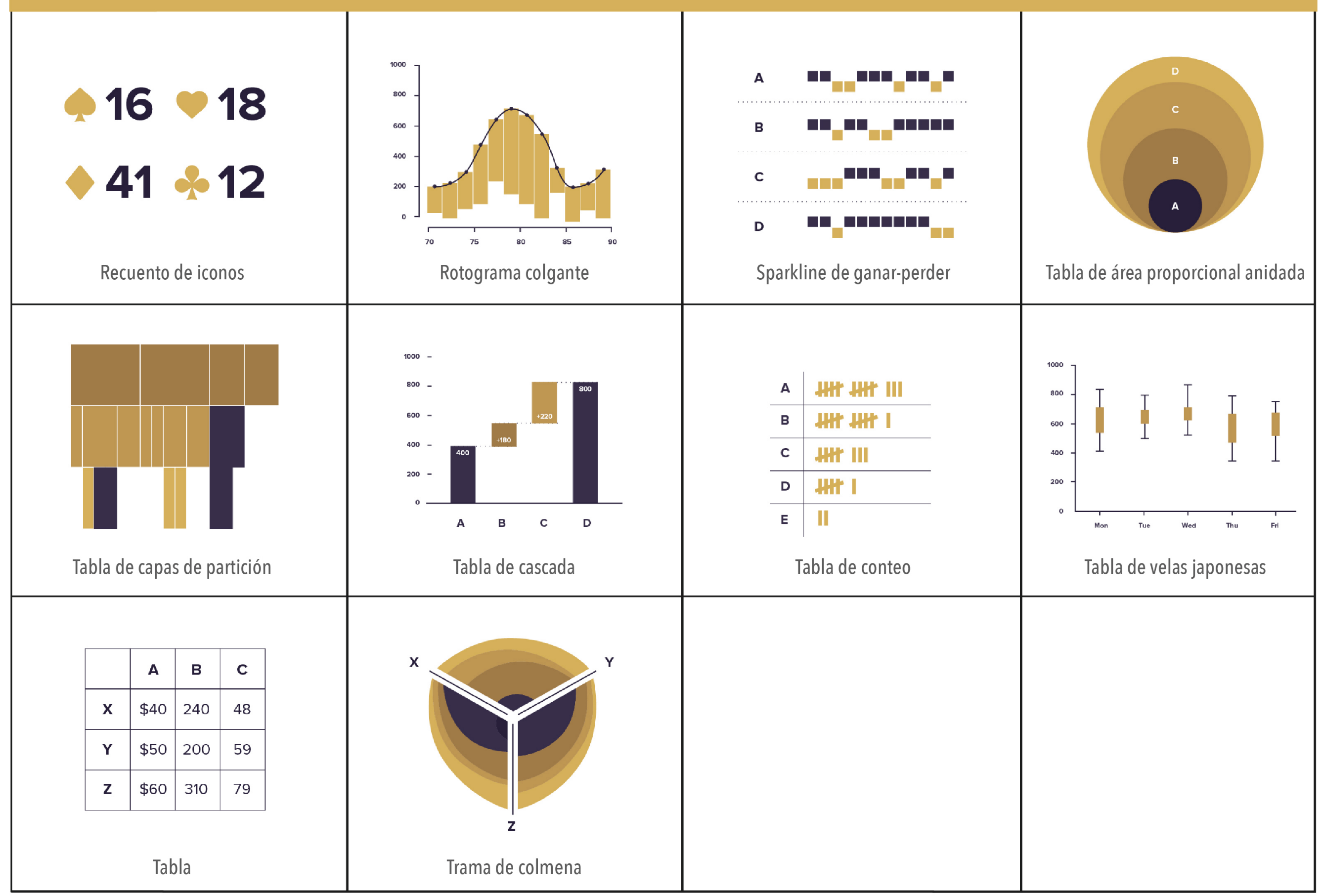





\section{Consentimiento informado}

Proyecto: NOMOLAS: Propuesta de guías de usabilidad para el diseño de interfaces gráficas de sistemas de visualización de información médica.

Nombre del estudio: Evaluación de usabilidad de propuestas editoriales de las guías de usabilidad NOMOLAS con usuarios (lectores) de las mismas.

Lugar y fecha:

\section{Número de registro:}

Justificación y objetivo del estudio: La forma en que se presenta la información es importante para que ésta sea comprendida de la mejor manera posible. Este estudio tiene como propósito elegir la mejor propuesta editorial para implementarla en toda la composición visual del proyecto llamado "NOMOLAS: Propuesta de guías de usabilidad para el diseño de interfaces gráficas de sistemas de visualización de información médica", que es a su vez, trabajo de investigación doctoral.

Procedimientos: Primero, se le explicaran los objetivos y el procedimiento de la sesión; describiendo como se llevará a cabo la prueba. Segundo, le pediremos que siga las instrucciones que le entregue el investigador encargado.

Posibles riesgos y molestias: En investigaciones similares no se han registrado dificultades o riesgos de ningún tipo, por tanto, durante su participación no se prevé ningún riesgo.

Posibles beneficios que recibirá al participar en el estudio: Al final de la prueba se le dará al participante $\$ 50.00$ pesos mexicanos en efectivo.

Participación o retiro: Si después de que Usted haya leído esta información y haya obtenido respuesta a las preguntas que pudiera tener, le vamos a pedir leer y firmar esta carta de consentimiento informado. Sin embargo, Usted puede retirarse en cualquier momento, por cualquier razón y nadie le va a preguntar sobre las razones por las cuales se retira.

Privacidad y confidencialidad: Para garantizar la confidencialidad toda la información será guardada y analizada sin usar los nombres reales de los participantes. Después de ser analizada, la información será guardada por un tiempo razonable y luego destruida.

En caso de dudas o aclaraciones relacionadas con el estudio podrá dirigirse con: Mtra. Mariel García Hernández quien conoce todos los detalles de este estudio. 2224924264 , Correo: mariel.garciahernandez@gmail.com

\section{Participante:}

Nombre:

\section{Quien obtiene el consentimiento:}

Nombre: 



\section{CUESTIONARIO PSSUQ}

Edad: Sexo: M I F Licenciatura: Manejo de llustrator: Si I No

Propuesta de guía: No. de cuestionario:

Este cuestionario es una oportunidad para registrar tus reacciones a la guía de usabilidad. Estas respuestas nos ayudarán a entender qué aspectos hay que mejorar y cuales son con los que no estás satisfechos. Para tener un mejor resultado, piensa en la tarea que se te pidió que realizaras con base a lo que las guías decían mientras contestas estas preguntas.

Instrucciones: Lea cada frase y señala qué tan de acuerdo o en desacuerdo estás y encierra en un circulo un número de la escala. Al terminar, revisaremos juntos el cuestionario para asegurarnos de que entendamos bien la información presentada en este cuestionario.

¡Gracias!

a) La organización de la información proporcionada por las guías me fue clara.

Totalmente en desacuerdo

Totalmente de acuerdo$$
1 \text { - } 1
$$

3

4

45

56

7

b) Fui capaz de completar las tareas que se me indicaron rápidamente con la información proporcionada en las guías.

Totalmente en desacuerdo

$$
12
$$

2

3

4

5

Totalmente de acuerdo

c) La información proporcionada por las guías fue fácil de entender.

Totalmente en desacuerdo
1

2

3

d) La apariencia de las guías es agradable.

Totalmente en desacuerdo

$$
12
$$

3
Totalmente de acuerdo

5

6

7

Totalmente de acuerdo $5 \quad 6$

e) En general estoy satisfecho con el acomodo y presentación visual de la información.

Totalmente en desacuerdo

Totalmente de acuerdo

1

2

3

4

5

6 

Anexo 5. Material para la evaluación FASE 1. Tarea a realizar por el usuario.

\section{LISTA DE CHEQUEO DEL ANÁLISIS DE TAREAS}

Evaluador:

Cuestionario:

Fecha:

Propuesta a evaluar:

\begin{tabular}{|l|l|l|}
\hline Premisa & Si & No \\
\hline El diseñador generó una paleta de cuatro colores. & & \\
\hline $\begin{array}{l}\text { El diseñador relacionó correctamente los lineamientos de } \\
\text { codificación de información en dispositivos médicos y los } \\
\text { aplicó en las secciones de la gráfica de acuerdo a su signi- } \\
\text { ficado. }\end{array}$ & & \\
\hline $\begin{array}{l}\text { El diseñador estableció un buen contraste entre fondo, } \\
\text { figura y texto. }\end{array}$ & & \\
\hline Tiempo en que tardó en leer la página el diseñador. & & \\
\hline Veces en que volvió a consultar la página el diseñador. & & \\
\hline Tiempo en que tardó en completar la tarea el diseñador. & & \\
\hline
\end{tabular}

Anexo 6. Material para la evaluación FASE 1. Enunciados del análisis de tareas

\section{ANÁLISIS DE TAREAS}

1. Abre el archivo de Illustrator llamado "EVA 1" que se encuentra en el escritorio.

2. Modifica la figura de acuerdo a los lineamientos de color presentados en las guías.

3. Al terminar de modificar la figura, guarda el archivo con el comando "Archivo/Guardar". 

Anexo 7. Material para la evaluación FASE 1. Captura de pantalla del archivo "EVA 1"a modificar como parte del análisis de tareas.

\section{GRAVEDAD DE DAÑO DEL PACIENTE}

De acuerdo con la Organización Mundial de la Salud (OMS), el grado del daño "es la gravedad, la duración y las reper-

cusiones terapéuticas del daño derivado de un incidente". A continuación presentamos una gráfica acerca de el

número de pacientes recibidos en la Clínica Mayo en el año del 2018, con base al grado de daño presentado.

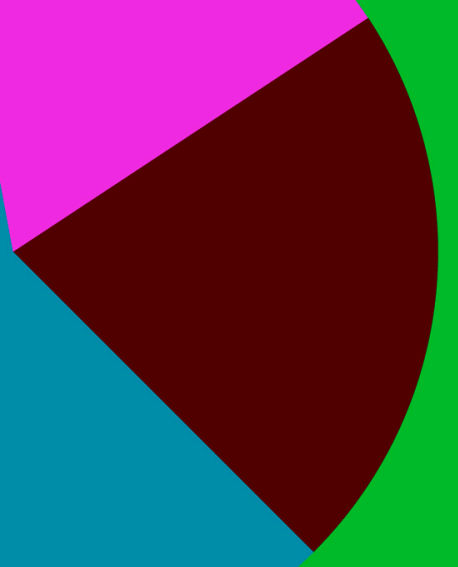

DAÑO LEVE

DAÑO MEDIO

DAÑO GRAVE 

Se recomienda que la elección de color para la interfaz gráfica no se haga mediante gustos personales o juicios del propio diseñador.

Se sugiere elegir el color a usar a partir de las necesidades y objetivo de la interfaz gráfica.

- De acuerdo a lo que establece Wiklund 3 (1995), the Human Engineering Committee of the Association for the Advancement of Medical Instrumentation (AAMI) hace las siguientes sugerencias de uso del color para codificación de información en dispositivos médicos (Figura 22).

\begin{tabular}{|l|l|}
\hline \multicolumn{2}{|c|}{ COLOR } \\
\hline \multirow{2}{*}{ Rojo } & \multicolumn{1}{c|}{ SIGNIFICADO } \\
& Prioridad alta. Advertencia. \\
& Alarma. Emergencia. \\
& Alto. Apagado. \\
Nivel alto. \\
Amarillo & Prioridad Media. \\
& Precaución. \\
& Amenaza potencial. \\
& Nivel medio. \\
Verde & Estado normal. Inicio. \\
& Endendido. Listo. \\
& Nivel estándar. \\
\hline
\end{tabular}

Figura 22. Uso del color para codificación de información en dispositivos médicos. según the Human Engineering Committee of the Association for the Advancement of Medical Instrumentation (AAMI) (1995).

Según Lonsdale \& Lonsdale (2019), es conveniente usar una paleta de color que solo contemple cuatros colores, ya que el exceso de color puede resultar abrumador para el usuario.

Para una alta legibilidad, de acuerdo a Nielsen \& Loranger (2006) debe mantenerse un buen contraste entre el texto, el color y el fondo (ver Figura 23).

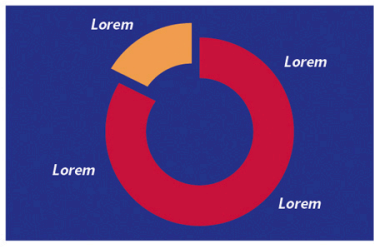

Ejemplo de buen contraste entre los elemento

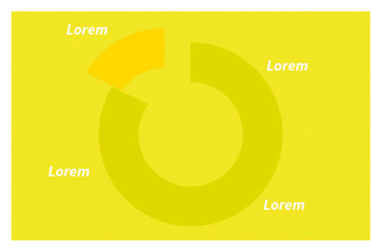

Ejemplo de mal contraste entre los elementos

Figura 23. Es recomendable elegir un buen contraste entre el texto, el color y el fondo.

Es muy importante usar un fondo de color que no generé "ruido visual" en contraste con el color de la tipografía y demás elementos gráficos de la interfaz gráfica. Es decir, se recomienda evitar usar colores que generen un contraste "pesado" a la vista y a la lectura, según los autores anteriores, (Figura 24).

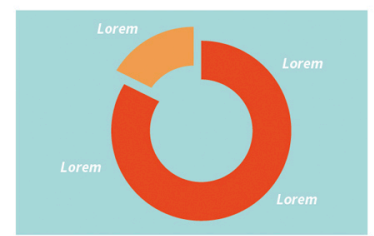

Figura 24. Ejemplo de fondo de color que no generá "ruido" y tiene buen contraste con demás elementos. 

Se recomienda que la elección de color para la interfaz gráfica no se haga mediante gustos personales o juicios del propio diseñador.

Se sugiere elegir el color a usar a partir de las necesidades y objetivo de la interfaz gráfica.

2 De acuerdo a lo que establece Wiklund (1995), the Human Engineering Committee of the Association for the Advancement of Medical Instrumentation (AAMI) hace las siguientes sugerencias de uso del color para codificación de información en dispositivos médicos (Figura 22).

\begin{tabular}{|c|c|}
\hline COLOR & SIGNIFICADO \\
\hline Rojo & $\begin{array}{l}\text { Prioridad alta. Advertencia. } \\
\text { Alarma. Emergencia. } \\
\text { Alto. Apagado. } \\
\text { Nivel alto. }\end{array}$ \\
\hline Amarillo & $\begin{array}{l}\text { Prioridad Media. } \\
\text { Precaución. } \\
\text { Amenaza potencial. } \\
\text { Nivel medio. }\end{array}$ \\
\hline Verde & $\begin{array}{l}\text { Estado normal. Inicio. } \\
\text { Endendido. Listo. } \\
\text { Nivel estándar. }\end{array}$ \\
\hline
\end{tabular}

Figura 22. Uso del color para codificación de información en dispositivos médicos según the Human Engineering Committee of the Association for the

Según Lonsdale \& Lonsdale (2019), es conveniente usar una paleta de color que solo contemple cuatros colores, ya que el exceso de color puede resultar abrumador para el usuario.

5 Para una alta legibilidad, de acuerdo a Nielsen \& Loranger (2006) debe mantenerse un buen contraste entre el texto, el color y el fondo.

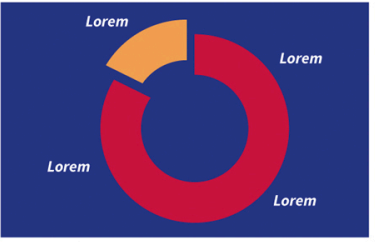

Ejemplo de buen contraste entre los elementos

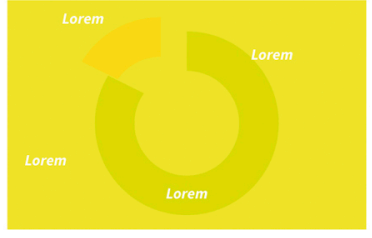

Ejemplo de mal contraste entre los elementos

Figura 23. Es recomendable elegir un buen contraste entre el texto, el color y el fondo. 

Anexo 10. Material de resultados de la evaluación de la propuesta editorial " $A$ ": consentimiento informado, lista de chequedo de análisis de tareas y cuestionario PSSUQ. 
Anexo 10.1. USUARIO 1: Material de resultados de la evaluación de la propuesta editorial "A": consentimiento informado, lista de chequedo de análisis de tareas y cuestionario PSSUQ. 


\section{Consentimiento informado}

Proyecto: NOMOLAS: Propuesta de guias de usabilidad para el diseño de interfaces gráficas de sistemas de visualización de información médica.

Nombre del estudio: Evaluación de usabilidad de propuestas editoriales de las guías de usabilidad NOMOLAS con usuarios (lectores) de las mismas.

Lugar y fecha: UAM Azcapotralco 23 oct. 2019

Número de registro:

Justificación y objetivo del estudio: La forma en que se presenta la información es importante para que ésta sea comprendida de la mejor manera posible. Este estudio tiene como propósito elegir la mejor propuesta editorial para implementarla en toda la composición visual del proyecto llamado "NOMOLAS: Propuesta de guías de usabilidad para el diseño de interfaces gráficas de sistemas de visualización de información médica", que es a su vez, trabajo de investigación doctoral.

Procedimientos: Primero, se le explicaran los objetivos y el procedimiento de la sesión; describiendo como se llevará a cabo la prueba. Segundo, le pediremos que siga las instrucciones que le entregue el investigador encargado.

Posibles riesgos y molestias: En investigaciones similares no se han registrado dificultades o riesgos de ningún tipo, por tanto, durante su participación no se prevé ningún riesgo.

Posibles beneficios que recibirá al participar en el estudio: Al final de la prueba se le dará al participante $\$ 50.00$ pesos mexicanos en efectivo.

Participación o retiro: Si después de que Usted haya leido esta información y haya obtenido respuesta a las preguntas que pudiera tener, le vamos a pedir leer y firmar esta carta de consentimiento informado. Sin embargo, Usted puede retirarse en cualquier momento, por cualquier razón y nadie le va a preguntar sobre las razones por las cuales se retira.

Privacidad y confidencialidad: Para garantizar la confidencialidad toda la información será guardada y analizada sin usar los nombres reales de los participantes. Después de ser analizada, la información será guardada por un tiempo razonable y luego destruida.

En caso de dudas o aclaraciones relacionadas con el estudio podrá dirigirse con: Mtra. Mariel García Hernández quien conoce todos los detalles de este estudio. 22249242 64, Correo: mariel.garciahernandez@gmail.com

Participante:

Nombre: Gloria Takagu Conscelos

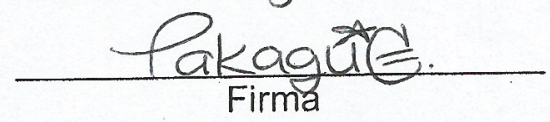

Quien obtiene el consentimiento:

Nombre: Uavel Garcia Hemändec

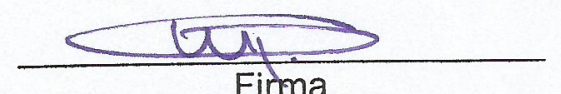




\section{CUESTIONARIOPSSUQ}

Edad:25 Sexo: M / Picenciatura: Diseño de la comunicaciēn gréficamanejo de llustrator: sí I No Propuesta de guía: No. de cuestionario: 1

Este cuestionario es una oportunidad para registrar tus reacciones a la guia de usabilidad. Estas respuestas nos ayudarán a entender qué aspectos hay que mejorar y cuales son con los que no estás satisfechos. Para tener un mejor resultado, piensa en la tarea que se te pidió que realizaras con base a lo que las guias decian mientras contestas estas preguntas.

Instrucciones: Lea cada frase y señala qué tan de acuerdo o en desacuerdo estás y encierra en un circulo un número de la escala. Al terminar, revisaremos juntos el cuestionario para asegurarnos de que entendamos bien la información presentada en este cuestionario.

\section{¡Gracias!}

a) La organización de la información proporcionada por las guías me fue clara.

Totalmente en desacuerdo

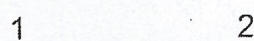

2

3

4

5

Totalmente de acuerdo

(7)

b) Fui capaz de completar las tareas que se me indicaron rápidamente con la información proporcionada en las guías.

Totalmente en desacuerdo

1

2

3

4

5

Totalmente de acuerdo

$+3$

c) La información proporcionada por las guías fue fácil de entender.

Totalmente en desacuerdo

1

2

3

4

5

Totalmente de acuerdo

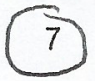

d) La apariencia de las guias es agradable.

Totalmente en desacuerdo

1

2

3

4

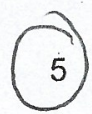

Totalmente de acuerdo

6

7

e) En general estoy satisfecho con el acomodo y presentación visual de la información.

Totalmente en desacuerdo

1

2

3

4

5

Totalmente de acuerdo 
LISTA DE CHEQUEO DEL ANÁLISIS DE TAREAS

Evaluador: Manel Cuestionario: Fecha: $23 \cdot 10 \cdot 19$

Propuesta a evaluar:

\begin{tabular}{|l|c|c|}
\hline Premisa & Si & No \\
\hline El diseñador generó una paleta de cuatro colores. & & \\
\hline $\begin{array}{l}\text { El diseñador relacionó correctamente los lineamientos de } \\
\text { codificación de información en dispositivos médicos y los } \\
\text { aplicó en las secciones de la gráfica de acuerdo a su signi- } \\
\text { ficado. }\end{array}$ & & \\
\hline $\begin{array}{l}\text { El diseñador estableció un buen contraste entre fondo, } \\
\text { figura y texto. }\end{array}$ & & \\
\hline Tiempo en que tardó en leer la página el diseñador. & 56 & \\
\hline Veces en que volvió a consultar la página el diseñador. & 1 & $5: 48: 19$ \\
\hline Tiempo en que tardó en completar la tarea el diseñador. & \\
\hline
\end{tabular}


Anexo 10.2. USUARIO 2: Material de resultados de la evaluación de la propuesta editorial "A": consentimiento informado, lista de chequedo de análisis de tareas y cuestionario PSSUQ. 


\section{Consentimiento informado}

Proyecto: NOMOLAS: Propuesta de guías de usabilidad para el diseño de interfaces gráficas de sistemas de visualización de información médica.

Nombre del estudio: Evaluación de usabilidad de propuestas editoriales de las guías de usabilidad NOMOLAS con usuarios (lectores) de las mismas.

Lugar y fecha:

Número de registro:

02

Justificación y objetivo del estudio: La forma en que se presenta la información es importante para que ésta sea comprendida de la mejor manera posible. Este estudio tiene como propósito elegir la mejor propuesta editorial para implementarla en toda la composición visual del proyecto llamado "NOMOLAS: Propuesta de guías de usabilidad para el diseño de interfaces gráficas de sistemas de visualización de información médica", que es a su vez, trabajo de investigación doctoral.

Procedimientos: Primero, se le explicaran los objetivos y el procedimiento de la sesión; describiendo como se llevará a cabo la prueba. Segundo, le pediremos que siga las instrucciones que le entregue el investigador encargado.

Posibles riesgos y molestias: En investigaciones similares no se han registrado dificultades 0 riesgos de ningún tipo, por tanto, durante su participación no se prevé ningún riesgo.

Posibles beneficios que recibirá al participar en el estudio: Al final de la prueba se le dará al participante $\$ 50.00$ pesos mexicanos en efectivo.

Participación o retiro: Si después de que Usted haya leído esta información y haya obtenido respuesta a las preguntas que pudiera tener, le vamos a pedir leer y firmar esta carta de consentimiento informado. Sin embargo, Usted puede retirarse en cualquier momento, por cualquier razón y nadie le va a preguntar sobre las razones por las cuales se retira.

Privacidad y confidencialidad: Para garantizar la confidencialidad toda la información será guardada y analizada sin usar los nombres reales de los participantes. Después de ser analizada, la información será guardada por un tiempo razonable y luego destruida.

En caso de dudas o aclaraciones relacionadas con el estudio podrá dirigirse con: Mtra. Mariel García Hernández quien conoce todos los detalles de este estudio. 2224924264 , Correo: mariel.garciahernandez@gmail.com

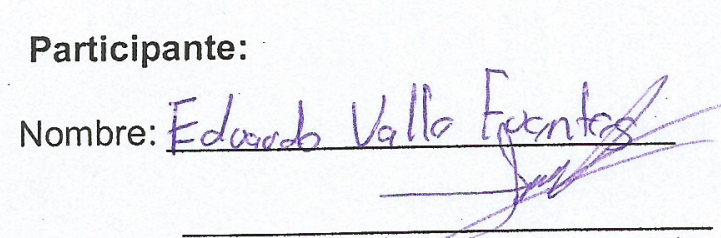

Firma
Quien obtiene el consentimiento:

Nombre: Uamel Garcia Hemānder

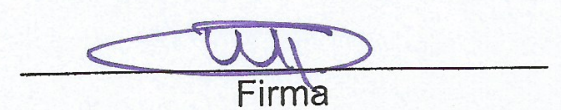




\title{
CUESTIONARIO PSSUQ
}

Edad:26 sexo: M I F Licenciatura: Diseño de la comunicacióng Manejo de llustrator: si I No Propuesta de guía: No. de cuestionario: 2

Este cuestionario es una oportunidad para registrar tus reacciones a la guia de usabilidad. Estas respuestas nos ayudarán a entender qué aspectos hay que mejorar y cuales son con los que no estás satisfechos. Para tener un mejor resultado, piensa en la tarea que se te pidió que realizaras con base a lo que las guías decian mientras contestas estas preguntas.

Instrucciones: Lea cada frase y señala qué tan de acuerdo o en desacuerdo estás y encierra en un circulo un número de la escala. Al terminar, revisaremos juntos el cuestionario para asegurarnos de que entendamos bien la información presentada en este cuestionario.

¡Gracias!

a) La organización de la información proporcionada por las guías me fue clara.

Totalmente en desacuerdo

$$
1 \quad 2
$$

2

3

4

(5)

Totalmente de acuerdo 7

b) Fui capaz de completar las tareas que se me indicaron rápidamente con la información proporcionada en las guías.

Totalmente en desacuerdo$$
12
$$

2

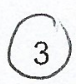

4

5

Totalmente de acuerdo

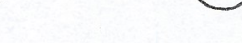

c) La información proporcionada por las guías fue fácil de entender.

Totalmente en desacuerdo

1

2

3

4

5

Totalmente de acuerdo

7

d) La apariencia de las guías es agradable.

Totalmente en desacuerdo

$$
1
$$

2

3

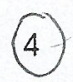

5

Totalmente de acuerdo

e) En general estoy satisfecho con el acomodo y presentación visual de la información.

Totalmente en desacuerdo

1 2

3

\begin{abstract}
4
\end{abstract}

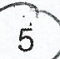

Totalmente de acuerdo

6 


\section{LISTA DE CHEQUEO DEL ANÁLISIS DE TAREAS}

Evaluador: Manlel_Cuestionario:__ Fecha: $23 \cdot 0.19$ Propuesta a evaluar: $A$

\begin{tabular}{|l|l|l|}
\hline Premisa & Si & No \\
\hline El diseñador generó una paleta de cuatro colores. & & \\
\hline $\begin{array}{l}\text { El diseñador relacionó correctamente los lineamientos de } \\
\text { codificación de información en dispositivos médicos y los } \\
\text { aplicó en las secciones de la gráfica de acuerdo a su signi- } \\
\text { ficado. }\end{array}$ & & \\
\hline $\begin{array}{l}\text { El diseñador estableció un buen contraste entre fondo, } \\
\text { figura y texto. }\end{array}$ & & \\
\hline Tiempo en que tardó en leer la página el diseñador. & 50 & seg. \\
\hline Veces en que volvió a consultar la página el diseñador. & $3: 37.85$ \\
\hline Tiempo en que tardó en completar la tarea el diseñador.
\end{tabular}


Anexo 10.3. USUARIO 3: Material de resultados de la evaluación de la propuesta editorial "A": consentimiento informado, lista de chequedo de análisis de tareas y cuestionario PSSUQ. 


\section{Consentimiento informado}

Proyecto: NOMOLAS: Propuesta de guias de usabilidad para el diseño de interfaces gráficas de sistemas de visualización de información médica.

Nombre del estudio: Evaluación de usabilidad de propuestas editoriales de las guías de usabilidad NOMOLAS con usuarios (lectores) de las mismas.

Lugar y fecha: UAM Azcapotzal co 23 octubre. 2019

Número de registro:

Justificación y objetivo del estudio: La forma en que se presenta la información es importante para que ésta sea comprendida de la mejor manera posible. Este estudio tiene como propósito elegir la mejor propuesta editorial para implementarla en toda la composición visual del proyecto llamado "NOMOLAS: Propuesta de guías de usabilidad para el diseño de interfaces gráficas de sistemas de visualización de información médica", que es a su vez, trabajo de investigación doctoral.

Procedimientos: Primero, se le explicaran los objetivos y el procedimiento de la sesión; describiendo como se llevará a cabo la prueba. Segundo, le pediremos que siga. las instrucciones que le entregue el investigador encargado.

Posibles riesgos y molestias: En investigaciones similares no se han registrado dificultades o riesgos de ningún tipo, por tanto, durante su participación no se prevé ningún riesgo.

Posibles beneficios que recibirá al participar en el estudio: Al final de la prueba se le dará al participante $\$ 50.00$ pesos mexicanos en efectivo.

Participación o retiro: Si después de que Usted haya leido esta información y haya obtenido respuesta a las preguntas que pudiera tener, le vamos a pedir leer y firmar esta carta de consentimiento informado. Sin embargo, Usted puede retirarse en cualquier momento, por cualquier razón y nadie le va a preguntar sobre las razones por las cuales se retira.

Privacidad y confidencialidad: Para garantizar la confidencialidad toda la información será guardada y analizada sin usar los nombres reales de los participantes. Después de ser analizada, la información será guardada por un tiempo razonable y luego destruida.

En caso de dudas o aclaraciones relacionadas con el estudio podrá dirigirse con: Mtra. Mariel García Hernández quien conoce todos los detalles de este estudio. 2224924264 , Correo: mariel.garciahernandez@gmail.com

\section{Participante:}

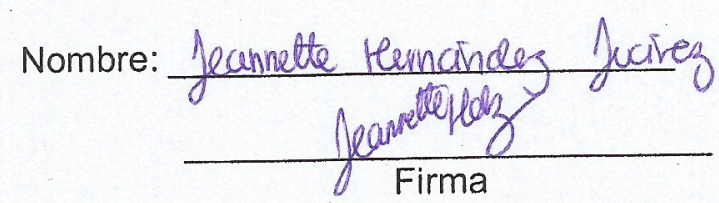

Quien obtiene el consentimiento:

Nombre: Ulanel Garia Hemànder

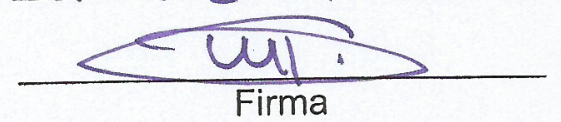




\section{CUESTIONARIO PSSUQ}

Edad:22 Sexo: M I F Licenciatura: Diseñ a la Comanicación Grätica Manejo de llustrator: (si) I No Propuesta de guía: No. de cuestionario:

Este cuestionario es una oportunidad para registrar tus reacciones a la guia de usabilidad. Estas respuestas nos ayudarán a entender qué aspectos hay que mejorar y cuales son con los que no estás satisfechos. Para tener un mejor resultado, piensa en la tarea que se te pidió que realizaras con base a lo que las guías decian mientras contestas estas preguntas.

Instrucciones: Lea cada frase y señala qué tan de acuerdo o en desacuerdo estás y encierra en un circulo un número de la escala. Al terminar, revisaremos juntos el cuestionario para asegurarnos de que entendamos bien la información presentada en este cuestionario.

\section{¡Gracias!}

a) La organización de la información proporcionada por las guías me fue clara.

Totalmente en desacuerdo

$$
1 \quad 2
$$

3

4

5

Totalmente de acuerdo

6 (7)

b) Fui capaz de completar las tareas que se me indicaron rápidamente con la información proporcionada en las guías.

Totalmente en desacuerdo

1

3

4

5

Totalmente de acuerdo

2

c) La información proporcionada por las guías fue fácil de entender.

Totalmente en desacuerdo

1

2

3

4

5

Totalmente de acuerdo

3

d) La apariencia de las guías es agradable.

Totalmente en desacuerdo

1

23

3

4

5

Totalmente de acuerdo

e) En general estoy satisfecho con el acomodo y presentación visual de la información.

Totalmente en desacuerdo

5 


\section{LISTA DE CHEQUEO DEL ANÁLISIS DE TAREAS}

Evaluador: Manel Cuestionario: 3 Fecha: $23.04 \cdot 19$ Propuesta a evaluar: A

\begin{tabular}{|l|c|l|}
\hline Premisa & Si & No \\
\hline El diseñador generó una paleta de cuatro colores. & & \\
\hline $\begin{array}{l}\text { El diseñador relacionó correctamente los lineamientos de } \\
\text { codificación de información en dispositivos médicos y los } \\
\text { aplicó en las secciones de la gráfica de acuerdo a su signi- } \\
\text { ficado. }\end{array}$ & $\checkmark$ & \\
\hline $\begin{array}{l}\text { El diseñador estableció un buẹn contraste entre fondo, } \\
\text { figura y texto. }\end{array}$ & 55 & \\
\hline Tiempo en que tardó en leer la página el diseñador. & & \\
\hline Veces en que volvió a consultar la página el diseñador. & $2: 03: 60$ \\
\hline Tiempo en que tardó en completar la tarea el diseñador. &
\end{tabular}


Anexo 10.4. USUARIO 4: Material de resultados de la evaluación de la propuesta editorial "A": consentimiento informado, lista de chequedo de análisis de tareas y cuestionario PSSUQ. 


\section{Consentimiento informado}

Proyecto: NOMOLAS: Propuesta de guias de usabilidad para el diseño de interfaces gráficas de sistemas de visualización de información médica.

Nombre del estudio: Evaluación de usabilidad de propuestas editoriales de las guías de usabilidad NOMOLAS con usuarios (lectores) de las mismas.

Lugar y fecha: UAM ACC

Número de registro:

04

Justificación y objetivo del estudio: La forma en que se presenta la información es importante para que ésta sea comprendida de la mejor manera posible. Este estudio tiene como propósito elegir la mejor propuesta editorial para implementarla en toda la composición visual del proyecto llamado "NOMOLAS: Propuesta de guías de usabilidad para el diseño de interfaces gráficas de sistemas de visualización de información médica", que es a su vez, trabajo de investigación doctoral.

Procedimientos: Primero, se le explicaran los objetivos y el procedimiento de la sesión; describiendo como se llevará a cabo la prueba. Segundo, le pediremos que siga. las instrucciones que le entregue el investigador encargado.

Posibles riesgos y molestias: En investigaciones similares no se han registrado dificultades o riesgos de ningún tipo, por tanto, durante su participación no se prevé ningún riesgo.

Posibles beneficios que recibirá al participar en el estudio: Al final de la prueba se le dará al participante $\$ 50.00$ pesos mexicanos en efectivo.

Participación o retiro: Si después de que Usted haya leído esta información y haya obtenido respuesta a las preguntas que pudiera tener, le vamos a pedir leer y firmar esta carta de consentimiento informado. Sin embargo, Usted puede retirarse en cualquier momento, por cualquier razón y nadie le va a preguntar sobre las razones por las cuales se retira.

Privacidad y confidencialidad: Para garantizar la confidencialidad toda la información será guardada y analizada sin usar los nombres reales de los participantes. Después de ser analizada, la información será guardada por un tiempo razonable y luego destruida.

En caso de dudas o aclaraciones relacionadas con el estudio podrá dirigirse con: Mtra. Mariel García Hernández quien conoce todos los detalles de este estudio. 2224924264 , Correo: mariel.garciahernandez@gmail.com

\section{Participante:}

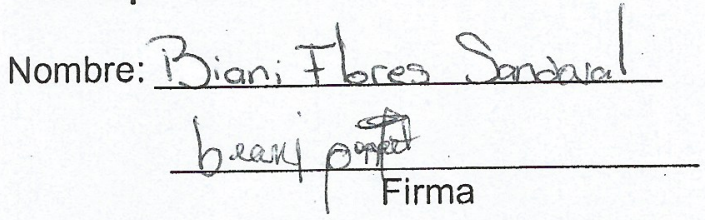

Quien obtiene el consentimiento:

Nombre: Uarel Garéia Hernainder

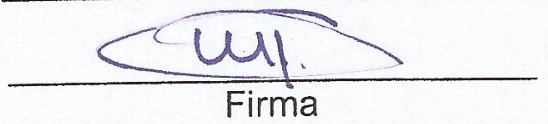




\section{CUESTIONARIO PSSUQ}

Edad:23 Sexo: M / (e) Licenciatura: Diseño de la Conunicaciómanejo de llustrator: Si / No Propuesta de guía: No. de cuestionario: 4

Este cuestionario es una oportunidad para registrar tus reacciones a la guia de usabilidad. Estas respuestas nos ayudarán a entender qué aspectos hay que mejorar y cuales son con los que no estás satisfechos. Para tener un mejor resultado, piensa en la tarea que se te pidió que realizaras con base a lo que las guías decian mientras contestas estas preguntas.

Instrucciones: Lea cada frase y señala qué tan de acuerdo o en desacuerdo estás y encierra en un circulo un número de la escala. Al terminar, revisaremos juntos el cuestionario para asegurarnos de que entendamos bien la información presentada en este cuestionario.

¡Gracias!

a) La organización de la información proporcionada por las guías me fue clara.

Totalmente en desacuerdo

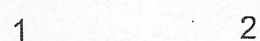
2 3

4

5 Totalmente de acuerdo

4

b) Fui capaz de completar las tareas que se me indicaron rápidamente con la información proporcionada en las guías.

Totalmente en desacuerdo
1
2

3

4

Totalmente de acuerdo

c) La información proporcionada por las guías fue fácil de entender.

Totalmente en desacuerdo

1

2

3

4

5
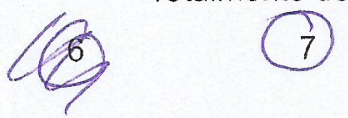

d) La apariencia de las guías es agradable.

Totalmente en desacuerdo

$$
12
$$

2

3

4

5

Totalmente de acuerdo

6

Totalmente de acuerdo

6

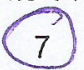

e) En general estoy satisfecho con el acomodo y presentación visual de la información.

Totalmente en desacuerdo

1

2

3

4

5

Totalmente de acuerdo

\section{6}

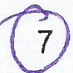




\section{LISTA DE CHEQUEO DEL ANÁLISIS DE TAREAS}

Evaluador: Wariel Cuestionario: 4 Fecha: $23 \cdot 10 \cdot 19$ Propuesta a evaluar: A

\begin{tabular}{|l|c|c|}
\hline Premisa & Si & No \\
\hline El diseñador generó una paleta de cuatro colores. & & \\
\hline $\begin{array}{l}\text { El diseñador relacionó correctamente los lineamientos de } \\
\text { codificación de información en dispositivos médicos y los } \\
\text { aplicó en las secciones de la gráfica de acuerdo a su signi- } \\
\text { ficado. }\end{array}$ & & \\
\hline $\begin{array}{l}\text { El diseñador estableció un buen contraste entre fondo, } \\
\text { figura y texto. }\end{array}$ & & \\
\hline Tiempo en que tardó en leer la página el diseñador. & 55 & \\
\hline Veces en que volvió a consultar la página el diseñador. & $3: 03: 05$ & \\
\hline Tiempo en que tardó en completar la tarea el diseñador. & & \\
\hline
\end{tabular}


Anexo 10.5. USUARIO 5: Material de resultados de la evaluación de la propuesta editorial "A": consentimiento informado, lista de chequedo de análisis de tareas y cuestionario PSSUQ. 


\section{Consentimiento informado}

Proyecto: NOMOLAS: Propuesta de guías de usabilidad para el diseño de interfaces gráficas de sistemas de visualización de información médica.

Nombre del estudio: Evaluación de usabilidad de propuestas editoriales de las guías de usabilidad NOMOLAS con usuarios (lectores) de las mismas.

Lugary fecha: \AM ACC CDMX

Número de registro:

05

Justificación y objetivo del estudio: La forma en que se presenta la información es importante para que ésta sea comprendida de la mejor manera posible. Este estudio tiene como propósito elegir la mejor propuesta editorial para implementarla en toda la composición visual del proyecto llamado "NOMOLAS: Propuesta de guias de usabilidad para el diseño de interfaces gráficas de sistemas de visualización de información médica", que es a su vez, trabajo de investigación doctoral.

Procedimientos: Primero, se le explicaran los objetivos y el procedimiento de la sesión; describiendo como se llevará a cabo la prueba. Segundo, le pediremos que siga las instrucciones que le entregue el investigador encargado.

Posibles riesgos y molestias: En investigaciones similares no se han registrado dificultades o riesgos de ningún tipo, por tanto, durante su participación no se prevé ningún riesgo.

Posibles beneficios que recibirá al participar en el estudio: Al final de la prueba se le dará al participante $\$ 50.00$ pesos mexicanos en efectivo.

Participación o retiro: Si después de que Usted haya leído esta información y haya obtenido respuesta a las preguntas que pudiera tener, le vamos a pedir leer y firmar esta carta de consentimiento informado. Sin embargo, Usted puede retirarse en cualquier momento, por cualquier razón y nadie le va a preguntar sobre las razones por las cuales se retira.

Privacidad y confidencialidad: Para garantizar la confidencialidad toda la información será guardada y analizada sin usar los nombres reales de los participantes. Después de ser analizada, la información será guardada por un tiempo razonable y luego destruida.

En caso de dudas o aclaraciones relacionadas con el estudio podrá dirigirse con: Mtra. Mariel García Hernández quien conoce todos los detalles de este estudio. 22249242 64, Correo: mariel.garciahernandez@gmail.com

Participante:

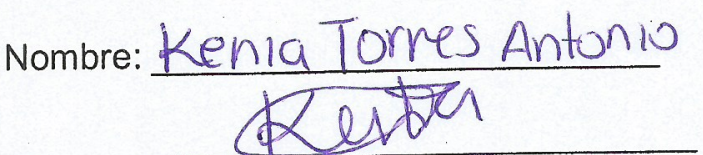

Firma
Quien obtiene el consentimiento:

Nombre: Unanel Garcia Hernänder

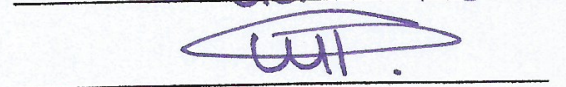

Firma 


\section{CUESTIONARIO PSSUQ}

Edad:20 Sexo: M I F Licenciatura: Diseño Comunicación Grátic Manejo de llustrator: SK I No Propuesta de guía: A No. de cuestionario: 115

Este cuestionario es una oportunidad para registrar tus reacciones a la guia de usabilidad. Estas respuestas nos ayudarán a entender qué aspectos hay que mejorar y cuales son con los que no estás satisfechos. Para tener un mejor resultado, piensa en la tarea que se te pidió que realizaras con base a lo que las guias decian mientras contestas estas preguntas.

Instrucciones: Lea cada frase y señala qué tan de acuerdo o en desacuerdo estás y encierra en un circulo un número de la escala. Al terminar, revisaremos juntos el cuestionario para asegurarnos de que entendamos bien la información presentada en este cuestionario.

¡Gracias!

a) La organización de la información proporcionada por las guías me fue clara.

Totalmente en desacuerdo

1

2

3

4

5

Totalmente de acuerdo

.

6

b) Fui capaz de completar las tareas que se me indicaron rápidamente con la información proporcionada en las guías.

Totalmente en desacuerdo

1

2

3

4

Totalmente de acuerdo

c) La información proporcionada por las guías fue fácil de entender.

Totalmente en desacuerdo

1

2

3

4

5

Totalmente de acuerdo

2

d) La apariencia de las guias es agradable.

Totalmente en desacuerdo

1

2

3

4

5

Totalmente de acuerdo

e) En general estoy satisfecho con el acomodo y presentación visual de la información.

Totalmente en desacuerdo

1

2

3

4

5

Totalmente de acuerdo . 
LISTA DE CHEQUEO DEL ANÁLISIS DE TAREAS

Evaluador: Mariel_Cuestionario: 5

Fecha: $23 \cdot 0.19$ Propuesta a evaluar: $A$

\begin{tabular}{|l|c|c|}
\hline Premisa & Si & No \\
\hline El diseñador generó una paleta de cuatro colores. & $\checkmark$ & \\
\hline $\begin{array}{l}\text { El diseñador relacionó correctamente los lineamientos de } \\
\text { codificación de información en dispositivos médicos y los } \\
\text { aplicó en las secciones de la gráfica de acuerdo a su signi- } \\
\text { ficado. }\end{array}$ & & \\
\hline $\begin{array}{l}\text { El diseñador estableció un buen contraste entre fondo, } \\
\text { figura y texto. }\end{array}$ & $1: 00: 02$ \\
\hline Tiempo en que tardó en leer la página el diseñador. & $11(2)$ & \\
\hline Veces en que volvió a consultar la página el diseñador. & $4: 39$ & \\
\hline Tiempo en que tardó en completar la tarea el diseñador. & \\
\hline
\end{tabular}


Anexo 10.6. USUARIO 6: Material de resultados de la evaluación de la propuesta editorial "A": consentimiento informado, lista de chequedo de análisis de tareas y cuestionario PSSUQ. 


\section{Consentimiento informado}

Proyecto: NOMOLAS: Propuesta de guías de usabilidad para el diseño de interfaces gráficas de sistemas de visualización de información médica.

Nombre del estudio: Evaluación de usabilidad de propuestas editoriales de las guías de usabilidad NOMOLAS con usuarios (lectores) de las mismas.

Lugary fecha: UAM ACC CDMX

Número de registro:

06

Justificación y objetivo del estudio: La forma en que se presenta la información es importante para que ésta sea comprendida de la mejor manera posible. Este estudio tiene como propósito elegir la mejor propuesta editorial para implementarla en toda la composición visual del proyecto llamado "NOMOLAS: Propuesta de guías de usabilidad para el diseño de interfaces gráficas de sistemas de visualización de información médica", que es a su vez, trabajo de investigación doctoral.

Procedimientos: Primero, se le explicaran los objetivos y el procedimiento de la sesión; describiendo como se llevará a cabo la prueba. Segundo, le pediremos que siga las instrucciones que le entregue el investigador encargado.

Posibles riesgos y molestias: En investigaciones similares no se han registrado dificultades o riesgos de ningún tipo, por tanto, durante su participación no se prevé ningún riesgo.

Posibles beneficios que recibirá al participar en el estudio: Al final de la prueba se le dará al participante $\$ 50.00$ pesos mexicanos en efectivo.

Participación o retiro: Si después de que Usted haya leído esta información y haya obtenido respuesta a las preguntas que pudiera tener, le vamos a pedir leer y firmar esta carta de consentimiento informado. Sin embargo, Usted puede retirarse en cualquier momento, por cualquier razón y nadie le va a preguntar sobre las razones por las cuales se retira.

Privacidad y confidencialidad: Para garantizar la confidencialidad toda la información será guardada y analizada sin usar los nombres reales de los participantes. Después de ser analizada, la información será guardada por un tiempo razonable y luego destruida.

En caso de dudas o aclaraciones relacionadas con el estudio podrá dirigirse con: Mtra. Mariel García Hernández quien conoce todos los detalles de este estudio. 2224924264 , Correo: mariel.garciahernandez@gmail.com

Participante:

Nombre: Alade Victoria Villegos Macias

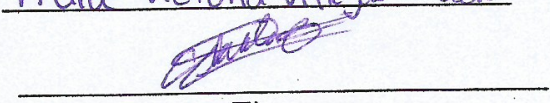

Firma

\section{Quien obtiene el consentimiento:}

Nombre: Wariel Gareta Hernöuder

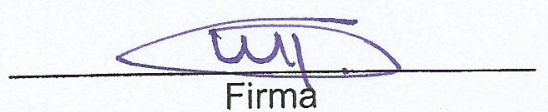




\section{CUESTIONARIO PSSUQ}

Edad: 21 Sexo: M \& Licenciatura: $D C G$ Manejo de llustrator: 8i I No Propuesta de guía: A No. de cuestionario: 6

Este cuestionario es una oportunidad para registrar tus reacciones a la guia de usabilidad. Estas respuestas nos ayudarán a entender qué aspectos hay que mejorar y cuales son con los que no estás satisfechos. Para tener un mejor resultado, piensa en la tarea que se te pidió que realizaras con base a lo que las guías decian mientras contestas estas preguntas.

Instrucciones: Lea çada frase y señala qué tan de acuerdo o en desacuerdo estás y encierra en un circulo un número de la escala. Al terminar, revisaremos juntos el cuestionario para asegurarnos de que entendamos bien la información presentada en este cuestionario.

¡Gracias!

a) La organización de la información proporcionada por las guías me fue clara.

Totalmente en desacuerdo$$
12
$$

2

3

4

5

Totalmente de acuerdo

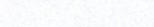

6 7

b) Fui capaz de completar las tareas que se me indicaron rápidamente con la información proporcionada: en las guías.

Totalmente en desacuerdo

$$
1.2
$$

3

(4)

5

Totalmente de acuerdo

7

c) La información proporcionada por las guias fue fácil de entender.

Totalmente en desacuerdo

1

2

3

4

5

Totalmente de acuerdo

2

d) La apariencia de las guías es agradable.

Totalmente en desacuerdo$$
1
$$

2

3

4

5

Totalmente de acuerdo

\section{7}

e) En general estoy satisfecho con el acomodo y presentación visual de la información.

Totalmente en desacuerdo

1

2

3

4

5

Totalmente de acuerdo

1 .

.

4


Evaluador: Wariel Cuestionario: 6 Fecha: $23-10 \cdot 19$ Propuesta a evaluar: $A$

\begin{tabular}{|l|c|c|}
\hline Premisa & Si & No \\
\hline El diseñador generó una paleta de cuatro colores. & & \\
\hline $\begin{array}{l}\text { El diseñador relacionó correctamente los lineamientos de } \\
\text { codificación de información en dispositivos médicos y los } \\
\text { aplicó en las secciones de la gráfica de acuerdo a su signi- } \\
\text { ficado. }\end{array}$ & & \\
\hline $\begin{array}{l}\text { El diseñador estableció un buen contraste entre fondo, } \\
\text { figura y texto. }\end{array}$ & 36 seg & \\
\hline Tiempo en que tardó en leer la página el diseñador. & - & $6: 22: 86$ \\
\hline Veces en que volvió a consultar la página el diseñador. & \\
\hline Tiempo en que tardó en completar la tarea el diseñador. & \\
\hline
\end{tabular}


Anexo 10.7. USUARIO 7: Material de resultados de la evaluación de la propuesta editorial "A": consentimiento informado, lista de chequedo de análisis de tareas y cuestionario PSSUQ. 


\section{Consentimiento informado}

Proyecto: NOMOLAS: Propuesta de guías de usabilidad para el diseño de interfaces gráficas de sistemas de visualización de información médica.

Nombre del estudio: Evaluación de usabilidad de propuestas editoriales de las guías de usabilidad NOMOLAS con usuarios (lectores) de las mismas.

Lugary fecha: UAM ACC CDMX

Número de registro:

Justificación y objetivo del estudio: La forma en que se presenta la información es importante para que ésta sea comprendida de la mejor manera posible. Este estudio tiene como propósito elegir la mejor propuesta editorial para implementarla en toda la composición visual del proyecto llamado "NOMOLAS: Propuesta de guías de usabilidad para el diseño de interfaces gráficas de sistemas de visualización de información médica", que es a su vez, trabajo de investigación doctoral.

Procedimientos: Primero, se le explicaran los objetivos y el procedimiento de la sesión; describiendo como se llevará a cabo la prueba. Segundo, le pediremos que siga las instrucciones que le entregue el investigador encargado.

Posibles riesgos y molestias: En investigaciones similares no se han registrado dificultades o riesgos de ningún tipo, por tanto, durante su participación no se prevé ningún riesgo.

Posibles beneficios que recibirá al participar en el estudio: Al final de la prueba se le dará al participante $\$ 50.00$ pesos mexicanos en efectivo.

Participación o retiro: Si después de que Usted haya leído esta información y haya obtenido respuesta a las preguntas que pudiera tener, le vamos a pedir leer y firmar esta carta de consentimiento informado. Sin embargo, Usted puede retirarse en cualquier momento, por cualquier razón y nadie le va a preguntar sobre las razones por las cuales se retira.

Privacidad y confidencialidad: Para garantizar la confidencialidad toda la información será guardada y analizada sin usar los nombres reales de los participantes. Después de ser analizada, la información será guardada por un tiempo razonable y luego destruida.

En caso de dudas o aclaraciones relacionadas con el estudio podrá dirigirse con: Mtra. Mariel García Hernández quien conoce todos los detalles de este estudio. 2224924264 , Correo: mariel.garciahernandez@gmail.com

\section{Participante:}

Nombre: Sanora Rubio de va Rosa

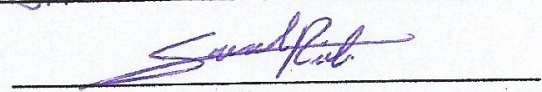

Firma

\section{Quien obtiene el consentimiento:}

Nombre: Uarlel Gartia Hemiòudez

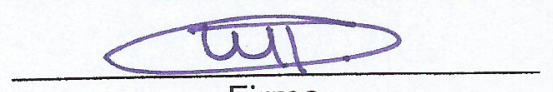

Firma 


\section{CUESTIONARIO PSSUQ}

Edad: 22 Sexo: M / F Licenciatura: Diseño oe ea Gomunicacion Mánejo de llustrator: (Si) I No Propuesta de guía: A No. de cuestionario: 7

Este cuestionario es una oportunidad para registrar tus reacciones a la guia de usabilidad. Estas respuestas nos ayudarán a entender qué aspectos hay que mejorar y cuales son con los que no estás satisfechos. Para tener un mejor resultado, piensa en la tarea que se te pidió que realizaras con base a lo que las guías decian mientras contestas estas preguntas.

Instrucciones: Lea cada frase y señala qué tan de acuerdo o en desacuerdo estás y encierra en un circulo un número de la escala. Al terminar, revisaremos juntos el cuestionario para asegurarnos de que entendamos bien la información presentada en este cuestionario.

¡Gracias!

a) La organización de la información proporcionada por las guías me fue clara.

Totalmente en desacuerdo

$$
1 \quad 2
$$

2

3

4

5

Totalmente de acuerdo

b) Fui capaz de completar las tareas que se me indicaron rápidamente con la información proporcionada en las guías.

Totalmente en desacuerdo

$1-2$

3

4

5

Totalmente de acuerdo

6

(7)

c) La información proporcionada por las guias fue fácil de entender.

Totalmente en desacuerdo$$
1
$$

3

4

5

Totalmente de acuerdo

6

(7)

d) La apariencia de las guías es agradable.

Totalmente en desacuerdo

$$
12
$$

2

3

4

5

Totalmente de acuerdo

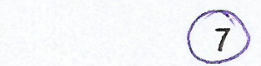

e) En general estoy satisfecho con el acomodo y presentación visual de la información.

Totalmente en desacuerdo 


\section{LISTA DE CHEQUEO DEL ANÁLISIS DE TAREAS}

Evaluador: Wariel Cuestionario: 7 Fecha: $23 \cdot 10 \cdot 19$ Propuesta a evaluar: A

\begin{tabular}{|l|c|c|}
\hline Premisa & Si & No \\
\hline El diseñador generó una paleta de cuatro colores. & & \\
\hline $\begin{array}{l}\text { El diseñador relacionó correctamente los lineamientos de } \\
\text { codificación de información en dispositivos médicos y los } \\
\text { aplicó en las secciones de la gráfica de acuerdo a su signi- } \\
\text { ficado. }\end{array}$ & & \\
\hline $\begin{array}{l}\text { El diseñador estableció un buen contraste entre fondo, } \\
\text { figura y texto. }\end{array}$ & $1: 14: 88 \mathrm{~min} \mathrm{C8}$ \\
\hline \begin{tabular}{l} 
Tiempo en que tardó en leer la página el diseñador. \\
\hline Veces en que volvió a consultar la página el diseñador.
\end{tabular} & $2: 14.60 \mathrm{O}$ \\
\hline Tiempo en que tardó en completar la tarea el diseñador. & $2: 14: 64 \mathrm{~min}$ \\
\hline
\end{tabular}


Anexo 10.8. USUARIO 8: Material de resultados de la evaluación de la propuesta editorial "A": consentimiento informado, lista de chequedo de análisis de tareas y cuestionario PSSUQ. 


\section{Consentimiento informado}

Proyecto: NOMOLAS: Propuesta de guías de usabilidad para el diseño de interfaces gráficas de sistemas de visualización de información médica.

Nombre del estudio: Evaluación de usabilidad de propuestas editoriales de las guías de usabilidad NOMOLAS con usuarios (lectores) de las mismas.

Lugar y fecha: UAM AeC CDMX

Número de registro:

08

Justificación y objetivo del estudio: La forma en que se presenta la información es importante para que ésta sea comprendida de la mejor manera posible. Este estudio tiene como propósito elegir la mejor propuesta editorial para implementarla en toda la composición visual del proyecto llamado "NOMOLAS: Propuesta de guías de usabilidad para el diseño de interfaces gráficas de sistemas de visualización de información médica", que es a su vez, trabajo de investigación doctoral.

Procedimientos: Primero, se le explicaran los objetivos y el procedimiento de la sesión; describiendo como se llevará a cabo la prueba. Segundo, le pediremos que siga. las instrucciones que le entregue el investigador encargado.

Posibles riesgos y molestias: En investigaciones similares no se han registrado dificultades o riesgos de ningún tipo, por tanto, durante su participación no se prevé ningún riesgo.

Posibles beneficios que recibirá al participar en el estudio: Al final de la prueba se le dará al participante $\$ 50.00$ pesos mexicanos en efectivo.

Participación o retiro: Si después de que Usted haya leído esta información y haya obtenido respuesta a las preguntas que pudiera tener, le vamos a pedir leer y firmar esta carta de consentimiento informado. Sin embargo, Usted puede retirarse en cualquier momento, por cualquier razón y nadie le va a preguntar sobre las razones por las cuales se retira.

Privacidad y confidencialidad: Para garantizar la confidencialidad toda la información será guardada y analizada sin usar los nombres reales de los participantes. Después de ser analizada, la información será guardada por un tiempo razonable y luego destruida.

En caso de dudas o aclaraciones relacionadas con el estudio podrá dirigirse con: Mtra. Mariel García Hernández quien conoce todos los detalles de este estudio. 2224924264 , Correo: mariel.garciahernandez@gmail.com

Participante:

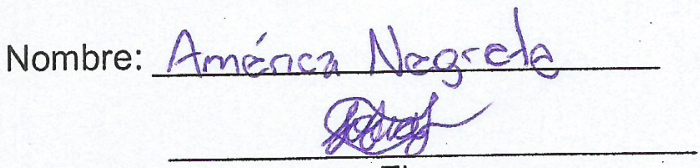

Firma
Quien obtiene el consentimiento:

Nombre: Warel Garcia Hekuouder

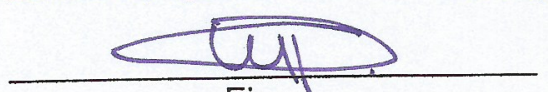

Firma 


\section{CUESTIONARIO PSSUQ}

Edad: Sexo: M / F Licenciatura:

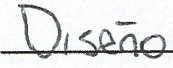

de 1

Propuesta de guía:

No. de cuestionario: grafich

Este cuestionario es una oportunidad para registrar tus reacciones a la guia de usabilidad. Estas respuestas nos ayudarán a entender qué aspectos hay que mejorar y cuales son con los que no estás satisfechos. Para tener un mejor resultado, piensa en la tarea que se te pidió que realizaras con base a lo que las guías decían mientras contestas estas preguntas.

Instrucciones: Lea cada frase y señala qué tan de acuerdo o en desacuerdo estás y encierra en un circulo un número de la escala. Al terminar, revisaremos juntos el cuestionario para asegurarnos de que entendamos bien la información presentada en este cuestionario.

\section{¡Gracias!}

a) La organización de la información proporcionada por las guías me fue clara.

Totalmente en desacuerdo

$$
1 \quad 2
$$

2

Totalmente de acuerdo
3
4
5
4
62

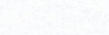

b) Fui capaz de completar las tareas que se me indicaron rápidamente con la información proporcionada en las guías.

Totalmente en desacuerdo

$$
12
$$

2

3

4

5

Totalmente de acuerdo

2

c) La información proporcionada por las guias fue fácil de entender.

Totalmente en desacuerdo$$
1
$$

2

3

4

5

Totalmente de acuerdo

(1)

es agradable.

d) La apariencia de las guias es agradable.

Totalmente en desacuerdo

$$
12
$$

2

3

4

5

Totalmente de acuerdo

e) En general estoy satisfecho con el acomodo y presentación visual de la información. Totalmente en desacuerdo

5

Totalmente de acuerdo

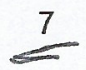




\section{LISTA DE CHEQUEO DEL ANÁLISIS DE TAREAS}

Evaluador: Uanel cuestionario: 8 Fecha: $8^{23 \cdot 10 \cdot 19}$ Propuesta a evaluar: A

\begin{tabular}{|l|l|l|}
\hline Premisa & Si & No \\
\hline El diseñador generó una paleta de cuatro colores. & & \\
\hline $\begin{array}{l}\text { El diseñador relacionó correctamente los lineamientos de } \\
\text { codificación de información en dispositivos médicos y los } \\
\text { aplicó en las secciones de la gráfica de acuerdo a su signi- } \\
\text { ficado. }\end{array}$ & & \\
\hline $\begin{array}{l}\text { El diseñador estableció un buen contraste entre fondo, } \\
\text { figura y texto. }\end{array}$ & & \\
\hline Tiempo en que tardó en leer la página el diseñador. & $53 \mathrm{seg}$. & \\
\hline Veces en que volvió a consultar la página el diseñador. & 1 \\
\hline Tiempo en que tardó en completar la tarea el diseñador. & $28350.5 \mathrm{~min}$ \\
\hline
\end{tabular}


Anexo 10.9. USUARIO 9: Material de resultados de la evaluación de la propuesta editorial "A": consentimiento informado, lista de chequedo de análisis de tareas y cuestionario PSSUQ. 


\section{Consentimiento informado}

Proyecto: NOMOLAS: Propuesta de guias de usabilidad para el diseño de interfaces gráficas de sistemas de visualización de información médica.

Nombre del estudio: Evaluación de usabilidad de propuestas editoriales de las guias de usabilidad NOMOLAS con usuarios (lectores) de las mismas.

Lugar y fecha: LAM AZC CDMX

Número de registro:

09

Justificación y objetivo del estudio: La forma en que se presenta la información es importante para que ésta sea comprendida de la mejor manera posible. Este estudio tiene como propósito elegir la mejor propuesta editorial para implementarla en toda la composición visual del proyecto llamado "NOMOLAS: Propuesta de guías de usabilidad para el diseño de interfaces gráficas de sistemas de visualización de información médica", que es a su vez, trabajo de investigación doctoral.

Procedimientos: Primero, se le explicaran los objetivos y el procedimiento de la sesión; describiendo como se llevará a cabo la prueba. Segundo, le pediremos que siga las instrucciones que le entregue el investigador encargado.

Posibles riesgos y molestias: En investigaciones similares no se han registrado dificultades o riesgos de ningún tipo, por tanto, durante su participación no se prevé ningún riesgo.

Posibles beneficios que recibirá al participar en el estudio: Al final de la prueba se le dará al participante $\$ 50.00$ pesos mexicanos en efectivo.

Participación o retiro: Si después de que Usted haya leído esta información y haya obtenido respuesta a las preguntas que pudiera tener, le vamos a pedir leer y firmar esta carta de consentimiento informado. Sin embargo, Usted puede retirarse en cualquier momento, por cualquier razón y nadie le va a preguntar sobre las razones por las cuales se retira.

Privacidad y confidencialidad: Para garantizar la confidencialidad toda la información será guardada y analizada sin usar los nombres reales de los participantes. Después de ser analizada, la información será guardada por un tiempo razonable y luego destruida.

En caso de dudas o aclaraciones relacionadas con el estudio podrá dirigirse con: Mtra. Mariel Garcia Hernández quien conoce todos los detalles de este estudio. 2224924264 , Correo: mariel.garciahernandez@gmail.com

\section{Participante:}

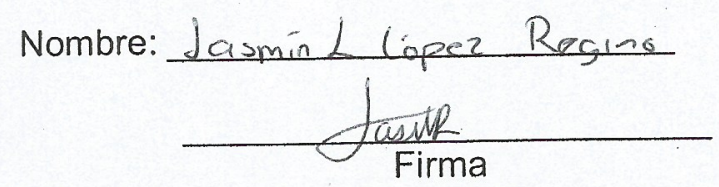

Quien obtiene el consentimiento:

Nombre: Warrel Eareia Heunänder

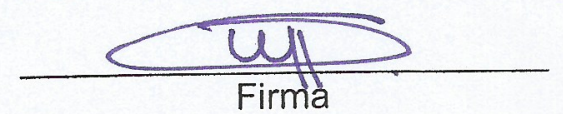




\section{CUESTIONARIO PSSUQ}

Edad: 22 Sexo: M / F Licenciatura:D15.Com Grafica_ Manejo de llustrator: (Si)/ No

Propuesta de guía: $A$

No. de cuestionario:

Este cuestionario es una oportunidad para registrar tus reacciones a la guia de usabilidad. Estas respuestas nos ayudarán a entender qué aspectos hay que mejorar y cuales son con los que no estás satisfechos. Para tener un mejor resultado, piensa en la tarea que se te pidió que realizaras con base a lo que las guías decian mientras contestas estas preguntas.

Instrucciones: Lea cada frase y señala quẻ tan de acuerdo o en desacuerdo estás y encierra en un circulo un número de la escala. Al terminar, revisaremos juntos el cuestionario para asegurarnos de que entendamos bien la información presentada en este cuestionario.

¡Gracias!

a) La organización de la información proporcionada por las guias me fue clara.

Totalmente en desacuerdo

$$
1 \quad 2
$$

2

3

4

5

Totalmente de acuerdo<smiles>c1ccccc1</smiles>

7

b) Fui capaz de completar las tareas que se me indicaron rápidamente con la información proporcionada en las guías.

Totalmente en desacuerdo

$$
1
$$

2

3

4

5

Totalmente de acuerdo

7

c) La información proporcionada por las guías fue fácil de entender.

Totalmente en desacuerdo

1

2

3

4

5

Totalmente de acuerdo

6

(7)

d) La apariencia de las guías es agradable.

Totalmente en desacuerdo

$$
1
$$

2

3

4

5

Totalmente de acuerdo

6

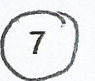

e) En general estoy satisfecho con el acomodo y presentación visual de la información.

Totalmente en desacuerdo 


\section{LISTA DE CHEQUEO DEL ANÁLISIS DE TAREAS}

Evaluador: Uanel Cuestionario: 9 Fecha: $23 \cdot 10 \cdot 19$ Propuesta a evaluar: $A$

\begin{tabular}{|l|c|c|}
\hline Premisa & Si & No \\
\hline El diseñador generó una paleta de cuatro colores. & & \\
\hline $\begin{array}{l}\text { El diseñador relacionó correctamente los lineamientos de } \\
\text { codificación de información en dispositivos médicos y los } \\
\text { aplicó en las secciones de la gráfica de acuerdo a su signi- } \\
\text { ficado. }\end{array}$ & & \\
\hline $\begin{array}{l}\text { El diseñador estableció un buen contraste entre fondo, } \\
\text { figura y texto. }\end{array}$ & 37 sey & \\
\hline Tiempo en que tardó en leer la página el diseñador. & 111 & \\
\hline Veces en que volvió a consultar la página el diseñador. & 3778 & \\
\hline Tiempo en que tardó en completar la tarea el diseñador. & & \\
\hline
\end{tabular}


Anexo 10.10. USUARIO 10: Material de resultados de la evaluación de la propuesta editorial "A": consentimiento informado, lista de chequedo de análisis de tareas y cuestionario PSSUQ. 


\section{Consentimiento informado}

Proyecto: NOMOLAS: Propuesta de guias de usabilidad para el diseño de interfaces gráficas de sistemas de visualización de información médica.

Nombre del estudio: Evaluación de usabilidad de propuestas editoriales de las guias de usabilidad NOMOLAS con usuarios (lectores) de las mismas.

Lugar y fecha: UAMACC ODMX

Número de registro:

10

Justificación y objetivo del estudio: La forma en que se presenta la información es importante para que ésta sea comprendida de la mejor manera posible. Este estudio tiene como propósito elegir la mejor propuesta editorial para implementarla en toda la composición visual del proyecto llamado "NOMOLAS: Propuesta de guías de usabilidad para el diseño de interfaces gráficas de sistemas de visualización de información médica", que es a su vez, trabajo de investigación doctoral.

Procedimientos: Primero, se le explicaran los objetivos y el procedimiento de la sesión; describiendo como se llevará a cabo la prueba. Segundo, le pediremos que siga las instrucciones que le entregue el investigador encargado.

Posibles riesgos y molestias: En investigaciones similares no se han registrado dificultades o riesgos de ningún tipo, por tanto, durante su participación no se prevé ningún riesgo.

Posibles beneficios que recibirá al participar en el estudio: Al final de la prueba se le dará al participante $\$ 50.00$ pesos mexicanos en efectivo.

Participación o retiro: Si después de que Usted haya leído esta información y haya obtenido respuesta a las preguntas que pudiera tener, le vamos a pedir leer y firmar esta carta de consentimiento informado. Sin embargo, Usted puede retirarse en cualquier momento, por cualquier razón y nadie le va a preguntar sobre las razones por las cuales se retira.

Privacidad y confidencialidad: Para garantizar la confidencialidad toda la información será guardada y analizada sin usar los nombres reales de los participantes. Después de ser analizada, la información será guardada por un tiempo razonable y luego destruida.

En caso de dudas o aclaraciones relacionadas con el estudio podrá dirigirse con: Mtra. Mariel García Hernández quien conoce todos los detalles de este estudio. 2224924264 , Correo: mariel.garciahernandez@gmail.com

\section{Participante:}

Nombre: Mavio Alberto Agurlar lskes

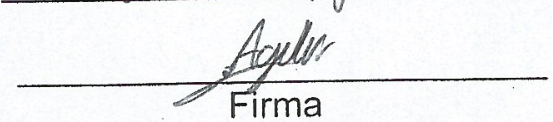

Quien obtiene el consentimiento:

Nombre: Uarlel Garēa Heruōude

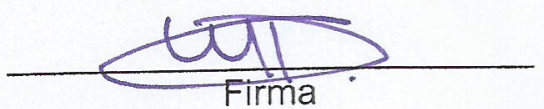




\section{CUESTIONARIO PSSUQ}

Edad:20 sexo: M I F Licenciatura: Diseño de la Coumunícriconle Manejo de llustrator: si I No Propuesta de guía: A No. de cuestionario: 10

Este cuestionario es una oportunidad para registrar tus reacciones a la guía de usabilidad. Estas respuestas nos ayudarán a entender qué aspectos hay que mejorar y cuales son con los que no estás satisfechos. Para tener un mejor resultado, piensa en la tarea que se te pidió que realizaras con base a lo que las guías decían mientras contestas estas preguntas.

Instrucciones: Lea cada frase y señala qué tan de acuerdo o en desacuerdo estás y encierra en un circulo un número de la escala. Al terminar, revisaremos juntos el cuestionario para asegurarnos de que entendamos bien la información presentada en este cuestionario.

¡Gracias!

a) La organización de la información proporcionada por las guías me fue clara.

Totalmente en desacuerdo

$$
1 \quad 2
$$

3

4

5

Totalmente de acuerdo

.

b) Fui capaz de completar las tareas que se me indicaron rápidamente con la información proporcionada:en las guías.

Totalmente en desacuerdo

1

2

3

4

5

Totalmente de acuerdo

(2)

c) La información proporcionada por las guias fue fácil de entender.

Totalmente en desacuerdo

1

2

3

4

5

Totalmente de acuerdo

as

d) La apariencia de las guias es agradable.

Totalmente en desacuerdo

12

23

34

5

Totalmente de acuerdo

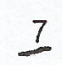

e) En general estoy satisfecho con el acomodo y presentación visual de la información.

Totalmente en desacuerdo 
Evaluador: Waliel_Cuestionario: 10 Fecha: $23 \cdot 10^{-19}$ Propuesta a evaluar: $A$

\begin{tabular}{|l|c|c|}
\hline Premisa & Si & No \\
\hline El diseñador generó una paleta de cuatro colores. & & \\
\hline $\begin{array}{l}\text { El diseñador relacionó correctamente los lineamientos de } \\
\text { codificación de información en dispositivos médicos y los } \\
\text { aplicó en las secciones de la gráfica de acuerdo a su signi- } \\
\text { ficado. }\end{array}$ & & \\
\hline $\begin{array}{l}\text { El diseñador estableció un buen contraste entre fondo, } \\
\text { figura y texto. }\end{array}$ & $40.98 \mathrm{seg}$ \\
\hline Tiempo en que tardó en leer la página el diseñador. & - & $1: 58 \mathrm{~min}$ \\
\hline Veces en que volvió a consultar la página el diseñador. & \\
\hline Tiempo en que tardó en completar la tarea el diseñador. & & \\
\hline
\end{tabular}


Anexo 10.11. USUARIO 11: Material de resultados de la evaluación de la propuesta editorial "A": consentimiento informado, lista de chequedo de análisis de tareas y cuestionario PSSUQ. 


\section{Consentimiento informado}

Proyecto: NOMOLAS: Propuesta de guias de usabilidad para el diseño de interfaces gráficas de sistemas de visualización de información médica.

Nombre del estudio: Evaluación de usabilidad de propuestas editoriales de las guías de usabilidad NOMOLAS con usuarios (lectores) de las mismas.

Lugar y fecha: 24 de oct. 2019 cholula, pue.

Número de registro:

11

Justificación y objetivo del estudio: La forma en que se presenta la información es importante para que ésta sea comprendida de la mejor manera posible. Este estudio tiene como propósito elegir la mejor propuesta editorial para implementarla en toda la composición visual del proyecto llamado "NOMOLAS: Propuesta de guias de usabilidad para el diseño de interfaces gráficas de sistemas de visualización de información médica", que es a su vez, trabajo de investigación doctoral.

Procedimientos: Primero, se le explicaran los objetivos y el procedimiento de la sesión; describiendo como se llevará a cabo la prueba. Segundo, le pediremos que siga las instrucciones que le entregue el investigador encargado.

Posibles riesgos y molestias: En investigaciones similares no se han registrado dificultades o riesgos de ningún tipo, por tanto, durante su participación no se prevé ningún riesgo.

Posibles beneficios que recibirá al participar en el estudio: Al final de la prueba se le dará al participante $\$ 50.00$ pesos mexicanos en efectivo.

Participación o retiro: Si después de que Usted haya leido esta información y haya obtenido respuesta a las preguntas que pudiera tener, le vamos a pedir leer y firmar esta carta de consentimiento informado. Sin embargo, Usted puede retirarse en cualquier momento, por cualquier razón y nadie le va a preguntar sobre las razones por las cuales se retira.

Privacidad y confidencialidad: Para garantizar la confidencialidad toda la información será guardada y analizada sin usar los nombres reales de los participantes. Después de ser analizada, la información será guardada por un tiempo razonable y luego destruida.

En caso de dudas o aclaraciones relacionadas con el estudio podrá dirigirse con: Mtra. Mariel García Hernández quien conoce todos los detalles de este estudio. 2224924264 , Correo: mariel.garciahernandez@gmail.com

\section{Participante:}

Nombre: Irán Carolina Leal

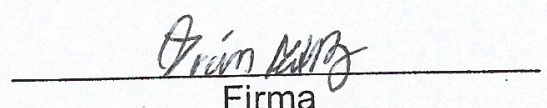

Quien obtiene el consentimiento:

Nombre: Wahel Earria Helnänder

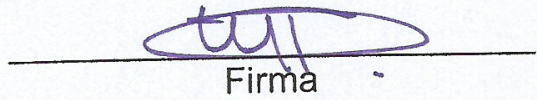




\section{CUESTIONARIO PSSUQ}

Edad:20 Sexo: M I (F) Licenciatura: Diseño de In formación Visual Manejo de llustrator:Si I No Propuesta de guía:

No. de cuestionario: 11

Este cuestionario es una oportunidad para registrar tus reacciones a la guía de usabilidad. Estas respuestas nos ayudarán a entender qué aspectos hay que mejorar y cuales son con los que no estás satisfechos. Para tener un mejor resultado, piensa en la tarea que se te pidió que realizaras con base a lo que las guias decian mientras contestas estas preguntas.

Instrucciones: Lea cada frase y señala qué tan de acuerdo o en desacuerdo estás y encierra en un circulo un número de la escala. Al terminar, revisaremos juntos el cuestionario para asegurarnos de que entendamos bien la información presentada en este cuestionario.

¡Gracias!

a) La organización de la información proporcionada por las guías me fue clara.

Totalmente en desacuerdo

$1 \quad 2$

2.3

34

45

6

Totalmente de acuerdo

(7)

b) Fui capaz de completar las tareas que se me indicaron rápidamente con la información proporcionada en las guías.

Totalmente en desacuerdo

1

2

3

4

5

Totalmente de acuerdo

3

c) La información proporcionada por las guías fue fácil de entender.

Totalmente en desacuerdo

1

2

3

4

5

Totalmente de acuerdo

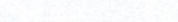

d) La apariencia de las guías es agradable.

Totalmente en desacuerdo

1

2

3

4

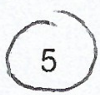

Totalmente de acuerdo

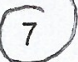

e) En general estoy satisfecho con el acomodo y presentación visual de la información.

Totalmente en desacuerdo

1

2

3

4

5

Totalmente de acuerdo 


\section{LISTA DE CHEQUEO DEL ANÁLISIS DE TAREAS}

Evaluador: Wavel_Cuestionario:_ 11 Fecha:24.0Ct Propuesta a evaluar: A

\begin{tabular}{|l|l|l|}
\hline Premisa & Si & No \\
\hline El diseñador generó una paleta de cuatro colores. & & $\times$ \\
\hline $\begin{array}{l}\text { El diseñador relacionó correctamente los lineamientos de } \\
\text { codificación de información en dispositivos médicos y los } \\
\text { aplicó en las secciones de la gráfica de acuerdo a su signi- } \\
\text { ficado. }\end{array}$ & & \\
\hline $\begin{array}{l}\text { El diseñador estableció un buen contraste entre fondo, } \\
\text { figura y texto. }\end{array}$ & & \\
\hline $\begin{array}{l}\text { Tiempo en que tardó en leer la página el diseñador. } \\
\text { Veces en que volvió a consultar la página el diseñador. }\end{array}$ & $1 / 1(3)$ & \\
\hline Tiempo en que tardó en completar la tarea el diseñador. & $5173 !$ & \\
\hline
\end{tabular}


Anexo 10.12. USUARIO 12: Material de resultados de la evaluación de la propuesta editorial "A": consentimiento informado, lista de chequedo de análisis de tareas y cuestionario PSSUQ. 


\section{Consentimiento informado}

Proyecto: NOMOLAS: Propuesta de guías de usabilidad para el diseño de interfaces gráficas de sistemas de visualización de información médica.

Nombre del estudio: Evaluación de usabilidad de propuestas editoriales de las guias de usabilidad NOMOLAS con usuarios (lectores) de las mismas.

Lugar y fecha:
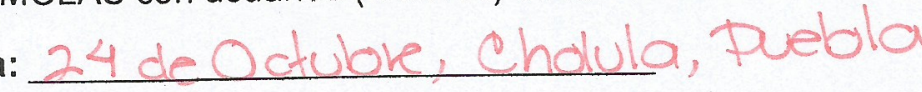

Número de registro:

12.

Justificación y objetivo del estudio: La forma en que se presenta la información es importante para que ésta sea comprendida de la mejor manera posible. Este estudio tiene como propósito elegir la mejor propuesta editorial para implementarla en toda la composición visual del proyecto llamado "NOMOLAS: Propuesta de guías de usabilidad para el diseño de interfaces gráficas de sistemas de visualización de información médica", que es a su vez, trabajo de investigación doctoral.

Procedimientos: Primero, se le explicaran los objetivos y el procedimiento de la sesión; describiendo como se llevará a cabo la prueba. Segundo, le pediremos que siga las instrucciones que le entregue el investigador encargado.

Posibles riesgos y molestias: En investigaciones similares no se han registrado dificultades o riesgos de ningún tipo, por tanto, durante su participación no se prevé ningún riesgo.

Posibles beneficios que recibirá al participar en el estudio: Al final de la prueba se le dará al participante $\$ 50.00$ pesos mexicanos en efectivo.

Participación o retiro: Si después de que Usted haya leido esta información y haya obtenido respuesta a las preguntas que pudiera tener, le vamos a pedir leer y firmar esta carta de consentimiento informado. Sin embargo, Usted puede retirarse en cualquier momento, por cualquier razón y nadie le va a preguntar sobre las razones por las cuales se retira.

Privacidad y confidencialidad: Para garantizar la confidencialidad toda la información será guardada y analizada sin usar los nombres reales de los participantes. Después de ser analizada, la información será guardada por un tiempo razonable y luego destruida.

En caso de dudas o aclaraciones relacionadas con el estudio podrá dirigirse con: Mtra. Mariel García Hernández quien conoce todos los detalles de este estudio. 2224924264 , Correo: mariel.garciahernandez@gmail.com

Participante:

Quien obtiene el consentimiento:

Nombre: Mavia de Jejus Quiñonanombre: Warrel Garéa Hemandez

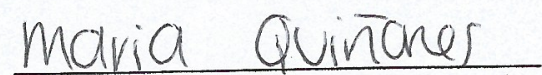

\& R. Firma

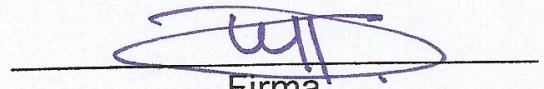

Firma 


\section{CUESTIONARIO PSSUQ}

Edad:20 Sexo: M / F Licenciatura:

Manejo de llustrator: Si / No

Propuesta de guía:

No. de cuestionario: 12

Este cuestionario es una oportunidad para registrar tus reacciones a la guia de usabilidad. Estas respuestas nos ayudarán a entender qué aspectos hay que mejorar y cuales son con los que no estás satisfechos. Para tener un mejor resultado, piensa en la tarea que se te pidió que realizaras con base a lo que las guías decian mientras contestas estas preguntas.

Instrucciones: Lea cada frase y señala qué tan de acuerdo o en desacuerdo estás y encierra en un circulo un número de la escala. Al terminar, revisaremos juntos el cuestionario para asegurarnos de que entendamos bien la información presentada en este cuestionario.

\section{¡Gracias!}

a) La organización de la información proporcionada por las guías me fue clara.

Totalmente en desacuerdo

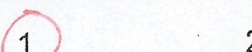

2

3

4

5

Totalmente de acuerdo

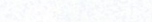

6

7

b) Fui capaz de completar las tareas que se me indicaron rápidamente con la información proporcionada en las guías.

Totalmente en desacuerdo
1
(2)
3
4
5
7

Totalmente de acuerdo

c) La información proporcionada por las guías fue fácil de entender.

Totalmente en desacuerdo

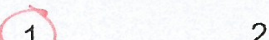

2

3

4

5

Totalmente de acuerdo

6

7

d) La apariencia de las guías es agradable.

Totalmente en desacuerdo

1

(2) 3

34

45

Totalmente de acuerdo

$6 \quad 7$

e) En general estoy satisfecho con el acomodo y presentación visual de la información.

Totalmente en desacuerdo

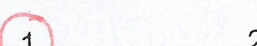

(1)

2

3

4

5

Totalmente de acuerdo 


\section{LISTA DE CHEQUEO DEL ANÁLISIS DE TAREAS}

Evaluador: Uhariel Cuestionario: 12 Fecha: $24 \cdot 0 \mathrm{ct} .19$ Propuesta a evaluar: A

\begin{tabular}{|l|c|l|}
\hline Premisa & Si & No \\
\hline El diseñador generó una paleta de cuatro colores. & $\checkmark$ & \\
\hline $\begin{array}{l}\text { El diseñador relacionó correctamente los lineamientos de } \\
\text { codificación de información en dispositivos médicos y los } \\
\text { aplicó en las secciones de la gráfica de acuerdo a su signi- } \\
\text { ficado. }\end{array}$ & & \\
\hline $\begin{array}{l}\text { El diseñador estableció un buen contraste entre fondo, } \\
\text { figura y texto. }\end{array}$ & 47.79 seg \\
\hline $\begin{array}{l}\text { Tiempo en que tardó en leer la página el diseñador. } \\
\text { Veces en que volvió a consultar la página el diseñador. }\end{array}$ & $0.58 .91 \mathrm{~min}$ \\
\hline Tiempo en que tardó en completar la tarea el diseñador. & 0.58 & \\
\hline
\end{tabular}


Anexo 10.13. USUARIO 13: Material de resultados de la evaluación de la propuesta editorial "A": consentimiento informado, lista de chequedo de análisis de tareas y cuestionario PSSUQ. 


\section{Consentimiento informado}

Proyecto: NOMOLAS: Propuesta de guias de usabilidad para el diseño de interfaces gráficas de sistemas de visualización de información médica.

Nombre del estudio: Evaluación de usabilidad de propuestas editoriales de las guias de usabilidad NOMOLAS con usuarios (lectores) de las mismas.

Lugar y fecha:
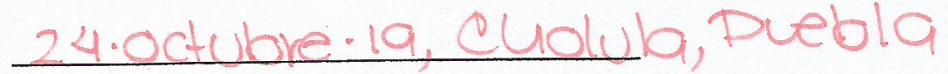

Número de registro:

13

Justificación y objetivo del estudio: La forma en que se presenta la información es importante para que ésta sea comprendida de la mejor manera posible. Este estudio tiene como propósito elegir la mejor propuesta editorial para implementarla en toda la composición visual del proyecto llamado "NOMOLAS: Propuesta de guías de usabilidad para el diseño de interfaces gráficas de sistemas de visualización de información médica", que es a su vez, trabajo de investigación doctoral.

Procedimientos: Primero, se le explicaran los objetivos y el procedimiento de la sesión; describiendo como se llevará a cabo la prueba. Segundo, le pediremos que siga las instrucciones que le entregue el investigador encargado.

Posibles riesgos y molestias: En investigaciones similares no se han registrado dificultades o riesgos de ningún tipo, por tanto, durante su participación no se prevé ningún riesgo.

Posibles beneficios que recibirá al participar en el estudio: Al final de la prueba se le dará al participante $\$ 50.00$ pesos mexicanos en efectivo.

Participación o retiro: Si después de que Usted haya leído esta información y haya obtenido respuesta a las preguntas que pudiera tener, le vamos a pedir leer y firmar esta carta de consentimiento informado. Sin embargo, Usted puede retirarse en cualquier momento, por cualquier razón y nadie le va a preguntar sobre las razones por las cuales se retira.

Privacidad y confidencialidad: Para garantizar la confidencialidad toda la información será guardada y analizada sin usar los nombres reales de los participantes. Después de ser analizada, la información será guardada por un tiempo razonable y luego destruida.

En caso de dudas o aclaraciones relacionadas con el estudio podrá dirigirse con: Mtra. Mariel García Hernández quien conoce todos los detalles de este estudio. 2224924264 , Correo: mariel.garciahernandez@gmail.com

\section{Participante:}

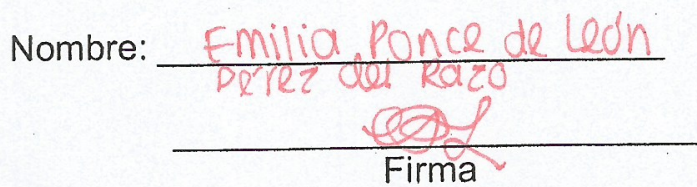

\section{Quien obtiene el consentimiento:}

Nombre: Ulanel Garcia Hernóncler

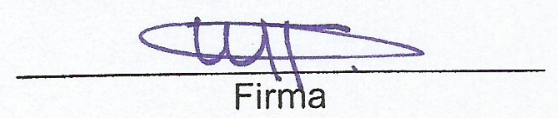




\section{CUESTIONARIO PSSUQ}

Edad: 19 Sexo: M I F Licenciatura: Diseño de Información Vifual Manejo de llustrator: Si I No Propuesta de guía: A No. de cuestionario: 13

Este cuestionario es una oportunidad para registrar tus reacciones a la guía de usabilidad. Estas respuestas nos ayudarán a entender qué aspectos hay que mejorar y cuales son con los que no estás satisfechos. Para tener un mejor resultado, piensa en la tarea que se te pidió que realizaras con base a lo que las guías decian mientras contestas estas preguntas.

Instrucciones: Lea cada frase y señala qué tan de acuerdo o en desacuerdo estás y encierra en un circulo un número de la escala. Al terminar, revisaremos juntos el cuestionario para asegurarnos de que entendamos bien la información presentada en este cuestionario.

¡Gracias!

a) La organización de la información proporcionada por las guías me fue clara.

Totalmente en desacuerdo

$$
1 \quad 2
$$

2

3

4

5

Totalmente de acuerdo

b) Fui capaz de completar las tareas que se me indicaron rápidamente con la información proporcionada:en las guías.

Totalmente en desacuerdo

1

2

3

4

5

Totalmente de acuerdo

c) La información proporcionada por las guías fue fácil de entender.

Totalmente en desacuerdo

1

2

3

4

5

Totalmente de acuerdo

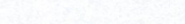

67

d) La apariencia de las guías es agradable.

Totalmente en desacuerdo

1

2

3

4

5

Totalmente de acuerdo

6

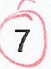

e) En general estoy satisfecho con el acomodo y presentación visual de la información.

Totalmente en desacuerdo

Totalmente de acuerdo

1




\section{LISTA DE CHEQUEO DEL ANÁLISIS DE TAREAS}

Evaluador: Uavel_Cuestionario: 13 Fecha: $24 \cdot 10 \cdot 19$ Propuesta a evaluar: A

\begin{tabular}{|l|l|l|}
\hline Premisa & Si & No \\
\hline El diseñador generó una paleta de cuatro colores. & $\checkmark$ & \\
\hline $\begin{array}{l}\text { El diseñador relacionó correctamente los lineamientos de } \\
\text { codificación de información en dispositivos médicos y los } \\
\text { aplicó en las secciones de la gráfica de acuerdo a su signi- } \\
\text { ficado. }\end{array}$ & & \\
\hline $\begin{array}{l}\text { El diseñador estableció un buen contraste entre fondo, } \\
\text { figura y texto. }\end{array}$ & & \\
\hline $\begin{array}{l}\text { Tiempo en que tardó en leer la página el diseñador. } \\
\text { Veces en que volvió a consultar la página el diseñador. }\end{array}$ & $111(3) 9 \mathrm{seg}$ \\
\hline Tiempo en que tardó en completar la tarea el diseñador. & $2: 36.29 \mathrm{~min}$ \\
\hline
\end{tabular}


Anexo 10.14. USUARIO 14: Material de resultados de la evaluación de la propuesta editorial "A": consentimiento informado, lista de chequedo de análisis de tareas y cuestionario PSSUQ. 


\section{Consentimiento informado}

Proyecto: NOMOLAS: Propuesta de guias de usabilidad para el diseño de interfaces gráficas de sistemas de visualización de información médica.

Nombre del estudio: Evaluación de usabilidad de propuestas editoriales de las guías de usabilidad NOMOLAS con usuarios (lectores) de las mismas.

Lugar y fecha: _ MAt 24 de Octube del 2019

Número de registro: $\quad 14$

Justificación y objetivo del estudio: La forma en que se presenta la información es importante para que ésta sea comprendida de la mejor manera posible. Este estudio tiene como propósito elegir la mejor propuesta editorial para implementarla en toda la composición visual del proyecto llamado "NOMOLAS: Propuesta de guías de usabilidad para el diseño de interfaces gráficas de sistemas de visualización de información médica", que es a su vez, trabajo de investigación doctoral.

Procedimientos: Primero, se le explicaran los objetivos y el procedimiento de la sesión; describiendo como se llevará a cabo la prueba. Segundo, le pediremos que siga. las instrucciones que le entregue el investigador encargado.

Posibles riesgos y molestias: En investigaciones similares no se han registrado dificultades o riesgos de ningún tipo, por tanto, durante su participación no se prevé ningún riesgo.

Posibles beneficios que recibirá al participar en el estudio: Al final de la prueba se le dará al participante $\$ 50.00$ pesos mexicanos en efectivo.

Participación o retiro: Si después de que Usted haya leído esta información y haya obtenido respuesta a las preguntas que pudiera tener, le vamos a pedir leer y firmar esta carta de consentimiento informado. Sin embargo, Usted puede retirarse en cualquier momento, por cualquier razón y nadie le va a preguntar sobre las razones por las cuales se retira.

Privacidad y confidencialidad: Para garantizar la confidencialidad toda la información será guardada y analizada sin usar los nombres reales de los participantes. Después de ser analizada, la información será guardada por un tiempo razonable y luego destruida.

En caso de dudas o aclaraciones relacionadas con el estudio podrá dirigirse con: Mtra. Mariel García Hernández quien conoce todos los detalles de este estudio. 2224924264 , Correo: mariel.garciahernandez@gmail.com

Participante:

Quien obtiene el consentimiento:

Nombre: Ana Ceelia Barrena leo Nombre: Uarlel Garcia Heruouder
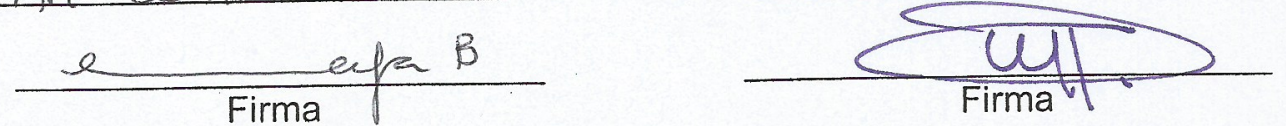


\section{CUESTIONARIO PSSUQ}

Edad: 19 sexo: M I F Licenciatura: Diseño de lnfo Vsud Manejo de llustrator Si I No Propuesta de guía:A No. de cuestionario: 14

Este cuestionario es una oportunidad para registrar tus reacciones a la guia de usabilidad. Estas respuestas nos ayudarán a entender qué aspectos hay que mejorar y cuales son con los que no estás satisfechos. Para tener un mejor resultado, piensa en la tarea que se te pidió que realizaras con base a lo que las guias decian mientras contestas estas preguntas.

Instrucciones: Lea cada frase y señala qué tan de acuerdo o en desacuerdo estás y encierra en un circulo un número de la escala. Al terminar, revisaremos juntos el cuestionario para asegurarnos de que entendamos bien la información presentada en este cuestionario.

¡Gracias!

a) La organización de la información proporcionada por las guías me fue clara.

Totalmente en desacuerdo

$$
12
$$

34

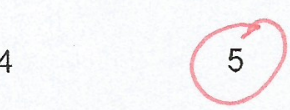

Totalmente de acuerdo 6

b) Fui capaz de completar las tareas que se me indicaron rápidamente con la información proporcionada en las guías.

Totalmente en desacuerdo

1

2

3

4

5

Totalmente de acuerdo

c) La información proporcionada por las guías fue fácil de entender.

Totalmente en desacuerdo

1

2
3

4

d) La apariencia de las guías es agradable.

Totalmente en desacuerdo

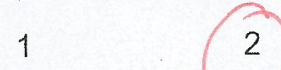

1

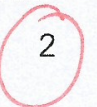

3

4

e) En general estoy satisfecho con el acomodo y presentación visual de la información. Totalmente en desacuerdo

1

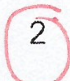

Totalmente de acuerdo

6
Totalmente de acuerdo

7
Totalmente de acuerdo

7 


\section{LISTA DE CHEQUEO DEL ANÁLISIS DE TAREAS}

Evaluador: Uane Cuestionario: 14 Fecha: $24 \cdot 0 \mathrm{ct} \cdot 19$ Propuesta a evaluar: A

\begin{tabular}{|l|c|l|}
\hline Premisa & Si & No \\
\hline El diseñador generó una paleta de cuatro colores. & & \\
\hline $\begin{array}{l}\text { El diseñador relacionó correctamente los lineamientos de } \\
\text { codificación de información en dispositivos médicos y los } \\
\text { aplicó en las secciones de la gráfica de acuerdo a su signi- } \\
\text { ficado. }\end{array}$ & & \\
\hline $\begin{array}{l}\text { El diseñador estableció un buen contraste entre fondo, } \\
\text { figura y texto. }\end{array}$ & & \\
\hline Tiempo en que tardó en leer la página el diseñador. & $22.03 \mathrm{seg}$ \\
\hline Veces en que volvió a consultar la página el diseñador. & 1 \\
\hline Tiempo en que tardó en completar la tarea el diseñador. & $1.44 .58 \mathrm{~min}$ \\
\hline
\end{tabular}


Anexo 10.15. USUARIO 15: Material de resultados de la evaluación de la propuesta editorial "A": consentimiento informado, lista de chequedo de análisis de tareas y cuestionario PSSUQ. 


\section{Consentimiento informado}

Proyecto: NOMOLAS: Propuesta de guias de usabilidad para el diseño de interfaces gráficas de sistemas de visualización de información médica.

Nombre del estudio: Evaluación de usabilidad de propuestas editoriales de las guías de usabilidad NOMOLAS con usuarios (lectores) de las mismas.

Lugar y fecha:

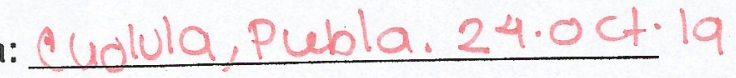

Número de registro:

15

Justificación y objetivo del estudio: La forma en que se presenta la información es importante para que ésta sea comprendida de la mejor manera posible. Este estudio tiene como propósito elegir la mejor propuesta editorial para implementarla en toda la composición visual del proyecto llamado "NOMOLAS: Propuesta de guías de usabilidad para el diseño de interfaces gráficas de sistemas de visualización de información médica", que es a su vez, trabajo de investigación doctoral.

Procedimientos: Primero, se le explicaran los objetivos y el procedimiento de la sesión; describiendo como se llevará a cabo la prueba. Segundo, le pediremos que siga. las instrucciones que le entregue el investigador encargado.

Posibles riesgos y molestias: En investigaciones similares no se han registrado dificultades o riesgos de ningún tipo, por tanto, durante su participación no se prevé ningún riesgo.

Posibles beneficios que recibirá al participar en el estudio: Al final de la prueba se le dará al participante $\$ 50.00$ pesos mexicanos en efectivo.

Participación o retiro: Si después de que Usted haya leido esta información y haya obtenido respuesta a las preguntas que pudiera tener, le vamos a pedir leer y firmar esta carta de consentimiento informado. Sin embargo, Usted puede retirarse en cualquier momento, por cualquier razón y nadie le va a preguntar sobre las razones por las cuales se retira.

Privacidad y confidencialidad: Para garantizar la confidencialidad toda la información será guardada y analizada sin usar los nombres reales de los participantes. Después de ser analizada, la información será guardada por un tiempo razonable y luego destruida.

En caso de dudas o aclaraciones relacionadas con el estudio podrá dirigirse con: Mtra. Mariel García Hernández quien conoce todos los detalles de este estudio. 2224924264 , Correo: mariel.garciahernandez@gmail.com

Participante:

Nombre:

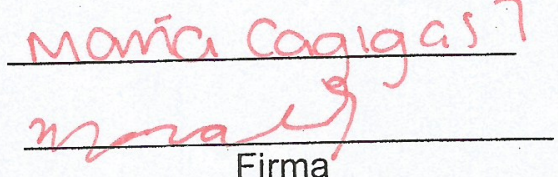

Quien obtiene el consentimiento:

Nombre: Wariel Garcia Hernāndec

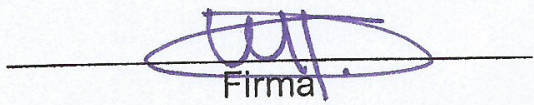




\section{CUESTIONARIO PSSUQ}

Edad:19 Sexo: M / F Licenciatura:Disefnedein formoclónManejo de llustrator: Si / No Propuesta de guía: A No. de cuestionario: 15

Este cuestionario es una oportunidad para registrar tus reacciones a la guia de usabilidad. Estas respuestas nos ayudarán a entender qué aspectos hay que mejorar y cuales son con los que no estás satisfechos. Para tener un mejor resultado, piensa en la tarea que se te pidió que realizaras con base a lo que las guías decian mientras contestas estas preguntas.

Instrucciones: Lea cada frase y señala qué tan de acuerdo o en desacuerdo estás y encierra en un circulo un número de la escala. Al terminar, revisaremos juntos el cuestionario para asegurarnos de que entendamos bien la información presentada en este cuestionario.

¡Gracias!

a) La organización de la información proporcionada por las guías me fue clara.

Totalmente en desacuerdo

$$
12
$$

2

3

4

5

Totalmente de acuerdo

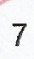

b) Fui capaz de completar las tareas que se me indicaron rápidamente con la información proporcionada en las guías.

Totalmente en desacuerdo

$$
12
$$

2

3

4

5

Totalmente de acuerdo

c) La información proporcionada por las guías fue fácil de entender.

Totalmente en desacuerdo

1

2
4

d) La apariencia de las guías es agradable.

Totalmente en desacuerdo

12
3

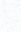

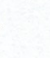

Totalmente de acuerdo

6

Totalmente de acuerdo 7

e) En general estoy satisfecho con el acomodo y presentación visual de la información.

Totalmente en desacuerdo

1

2

3

4

5

Totalmente de acuerdo 


\section{LISTA DE CHEQUEO DEL ANÁLISIS DE TAREAS}

Evaluador: Warel_Cuestionario: 15 Fecha:24.0ct.19 Propuesta a evaluar: A

\begin{tabular}{|l|c|c|}
\hline Premisa & Si & No \\
\hline El diseñador generó una paleta de cuatro colores. & $\checkmark$ & \\
\hline $\begin{array}{l}\text { El diseñador relacionó correctamente los lineamientos de } \\
\text { codificación de información en dispositivos médicos y los } \\
\text { aplicó en las secciones de la gráfica de acuerdo a su signi- } \\
\text { ficado. }\end{array}$ & $\sqrt{ }$ & \\
\hline $\begin{array}{l}\text { El diseñador estableció un buen contraste entre fondo, } \\
\text { figura y texto. }\end{array}$ & $1 \mathrm{~S} \cdot 11 \mathrm{seg}$ \\
\hline Tiempo en que tardó en leer la página el diseñador. & $2 \mathrm{~min}$ \\
\hline Veces en que volvió a consultar la página el diseñador. & \\
\hline Tiempo en que tardó en completar la tarea el diseñador. & & \\
\hline
\end{tabular}



Anexo 10.16. USUARIO 16: Material de resultados de la evaluación de la propuesta editorial "B": consentimiento informado, lista de chequedo de análisis de tareas y cuestionario PSSUQ. 


\section{Consentimiento informado}

Proyecto: NOMOLAS: Propuesta de guías de usabilidad para el diseño de interfaces gráficas de sistemas de visualización de información médica.

Nombre del estudio: Evaluación de usabilidad de propuestas editoriales de las guías de usabilidad NOMOLAS con usuarios (lectores) de las mismas.

Lugar y fecha: Cuolula, Puebla.

Número de registro:

16

Justificación y objetivo del estudio: La forma en que se presenta la información es importante para que ésta sea comprendida de la mejor manera posible. Este estudio tiene como propósito elegir la mejor propuesta editorial para implementarla en toda la composición visual del proyecto llamado "NOMOLAS: Propuesta de guías de usabilidad para el diseño de interfaces gráficas de sistemas de visualización de información médica", que es a su vez, trabajo de investigación doctoral.

Procedimientos: Primero, se le explicaran los objetivos y el procedimiento de la sesión; describiendo como se llevará a cabo la prueba. Segundo, le pediremos que siga. las instrucciones que le entregue el investigador encargado.

Posibles riesgos y molestias: En investigaciones similares no se han registrado dificultades 0 riesgos de ningún tipo, por tanto, durante su participación no se prevé ningún riesgo.

Posibles beneficios que recibirá al participar en el estudio: Al final de la prueba se le dará al participante $\$ 50.00$ pesos mexicanos en efectivo.

Participación o retiro: Si después de que Usted haya leído esta información y haya obtenido respuesta a las preguntas que pudiera tener, le vamos a pedir leer y firmar esta carta de consentimiento informado. Sin embargo, Usted puede retirarse en cualquier momento, por cualquier razón y nadie le va a preguntar sobre las razones por las cuales se retira.

Privacidad y confidencialidad: Para garantizar la confidencialidad toda la información será guardada y analizada sin usar los nombres reales de los participantes. Después de ser analizada, la información será guardada por un tiempo razonable y luego destruida.

En caso de dudas o aclaraciones relacionadas con el estudio podrá dirigirse con: Mtra. Mariel García Hernández quien conoce todos los detalles de este estudio. 2224924264 , Correo: mariel.garciahernandez@gmail.com

\section{Participante:}

Nombre: Paola lbarra Alwarzz

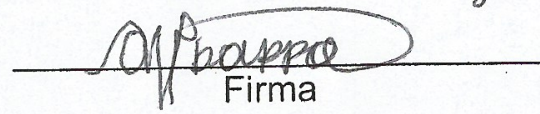

\section{Quien obtiene el consentimiento:}

Nombre: Uarel Garia Hevidudec

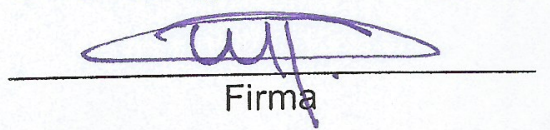




\section{CUESTIONARIO PSSUQ}

Edad: 19 sexo: M IF Licenciatura: D Beño de infoim. Manejo de llustrator: Si I No Propuesta de guía: $B$ No. de cuestionario: 16

Este cuestionario es una oportunidad para registrar tus reacciones a la guía de usabilidad. Estas respuestas nos ayudarán a entender qué aspectos hay que mejorar y cuales son con los que no estás satisfechos. Para tener un mejor resultado, piensa en la tarea que se te pidió que realizaras con base a lo que las guías decian mientras contestas estas preguntas.

Instrucciones: Lea cada frase y señala qué tan de acuerdo o en desacuerdo estás y encierra en un circulo un número de la escala. Al terminar, revisaremos juntos el cuestionario para asegurarnos de que entendamos bien la información presentada en este cuestionario.

¡Gracias!

a) La organización de la información proporcionada por las guías me fue clara.

Totalmente en desacuerdo

1

2

3

4

5

6

Totalmente de acuerdo

.

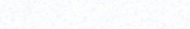

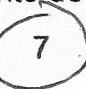

b) Fui capaz de completar las tareas que se me indicaron rápidamente con la información proporcionada en las guías.

Totalmente en desacuerdo

1

2

3

4

5

Totalmente de acuerdo

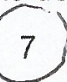

c) La información proporcionada por las guías fue fácil de entender.

Totalmente en desacuerdo

1

2

3

4

5

Totalmente de acuerdo

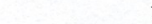

d) La apariencia de las guías es agradable.

Totalmente en desacuerdo

1

2

3

4

5

Totalmente de acuerdo

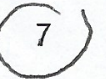

e) En general estoy satisfecho con el acomodo y presentación visual de la información.

Totalmente en desacuerdo

1

2

3

4

5

Totalmente de acuerdo

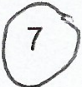


Evaluador: Ulanel Cuestionario: 16 Fecha: $28.00+19$

\begin{tabular}{|l|c|l|}
\hline Premisa & Si & No \\
\hline El diseñador generó una paleta de cuatro colores. & $V$ & \\
\hline $\begin{array}{l}\text { El diseñador relacionó correctamente los lineamientos de } \\
\text { codificación de información en dispositivos médicos y los } \\
\text { aplicó en las secciones de la gráfica de acuerdo a su signi- } \\
\text { ficado. }\end{array}$ & $\checkmark$ & \\
\hline $\begin{array}{l}\text { El diseñador estableció un buen contraste entre fondo, } \\
\text { figura y texto. }\end{array}$ & & \\
\hline Tiempo en que tardó en leer la página el diseñador. & $48.68 \mathrm{seg}$ \\
\hline Veces en que volvió a consultar la página el diseñador. & $2: 03.08$ \\
\hline Tiempo en que tardó en completar la tarea el diseñador. & 2 & \\
\hline
\end{tabular}


Anexo 10.17. USUARIO 17: Material de resultados de la evaluación de la propuesta editorial "B": consentimiento informado, lista de chequedo de análisis de tareas y cuestionario PSSUQ. 


\section{Consentimiento informado}

Proyecto: NOMOLAS: Propuesta de guias de usabilidad para el diseño de interfaces gráficas de sistemas de visualización de información médica.

Nombre del estudio: Evaluación de usabilidad de propuestas editoriales de las guías de usabilidad NOMOLAS con usuarios (lectores) de las mismas.

Lugar y fecha:Cuolula, Puebla. 2 a oct.la

Número de registro:

17

Justificación y objetivo del estudio: La forma en que se presenta la información es importante para que ésta sea comprendida de la mejor manera posible. Este estudio tiene como propósito elegir la mejor propuesta editorial para implementarla en toda la composición visual del proyecto llamado "NOMOLAS: Propuesta de guías de usabilidad para el diseño de interfaces gráficas de sistemas de visualización de información médica", que es a su vez, trabajo de investigación doctoral.

Procedimientos: Primero, se le explicaran los objetivos y el procedimiento de la sesión; describiendo como se llevará a cabo la prueba. Segundo, le pediremos que siga las instrucciones que le entregue el investigador encargado.

Posibles riesgos y molestias: En investigaciones similares no se han registrado dificultades o riesgos de ningún tipo, por tanto, durante su participación no se prevé ningún riesgo.

Posibles beneficios que recibirá al participar en el estudio: Al final de la prueba se le dará al participante $\$ 50.00$ pesos mexicanos en efectivo.

Participación o retiro: Si después de que Usted haya leido esta información y haya obtenido respuesta a las preguntas que pudiera tener, le vamos a pedir leer y firmar esta carta de consentimiento informado. Sin embargo, Usted puede retirarse en cualquier momento, por cualquier razón y nadie le va a preguntar sobre las razones por las cuales se retira.

Privacidad y confidencialidad: Para garantizar la confidencialidad toda la información será guardada y analizada sin usar los nombres reales de los participantes. Después de ser analizada, la información será guardada por un tiempo razonable y luego destruida.

En caso de dudas o aclaraciones relacionadas con el estudio podrá dirigirse con: Mtra. Mariel García Hernández quien conoce todos los detalles de este estudio. 22249242 64, Correo: mariel.garciahernandez@gmail.com

Participante:

Nombre: Sofía Ramitez Garzón

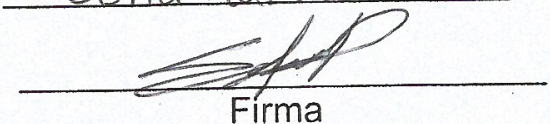

Quien obtiene el consentimiento:

Nombre: Marel García Heruöuder

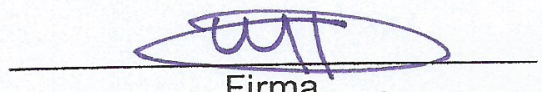




\section{CUESTIONARIO PSSUQ}

Edad: 19 sexo: M I (F) Licenciatura: Diseño de Informoldón Visual manejo de llustrator: (si) I No Propuesta de guía: B No. de cuestionario: 17

Este cuestionario es una oportunidad para registrar tus reacciones a la guía de usabilidad. Estas respuestas nos ayudarán a entender qué aspectos hay que mejorar y cuales son con los que no estás satisfechos. Para tener un mejor resultado, piensa en la tarea que se te pidió que realizaras con base a lo que las guías decian mientras contestas estas preguntas.

Instrucciones: Lea cada frase y señala qué tan de acuerdo o en desacuerdo estás y encierra en un circulo un número de la escala. Al terminar, revisaremos juntos el cuestionario para asegurarnos de que entendamos bien la información presentada en este cuestionario.

\section{¡Gracias!}

a) La organización de la información proporcionada por las guías me fue clara.

Totalmente en desacuerdo

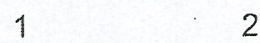

2

3

4

5

Totalmente de acuerdo

6

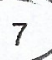

b) Fui capaz de completar las tareas que se me indicaron rápidamente con la información proporcionada en las guías.

Totalmente en desacuerdo

12

3

4

5

Totalmente de acuerdo

6

c) La información proporcionada por las guías fue fácil de entender.

Totalmente en desacuerdo

1

2

3

4

5

Totalmente-de acuerdo

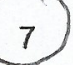

d) La apariencia de las guías es agradable.

Totalmente en desacuerdo

1

2

3

4

5

Totalmente de acuerdo

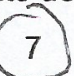

e) En general estoy satisfecho con el acomodo y presentación visual de la información.

Totalmente en desacuerdo

1

2

3

4

5

Totalmente de acuerdo

6 


\section{LISTA DE CHEQUEO DEL ANÁLISIS DE TAREAS}

Evaluador: Mharcel Cuestionario: 17 Fecha: $28.0 \mathrm{ct} .19$ Propuesta a evaluar: $B$

\begin{tabular}{|l|l|l|}
\hline Premisa & Si & No \\
\hline El diseñador generó una paleta de cuatro colores. & & $\times$ \\
\hline $\begin{array}{l}\text { El diseñador relacionó correctamente los lineamientos de } \\
\text { codificación de información en dispositivos médicos y los } \\
\text { aplicó en las secciones de la gráfica de acuerdo a su signi- } \\
\text { ficado. }\end{array}$ & X & \\
\hline $\begin{array}{l}\text { El diseñador estableció un buen contraste entre fondo, } \\
\text { figura y texto. }\end{array}$ & - & \\
\hline $\begin{array}{l}\text { Tiempo en que tardó en leer la página el diseñador. } \\
\text { Veces en que volvió a consultar la página el diseñador. }\end{array}$ & $2.25 .48 \mathrm{~min}$ \\
\hline Tiempo en que tardó en completar la tarea el diseñador.
\end{tabular}


Anexo 10.18. USUARIO 18: Material de resultados de la evaluación de la propuesta editorial "B": consentimiento informado, lista de chequedo de análisis de tareas y cuestionario PSSUQ. 


\section{Consentimiento informado}

Proyecto: NOMOLAS: Propuesta de guías de usabilidad para el diseño de interfaces gráficas de sistemas de visualización de información médica.

Nombre del estudio: Evaluación de usabilidad de propuestas editoriales de las guías de usabilidad NOMOLAS con usuarios (lectores) de las mismas.

Lugar y fecha: 4. Uomeuble 19 , Puebla, Ouebla.

Número de registro:

18

Justificación y objetivo del estudio: La forma en que se presenta la información es importante para que ésta sea comprendida de la mejor manera posible. Este estudio tiene como propósito elegir la mejor propuesta editorial para implementarla en toda la composición visual del proyecto Ilamado "NOMOLAS: Propuesta de guías de usabilidad para el diseño de interfaces gráficas de sistemas de visualización de información médica", que es a su vez, trabajo de investigación doctoral.

Procedimientos: Primero, se le explicaran los objetivos y el procedimiento de la sesión; describiendo como se llevará a cabo la prueba. Segundo, le pediremos que siga las instrucciones que le entregue el investigador encargado.

Posibles riesgos y molestias: En investigaciones similares no se han registrado dificultades o riesgos de ningún tipo, por tanto, durante su participación no se prevé ningún riesgo.

Posibles beneficios que recibirá al participar en el estudio: Al final de la prueba se le dará al participante $\$ 50.00$ pesos mexicanos en efectivo.

Participación o retiro: Si después de que Usted haya leído esta información y haya obtenido respuesta a las preguntas que pudiera tener, le vamos a pedir leer y firmar esta carta de consentimiento informado. Sin embargo, Usted puede retirarse en cualquier momento, por cualquier razón y nadie le va a preguntar sobre las razones por las cuales se retira.

Privacidad y confidencialidad: Para garantizar la confidencialidad toda la información será guardada y analizada sin usar los nombres reales de los participantes. Después de ser analizada, la información será guardada por un tiempo razonable y luego destruida.

En caso de dudas o aclaraciones relacionadas con el estudio podrá dirigirse con: Mtra. Mariel García Hernández quien conoce todos los detalles de este estudio. 2224924264 , Correo: mariel.garciahernandez@gmail.com

\section{Participante:}

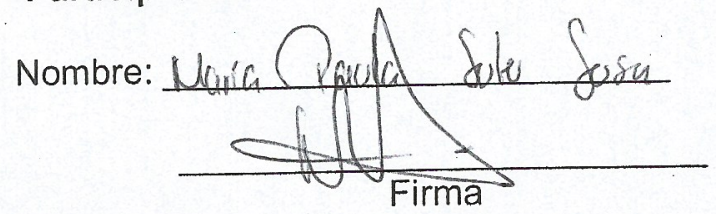

Quien obtiene el consentimiento:

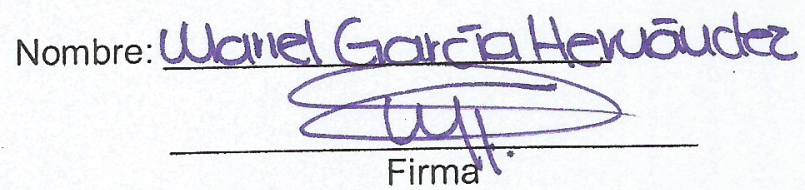




\section{CUESTIONARIO PSSUQ} Edad: 22 Sexo: M, Licenciatura: Difñ Grifice y Digital Manejo de llustrator: \& 1 No
Propuesta de guía: B No. de cuestionario: 18

Este cuestionario es una oportunidad para registrar tus reacciones a la guia de usabilidad. Estas respuestas nos ayudarán a entender qué aspectos hay que mejorar y cuales son con los que no estás satisfechos. Para tener un mejor resultado, piensa en la tarea que se te pidió que realizaras con base a lo que las guías decian mientras contestas estas preguntas.

Instrucciones: Lea cada frase y señala qué tan de acuerdo o en desacuerdo estás y encierra en un circulo un número de la escala. Al terminar, revisaremos juntos el cuestionario para asegurarnos de que entendamos bien la información presentada en este cuestionario.

¡Gracias!

a) La organización de la información proporcionada por las guías me fue clara.

Totalmente en desacuerdo

$$
1 \quad 2
$$
2
3

4

5

Totalmente de acuerdo

b) Fui capaz de completar las tareas que se me indicaron rápidamente con la información proporcionada en las guías.

Totalmente en desacuerdo

1

2

3

4

5

Totalmente de acuerdo

c) La información proporcionada por las guias fue fácil de entender.

Totalmente en desacuerdo

$$
1
$$

2

3

4

5

Totalmente de acuerdo

d) La apariencia de las guías es agradable.

Totalmente en desacuerdo

$$
1 \quad 2
$$
2
3

4

5

Totalmente de acuerdo

e) En general estoy satisfecho con el acomodo y presentación visual de la información.

Totalmente en desacuerdo 


\section{LISTA DE CHEQUEO DEL ANÁLISIS DE TAREAS}

Evaluador: Wanel Cuestionario: 18 Fecha: $4.499^{\circ}$ Propuesta a evaluar: B

\begin{tabular}{|l|c|c|}
\hline Premisa & Si & No \\
\hline El diseñador generó una paleta de cuatro colores. & $\checkmark$ & \\
\hline $\begin{array}{l}\text { El diseñador relacionó correctamente los lineamientos de } \\
\text { codificación de información en dispositivos médicos y los } \\
\text { aplicó en las secciones de la gráfica de acuerdo a su signi- } \\
\text { ficado. }\end{array}$ & $\checkmark$ & $1: 02: 47 \mathrm{mih}$ \\
\hline $\begin{array}{l}\text { El diseñador estableció un buen contraste entre fondo, } \\
\text { figura y texto. }\end{array}$ & $-4: 25 \cdot 53$ \\
\hline Tiempo en que tardó en leer la página el diseñador. & - & \\
\hline Veces en que volvió a consultar la página el diseñador. & \\
\hline Tiempo en que tardó en completar la tarea el diseñador. & \\
\hline
\end{tabular}


Anexo 10.19. USUARIO 19: Material de resultados de la evaluación de la propuesta editorial "B": consentimiento informado, lista de chequedo de análisis de tareas y cuestionario PSSUQ. 


\section{Consentimiento informado}

Proyecto: NOMOLAS: Propuesta de guías de usabilidad para el diseño de interfaces gráficas de sistemas de visualización de información médica.

Nombre del estudio: Evaluación de usabilidad de propuestas editoriales de las guias de usabilidad NOMOLAS con usuarios (lectores) de las mismas.

Lugar y fecha: Puebla, Pue. 4. UOv-19

Número de registro:

19

Justificación y objetivo del estudio: La forma en que se presenta la información es importante para que ésta sea comprendida de la mejor manera posible. Este estudio tiene como propósito elegir la mejor propuesta editorial para implementarla en toda la composición visual del proyecto llamado "NOMOLAS: Propuesta de guías de usabilidad para el diseño de interfaces gráficas de sistemas de visualización de información médica", que es a su vez, trabajo de investigación doctoral.

Procedimientos: Primero, se le explicaran los objetivos y el procedimiento de la sesión; describiendo como se llevará a cabo la prueba. Segundo, le pediremos que siga las instrucciones que le entregue el investigador encargado.

Posibles riesgos y molestias: En investigaciones similares no se han registrado dificultades o riesgos de ningún tipo, por tanto, durante su participación no se prevé ningún riesgo.

Posibles beneficios que recibirá al participar en el estudio: Al final de la prueba se le dará al participante $\$ 50.00$ pesos mexicanos en efectivo.

Participación o retiro: Si después de que Usted haya leido esta información y haya obtenido respuesta a las preguntas que pudiera tener, le vamos a pedir leer y firmar esta carta de consentimiento informado. Sin embargo, Usted puede retirarse en cualquier momento, por cualquier razón y nadie le va a preguntar sobre las razones por las cuales se retira.

Privacidad y confidencialidad: Para garantizar la confidencialidad toda la información será guardada y analizada sin usar los nombres reales de los participantes. Después de ser analizada, la información será guardada por un tiempo razonable y luego destruida.

En caso de dudas o aclaraciones relacionadas con el estudio podrá dirigirse con: Mtra. Mariel García Hernández quien conoce todos los detalles de este estudio. 2224924264 , Correo: mariel.garciahernandez@gmail.com

\section{Participante:}

Nombre: María José Ramírez Arrieta:

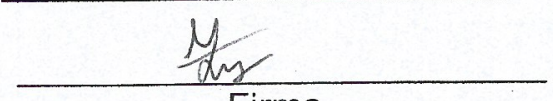

Firma
Quien obtiene el consentimiento:

Nombre: Marlel Garcia Hemōuder

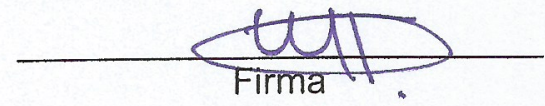




\section{CUESTIONARIO PSSUQ}

Edad:22 Sexo: M / X Licenciatura: Diseño gráfico y digital Manejo de llustrator: \$ 1 No Propuesta de guía: $B$ No. de cuestionario: 19

Este cuestionario es una oportunidad para registrar tus reacciones a la guia de usabilidad. Estas respuestas nos ayudarán a entender qué aspectos hay que mejorar y cuales son con los que no estás satisfechos. Para tener un mejor resultado, piensa en la tarea que se te pidió que realizaras con base a lo que las guías decian mientras contestas estas preguntas.

Instrucciones: Lea cada frase y señala qué tan de acuerdo o en desacuerdo estás y encierra en un circulo un número de la escala. Al terminar, revisaremos juntos el cuestionario para asegurarnos de que entendamos bien la información presentada en este cuestionario.

|Gracias!

a) La organización de la información proporcionada por las guías me fue clara.

Totalmente en desacuerdo

1.2
2
3

4

5

Totalmente de acuerdo

7

b) Fui capaz de completar las tareas que se me indicaron rápidamente con la información proporcionada en las guías.

Totalmente en desacuerdo

1

2

3

4

Totalmente de acuerdo

-

c) La información proporcionada por las guías fue fácil de entender.

Totalmente en desacuerdo

1

2

3

4

5

Totalmente de acuerdo

astable.

d) La apariencia de las guias es agradable.

Totalmente en desacuerdo

12

23

34

45

Totalmente de acuerdo

ॠ 7

Totalmente en desacuerdo

1

2

3

4

5

Totalmente de acuerdo

\section{6}




\section{LISTA DE CHEQUEO DEL ANÁLISIS DE TAREAS}

Evaluador: Uaviel Cuestionario: 19 Fecha: $4 \cdot 11 \cdot 19$ Propuesta a evaluar: B

\begin{tabular}{|l|c|c|}
\hline Premisa & Si & No \\
\hline El diseñador generó una paleta de cuatro colores. & $\checkmark$ & \\
\hline $\begin{array}{l}\text { El diseñador relacionó correctamente los lineamientos de } \\
\text { codificación de información en dispositivos médicos y los } \\
\text { aplicó en las secciones de la gráfica de acuerdo a su signi- } \\
\text { ficado. }\end{array}$ & $\checkmark$ & \\
\hline $\begin{array}{l}\text { El diseñador estableció un buen contraste entre fondo, } \\
\text { figura y texto. }\end{array}$ & $1.24 .53 \mathrm{culu}$ \\
\hline Tiempo en que tardó en leer la página el diseñador. & 1 & $2: 29.99 \mathrm{mil}$ \\
\hline Veces en que volvió a consultar la página el diseñador. & \\
\hline Tiempo en que tardó en completar la tarea el diseñador. & & \\
\hline
\end{tabular}


Anexo 10.20. USUARIO 20: Material de resultados de la evaluación de la propuesta editorial "B": consentimiento informado, lista de chequedo de análisis de tareas y cuestionario PSSUQ. 


\section{Consentimiento informado}

Proyecto: NOMOLAS: Propuesta de guías de usabilidad para el diseño de interfaces gráficas de sistemas de visualización de información médica.

Nombre del estudio: Evaluación de usabilidad de propuestas editoriales de las guías de usabilidad NOMOLAS con usuarios (lectores) de las mismas.

Lugar y fecha: Puebla, Pue. 4 - UOu' iq

Número de registro:

Justificación y objetivo del estudio: La forma en que se presenta la información es importante para que ésta sea comprendida de la mejor manera posible. Este estudio tiene como propósito elegir la mejor propuesta editorial para implementarla en toda la composición visual del proyecto llamado "NOMOLAS: Propuesta de guías de usabilidad para el diseño de interfaces gráficas de sistemas de visualización de información médica", que es a su vez, trabajo de investigación doctoral.

Procedimientos: Primero, se le explicaran los objetivos y el procedimiento de la sesión; describiendo como se llevará a cabo la prueba. Segundo, le pediremos que siga. las instrucciones que le entregue el investigador encargado.

Posibles riesgos y molestias: En investigaciones similares no se han registrado dificultades o riesgos de ningún tipo, por tanto, durante su participación no se prevé ningún riesgo.

Posibles beneficios que recibirá al participar en el estudio: Al final de la prueba se le dará al participante $\$ 50.00$ pesos mexicanos en efectivo.

Participación o retiro: Si después de que Usted haya leido esta información y haya obtenido respuesta a las preguntas que pudiera tener, le vamos a pedir leer y firmar esta carta de consentimiento informado. Sin embargo, Usted puede retirarse en cualquier momento, por cualquier razón y nadie le va a preguntar sobre las razones por las cuales se retira.

Privacidad y confidencialidad: Para garantizar la confidencialidad toda la información será guardada y analizada sin usar los nombres reales de los participantes. Después de ser analizada, la información será guardada por un tiempo razonable y luego destruida.

En caso de dudas o aclaraciones relacionadas con el estudio podrá dirigirse con: Mtra. Mariel Garcia Hernández quien conoce todos los detalles de este estudio. 2224924264 , Correo: mariel.garciahernandez@gmail.com

Participante:

Quien obtiene el consentimiento:

Nombre: Cnstiadasué Castello Castro Nombre: Uanel Garcia Heviöudec
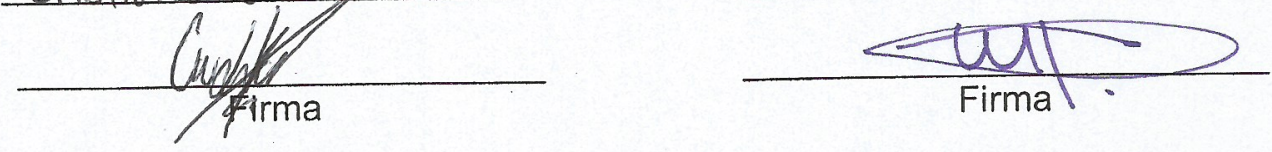


\section{CUESTIONARIO PSSUQ}

Edad:22 Sexo: M I F Licenciatura: DiseñográGio y digital Manejo de llustrator: Si I No Propuesta de guía: $B \quad$ No. de cuestionario: 20

Este cuestionario es una oportunidad para registrar tus reacciones a la guía de usabilidad. Estas respuestas nos ayudarán a entender qué aspectos hay que mejorar y cuales son con los que no estás satisfechos. Para tener un mejor resultado, piensa en la tarea que se te pidió que realizaras con base a lo que las guías decian mientras contestas estas preguntas.

Instrucciones: Lea cada frase y señala qué tan de acuerdo o en desacuerdo estás y encierra en un circulo un número de la escala. Al terminar, revisaremos juntos el cuestionario para asegurarnos de que entendamos bien la información presentada en este cuestionario.

¡Gracias!

a) La organización de la información proporcionada por las guías me fue clara.

Totalmente en desacuerdo

12

2

3

4

5

Totalmente de acuerdo<smiles>C1CCCCCC1</smiles>

b) Ful capaz de completar las tareas que se me indicaron rápidamente con la información proporcionada. en las guías.

Totalmente en desacuerdo

1

2

3

4

5

Totalmente de acuerdo

7

c) La información proporcionada por las guías fue fácil de entender.

Totalmente en desacuerdo

1

2

3

4

5

Totalmente de acuerdo

d) La apariencia de las guias es agradable.

Totalmente en desacuerdo

$$
1 \quad 2
$$

2

3

4

5

Totalmente de acuerdo

e) En general estoy satisfecho con el acomodo y presentación visual de la información.

Totalmente en desacuerdo

1

2

3

4

5

Totalmente de acuerdo

6 
Evaluador: Uanel Cuestionario: 20 Fecha: $4 \cdot 11 \cdot 19$ Propuesta a evaluar: B

\begin{tabular}{|l|c|c|}
\hline Premisa & Si & No \\
\hline El diseñador generó una paleta de cuatro colores. & & \\
\hline $\begin{array}{l}\text { El diseñador relacionó correctamente los lineamientos de } \\
\text { codificación de información en dispositivos médicos y los } \\
\text { aplicó en las secciones de la gráfica de acuerdo a su signi- } \\
\text { ficado. }\end{array}$ & $x$ \\
\hline $\begin{array}{l}\text { El diseñador estableció un buen contraste entre fondo, } \\
\text { figura y texto. }\end{array}$ & 3.39 seg \\
\hline $\begin{array}{l}\text { Tiempo en que tardó en leer la página el diseñador. } \\
\text { Veces en que volvió a consultar la página el diseñador. }\end{array}$ & 1 \\
\hline Tiempo en que tardó en completar la tarea el diseñador. & 3.37 .43 \\
\hline
\end{tabular}


Anexo 10.21. USUARIO 21: Material de resultados de la evaluación de la propuesta editorial "B": consentimiento informado, lista de chequedo de análisis de tareas y cuestionario PSSUQ. 


\section{Consentimiento informado}

Proyecto: NOMOLAS: Propuesta de guías de usabilidad para el diseño de interfaces gráficas de sistemas de visualización de información médica.

Nombre del estudio: Evaluación de usabilidad de propuestas editoriales de las guías de usabilidad NOMOLAS con usuarios (lectores) de las mismas.

Lugar y fecha: Puebla, Pue. 4. Mov.19

Número de registro:

21

Justificación y objetivo del estudio: La forma en que se presenta la información es importante para que ésta sea comprendida de la mejor manera posible. Este estudio tiene como propósito elegir la mejor propuesta editorial para implementarla en toda la composición visual del proyecto Ilamado "NOMOLAS: Propuesta de guías de usabilidad para el diseño de interfaces gráficas de sistemas de visualización de información médica", que es a su vez, trabajo de investigación doctoral.

Procedimientos: Primero, se le explicaran los objetivos y el procedimiento de la sesión; describiendo como se llevará a cabo la prueba. Segundo, le pediremos que siga las instrucciones que le entregue el investigador encargado.

Posibles riesgos y molestias: En investigaciones similares no se han registrado dificultades o riesgos de ningún tipo, por tanto, durante su participación no se prevé ningún riesgo.

Posibles beneficios que recibirá al participar en el estudio: Al final de la prueba se le dará al participante $\$ 50.00$ pesos mexicanos en efectivo.

Participación o retiro: Si después de que Usted haya leído esta información y haya obtenido respuesta a las preguntas que pudiera tener, le vamos a pedir leer y firmar esta carta de consentimiento informado. Sin embargo, Usted puede retirarse en cualquier momento, por cualquier razón y nadie le va a preguntar sobre las razones por las cuales se retira.

Privacidad y confidencialidad: Para garantizar la confidencialidad toda la información será guardada y analizada sin usar los nombres reales de los participantes. Después de ser analizada, la información será guardada por un tiempo razonable y luego destruida.

En caso de dudas o aclaraciones relacionadas con el estudio podirá dirigirse con: Mtra. Mariel García Hernández quien conoce todos los detalles de este estudio. 22249242 64, Correo: mariel.garciahernandez@gmail.com

Participante:

Quien obtiene el consentimiento:

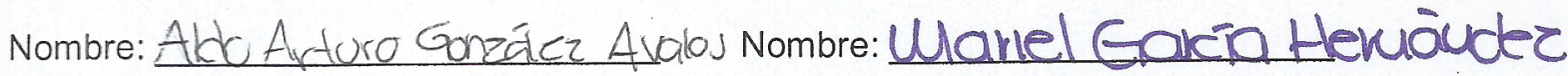
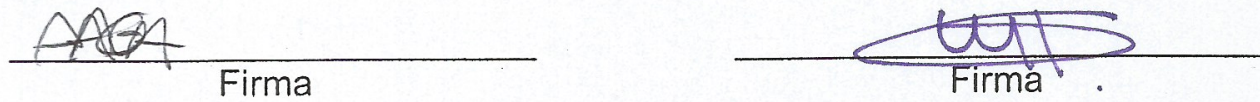


\section{CUESTIONARIO PSSUQ}

Edad:22 Sexo:M I F Licenciatura: Diseño gráfico y digitalmanejo de llustrator: Si I No Propuesta de guía: B No. de cuestionario: 21

Este cuestionario es una oportunidad para registrar tus reacciones a la guia de usabilidad. Estas respuestas nos ayudarán a entender qué aspectos hay que mejorar y cuales son con los que no estás satisfechos. Para tener un mejor resultado, piensa en la tarea que se te pidió que realizaras con base a lo que las guías decían mientras contestas estas preguntas.

Instrucciones: Lea cada frase y señala qué tan de acuerdo o en desacuerdo estás y encierra en un circulo un número de la escala. Al terminar, revisaremos juntos el cuestionario para asegurarnos de que entendamos bien la información presentada en este cuestionario.

¡Gracias!

a) La organización de la información proporcionada por las guías me fue clara.

Totalmente en desacuerdo

1

2

3

4

5

Totalmente de acuerdo

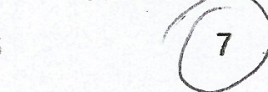

b) Fui capaz de completar las tareas que se me indicaron rápidamente con la información proporcionada en las guías.

Totalmente en desacuerdo

1

2

3

4

5

Totalmente de acuerdo

c) La información proporcionada por las guias fue fácil de entender.

Totalmente en desacuerdo

1

2

3

4

5

Totalmente de acuerdo

d) La apariencia de las guías es agradable.

Totalmente en desacuerdo

1

2

3

4

5

Totalmente de acuerdo

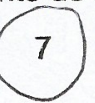

e) En general estoy satisfecho con el acomodo y presentación visual de la información.

Totalmente en desacuerdo

1

4

5

Totalmente de acuerdo

6

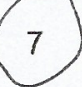




\section{LISTA DE CHEQUEO DEL ANÁLISIS DE TAREAS}

Evaluador: Uarel Cuestionario: 21 Fecha: $21.11 \cdot 19$ Propuesta a evaluar: B

\begin{tabular}{|l|c|c|}
\hline Premisa & Si & No \\
\hline El diseñador generó una paleta de cuatro colores. & $\checkmark$ & \\
\hline $\begin{array}{l}\text { El diseñador relacionó correctamente los lineamientos de } \\
\text { codificación de información en dispositivos médicos y los } \\
\text { aplicó en las secciones de la gráfica de acuerdo a su signi- } \\
\text { ficado. }\end{array}$ & $\checkmark$ & \\
\hline $\begin{array}{l}\text { El diseñador estableció un buen contraste entre fondo, } \\
\text { figura y texto. }\end{array}$ & $1.05 .50 \mathrm{~min}$ \\
\hline $\begin{array}{l}\text { Tiempo en que tardó en leer la página el diseñador. } \\
\text { Veces en que volvió a consultar la página el diseñador. }\end{array}$ & $2.55 .01 \mathrm{~min}$ \\
\hline Tiempo en que tardó en completar la tarea el diseñador. & & \\
\hline
\end{tabular}


Anexo 10.22. USUARIO 22: Material de resultados de la evaluación de la propuesta editorial "B": consentimiento informado, lista de chequedo de análisis de tareas y cuestionario PSSUQ. 


\section{CUESTIONARIO PSSUQ}

Edad:21 Sexo: M I (E) Licenciatura: Deseño grafice y digital Manejo de llustrator: (Si) I No Propuesta de guía: $B$ No. de cuestionario: 22

Este cuestionario es una oportunidad para registrar tus reacciones a la guia de usabilidad. Estas respuestas nos ayudarán a entender qué aspectos hay que mejorar y cuales son con los que no estás satisfechos. Para tener un mejor resultado, piensa en la tarea que se te pidió que realizaras con base a lo que las guias decian mientras contestas estas preguntas.

Instrucciones: Lea cada frase y señala qué tan de acuerdo o en desacuerdo estás y encierra en un circulo un número de la escala. Al terminar, revisaremos juntos el cuestionario para asegurarnos de que entendamos bien la información presentada en este cuestionario.

¡Gracias!

a) La organización de la información proporcionada por las guías me fue clara.

Totalmente en desacuerdo

$$
1 \quad 2
$$

2

3

4

5

Totalmente de acuerdo<smiles>c1ccccc1</smiles>

7

b) Fui capaz de completar las tareas que se me indicaron rápidamente con la información proporcionada en las guías.

Totalmente en desacuerdo$$
12
$$

3

4

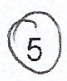

Totalmente de acuerdo

2

c) La información proporcionada por las guías fue fácil de entender.

Tntalmente en desacuerdo

1

2

3

4

5

Totalmente de acuerdo

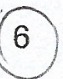

7

d) La apariencia de las guías es agradable.

Totalmente en desacuerdo

1

23

4

5

Totalmente de acuerdo

7

e) En general estoy satisfecho con el acomodo y presentación visual de la información.

Totalmente en desacuerdo

1

2

3

4

5

Totalmente de acuerdo 
LISTA DE CHEQUEO DEL ANÁLISIS DE TAREAS

Evaluador: Mariel Cuestionario: 22 Fecha: $4 \cdot 40$ V.19 Propuesta a evaluar:

B

\begin{tabular}{|l|c|l|}
\hline Premisa & Si & No \\
\hline El diseñador generó una paleta de cuatro colores. & & \\
\hline $\begin{array}{l}\text { El diseñador relacionó correctamente los lineamientos de } \\
\text { codificación de información en dispositivos médicos y los } \\
\text { aplicó en las secciones de la gráfica de acuerdo a su signi- } \\
\text { ficado. }\end{array}$ & & \\
\hline $\begin{array}{l}\text { El diseñador estableció un buen contraste entre fondo, } \\
\text { figura y texto. }\end{array}$ & $1.09 .56 \mathrm{culv}$ \\
\hline $\begin{array}{l}\text { Tiempo en que tardó en leer la página el diseñador. } \\
\text { Veces en que volvió a consultar la página el diseñador. }\end{array}$ & 1 & $2: 34.59$ \\
\hline Tiempo en que tardó en completar la tarea el diseñador. & 2.06 \\
\hline
\end{tabular}




\section{Consentimiento informado}

Proyecto: NOMOLAS: Propuesta de guías de usabilidad para el diseño de interfaces gráficas de sistemas de visualización de información médica.

Nombre del estudio: Evaluación de usabilidad de propuestas editoriales de las guías de usabilidad NOMOLAS con usuarios (lectores) de las mismas.

Lugary fecha: Puebla, Puebla. $4 \cdot 40 u \cdot 19$

Número de registro:

22

Justificación y objetivo del estudio: La forma en que se presenta la información es importante para que ésta sea comprendida de la mejor manera posible. Este estudio tiene como propósito elegir la mejor propuesta editorial para implementarla en toda la composición visual del proyecto llamado "NOMOLAS: Propuesta de guías de usabilidad para el diseño de interfaces gráficas de sistemas de visualización de información médica", que es a su vez, trabajo de investigación doctoral.

Procedimientos: Primero, se le explicaran los objetivos y el procedimiento de la sesión; describiendo como se llevará a cabo la prueba. Segundo, le pediremos que siga las instrucciones que le entregue el investigador encargado.

Posibles riesgos y molestias: En investigaciones similares no se han registrado dificultades o riesgos de ningún tipo, por tanto, durante su participación no se prevé ningún riesgo.

Posibles beneficios que recibirá al participar en el estudio: Al final de la prueba se le dará al participante $\$ 50.00$ pesos mexicanos en efectivo.

Participación o retiro: Si después de que Usted haya leido esta información y haya obtenido respuesta a las preguntas que pudiera tener, le vamos a pedir leer y firmar esta carta de consentimiento informado. Sin embargo, Usted puede retirarse en cualquier momento, por cualquier razón y nadie le va a preguntar sobre las razones por las cuales se retira.

Privacidad y confidencialidad: Para garantizar la confidencialidad toda la información será guardada y analizada sin usar los nombres reales de los participantes. Después de ser analizada, la información será guardada por un tiempo razonable y luego destruida.

En caso de dudas o aclaraciones relacionadas con el estudio podrá dirigirse con: Mtra. Mariel García Hernández quien conoce todos los detalles de este estudio. 22249242 64, Correo: mariel.garciahernandez@gmail.com

Participante:

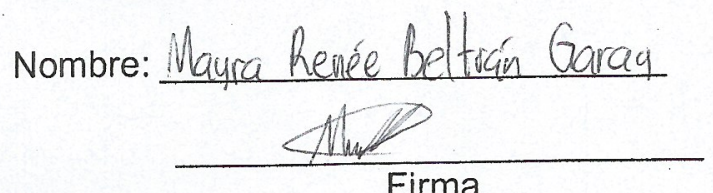

$$
\text { Firma }
$$

\section{Quien obtiene el consentimiento:}

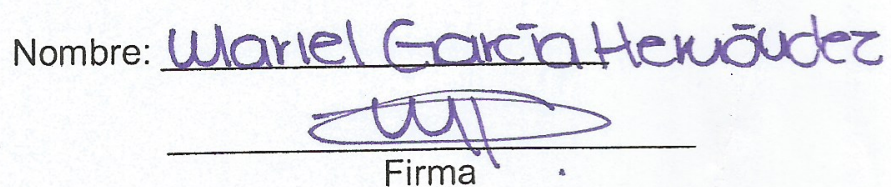


Anexo 10.23. USUARIO 23: Material de resultados de la evaluación de la propuesta editorial "B": consentimiento informado, lista de chequedo de análisis de tareas y cuestionario PSSUQ. 


\section{Consentimiento informado}

Proyecto: NOMOLAS: Propuesta de guias de usabilidad para el diseño de interfaces gráficas de sistemas de visualización de información médica.

Nombre del estudio: Evaluación de usabilidad de propuestas editoriales de las guías de usabilidad NOMOLAS con usuarios (lectores) de las mismas.

Lugar y fecha: Puebla, Pue. 40 Uovieubre - 19

Número de registro:

23

Justificación y objetivo del estudio: La forma en que se presenta la información es importante para que ésta sea comprendida de la mejor manera posible. Este estudio tiene como propósito elegir la mejor propuesta editorial para implementarla en toda la composición visual del proyecto llamado "NOMOLAS: Propuesta de guías de usabilidad para el diseño de interfaces gráficas de sistemas de visualización de información médica", que es a su vez, trabajo de investigación doctoral.

Procedimientos: Primero, se le explicaran los objetivos y el procedimiento de la sesión; describiendo como se llevará a cabo la prueba. Segundo, le pediremos que siga. las instrucciones que le entregue el investigador encargado.

Posibles riesgos y molestias: En investigaciones similares no se han registrado dificultades 0 riesgos de ningún tipo, por tanto, durante su participación no se prevé ningún riesgo.

Posibles beneficios que recibirá al participar en el estudio: Al final de la prueba se le dará al participante $\$ 50.00$ pesos mexicanos en efectivo.

Participación o retiro: Si después de que Usted haya leído esta información y haya obtenido respuesta a las preguntas que pudiera tener, le vamos a pedir leer y firmar esta carta de consentimiento informado. Sin embargo, Usted puede retirarse en cualquier momento, por cualquier razón y nadie le va a preguntar sobre las razones por las cuales se retira.

Privacidad y confidencialidad: Para garantizar la confidencialidad toda la información será guardada y analizada sin usar los nombres reales de los participantes. Después de ser analizada, la información será guardada por un tiempo razonable y luego destruida.

En caso de dudas o aclaraciones relacionadas con el estudio podrá dirigirse con: Mtra. Mariel García Hernández quien conoce todos los detalles de este estudio. 22249242 64, Correo: mariel.garciahernandez@gmail.com

Participante:

Nombre: MICHEL A. HUERTA TORRES

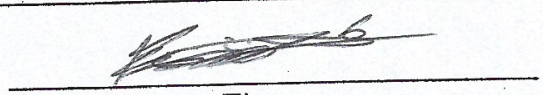

Firma

\section{Quien obtiene el consentimiento:}

Nombre: Mlarrel GareTa Heruãder

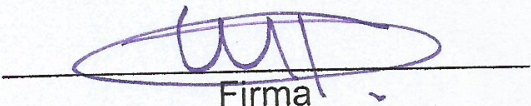




\section{CUESTIONARIO PSSUQ}

Edad:24 Sexo:M I F Licenciatura: DISEÑO GRAFICo Y DIGITAL Manejo de Ilustrator: Si I No Propuesta de guía: $B$ No. de cuestionario: 23

Este cuestionario es una oportunidad para registrar tus reacciones a la guia de usabilidad. Estas respuestas nos ayudarán a entender qué aspectos hay que mejorar y cuales son con los que no estás satisfechos. Para tener un mejor resultado, piensa en la tarea que se te pidió que realizaras con base a lo que las guías decian mientras contestas estas preguntas.

Instrucciones: Lea cada frase y señala qué tan de acuerdo o en desacuerdo estás y encierra en un circulo un número de la escala. Al terminar, revisaremos juntos el cuestionario para asegurarnos de que entendamos bien la información presentada en este cuestionario.

¡Gracias!

a) La organización de la información proporcionada por las guías me fue clara.

Totalmente en desacuerdo

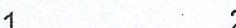

2

3

4

5

Totalmente de acuerdo

$$
1
$$

(2.

6 (7)

b) Fui capaz de completar las tareas que se me indicaron rápidamente con la información proporcionada en las guías.

Totalmente en desacuerdo

1

2

3

4

5

Totalmente de acuerdo

c) La información proporcionada por las guías fue fácil de entender.

Totalmente en desacuerdo

1

2

3

4

5

Totalmente de acuerdo

-

(n)

6

(7)

d) La apariencia de las guías es agradable.

Totalmente en desacuerdo

1

2

3

4

5

Totalmente de acuerdo

\section{7}

e) En general estoy satisfecho con el acomodo y presentación visual de la información. Totalmente en desacuerdo

1 


\section{LISTA DE CHEQUEO DEL ANÁLISIS DE TAREAS}

Evaluador: Uariel cuestionario: 23 Fecha: $4 \cdot 11 \cdot 19$ Propuesta a evaluar:

B

\begin{tabular}{|l|c|l|}
\hline Premisa & Si & No \\
\hline El diseñador generó una paleta de cuatro colores. & $\checkmark$ & \\
\hline $\begin{array}{l}\text { El diseñador relacionó correctamente los lineamientos de } \\
\text { codificación de información en dispositivos médicos y los } \\
\text { aplicó en las secciones de la gráfica de acuerdo a su signi- } \\
\text { ficado. }\end{array}$ & $\checkmark$ & \\
\hline $\begin{array}{l}\text { El diseñador estableció un buen contraste entre fondo, } \\
\text { figura y texto. }\end{array}$ & $\checkmark .18 .40$ \$ 14 \\
\hline Tiempo en que tardó en leer la página el diseñador. & - \\
\hline Veces en que volvió a consultar la página el diseñador. & $1: 37.12$ \\
\hline Tiempo en que tardó en completar la tarea el diseñador. & \\
\hline
\end{tabular}


Anexo 10.24. USUARIO 24: Material de resultados de la evaluación de la propuesta editorial "B": consentimiento informado, lista de chequedo de análisis de tareas y cuestionario PSSUQ. 


\section{Consentimiento informado}

Proyecto: NOMOLAS: Propuesta de guías de usabilidad para el diseño de interfaces gráficas de sistemas de visualización de información médica.

Nombre del estudio: Evaluación de usabilidad de propuestas editoriales de las guias de usabilidad NOMOLAS con usuarios (lectores) de las mismas.

Lugar y fecha: Puenca 4 /Novembre 12019

Número de registro: $\quad 24$

Justificación y objetivo del estudio: La forma en que se presenta la información es importante para que ésta sea comprendida de la mejor manera posible. Este estudio tiene como propósito elegir la mejor propuesta editorial para implementarla en toda la composición visual del proyecto llamado "NOMOLAS: Propuesta de guías de usabilidad para el diseño de interfaces gráficas de sistemas de visualización de información médica", que es a su vez, trabajo de investigación doctoral.

Procedimientos: Primero, se le explicaran los objetivos y el procedimiento de la sesión; describiendo como se llevará a cabo la prueba. Segundo, le pediremos que siga las instrucciones que le entregue el investigador encargado.

Posibles riesgos y molestias: En investigaciones similares no se han registrado dificultades o riesgos de ningún tipo, por tanto, durante su participación no se prevé ningún riesgo.

Posibles beneficios que recibirá al participar en el estudio: Al final de la prueba se le dará al participante $\$ 50.00$ pesos mexicanos en efectivo.

Participación o retiro: Si después de que Usted haya leído esta información y haya obtenido respuesta a las preguntas que pudiera tener, le vamos a pedir leer y firmar esta carta de consentimiento informado. Sin embargo, Usted puede retirarse en cualquier momento, por cualquier razón y nadie le va a preguntar sobre las razones por las cuales se retira.

Privacidad y confidencialidad: Para garantizar la confidencialidad toda la información será guardada y analizada sin usar los nombres reales de los participantes. Después de ser analizada, la información será guardada por un tiempo razonable y luego destruida.

En caso de dudas o aclaraciones relacionadas con el estudio podrá dirigirse con: Mtra. Mariel Garcia Hernández quien conoce todos los detalles de este estudio. 2224924264 , Correo: mariel.garciahernandez@gmail.com

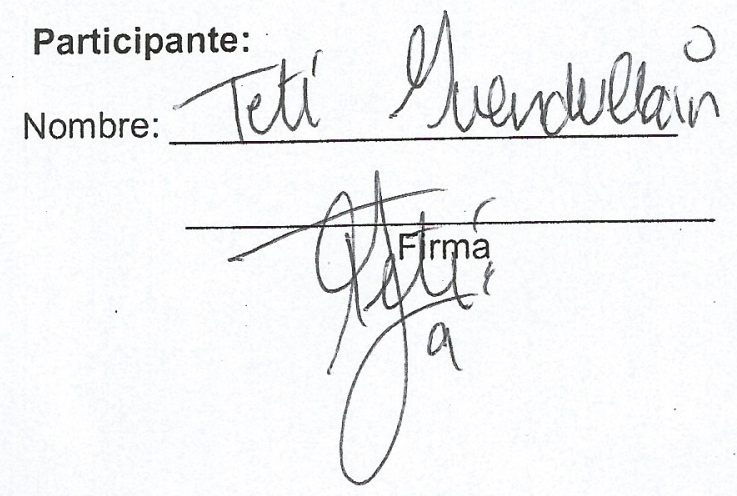

Quien obtiene el consentimiento:

Nombre: Marlel Garcia Herciōuder

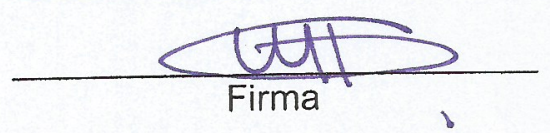




\section{CUESTIONARIO PSSUQ}

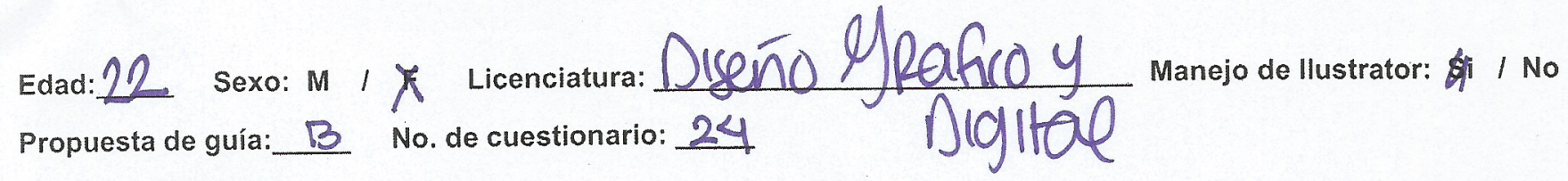

Este cuestionario es una oportunidad para registrar tus reacciones a la guía de usabilidad. Estas respuestas nos ayudarán a entender qué aspectos hay que mejorar y cuales son con los que no estás satisfechos. Para tener un mejor resultado, piensa en la tarea que se te pidió que realizaras con base a lo que las guías decian mientras contestas estas preguntas.

Instrucciones: Lea cada frase y señala qué tan de acuerdo o en desacuerdo estás y encierra en un circulo un número de la escala. Al terminar, revisaremos juntos el cuestionario para asegurarnos de que entendamos bien la información presentada en este cuestionario.

¡Gracias!

a) La organización de la información proporcionada por las guías me fue clara.

Totalmente en desacuerdo

Totalmente de acuerdo
1
2
3
4
5
$(6)$

7

b) Fui capaz de completar las tareas que se me indicaron rápidamente con la información proporcionada en las guías.

Totalmente en desacuerdo

$$
12
$$
2
3

4

5

Totalmente de acuerdo

c) La información proporcionada por las guías fue fácil de entender.

Totalmente en desacuerdo

2

3

4

5

Totalmente de acuerdo

1

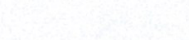

d) La apariencia de las guías es agradable.

Totalmente en desacuerdo

12

2

3

4

5

Totalmente de acuerdo

7

e) En general estoy satisfecho con el acomodo y presentación visual de la información.

Totalmente en desacuerdo 
Evaluador: Wariel_Cuestionario: 24 Fecha: $\underline{4 \cdot 11 \cdot 19}$ Propuesta a evaluar: $B$

\begin{tabular}{|l|c|l|}
\hline Premisa & Si & No \\
\hline El diseñador generó una paleta de cuatro colores. & & \\
\hline $\begin{array}{l}\text { El diseñador relacionó correctamente los lineamientos de } \\
\text { codificación de información en dispositivos médicos y los } \\
\text { aplicó en las secciones de la gráfica de acuerdo a su signi- } \\
\text { ficado. }\end{array}$ & $1: 31.88 \mathrm{~min}$ \\
\hline $\begin{array}{l}\text { El diseñador estableció un buen contraste entre fondo, } \\
\text { figura y texto. }\end{array}$ & 1 & \\
\hline Tiempo en que tardó en leer la página el diseñador. & $3: 25.12 \mathrm{~min}$ \\
\hline Veces en que volvió a consultar la página el diseñador.
\end{tabular}


Anexo 10.25. USUARIO 25: Material de resultados de la evaluación de la propuesta editorial "B": consentimiento informado, lista de chequedo de análisis de tareas y cuestionario PSSUQ. 


\section{Consentimiento informado}

Proyecto: NOMOLAS: Propuesta de guías de usabilidad para el diseño de interfaces gráficas de sistemas de visualización de información médica.

Nombre del estudio: Evaluación de usabilidad de propuestas editoriales de las guias de usabilidad NOMOLAS con usuarios (lectores) de las mismas.

Lugar y fecha: Puebla, Puebla. $4 \cdot 40 \mathrm{~V} \cdot 19$

Número de registro:

25

Justificación y objetivo del estudio: La forma en que se presenta la información es importante para que ésta sea comprendida de la mejor manera posible. Este estudio tiene como propósito elegir la mejor propuesta editorial para implementarla en toda la composición visual del proyecto llamado "NOMOLAS: Propuesta de guías de usabilidad para el diseño de interfaces gráficas de sistemas de visualización de información médica", que es a su vez, trabajo de investigación doctoral.

Procedimientos: Primero, se le explicaran los objetivos y el procedimiento de la sesión; describiendo como se llevará a cabo la prueba. Segundo, le pediremos que siga las instrucciones que le entregue el investigador encargado.

Posibles riesgos y molestias: En investigaciones similares no se han registrado dificultades o riesgos de ningún tipo, por tanto, durante su participación no se prevé ningún riesgo.

Posibles beneficios que recibirá al participar en el estudio: Al final de la prueba se le dará al participante $\$ 50.00$ pesos mexicanos en efectivo.

Participación o retiro: Si después de que Usted haya leido esta información y haya obtenido respuesta a las preguntas que pudiera tener, le vamos a pedir leer y firmar esta carta de consentimiento informado. Sin embargo, Usted puede retirarse en cualquier momento, por cualquier razón y nadie le va a preguntar sobre las razones por las cuales se retira.

Privacidad y confidencialidad: Para garantizar la confidencialidad toda la información será guardada y analizada sin usar los nombres reales de los participantes. Después de ser analizada, la información será guardada por un tiempo razonable y luego destruida.

En caso de dudas o aclaraciones relacionadas con el estudio podrá dirigirse con: Mtra. Mariel García Hernández quien conoce todos los detalles de este estudio. 2224924264 , Correo: mariel.garciahernandez@gmail.com

Participante:

Quien obtiene el consentimiento:

Nombre: hosemary Susana Fgaredo Ĺpen Nombre: Uavel Garéra Hexöludez
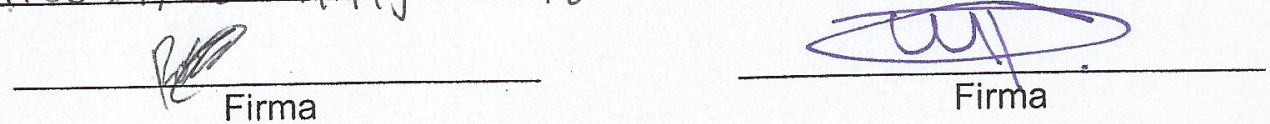

Firma 


\section{CUESTIONARIO PSSUQ}

Edad:21 sexo: M I ( L Licenciatura: Diseño Gráfico y Digital manejo de llustrator: (Si I No Propuesta de guía: $B$ No. de cuestionario: 25

Este cuestionario es una oportunidad para registrar tus reacciones a la guía de usabilidad. Estas respuestas nos ayudarán a entender qué aspectos hay que mejorar y cuales son con los que no estás satisfechos. Para tener un mejor resultado, piensa en la tarea que se te pidió que realizaras con base a lo que las guías decian mientras contestas estas preguntas.

Instrucciones: Lea cada frase y señala qué tan de acuerdo o en desacuerdo estás y encierra en un circulo un número de la escala. Al terminar, revisaremos juntos el cuestionario para asegurarnos de que entendamos bien la información presentada en este cuestionario.

¡Gracias!

a) La organización de la información proporcionada por las guías me fue clara.

Totalmente en desacuerdo
1
2
3
4
5

Totalmente de acuerdo

7

b) Fui capaz de completar las tareas que se me indicaron rápidamente con la información proporcionada en las guías.

Totalmente en desacuerdo

$$
1
$$

\section{2}

3

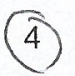

5

Totalmente de acuerdo

c) La información proporcionada por las guías fue fácil de entender.

Totalmente en desacuerdo

1 2

3

4

5

Totalmente de acuerdo

(6)

7

d) La apariencia de las guías es agradable.

Totalmente en desacuerdo$$
1
$$

3

4

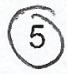

Totalmente de acuerdo

6

7

e) En general estoy satisfecho con el acomodo y presentación visual de la información.

Totalmente en desacuerdo

1

2

3

4

5

Totalmente de acuerdo 


\section{LISTA DE CHEQUEO DEL ANÁLISIS DE TAREAS}

Evaluador: Wanel Cuestionario: 25 Fecha: $4000 \mathrm{~V} \cdot 19$ Propuesta a evaluar: B

\begin{tabular}{|l|c|c|}
\hline Premisa & Si & No \\
\hline El diseñador generó una paleta de cuatro colores. & $\checkmark$ & \\
\hline $\begin{array}{l}\text { El diseñador relacionó correctamente los lineamientos de } \\
\text { codificación de información en dispositivos médicos y los } \\
\text { aplicó en las secciones de la gráfica de acuerdo a su signi- } \\
\text { ficado. }\end{array}$ & $\checkmark$ & \\
\hline $\begin{array}{l}\text { El diseñador estableció un buen contraste entre fondo, } \\
\text { figura y texto. }\end{array}$ & $1: 32.39 \mathrm{~min}$ \\
\hline \begin{tabular}{l} 
Tiempo en que tardó en leer la página el diseñador. \\
\hline Veces en que volvió a consultar la página el diseñador.
\end{tabular} & $11(2)$ \\
\hline Tiempo en que tardó en completar la tarea el diseñador. & $3: 48.75 \mathrm{~min}$ \\
\hline
\end{tabular}


Anexo 10.26. USUARIO 26: Material de resultados de la evaluación de la propuesta editorial "B": consentimiento informado, lista de chequedo de análisis de tareas y cuestionario PSSUQ. 


\section{Consentimiento informado}

Proyecto: NOMOLAS: Propuesta de guias de usabilidad para el diseño de interfaces gráficas de sistemas de visualización de información médica.

Nombre del estudio: Evaluación de usabilidad de propuestas editoriales de las guías de usabilidad NOMOLAS con usuarios (lectores) de las mismas.

Lugar y fecha: Duebla, Puebla. 4. 4OU. 19

Número de registro:

26

Justificación y objetivo del estudio: La forma en que se presenta la información es importante para que ésta sea comprendida de la mejor manera posible. Este estudio tiene como propósito elegir la mejor propuesta editorial para implementarla en toda la composición visual del proyecto llamado "NOMOLAS: Propuesta de guias de usabilidad para el diseño de interfaces gráficas de sistemas de visualización de información médica", que es a su vez, trabajo de investigación doctoral.

Procedimientos: Primero, se le explicaran los objetivos y el procedimiento de la sesión; describiendo como se llevará a cabo la prueba. Segundo, le pediremos que siga las instrucciones que le entregue el investigador encargado.

Posibles riesgos y molestias: En investigaciones similares no se han registrado dificultades o riesgos de ningún tipo, por tanto, durante su participación no se prevé ningún riesgo.

Posibles beneficios que recibirá al participar en el estudio: Al final de la prueba se le dará al participante $\$ 50.00$ pesos mexicanos en efectivo.

Participación o retiro: Si después de que Usted haya leido esta información y haya obtenido respuesta a las preguntas que pudiera tener, le vamos a pedir leer y firmar esta carta de consentimiento informado. Sin embargo, Usted puede retirarse en cualquier momento, por cualquier razón y nadie le va a preguntar sobre las razones por las cuales se retira.

Privacidad y confidencialidad: Para garantizar la confidencialidad toda la información será guardada y analizada sin usar los nombres reales de los participantes. Después de ser analizada, la información será guardada por un tiempo razonable y luego destruida.

En caso de dudas o aclaraciones relacionadas con el estudio podrá dirigirse con: Mtra. Mariel García Hernández quien conoce todos los detalles de este estudio. 2224924264 , Correo: mariel.garciahernandez@gmail.com

\section{Participante:}

Nombre: Aime Estrada Zorrilla

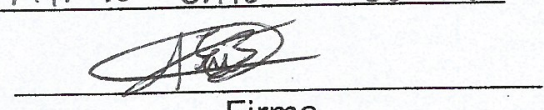

Firma
Quien obtiene el consentimiento:

Nombre: Uanel Gakia Hemöuder

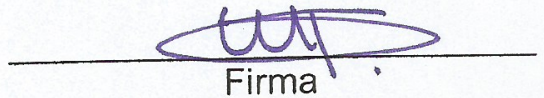




\section{CUESTIONARIO PSSUQ}

Edad:23 Sexo: M $\{$ Licenciatura: Dijeño Gráfico y Digital Manejo de llustrator: Sfi I No Propuesta de guía: $B$ No. de cuestionario: 26

Este cuestionario es una oportunidad para registrar tus reacciones a la guia de usabilidad. Estas respuestas nos ayudarán a entender qué aspectos hay que mejorar y cuales son con los que no estás satisfechos. Para tener un mejor resultado, piensa en la tarea que se te pidió que realizaras con base a lo que las guías decian mientras contestas estas preguntas.

Instrucciones: Lea cada frase y señala qué tan de acuerdo o en desacuerdo estás y encierra en un circulo un número de la escala. Al terminar, revisaremos juntos el cuestionario para asegurarnos de que entendamos bien la información presentada en este cuestionario.

¡Gracias!

a) La organización de la información proporcionada por las guías me fue clara.

Totalmente en desacuerdo

$1 \cdot 2$ 2 3

4

5 Totalmente de acuerdo 6 $x$

b) Fui capaz de completar las tareas que se me indicaron rápidamente con la información proporcionada en las guías.

Totalmente en desacuerdo

1

3

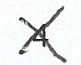

5 Totalmente de acuerdo $2+3$

c) La información proporcionada por las guías fue fácil de entender.

Totalmente en desacuerdo

1 2 3 4 5 Totalmente de acuerdo (n)

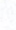

4.20

d) La apariencia de las guías es agradable.

Totalmente en desacuerdo

$$
1
$$

2

3

4

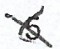
Totalmente de acuerdo 7

e) En general estoy satisfecho con el acomodo y presentación visual de la infớmación. Totalmente en desacuerdo 
Evaluador: Wanel_Cuestionario: 26 Fecha: 1.11 .19 Propuesta a evaluar: $B$

\begin{tabular}{|c|c|c|}
\hline Premisa & Si & No \\
\hline El diseñador generó una paleta de cuatro colores. & 1 & \\
\hline $\begin{array}{l}\text { El diseñador relacionó correctamente los lineamientos de } \\
\text { codificación de información en dispositivos médicos y los } \\
\text { aplicó en las secciones de la gráfica de acuerdo a su signi- } \\
\text { ficado. }\end{array}$ & $\checkmark$ & \\
\hline $\begin{array}{l}\text { El diseñador estableció un buen contraste entre fondo, } \\
\text { figura y texto. }\end{array}$ & $\gamma$ & \\
\hline Tiempo en que tardó en leer la página el diseñador. & $1: 09.65$ & wily \\
\hline Veces en que volvió a consultar la página el diseñador. & $(1)$ & \\
\hline Tiempo en que tardó en completar la tarea el diseñador. & $1: 45.70 r$ & in \\
\hline
\end{tabular}


Anexo 10.27. USUARIO 27: Material de resultados de la evaluación de la propuesta editorial "B": consentimiento informado, lista de chequedo de análisis de tareas y cuestionario PSSUQ. 


\section{Consentimiento informado}

Proyecto: NOMOLAS: Propuesta de guías de usabilidad para el diseño de interfaces gráficas de sistemas de visualización de información médica.

Nombre del estudio: Evaluación de usabilidad de propuestas editoriales de las guías de usabilidad NOMOLAS con usuarios (lectores) de las mismas.

Lugar y fecha: Duebla, Puebla.40 Uoveubre 19

Número de registro:

27

Justificación y objetivo del estudio: La forma en que se presenta la información es importante para que ésta sea comprendida de la mejor manera posible. Este estudio tiene como propósito elegir la mejor propuesta editorial para implementarla en toda la composición visual del proyecto llamado "NOMOLAS: Propuesta de guías de usabilidad para el diseño de interfaces gráficas de sistemas de visualización de información médica", que es a su vez, trabajo de investigación doctoral.

Procedimientos: Primero, se le explicaran los objetivos y el procedimiento de la sesión; describiendo como se llevará a cabo la prueba. Segundo, le pediremos que siga las instrucciones que le entregue el investigador encargado.

Posibles riesgos y molestias: En investigaciones similares no se han registrado dificultades o riesgos de ningún tipo, por tanto, durante su participación no se prevé ningún riesgo.

Posibles beneficios que recibirá al participar en el estudio: Al final de la prueba se le dará al participante $\$ 50.00$ pesos mexicanos en efectivo.

Participación o retiro: Si después de que Usted haya leído esta información y haya obtenido respuesta a las preguntas que pudiera tener, le vamos a pedir leer y firmar esta carta de consentimiento informado. Sin embargo, Usted puede retirarse en cualquier momento, por cualquier razón y nadie le va a preguntar sobre las razones por las cuales se retira.

Privacidad y confidencialidad: Para garantizar la confidencialidad toda la información será guardada y analizada sin usar los nombres reales de los participantes. Después de ser analizada, la información será guardada por un tiempo razonable y luego destruida.

En caso de dudas o aclaraciones relacionadas con el estudio podrá dirigirse con: Mtra. Mariel García Hernández quien conoce todos los detalles de este estudio. 2224924264 , Correo: mariel.garciahernandez@gmail.com

\section{Participante:}

Nombre: Renata Campos Escalante

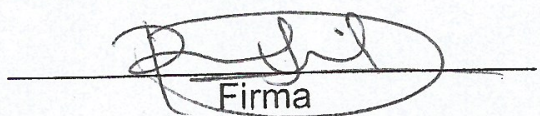

Quien obtiene el consentimiento:

Nombre: Uarlel Gareia tenóuder

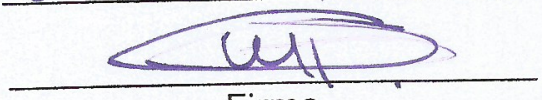

Firma 


\section{CUESTIONARIO PSSUQ}

Edad:21 Sexo: M If Licenciatura: Diseño Gráfico \& Digital Manejo de llustrator: Sí I No Propuesta de guía: $B$ No. de cuestionario: 27

Este cuestionario es una oportunidad para registrar tus reacciones a la guia de usabilidad. Estas respuestas nos ayudarán a entender qué aspectos hay que mejorar y cuales son con los que no estás satisfechos. Para tener un mejor resultado, piensa en la tarea que se te pidió que realizaras con base a lo que las guías decian mientras contestas estas preguntas.

Instrucciones: Lea cada frase y señala qué tan de acuerdo o en desacuerdo estás y encierra en un circulo un número de la escala. Al terminar, revisaremos juntos el cuestionario para asegurarnos de que entendamos bien la información presentada en este cuestionario.

¡Gracias!

a) La organización de la información proporcionada por las guías me fue clara.

Totalmente en desacuerdo

$$
1 \quad 2
$$

3

4

5

Totalmente de acuerdo

$4 \cdot 2 \cdot 5$

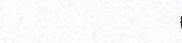

$6 \quad 7$

b) Fui capaz de completar las tareas que se me indicaron rápidamente con la información proporcionada en las guías.

Totalmente en desacuerdo

1

3

4

5

Totalmente de acuerdo

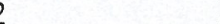

c) La información proporcionada por las guías fue fácil de entender.

Totalmente en desacuerdo

1

2

3

4

5

Totalmente de acuerdo

6

7

d) La apariencia de las guías es agradable.

Totalmente en desacuerdo

$$
12
$$

3

4

5

Totalmente de acuerdo

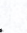

$6 \quad \underline{7}$

e) En general estoy satisfecho con el acomodo y presentación visual de la información. Totalmente en desacuerdo

1 2

3

4

5

Totalmente de acuerdo 


\section{LISTA DE CHEQUEO DEL ANÁLISIS DE TAREAS}

Evaluador: manel Cuestionario: 27 Fecha: $4 \cdot 11$ '19 Propuesta a evaluar: $B$

\begin{tabular}{|l|c|c|}
\hline Premisa & Si & No \\
\hline El diseñador generó una paleta de cuatro colores. & $\checkmark$ & \\
\hline $\begin{array}{l}\text { El diseñador relacionó correctamente los lineamientos de } \\
\text { codificación de información en dispositivos médicos y los } \\
\text { aplicó en las secciones de la gráfica de acuerdo a su signi- } \\
\text { ficado. }\end{array}$ & 1 & \\
\hline $\begin{array}{l}\text { El diseñador estableció un buen contraste entre fondo, } \\
\text { figura y texto. }\end{array}$ & $1: 01.25 \mathrm{Seg}$ \\
\hline Tiempo en que tardó en leer la página el diseñador. & $11.23 .92 \mathrm{~min}$ \\
\hline Veces en que volvió a consultar la página el diseñador. & $(11)$ & \\
\hline Tiempo en que tardó en completar la tarea el diseñador. & & \\
\hline
\end{tabular}


Anexo 10.28. USUARIO 28: Material de resultados de la evaluación de la propuesta editorial "B": consentimiento informado, lista de chequedo de análisis de tareas y cuestionario PSSUQ. 


\section{Consentimiento informado}

Proyecto: NOMOLAS: Propuesta de guías de usabilidad para el diseño de interfaces gráficas de sistemas de visualización de información médica.

Nombre del estudio: Evaluación de usabilidad de propuestas editoriales de las guias de usabilidad NOMOLAS con usuarios (lectores) de las mismas.

Lugary fecha: Puebla, Pue. 4. UOU.19

Número de registro:

28

Justificación y objetivo del estudio: La forma en que se presenta la información es importante para que ésta sea comprendida de la mejor manera posible. Este estudio tiene como propósito elegir la mejor propuesta editorial para implementarla en toda la composición visual del proyecto llamado "NOMOLAS: Propuesta de guías de usabilidad para el diseño de interfaces gráficas de sistemas de visualización de información médica", que es a su vez, trabajo de investigación doctoral.

Procedimientos: Primero, se le explicaran los objetivos y el procedimiento de la sesión; describiendo como se llevará a cabo la prueba. Segundo, le pediremos que siga las instrucciones que le entregue el investigador encargado.

Posibles riesgos y molestias: En investigaciones similares no se han registrado dificultades o riesgos de ningún tipo, por tanto, durante su participación no se prevé ningún riesgo.

Posibles beneficios que recibirá al participar en el estudio: Al final de la prueba se le dará al participante $\$ 50.00$ pesos mexicanos en efectivo.

Participación o retiro: Si después de que Usted haya leido esta información y haya obtenido respuesta a las preguntas que pudiera tener, le vamos a pedir leer y firmar esta carta de consentimiento informado. Sin embargo, Usted puede retirarse en cualquier momento, por cualquier razón y nadie le va a preguntar sobre las razones por las cuales se retira.

Privacidad y confidencialidad: Para garantizar la confidencialidad toda la información será guardada y analizada sin usar los nombres reales de los participantes. Después de ser analizada, la información será guardada por un tiempo razonable y luego destruida.

En caso de dudas o aclaraciones relacionadas con el estudio podrá dirigirse con: Mtra. Mariel García Hernández quien conoce todos los detalles de este estudio. 2224924264 , Correo: mariel.garciahernandez@gmail.com

Participante:

Nombre: Ma. Monilsewat Manturo S.

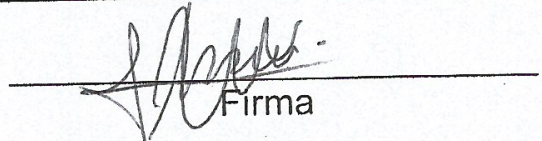

Quien obtiene el consentimiento:

Nombre:Uanel Gavía Hewionder

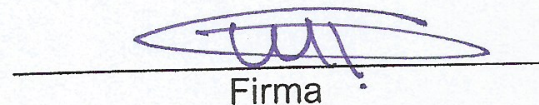




\section{CUESTIONARIO PSSUQ}

Edad:22 Sexo: M IF Licenciatura: Diseño Gráfico y Digilal. Manejo de llustrator. Si I No Propuesta de guía: 3 No. de cuestionario: 28

Este cuestionario es una oportunidad para registrar tus reacciones a la guía de usabilidad. Estas respuestas nos ayudarán a entender qué aspectos hay que mejorar y cuales son con los que no estás satisfechos. Para tener un mejor resultado, piensa en la tarea que se te pidió que realizaras con base a lo que las guías decían mientras contestas estas preguntas.

Instrucciones: Lea cada frase y señala qué tan de acuerdo o en desacuerdo estás y encierra en un circulo un número de la escala. Al terminar, revisaremos juntos el cuestionario para asegurarnos de que entendamos bien la información presentada en este cuestionario.

\section{¡Gracias!}

a) La organización de la información proporcionada por las guías me fue clara.

Totalmente en desacuerdo$$
1 \text {. }
$$

2

3

4

5

Totalmente de acuerdo

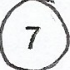

b) Fui capaz de completar las tareas que se me indicaron rápidamente con la información proporcionada en las guías.

Totalmente en desacuerdo

$$
12
$$

3

4

5

Totalmente de acuerdo

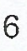

7

c) La información proporcionada por las guias fue fácil de entender.

Totalmente en desacuerdo

1

2

3

4

5

Totalmente de acuerdo

6

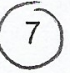

d) La apariencia de las guías es agradable.

Totalmente en desacuerdo

1

2

3

4

5

Totalmente de acuerdo

7

e) En general estoy satisfecho con el acomodo y presentación visual de la información.

Totalmente en desacuerdo

Totalmente de acuerdo

1

2

3

4

$\dot{5}$

6 
LISTA DE CHEQUEO DEL ANÁLISIS DE TAREAS

Evaluador: Wanel Cuestionario: 28 Fecha: $4 \cdot 40 \mathrm{~V} \cdot 19$ Propuesta a evaluar: $B$

\begin{tabular}{|l|c|c|}
\hline Premisa & Si & No \\
\hline El diseñador generó una paleta de cuatro colores. & $\checkmark$ & \\
\hline $\begin{array}{l}\text { El diseñador relacionó correctamente los lineamientos de } \\
\text { codificación de información en dispositivos médicos y los } \\
\text { aplicó en las secciones de la gráfica de acuerdo a su signi- } \\
\text { ficado. }\end{array}$ & & \\
\hline $\begin{array}{l}\text { El diseñador estableció un buen contraste entre fondo, } \\
\text { figura y texto. }\end{array}$ & $1: 18.25 \mathrm{~min}$ \\
\hline \begin{tabular}{l} 
Tiempo en que tardó en leer la página el diseñador. \\
\hline Veces en que volvió a consultar la página el diseñador.
\end{tabular} & $2: 20 \mathrm{mill}$ \\
\hline Tiempo en que tardó en completar la tarea el diseñador. & 20 \\
\hline
\end{tabular}


Anexo 10.29. USUARIO 29: Material de resultados de la evaluación de la propuesta editorial "B": consentimiento informado, lista de chequedo de análisis de tareas y cuestionario PSSUQ. 


\section{Consentimiento informado}

Proyecto: NOMOLAS: Propuesta de guías de usabilidad para el diseño de interfaces gráficas de sistemas de visualización de información médica.

Nombre del estudio: Evaluación de usabilidad de propuestas editoriales de las guías de usabilidad NOMOLAS con usuarios (lectores) de las mismas.

Lugar y fecha: Puebla, Puebla. 4. 4ovieubre. 19

Número de registro:

29

Justificación y objetivo del estudio: La forma en que se presenta la información es importante para que ésta sea comprendida de la mejor manera posible. Este estudio tiene como propósito elegir la mejor propuesta editorial para implementarla en toda la composición visual del proyecto llamado "NOMOLAS: Propuesta de guías de usabilidad para el diseño de interfaces gráficas de sistemas de visualización de información médica", que es a su vez, trabajo de investigación doctoral.

Procedimientos: Primero, se le explicaran los objetivos y el procedimiento de la sesión; describiendo como se llevará a cabo la prueba. Segundo, le pediremos que siga las instrucciones que le entregue el investigador encargado.

Posibles riesgos y molestias: En investigaciones similares no se han registrado dificultades o riesgos de ningún tipo, por tanto, durante su participación no se prevé ningủn riesgo.

Posibles beneficios que recibirá al participar en el estudio: Al final de la prueba se le dará al participante $\$ 50.00$ pesos mexicanos en efectivo.

Participación o retiro: Si después de que Usted haya leído esta información y haya obtenido respuesta a las preguntas que pudiera tener, le vamos a pedir leer y firmar esta carta de consentimiento informado. Sin embargo, Usted puede retirarse en cualquier momento, por cualquier razón y nadie le va a preguntar sobre las razones por las cuales se retira.

Privacidad y confidencialidad: Para garantizar la confidencialidad toda la información será guardada y analizada sin usar los nombres reales de los participantes. Después de ser analizada, la información será guardada por un tiempo razonable y luego destruida.

En caso de dudas o aclaraciones relacionadas con el estudio podrá dirigirse con: Mtra. Mariel García Hernández quien conoce todos los detalles de este estudio. 2224924264 , Correo: mariel.garciahernandez@gmail.com

\section{Participante:}

Nombre: Azalea tlernander.

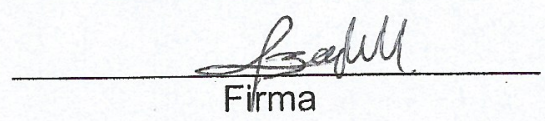

Quien obtiene el consentimiento:

Nombre: Marrel Garcia Heriöudec

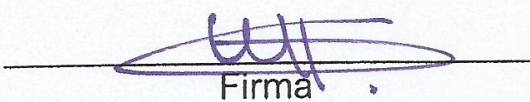




\section{CUESTIONARIO PSSUQ}

Edad:21 Sexo: M /(F) Licenciatura: Discño Grúfico Manejo de llustrator: (Si) / No Propuesta de guía: 3 No. de cuestionario: 29

Este cuestionario es una oportunidad para registrar tus reacciones a la guía de usabilidad. Estas respuestas nos ayudarán a entender qué aspectos hay que mejorar y cuales son con los que no estás satisfechos. Para tener un mejor resultado, piensa en la tarea que se te pidió que realizaras con base a lo que las guías decian mientras contestas estas preguntas.

Instrucciones: Lea cada frase y señala qué tan de acuerdo o en desacuerdo estás y encierra en un circulo un número de la escala. Al terminar, revisaremos juntos el cuestionario para asegurarnos de que entendamos bien la información presentada en este cuestionario.

¡Gracias!

a) La organización de la información proporcionada por las guías me fue clara.

Totalmente en desacuerdo

1

2

3

4

5

Totalmente de acuerdo

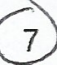

b) Ful capaz de completar las tareas que se me indicaron rápidamente con la información proporcionada en las guías.

Totalmente en desacuerdo

1

2

3

4

5

Totalmente de acuerdo

c) La información proporcionada por las guías fue fácil de entender.

Totalmente en desacuerdo

1

2

3

4

5

Totalmente de acuerdo

d) La apariencia de las guías es agradable.

Totalmente en desacuerdo

1

2

3

4

5

Totalmente de acuerdo

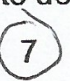

e) En general estoy satisfecho con el acomodo y presentación visual de la infởmación.

Totalmente en desacuerdo

1

2

3

4

5

Totalmente de acuerdo 


\section{LISTA DE CHEQUEO DEL ANÁLISIS DE TAREAS}

Evaluador: Wahel Cuestionario: 29 Fecha: $4 \cdot 40 v \cdot 19$ Propuesta a evaluar: B

\begin{tabular}{|c|c|c|}
\hline Premisa & $\mathrm{Si}$ & No \\
\hline El diseñador generó una paleta de cuatro colores. & $\checkmark$ & \\
\hline $\begin{array}{l}\text { El diseñador relacionó correctamente los lineamientos de } \\
\text { codificación de información en dispositivos médicos y los } \\
\text { aplicó en las secciones de la gráfica de acuerdo a su signi- } \\
\text { ficado. }\end{array}$ & / & \\
\hline $\begin{array}{l}\text { El diseñador estableció un buen contraste entre fondo, } \\
\text { figura y texto. }\end{array}$ & $\checkmark$ & \\
\hline Tiempo en que tardó en leer la página el diseñador. & \multicolumn{2}{|c|}{$1: 05.43$ unin } \\
\hline Veces en que volvió a consultar la página el diseñador. & \multicolumn{2}{|l|}{-} \\
\hline Tiempo en que tardó en completar la tarea el diseñador. & \multicolumn{2}{|c|}{2.38 .52 un } \\
\hline
\end{tabular}


Anexo 10.30. USUARIO 30: Material de resultados de la evaluación de la propuesta editorial "B": consentimiento informado, lista de chequedo de análisis de tareas y cuestionario PSSUQ. 


\section{Consentimiento informado}

Proyecto: NOMOLAS: Propuesta de guías de usabilidad para el diseño de interfaces gráficas de sistemas de visualización de información médica.

Nombre del estudio: Evaluación de usabilidad de propuestas editoriales de las guías de usabilidad NOMOLAS con usuarios (lectores) de las mismas.

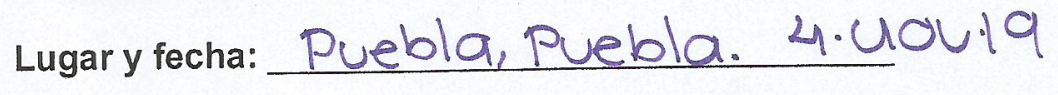

Número de registro: 30

Justificación y objetivo del estudio: La forma en que se presenta la información es importante para que ésta sea comprendida de la mejor manera posible. Este estudio tiene como propósito elegir la mejor propuesta editorial para implementarla en toda la composición visual del proyecto llamado "NOMOLAS: Propuesta de guías de usabilidad para el diseño de interfaces gráficas de sistemas de visualización de información médica", que es a su vez, trabajo de investigación doctoral.

Procedimientos: Primero, se le explicaran los objetivos y el procedimiento de la sesión; describiendo como se llevará a cabo la prueba. Segundo, le pediremos que siga las instrucciones que le entregue el investigador encargado.

Posibles riesgos y molestias: En investigaciones similares no se han registrado dificultades o riesgos de ningún tipo, por tanto, durante su participación no se prevé ningún riesgo.

Posibles beneficios que recibirá al participar en el estudio: Al final de la prueba se le dará al participante $\$ 50.00$ pesos mexicanos en efectivo.

Participación o retiro: Si después de que Usted haya leído esta información y haya obtenido respuesta a las preguntas que pudiera tener, le vamos a pedir leer y firmar esta carta de consentimiento informado. Sin embargo, Usted puede retirarse en cualquier momento, por cualquier razón y nadie le va a preguntar sobre las razones por las cuales se retira.

Privacidad y confidencialidad: Para garantizar la confidencialidad toda la información será guardada y analizada sin usar los nombres reales de los participantes. Después de ser analizada, la información será guardada por un tiempo razonable y luego destruida.

En caso de dudas o aclaraciones relacionadas con el estudio podrá dirigirse con: Mtra. Mariel García Hernández quien conoce todos los detalles de este estudio. 2224924264 , Correo: mariel.garciahernandez@gmail.com

Participante:

Nombre: $\frac{\text { Michelle Pérez Ramirez }}{\text { AmantletDD }}$
Quien obtiene el consentimiento:

Nombre: Uahel Garcia Hewoudec

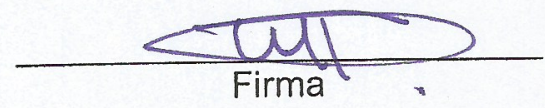




\section{CUESTIONARIO PSSUQ}

Edad: 20 Sexo: M / F Licenciatura: Diseño gráfico y digital Manejo de llustrator: (Si) I No Propuesta de guía: $B$ No. de cuestionario: 30

Este cuestionario es una oportunidad para registrar tus reacciones a la guia de usabilidad. Estas respuestas nos ayudarán a entender qué aspectos hay que mejorar y cuales son con los que no estás satisfechos. Para tener un mejor resultado, piensa en la tarea que se te pidió que realizaras con base a lo que las guías decian mientras contestas estas preguntas.

Instrucciones: Lea cada frase y señala qué tan de acuerdo o en desacuerdo estás y encierra en un circulo un número de la escala. Al terminar, revisaremos juntos el cuestionario para asegurarnos de que entendamos bien la información presentada en este cuestionario.

¡Gracias!

a) La organización de la información proporcionada por las guías me fue clara.

Totalmente en desacuerdo

1 2

3

4

5

Totalmente de acuerdo

b) Fui capaz de completar las tareas que se me indicaron rápidamente con la información proporcionada en las guías.

Totalmente en desacuerdo

12

3

4

5

Totalmente de acuerdo

c) La información proporcionada por las guías fue fácil de entender.

Totalmente en desacuerdo

1

3

4

5

Totalmente de acuerdo

d) La apariencia de las guías es agradable.

Totalmente en desacuerdo

1 2 3

4

5

Totalmente de acuerdo

(7)

e) En general estoy satisfecho con el acomodo y presentación visual de la información.

Totalmente en desacuerdo

Totalmente de acuerdo

1

2

3

4

5

6 


\section{LISTA DE CHEQUEO DEL ANÁLISIS DE TAREAS}

Evaluador: Uamel Cuestionario: 30 Fecha: $4 \cdot 11 \cdot 19$ Propuesta a evaluar:

B

\begin{tabular}{|l|l|l|}
\hline Premisa & Si & No \\
\hline El diseñador generó una paleta de cuatro colores. & & \\
\hline $\begin{array}{l}\text { El diseñador relacionó correctamente los lineamientos de } \\
\text { codificación de información en dispositivos médicos y los } \\
\text { aplicó en las secciones de la gráfica de acuerdo a su signi- } \\
\text { ficado. }\end{array}$ & $1: 52.09 \mathrm{~min}$ \\
\hline $\begin{array}{l}\text { El diseñador estableció un buen contraste entre fondo, } \\
\text { figura y texto. }\end{array}$ & & \\
\hline Tiempo en que tardó en leer la página el diseñador. & $2: 43.09 \mathrm{u}$. & \\
\hline Veces en que volvió a consultar la página el diseñador. & \\
\hline Tiempo en que tardó en completar la tarea el diseñador. & & \\
\hline
\end{tabular}



Anexo 11. Material para la evaluación de la FASE 2. 
Anexo 11.1. Material para de la evaluación FASE 2. Pieza publicitaria para redes sociales buscando la promoción del workshop.

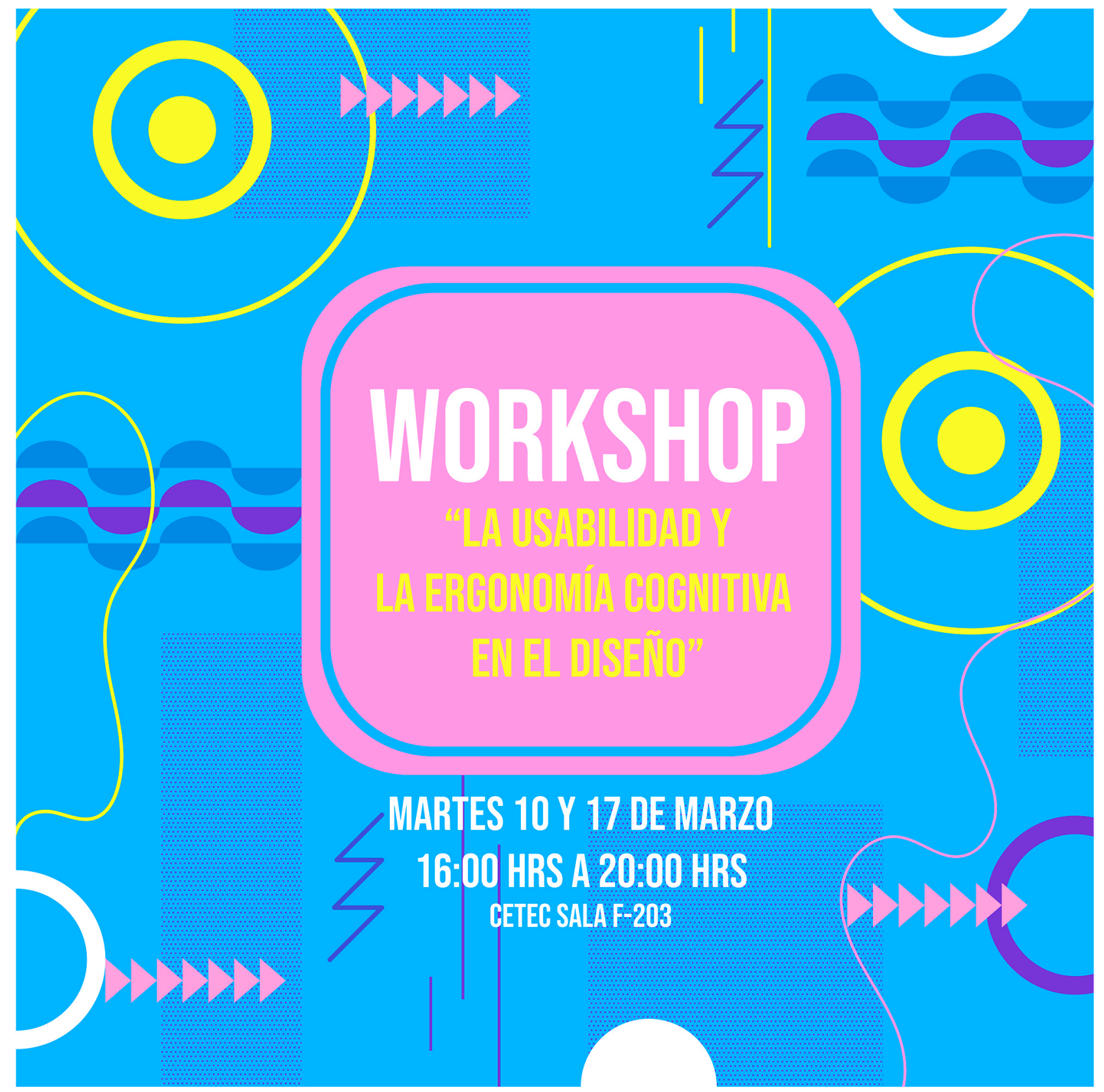


Anexo 11.2. Material para de la evaluación FASE 2. Captura de pantalla del formulario en la plataforma "Google Forms" para el workshop.

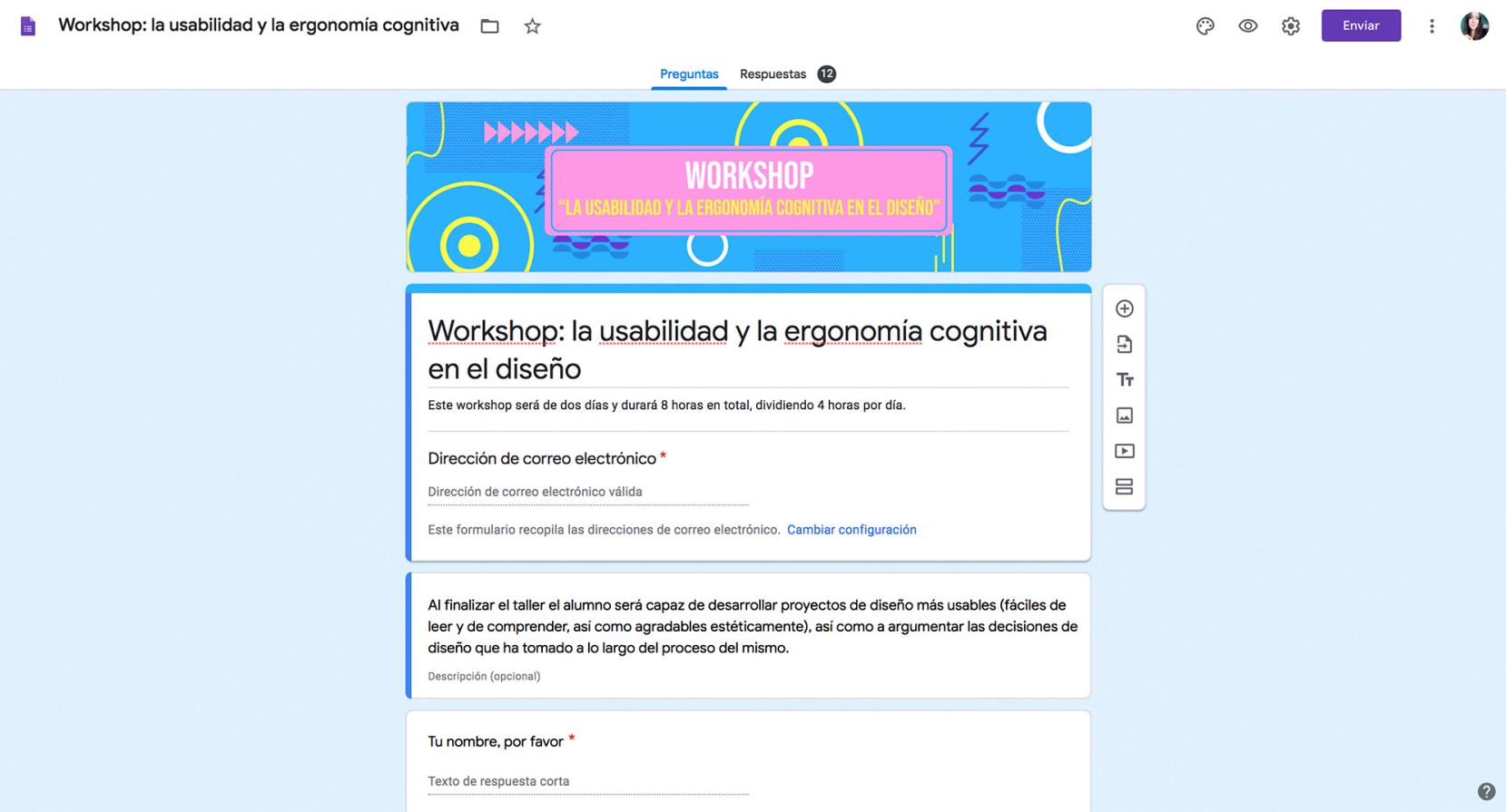


Anexo 11.3. Material para de la evaluación FASE 2. Láminas de la presentación usada durante el workshop.
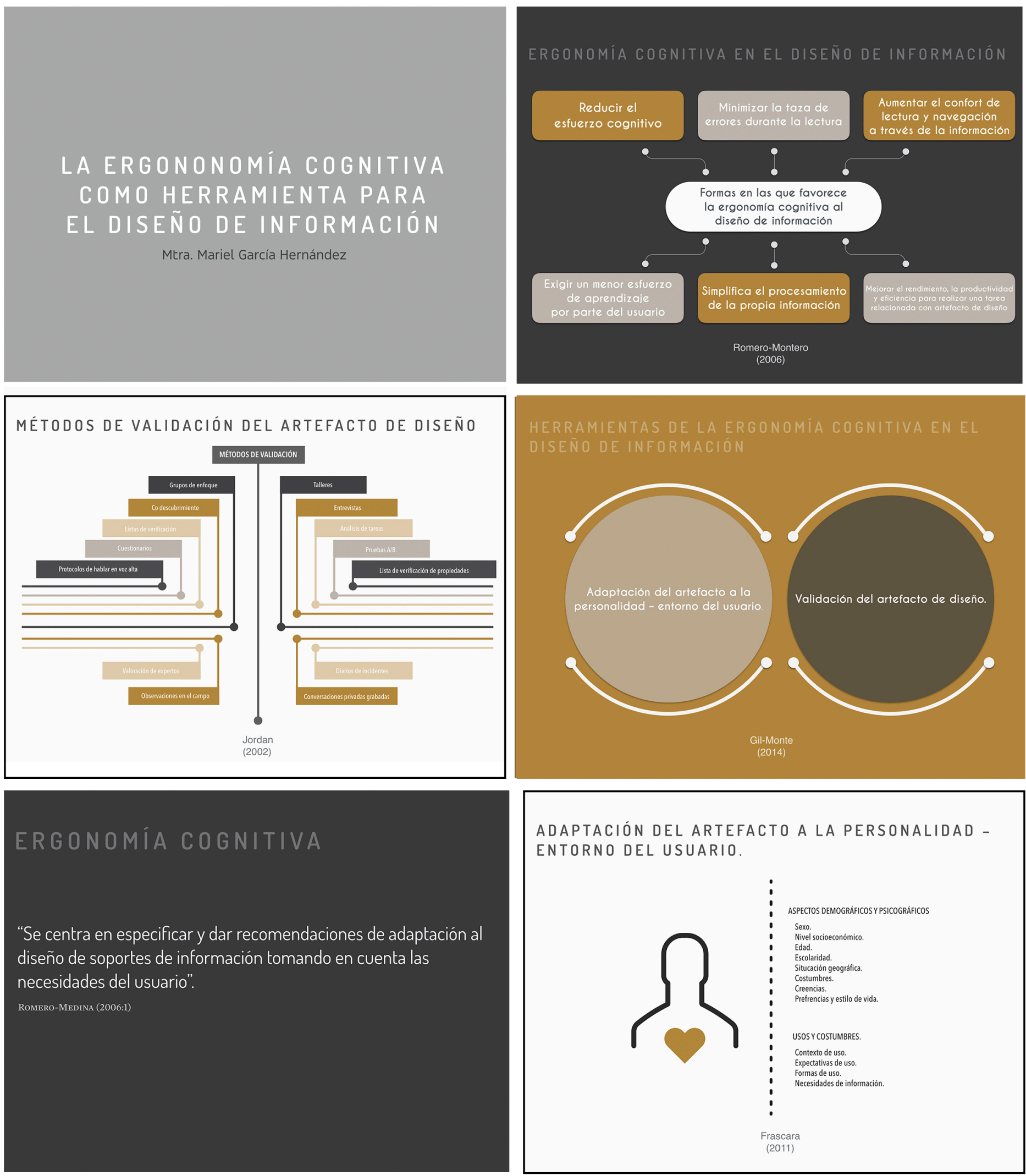

ADAPTACIÓN DEL ARTEFACTO A LA PERSONALIDAD ENTORNO DEL USUARIO

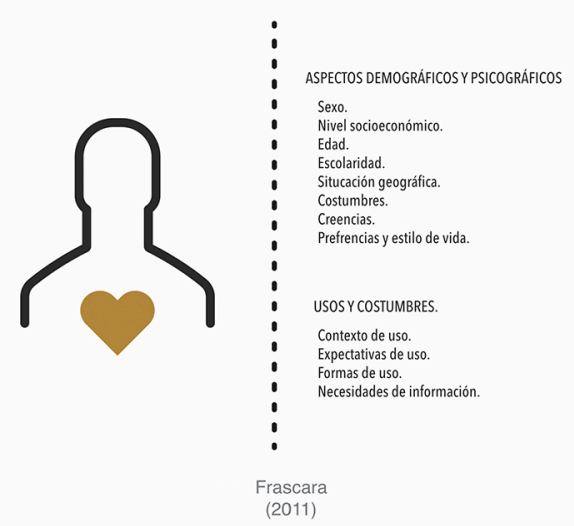


Anexo 11.4. Material para la evaluación de la FASE 2. Lámina de la presentación con la tarea a realizar de la herramienta Análisis de Tareas.

\section{ACTIVIDAD}

Objetivo: Re diseñar el historial clínico de un paciente con diabetes tomando como base las guías NOMOLAS.

\section{Instrucciones:}

1) Reunirse en parejas.

2) Identificar la información con la que se va a trabajar.

3) Llenar el lienzo el apartado de “USUARIO” del LEAN CANVAS DECISIONES DE DISEÑO.

4] Desarrollar tres bocetos a lápiz.

5) Digitalizar el boceto ganador.

6] Comenzar a llenar los demás apartados del LEAN CANVAS DECISIONES DE DISEÑO.

7) Desarrollar el historial clínico de un paciente con diabetes con base a las guias.

8) Al finalizar el historial clinico enviar al correo mariel.garciahernandez@gmail.com

9) Contestar el cuestionario PSSUQ que se les entregará. 
Anexo 11.5. Material para de la evaluación FASE 2. Fotos como evidencia de la impartición del workshop.
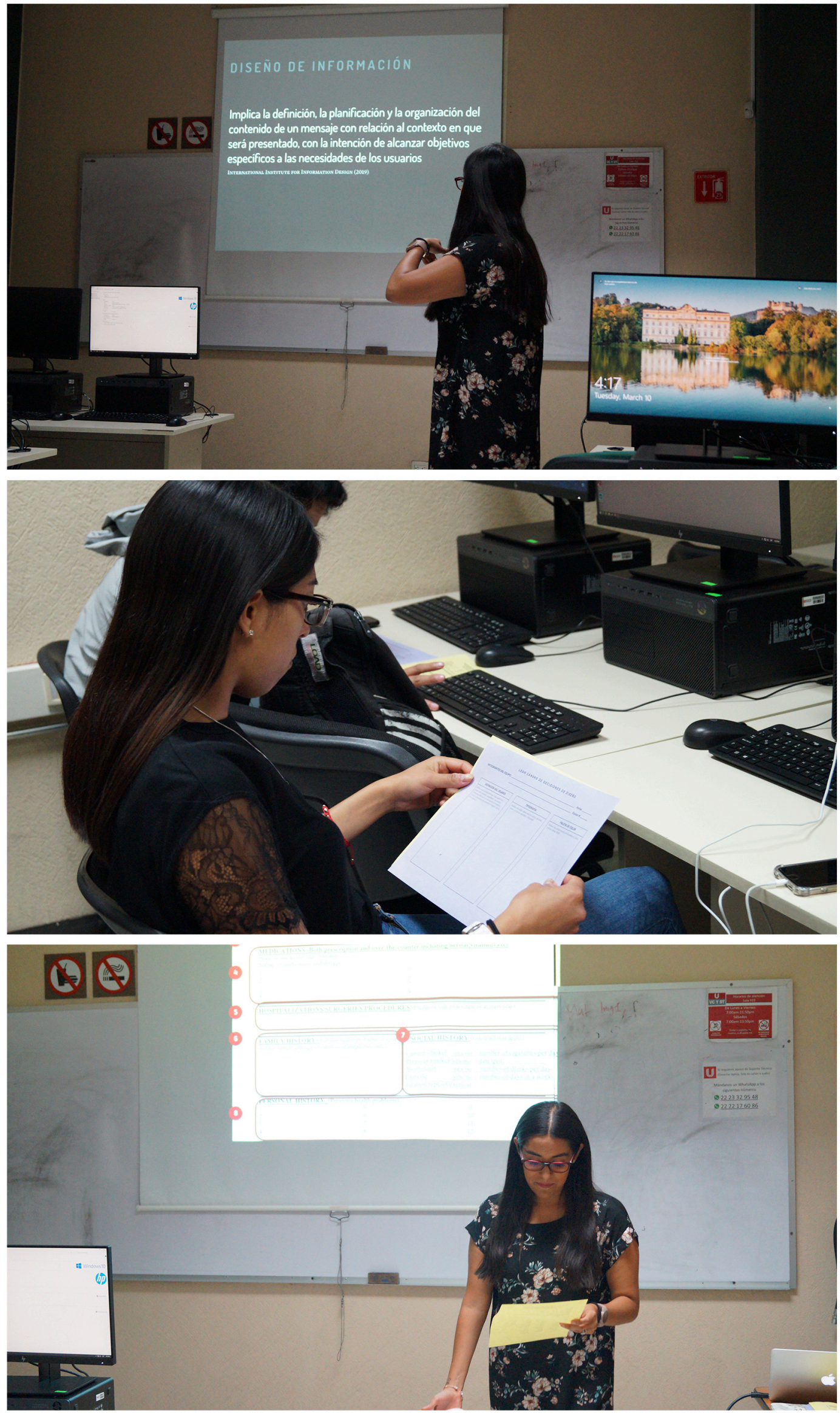
Anexo 11.6. Material para de la evaluación FASE 2. Lean Canvas de decisiones de diseño.

\section{LEAN CANVAS DE DECISIONES DE DISEÑO}

INTEGRANTES DEL EQUIPO:

Fecha:

Equipo \#:

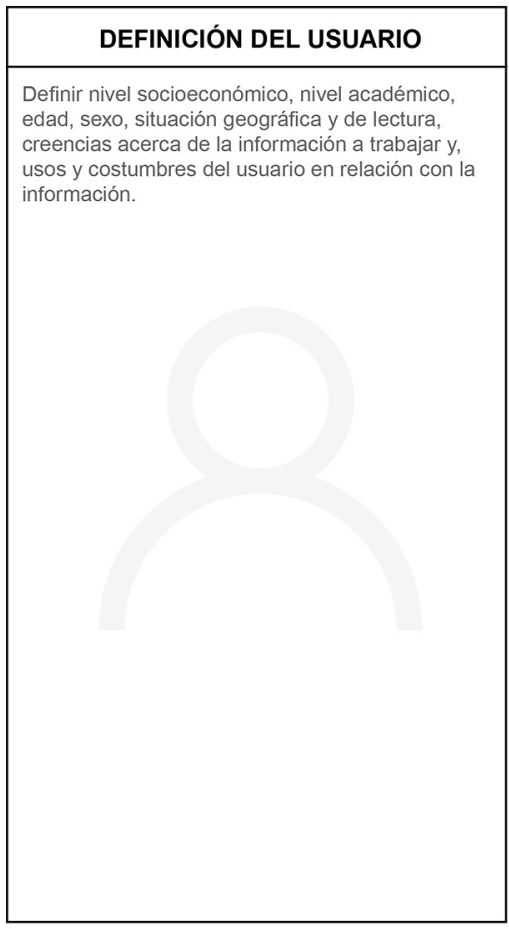

TIPOGRAFÍA

Señalar tipografía usada para el cuerpo del texto, títulos, subtítulos, leyendas y etiquetas.

\section{PALETA DE COLOR}

Señalar los colores usados en la paleta de color (indicar código RGB). 


\begin{tabular}{|c|c|c|}
\hline $\begin{array}{l}\quad \text { LISTA DE CHEQUEO DEL ANÁLISIS DE TAREAS } \\
\text { Evaluador: } \\
\text { SECCIÓN DE LAS GUÍAS NOMOLAS }\end{array}$ & \multirow[b]{2}{*}{ Si } & \multirow[b]{2}{*}{ No } \\
\hline USUARIO & & \\
\hline El diseñador definió el nivel socioeconómico. & & \\
\hline El diseñador definió el nivel académico. & & \\
\hline El diseñador definió edad. & & \\
\hline El diseñador definió sexo. & & \\
\hline El diseñador definió situación geográfica. & & \\
\hline El diseñador definió situación de lectura. & & \\
\hline El diseñador definió creencias sobre la información. & & \\
\hline El diseñador definió usos y costumbres presentadas alrededor de la información. & & \\
\hline ESTRUCTURA DE LA INFORMACIÓN & Si & No \\
\hline El diseñador utilizó una retícula para generar la composición de su gráfica. & & \\
\hline La información presentada de manera visual tiene congruencia y presenta jerarquía en relación al contenido. & & \\
\hline La navegación de lectura se hace de izquierda a derecha y en forma de zig-zag. & & \\
\hline TIPOGRAFÍA & Si & No \\
\hline El diseñador utilizó alguna de las fuentes sugeridas en las guías. & & \\
\hline El diseñador utilizó un espacio interlineal de 1.5 & & \\
\hline El diseñador evitó la aparición de "viudas" en la composición. & & \\
\hline El diseñador evitó la aparición de "ríos" en la composición. & & \\
\hline El diseñador utilizó la variante negrita para hacer énfasis en palabras clave. & & \\
\hline El diseñador utilizó la variante cursiva para hacer referencia a palabras en idioma extranjero. & & \\
\hline El diseñador utilizó un puntaje de carácter para el cuerpo de texto de no menor a 8 puntos. & & \\
\hline El diseñador utilizó para los títulos tipografías sans serif. & & \\
\hline Los títulos están alienados a la izquierda o centrados. & & \\
\hline Los títulos están en variante negrita y en un puntaje mayor al del cuerpo de texto. & & \\
\hline El cuerpo de texto está alienado a la izquierda. & & \\
\hline El texto y el fondo de la interfaz tienen un buen contraste. & & \\
\hline El diseñador combinó tipografías serif y sans serif en la composición de la pieza de diseño. & & \\
\hline COLOR & Si & No \\
\hline El diseñador utilizó cuatro colores dentro de la composición. & & \\
\hline El diseñador cuidó el buen contraste entre figura, fondo y texto en la pieza de diseño. & & \\
\hline El diseñador tomó en consideración el uso de contraste de color entre fondo y texto. & & \\
\hline El diseñador evitó el uso de degradados. & & \\
\hline El diseñador utilizó el mismo color para representar un mismo tipo de dato. & & \\
\hline El diseñador creo codificaciones de información a través del color. & & \\
\hline ELEMENTOS GRÁFICOS & Si & No \\
\hline Todos los elementos conserven un mismo estilo gráfico. & & \\
\hline El diseñador implementó imágenes que tienen la misma orientación & & \\
\hline El diseñador evitó el uso de emojis. & & \\
\hline El diseñador usó etiquetas o leyendas debajo de los elementos gráficos que necesitaban algún tipo de aclaración. & & \\
\hline $\begin{array}{l}\text { El diseñador usó bullets point, listas numéricas y flechas para enfatizar información que pertenecía a una misma } \\
\text { categoría. }\end{array}$ & & \\
\hline El diseñador evitó el uso de elementos o información innecesarios, extraños, decorativos o irre & & \\
\hline
\end{tabular}


Anexo 11.8. Material para de la evaluación FASE 2. Cuestionario PSSUQ.

\section{CUESTIONARIO PSSUQ}

Edad:

Sexo: M / F Licenciatura:

Manejo de llustrator: Si / No

Este cuestionario es una oportunidad para registrar tus reacciones a la guía de usabilidad. Estas respuestas nos ayudarán a entender que aspectos hay que mejorar y cuales son con los que no estás satisfechos. Para tener un mejor resultado, piensa en la tarea que se te pidió que realizaras con base a lo que las guías decían mientras contestas estas preguntas.

Instrucciones: Lea cada frase y señala qué tan de acuerdo o en desacuerdo estás y encierra en un circulo un número de la escala. Al terminar, revisaremos juntos con usted el cuestionario para asegurarnos de que entendamos bien la información presentada en este cuestionario.

\section{¡Gracias!}

a) La organización de la información proporcionada por las guías me fue clara.

Totalmente en desacuerdo

Totalmente de acuerdo

1

3

4

5

7

b) Fui capaz de completar la tarea que se me indicó rápidamente con la información proporcionada en las guías.

Totalmente en desacuerdo

Totalmente de acuerdo

$$
1
$$

2

3

4

5

6

7

c) La información proporcionada por las guías fue fácil de entender.

Totalmente de desacuerdo

1

$$
2
$$

3

4

5

Totalmente de acuerdo

d) La apariencia de las guías es agradable.

Totalmente en desacuerdo

$$
1
$$

2

3

4

5

Totalmente de acuerdo

e) En general estoy satisfecho con el acomodo y presentación visual de la información.

Totalmente en desacuerdo

Totalmente de acuerdo

1

2

3

4

5

6

7 
Anexo 11.9. Material para de la evaluación FASE 2. Guías de usabilidad para del desarrollo de interfaces gráficas de visualizaciones de información médica. 

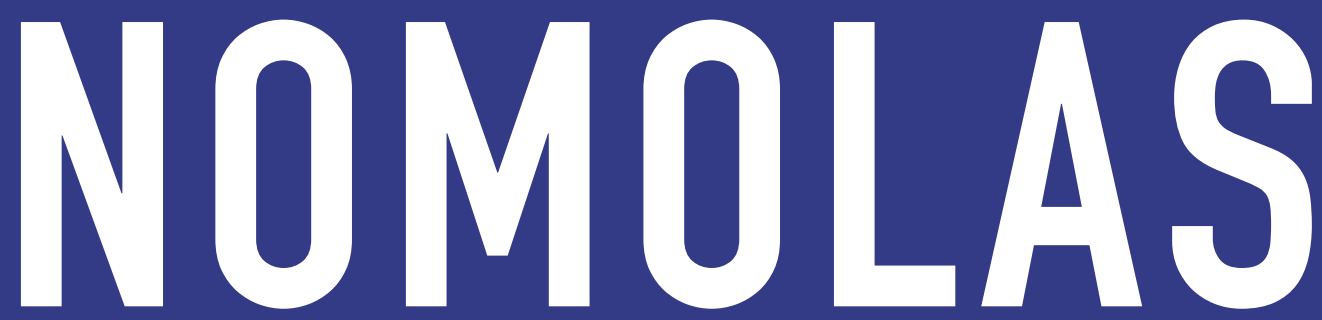

Gúas de usabilindad para el diseño de interfaces graficas de sistemas de visualización de información médica 



\section{INTRODUCCIÓN}

La problemática principal de este trabajo de investigación da como resultado una propuesta de guías que permitan al diseñador desarrollar interfaces gráficas de sistemas de visualización de información médica que aseguren usabilidad de estos para su usuario.

Dicha problemática tiene su origen, de acuerdo a lo que plantea Few (2004), en que la mayoría de los sistemas de visualización de información son difíciles de desarrollar de una forma ra de los siste clara, ya que suen estar llension de información son dificiles de doc propensos a erros $y$, por ende, pú pecto al conocimiento que se está intentando transmitir o proyectar a través de éstos. Las o lector.

El uso de tipografías ilegibles, de elementos visuales usados con un objetivo ornamental y no como un potenciador cognitivo, colores que generan mal contraste entre sí, información desordenada y mal estructurada compromete de manera grave el objetivo de comunicación de la interfaz gráfica (consultar la sección de anexo para ver ejemplos).

Las guías que se exponen a continuación como producto de este trabajo de investigación están divididas de la siguiente manera:

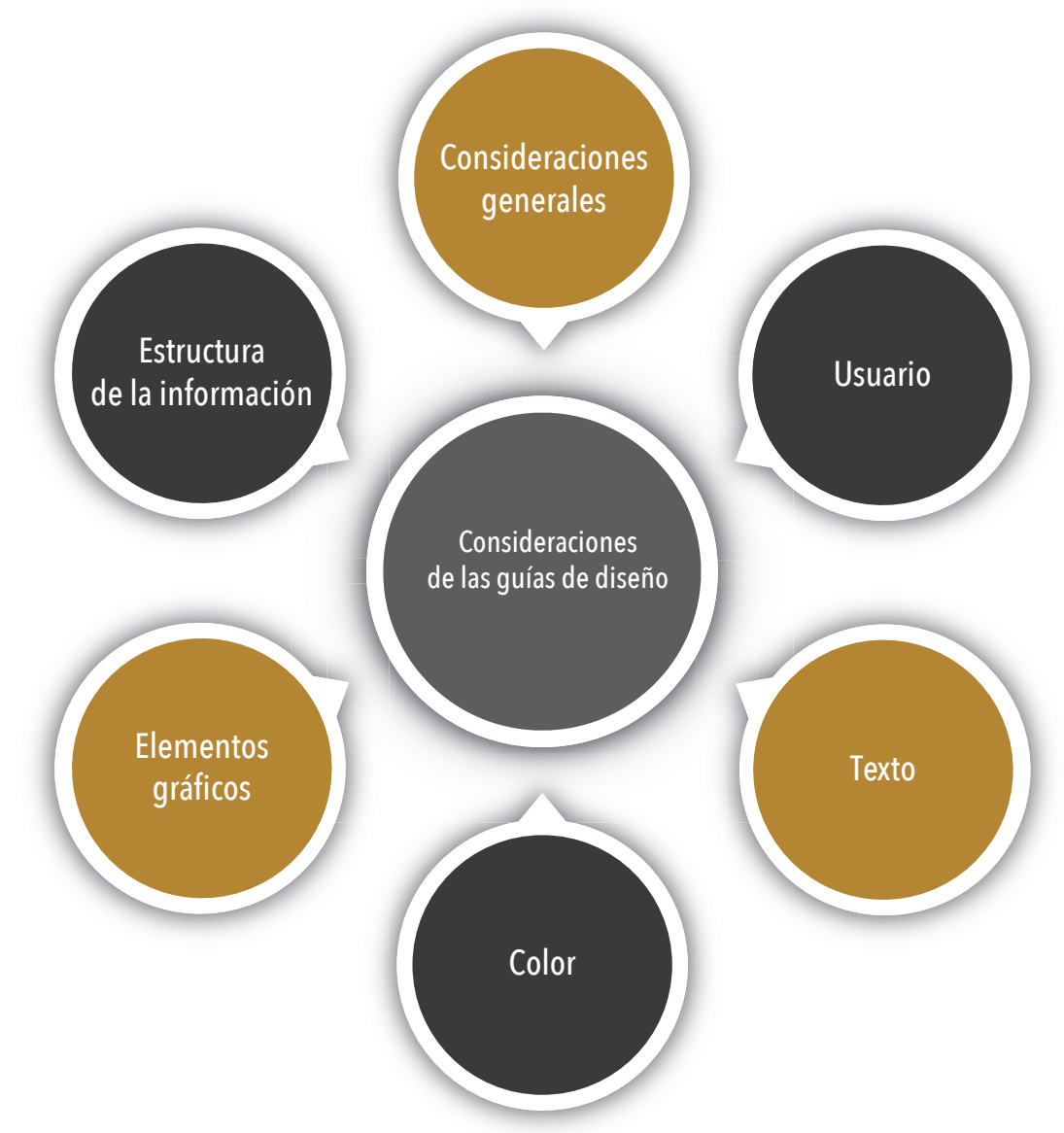




\section{ÍNDICE}

5 Consideraciones generales

9 Usuario

13 Estructura de la información

21 Texto

33 Color

41 Elementos gráficos

49 Figuras en la visualización de información

81 Referencias 


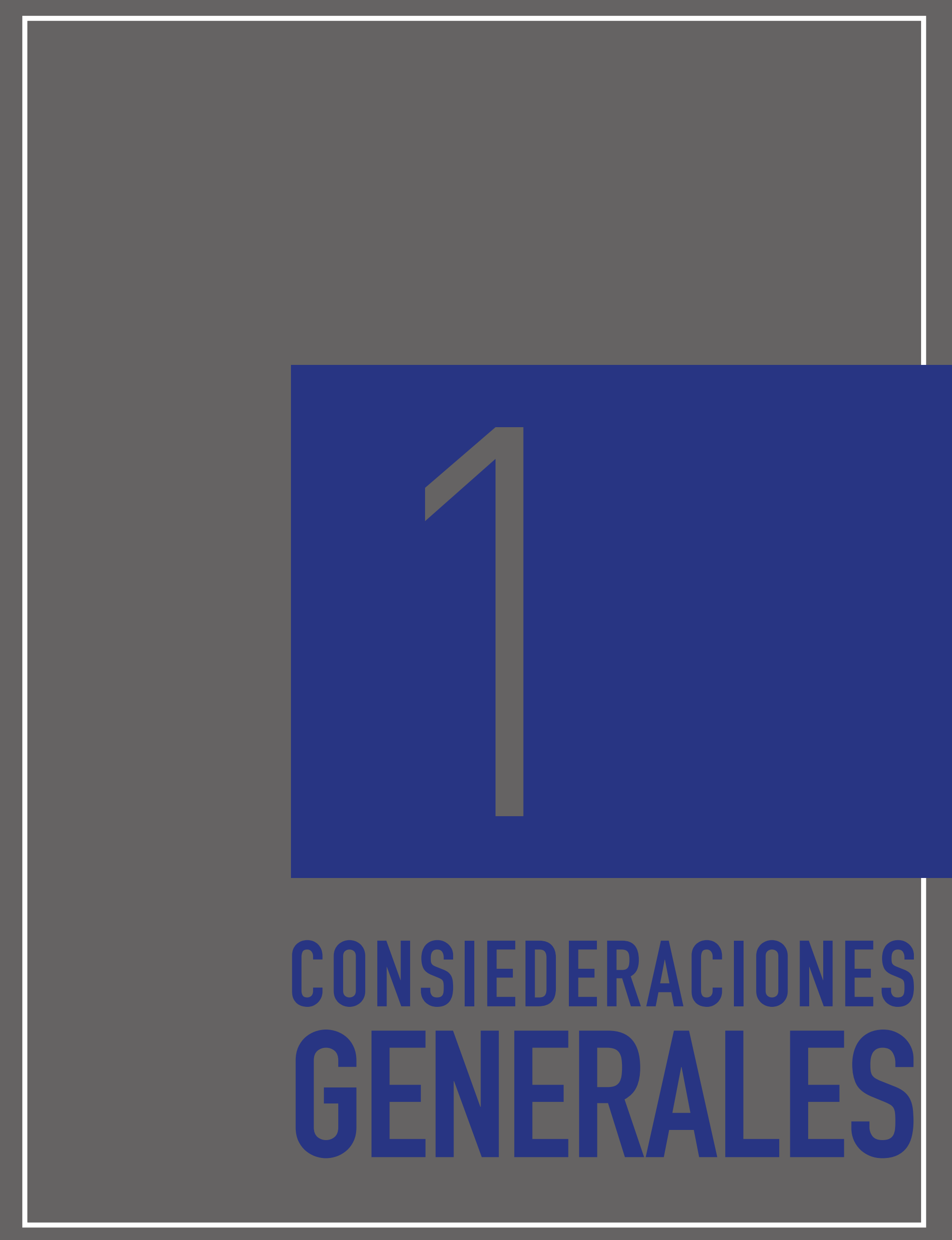


1 Agrupación de información. Cada uno de los elementos que se utilicen en la interfaz gráfica deben agruparse de manera significativa, ya que el usuario logrará su comprensión si éstos le son presentados de una manera agrupada, de acuerdo a las Leyes de la Gestalt. De esta forma, el lector podrá recordar y comprender la información de una mejor manera.

2 Recordatorios o texto de apoyo. Se recomienda auxiliarse de señales visuales que ayuden al usuario a recordar la clase de información con la que están interactuando o que aporten un poco de contexto previo a dicha información.

3 Uso de elementos familiares. Es recomendable que la forma en que se visualiza la información en una interfaz gráfica se base en el conocimiento que el usuario pueda tener con respecto a los símbolos, imágenes o elementos gráficos utilizados. De esta manera, se le aporta un valor más significativo a la información y refuerza la transmisión del propio conocimiento que se está tratando de proyectar. Debe utilizarse un diseño simple y directo con una riqueza de datos, reduciendo la necesidad de inferencias, haciendo comparaciones claras y explícitas en la información de ser el caso.

\section{4}

Uso de elementos gráficos limitados. Aunque un sistema de visualización de información tiene como fin hacer que la información que se presenta sea más accesible y rápida de interpretar para el usuario, se recomienda que el uso de elementos gráficos en cada sección de cualquier sistema de visualización sea limitado, así se evitará que el usuario haga esfuerzos cognitivos extras para determinar la razón de ser de cada uno de los elementos gráficos utilizados en el sistema. Cualquier elemento gráfico que no aporte significado o no favorezca el procesamiento y la comprensión de información debe omitirse. Deben minimizarse los patrones de distracción, colores predominantes, sombreado, 3D, cuadrículas innecesarias, etc.

\section{5}

Jerarquía. Aunque un sistema de visualización de información tiene como fin hacer que la información. Es importante ordenar la información de modo en que ésta resulte más relevante para el objetivo de comunicación, se sugiere que vaya primero u ocupe el foco visual de la interfaz gráfica, ya que esto afectará la forma en que los usuarios la información. El objetivo es priorizar la información en orden de importancia para el usuario.

6 Consistencia. Se debe presentar de una forma coherente la información que se va a incluir en el sistema de información, ya que así el usuario la encontrará más fácil de comprender. La calidad y simplicidad de la información se debe garantizar manteniendo símbolos, colores, texto y métricas consistentes, seleccionando cuidadosamente los elementos visuales para ayudar a y métricas consistentes, seleccionando cuidadosamente los elementos visuales para ayudar a
aclarar el significado de los datos, auxiliarse de títulos claros para cada sección o bloque de información y, del uso anotaciones sobre cómo interpretar la visualización. 
7 Énfasis. Es muy importante generar énfasis visual en la información que sea de suma relevancia para el objetivo de comunicación de la interfaz gráfica. El diseñador se puede auxiliar desde un acomodo en la retícula que resalte dicha información hasta el uso de colores, elementos visuales o algún tipo de juego gráfico que aluda a este fin. Esto favorecerá a la memoria icónica para el procesamiento y comprensión de información que le es presentada al lector o usuario. 8 Simplicidad. El sistema de visualización de información debe presentar de una manera sencilla y accesible la información con la que se está trabajando. Es decir, que este sistema no reque

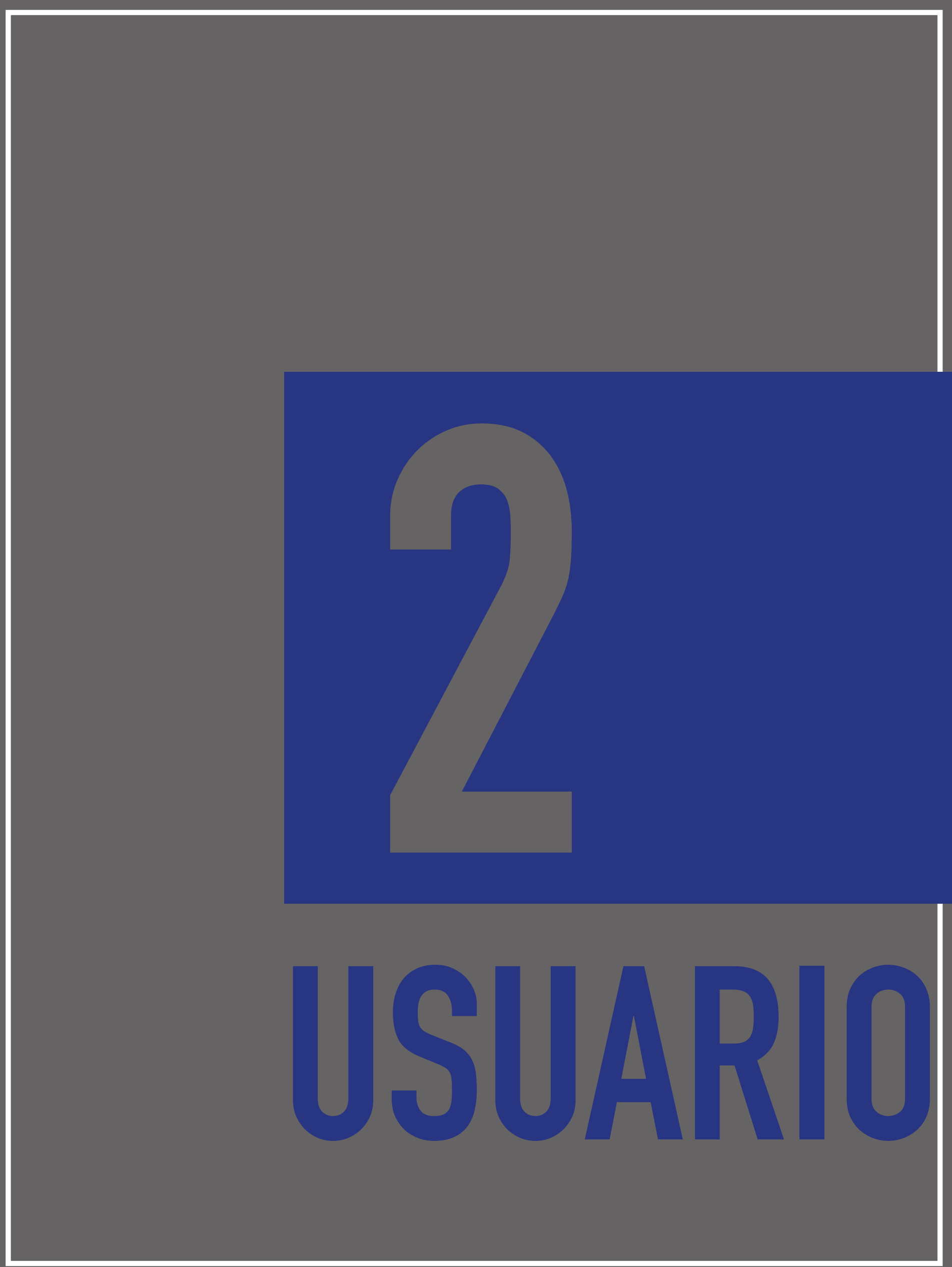


2 De acuerdo a Frascara (2000) se recomienda segmentar y definir al usuario de la siguiente manera:

1. Nivel socioeconómico: Este punto hace referencia al nivel jerárquico que ocupa el usuario de acuerdo a su bienestar económico y social.

2. Nivel de escolaridad o académicos: Hace referencia al grado de estudios máximo alcanzado por el usuario.

3. Edad: Rango de tiempo que ha vivido el usuario.

4. Sexo: Características biológicas y fisiológicas que clasifican al usuario como femenino o masculino.

5. Situación geográfica: Este punto se refiere al lugar de residencia del usuario.

6. Situación de lectura: Hace referencia al medio por donde el usuario interactuará con la información, tomando en cuenta que puede ser a través de un medio impreso o digital.

\section{Creencias sobre la información que se le va a presentar.}

8. Usos y costumbres: Este rubro hace referencia a la manera en que se relaciona el usuario con la información que se trabajará en la interfaz gráfica.

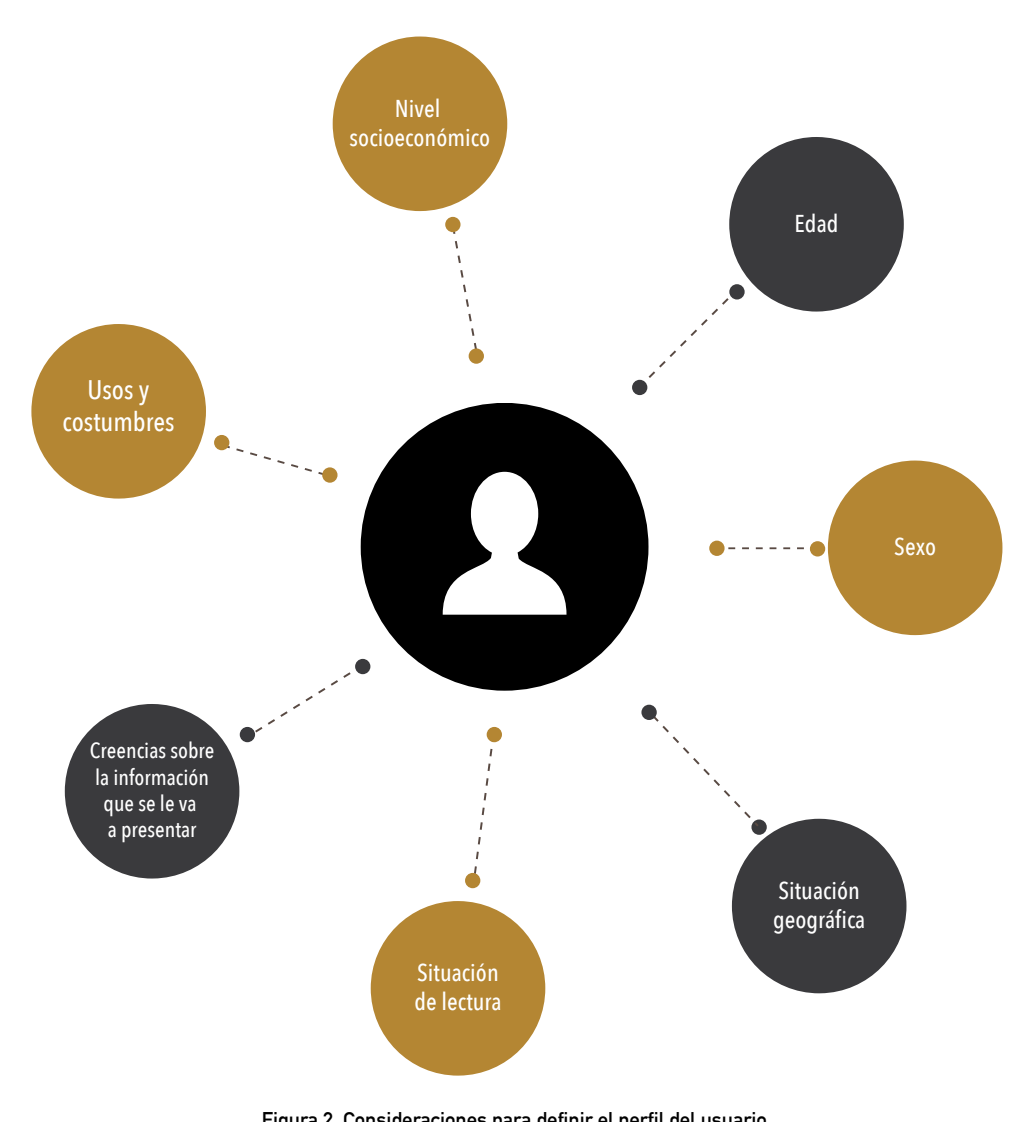

Figura 2. Consideraciones para definir e l perfil del usuario 
3 Ya definiendo los puntos anteriores, se sugiere tener esto siempre presente a la hora de tomar

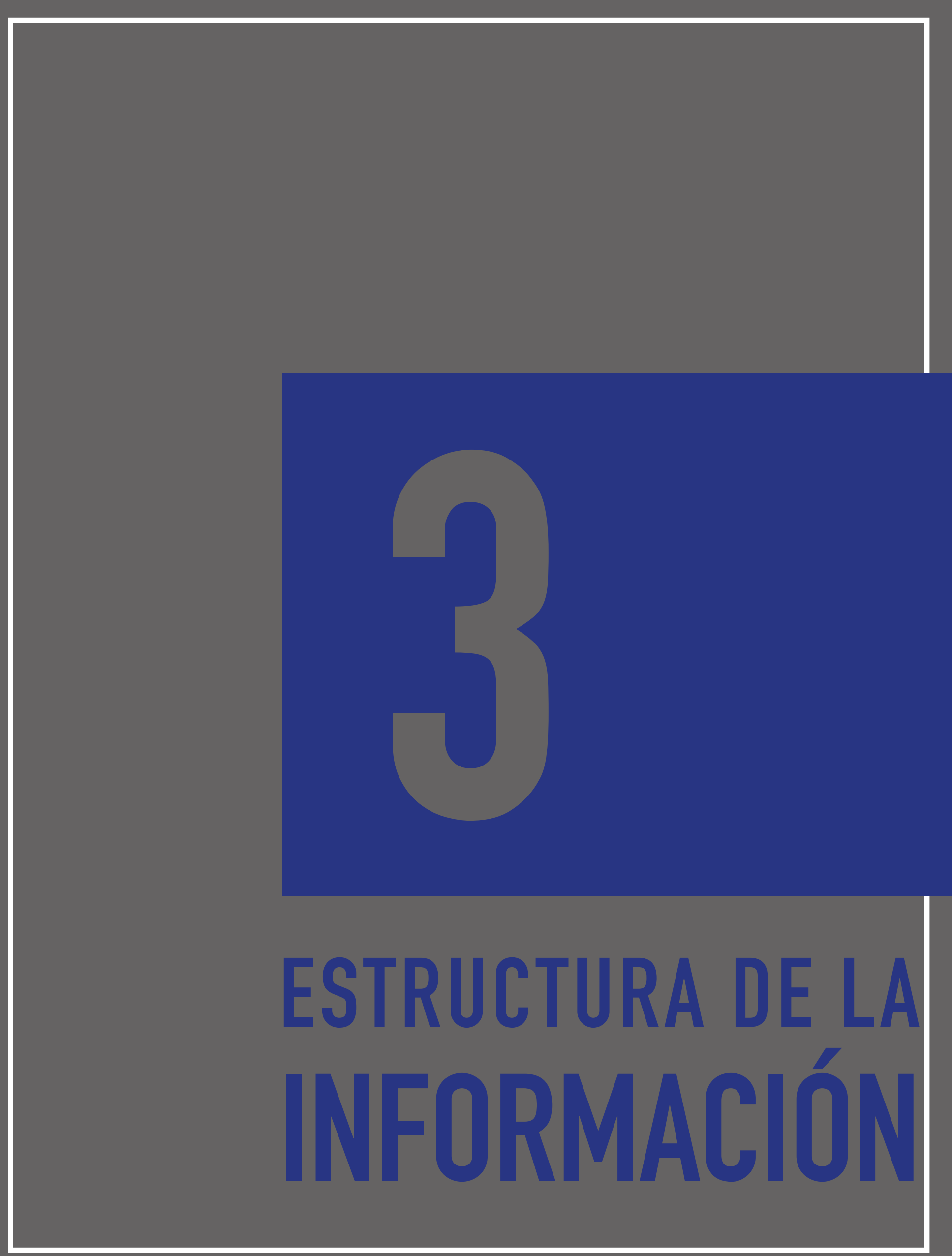


1 Es primordial leer y relacionarse con la información que se va a trabajar. Sí hubiera dudas es recomendable hondar en el tema, según lo establece Cairo (2011).

2 De acuerdo al autor anterior, es importante que se estructure la información de una forma en que haya congruencia y secuencia entre términos y conceptos.

3 La estructura en sí de la propia información que se está trabajando en el sistema de visualización de información debe mostrar una jerarquía clara y bien planificada que ayude al lector a identificar dicho orden, acorde a lo que Lonsdale \& Lonsdale (2019) señalan. $4 \begin{aligned} & \text { Para ayudar al usuario a procesar la información dentro de cuadros complejos, debe existir } \\ & \text { una jerarquía visual clara en la que se resalten los elementos importantes, se eliminen las }\end{aligned}$ distracciones y se establezca el orden visual, según Cairo (2011).

5 Se sugiere, de acuerdo a lo que analizan Nielsen \& Loranger (2016), un diseño en el cual la navegación se haga de izquierda a derecha y en forma de zigzag, ya que esto responde a la forma natural en que nuestros ojos leen la información.

Todos los elementos gráficos que se utilizan, deben apoyar a la estructuración jerárquica de información, así como también, deben ser consistentes visualmente hablando entre ellos, según argumenta Cairo (2011).

7 El texto y las imágenes que se encuentren relacionados entre sí bajo términos de concepto se recomienda que se coloquen muy juntos en términos de proximidad perceptiva (y con la ayuda de guías visuales, si corresponde) para dirigir el ojo desde el texto a las imágenes y la espalda, y facilitar la integración de la información, de acuerdo a lo que establecen Lonsdale \& Lonsdale (2019). Es recomendable el uso de retículas para estructurar todos los elementos que contenga el
sistema de visualización de información. Las retículas más usadas en el diseño de interfaces gráficas son las siguientes (ver en la próxima página): 
Retícula de manuscrito. Este tipo de retícula se usa generalmente para bloques de texto largos. Está compuesta por márgenes amplios que enmarcan un rectángulo en donde se vaciará la información. Los títulos, pies y número de página se encuentran dentro de los marcadores que se localizan fuera de los márgenes, así como lo muestra la siguiente figura.

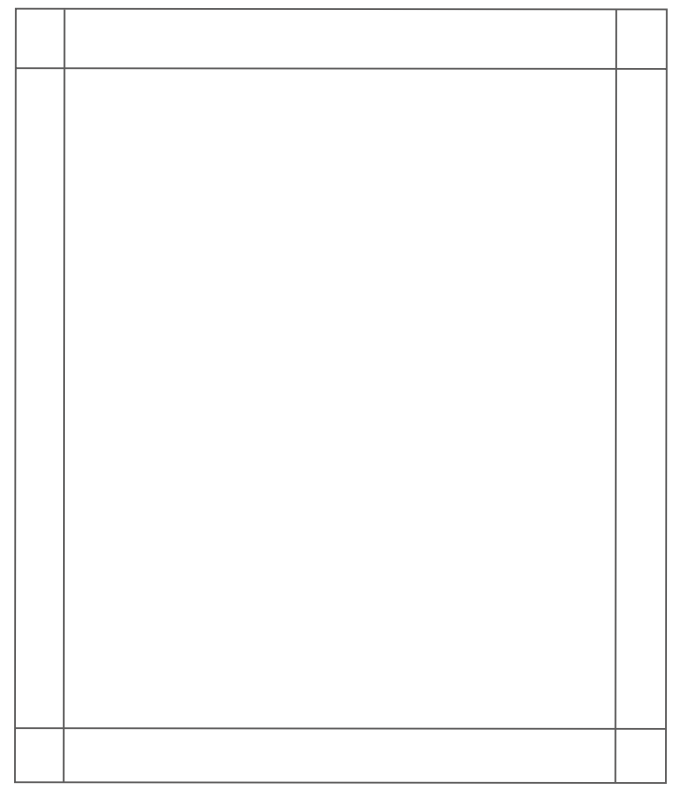

Figura 3. Reticula de manuscrito

Retícula de columna. Esta retícula resulta ser bastante flexible en cuanto al acomodo de la información. El número de columnas va a depender de la cantidad de información que se esté manejando, es decir, entre más información mayor número de columnas.

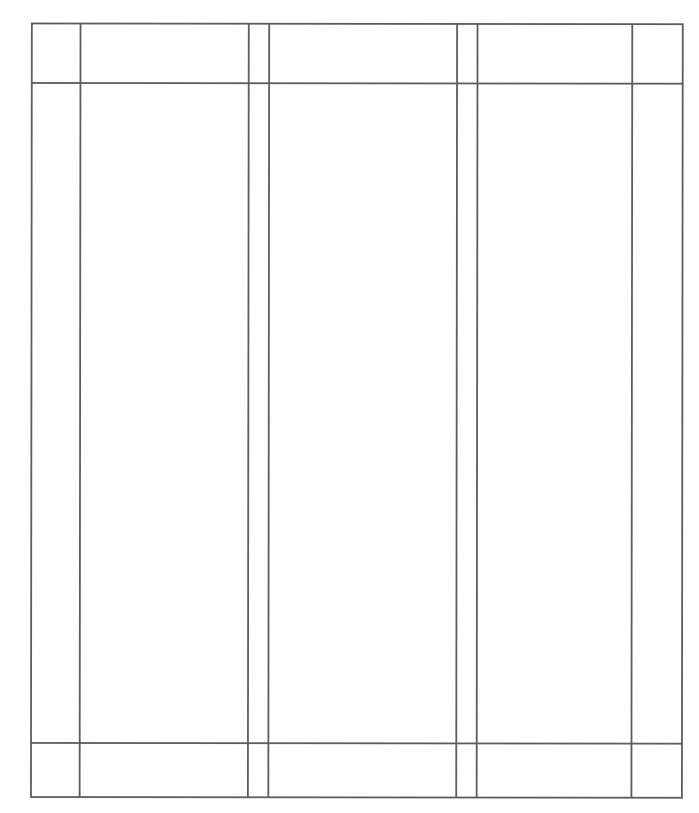

Retícula modular. Este sistema reticular está compuesto por módulos del mismo tamaño. Se puede diagramar con base al número de módulos que se tengan sobre el lienzo, ya que a través de estos se puede crear zonas espaciales ${ }^{2}$ para insertar imágenes y texto. Entre más módulos tenga la retícula más flexible será para el acomodo de la información, sin embargo, esto aumentará el nivel de complejidad para mantener la estética de la interfaz.

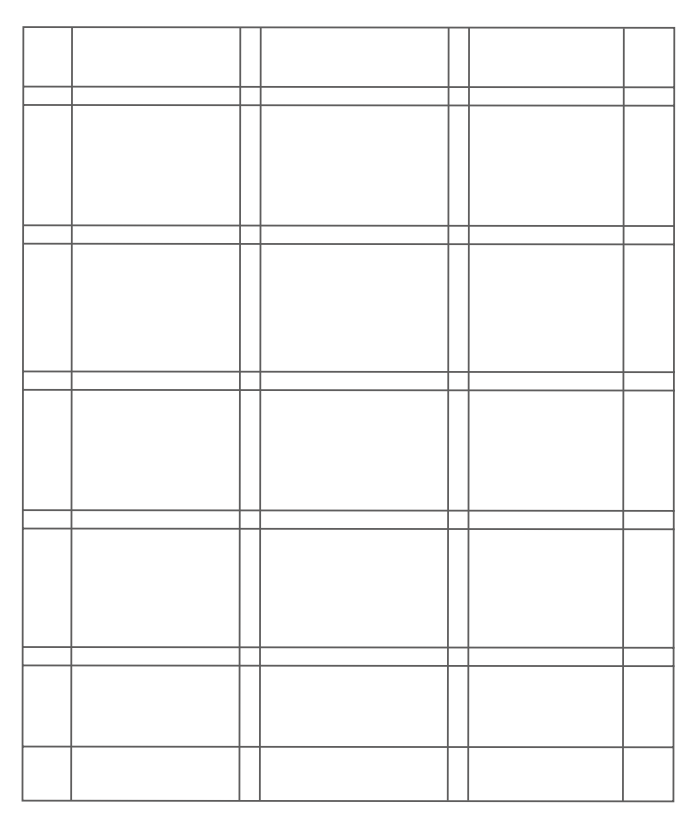

Figura 5. Reticula modular

Retícula jerarquíca. Este tipo de retícula, al contrario de las anteriores, no se rige a través de módulos, columnas o márgenes. Esta retícula se adapta al contenido y no éste a ella. Este sistema reticular se establece a través de los niveles de jerarquía de la propia información.

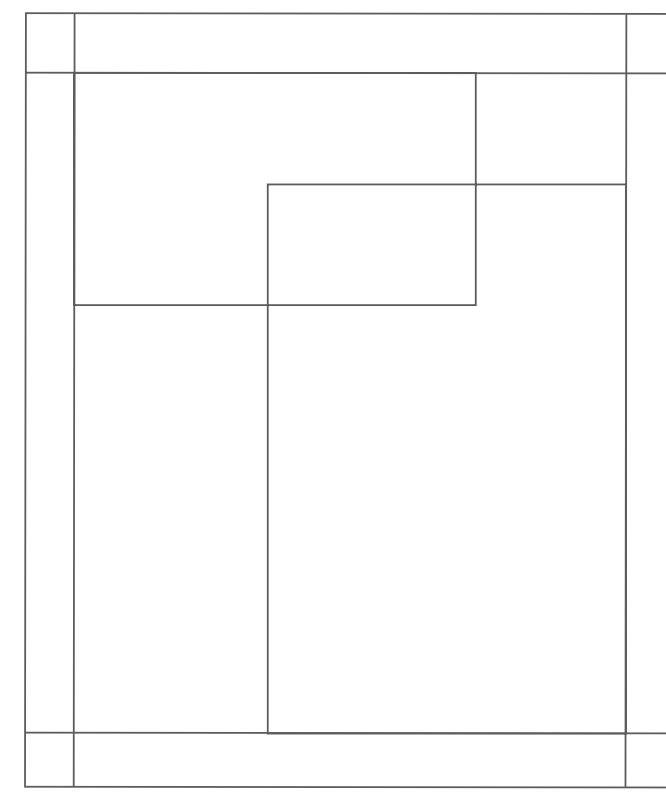

Figura 6. Reticula jerarquica 
Al ser estas guías que se enfocan en el desarrollo de sistemas de visualización médica es importante mencionar los datos médicos y sus diversas clasificaciones basándose en el caso de estudio de esta investigación que es la diabetes. Los datos médicos que se pueden trabajar respecto a esta patología son los siguientes:

Historial clínico. El historial clínico es un compendio de información que alude a datos de identificación y evolución del propio paciente. En éste se asienta la evolución de la patología. Dentro de este bloque de información, de acuerdo a Castro \& Gámez, (2002), se encuentran a su vez los siguientes datos:

\section{Datos de identificación.}

a. Número de historia clínica.

a. Nombre y apellido clinica.

b. Nombre apellido del paciente.

c. Fecha de nacimiento del paciente.
d. Género del paciente.

d. Genero del paciente.

e. Edad del paciente.

. Domicilio particular del paciente

g. Número telefónico de contacto.

h. Peso del paciente.

i. Altura del paciente.

. Signos vitales del paciente (temperatura, presión, pulso, frecuencia respiratoria, nivel de glucosa).

2. Datos relativos al centro de salud o del doctor tratante.

a. Nombre de la unidad o centro de salud donde ingresa el paciente.

b. Nombre del doctor a cargo del caso clínico.

d. Persona facultativa a cargo del ingreso del paciente.

\section{Datos referidos al proceso de ingreso.}

a. Fecha de admisión del paciente.

a. Fecha de admisión del paciente.

c. Diagnóstico principal.

d. Procedimientos quirúrgicos u obstétricos que ha tenido el paciente.

e. Otros procedimientos significativos que haya tenido el paciente.

\section{Datos referidos a antecedentes clínicos.}

a. Antecedentes familiares de enfermedades (diabetes, hipertensión, cáncer, enfermedades del corazón, etc).

b. Si el paciente tiene hijos y, en caso de ser afirmativo, cuáles son las edades de éstos.

c. Historial social, tales como cuál es su trabajo, su jornada laboral, dónde vive, cuál es el ambiente emocional en el que el paciente habita. d. Hábitos del paciente. Si hace ejercicio y con qué frecuencia realiza esta actividad, si fuma, se droga y toma, y la periodicidad con la que desarrolla o desarrolló estas actividades. Si se droga (o drogaba), que estupefaciente usa o usó. Patrón de sueño, a qué hora duerme y más o Alergis a medicamentos y alin

\section{Datos referentes a la historia de la enfermedad actual.}

a. Fecha de diagnostico de diabetes.

b. Nombre del médico que trata actualmente la diabetes del paciente. c. Dirección del médico que trata actualmente la diabetes del paciente. d. Fecha de última revisión de parte del médico tratante por diabetes. e. Si el paciente está siguiendo una dieta en especial.

. Consumo aproximado de calorías al día.

g. Si el paciente está tomando insulina.

i. Unidades de insulina.

iii. Hora en que se inyecta la dosis de insulina.

h. Si el paciente ha sufrido un coma diabético, fecha de éste y frecuen-

Si el paciente se ha realizado análisis de glucosa en la orina. En caso de ser afirmativo, mencionar las últimas dos fechas de éstos.

j. Si el paciente ha tenido alguno de estos padecimientos:

i. Infecciones dentales.

ii. Trastornos en la visión.

iii. Problemas en el corazón.

v. Presión alta.

v. Problemas en los riñones o en las vías urinarias.

vi. Alguna enfermedad recurrente o prolongada. En caso de ser afirmativo, mencionar cuál.

k. Niveles de glucosa.

i. En ayunas.

ii. Después de la comida.

iii. Antes de la cena.

l. Sí se le ha realizado un electrocardiograma. En caso de ser afirmativo, establecer la fecha.

$m$. Si se le ha realizado una radiografía de tórax. En caso de ser afirmativo, indicar la fecha.

6. Datos bioquímicos relacionados con el control de la diabetes.

a. Triglicéridos $(\mathrm{mg} / \mathrm{dL})$.

b. Glucosa (mg/D).

. Hemoglobina glucosilada (HbA1c).

. Colesterol total $(\mathrm{mg} / \mathrm{dL})$

e. Colesterol de alta densidad (mg/dL).

. Colesterol de baja intensidad (mg/dL).

g. Colesterol de muy baja intensidad (mg/dL).

h. Índice de riesgo coronario.

i. Examen de orina.

i. Color.

ii. Aspecto.

iii. Gravedad específica.

iv. $\mathrm{Ph}$

v. Sedimiento

vi. Proteínas $(\mathrm{mg} / \mathrm{dL})$

vii. Glusoca $(g / d L)$.

viii. Hemoglobina.

ix. Bilirubina.

$x$. Cetonas.

xi. Urobilinor

xi. Urobilinogeno $(\mathrm{mg} / \mathrm{dL})$

xii. Esterasa Leucocitaria (Leu/uL).

xiii. Nitritos. 


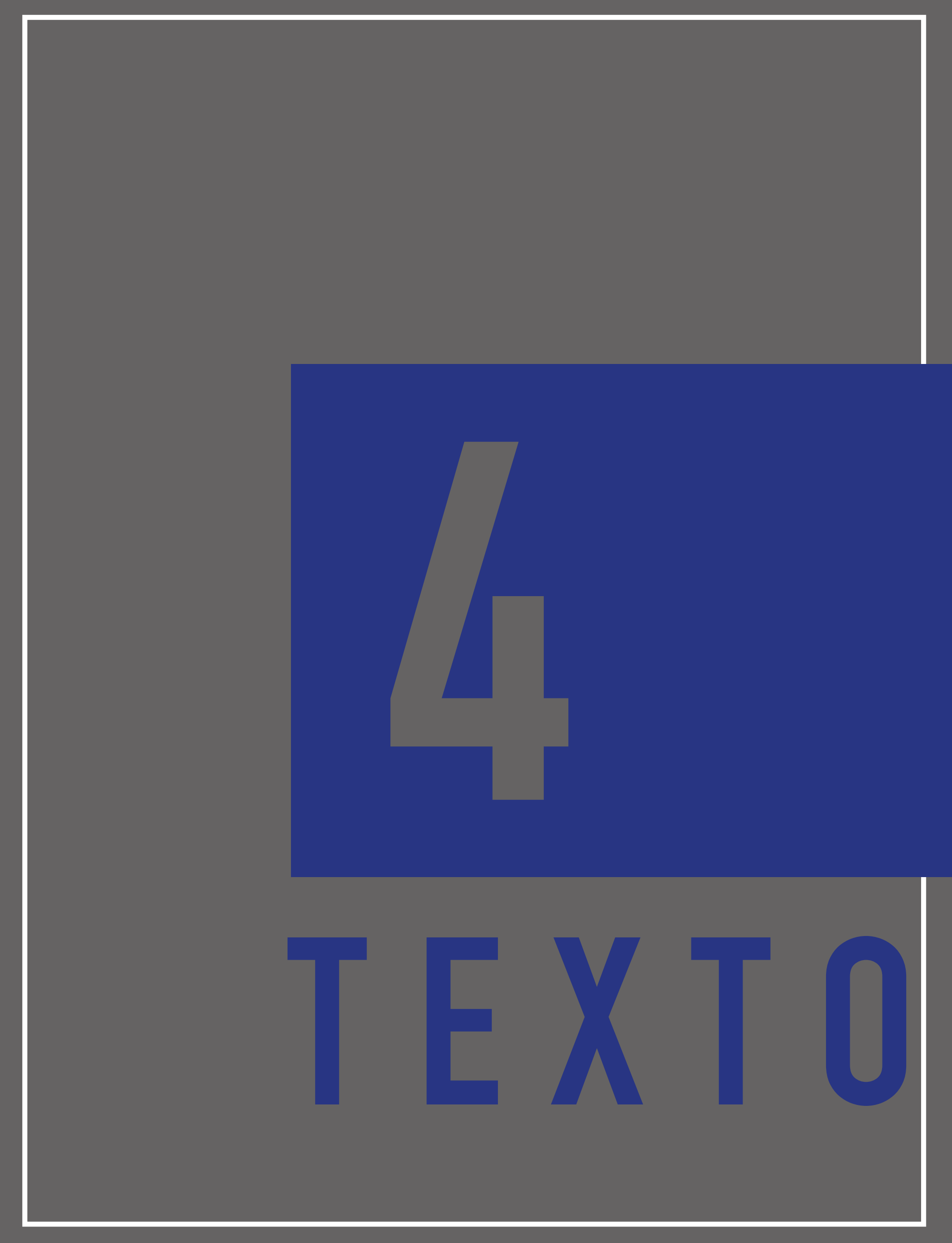




\section{ELECCIÓNTIPOGRÁFICA}

1 Según a Nielsen \& Loranger (2006), la tipografía debe elegirse de manera apropiada para su función, es decir, para transmitir el mensaje de manera efectiva.

2 El tipo de letra seleccionada deben coincidir con el tema de la información que se trabajará. 3

Las fuentes tipográficas, según determina Nielsen \& Loranger (2006) son las siguientes:

\begin{tabular}{|c|c|c|}
\hline FUENTE TIPOGRÁFICA & LEGIBILIDAD & CARÁCTER/TONO \\
\hline Arial & $\begin{array}{l}\text { Es una tipografía legible. Se recomienda } \\
\text { usar en puntajes superiores a } 10 \text { puntos. }\end{array}$ & $\begin{array}{l}\text { Moderna, básica y sin adornos. } \\
\text { Suele gustar a los usuarios de } \\
\text { todas las edades. }\end{array}$ \\
\hline Georgia & $\begin{array}{l}\text { La mejor fuente serif diseñada para la } \\
\text { lectura online. Generalmente buena en } \\
\text { tamaños de letra } 10 \text { o más. }\end{array}$ & $\begin{array}{l}\text { De aspecto tradicional, pero más } \\
\text { moderna y legible que Times } \\
\text { New Roman. }\end{array}$ \\
\hline Times New Roman & $\begin{array}{l}\text { Tiene buen rendimiento en materiales } \\
\text { impresos, ya que en la pantalla, la legibili } \\
\text { dad disminuye en pequeños puntajes. } \\
\text { Se sugiere su uso a partir de } 12 \text { puntos. }\end{array}$ & $\begin{array}{l}\text { Es una tipografía que no es } \\
\text { prefererida por la mayoría de los } \\
\text { usuarios. Tiene un aspecto } \\
\text { profesional. }\end{array}$ \\
\hline Trebuchet MS & $\begin{array}{l}\text { Es una tipografía legible. Se recomienda } \\
\text { usar en puntajes superiores a } 10 \text { puntos. }\end{array}$ & $\begin{array}{l}\text { Tiene un aspecto moderno, } \\
\text { sencillo y vanguardista. }\end{array}$ \\
\hline Verdana & $\begin{array}{l}\text { La tipografía con mayor legibilidad. } \\
\text { Recomendada para usarla en cuerpo de } \\
\text { texto. }\end{array}$ & $\begin{array}{l}\text { De aspecto simple, moderno y } \\
\text { profesional. Alta preferencia por } \\
\text { parte del usuario. }\end{array}$ \\
\hline
\end{tabular}

Figurr 7. Tipografaías recomennadas por Nielesen \& Loranger 20006

1 No es recomendable los tipos de letra con características inusuales (Nielsen \& Loranger, de distracción durante el recorrido de la lectura

\section{Hamburguosa Bambuttututesa}


5

El tamaño del tipo, el espacio interlineal y la longitud de la línea se deben coordinar y elegir juntos.

6 Según lo que sugiere Götz (1988:58), "el espacio interlineal debe ser por lo menos uno y medio más grande que la altura de $x$, es decir, 1.5".

\section{Aturatidex Conej0}

Así mismo, la autora sugiere que se le de la importancia a este elemento tipográfico, ya que interviene en la legibilidad del texto y del mismo contenido en sí.

7 Siguiendo con las recomendaciones de la autora, el ancho normal de una línea debe tener alrededor de 50 caracteres.

8 Lonsdale \& Lonsdale (2019), hacen las siguientes recomendaciones acerca de la tipografía y su uso:

a. Debe evitarse dejar una sola palabra en un renglón dentro de una caja de texto. A esto se le llama viuda.

$$
\begin{aligned}
& \text { Lorem ipsum dolor sit amet, consectetuer adipiscing elit. Aenean com } \\
& \text { modo ligula eget dolor. Aenean massa. Cum sociis natoque penatibus } \\
& \text { etmagnis dis parturient montes, nascetur ridiculus mus. Donec quam }
\end{aligned}
$$
et magnis dis

Figura 10. Fjemplo de una "viuda" en una caja de texto

b. La variante "negrita" debe usarse sobre la variante "cursiva" para enfatizar el texto. La variante cursiva debe reservarse para situaciones en las que se utiliza una palabra extranjera o para títulos cortos.

Muy lejos, más allá de las montañas)de palabras, alejados de los países
de las vocales y las consonantes, viven los textos simulados. Un riachuelo llamado Pons fluye por su pueblo y los abastece con las normas necesarias. c. La variante "negrita" se puede usar para enfatizar información, y como una técnica para engrosar los caracteres cuando estos deben imprimirse o vers en un fondo oscuro $y / 0$ de color.

d. Se debe evitar utilizar la variante "cursiva" para grandes bloques de texto, ya que esta atrasa la lectura.

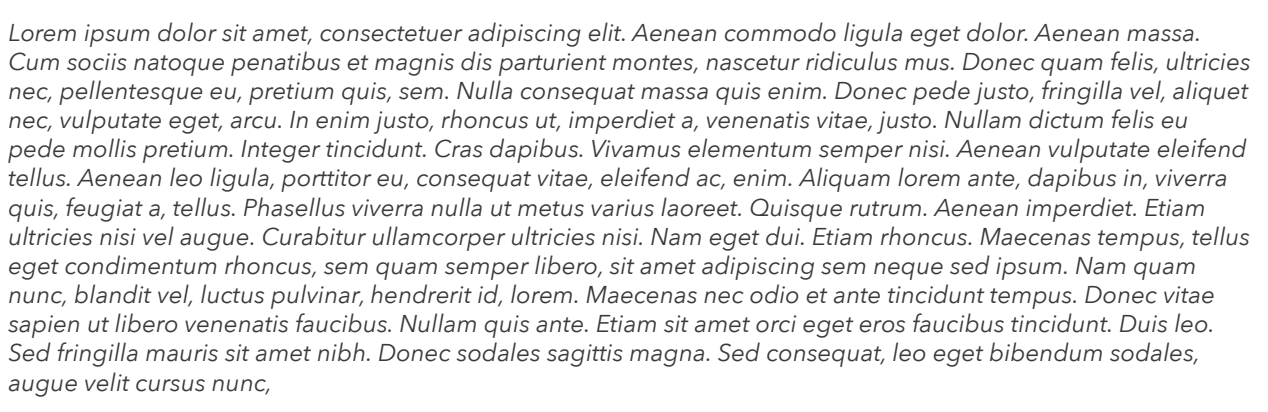

Figura 12 El uso de la

e. Se recomienda usar la variante "negrita" para aumentar la legibilidad en un fondo de color o sombreado.

f. La variante "negrita" no debe usarse para una gran cantidad de texto porque al resaltar todo, no se enfatizará nada del contenido a un nivel cognitivo.

\section{Lorem ipsum dolor sit amet, consectetuer adipiscing elit. Aenean commodo ligula eget dolor. Aenean massa.} vel, aliquet nec, vulputate egel, arcu. In enim justo, rhoncus ut, imperdiet a, venenatis vitae, justo. Nullam dictum eleifend tellus. Aenean leo ligula, porttitor eu, consequat vitae, eleifend ac, enim. Aliquam lorem ante, dapibus

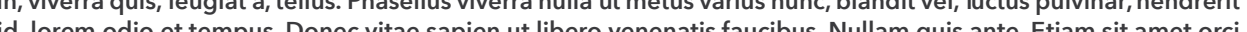
eget e ros faucibus tincidunt. Duis leo. Sed fringilla mauris sit a met nibh. Donec sodales sagitis magna. Sed

Figura 13. El luso de la variable "negrita" en todo el texto no logra enfatizar nada del contenido a un nivel cognitivo.

g. Se debe evitar la variante "subrayado" porque agrega bastante ruido y compromete la legibilidad del texto y de la información en sí.

h. No se deben usar diferentes tipos de letra para enfatizar el contenido en sí, no solo porque hace que la lectura sea más ardua, sino también porque altera la estética.

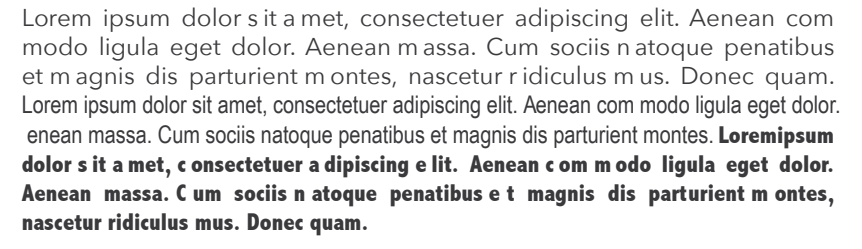

Figura 14. Ejemplo del mal uso de diversas variantes tipograficas en un bloque de texto. 
Según lineamientos que proponen Nielsen \& Loranger (2016) la lectura es más agradable y confortable para el usuario cuando se emplean tipografías serif 3 .

\section{Hamburguesa Hamburguesa}

Figura 15. Ejemplos de tipografía sans serify serit.

10 El puntaje mínimo recomendado para las cajas de texto es de 11 pts. y para las anotaciones o dato complementarios como fuentes de referencia es 8 pts, de acuerdo a Lonsdale \& Londsdale (2019).

11 Nielsen \& Loranger (2016) argumentan que el puntaje se debe elegir dependiendo del usuario al que la interfaz va dirigida, por lo cual se presentan las siguientes sugerencias de acuerdo al usuario:

\begin{tabular}{|l|c|}
\hline \multicolumn{1}{|c|}{ AUDIENCIA } & PUNTAJE \\
\hline Audiencia general & $0 \cdot 12$ \\
Personas mayores y personas con discapacidad visual. & $12 \cdot 14$ \\
Niños pequeños y otros lectores principiantes. & $12 \cdot 14$ \\
Adolescentes y adultos jovvenes & $10-12$ \\
\hline
\end{tabular}

Figura 16. Tamaño de puntaje recomendado de acuerdo a la audiencia por Nielse \& Loranger (2006).

12 La tipografía no debe ser demasiada fina o condensada en su forma, según plantean Lonsdale \& Lonsdale (2019).

\section{Figura 17. La tipografaín no debe ser demasiado fina ni condestan}

14

Los mismos autores recomiendan utilizar notas al pie para aclarar puntos en especiales del texto que se está leyendo.

\section{TÍTULOS}

15 Los títulos deben ser uno de los elementos más dominantes en la interfaz gráfica y deben presentar rápidamente el propósito del contenido y el enfoque del mensaje. El contraste entre el título, los subtítulos y el texto narrativo debe ser claro en términos de
diferencias de tamaño y las características del tipo de letra. 17 De acuerdo a lo que plantea Götz, (1988:56), las tipografías sans serif son utilizadas para los

18 Es recomendable no usar más de tres niveles de jerarquía en cuanto a texto, el nivel de mayor jerarquía puede distinguirse usando un puntaje de letra mayor con la variable "negritas" centrado en el lienzo, de acuerdo a lo que argumentan Nielsen \& Loranger (2006).

19 De acuerdo a Lonsdale \& Lonsdale (2019), los títulos pueden estar centrados o alineados a la izquierda, mientras que los encabezados deben alinearse a la izquierda.

20 Es recomendable que los títulos puedan ser usados en la variante "negrita" o un par de puntajes más grandes que el texto principal, según los mismos autores.

\section{TíTULO}

Subtitulo

Muy lejos, más allá de las montañas de palabras, alejados de los países de las vocales y las consonantes, viven los textos simulados. Viven aislados en casas de letras, en la costa de la semántica, un gran océano de lenguas. Un riachuelo llamado Pons fluye por su pueblo y los abastece con las normas necesarias.

$$
\text { Figura 18. Contraste de peso tipgoráfico entre el titulo, subtitulo y el texto. }
$$

\section{ETIQUETASYLEYENDAS}

21 Lonsdale \& Lonsdale (2019), hacen las siguientes recomendaciones sobre el uso de etiquetas y leyendas:

a. Las etiquetas se deben utilizar para proporcionar información detallada sobre los datos y se deben excluir si son redundantes o si el gráico se ve desordenado. 
b. Se sugiere que los textos de apoyo (etiquetas, leyendas, etc.) deben colocarse para ayudar al usuario a interpretar el gráfico, no para distraer o confundir.

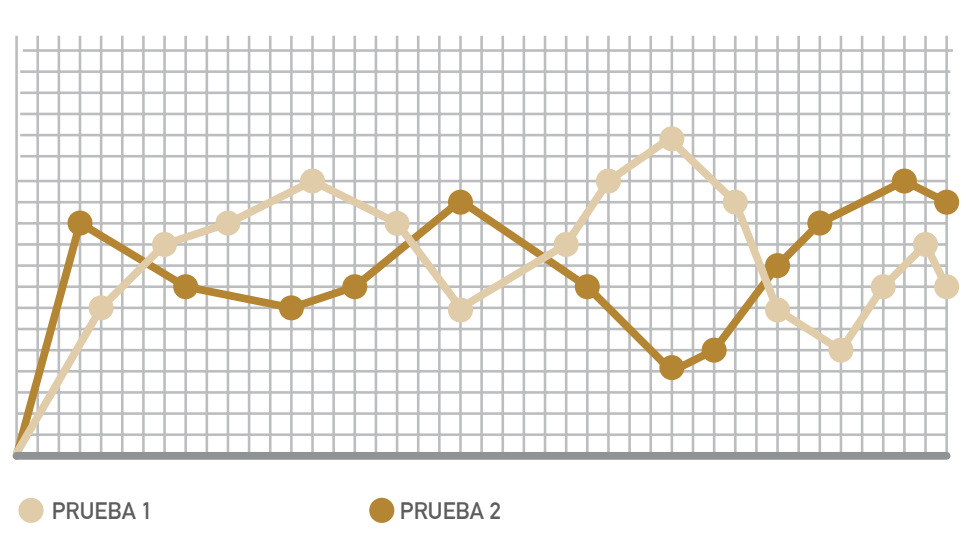

Figura 19. Uso de etiquetas para ayudar a lu suario a identificary y distinguri información.

c. Las etiquetas deben usarse con datos segmentados, con una amplia gama de datos y con áreas de datos (especialmente cuando se usa el volumen para representar el tamaño).

d. Se recomienda evitar usar etiquetas horizontales que se extiendan más allá de la tabla.

e. Las etiquetas no se deben usar cuando la tarea es solo para comprender tendencias generales o para comparar un elemento de datos con otro.

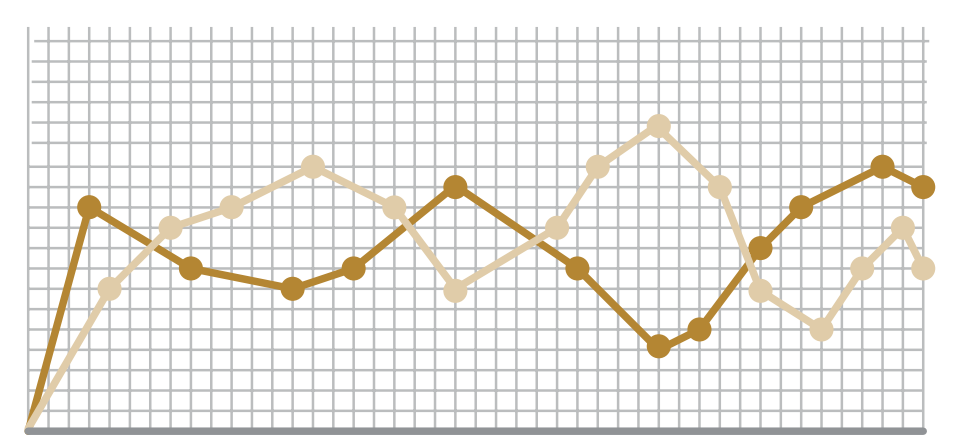

- Lorem issum dolor sit amet, consecteterer adipising elit. Aenean commodo ligula eget dolor. Aenean massa

Figura 20. Se debe evitar el uso de etiquetas que se extiendan más allá de la tabla.

f. Las etiquetas deben ser concisas y se debe tener cuidado de no usar grandes bloques de texto (especialmente debajo de una línea en un gráfico).

g. Las leyendas deben escribirse para que el cuadro se explique por sí mismo.

h. Una buena opción es incorporar las leyendas alrededor o dentro de la tabla, de tal forma en que no parezca un ente separado de la interfaz.

i. Es recomendable que las leyendas tengan el mismo orden que los elementos de contenido correspondientes en el gráfico. j. Los símbolos auto explicativos podrían usarse en ciertos contextos en lugar de una leyenda, pero todas las abreviaturas y símbolos deben estar claramente definidos.

k. Es conveniente utilizar verbos y adjetivos en una leyenda para sugerir o dejar claro cuál es la categoría general del mensaje que se usará en el gráfico.

I. El utilizar una leyenda y el área de datos como conjunto ayuda al usuario a completar la tarea más rápido

Continuando con las recomendaciones de los autores, Lonsdale \& Lonsdale (2019) plantean lo siguiente en cuanto al rendmiento visual del texto:

a. El texto y el color del fondo de la interfaz gráfica deben tener un buen contraste para ser legibles. Los fondos inadecuados, como los fondos de varios colores o degradados, deben evitarse para el texto.

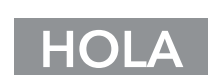

\section{$\mathbf{x}$}

HOLA

$\checkmark$

\section{$\boldsymbol{x}$}

Figura 21. Ejemplos de buen y mal contraste entre el texto ye color de fondo de la intertaz

b. Grandes cantidades de texto deben dejarse alineadas en lugar de centralizadas. La justificación centralizada debe limitarse a cantidades muy pequeñas de texto o texto / encabezados.

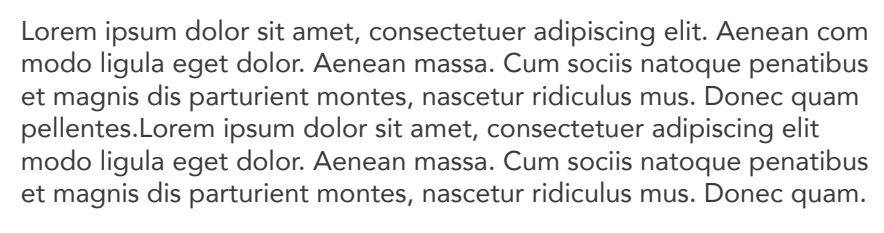

Lorem ipsum dolor sit amet, consectetuer a dipiscing elit. Aenean elitjadolien cjejd com
et magnis dis adf departurient

Grandes cantidades alineadas a la izquierda

Figura 22. Ejemplos de justificaciones de contenido apartir de la cantidad de texto.

c. Se deben evitar las mayúsculas siempre que se requiera una lectura rápida del contenido del texto.

d. El interletrado no debe ser demasiado ancho ni demasiado estrecho, ya que esto interrumpe el flujo normal de lectura. 
e. El espacio interlineal debe ser aproximadamente 2 puntos más alto que el tamaño del tipo para una lectura cómoda.

f. Se deben evitar los espacios amplios entre las palabras del texto, así como también el texto totalmente justificado, ya que generan un fenómeno visual llamado "ríos", (espacios blancos verticales que parecen rios que corren por la página) los cuales interrumpen la le

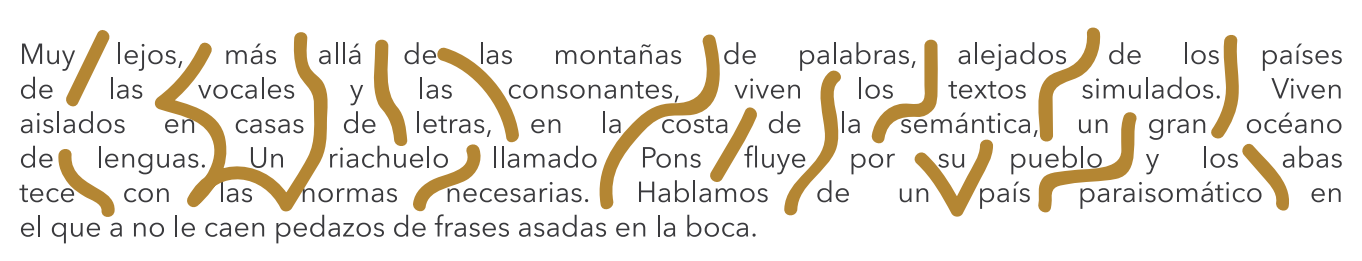

Figura 24. Ejemplo de "rios" en el texto

g. Se recomienda alinear los textos al lado izquierdo y usar líneas cortas para evitar los ríos en el acomodo del texto.

h. Los párrafos largos deben indicarse con una sangría moderada de 1 a 4 ems, o separados por un espacio de una línea. Los párrafos cortos, sin embargo, no deben estar separados por un espacio de una línea.

i. Se debe crear una paleta de fuentes para establecer qué tipos de letra funcionan juntos y qué tamaños, pesos y tipos de letra se utilizarán en las diferentes partes de la interfaz gráfica.

j. Los tamaños de la tipografía deben ser apropiados para el tamaño del gráfico y el área del mismo, si es que se llegan a utilizar.

k. Tanto las fuentes serif (con patín) como sans serif (sin patín) se pueden usar en combinación para crear una jerarquía visual y mantener la legibilidad. Por ejemplo, el uso de un tipo de letra sans serif para los encabezados y un tipo de letra serif para el text del párrafo crea un contraste y ayuda al usuario a navegar por los datos e identificar qué texto debe recibir atención primero.

\section{TíTULO}

Muy lejos, más allá de las montañas de palabras, alejados de los países de las vocales las consonantes, viven los textos simulados. Viven aislados en casas de letras, en la
costa de la semántica, un gran océano de lenguas. Un riachuelo llamado Pons fluyc por su pueblo y los abastece con las normas necesarias. Hablamos de un país parais mático en el que a uno le caen pedazos de frases asadas en la boca.

Figura 25. Ejemplo de jerarquúa tipográfica a traveśs de tuentes serify sans serif.

1. Otra forma de crear jerarquía a través de la tipografía es utilizando diferentes pesos de una misma tipografía.

m. Es una buena opción utilizar información numérica (numeración) y textual importante a la interfaz gráfica para aumentar la precisión. n. Los gráficos y el texto deben tener un formato consistente.

o. La tipografía no debe llamar más la atención de cualquier figura o diagrama que se encuentre en la interfaz gráfica.

p. La variación de tamaño también se puede utilizar para enfatizar información importante y captar la atención del usuario.

q. Se sugiere que el estilo de escritura debe ser simple, independientemente de se serif o sans serif.

r. Es recomendable usar mayúsculas y minúsculas en lugar de mayúsculas para el texto narrativo.

s. Para secuencias de palabras cortas (por ejemplo, títulos, etiquetas, palabras clave), es posible utilizar todas las mayúsculas.

t. A pesar de que el texto es importante en una interfaz gráfica, los principales entes actores deben de ser las figuras de visualización de información. 


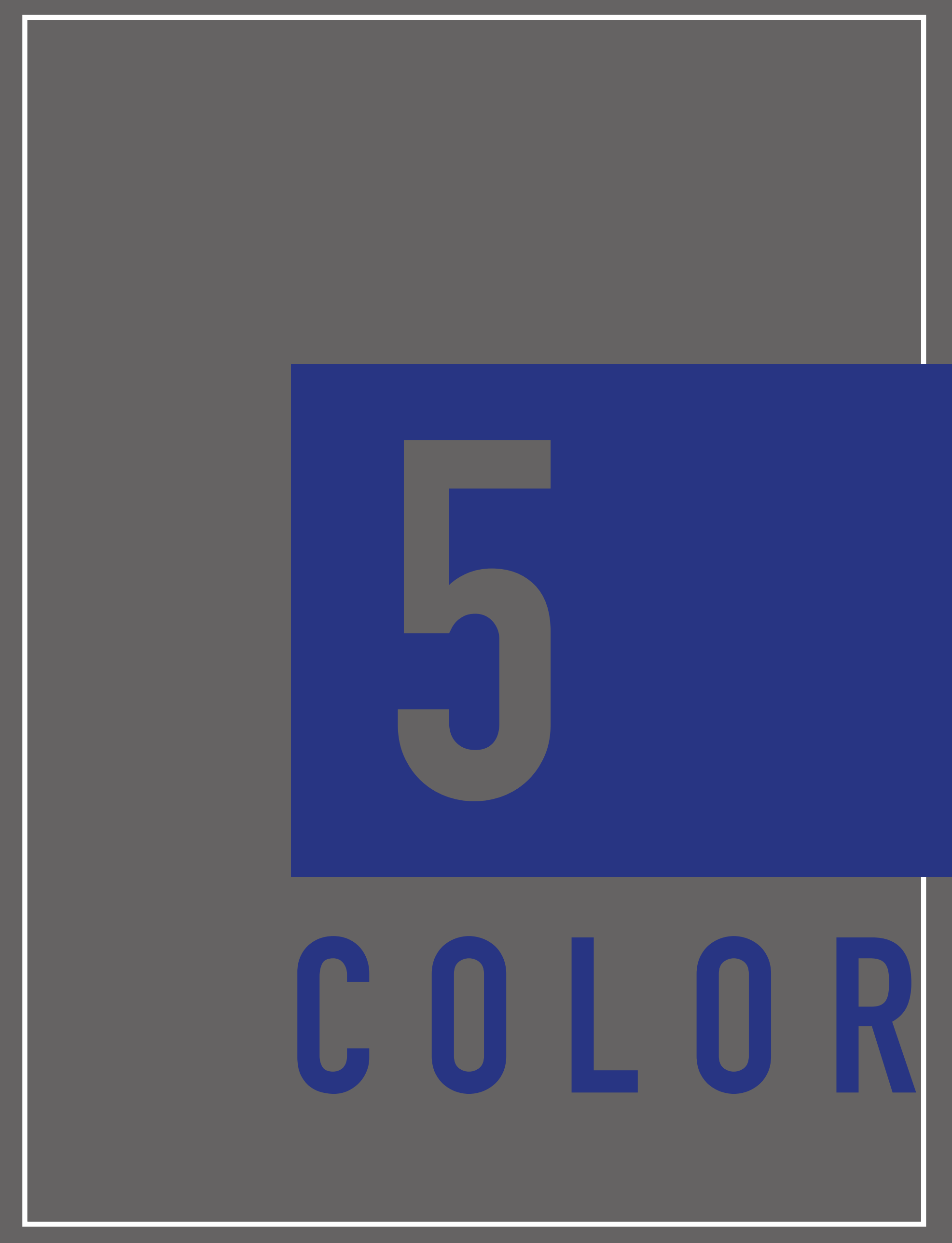


Se recomienda que la elección de color para la interfaz gráfica no se haga mediante gustos personales o juicios del propio diseñador.

2

Se sugiere elegir el color a usar a partir de las necesidades y objetivo de la interfaz gráfica.

2 De acuerdo a lo que establece Wiklund (1995) en the Human Engineering Committee of the Association for the Advancement of Medical Instrumentation (AAMI) se hacen las the Association for the Advancement of Medical Instrumentation (AAMI) se hacen las
siguientes sugerencias de uso del color para codificación de información en dispositivos médicos (Figura 22).

\begin{tabular}{|l|l|}
\hline \multicolumn{1}{|c|}{ COLOR } & \multicolumn{1}{|c|}{ SIGNIFICADO } \\
\hline Rojo & Prioridad alta. Advertencia. Alarma. Emergencia. Alto. Apagado. Nivel alto. \\
Amarillo & Prioridad Media. Precaución. Amenaza potencial. Nivel medio. \\
Verde & Estado normal. Inicio. Endendido. Listo. Nivel estándar. \\
\hline
\end{tabular}

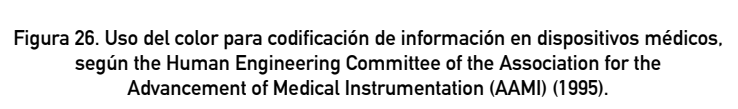
Según Lonsdale \& Lonsdale (2019), es conveniente usar una paleta de color que solo con-
temple cuatros colores, ya que el exceso de color puede resultar abrumador para el usuario. Para una alta legibilidad, de acuerdo a Nielsen \& Loranger (2006) debe mantenerse un buen
contraste entre el texto, el color y el fondo.

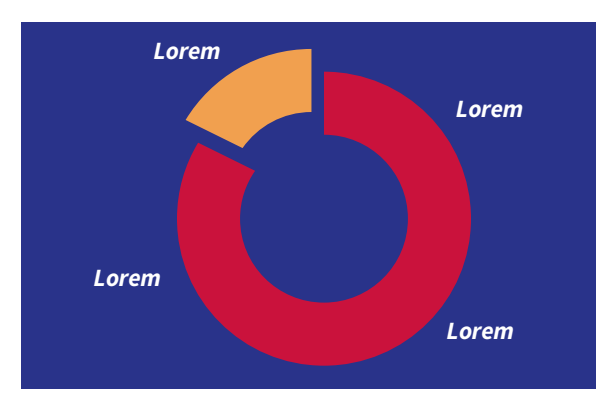


6 Por otra parte Götz, (1988:16), propone una relación entre algunos colores y su significado.

\begin{tabular}{|c|c|}
\hline COLOR & SIGNIFICADO \\
\hline Rojo & $\begin{array}{l}\text { Activo. Poderoso. Agresivo. Fuerte. Atractivo. } \\
\text { Dominante. Vigorazante. }\end{array}$ \\
\hline Rosa & Cuidado. Sensible. Dulce. \\
\hline Violeta & $\begin{array}{l}\text { Mistico. Sensual. Delicado. Encantadora. } \\
\text { Solitario. Inhibido. Turbio }\end{array}$ \\
\hline Azul & $\begin{array}{l}\text { Controlado. Misterioso. Harmonioso. Frío. } \\
\text { Profundo. Racional. Sensible. Intelectual. } \\
\text { Abstinencia. Agresivo. }\end{array}$ \\
\hline Verde & $\begin{array}{l}\text { Refrescante. Harmonioso. Calma. Gentill. } \\
\text { Cercano a la naturaleza. Conciliador. }\end{array}$ \\
\hline Amarillo & $\begin{array}{l}\text { Colorido. Extrovertido. Vivido. Lleno de alegria.a } \\
\text { Superficial. Joven. Alegre. Luz. }\end{array}$ \\
\hline Naranja & $\begin{array}{l}\text { Directo. Juguetón. Cálido.VVigoroso. Directo. } \\
\text { Vivo. Comunicativo. Posesivo. Intimo. }\end{array}$ \\
\hline
\end{tabular}

Figur 28. Colores y sus significados. según 6özz 1988:16

7 Es muy importante usar un fondo de color que no generé "ruido visual" en contraste con el color de la tipografía y demás elementos gráficos de la interfaz gráfica. Es decir, se recomienda evitar usar colores que generen un contraste "pesado" a la vista y a la lectura, según los autores anteriores.

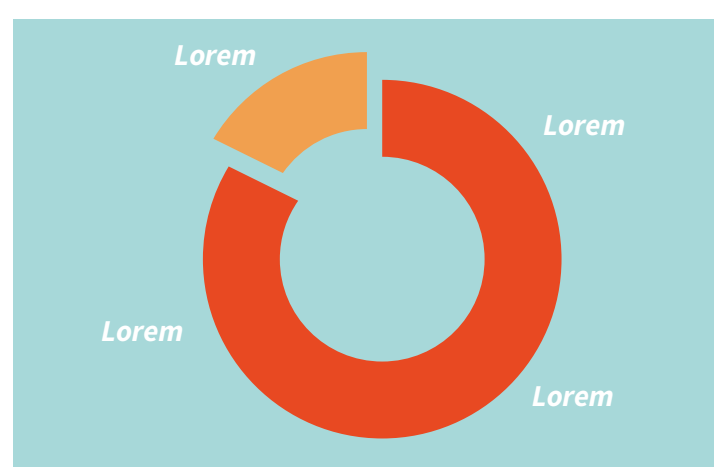

Figura 29. Fiemplo de fondo de color gue no generá "ruido" y tiene buen contraste con demás elementos

8 Según Nielsen \& Loranger (2006), la mejor combinación de colores para generar un buen contraste es el texto en color negro sobre fondo blanco o texto azul sobre fondo blanco. Estos mismos autores establecen la siguiente relación entre el contraste del color del texto
con el color fondo y el nivel de legibilidad de estos mismos elementos:

\begin{tabular}{|c|c|}
\hline COMBINACIÓN DE COLORES & NIVEL DE LEGIBLIDDAD \\
\hline Texto de color negro y fondo blanco & $\begin{array}{l}\text { Alto: Mayor valor de contraste. Diferenciación de los } \\
\text { elementos altamente perceptible. }\end{array}$ \\
\hline Texto de color azul y fondo blanco & $\begin{array}{l}\text { Alto: Mayor valor de contraste. Siempre y cuando se } \\
\text { use azul oscuro. }\end{array}$ \\
\hline Texto de color blanco y fondo gris & $\begin{array}{l}\text { Medio: Diferenciación de los elementos de un nivel } \\
\text { alto a medio, dependiendo de la saturación del gris. }\end{array}$ \\
\hline Texto de color blanco y fondo azul & $\begin{array}{l}\text { Bajo: Dificil de leer, ya que se percibe que el fondo } \\
\text { oscuro sobrepasa visualmente el texto blanco. }\end{array}$ \\
\hline Texto de color gris y fondo blanco & $\begin{array}{l}\text { Bajo: Bajo valor de contraste. Diferenciación de los } \\
\text { elementos casi inperceptible. }\end{array}$ \\
\hline Texto de color blanco y fondo gris & $\begin{array}{l}\text { Bajo: Bajo valor de contraste. Diferenciación de los } \\
\text { elementos casi inperceptible. }\end{array}$ \\
\hline Texto de color blanco y fondo azul & $\begin{array}{l}\text { Bajo: El contraste que generarlos colores hacen que la } \\
\text { lectura resulte cansada para el ojo. }\end{array}$ \\
\hline Texto de color gris y fondo blanco & $\begin{array}{l}\text { Bajo: El contraste que generarlos colores hacen que la } \\
\text { lectura resulte cansada para el ojo. }\end{array}$ \\
\hline
\end{tabular}

Figurr 30. Nivel de legibilidada de difierentes combinaciones de colores por Nielsen \& Loranger r200e)

10 El color se puede utilizar para centrar la atención del usuario y garantizar que todo el texto sea claro, legible y que se pueda leer rápidamente, de acuerdo a lo que plantean Lonsdale \& Lonsdale (2019).

11 De acuerdo a los mismos autores, el color se puede usar para ayudar a organizar fragmentos de información que compartan características en común. Por ejemplo, usar un color en especial para los títulos, otro para elementos gráficos, etc.

\section{TÍTULO \\ Subtitulo}

Muy lejos, más allá de las montañas de palabras, a lejados de los países de las vocales y las consonantes, viven los textos simulados. Viven aislados en casas de letras, en la costa de la abastece con las normas necesarias. Hablamos de un país paraisomático en el que a uno le caen pedazos de frases asadas en la boca.

Subtítulo

Muy lejos, más allá de las montañas de palabras, alejados de los países de las vocales y las
consonantes, viven los textos simulados. Viven aislados en casas de letras, en la costa de la semántica, un gran océano de lenguas. Un riachuelo llamado Pons fluye por su pueblo y los 
12 Lonsdale \& Londsdale (20019), señalan las siguientes recomendaciones sobre color:

a. Resulta esencial usar el color para enfatizar palabras, resaltar los encabezados, señalar relaciones dentro de un documento, mostrar niveles jerárquicos y proporcionar estructura y organización en un documento.

b. Se deben usar colores en contrastes claros, donde se recomienda un contraste del $70 \%$ entre un objeto y su fondo.

c. Los colores que se usen como fondo, se sugiere que estos deben proporcionar suficiente contraste con los objetos que estén sobre éste.

d. Se sugiere para comprobar rápidamente el contraste entre los valores, el diseño debe imprimirse en escala de grises o el monitor debe cambiarse a escala de grises. Si esto demuestra que los diferentes elementos visuales se mezclan, entonces los colores deben ajustarse para crear un buen contraste.

e. Se deben evitar los efectos de gradiente de color, ya que estos efectos dificultan la lectura del contenido de la interfaz gráica.

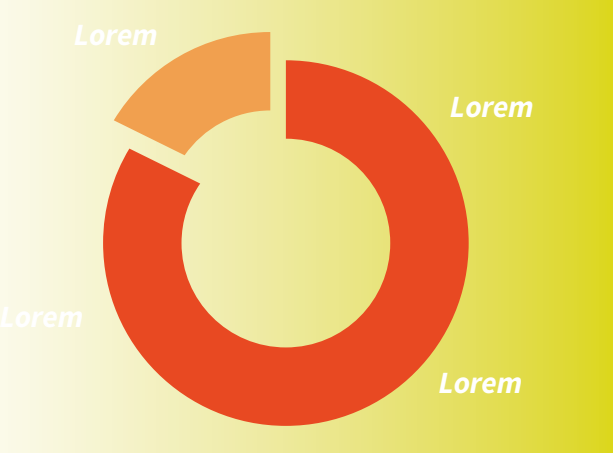

Figura 32. Eiemplo del mal uso del efecte de gradiente como fonde

f. Se sugiere no utilizar los colores brillantes, altamente saturados (primarios ${ }^{5}$ ), ya que son visualmente demasiado molestos y pueden crear problemas de legibilidad.

g. El texto coloreado, los bordes coloreados, los fondos coloreados o los patrones coloreados no se deben utilizar únicamente para la decoración.

h. Para las tareas de búsqueda e identificación, se recomienda usar una codificación de colores, ya que éstas funcionan mejor que la variación en la forma y el tamaño.

i. Para información categórica, se deben usar colores que sean complementarios en el círculo cromático 6 .

j. Se recomienda para datos continuos, utilizar saturación u oscuridad de los mismos colores.

k. Deben evitarse los colores adyacentes entre sí en el círculo cromático, ya que producen poco contraste cuando se usan juntos. Si se elije esta combinación, en- tonces su brillo debe ser lo suficientemente diferente para crear un contraste claro.

l. Los colores deben mantenerse uniformes en todos los gráficos de todos los elementos de la interfaz gráfica.

m. La codificación de colores se puede utilizar en gráficos para ayudar a los usuarios a interpretar los datos.

n. Resulta conveniente usar colores suaves en gráficos, en lugar de los colores del adyacentes en el círculo cromático (que tienen un alto contraste).
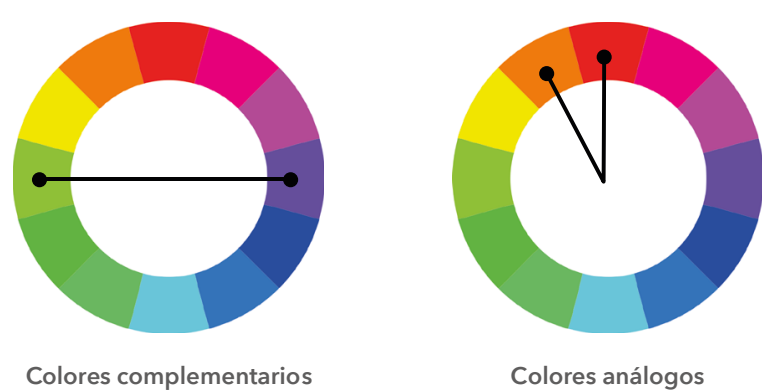

Colores análogos

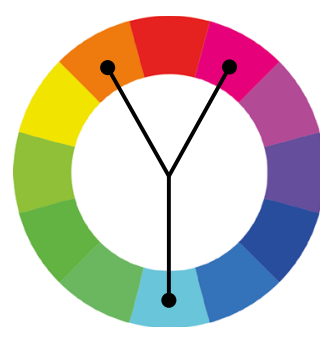

Colores adyacentes

Figura 33. Circulo cromatitco, colores complementariss, an

ñ. El contraste entre los colores se debe usar para la legibilidad, y diferentes valore dentro del mismo color también se pueden usar para definir capas de atención.

o. No se deben usar múltiples colores para representar el mismo tipo de datos (por ejemplo, diferentes colores para cada gráfico de barras en la misma categoría.

p. Se recomienda usar un tono más oscuro o más claro, o un color diferente, para enfatizar un punto específico o un valor de datos dentro de la interfaz gráicas.

q. El gris debería usarse para información contextual y de segundo nivel, así come para elementos estructurales como las líneas de cuadrícula.

r. El rojo no debe usarse para números positivos en un gráfico de barras, ya que está fuertemente asociado con la pérdida, pero se puede usar efectivamente para valores negativos. 


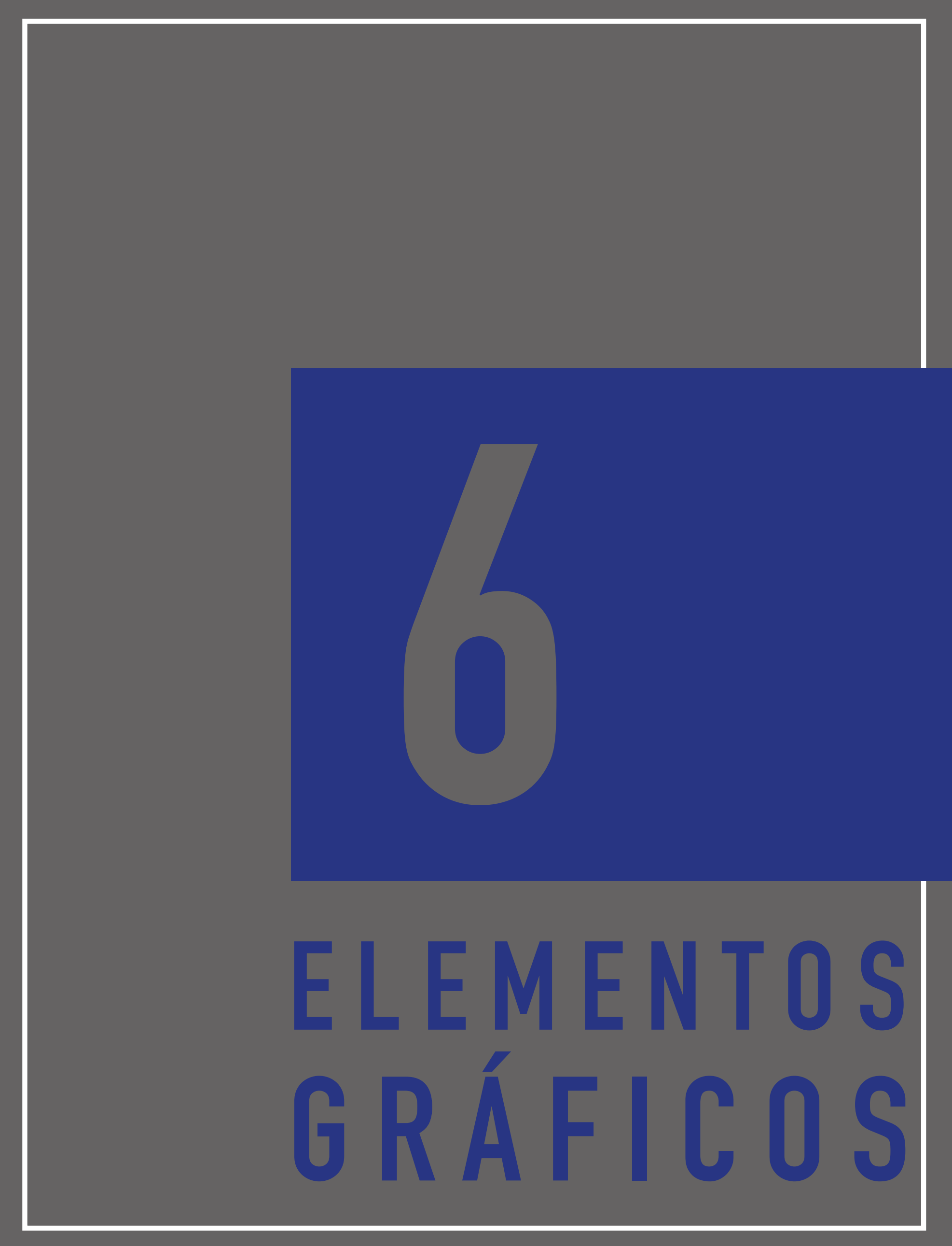


1 Resulta importante definir los elementos gráficos que se utilizarán en la pieza de diseño desde el principio del proceso de diseño.

2 Dentro de una interfaz gráfica se recomienda que todos los elementos conserven un mismo estilo gráfico.

3 Todos los elementos visuales deben usarse de manera efectiva y organizarse adecuadamente dentro de la estructura del sistema de visualización de información.

4 La carga cognitiva en la interfaz gráica que se está trabajando, de acuerdo a Lonsdale \& Lonsdale (2019) debe reducirse, se recomienda minimizar la cantidad de información que se transmite a través de gráficos, así como también se sugiere el uso de colores significativos, símbolos, líneas o barras de etiquetado directo.

5 Los elementos gráficos que se utilicen dentro de la interfaz gráfica deben aportar denotaciones relacionadas directamente con el objetivo de comunicación, de acuerdo a los autores ciones relacion
anteriores.

6 Todos los elementos gráficos que se utilizan, deben apoyar a la estructuración jerárquica de información, así como también, deben ser consistentes visualmente hablando entre ellos, según argumenta Cairo (2011)

7 Es importante implementar imágenes que tengan la misma orientación (horizontal o vertiEs importante implementar imágenes que tengan la misma orientación (horizontal o verti-
cal), dependiendo de la retícula del lienzo de trabajo sobre el cual se este diagramando, de tal manera que se facilita el acomodo de los elementos que forman parte del contenido de la interfaz gráfica, de acuerdo a lo que establecen Lonsdale \& Lonsdale (2019).

8 Las imágenes que sean usadas dentro de la interfaz gráfica deben responder a términos del objetivo de comunicación y la temática del mismo.

Wiklund (1995), sugiere utilizar pictogramas, ya que estos albergan significados universales en una imagen simple. 
10 Para generar claridad, Lonsdale \& Lonsdale (2019), recomiendan usar como contenedor un círculo para el uso de pictogramas.

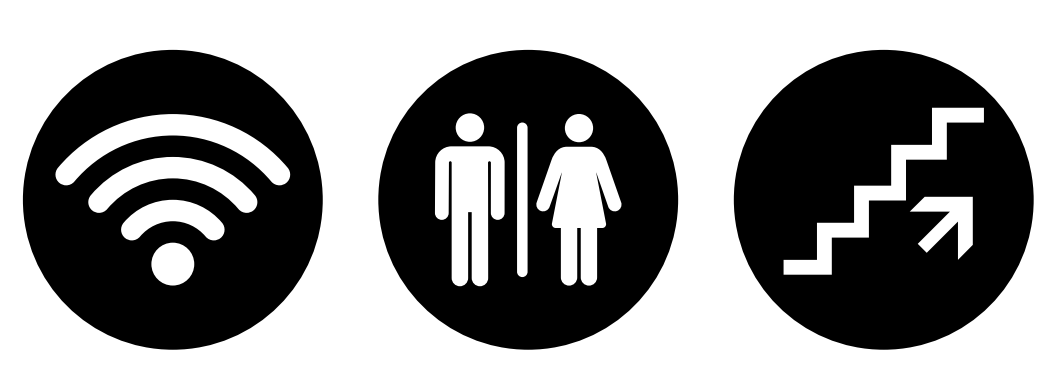

Figura 32. Uso de pictogramas parr englobar connotaciones de conceptos.

11 No es conveniente el uso de emojis ${ }^{8}$ otro tipo de elemento gráfico que tenga un significado amplio a su interpretación, según lo plantean Krajil Novak, Smailović, sluban, \& Mozetič (2015).

12 Lonsdale \& Lonsdale (2019), establecen que una manera efectiva de guiar al usuario a través de la lectura de la pieza de diseño es a través de flechas y líneas que puedan generar un recorrido visual.

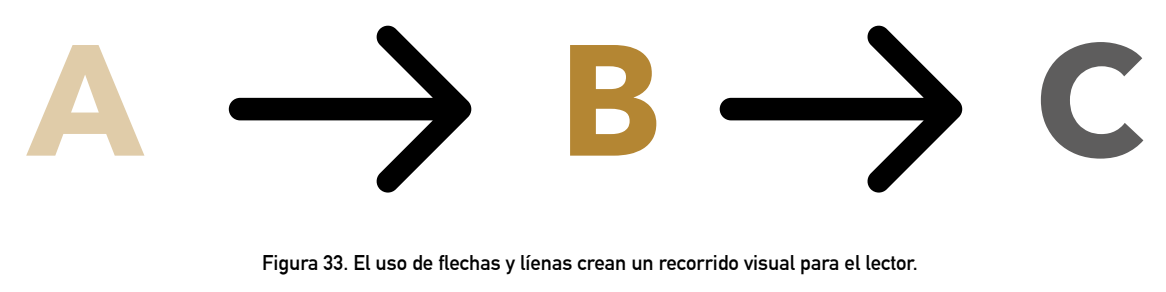

13 Resulta importante el uso de etiquetas o leyendas debajo de los elementos gráficos que necesiten algún tipo de aclaración, nota o título, establece los mismos autores.

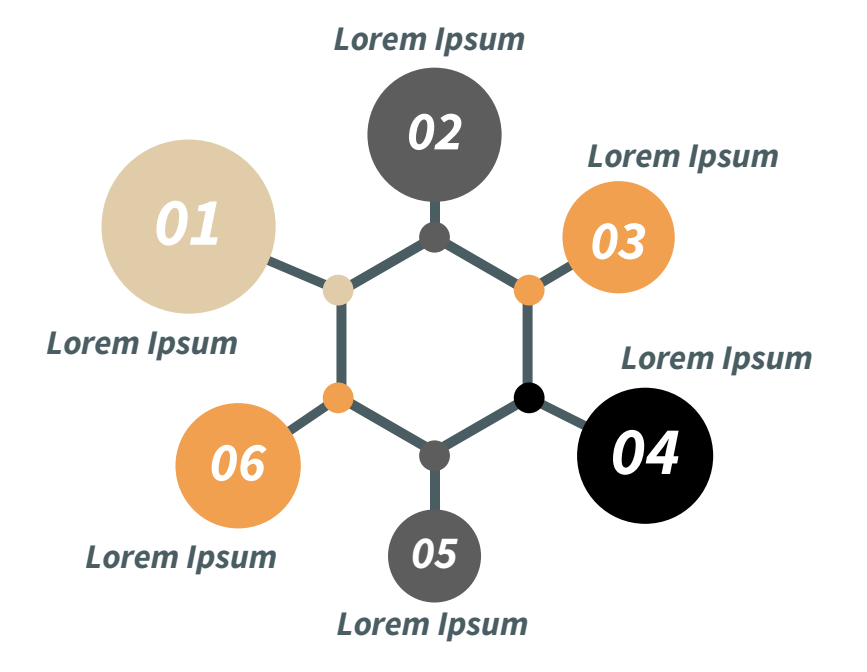

4 Es beneficioso para el diseño de la interfaz gráfica que los elementos visuales no distraigan al usuario del contenido que se le está presentando, según señalan Nielsen \& Loranger (2006).

15 De acuerdo a lo que sugieren los autores anteriores, los elementos gráficos del sistema de visualización deben respetar y usar la paleta de colores con la que se está trabajando. Ya que al usar colores que no estén dentro de ésta puede generar incongruencias visuales y de contenido dentro de la interfaz gráfica.

16 Según Lonsdale \& Lonsdale (2019) el uso de recuadros en blanco dentro de una interfaz gráfica de un sistema de visualización de información médica es recomendable para anotaciones textuales largas sobre un tópico en particular, por ejemplo, motivos de ingreso del paciente a la clínica o hospital.

17 Se sugiere, de acuerdo a los autores anteriores, el uso de bullets point, listas numéricas y flechas para enfatizar información que pertenezca a una misma categoría, la cual sea secuencial.

$\begin{array}{ll}\text { 1) Manzana. } & \text { - Gato. } \\ \text { 2) Pera. } & \text { - Piedra. } \\ \text { 3) Melón. } & \text { - Muñeca. } \\ \text { 4) Kiwi. } & \text { - Contenedor. } \\ \text { 5) Fresa. } & \text { Mariposa. } \\ \text { Ejemplo de lista númerica } & \text { Ejemplo de lista con bullet points }\end{array}$

Figura 35. Ejemplo de uso de etiquetas para hacer actaraciones sobre los elementos graficos presenntados

18 Los elementos que no tengan mucha relevancia dentro de la pieza de diseño, pero sigan siendo necesarios, se recomienda usar una tonalidad de gris o una opacidad de color equivalente al 40\%, de acuerdo a Lonsdale \& Lonsdale (2019).

19 El espacio en blanco es un buen elemento que se puede usar de manera efectiva para llamar la atención sobre el gráfico o para generar "aire" en donde hay una tensión visual por el exceso de contenido. No se recomienda el uso de degradados ni texturas en las secciones que conforman a las fi-
guras en la visualización de información, en su lugar, se sugiere el uso de plastas de colores, acorde a lo que establece Cairo (2011).

21 La relación de aspecto (altura y anchura relativas) y la densidad de datos (tamaño del gráfico) según señala Tufte (2001). 
22 Sí se llegará a requerir de usar un fondo en algún tipo de figura dentro de la interfaz gráfica, se sugiere que los elementos de fondo no deben se agrupen o fusionen con los elementos de contenido, de acuerdo con Cairo (2011).

23 Se sugiere, según a lo que Tufte (2001) indica el uso de puntos y las líneas, ya que son una buena opción para facilitar la comparación entre valores individuales en puntos específicos en el tiempo de datos.

Los elementos o información innecesarios, extraños, decorativos o irrelevantes en una figura de visualización de información deben eliminarse, mientras se mantiene el significado

25 Es importante usar informes estadísticos, según establece Cairo (2011) a través de figuras de visualización de información en lugar de informes solo narrativos, de esta mane la carga cognitiva de la información y se mejora la usabilidad de la interfaz gráfica.

26 Es de suma importancia el uso de figuras de visualización de información para condensa datos cuantitativos y cualitativos dentro del sistema de visualización de información médica. El criterio a seguir para la elección de las figuras de visualización de información es el siguiente:

1. ¿Qué necesita averiguar el usuario (en términos de información)?

2. ¿A qué categoría o método de codificación de información pertenece esta necesidad?

3. ¿Oué fiaura de visualización de información cubre esta necesidad?

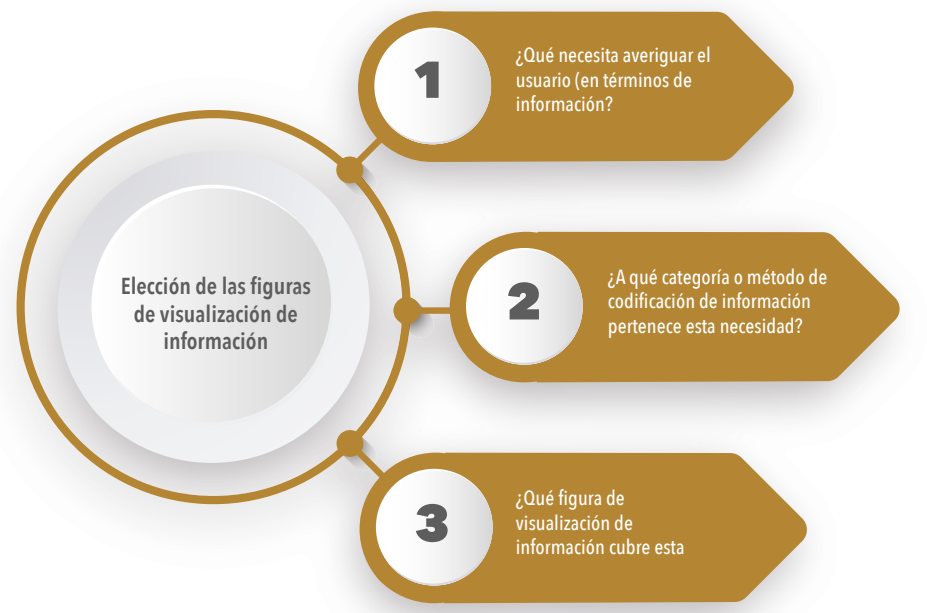

Existen diversas categorías que se clasifican de acuerdo a la función de la representación de la información con la que se está trabajando. Dichas categorías o métodos de codificación de información son las siguientes:

1. Comparación: Este método busca generar contaste entre conjuntos de datos. A través de está técnica se busca establecer una comparación visual entre las características o atributos de dichos conjuntos de datos.

2. Visualización de conceptos: Es la representación de uno o varios conceptos a través de gráfico.

3. Correlación o de patrones: Es la proporcionalidad entre atributos o características de uno o varios datos entre sí. Se centra en revelar formas o patrones en los datos para darle significado.

4. Distribución: Esta técnica busca distribuir un determinado dato en un lugar determinado por alguna característica o valor en especial.

5. Datos geográficos: Este método de visualización de información se encarga de representar datos que guardan relación con atributos de índole geográfica, ubicando a éstos en un lugar y espacio determinado.

6. Parte del todo: Es la representación de un conjunto de datos que forman parte de un todo.

7. Tendencia a través del tiempo: Esta técnica de visualización de información se ocupa de la representación de la evolución o perspectiva de un fenómeno a través del tiempo.

8. Jerarquía: Este método muestra la relación de cómo las entidades se pueden clasificar y ordenar dependiendo de su grado de importancia y pueden clasificar y ordenar dependiendo de su

9. Procesos y métodos: Esta técnica en la visualización de información ayuda a explicar como están hechos ciertos procesos o métodos, as como los pasos que están involucrados en éstos.

10. Funcionamiento de las cosas: Este método tiene como objetivo ilustrar el funcionamiento de algún objeto o sistema.

11. Movimiento o flujo: Herramienta que se encarga de mostrar el movimiento físico, proceso de transferencia o el flujo de conceptos abstractos través de un gráfico o figura visual. 

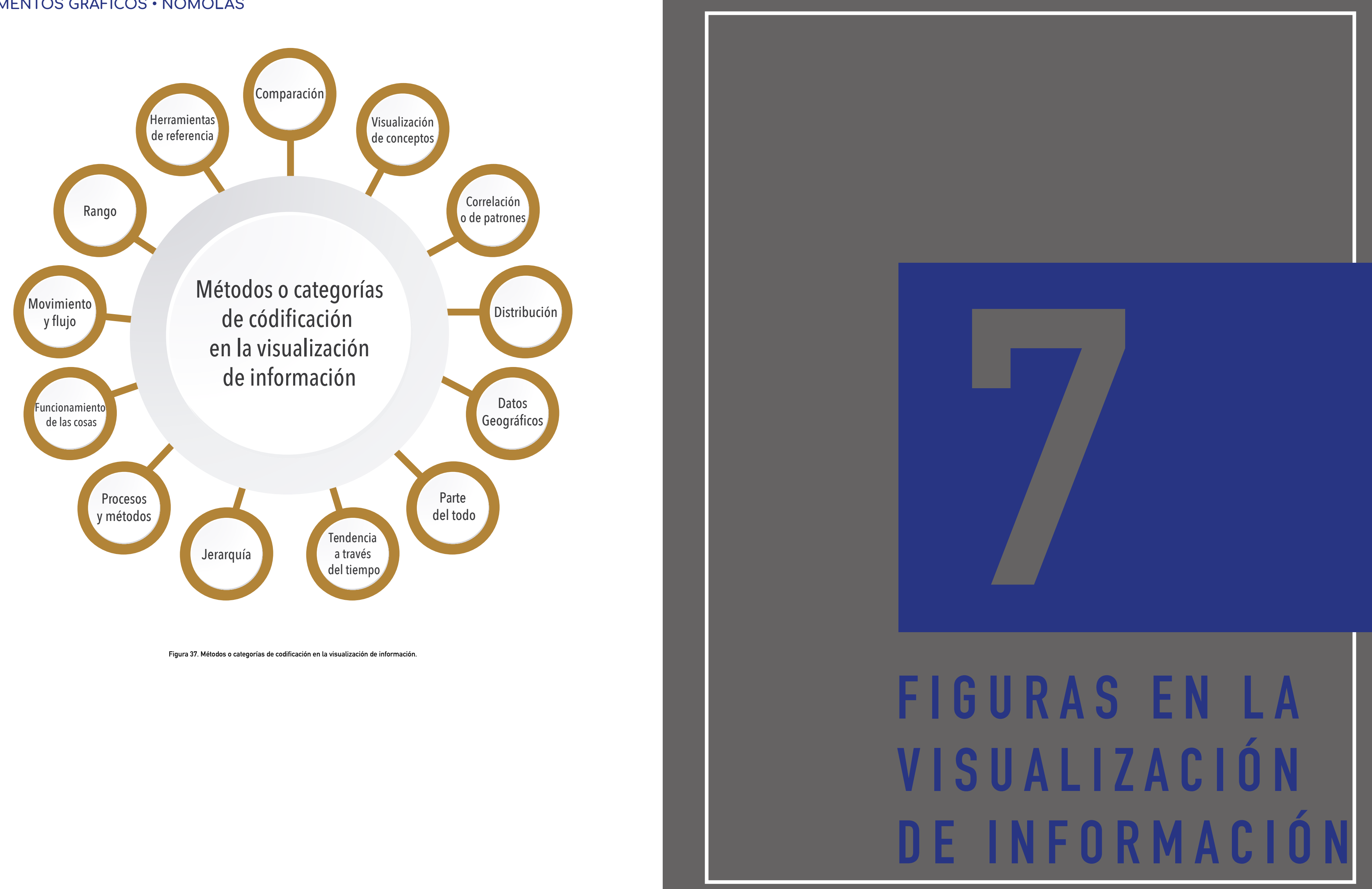


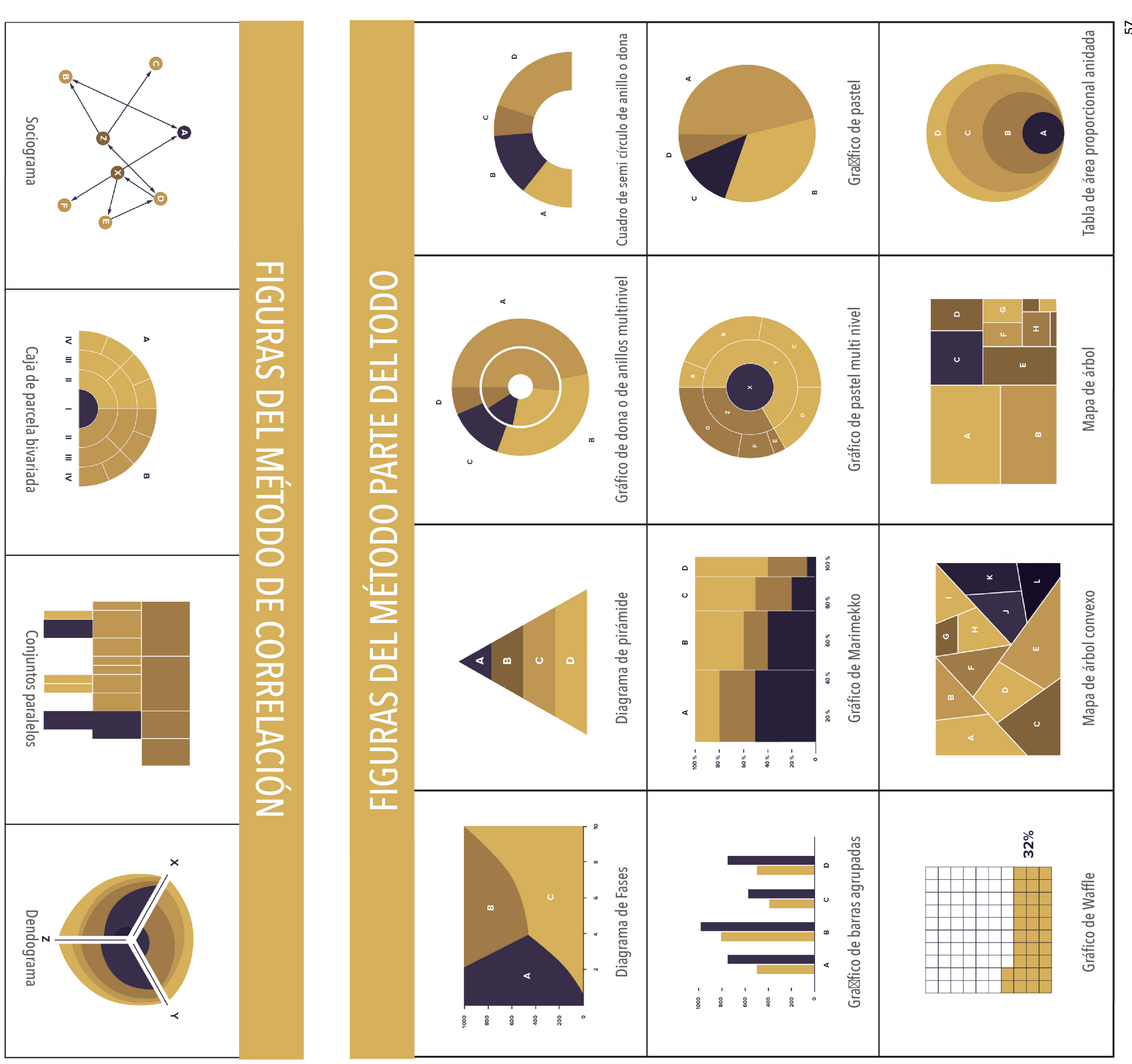




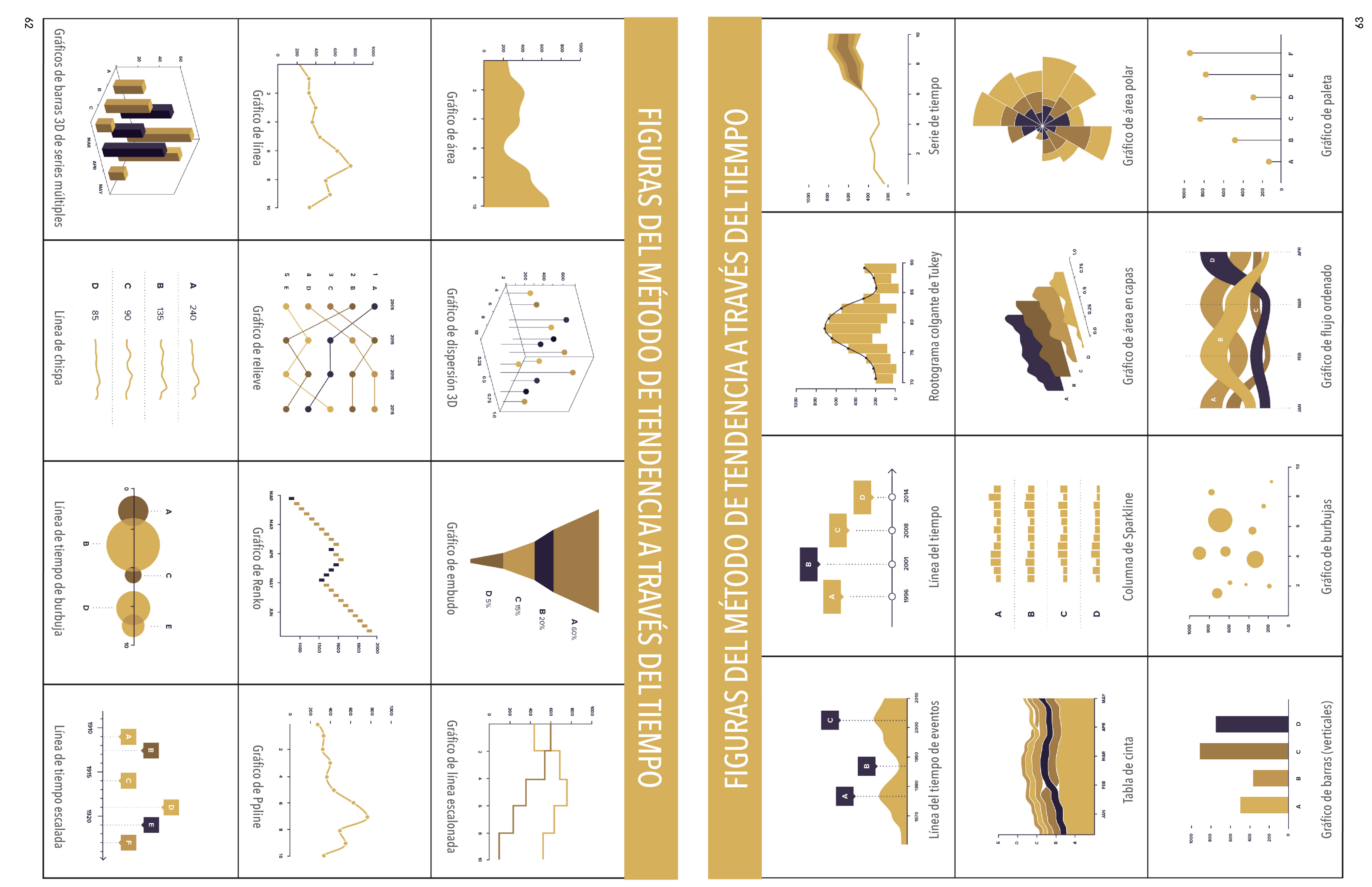




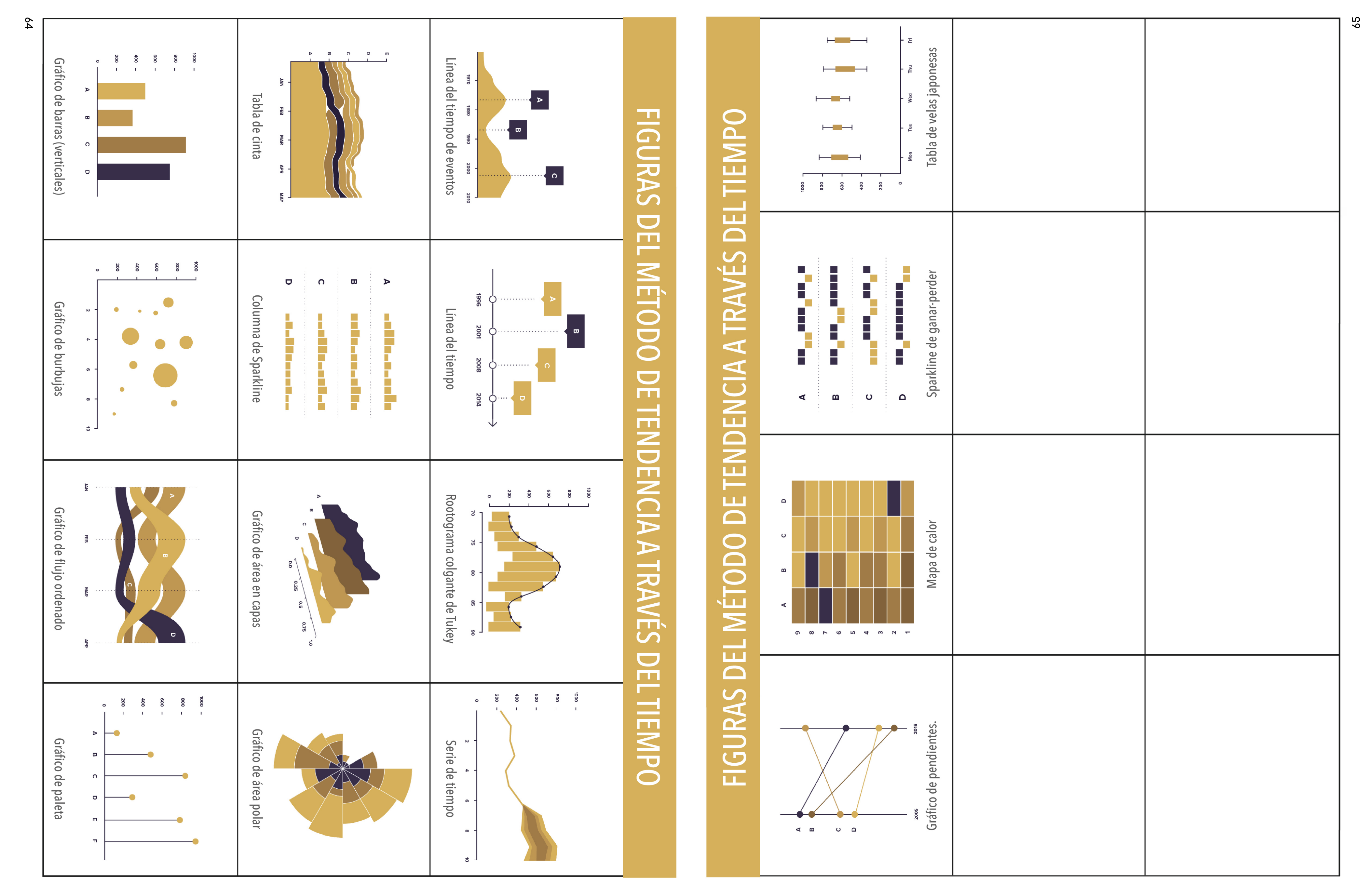




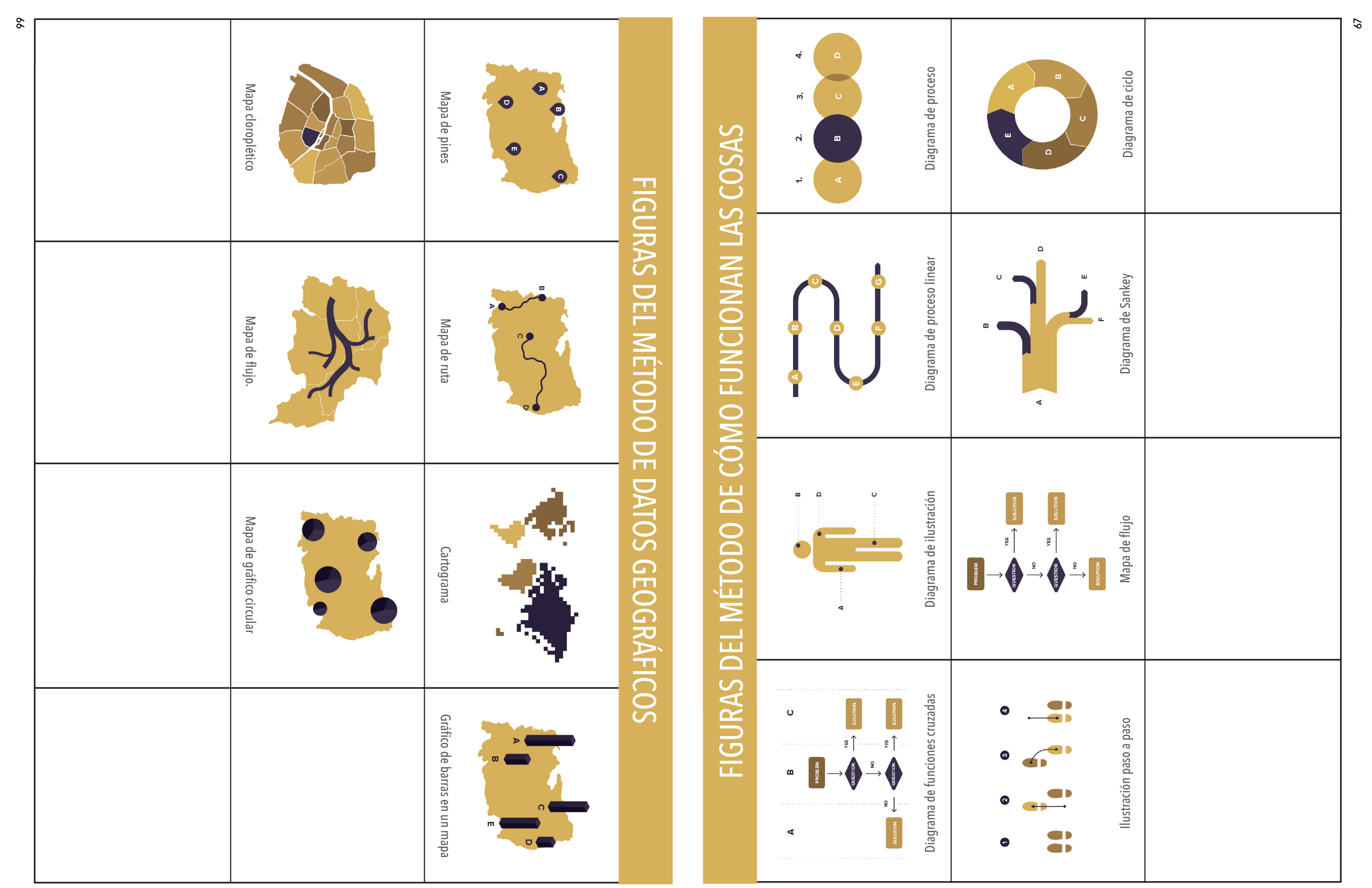




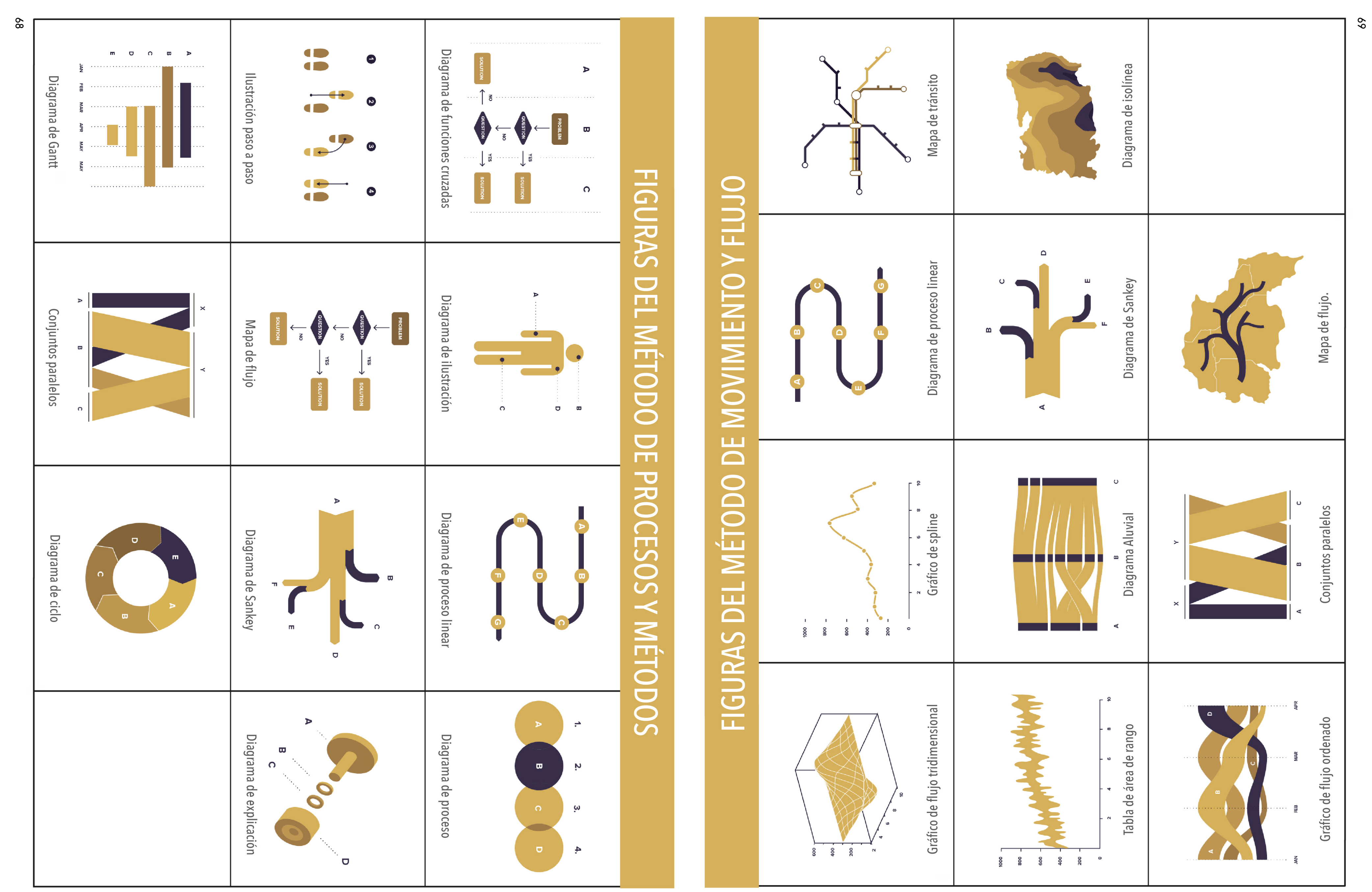




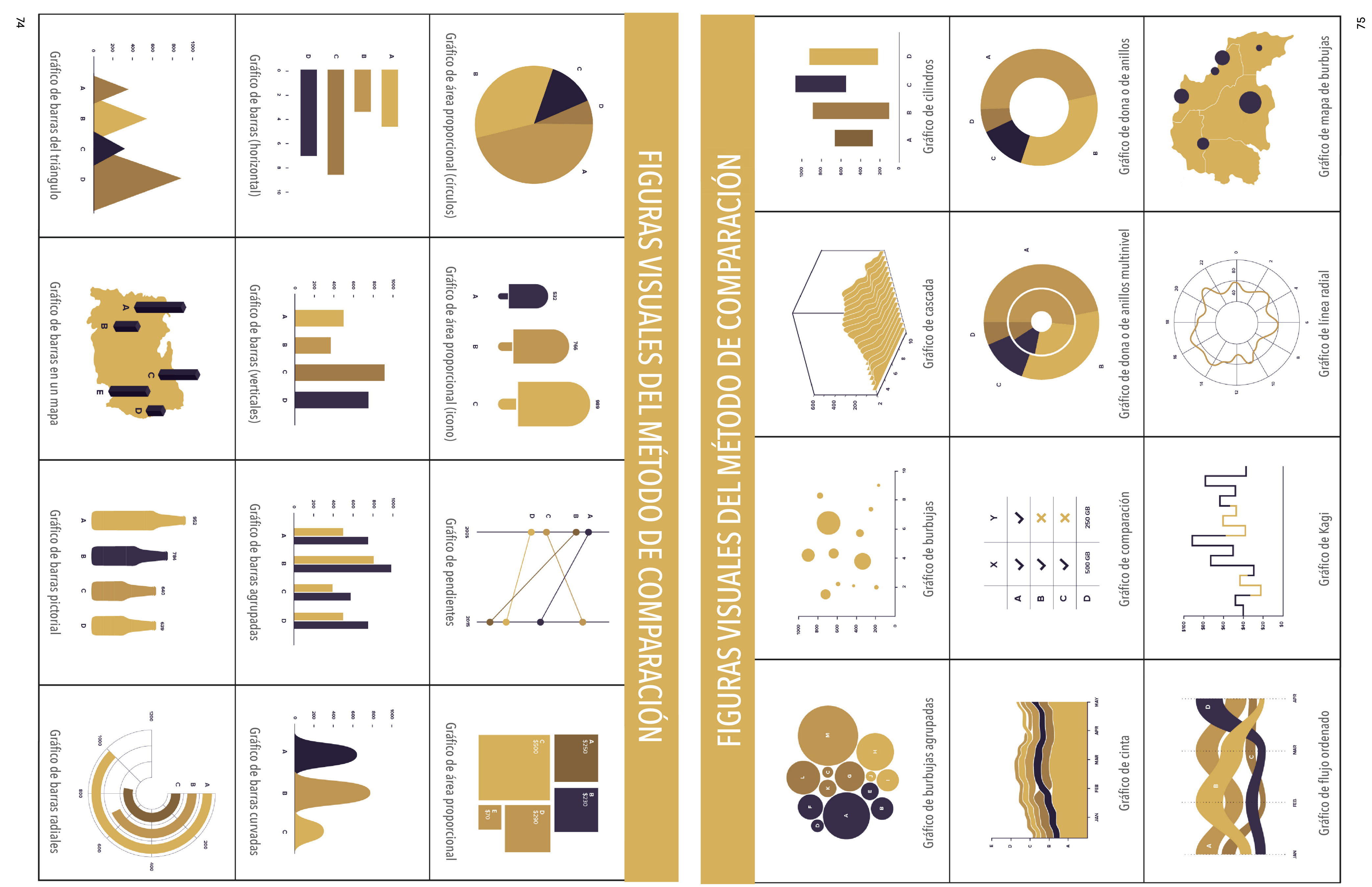




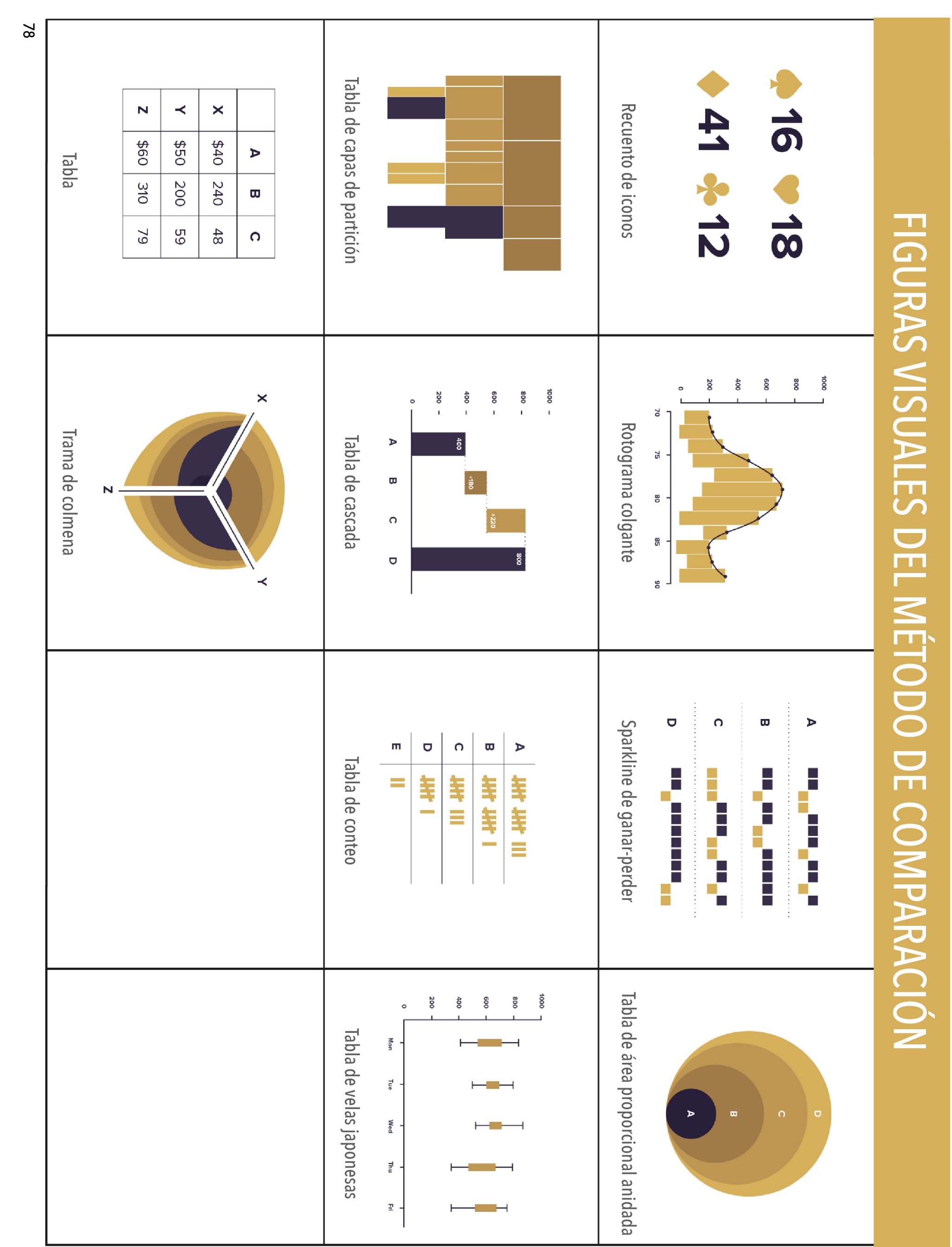




\title{
REFERENCIAS
}

Cairo, A. (2011). The Functional Art- An Introduction to Information Graphics and Visualization. (L. G. Prado, Ed.). Madrid: Alamut.

Castro, I., \& Gámez, M. (2002). 2.2. Historia clínica. In M. C. G. Planas (Ed.), Farmacia Hospitalaria (Tercera Ed, Pp. 295-305). Barcelona: Hospitalitaria, Fundación Española de Farmacia.

Few, S. (2004). Perceptual Edge Common Mistakes in Data Presentation Common Mistakes in Data Presentation Start with a Clear Message, 1-5. Retrieved from https://moodle. chatham.edu/pluginfile.php/712404/mod_resource/content/1/Common Mistakes in Data Presentation.pdf

Götz, V. (1988). Color \& Type for the screen. Suiza: RotoVision SA.

Krajil Novak, P., Smailović, J., Sluban, B., \& Mozetič, I. (2015). Sentiment of emojis. PloS ONE, 10(12).

Lonsdale and Lonsdale. (2019). Design2Inform: Information visualisation guidelines [Report 02]. Gov UK.

Nielsen, J., \& Loranger, H. (2006). Priorityzing Web Usability. California: New Riders.

Rodrigues, D., Prada, M., Gaspar, R., Garrido, M. V., \& Lopes, D. (2017). Lisbon Emoji and Emoticon Database (LEED): Norms for emoji and emoticons in seven evaluative dimensions. Behavior Research Methods, 50(1), 392.

Tufte, E. (2001). The visual display of quantitative information (Segunda Ed). Cheshire: Graphic Press.

Wiklund, M. (1995). Medical Device and Equipment Design: Usability engineering and ergo-

\author{
mics. Florida: Taylor \& Francis Group.
}



Anexo 11.10. Material a re diseñar: Hoja de ingreso de paciente con diabetes. 


\section{Denver Endocrinology, Diabetes \& Thyroid Center, P.C. \\ 799 E Hampden Ave, Suite 525, Englewood, CO 80113 \\ Phone: 303-321-2644 Fax: 303-321-2446 \\ Website: www.denverendocenter.com}

Patient Name

Today's Date

Date of Birth

Primary Care Provider

Occupation

Referring Physician(if not PCP)

Phone

Other Care Providers Phone

Main Concern(s)/Reason for visit today

ALLERGIES (Please include type of reaction to each allergy listed)

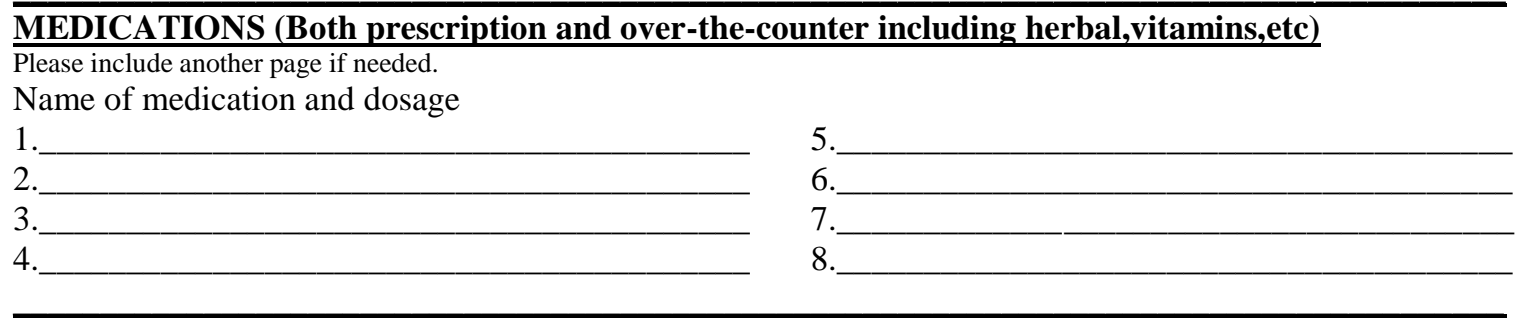

HOSPITALIZATIONS/SURGERIES/PROCEDURES (Please include exact date or at least year)

FAMILY HISTORY (List any health problems of your mother, father, siblings, children or grandparents only)

\section{SOCIAL HISTORY (Circle all that apply)}

Current smoker yes/no number of cigarettes per day Previous smoker yes/no date quit: Alcohol use yes/no number of drinks per day Exercise yes/no number of days in a week duration/type of exercise

PERSONAL HISTORY_(Previous health problems)

1.

2.

3.

4.
5.

6.

7.

8.
9.

10 .

11.

12.

REVIEW OF SYSTEM (Circle current problems/symptoms you are experiencing now in past 1 month)

\begin{tabular}{|c|c|c|c|}
\hline 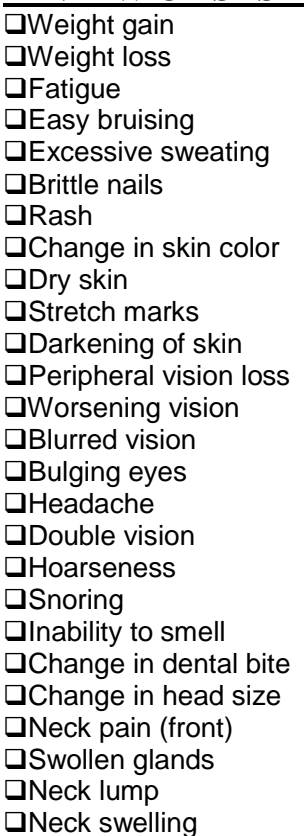 & 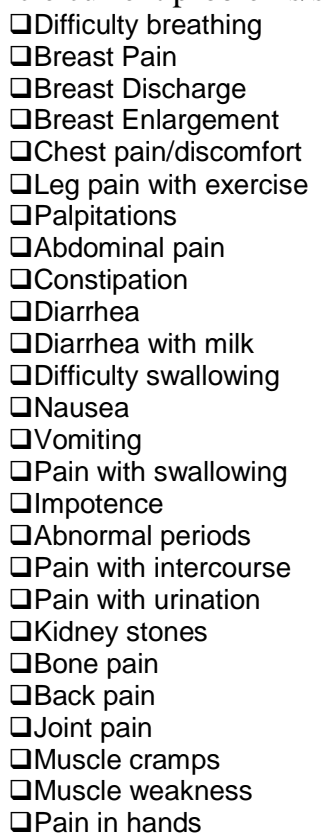 & 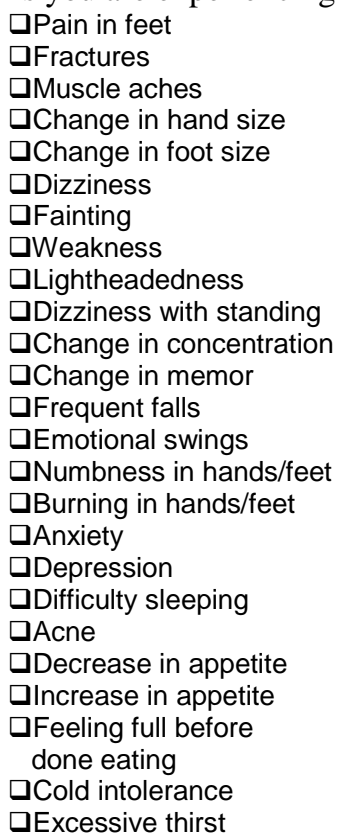 & 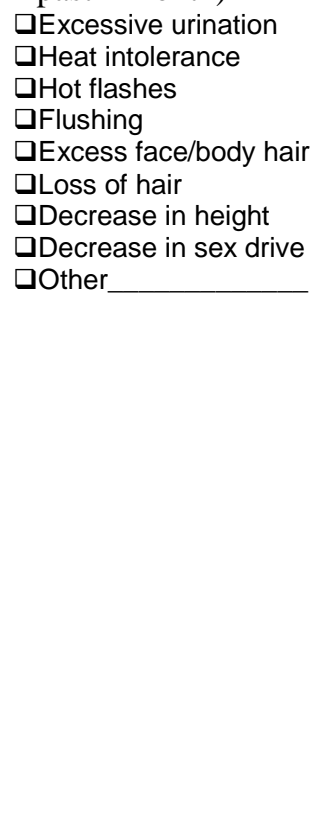 \\
\hline
\end{tabular}

Version Date: Oct 2012 
Anexo 11.11. Material de resultados para la evaluación de la FASE 2. 
Anexo 11.11.1. USUARIO 1. Material de resultados para la evaluación de la FASE 2. Lean Canvas de Decisiones de Diseño. Bocetaje. Propuesta de interfaz gráfica. Cuestionario PSSUQ contestado. Lista de chequeo de Análisis de Tareas contestada. 


\section{LEAN CANVAS DE DECISIONES DE DISEÑO}

integrantes del equipo: Cistion Joséé Castillo Castro

Fecha: $10-03-2020$ Equipo \#:
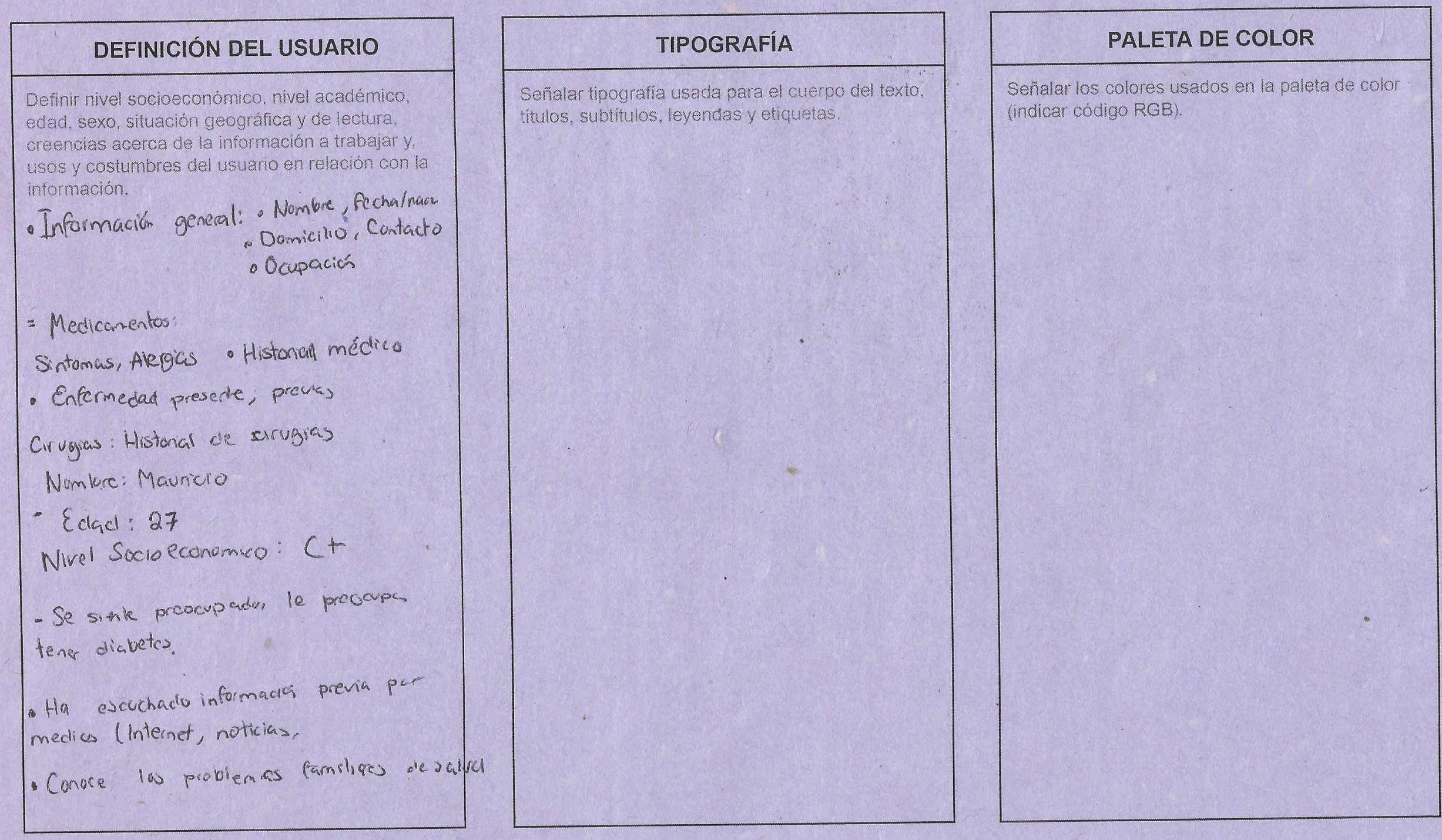

- Quere información rápida y mix effurenlé de leer 
DENVER ENDOCRINOLOGy DIABETES \& THYROID CENTER

Personal Info

NA ME

DATE

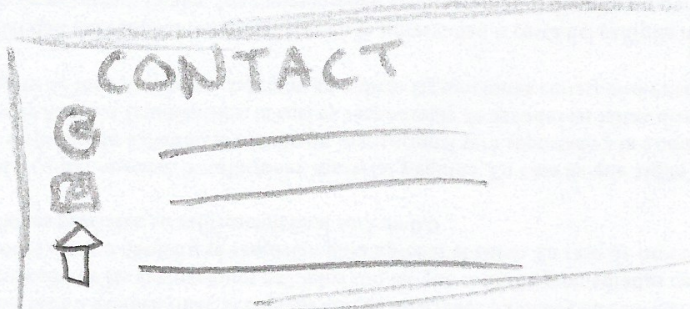

(8) Medications

(ii) Allergies

(5) HOSPITALIZATIONS/SURGERIE

(8) Social activities

B. REVIEW OF SYSTEM 
DENVER DIABETES \& THYROID CENTER

NAME

MEDiCATIONS

INFO:

SYSTEM

0

0

o

SYSTEM SCORE AND MEDICATION' / SOW TOWS
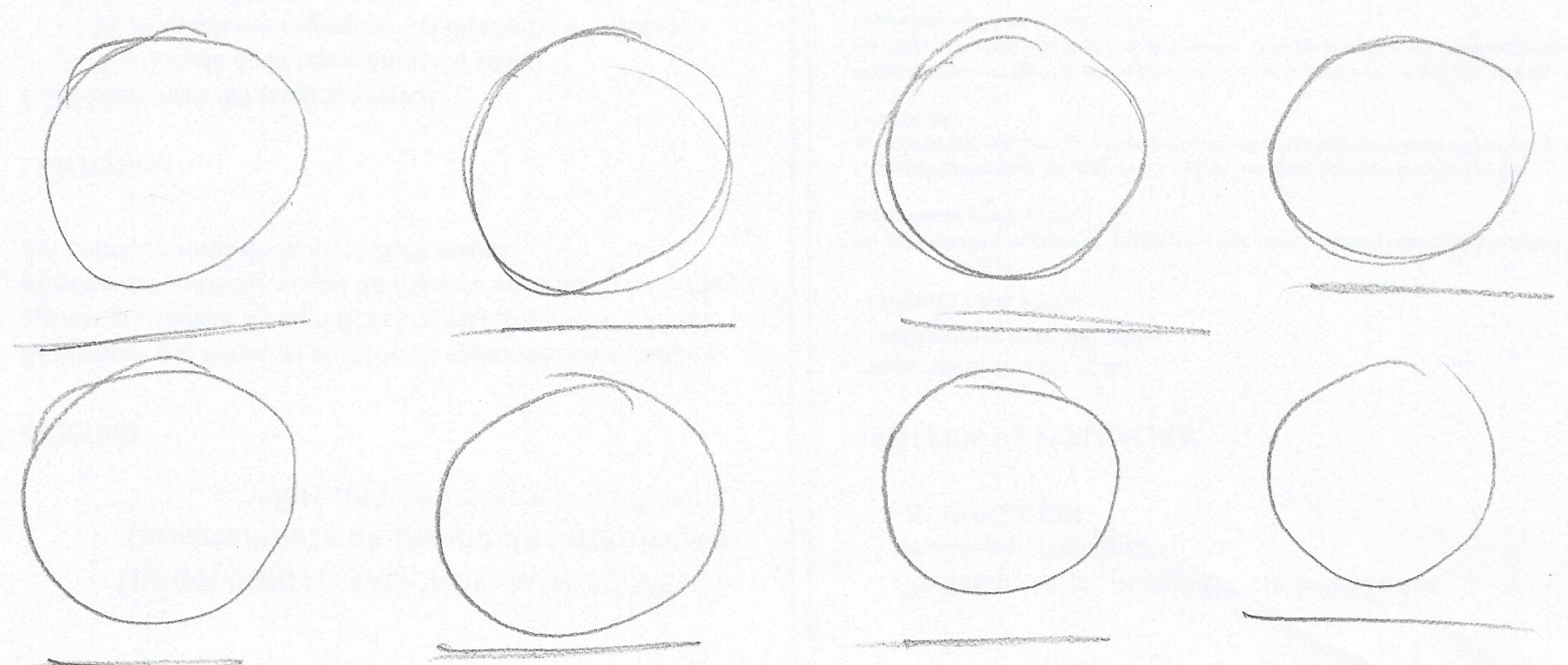


\section{Denver Endocrinology, Diabetes \& Thyroid Center, P.C.}

799 E Hampden Ave, Suite 525, Englewood, CO 80113

Phone: 303-321-2644 Fax: 303-321-2446

Website: www.denverendocenter.com

Today's Date

\section{Personal information}

Patient Name

Date of Birth

Primary Care Provider

Phone

Occupation

\section{Medications}

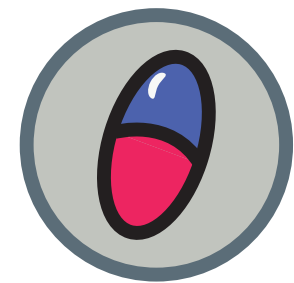

2.

4.

8

8.

\section{Social history}

Member 1.

Member 2.

Member 3.

Member 4.

Member 5.

Member 6.

Family history

Member 7.
1.
3.
4.
5.
6.
7.
8.

5.

\section{Hospitalizations/Surgeries}

\section{Personal history (previous health problems)}

1.$$
2 .
$$

3

4.

5.

6

7

8.
1.

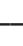

9.
10.
11.
12.
13.
14.
15.
16.

17.
18.
19.
20.
21.
22.
23.
24.

Review of system (Mark the little square)

$\otimes$ Weight gain

$\otimes$ Weight loss

$\triangle$ Fatigue

$\nabla$ Easy bruising

$\otimes$ Difficulty breathing

$\triangle$ Breast Pain

$\triangle$ Breast Discharge

$\triangle$ Breast Enlargement

$\triangle$ Pain in feet

$\triangle$ Fractures

$\otimes$ Muscle aches

$\otimes$ Change in hand size

$\triangle$ Excessive urination

$\nabla$ Heat intolerance

$\nabla$ Hot flashes

$\triangle$ Flushing

$\triangle$ Excessive sweating

$\otimes$ Brittle nails

$\otimes$ Rash

$\otimes$ Change in skin color

$\otimes$ Dry skin $\nabla$ Stretch marks

$\bigotimes$ Darkening of skin

$\triangle$ Peripheral vision loss

$\nabla$ Worsening vision

$\triangle$ Blurred vision

$\triangle$ Bulging eyes

$\nabla$ Headache

$\nabla$ Double vision

$\otimes$ Hoarseness

$\nabla$ Snoring

$\nabla$ Inability to smell

$\nabla$ Change in dental bite

$\nabla$ Change in head size

$\nabla$ Neck pain (front)

$\nabla$ Swollen glands

$\nabla$ Neck lump

$\otimes$ Neck swelling

$\otimes$ Diarrhea

$\triangle$ Diarrhea with milk

$\bigotimes$ Difficulty swallowing

$\nabla$ Nausea

$\triangle$ Vomiting

$\triangle$ Pain with swallowing $\nabla$ Change in foot size

$\triangle$ Dizziness

$\nabla$ Fainting

$\nabla$ Weakness

$\nabla$ Light headedness

$\triangle$ Dizziness with standing

$\nabla$ Change in concentration

$\nabla$ Change in memor

$\triangle$ Frequent falls

$\triangle$ Emotional swings

$\nabla$ Numbness in hands/feet

$\otimes$ Burning in hands/feet

\section{$\triangle$ Anxiety}

$\triangle$ Depression

$\otimes$ Difficulty sleeping

$\triangle$ Acne

$\nabla$ Decrease in appetite

$\triangle$ Increase in appetite

$\nabla$ Feeling full before done eating

$\nabla$ Cold intolerance 


\section{CUESTIONARIOPSSUQ}

Edad:_23_Sexo:M I F Licenciatura:_Diseño gráfico y digital___ Manejo de llustrator.SSi No

Este cuestionario es una oportunidad para registrar tus reacciones a la guía de usabilidad. Estas respuestas nos ayudarán a entender que aspectos hay que mejorar y cuales son con los que no estás satisfechos. Para tener un mejor resultado, piensa en la tarea que se te pidió que realizaras con base a lo que las guías decían mientras contestas estas preguntas.

Instrucciones: Lea cada frase y señala qué tan de acuerdo o en desacuerdo estás y encierra en un circulo un número de la escala. Al terminar, revisaremos juntos con usted el cuestionario para asegurarnos de que entendamos bien la información presentada en este cuestionario.

\section{¡Gracias!}

a) La organización de la información proporcionada por las guías me fue clara.

Totalmente en desacuerdo

1

2

3

4

5

6

Totalmente de acuerdo

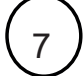

b) Fui capaz de completar la tarea que se me indicó rápidamente con la información proporcionada en las guías.

Totalmente en desacuerdo

12

3

(4)

5

Totalmente de acuerdo

3

4

c) La información proporcionada por las guías fue fácil de entender.

Totalmente de desacuerdo

1

2

3

4

5

Totalmente de acuerdo

riencia de las guías es agradable.

d) La apariencia de las guia
Totalmente en desacuerdo

12

23

3

5

Totalmente de acuerdo

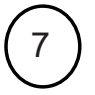

e) En general estoy satisfecho con el acomodo y presentación visual de la información.

Totalmente en desacuerdo

Totalmente de acuerdo

1 2

3

4

(5)

6 


\begin{tabular}{|c|c|c|}
\hline 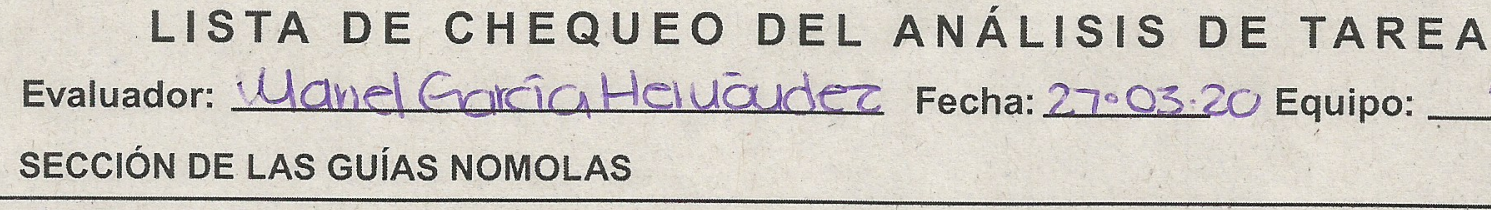 & & \\
\hline USUARIO & $\mathrm{Si}$ & No \\
\hline El diseñador definió el nivel socioeconómico. & 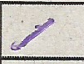 & \\
\hline El diseñador definió el nivel académico. & 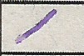 & \\
\hline El diseñador definió edad. & $\gamma$ & \\
\hline El diseñador definió sexo. & $<$ & \\
\hline El diseñador definió situación geográfica. & & $<$ \\
\hline El diseñador definió situación de lectura. & $\angle$ & \\
\hline El diseñador definió creencias sobre la información. & 2 & \\
\hline El diseñador definió usos y costumbres presentadas alrededor de la información. & $\angle$ & \\
\hline ESTRUCTURA DE LA INFORMACIÓN & Si & No \\
\hline El diseñador utilizó una retícula para generar la composición de su gráfica. & 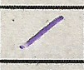 & \\
\hline La información presentada de manera visual tiene congruencia y presenta jerarquia en relación al contenido. & Z & \\
\hline La navegación de lectura se hace de izquierda a derecha y en forma de zig-zag. & 7 & \\
\hline TIPOGRAFIA & $\mathrm{Si}$ & No \\
\hline El diseñador utilizó alguna de las fuentes sugeridas en las guias. & $\alpha$ & \\
\hline El diseñador utilizó un espacio interlineal de 1.5 & 1 & \\
\hline El diseñador evitó la aparición de "viudas" en la composición. & 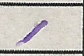 & \\
\hline El diseñador evitó la aparición de "ríos" en la composición. & 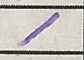 & \\
\hline El diseñador utilizó la variante negrita para hacer énfasis en palabras clave. & & 2 \\
\hline El diseñador utilizó la variante cursiva para hacer referencia a palabras en idioma extranjero. & & 2 \\
\hline El diseñador utilizó un puntaje de carácter para el cuerpo de texto de no menor a 8 puntos. & 7 & \\
\hline El diseñador utilizó para los titulos tipografias sans serif. & 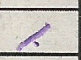 & \\
\hline Los titulos están alienados a la izquierda o centrados. & $\angle$ & \\
\hline Los titulos están en variante negrita y en un puntaje mayor al del cuerpo de texto. & & $\angle$ \\
\hline El cuerpo de texto está alienado a la izquierda. & 2 & \\
\hline El texto y el fondo de la interfaz tienen un buen contraste. & $\angle$ & \\
\hline El diseñador combinó tipografias serif y sans serif en la composición de la pieza de diseño. & & 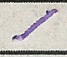 \\
\hline COLOR & Si & No \\
\hline El diseñador utilizó cuatro colores dentro de la composición. & & C. \\
\hline El diseñador cuidó el buen contraste entre figura, fondo y texto en la pieza de diseño. & 1 & \\
\hline El diseñador tomó en consideración el uso de contraste de color entre fondo y texto. & $\angle$ & \\
\hline El diseñador evitó el uso de degradados. & $\angle$ & \\
\hline El diseñador utilizó el mismo color para representar un mismo tipo de dato. & 2 & \\
\hline El diseñador creo codificaciones de información a través del color. & $\angle$ & \\
\hline ELEMENTOS GRÁFICOS & Si & No \\
\hline Todos los elementos conserven un mismo estilo gráfico. & 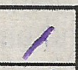 & (15) \\
\hline El diseñador implementó imágenes que tienen la misma orientación & 8 & \\
\hline El diseñador evitó el uso de emojis. & $\not$ & \\
\hline El diseñador usó etiquetas o leyendas debajo de los elementos gráficos que necesitaban algún tipo de aclaración. & l & \\
\hline $\begin{array}{l}\text { El diseñador usó bullets point, listas numéricas y flechas para enfatizar información que pertenecia a una misma } \\
\text { categoria. }\end{array}$ & 7 & \\
\hline El diseñador evitó el uso de elementos o información innecesarios, extraños, decorativos o irrelevantes. & 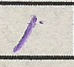 & \\
\hline
\end{tabular}


Anexo 11.11.2. USUARIO 2. Material de resultados para la evaluación de la FASE 2. Lean Canvas de Decisiones de Diseño. Bocetaje. Propuesta de interfaz gráfica. Cuestionario PSSUQ contestado. Lista de chequeo de Análisis de Tareas contestada. 


\section{LEAN CANVAS DE DECISIONES DE DISEÑO}

INTEGRANTES DEL EQUIPO:

Fecha: 1) Whese 2000

Equipo \#:
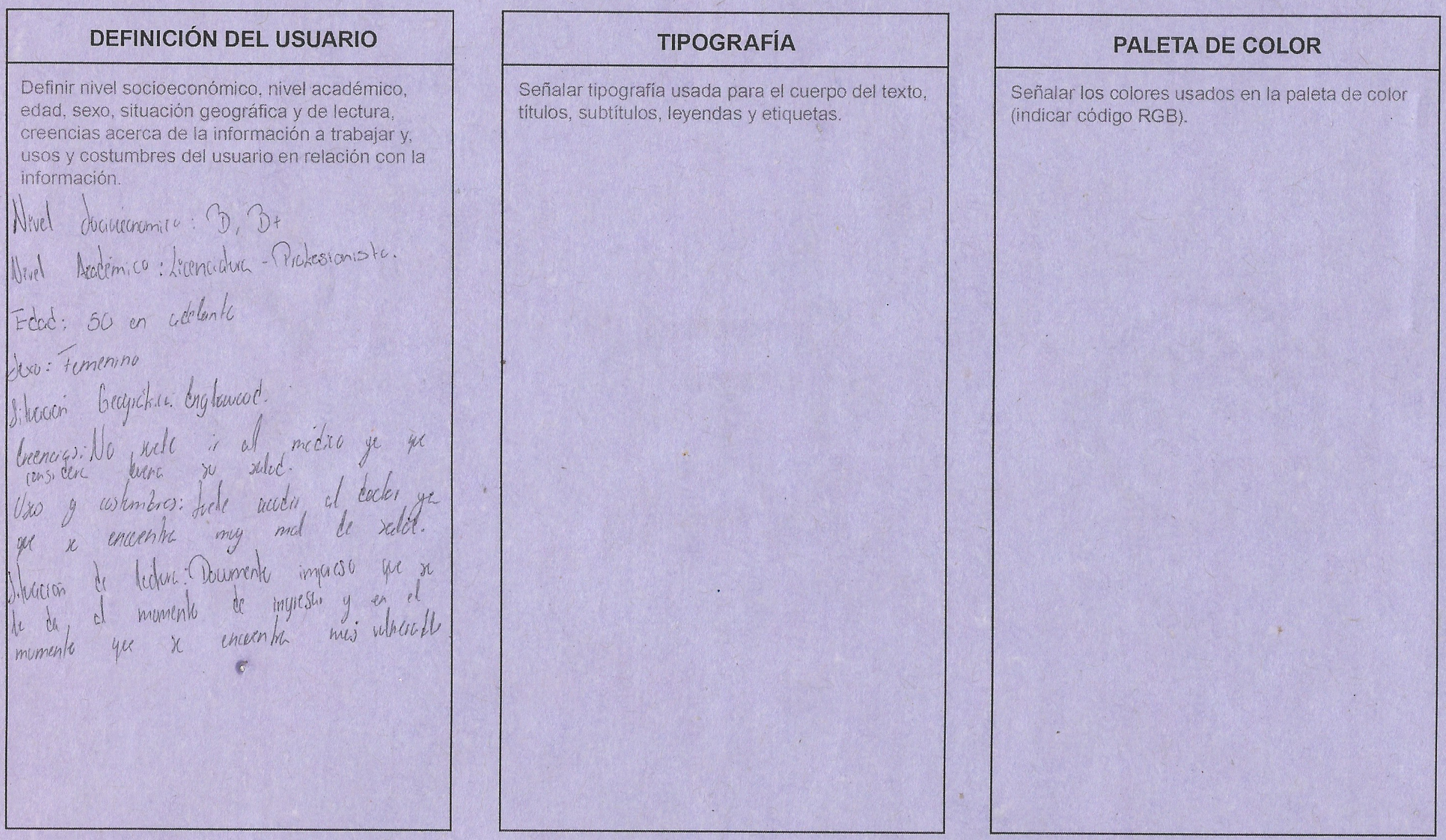
Denver endoorindegy lenter

Persenal Intarmatien.

Name.

Medications.
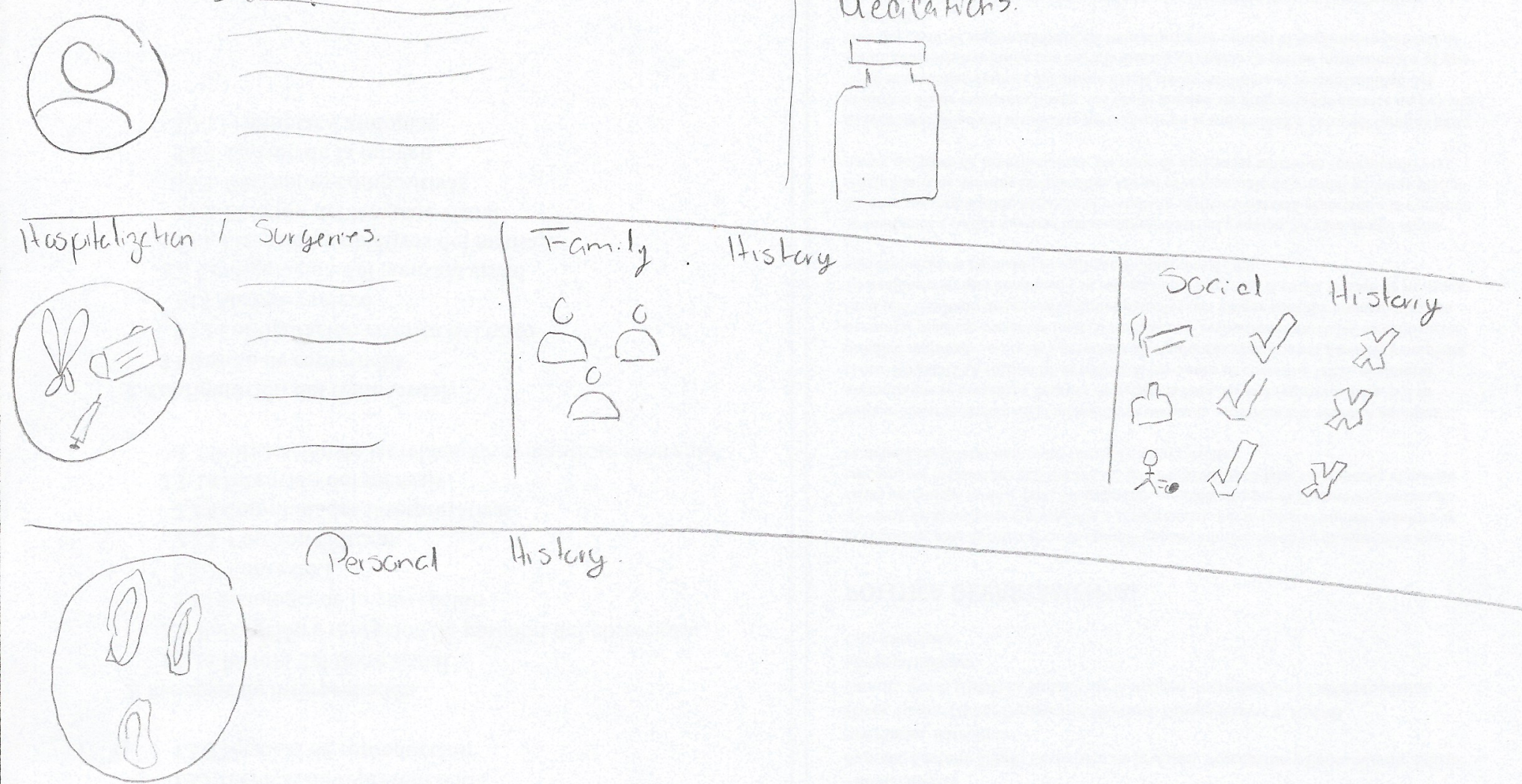

Persanal Histary.

Revew ot System.

$(8$

0

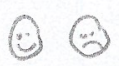

(2)

(1) 9

(2) $(5)$

(C)

(C)

$(\Theta$ 


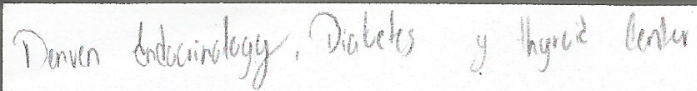

Stated It

Pahent Vame

Date Bith

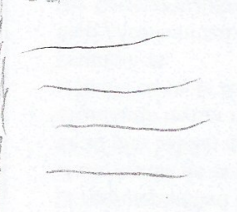

Medications

Hention o lypes (neme and dakge)

(co)
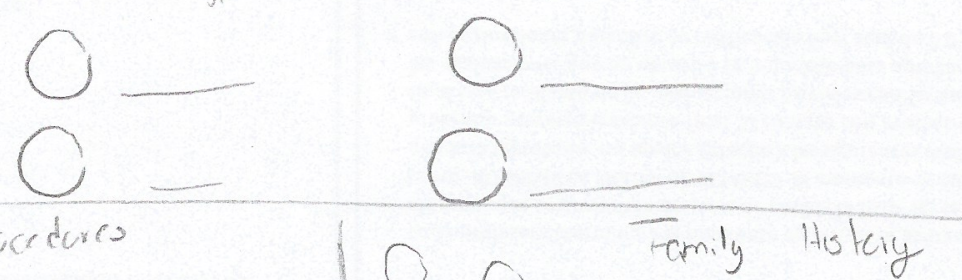

(ba)

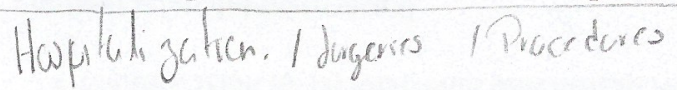

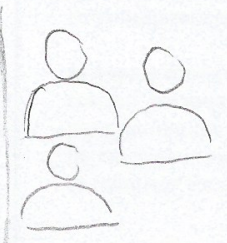

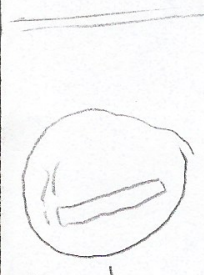

smoker

紧

How many? Haw Hang?

Sacid History

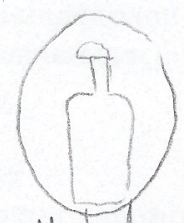

Alconal.

V 8

Hew Meny?

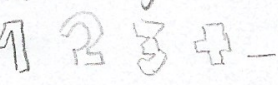

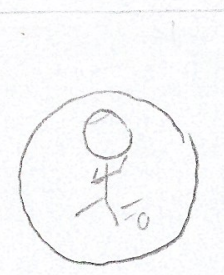

Personal

Exercise

$\sqrt{ } \times$

(4)

Fomily Histery<smiles>CC1CC1C(C)(C)C1CCCCC1</smiles>

$: \bar{I}$
$: \bar{I}$
$: \bar{I}$
$: \bar{I}$
$: \bar{I}$
$: \bar{I}$
$: \square$
$: \square$
$: \square$

Revicu ot System. 
Denver Endocrinology, Diabetes \& Thyrod Center, P.C.

799 E Hampden Av, Suite 525, Englewood, CO 80113

Phone: 303-321-2644 Fax: 303-321-2446

Website: www.denverendocenter.com

Today's Date:

Patient Name:

Date of Birth:

Occupation:

Primary Care Provider:

Referring Physician (If not PCP):

Other Care Providers:

Phone:

Phone:

Main Concern/Reason for visit today:

Phone:

Allergies (Please included type of reaction to each allergy listed):

\section{Social History}

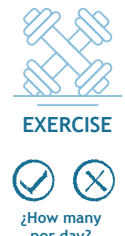

per day?

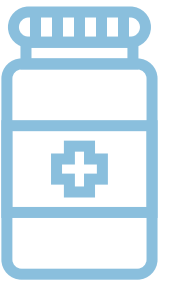

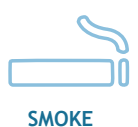

$\theta \otimes$ ¿How many

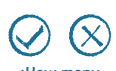
¿How many per day?

\section{Medications}

1.
2.
3.
4.
5.

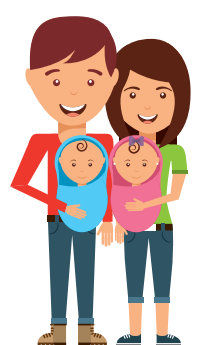

Family History

(List any health problems of your mother, father, siblings, children or grandparents only)

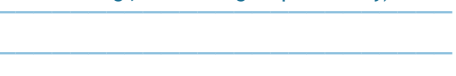

(1)

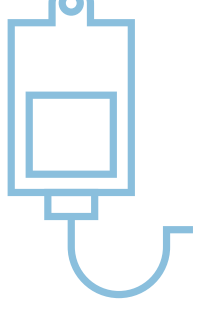

Hospitalizations

(Please include exact date or a least year)

\section{Personal History (Previus heath problems}

\section{Review of System}

\footnotetext{
Weight Gain

Weight Loss

-Fatigue

Easy Bruising

- Excessive Sweating

- Brittle Nails

- Rash

- Change in skin color

- Dry Skyn

- Stretch marks

- Darkening of Skin

- Peripheral vision loss

- Worsening vision
}

- Bulging eyes

- Headache

- Double vision

- Hoarseness

- Snoring

- Inability to smell

- Change in dental bite

- Change in head size

- Neck pain

- Swollen glands

- Neck lump

- Neck swelling

- Difficulty breathing

- Breast pain
- Breast discharge
Chest pain
- Leg pain with exercise
- Palpitations
- Abdominal pain
Constipation
- Diarrhea
- Diarrhea with milk
- Difficulty swallowing
- Vausea
- Painiting with swallowing

- Impotence

- Abnormal periods

- Pain with intercourse

- Pain with urination

- Kidney stones

- Bone pain

- Back pain

- Joint pain

- Muscle cramps

- Muscle weakness

- Pain in hands

- Pain in feet

- Fractures
- Muscle aches

- Change in hand size

- Change in foot size

- Dizziness

- Fainting

- Weakness

- Lightheadedness

- Frequent fails

- Emotional swings

- Anxiety

- Depression

- Acne

- Decrease in appetite 


\section{Selección Tipográfica}

Para los textos utilicé Trebuchet MS en sus diferentes variantes, ya que leyendo el Nomolas, es una tipografía escogida para esté tipo de documentos, además de que se adecua perfectamente a los distintos puntajes usados y a pesar de la paleta de color, considero que sigue siendo legible y amigable a la vista.

\section{Paleta de color.}

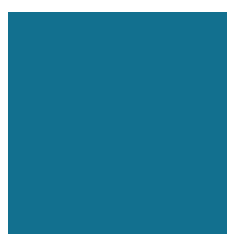

$\mathrm{R}=0$

$\mathrm{G}=112$

$B=143$

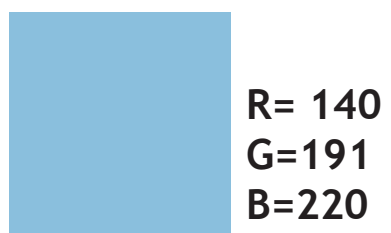

$R=255$

$\mathrm{G}=255$

$B=255$

Escogí está paleta de color porqué considero que es amigable con documentos de hospitales, ya que no se ve tan cargado, no molesta a la vista, es legible y no es agresivo para comunicar mensajes. 


\section{CUESTIONARIOPSSUQ}

\section{Edad:23 Sexo: M I Licenciatura:_Diseño Gráfico Y Digital Manejo de llustrator: I No}

Este cuestionario es una oportunidad para registrar tus reacciones a la guía de usabilidad. Estas respuestas nos ayudarán a entender que aspectos hay que mejorar y cuales son con los que no estás satisfechos. Para tener un mejor resultado, piensa en la tarea que se te pidió que realizaras con base a lo que las guías decían mientras contestas estas preguntas.

Instrucciones: Lea cada frase y señala qué tan de acuerdo o en desacuerdo estás y encierra en un circulo un número de la escala. Al terminar, revisaremos juntos con usted el cuestionario para asegurarnos de que entendamos bien la información presentada en este cuestionario.

\section{¡Gracias!}

a) La organización de la información proporcionada por las guías me fue clara.

Totalmente en desacuerdo

Totalmente de acuerdo

1

2

3

4

5

7

b) Fui capaz de completar la tarea que se me indicó rápidamente con la información proporcionada en las guías.

Totalmente en desacuerdo

Totalmente de acuerdo

$$
1
$$

2

3

4

5

7

c) La información proporcionada por las guías fue fácil de entender.

Totalmente de desacuerdo

1

2

3

4

5

Totalmente de acuerdo

7

d) La apariencia de las guías es agradable.

Totalmente en desacuerdo

Totalmente de acuerdo

1

2

3

4

5

7

e) En general estoy satisfecho con el acomodo y presentación visual de la información.

Totalmente en desacuerdo

Totalmente de acuerdo

1

2

3

4

5 


\section{LISTA DE CHEQUEO DEL ANÁLISIS DE TAREAS}

\section{Evaluador: Wariel Garéa Hevioucher Fecha: 27.03.20 Equipo: 2}

\section{SECCIÓN DE LAS GUÍAS NOMOLAS}

\section{USUARIO}

El diseñador definió el nivel socioeconómico.

El diseñador definió el nivel académico.

El diseñador definió edad.

El diseñador definió sexo.

El diseñador definió situación geográfica.

El diseñador definió situación de lectura.

El diseñador definió creencias sobre la información.

El diseñador definió usos y costumbres presentadas alrededor de la información.

\section{ESTRUCTURA DE LA INFORMACIÓN}

El diseñador utilizó una retícula para generar la composición de su gráfica

La información presentada de manera visual tiene congruencia y presenta jerarquia en relación al contenido.

La navegación de lectura se hace de izquierda a derecha y en forma de zig-zag.

\section{TIPOGRAFÍA}

El diseñador utilizó alguna de las fuentes sugeridas en las guias.

El diseñador utilizó un espacio interlineal de 1.5

El diseñador evitó la aparición de "viudas" en la composición.

El diseñador evitó la aparición de "ríos" en la composición.

El diseñador utilizó la variante negrita para hacer énfasis en palabras clave.

El diseñador utilizó la variante cursiva para hacer referencia a palabras en idioma extranjero.

El diseñador utilizó un puntaje de carácter para el cuerpo de texto de no menor a 8 puntos.

El diseñador utilizó para los títulos tipografías sans serif.

Los titulos están alienados a la izquierda o centrados.

Los titulos están en variante negrita y en un puntaje mayor al del cuerpo de texto.

El cuerpo de texto está alienado a la izquierda.

El texto y el fondo de la interfaz tienen un buen contraste.

El diseñador combinó tipografias serif y sans serif en la composición de la pieza de diseño.

\section{COLOR}

El diseñador utilizó cuatro colores dentro de la composición.

El diseñador cuidó el buen contraste entre figura, fondo y texto en la pieza de diseño. :

El diseñador tomó en consideración el uso de contraste de color entre fondo y texto.

El diseñador evitó el uso de degradados.

El diseñador utilizó el mismo color para representar un mismo tipo de dato.

El diseñador creo codificaciones de información a través del color

\section{ELEMENTOS GRÁFICOS}

Todos los elementos conserven un mismo estilo gráfico.

El diseñador implementó imágenes que tienen la misma orientación

El diseñador evitó el uso de emojis.

El diseñador usó etiquetas o leyendas debajo de los elementos gráficos que necesitaban algún tipo de aclaración. El diseñador usó bullets point, listas numéricas y flechas para enfatizar información que pertenecia a una misma categoria.

El diseñador evitó el uso de elementos o información innecesarios, extraños, decorativos o irrelevantes. 
Anexo 11.11.3. USUARIO 3. Material de resultados para la evaluación de la FASE 2. Lean Canvas de Decisiones de Diseño. Bocetaje. Propuesta de interfaz gráfica. Cuestionario PSSUQ contestado. Lista de chequeo de Análisis de Tareas contestada. 


\begin{tabular}{|l|}
\hline \multicolumn{1}{|c|}{ DEFINICIÓN DEL USUARIO } \\
\hline Definir nivel socioeconómico, nivel académico, \\
edad, sexo, situación geográfica y de lectura, \\
creencias acerca de la información a trabajar y, \\
usos y costumbres del usuario en relación con la \\
información. \\
Edad: 30 a 50 años. NSE: Medio Alto. \\
Sexo: Tendencia a ser más hombres que \\
mujeres. Radican en la ciudad de Engle- \\
wood, Colorado. Al ser una ciudad \\
pequeña es probable que no haya muchas \\
clínicas para tratar este padecimiento, por \\
lo que el usuario se siente muy estresado y \\
ansioso por su salud. El usuario se ha \\
sentido mal durante algunas semanas, \\
pero no logra descifrar lo que le está \\
pasando. Quiere obtener respuestas \\
rápidas y que se le atienda de una manera \\
discreta. Es probable que viva con su \\
familia pero en muchos de los casos \\
suelen mantener en secreto este tipo de \\
padecimientos por miedo a que les \\
tengan lástima. Consulta normalmente la \\
información del padecimiento en internet \\
o redes sociales, así que vive en un estado \\
de "mal información". El ir a la clínica ha \\
sido su último recuerdo ante esa "mal \\
información". \\
\end{tabular}

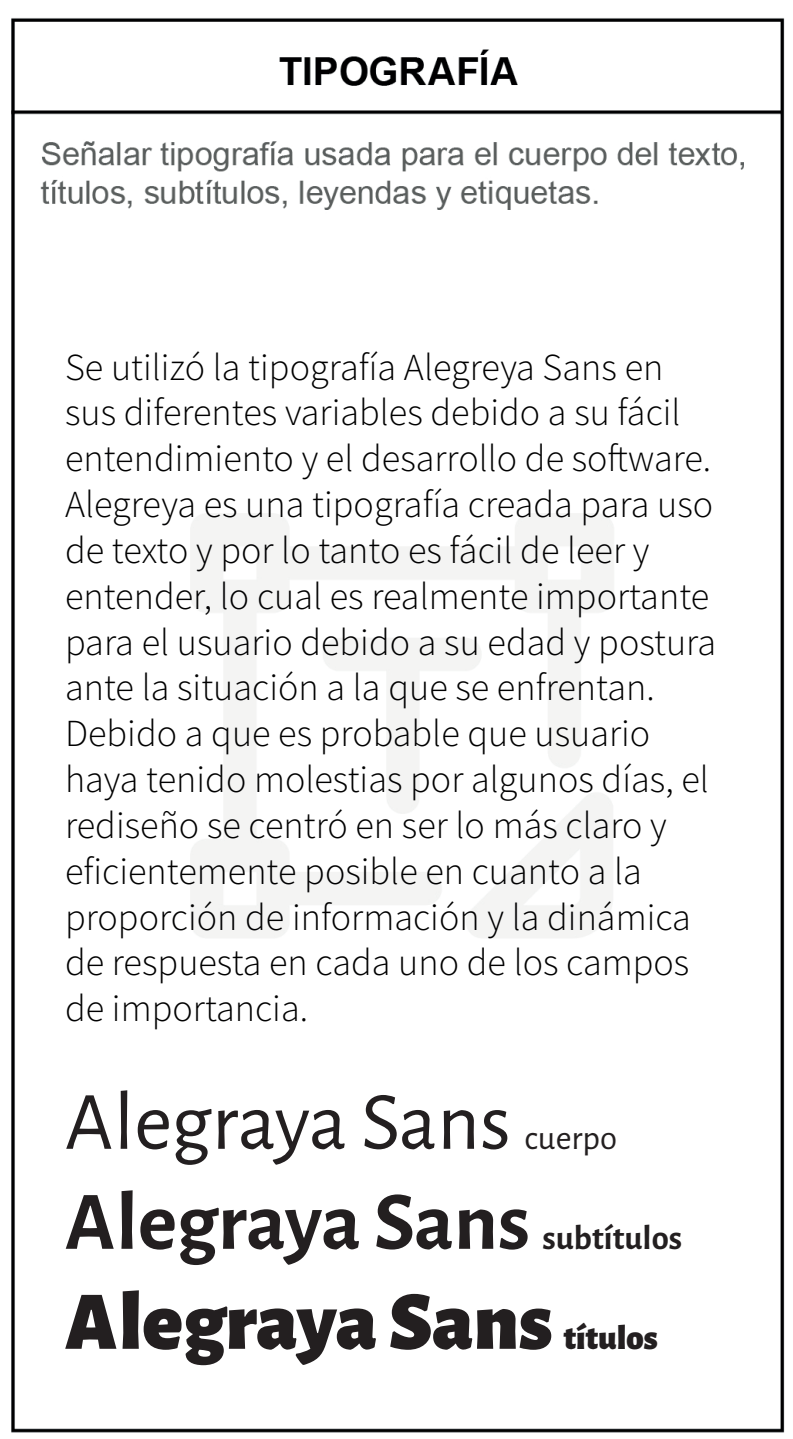

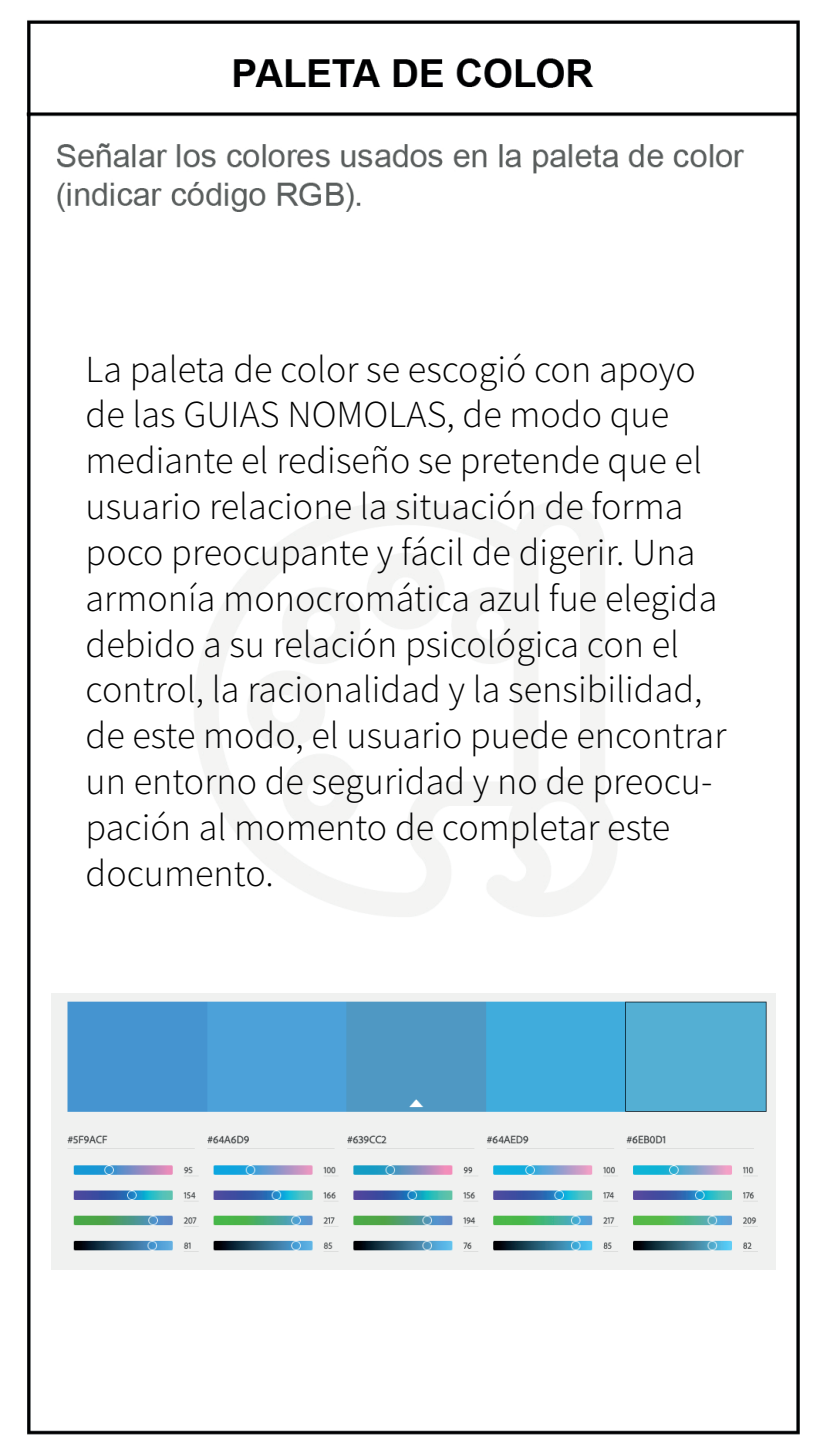


Denver endocrindogy

Diabetes \& thyroid enter pe into
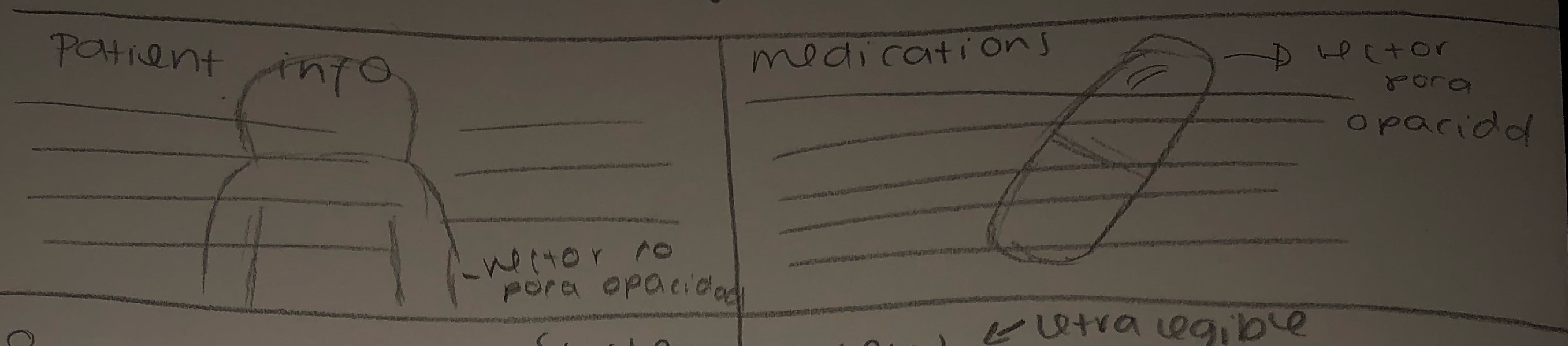

0

system review tetra legible

0

o

$0 \longrightarrow 0$

0

0

0

0

0

0

0

0

O

$0 \longdiv { - 2 }$

0

0

0

0

Hopitalization

procedure bate

social History

6

6

o.

ב

ye, no how many? -

yer no ne of days

family History

4

2

5

1

personal History

2

5

3

6

4

4 
Denver endocrinology, Diabetes \& thyroid center P.C,

patient name Date of birth
Today date occupation phone phone

All orgies r 1. name Medications

2.

5. name Dosage color 2

3.

4.

6

7 .

\begin{tabular}{l} 
Hospitalizations/surgaves \\
$\begin{array}{c}\text { Procedure date or year } \\
\text { Date }\end{array}$ \\
\hline
\end{tabular}

Social History

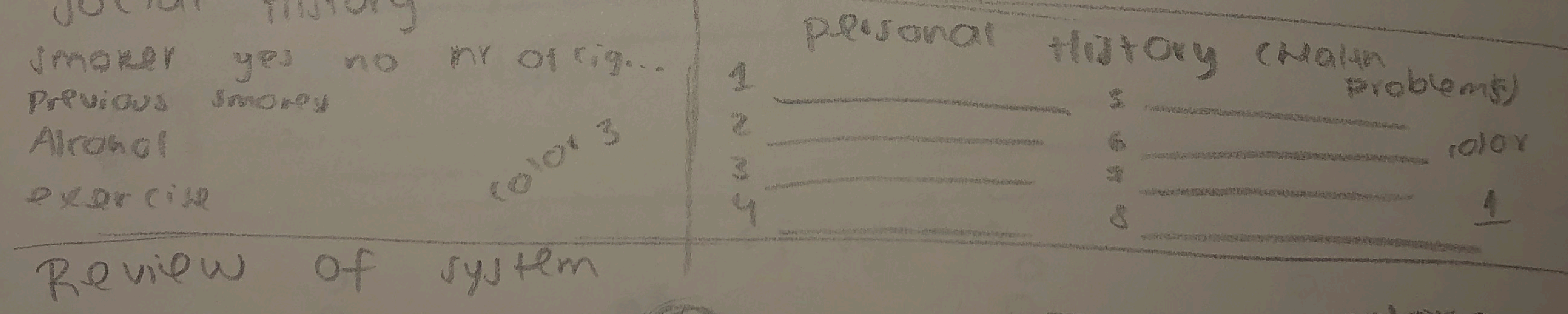

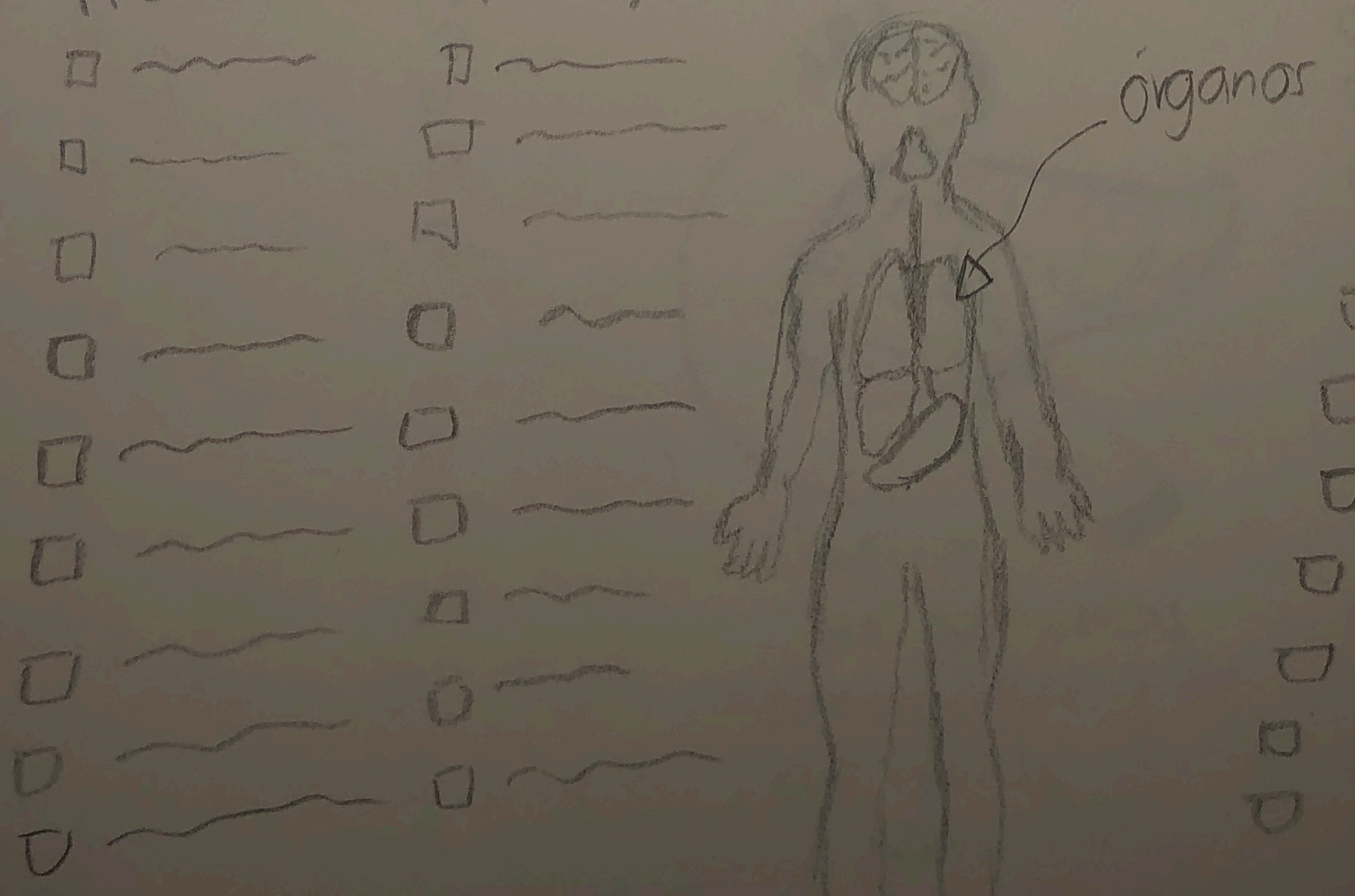
color? 


\section{Denver Endocrinology, Diabetes \& Thyroid Center, P.C.}

799 E Hampden Ave, Suite 525, Englewood, CO 80113

Phone: 303-321-2644

Fax: 303-321-2446

Website: www.denverendocenter.com

Primary Care Provider:

Phone:

Referring Physician(if not PCP):

Phone:

Other Care Providers:

Phone:

ALLERGIES (Please include type

of reaction to each allergy listed):

\section{Medications}

(Both prescription and over-the-counter including herbal,vitamins,etc) Please include another page if needed.

1.Name:

2.Name:

3.Name:

4.Name:

\section{Hospitalizations/surgeries/procedures}

(Please include exact date or at least year).
Dosage:

Dosage:

Dosage:

Dosage:

Family history (List any health problems of your mother, father, siblings, children or grandparents only).
Social history (Circle all that apply).

Current smoker yes/no number of cigarettes per day:

Previous smoker yes/no date quit:

Alcohol use yes/no number of drinks per day:

Exercise yes/no number of days in a week:

Weight gain

Weight loss

Fatigue

Easy bruising

Excessive sweating

Brittle nails

Rash

Change in skin color

Dry skin

Stretch marks

Darkening of skin

Peripheral vision loss

Worsening vision

Blurred vision

Bulging eyes

Headache

Double vision

Hoarseness

Snoring
Inability to smell

Change in dental bite

Change in head size

Neck pain (front)

Swollen glands

Neck lump

Neck swelling

Difficulty breathing

Breast Pain

Breast Discharge

Breast Enlargement

Chest pain/discomfort

Leg pain with exercise

Palpitations

Abdominal pain

Constipation

Diarrhea

Diarrhea with milk

Difficulty swallowing
Heat intolerance

Hot flashes

Flushing

\section{Review of system}

(Circle current problems/symptoms you are experiencing now in past 1 month)

Cold intolerance

Excessive thirst

Excessive urination

Personal history (Previous health problems).

Decrease in

sex drive

Other

Lightheadedness

Dizziness with standing

Change in concentration

Change in memor

Frequent falls

Emotional swings

Numbness in hands/feet

Burning in hands/feet

Anxiety

Depression

Difficulty sleeping

Acne

Decrease in appetite

Increase in appetite

Feeling full before done eating
Nausea

Vomiting

Pain with swallowing Impotence

Abnormal periods

Pain with intercourse

Pain with urination

Kidney stones

Bone pain

Back pain

Joint pain

Muscle cramps

Muscle weakness

Muscle aches

Pain in hands

Pain in feet

Fractures

Change in hand size

Change in foot size 


\section{CUESTIONARIOPSSUQ}

Edad: 21 Sexo: M I (F) Licenciatura: Diseño de infromación visual Manejo de llustrator: (Si) I No

Este cuestionario es una oportunidad para registrar tus reacciones a la guía de usabilidad. Estas respuestas nos ayudarán a entender que aspectos hay que mejorar y cuales son con los que no estás satisfechos. Para tener un mejor resultado, piensa en la tarea que se te pidió que realizaras con base a lo que las guías decían mientras contestas estas preguntas.

Instrucciones: Lea cada frase y señala qué tan de acuerdo o en desacuerdo estás y encierra en un circulo un número de la escala. Al terminar, revisaremos juntos con usted el cuestionario para asegurarnos de que entendamos bien la información presentada en este cuestionario.

\section{¡Gracias!}

a) La organización de la información proporcionada por las guías me fue clara.

Totalmente en desacuerdo

Totalmente de acuerdo$$
1
$$

2

3

4

5

6

(7)

b) Fui capaz de completar la tarea que se me indicó rápidamente con la información proporcionada en las guías.

Totalmente en desacuerdo

$$
1
$$

3

4

(5)

6

Totalmente de acuerdo

c) La información proporcionada por las guías fue fácil de entender.

Totalmente de desacuerdo$$
1
$$

2

3

4

5

Totalmente de acuerdo

d) La apariencia de las guías es agradable.

Totalmente en desacuerdo

$$
12
$$

2

3

4

5

Totalmente de acuerdo

(6)

7

e) En general estoy satisfecho con el acomodo y presentación visual de la información.

Totalmente en desacuerdo

Totalmente de acuerdo

1

2

3

4

5

6

(7) 


\section{LISTA DE CHEQUEO DEL ANÁLISIS DE TAREAS. \\ Evaluador: Wanel Garća Heluauder Fecha: 27.03 .20 Equipo: 3}

\section{SECCIÓN DE LAS GUÍAS NOMOLAS}

\section{USUARIO}

El diseñador definió el nivel socioeconómico.

El diseñador definió el nivel académico.

El diseñador definió edad.

El diseñador definió sexo.

El diseñador definió situación geográfica.

El diseñador definió situación de lectura.

El diseñador definió creencias sobre la información.

El diseñador definió usos y costumbres presentadas alrededor de la información.

\section{ESTRUCTURA DE LA INFORMACIÓN}

El diseñador utilizó una retícula para generar la composición de su gráfica.

La información presentada de manera visual tiene congruencia y presenta jerarquia en relación al contenido. La navegación de lectura se hace de izquierda a derecha y en forma de zig-zag.

\section{TIPOGRAFÍA}

El diseñador utilizó alguna de las fuentes sugeridas en las guias

El diseñador utilizó un espacio interlineal de 1.5

El diseñador evitó la aparición de "viudas" en la composición.

El diseñador evitó la aparición de "rios" en la composición.

El diseñador utilizó la variante negrita para hacer énfasis en palabras clave.

El diseñador utilizó la variante cursiva para hacer referencia a palabras en idioma extranjero

El diseñador utilizó un puntaje de carácter para el cuerpo de texto de no menor a 8 puntos.

El diseñador utilizó para los títulos tipografias sans serif.

Los títulos están alienados a la izquierda o centrados.

Los títulos están en variante negrita y en un puntaje mayor al del cuerpo de texto.

El cuerpo de texto está alienado a la izquierda

El texto y el fondo de la interfaz tienen un buen contraste.

El diseñador combinó tipografias serif y sans serif en la composición de la pieza de diseño COLOR

El diseñador utilizó cuatro colores dentro de la composición.

El diseñador cuidó el buen contraste entre figura, fondo y texto en la pieza de diseño.

El diseñador tomó en consideración el uso de contraste de color entre fondo y texto.

El diseñador evitó el uso de degradados.

El diseñador utilizó el mismo color para representar un mismo tipo de dato.

El diseñador creo codificaciones de información a través del color.

\section{ELEMENTOS GRÁFICOS}

Todos los elementos conserven un mismo estilo gráfico.

El diseñador implementó imágenes que tienen la misma orientación

El diseñador evitó el uso de emojis.

El diseñador usó etiquetas o leyendas debajo de los elementos gráficos que necesitaban algún tipo de aclaración El diseñador usó bullets point, listas numéricas y flechas para enfatizar información que pertenecia a una misma categoría.

El diseñador evitó el uso de elementos o información innecesarios, extraños, decorativos o irrelevantes.
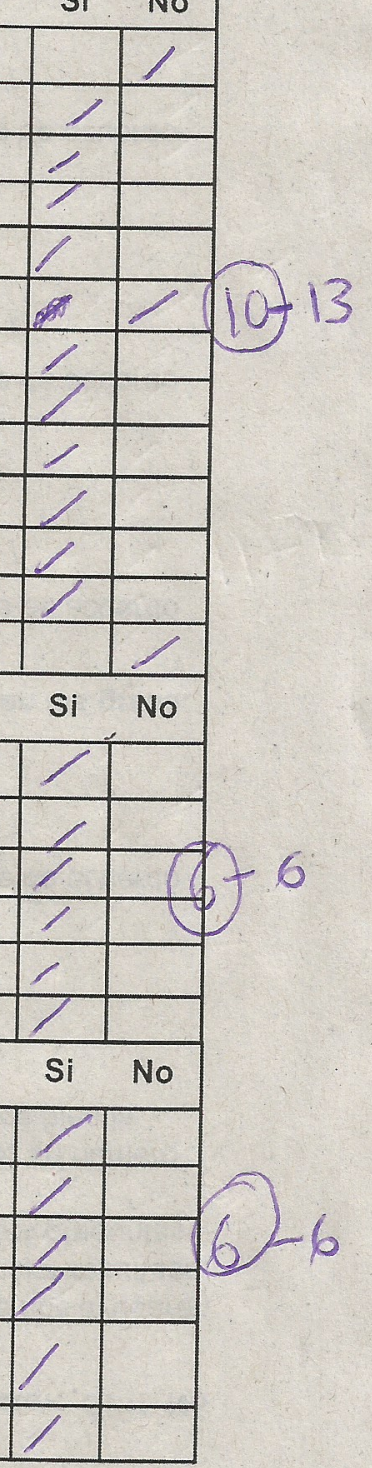
Anexo 11.11.4. USUARIO 4. Material de resultados para la evaluación de la FASE 2. Lean Canvas de Decisiones de Diseño. Bocetaje. Propuesta de interfaz gráfica. Cuestionario PSSUQ contestado. Lista de chequeo de Análisis de Tareas contestada. 
LEAN CANVAS DE DECISIONES DE DISEÑO

INTEGRANTES DEL EQUIPO: Jetto Garcia Castillo

Fecha: $25 / 03 / 20$

Equipo \#:

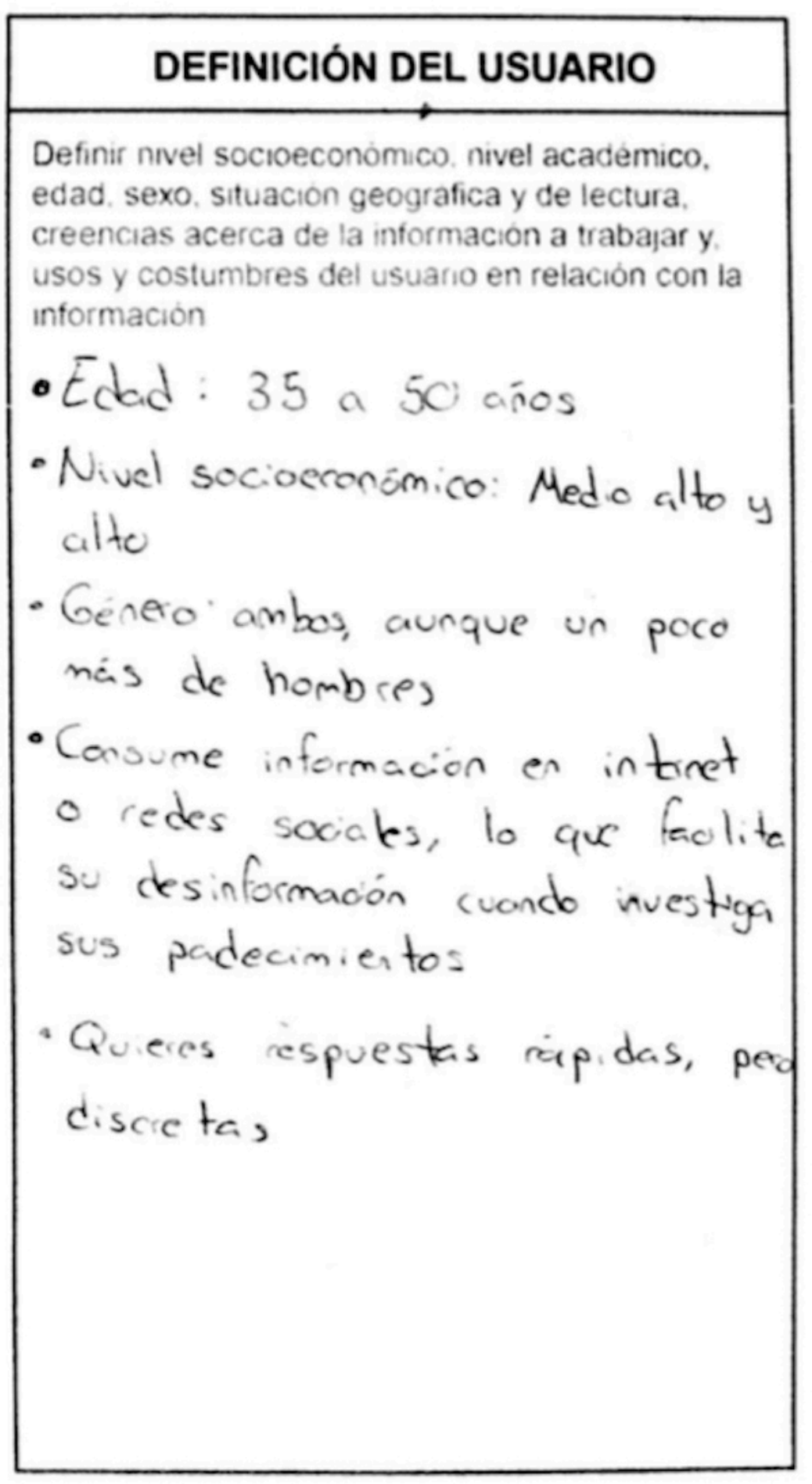

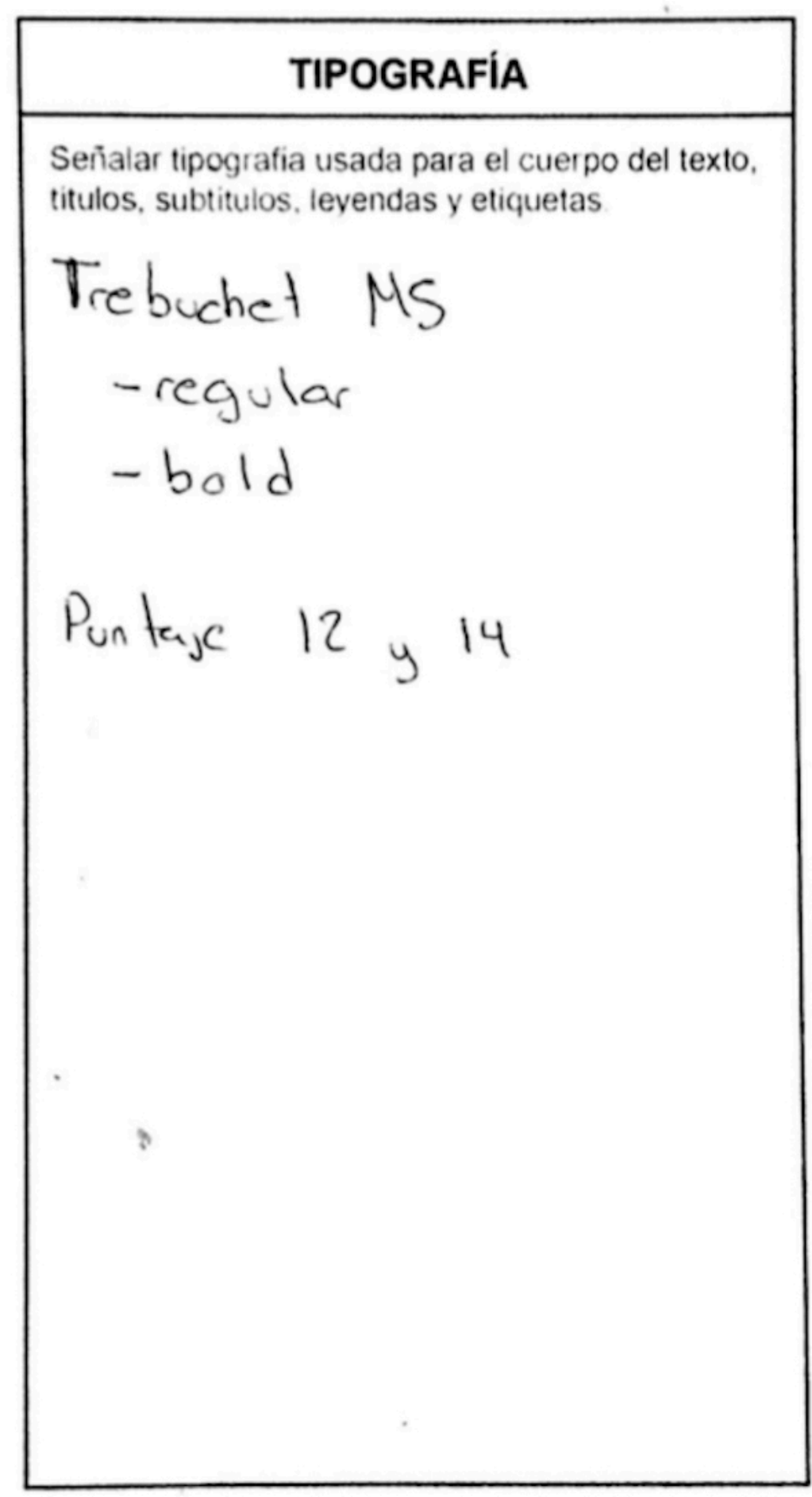

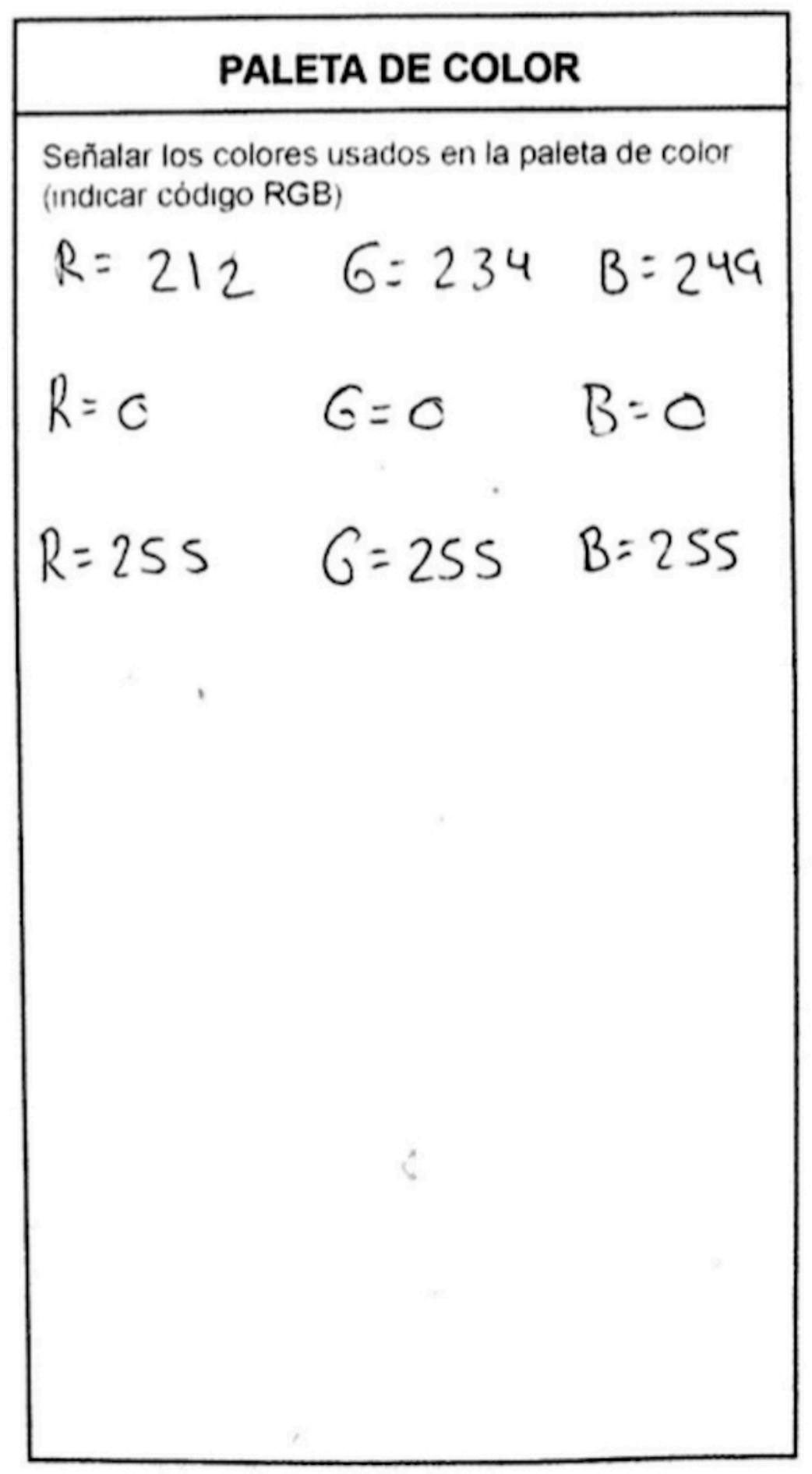




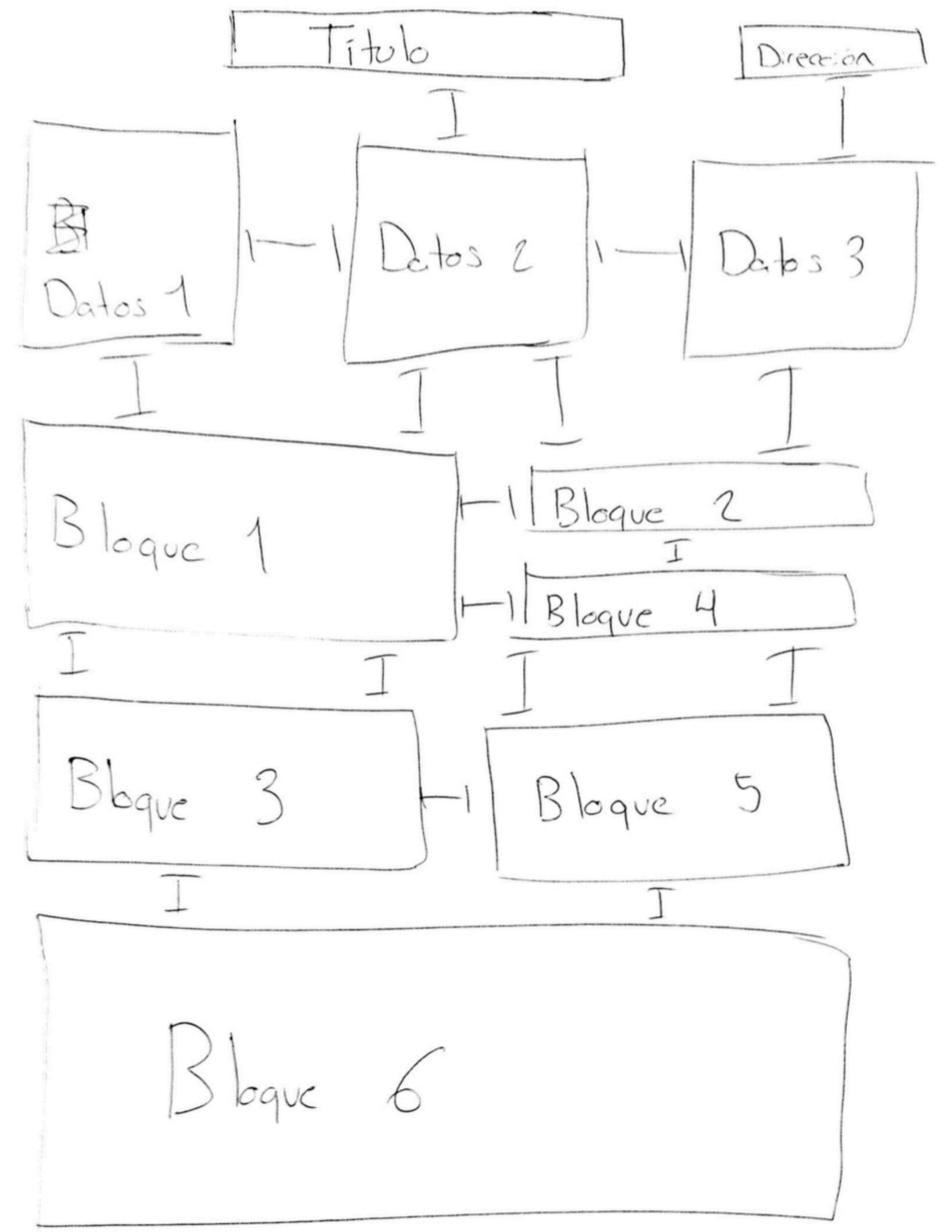




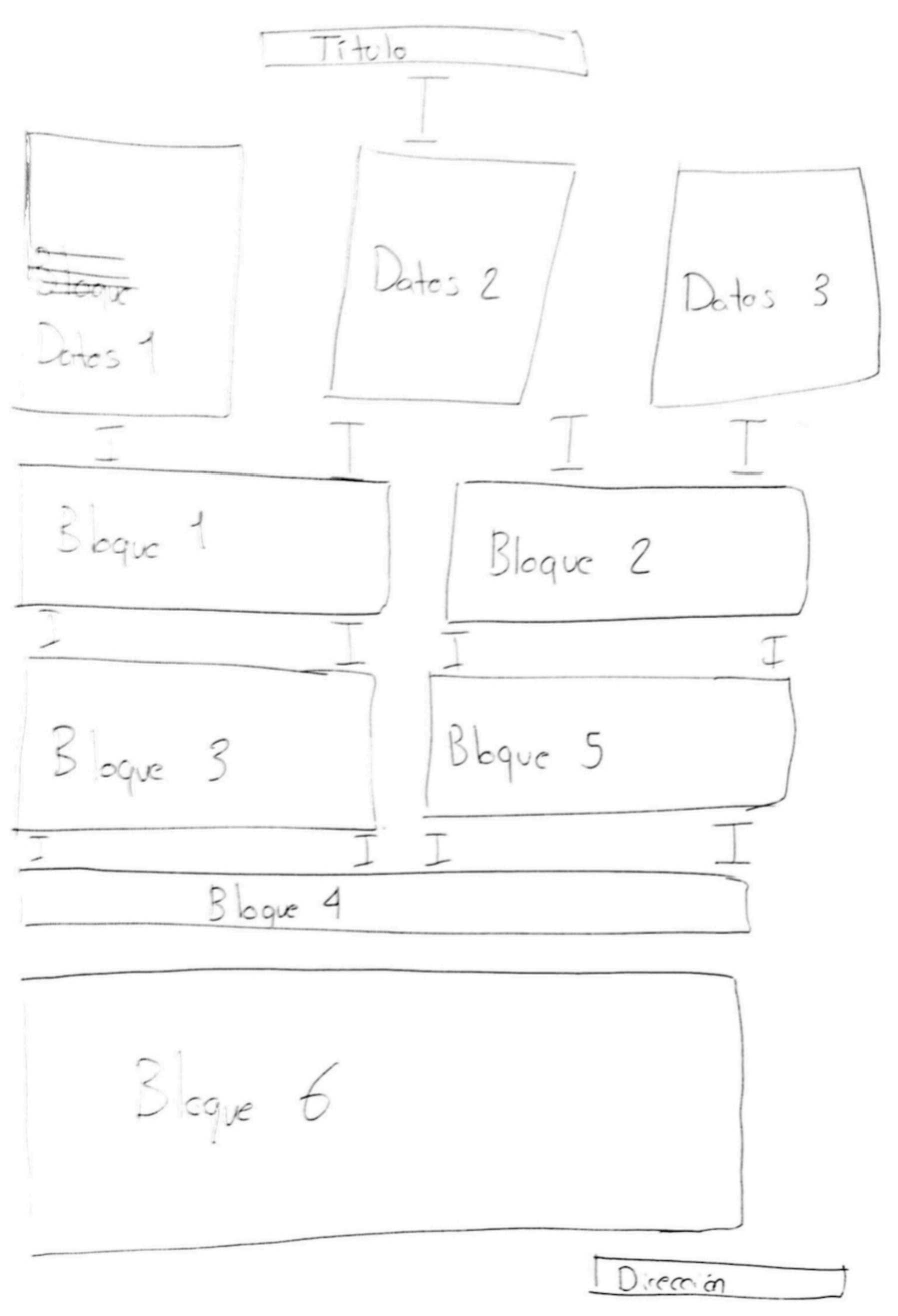




\section{Denver Endocrinology, Diabetes \& Thyroid Center, PC.}

Patient Name

Date of Birth

Primary Care Provider

Referring Physician (if not PCP)

Other Care Providers
Today's Date

Occupation

Phone

Phone

Phone

Main Concern(s)/Reasons for visit today

Allergies (please include type of reaction to each allergy listed)

Medications (Both prescription and over-the-counter including herbal, vitamins, etc.) Please, include another page if needed

1.

3.

5.

Hospitalizations/Surgeries/Procedures please include exact date or at least year

Family History (List any health problems of your mother, father, siblings, children, or grandparents only)

2.

4.

6.

Social History (Circle all that apply)

Current smoker yes/no

*Number of cigarretes per day

Previous smoker yes/no

*Date quit

Alcohol use yes/no

*Number of drinks per day

Exercise yes/no

*Number of days in a week duration/ type of exercise

Personal History (Previous problems) 
Review of system (Circle current problems/symptoms you aare experiencing now in past 1 month)

$\square$ Weight gain

Weight loss

Fatigue

Easy bruising

Excessive sweating

Brittle nails

Rash

Change in skin color

Dry skin

Stretch marks

Darkening of skin

Peripheral vision loss

Worsening vision

Blurred vision

Bulging eyes

Headache

Double vision

Hoarseness

Snoring

$\square$ Inability to smell

Change in dental bite

Change in head size

Neck pain (front)

Swollen glands

Neck lump

Neck swelling

Difficulty breathing

Breast pain

Breast discharge

Breast Enlargement
Chest pain

Leg pain with exercise

$\square$ Palpitations

Abdominal pain

$\square$ Constipation

Diarrhea

Diarrhea with milk

Difficulty swallowing

Nausea

Vomiting

Pain with swallowing

Impotence

Abnormal periods

Pain with intercourse

Pain with urination

Kidney stones

Bone pain

Back pain

Joint pain

Muscle cramps

$\square$ Muscle weakness

Pain in hands

Pain in feets

Fractures

Muscle aches

Change in hand size

Change in foot size

Dizziness

Fainting

Weakness
Lightheadedness

Dizziness with standing

Change concentration

$\square$ Change in memor

$\square$ Frequent falls

$\square$ Emotional swings

$\square$ Numbness in hands/feet

$\square$ Burning in hands/feets

$\square$ Anxiety

Depression

Difficulty sleeping

Acne

Decrease in appetite

$\square$ Increase in appetite

$\square$ Felling full before eat

Cold intolerance

$\square$ Excessive thirst

$\square$ Excessve urination

Heat intolerance

Hot flashes

Flushing

Excess face/body hair

$\square$ Loss hair

Decrease in height

Decrease in sex drive

Other

799 E Hampden Ave, Suite 525, Englewood, CO 80113 www.denverendocenter.com 


\section{CUESTIONARIO PSSUQ}

Edad: 21 Sexo: M I F Licenciatura: Diseio de icformicein Manojo de llustrator: ISI I No

Este cuestionario es una oportunidad para registrar tus reacciones a la guia de usabilidad. Estas respuestas nos ayudaran a entender que aspectos hay que mejorar y cuales son con los que no estas satisfechos. Para tener un mejor resultado. piensa en la tarea que se te pidio que realizaras con base a lo que las guias decian mientras contestas estas preguntas

Instrucciones: Lea cada frase y señala qué tan de acuerdo o en desacuerdo estás y encierra en un circulo un número de la escala. Al terminar, revisaremos juntos con usted el cuestionario para asegurarnos de que entendamos bien la información presentada en este cuestionario.

¡Gracias!

a) La organización de la información proporcionada por las guias me fue clara.

Totaimente en desacuerdo
2
3
4
5

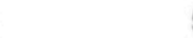
6
17

Totalmente de acuerdo

b) Fui capaz de completar la tarea que se me indicó rápidamente con la información proporcionada en las guias.

Totalmente en desacuerdo<smiles>[3H]</smiles>

2
3

c) La información proporcionada por las guias fue fácil de entender.

Totalmente de desacuerdo$$
2
$$

4

d) La apariencia de las guias es agradable.

Totalmente en desacuerdo

1

2
3
4
Totalmente de acuerdo

5

6

Totalmente de acuerdo

5

6

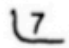

e) En general estoy satisfecho con el acomodo y presentación visual de la información. Totalmente en desacuerdo 


\section{LISTA DE CHEQUEO DEL ANÁLISIS DE TAREAS \\ Evaluador: Wanel Gareta Hewäder Fecha: 27.03.20 Equipo:}

\section{SECCIÓN DE LAS GUÍAS NOMOLAS}

USUARIO

El diseñador definió el nivel socioeconómico.

El diseñador definió el nivel académico.

El diseñador definió edad.

El diseñador definió sexo

El diseñador definió situación geográfica.

El diseñador definió situación de lectura.

El diseñador definió creencias sobre la información

El diseñador definió usos y costumbres presentadas alrededor de la información

\section{ESTRUCTURA DE LA INFORMACIÓN}

El diseñador utilizó una retícula para generar la composición de su gráfica.

La información presentada de manera visual tiene congruencia y presenta jerarquía en relación al contenido.

La navegación de lectura se hace de izquierda a derecha y en forma de zig-zag.

TIPOGRAFÍA

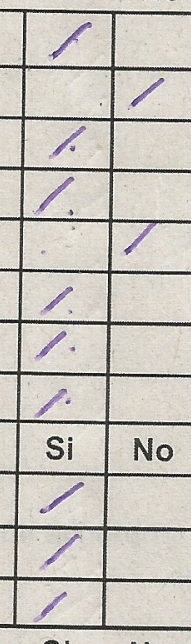

El diseñador utilizó alguna de las fuentes sugeridas en las guias.

El diseñador utilizó un espacio interlineal de 1.5

"El diseñador evitó la aparición de "viudas" en la composición.

El diseñador evitó la aparición de "ríos" en la composición.

El diseñador utilizó la variante negrita para hacer énfasis en palabras clave.

El diseñador utilizó la variante cursiva para hacer referencia a palabras en idioma extranjero.

El diseñador utilizó un puntaje de carácter para el cuerpo de texto de no menor a 8 puntos.

El diseñador utilizó para los títulos tipografias sans serif.

Los títulos están alienados a la izquierda o centrados.

Los títulos están en variante negrita y en un puntaje mayor al del cuerpo de texto.

El cuerpo de texto está alienado a la izquierda.

El texto y el fondo de la interfaz tienen un buen contraste.

El diseñador combinó tipografias serif y sans serif en la composición de la pieza de diseño

COLOR

El diseñador utilizó cuatro colores dentro de la composición.

El diseñador cuidó el buen contraste entre figura, fondo y texto en la pieza de diseño.

El diseñador tomó en consideración el uso de contraste de color entre fondo y texto.

El diseñador evitó el uso de degradados.

El diseñador utilizó el mismo color para representar un mismo tipo de dato.

El diseñador creo codificaciones de información a través del color.

\section{ELEMENTOS GRÁFICOS}

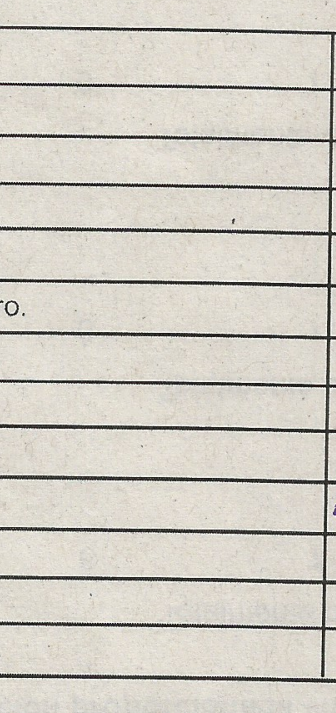

Todos los elementos conserven un mismo estilo gráfico.

El diseñador implementó imágenes que tienen la misma orientación

El diseñador evitó el uso de emojis.

El diseñador usó etiquetas o leyendas debajo de los elementos gráficos que necesitaban algún tipo de aclaración.

El diseñador usó bullets point, listas numéricas y flechas para enfatizar información que pertenecia a una misma categoría.

El diseñador evitó el uso de elementos o información innecesarios, extraños, decorativos o irrelevantes.

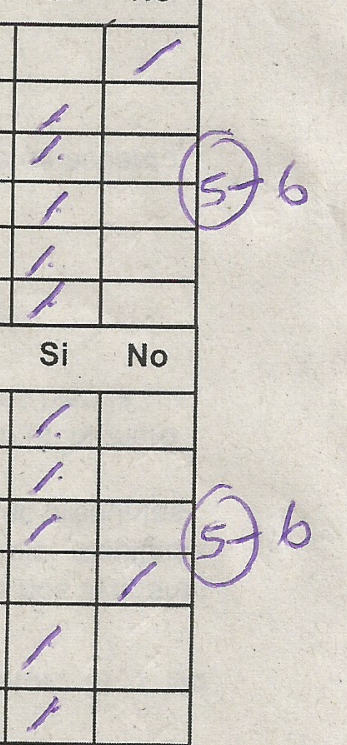


Anexo 11.11.5. USUARIO 5. Material de resultados para la evaluación de la FASE 2. Lean Canvas de Decisiones de Diseño. Bocetaje. Propuesta de interfaz gráfica. Cuestionario PSSUQ contestado. Lista de chequeo de Análisis de Tareas contestada. 


\section{LEAN CANVAS DE DECISIONES DE DISEÑO}

INTEGRANTES DEL EQUIPO:

Irán Carolina Leal

Fecha:

Equipo \#:

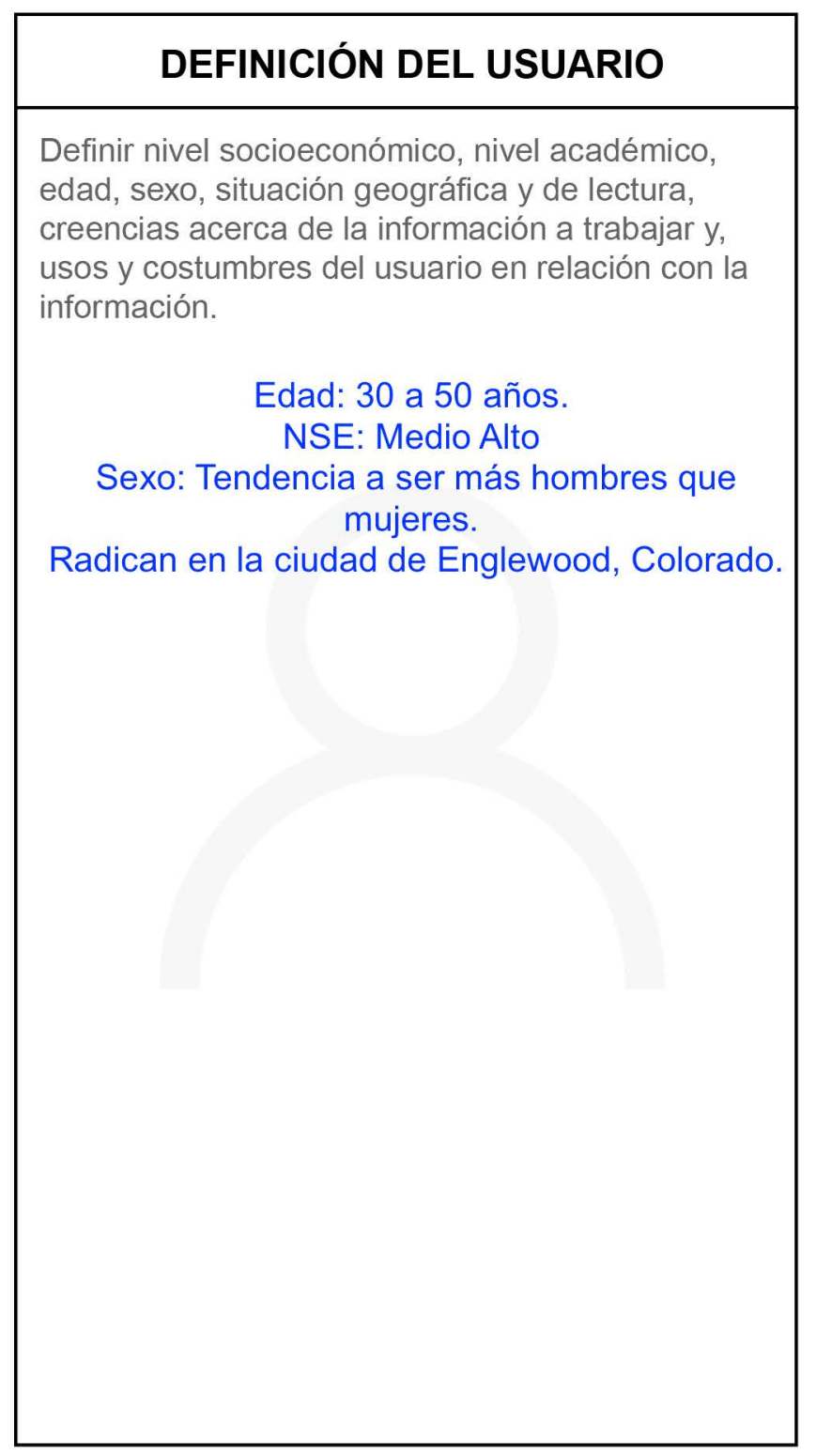

\begin{tabular}{|c|}
\hline TIPOGRAFÍA \\
\hline $\begin{array}{c}\text { Señalar tipografía usada para el cuerpo del texto, } \\
\text { títulos, subtítulos, leyendas y etiquetas. } \\
\text { Fira Sans-bold } \\
\text { para título y subtítulo }\end{array}$ \\
Verdana- Regular \\
para cuerpo de texto \\
Fira Sans book \\
para etiquetas \\
\\
\end{tabular}

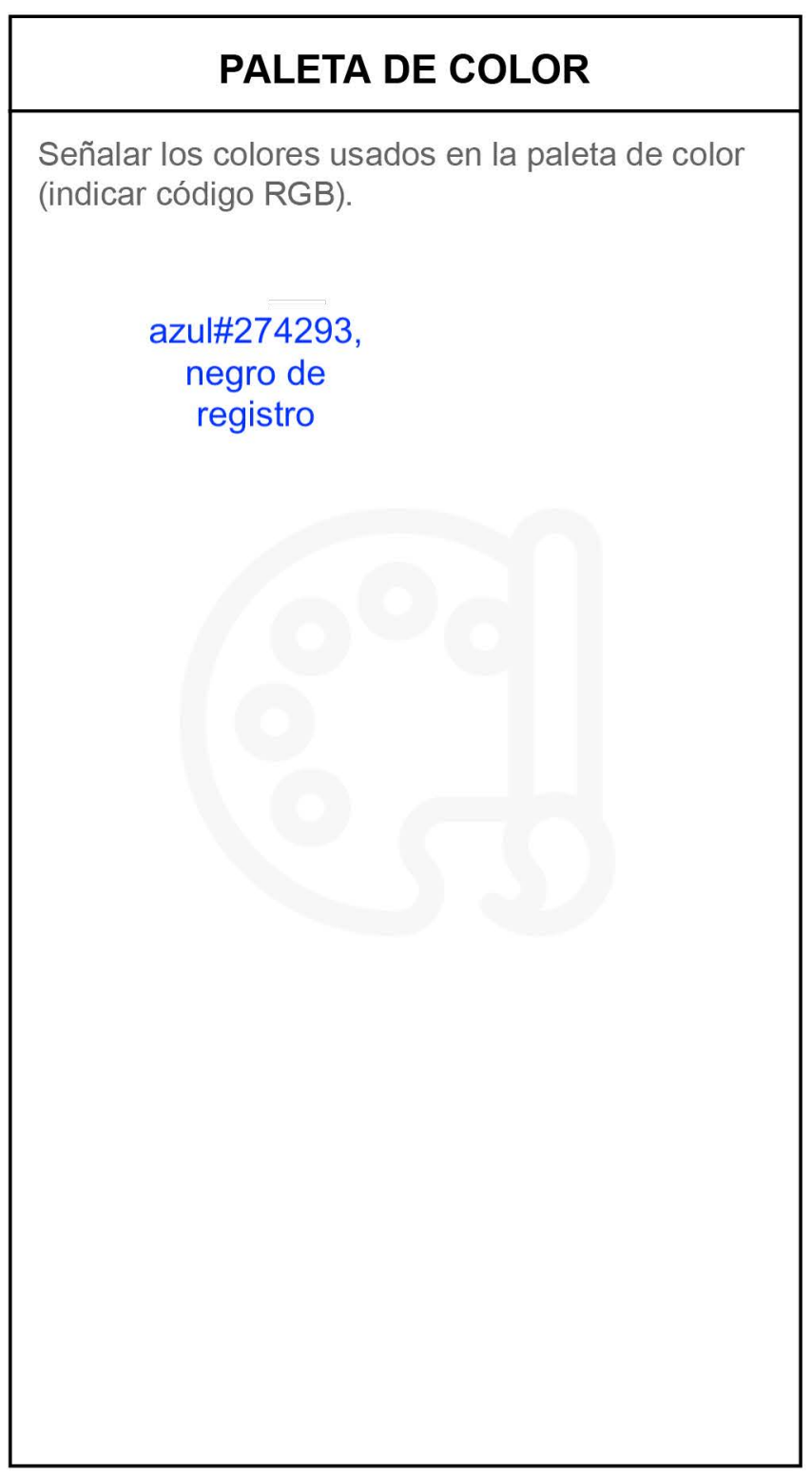




\section{INSTITUTION TITLE}

(1) subtitle

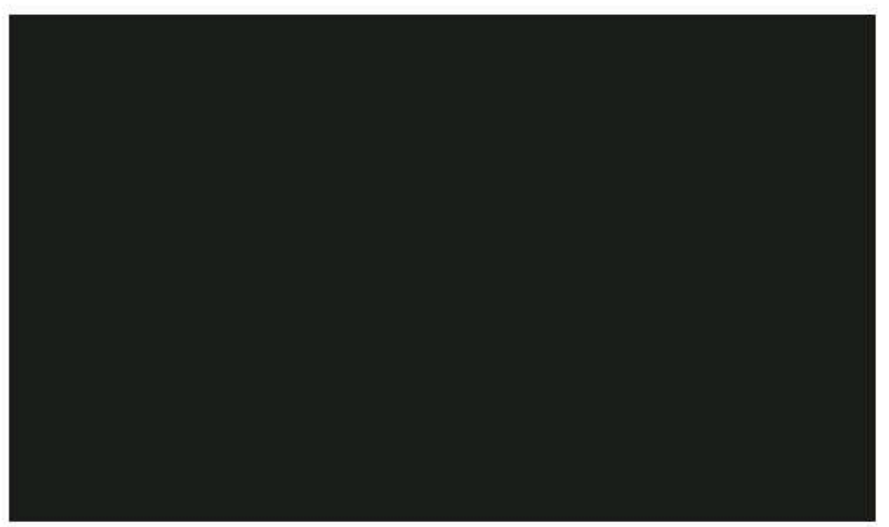

(2) SubtitLe

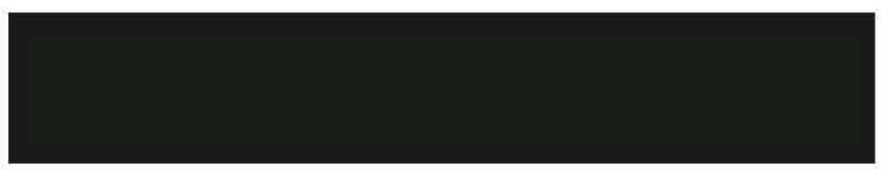

(3) REVIEW OF SYSTEM

\section{(4) SUBtitle}

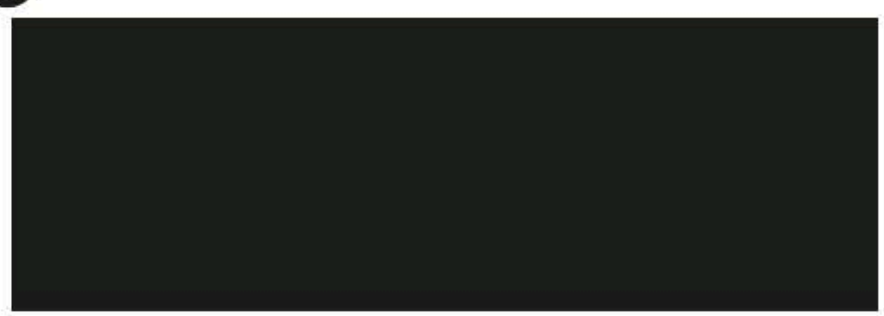

(5) SUbtitLe

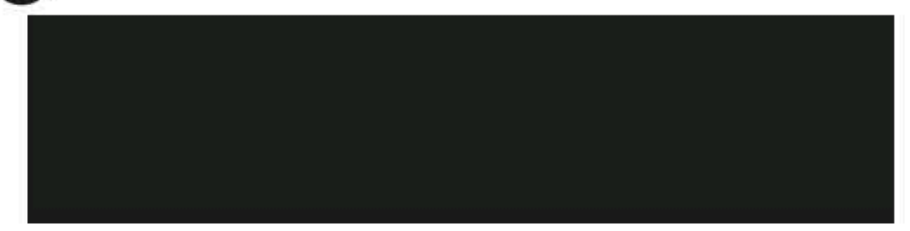

(6) SUBtitLe

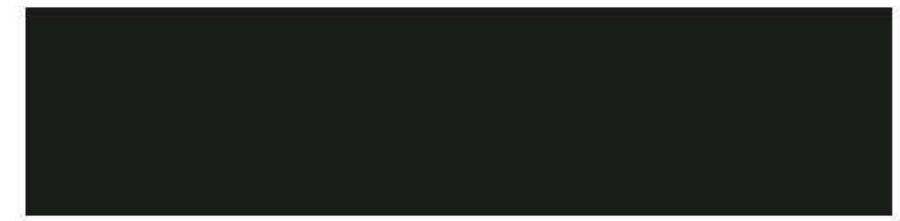

(7) Subtitle

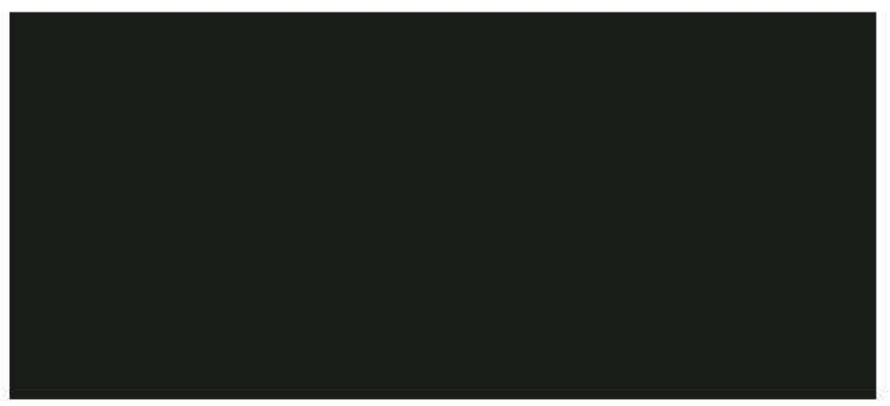

(8) SubTitLe

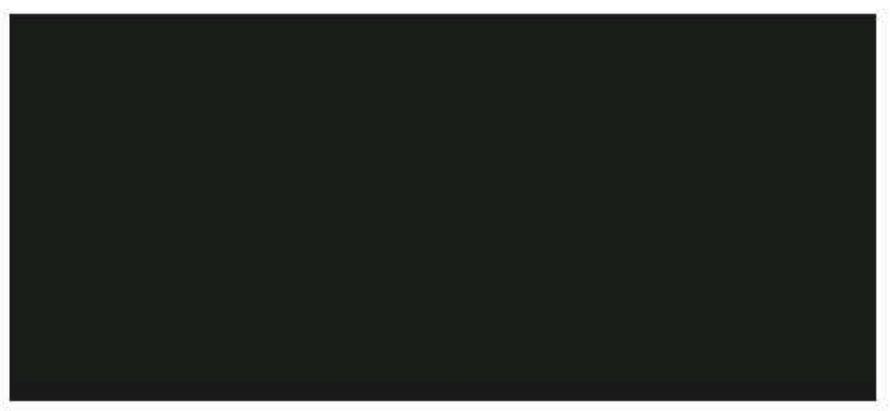




\section{TITLE INSTITUTION}

INFORMATION'S INSTITUTION

\section{SUBTITLE}

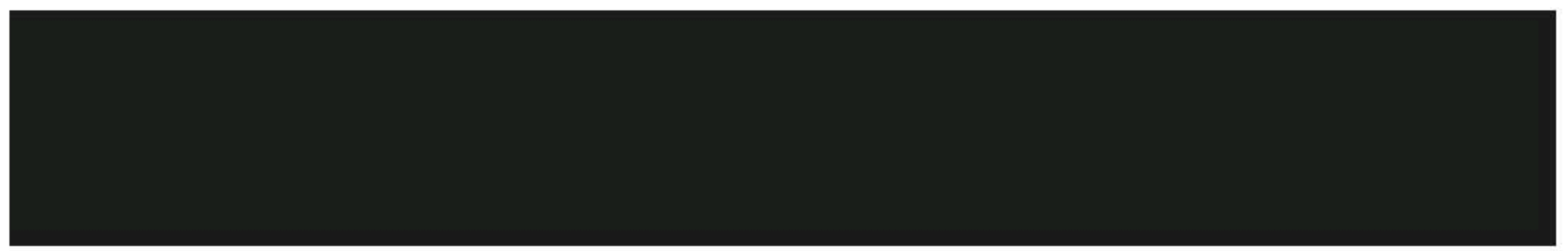

\section{SUBTITLE}

\section{SUBTITLE}

\section{SUBTITLE}

\section{SUBTITLE}

\section{SUBTITLE}

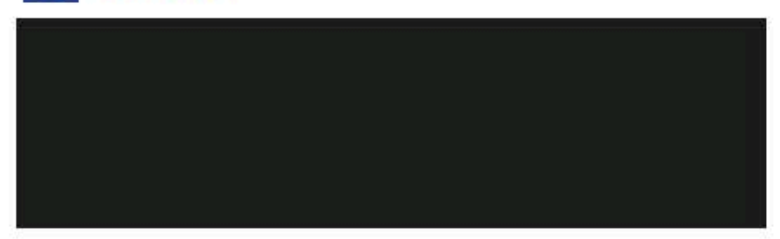

7 SUBTITLE

\section{SUBTITLE}

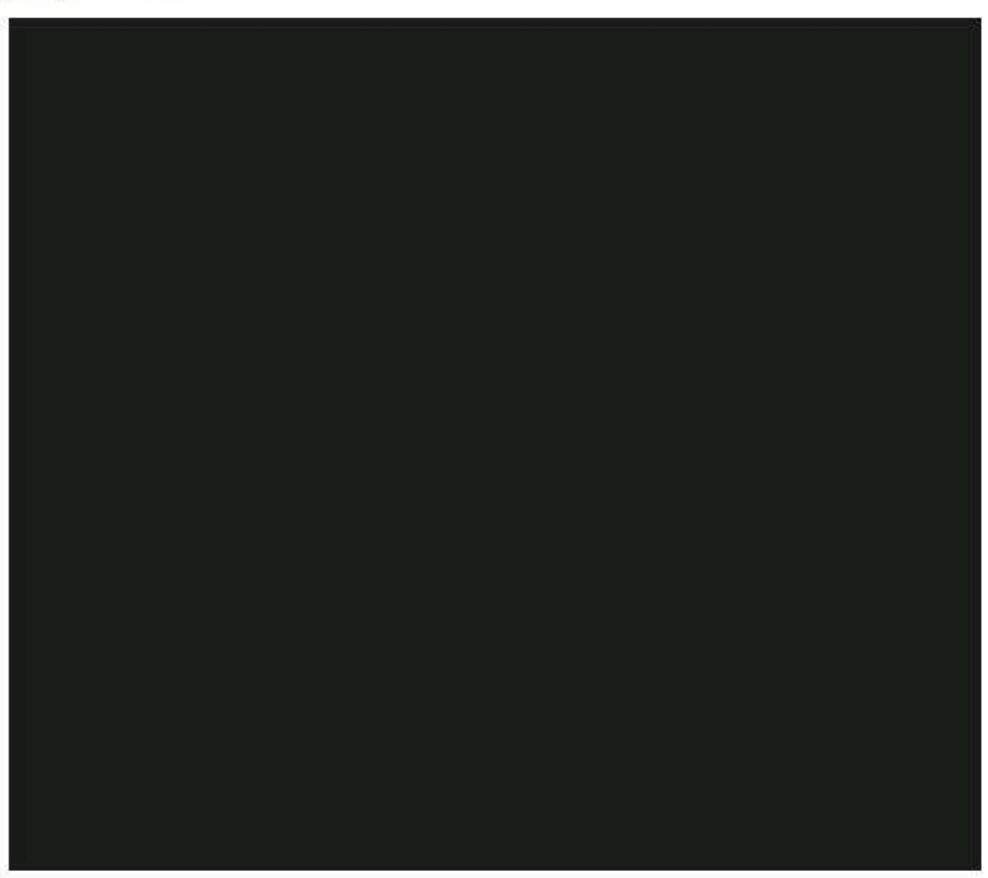




\section{INSTITUTION TITLE}

INFORMATION'S INSTITUTION

\section{SUBTITLE}

\section{SUBTITLE}

\section{SUBTITLE}

\section{SUBTITLE}

\section{SUBTITLE}

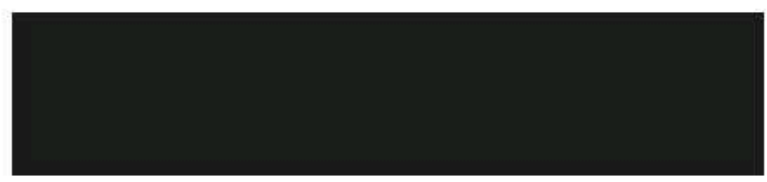

SUBTITLE
SUBTITLE

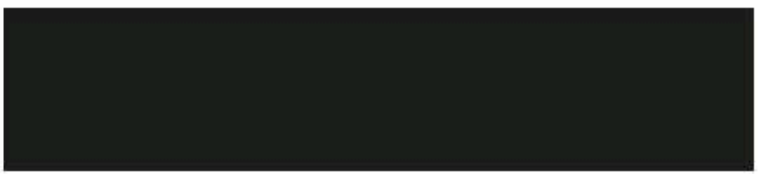

SUBTITLE
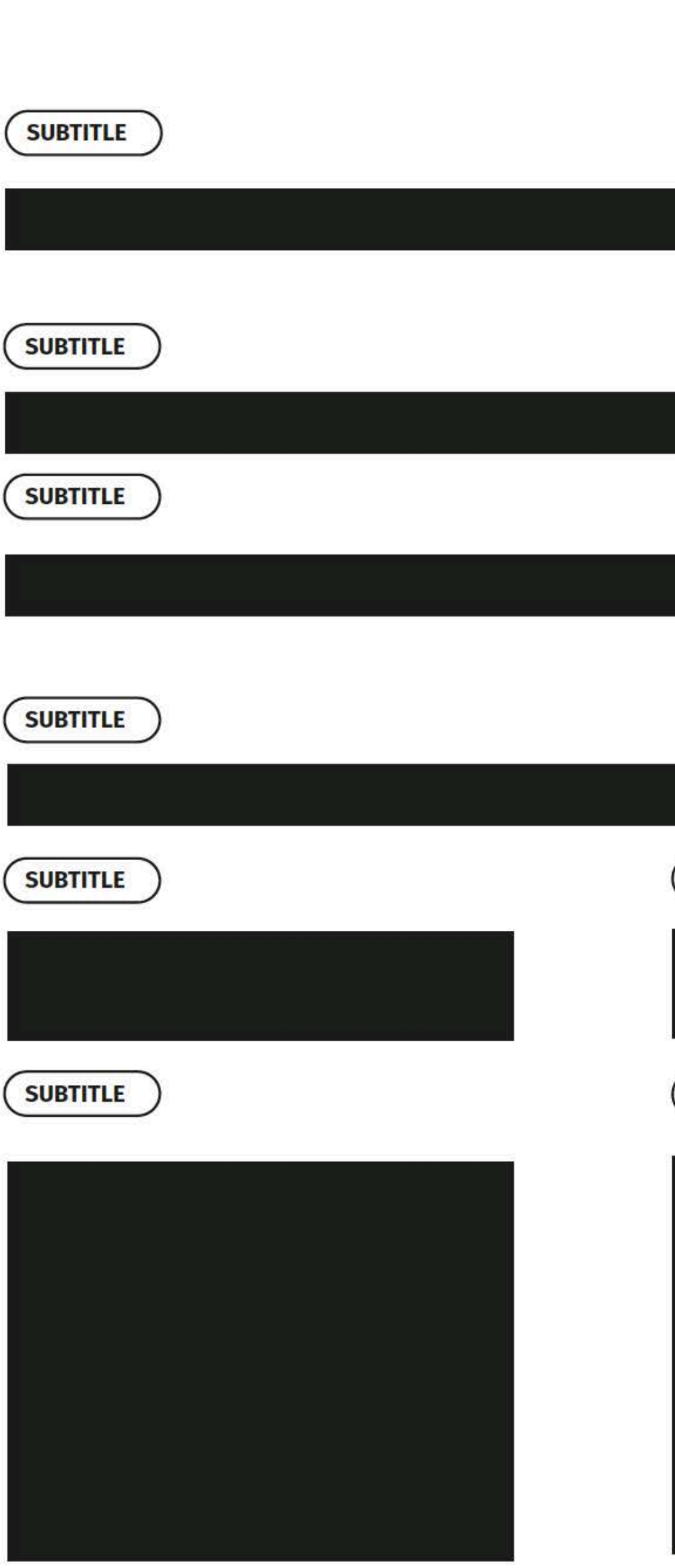


Today's Date: $\quad / l^{\text {month }}$ year

\section{PERSONAL INFORMATION}

Patient Name:

Date of Birth:

Occupation:

Primary Care Providente:

- - - - - - - - - - - - - - - - - - C-- - - - - - -

Referring Physician(if not PCP):

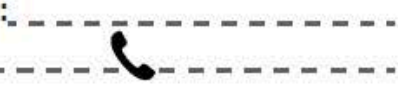

Other Care Providers:

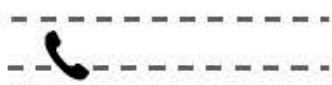

Main Concern(s)/Reason for visit today:

\section{ALLERGIES}

(Please include type of reaction to each allergy listed).

\section{REVIEW OF SYSTEM}

(Circle $\bigcirc$ current problems/symptoms you are experiencing now in past 1 month).

Weight gain

Weight loss

Fatigue

Easy bruising

Difficulty breathing

Breast Pain

Breast Discharge

Breast Enlargement

Pain in feet

Fractures

Muscle aches

Change in hand size

Excessive urination

Heat intolerance

Hot flashes

Flushing

Excessive sweating Brittle nails Rash

Change in skin color Dry skin

Stretch marks

Darkening of skin

Peripheral vision loss

Worsening vision

Blurred vision

Bulging eyes

Headache

Double vision
Hoarseness Snoring

Inability to smell

Change in dental bite

Change in head size

Neck pain (front)

Swollen glands

Neck lump

Neck swelling

Chest pain/discomfort

Leg pain with exercise

Palpitations

Abdominal pain

Constipation

Diarrhea

Diarrhea with milk

Difficulty swallowing Nausea Vomiting

Pain with swallowing Impotence

Abnormal periods

Pain with intercourse

Pain with urination

Kidney stones

Bone pain

Back pain

Joint pain

Muscle cramps
Muscle weakness Pain in hands

Change in foot size

Dizziness

Fainting

Weakness

Lightheadedness

Dizziness with standing

Change in concentration

Change in memor

Frequent falls

Emotional swings

Numbness in hands/feet

Burning in hands/feet Anxiety

Depression

Difficulty sleeping Acne

Decrease in appetite

Increase in appetite

Feeling full before done eating

Cold intolerance

Excessive thirst

Excess face/body hair Loss of hair

Decrease in height

Decrease in sex drive

Other:
$(4)$

MEDICATIONS

(Both prescription and over-the-counter including herbal,vitamins,etc)

-Please include another page if needed.

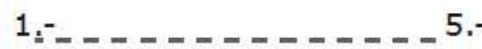

2:-

6.-

3.-

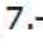

4:-

8.

5

HOSPITALIZATIONS/SURGERIES/PROCEDURES

(Please include exact date or at least year).
6

FAMILY HISTORY

(List any health problems of your mother, father, siblings, children or grandparents only). 


\section{CUESTIONARIO PSSUQ}

Edad: 20 Sexo: M /F Licenciatura: Diseño de la Información visual Manejo de llustrator:Si $/$ No

Este cuestionario es una oportunidad para registrar tus reacciones a la guía de usabilidad. Estas respuestas nos ayudarán a entender que aspectos hay que mejorar y cuales son con los que no estás satisfechos. Para tener un mejor resultado, piensa en la tarea que se te pidió que realizaras con base a lo que las guías decían mientras contestas estas preguntas.

Instrucciones: Lea cada frase y señala qué tan de acuerdo o en desacuerdo estás y encierra en un circulo un número de la escala. Al terminar, revisaremos juntos con usted el cuestionario para asegurarnos de que entendamos bien la información presentada en este cuestionario.

\section{¡Gracias!}

a) La organización de la información proporcionada por las guías me fue clara.

Totalmente en desacuerdo

Totalmente de acuerdo$$
1
$$

2

3

4

5

6

7

b) Fui capaz de completar la tarea que se me indicó rápidamente con la información proporcionada en las guías.

Totalmente en desacuerdo

Totalmente de acuerdo

12

3

4

5

6

7

c) La información proporcionada por las guías fue fácil de entender.

Totalmente de desacuerdo

1

2

3

4

5

Totalmente de acuerdo

d) La apariencia de las guías es agradable.

Totalmente en desacuerdo

Totalmente de acuerdo

$$
1
$$

2

3

4

5

6

7

e) En general estoy satisfecho con el acomodo y presentación visual de la información.

Totalmente en desacuerdo

Totalmente de acuerdo

1

2
3
4

5
6 


\begin{tabular}{|c|c|c|}
\hline 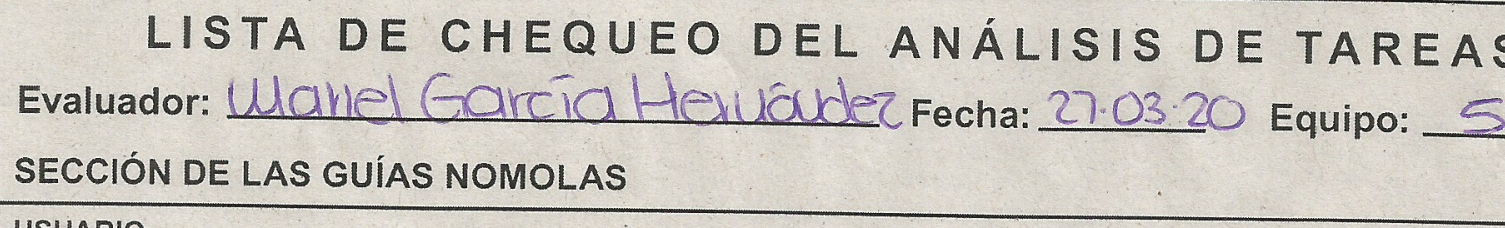 & & - \\
\hline USUARIO & $\mathrm{Si}$ & No \\
\hline El diseñador definió el nivel socioeconómico. & 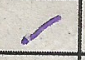 & \\
\hline El diseñador definió el nivel académico. & & $\angle$ \\
\hline El diseñador definió edad. & 8 & \\
\hline El diseñador definió sexo. & 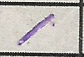 & \\
\hline El diseñador definió situación geográfica. & 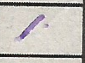 & \\
\hline El diseñador definió situación de lectura. & & 8 \\
\hline El diseñador definió creencias sobre la información. & & 8 \\
\hline El diseñador definió usos y costumbres presentadas alrededor de la información. & & 1 \\
\hline ESTRUCTURA DE LA INFORMACIÓN & $\mathrm{Si}$ & No \\
\hline El diseñador utilizó una reticula para generar la composición de su gráfica. & 1 & \\
\hline La información presentada de manera visual tiene congruencia y presenta jerarquia en relación al contenido. & 1 & \\
\hline La navegación de lectura se hace de izquierda a derecha y en forma de zig-zag. & 1 & \\
\hline TIPOGRAFÍA & $\mathrm{Si}$ & No \\
\hline El diseñador utilizó alguna de las fuentes sugeridas en las guias. & & $\gamma$ \\
\hline El diseñador utilizó un espacio interlineal de 1.5 & 1 & \\
\hline El diseñador evitó la aparición de "viudas". en la composición. & 1 & \\
\hline El diseñador evitó la aparición de "rios" en la composición. & 7 & \\
\hline El diseñador utilizó la variante negrita para hacer énfasis en palabras clave. & 1 & \\
\hline El diseñador utilizó la variante cursiva para hacer referencia a palabras en idioma extranjero. & 1 & \\
\hline El diseñador utilizó un puntaje de carácter para el cuerpo de texto de no menor a 8 puntos. & 8 & \\
\hline El diseñador utilizó para los titulos tipografias sans serif. & 1 & \\
\hline Los títulos están alienados a la izquierda o centrados: & 7 & \\
\hline Los titulos están en variante negrita y en un puntaje mayor al del cuerpo de texto. & 1 & \\
\hline $\begin{array}{l}\text { El cuerpo de texto está alienado a la izquierda. } \\
\text { El texto y el fondo de la interfaz tienen un buen contraste. }\end{array}$ & $\frac{1}{1}$ & \\
\hline $\begin{array}{l}\text { El texto y el fondo de la interfaz tienen un buen contraste. } \\
\text { El diseñador combinó tipografias serif y sans serif en la composición de la pieza de diseño. }\end{array}$ & $M$ & 7 \\
\hline El diseñador combinó tipografias serif y sans serif en la composición de la pieza de diseño. & Si & No \\
\hline El diseñador utilizó cuatro colores dentro de la composición. & 1 & \\
\hline $\begin{array}{l}\text { El diseñador utilizó cuatro colores dentro de la composición. } \\
\text { El diseñador cuidó el buen contraste entre figura, fondo y texto en la pieza de diseño. }\end{array}$ & 1 & \\
\hline El diseñador tomó en consideración el uso de contraste de color entre fondo y texto. & 1 & \\
\hline El diseñador evitó el uso de degradados. & 1 & \\
\hline El diseñador utilizó el mismo color para representar un mismo tipo de dato. & 7 & \\
\hline El diseñador creo codificaciones de información a través del color. & 7 & \\
\hline $\begin{array}{l}\text { Todos los elementos conserven un mismo estilo gráfico. } \\
\text { El diseñador implementó imágenes que tienen la misma orientación }\end{array}$ & $\frac{1}{t}$ & \\
\hline $\begin{array}{l}\text { El diseñador implementó imágenes que tienen la misma orientación } \\
\text { El diseñador evitó el uso de emojis. }\end{array}$ & 1 & \\
\hline $\begin{array}{l}\text { El diseñador evitó el uso de emojis. } \\
\text { El diseñador usó etiquetas o leyendas debajo de los elementos gráficos que necesitaban algún tipo de aclaración. }\end{array}$ & 1 & \\
\hline $\begin{array}{l}\text { El diseñador usó etiquetas o leyendas debajo de los elementos gráficos que necesitaban algún tipo de aclaración. } \\
\text { El diseñador usó bullets point, listas numéricas y flechas para enfatizar información que pertenecia a una misma } \\
\text { categoria. }\end{array}$ & I & \\
\hline El diseñador evitó el uso de elementos o información innecesarios, extraños, decorativos o irrelevantes. & 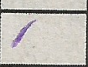 & \\
\hline
\end{tabular}





\section{Nuevas formas gráficas}

$(1765-1889)$

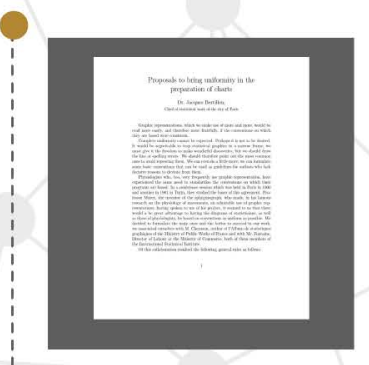

Primera línea del tiempo.

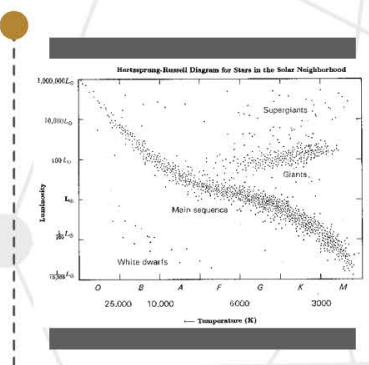

Primer mapa de tiempo (meteorológico).

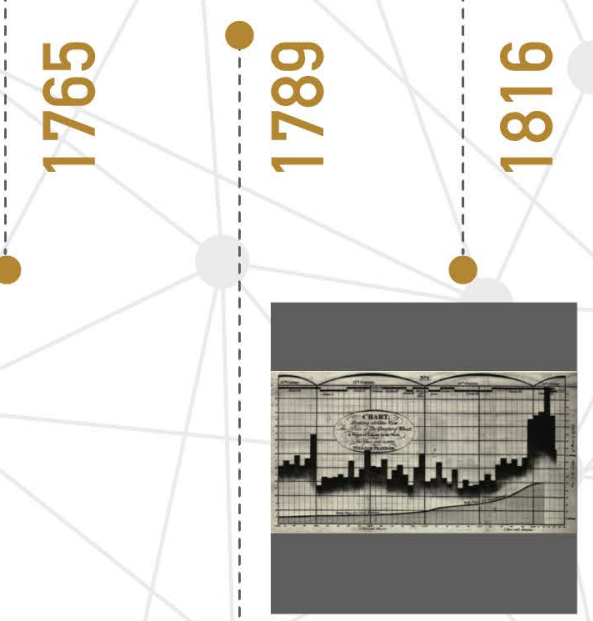

Primer registro histórico de gráfico circulares, barras

y series temporales

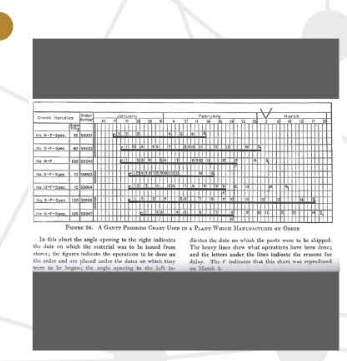

Creación del diagrama del círculo polar o diagrama de la rosa.

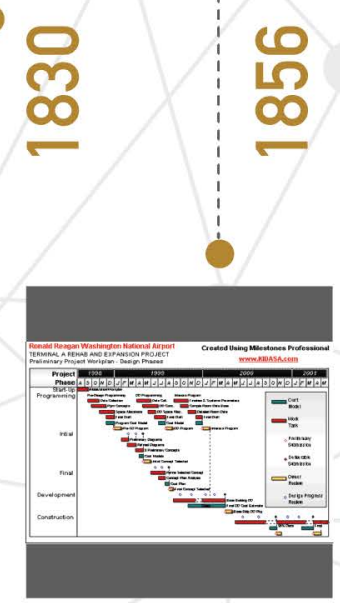

Primer mapa de puntos.

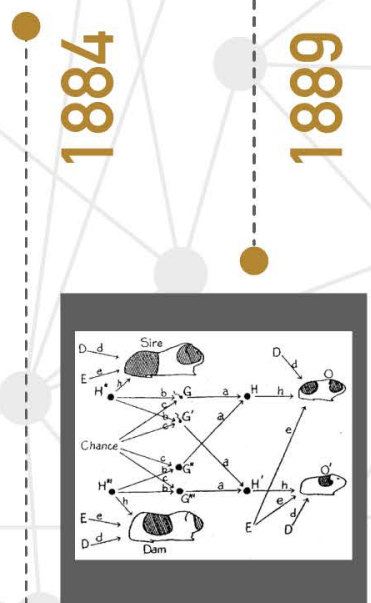

Pictogramas de Mullhal.

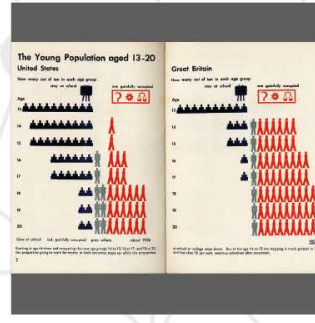

Códigos de color y mapeos.

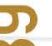

-

Figura 3. Historia de la visualización de información. Nuevas formas gráficas (1765 - 1889).

Fuente: Friendly, Michael. Denis, Daniel J. Milestones en The History of Thematic Cartography.

Statistical Graphics, and Data Visualization. York University. Canadá. 


\section{ANEXO 1. Línea del tiempo de la historia de la evolución de INFOVIS}

\section{Los primeros mapas y diagramas}

\section{(13,660 A.C. - 1375 D.C.)}

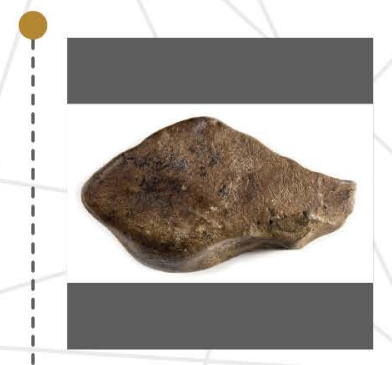

Bloque de piedra en Abauntz.

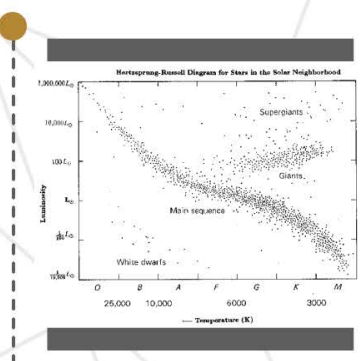

El primer mapa mundial.

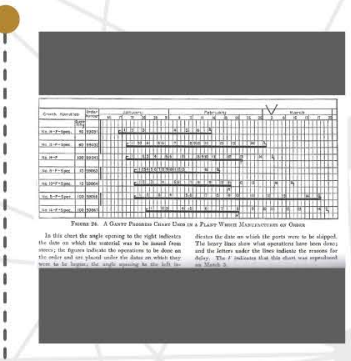

Mecanismo de Anticitera.

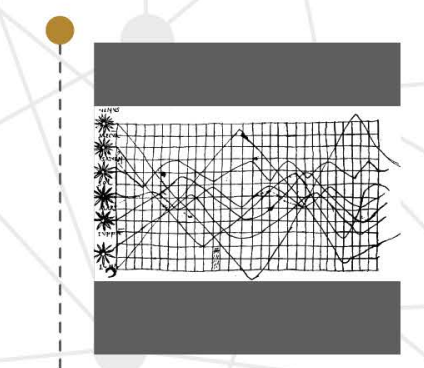

Primera construcción gráfica.

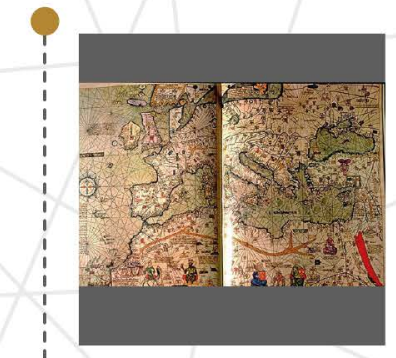

Atlas mundial de Abraham Cresques o Atlas Catalá.

0
6
6
$m$
$m$

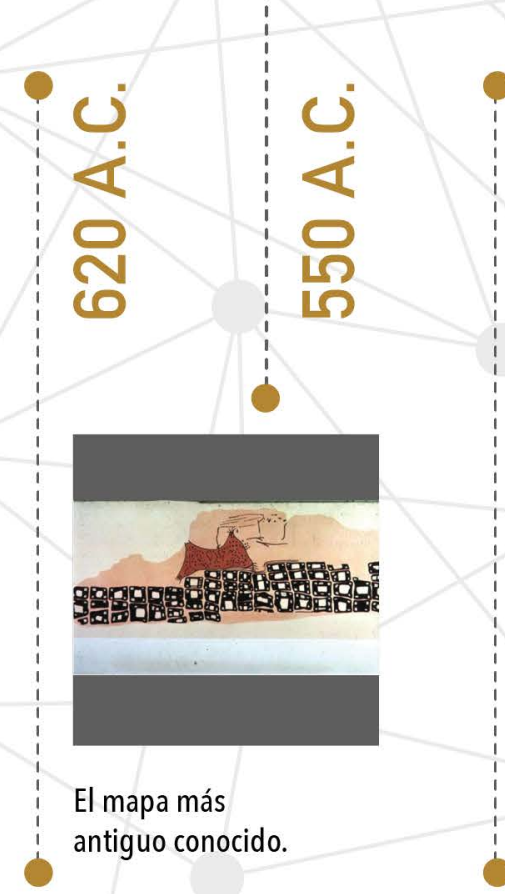

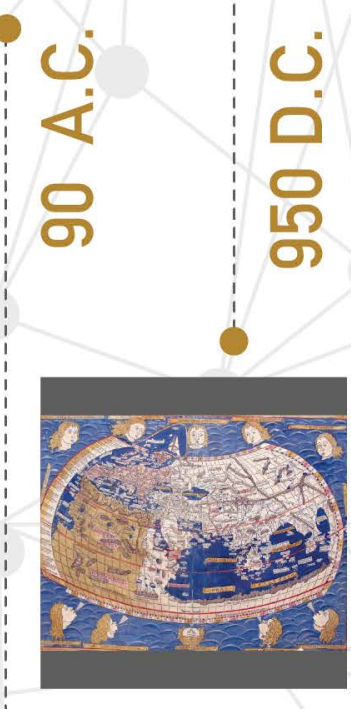

Mapa de Ptolomeo.

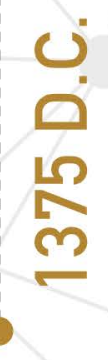

0

I

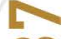

m $<$

10 m

م

m

0

西

م

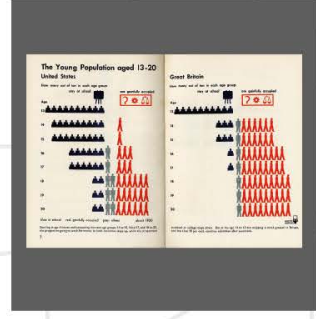

Construcción gráfica de Oresme.

Figura 1. Historia de la visualización de información.

Los primeros mapas y diagramas (13,660 A.C. - 1375 D.C).

Fuente: Friendly, Michael. Denis, Daniel J. Milestones en The History of Thematic Cartography,

Statistical Graphics, and Data Visualization. York University. Canadá. 


\section{Teoría y la medida de la realidad $(1626-1696)$}

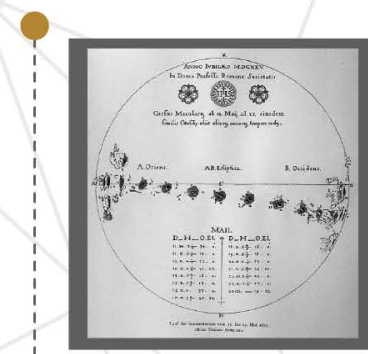

Secuencia visual de las manchas solares de Sheiner.

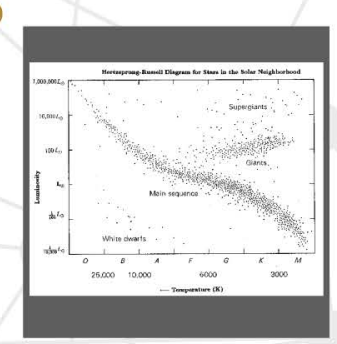

\section{"Le Geometrie"} de René Descartes.

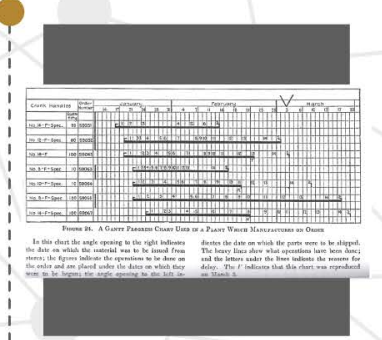

Primer mapa de datos meteorológicos.
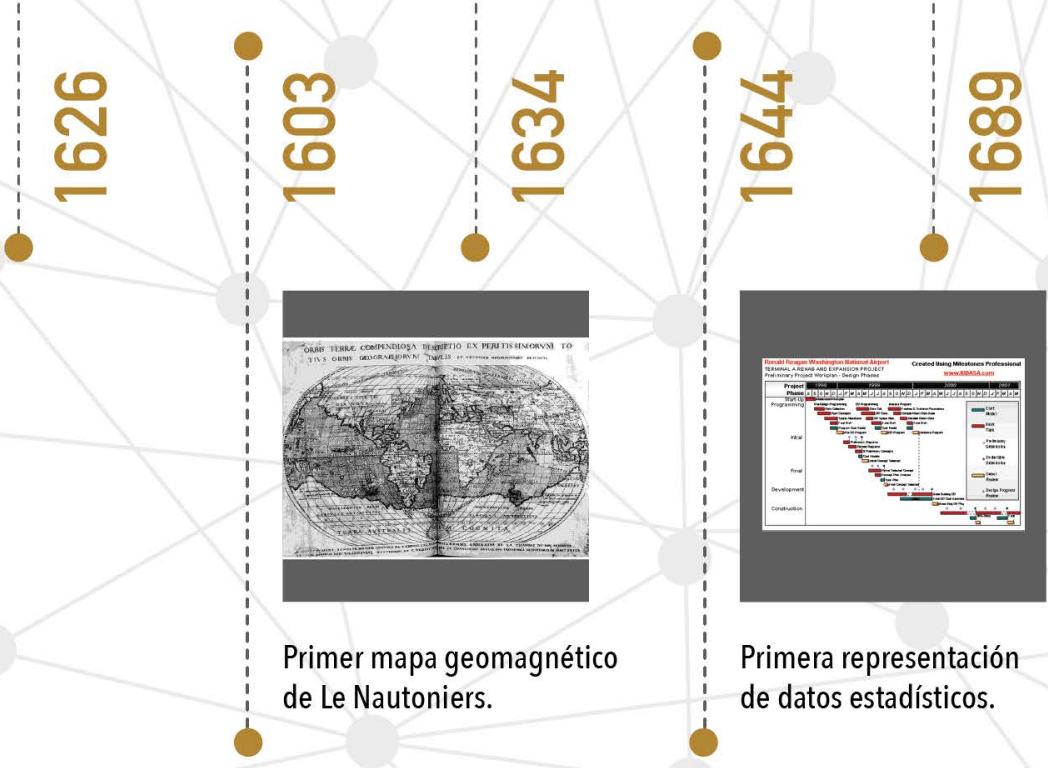

Primera representación de datos estadísticos.

Figura 2. Historia de la visualización de información.

Teoría y la medida de la realidad (1626. - 1696).

Fuente: Friendly, Michael. Denis, Daniel J. Milestones en The History of Thematic Cartography, Statistical Graphics, and Data Visualization. York University, Canadá. 


\section{Nuevas formas gráficas}

(1765 - 1889)

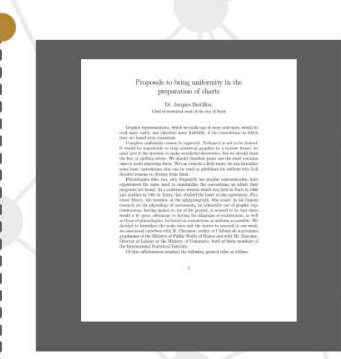

Primera línea del tiempo.

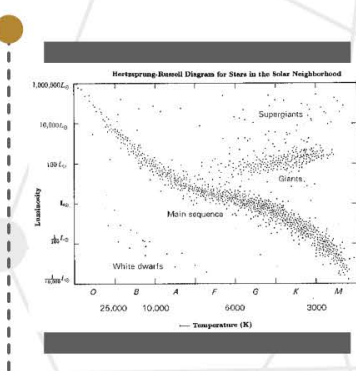

Primer mapa de tiempo (meteorológico).

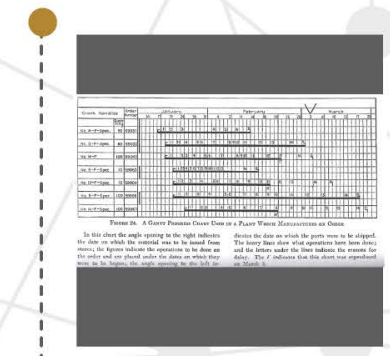

Creación del diagrama del círculo polar o diagrama de la rosa.

o

$\infty$

18

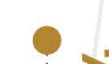

$+$

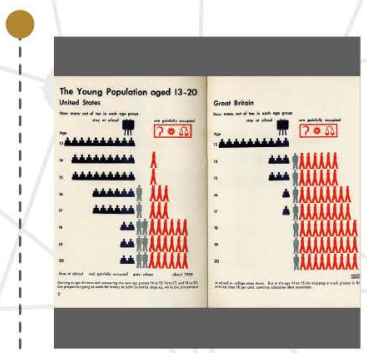

Códigos de color y mapeos.

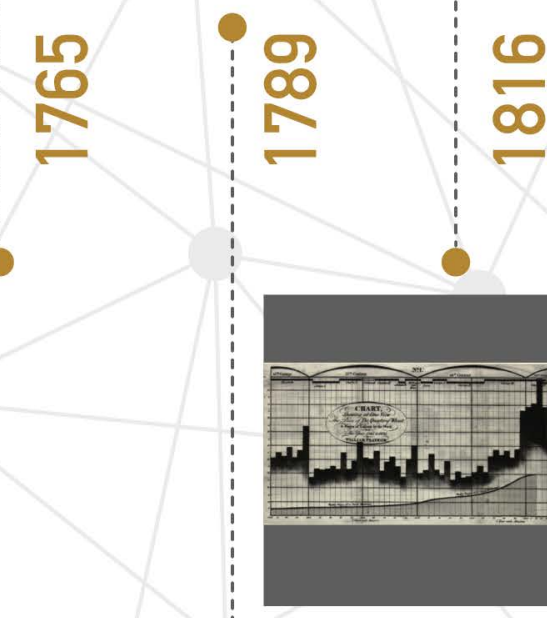

Primer registro histórico de gráfico circulares, barras

y series temporales

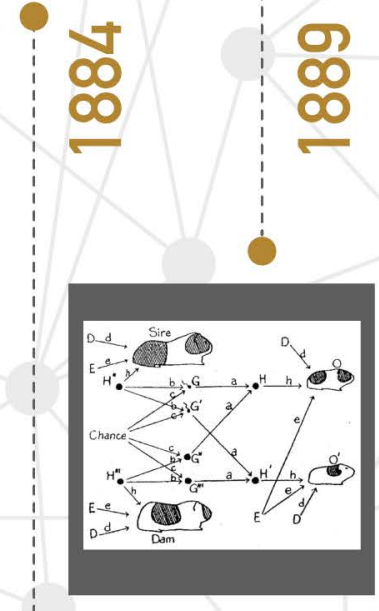

Pictogramas de Mullhal.

Primer mapa de puntos.

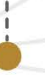

Figura 3. Historia de la visualización de información. Nuevas formas gráficas (1765 - 1889). Fuente: Friendly, Michael. Denis, Daniel J. Milestones en The History of Thematic Cartography. Statistical Graphics, and Data Visualization. York University, Canadá. 

ANEXO 2. Categorías de las figuras de visualización de información.

\section{FIGURAS DEL MÉTODO DE VISUALIZACIÓN DE CONCEPTOS}

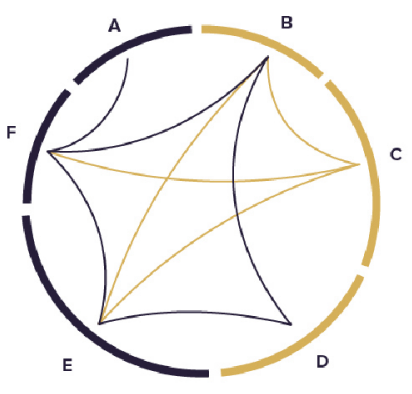

Diagrama de acorde sin cinta

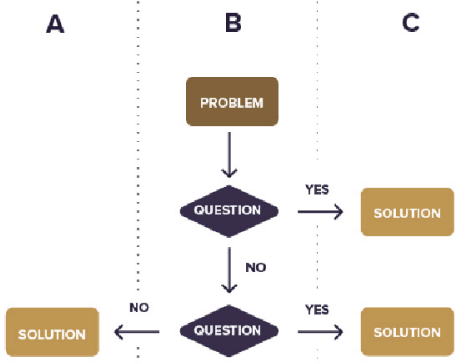

Diagrama de funciones cruzadas

\begin{tabular}{|l|l|l|l|}
\cline { 2 - 4 } \multicolumn{1}{c|}{} & $\mathbf{1}$ & $\mathbf{2}$ & $\mathbf{3}$ \\
\hline A & & & \\
\hline B & & $\bigcirc$ & \\
\hline C & 0 & & \\
\hline
\end{tabular}

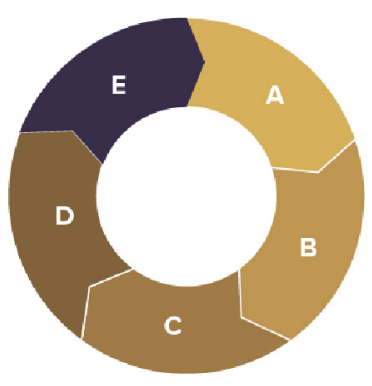

Diagrama de ciclo

A

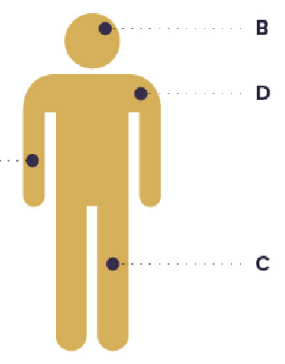

Diagrama de ilustración

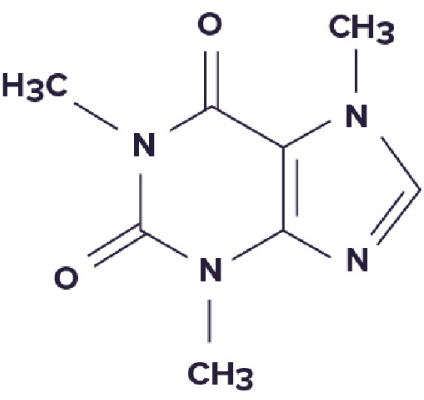

Diagrama de molécula

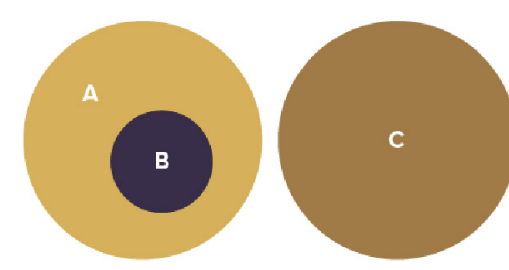

Diagrama de Euler

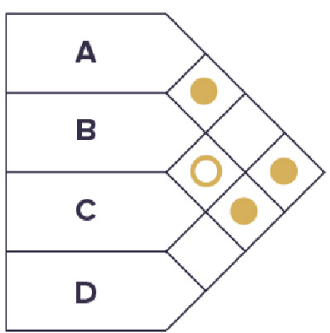

Diagrama de matriz (en forma de techo)

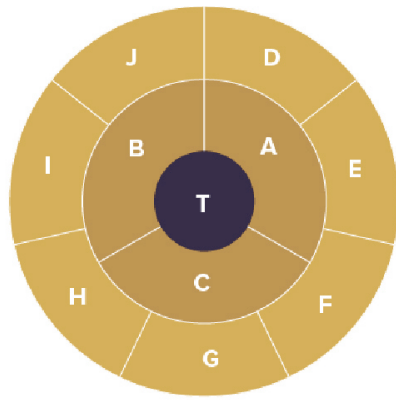

Diagrama de objetivos
A

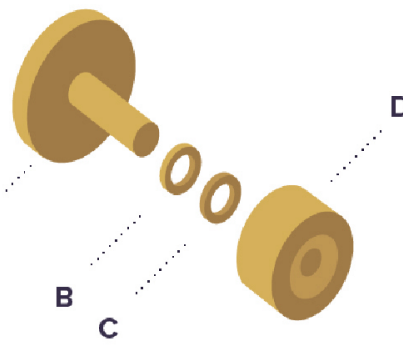

Diagrama de explicación

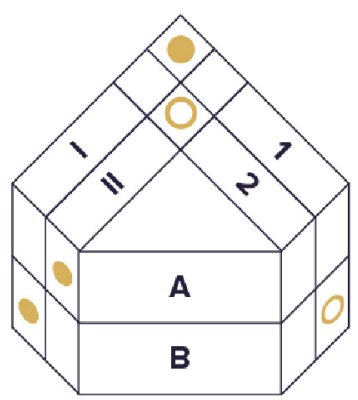

Diagrama de Matriz (En Y)

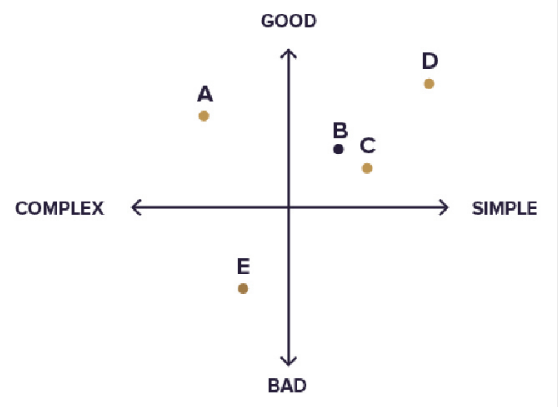

Diagrama opuesto 


\section{FIGURAS DEL MÉTODO DE VISUALIZACIÓN DE CONCEPTOS}

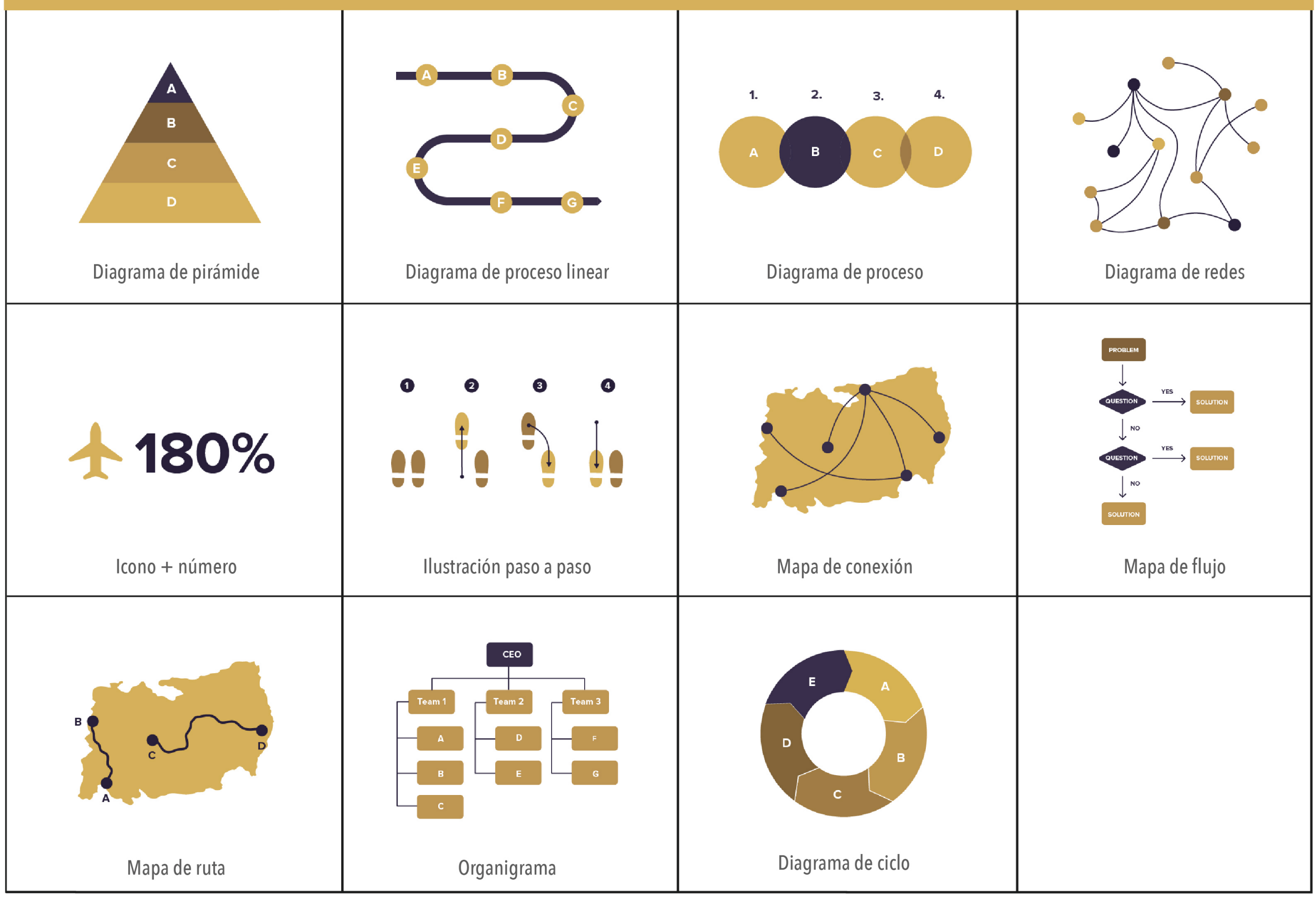




\section{FIGURAS DEL MÉTODO DE CORRELACIÓN}

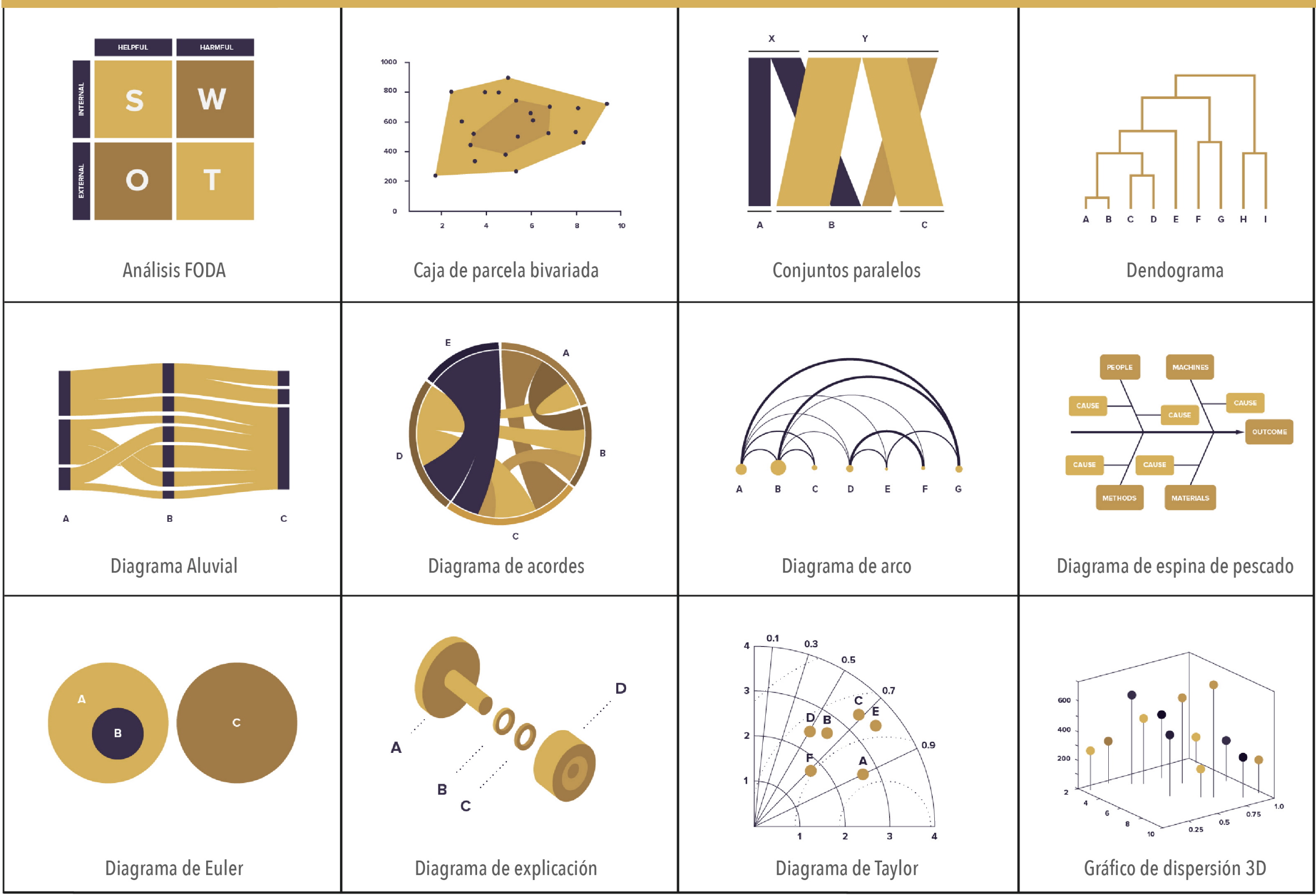




\section{FIGURAS DEL MÉTODO DE CORRELACIÓN}

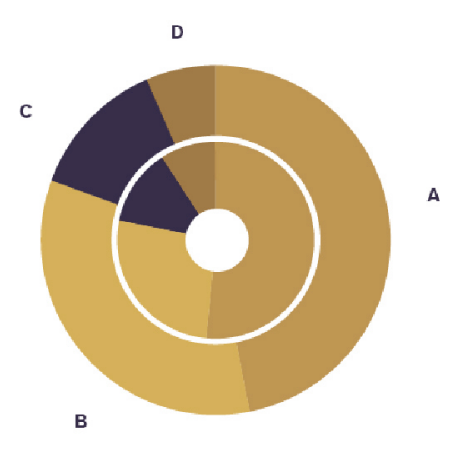

Gráfico de dona o de anillos multinivel

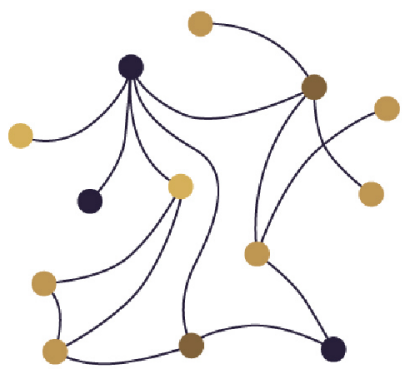

Gráfico de red

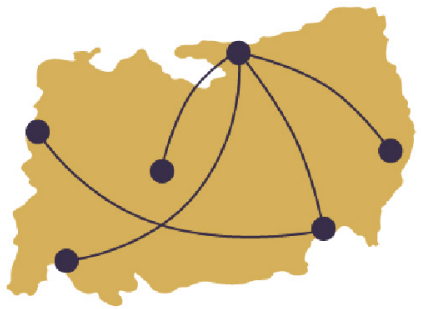

Mapa de conexión

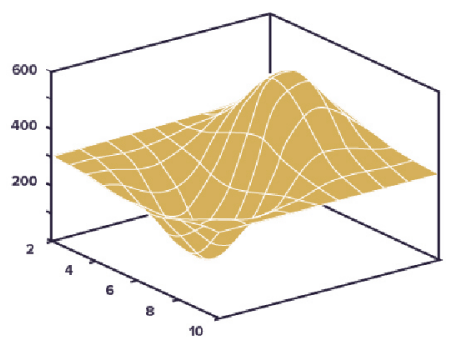

Gráfico de flujo tridimensional
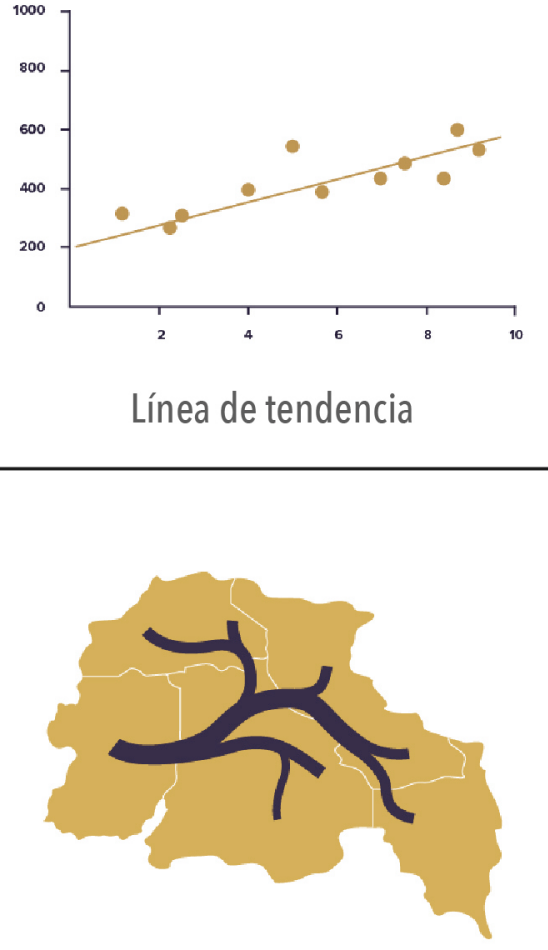

Mapa de flujo

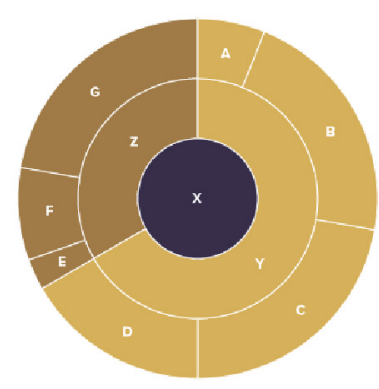

Gráfico de pastel multinivel

A B C D

Gráfico de puntos conectados

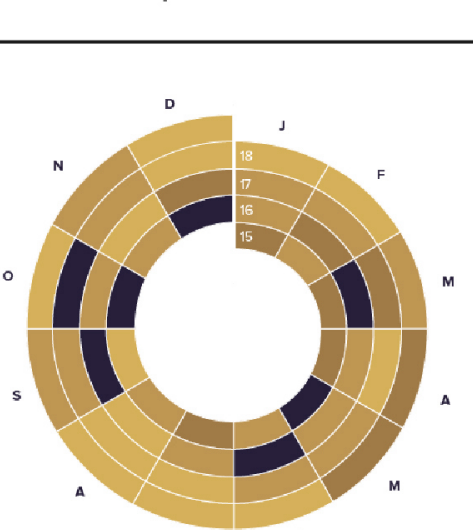

Mapa de calor en espiral

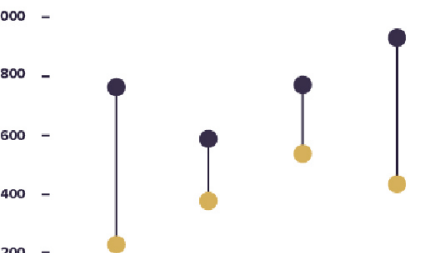

$200-$
Mapa de calor circular

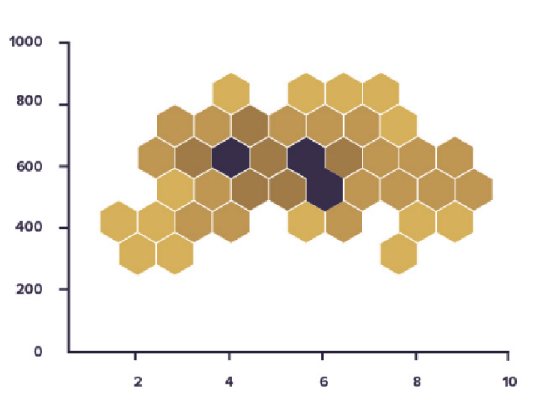

Parcela de cubo hexagonal

Red Radial 


\section{FIGURAS DEL MÉTODO DE CORRELACIÓN}

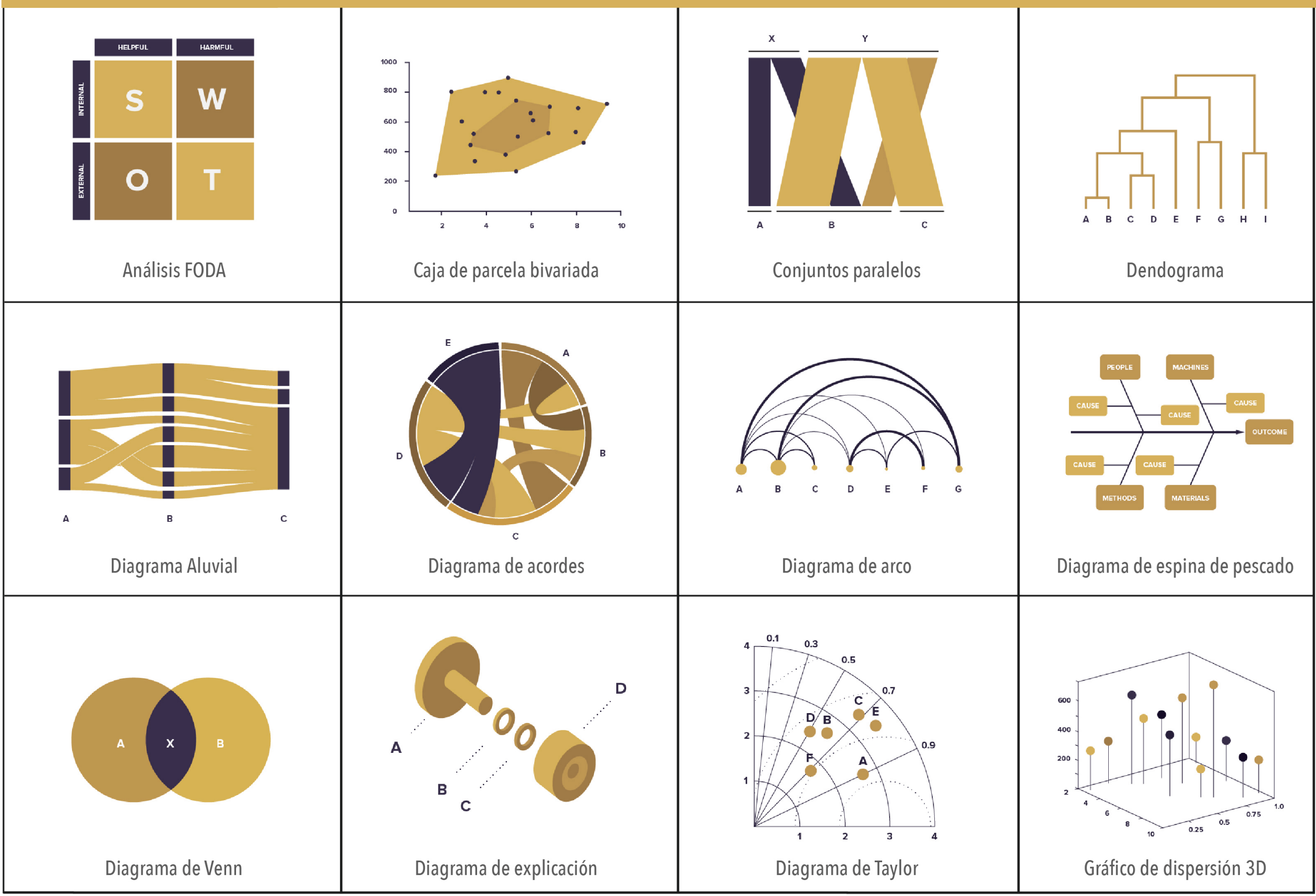




\section{FIGURAS DEL MÉTODO DE CORRELACIÓN}

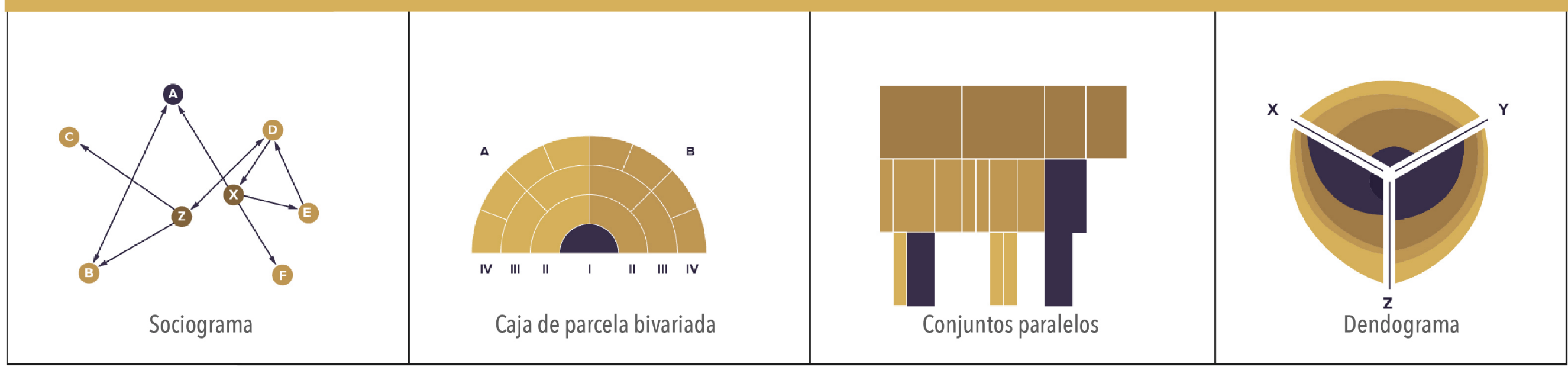




\section{FIGURAS DEL MÉTODO PARTE DEL TODO}

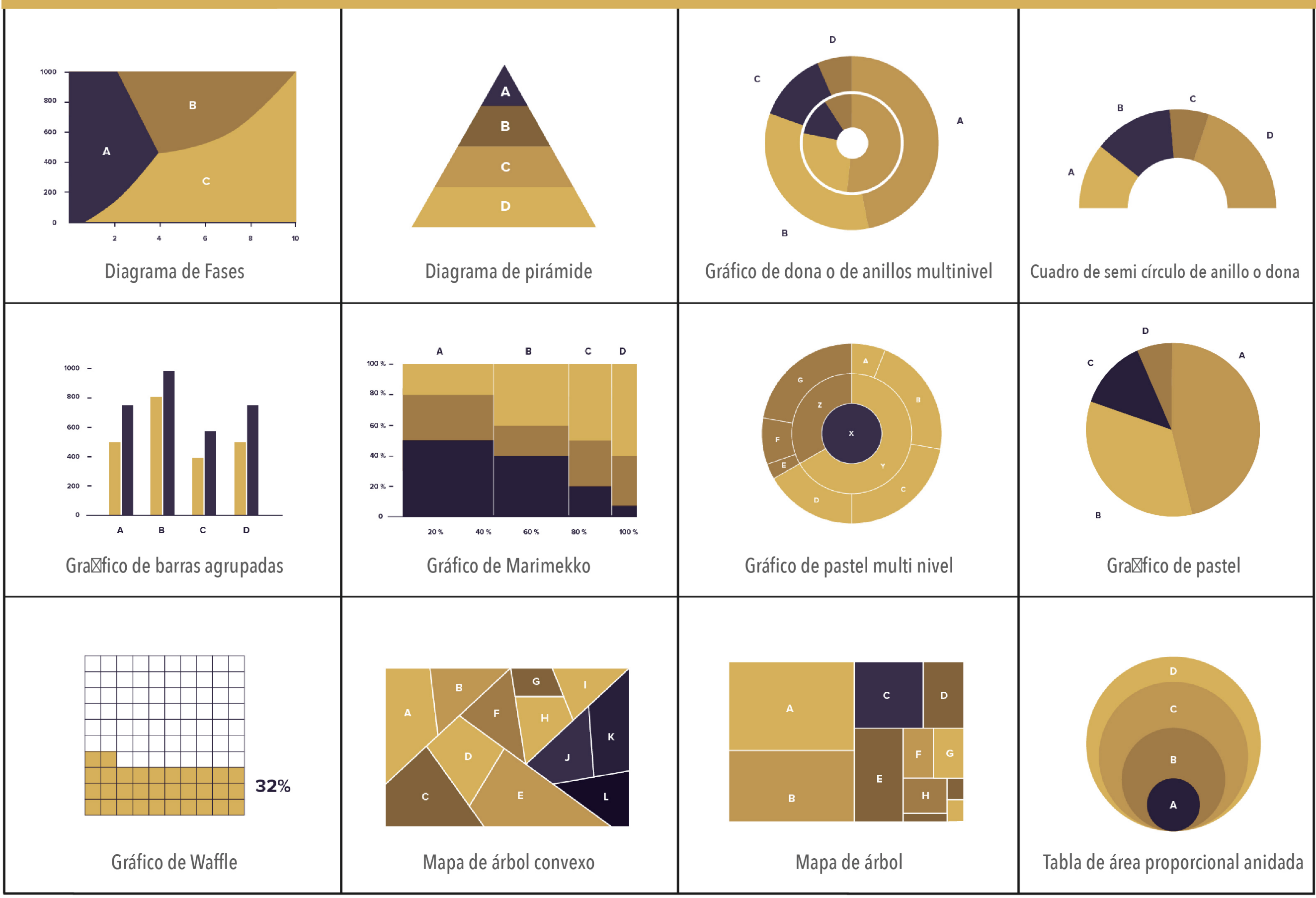




\section{FIGURAS DEL MÉTODO DE DISTRIBUCIÓN}

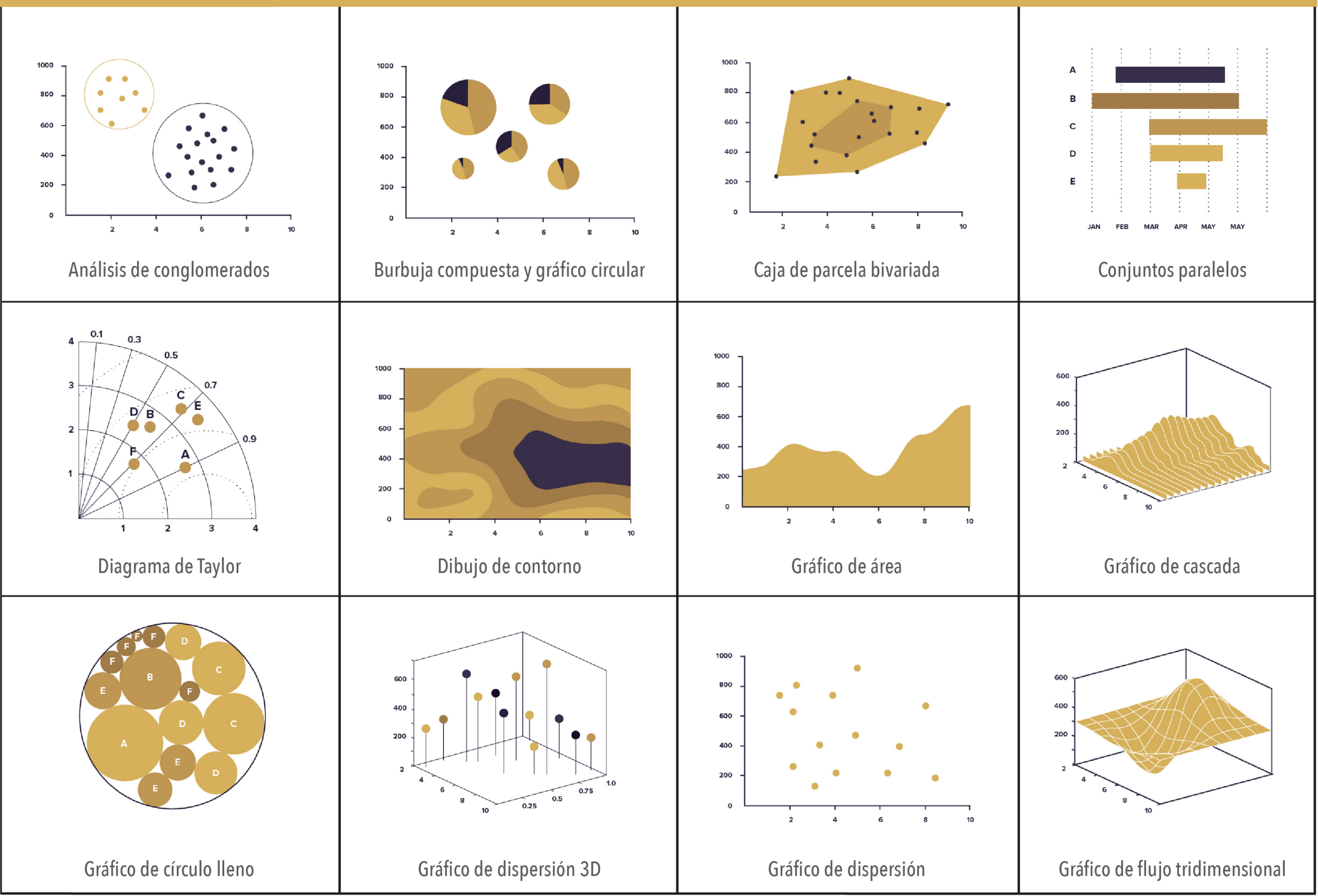




\section{FIGURAS DEL MÉTOODO DE DISTRIBUCIÓN}

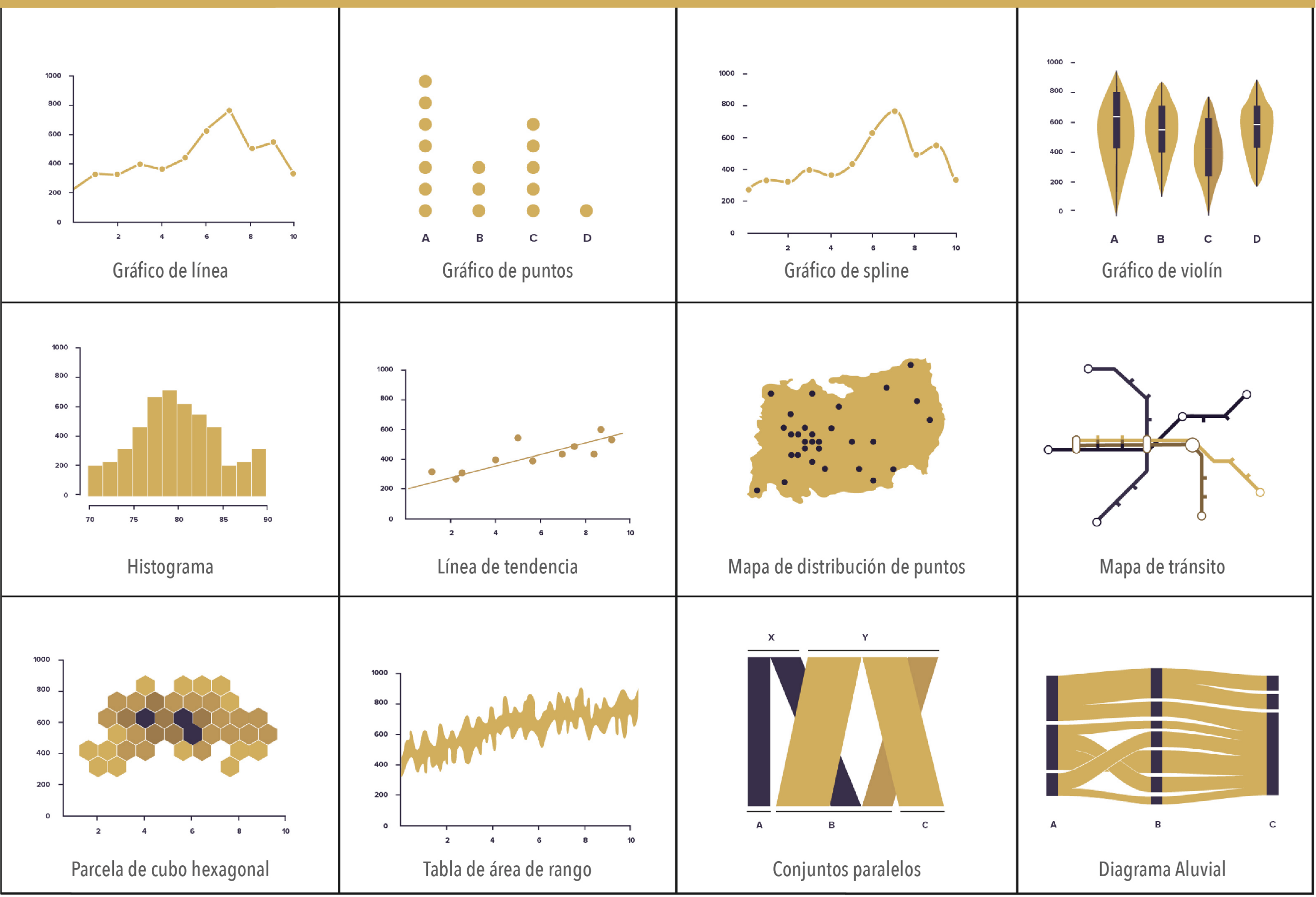




\section{FIGURAS DEL MÉTODO DE DISTRIBUCIÓN}

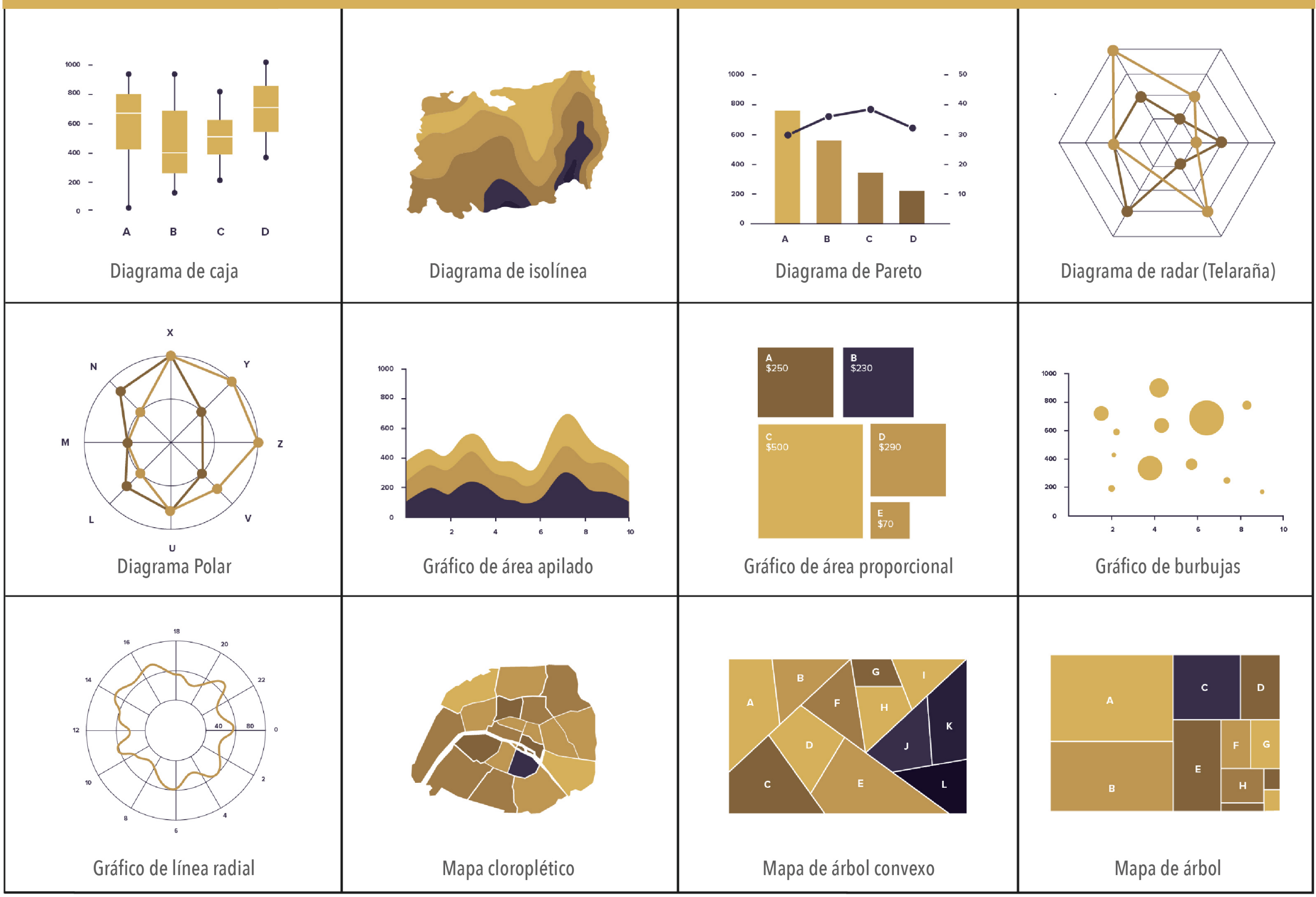




\section{FIGURAS DEL MÉTOODO DE DISTRIBUCIÓN}

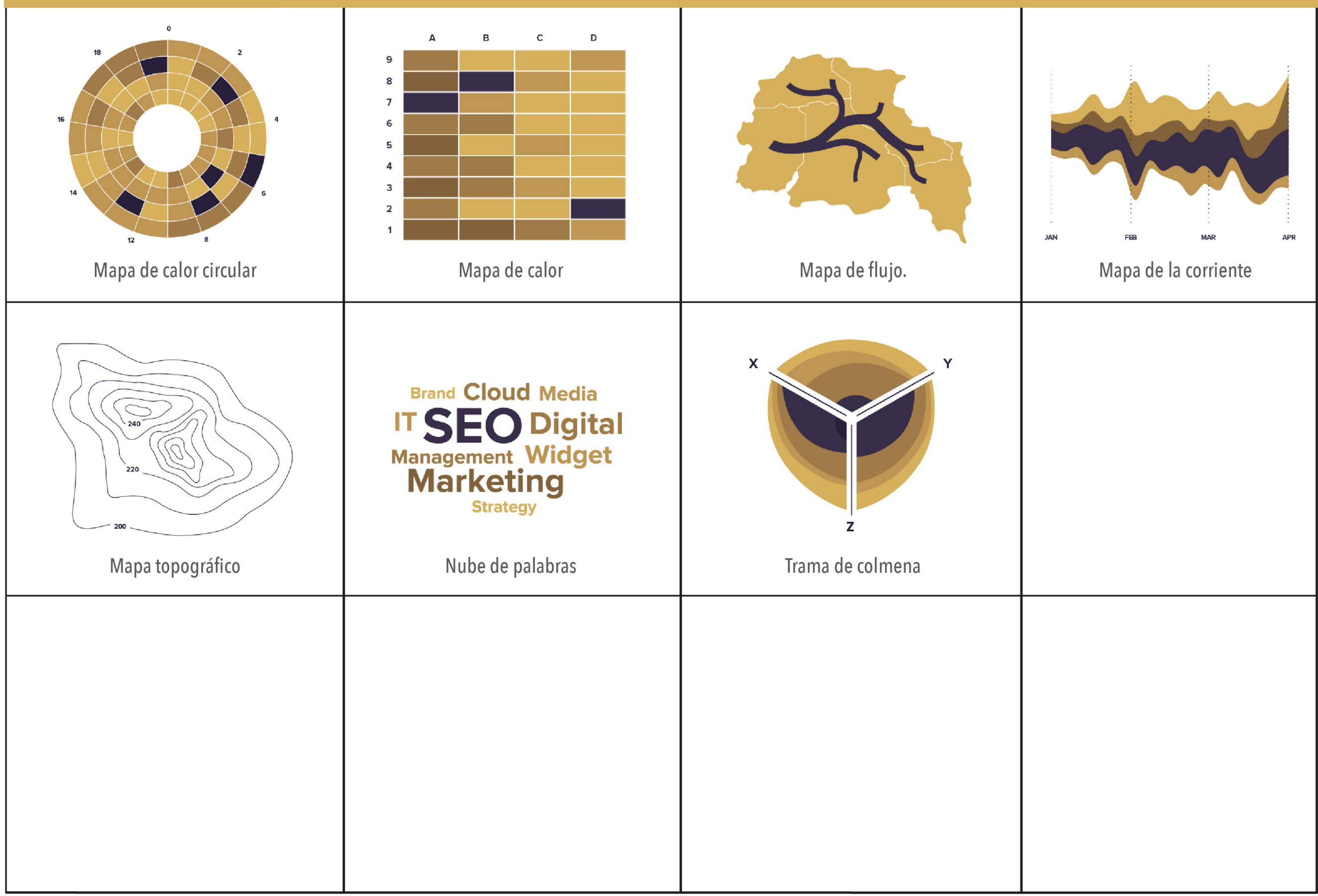




\section{FIGURAS DEL MÉTODO DE TENDENCIA A TRAVÉS DEL TIEMPO}

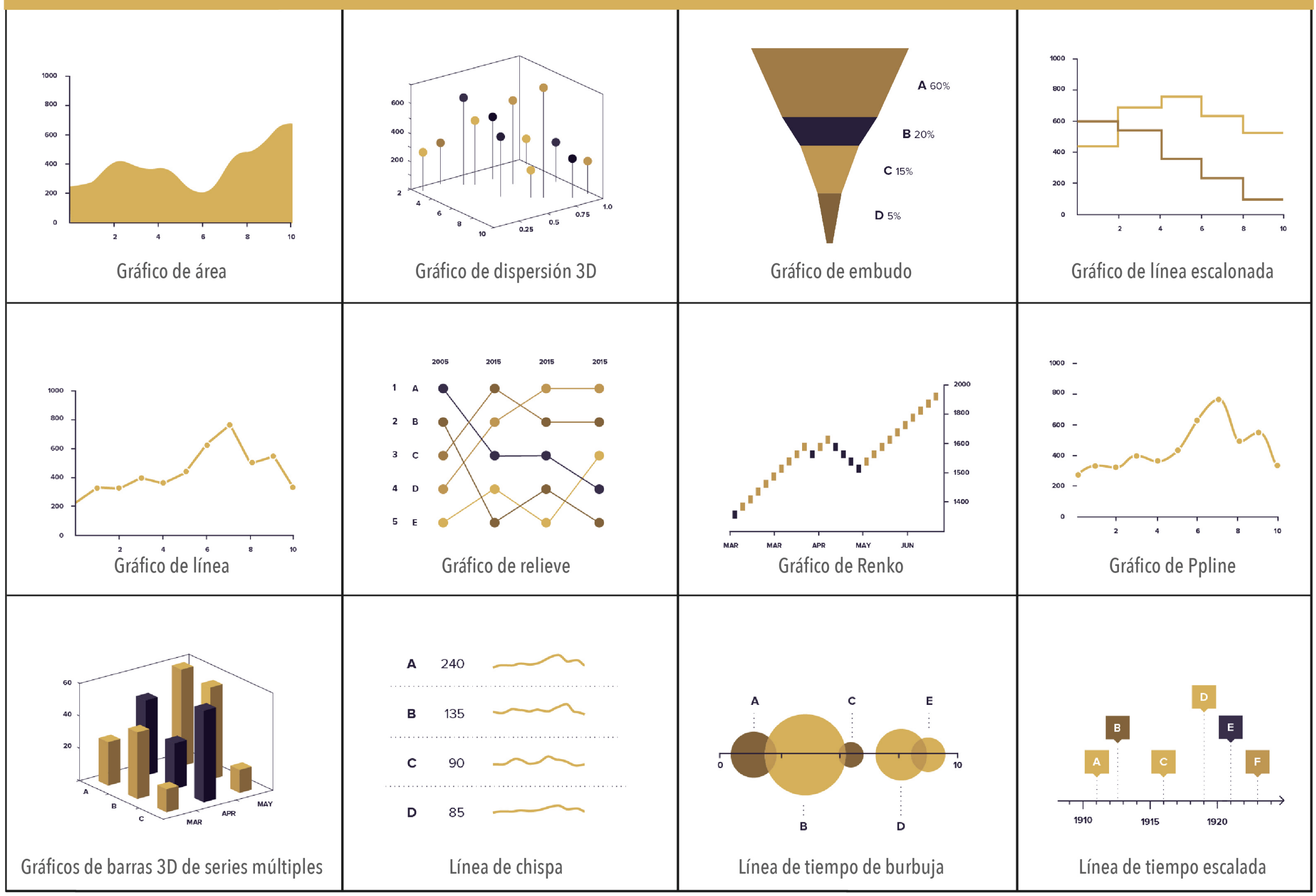




\section{FIGURAS DEL MÉTODO DE TENDENCIA A TRAVÉS DEL TIEMPO}

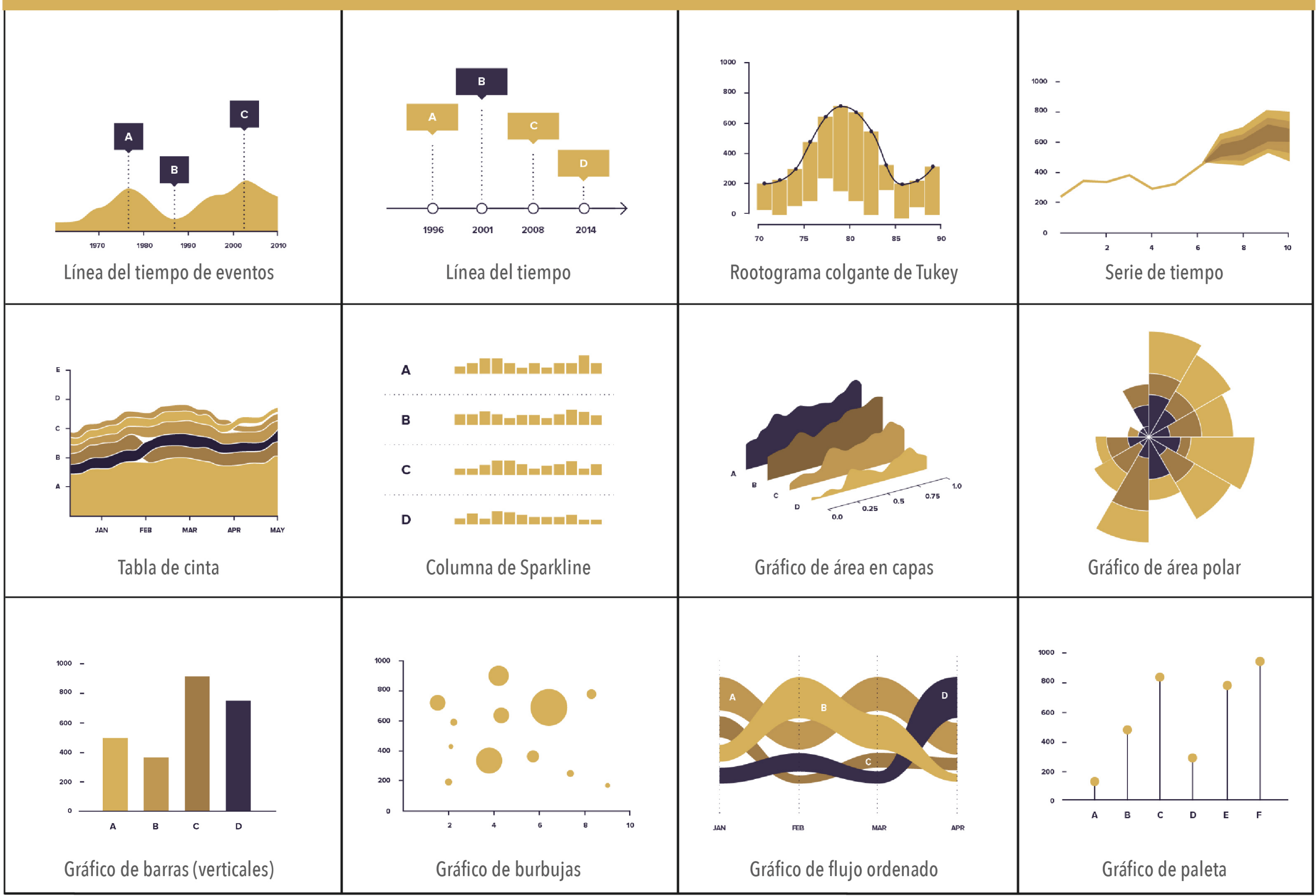




\section{FIGURAS DEL MÉTODO DE TENDENCIA A TRAVÉS DEL TIEMPO}

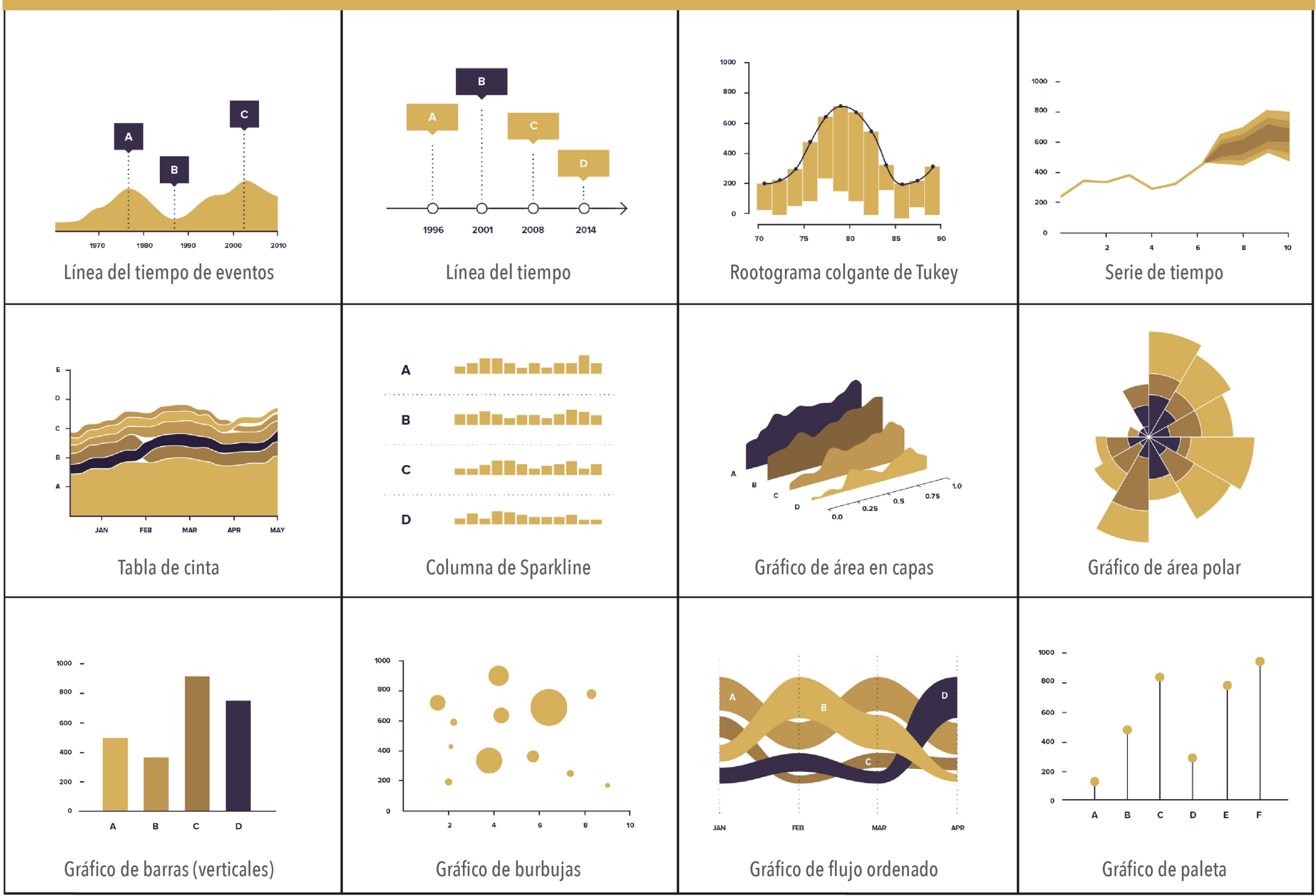




\section{FIGURAS DEL MÉTODO DE TENDENCIA A TRAVÉS DEL TIEMPO}

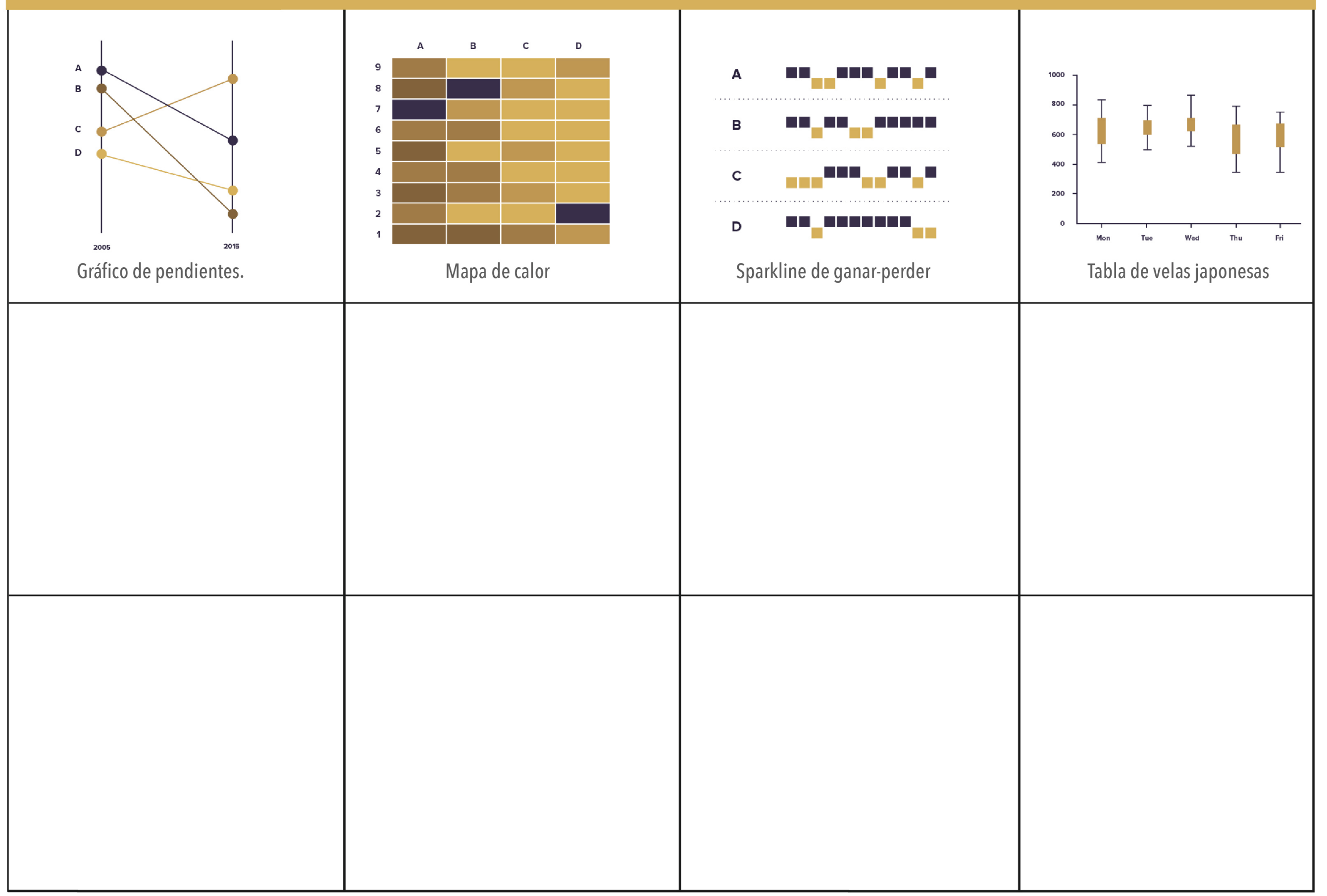




\section{FIGURAS DEL MÉTODO DE DATOS GEOGRÁFICOS}

\begin{tabular}{|l|l|l|}
\hline Mapa de pines & Gáfico de barras en un mapa \\
\hline Mapa cloroplético & Mapa de grático circular & \\
\hline
\end{tabular}




\section{FIGURAS DEL MÉTODO DE CÓMO FUNCIONAN LAS COSAS}

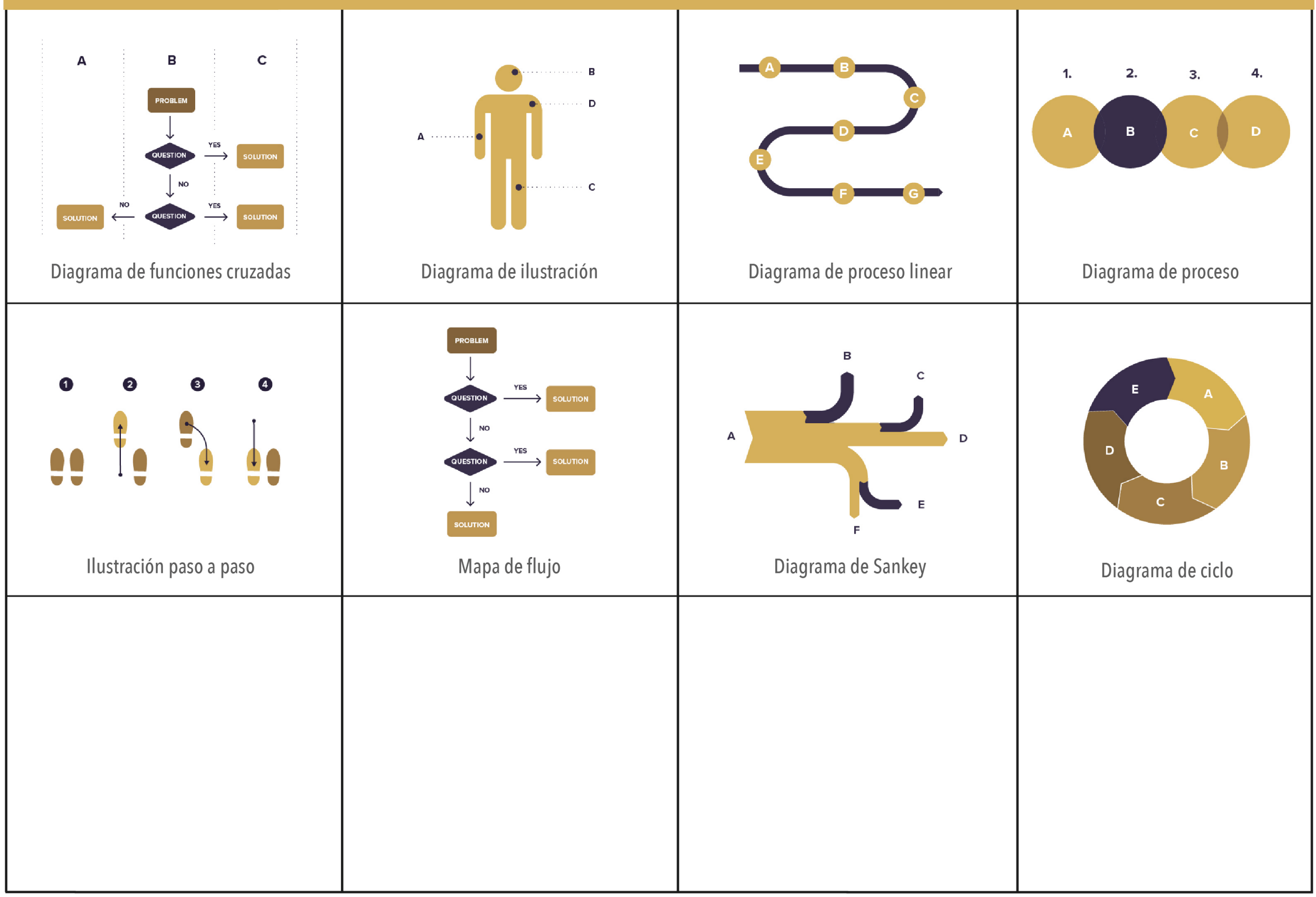




\section{FIGURAS DEL MÉTODO DE PROCESOS Y MÉTODOS}

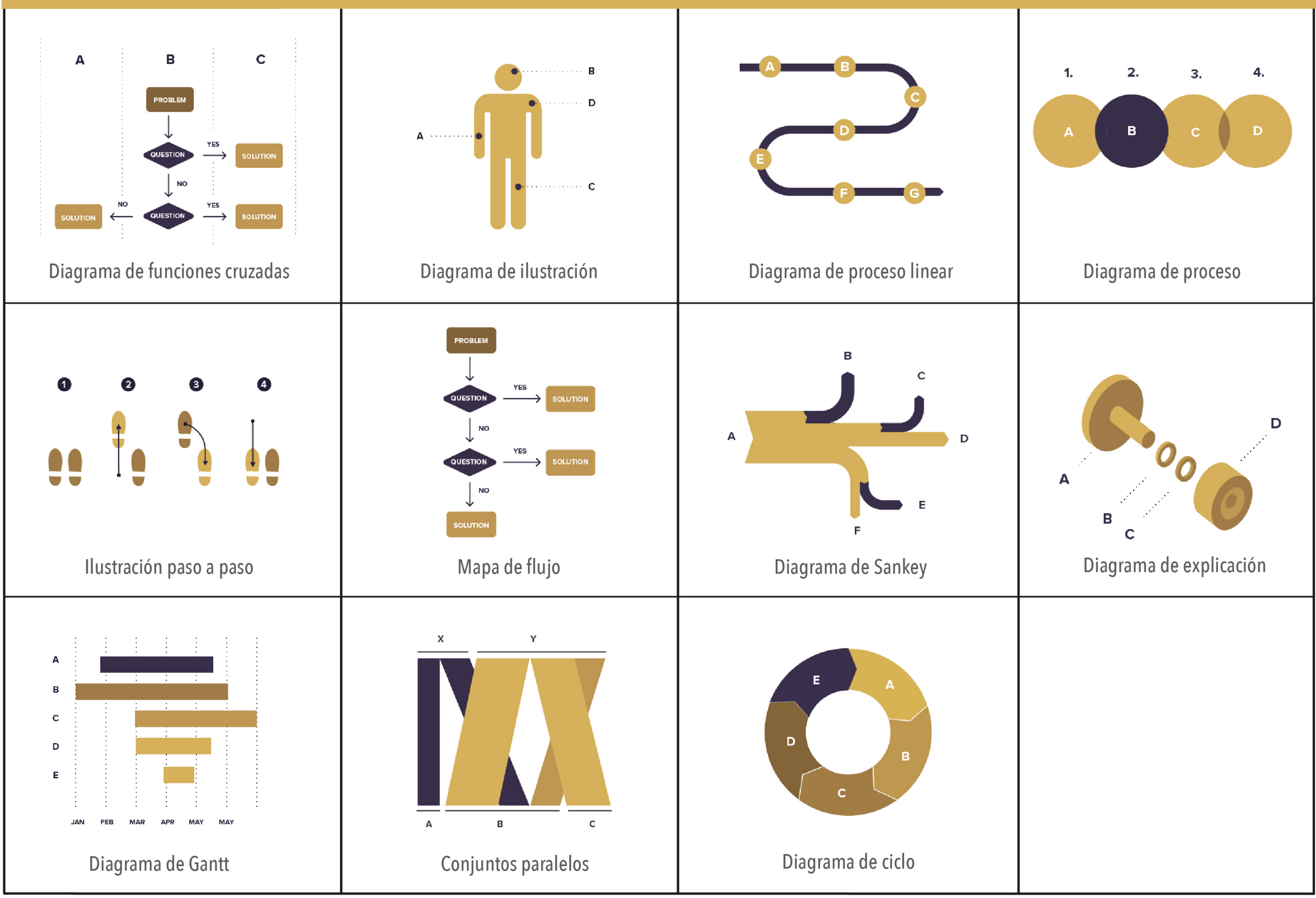




\section{FIGURAS DEL MÉTODO DE MOVIMIENTO Y FLUJO}

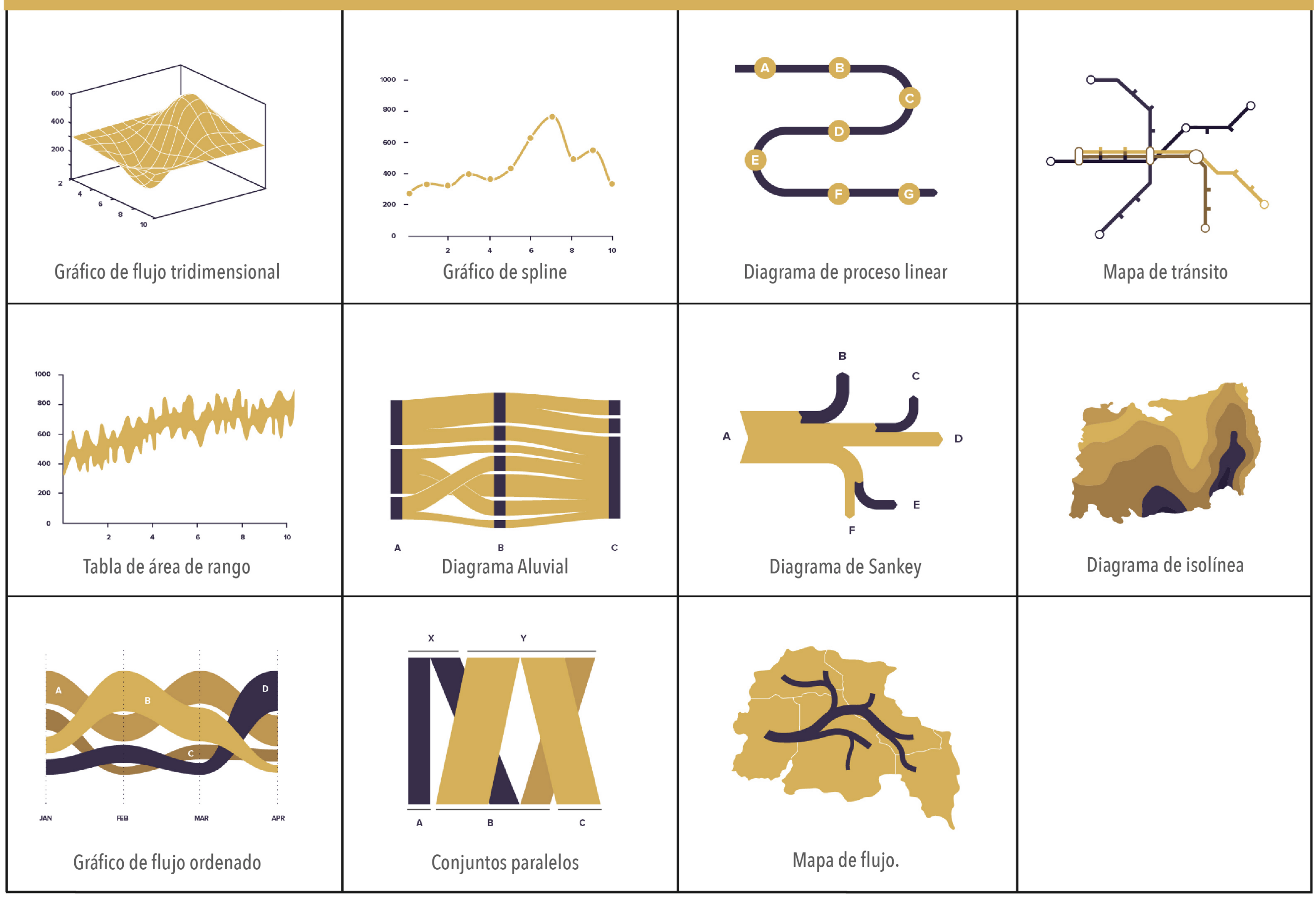




\section{FIGURAS DEL MÉTODO DE JERARQUÍA}

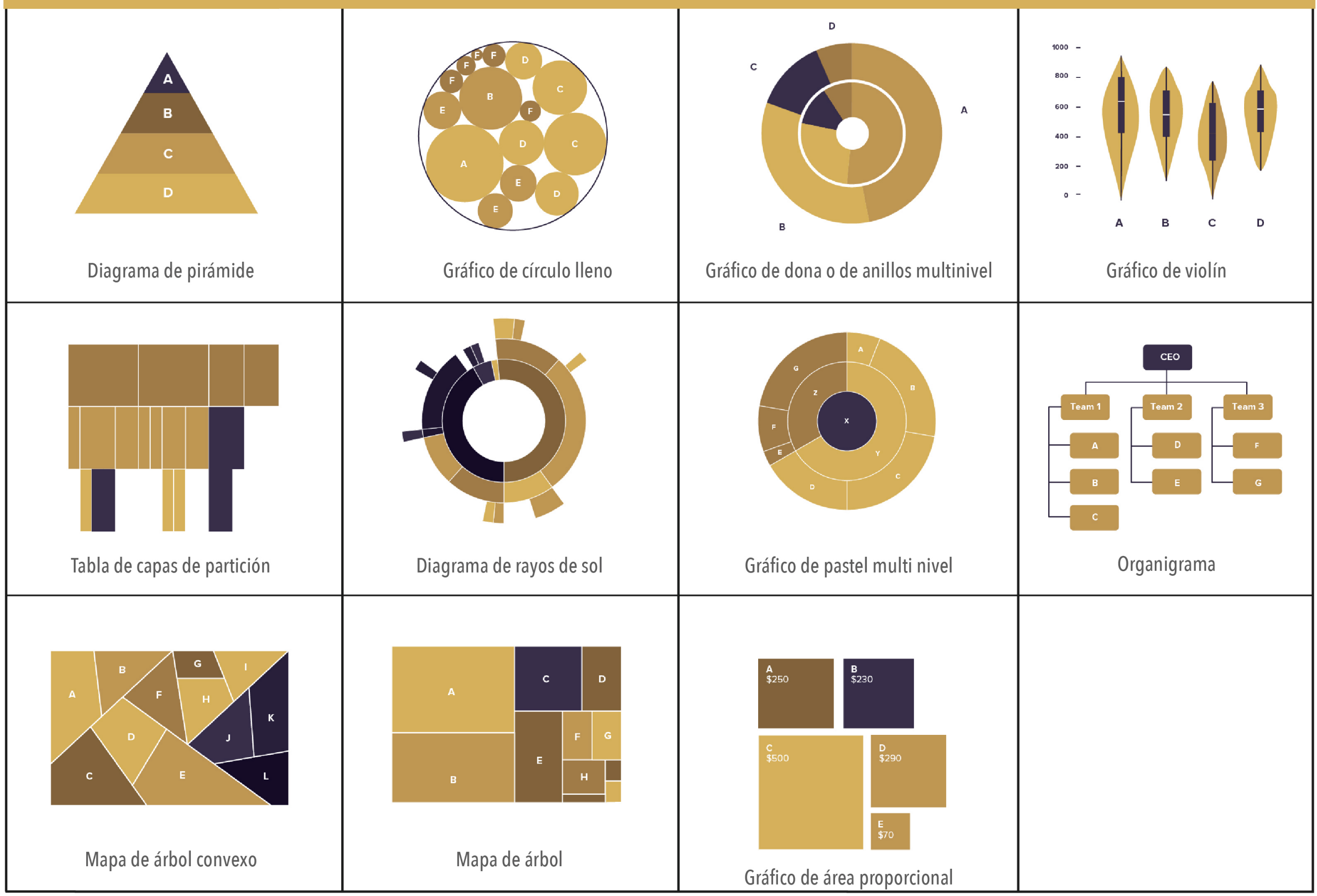




\section{FIGURAS DEL MÉTODO DE RANGO}

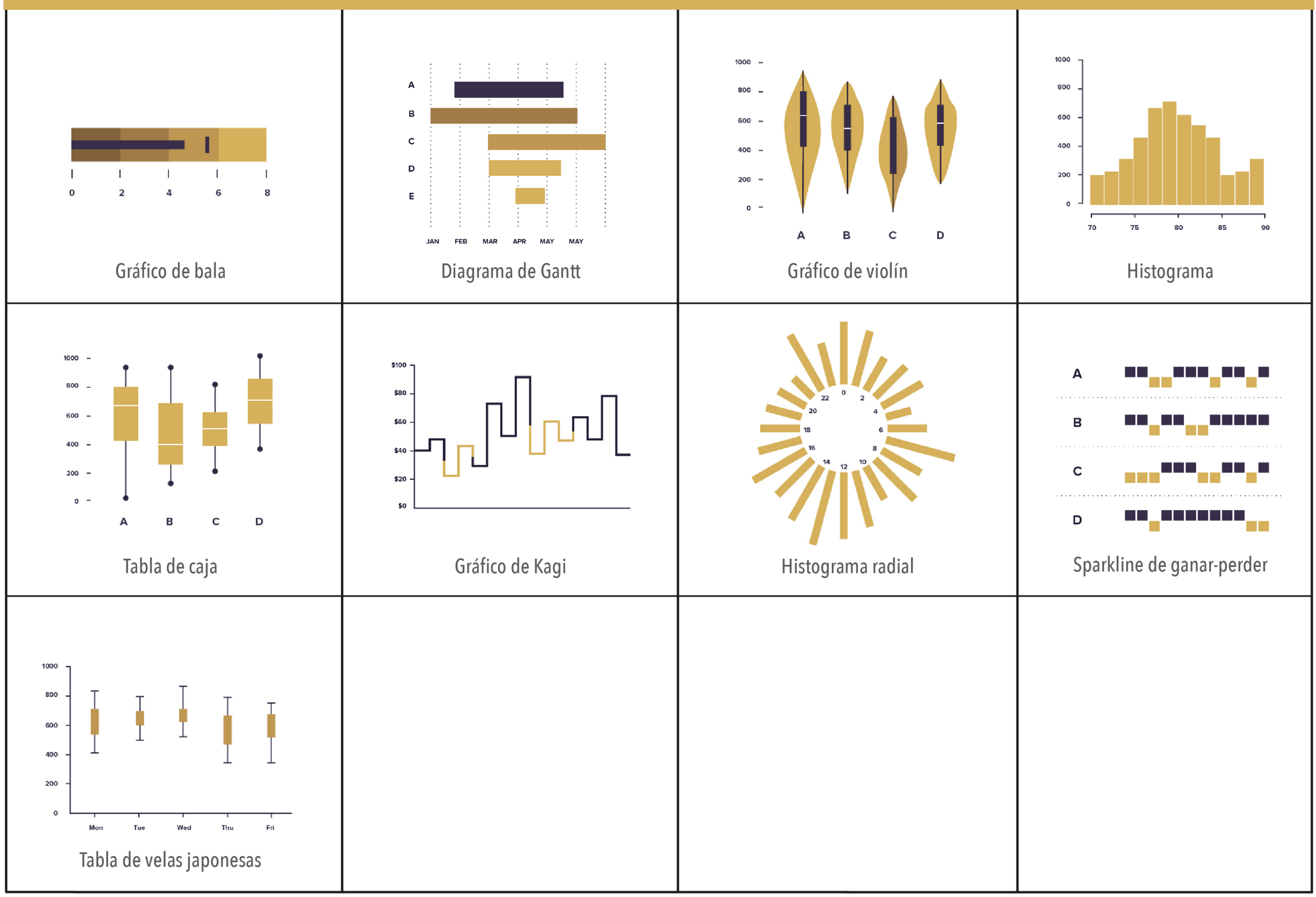




\section{FIGURAS VISUALES DEL MÉTODO DE COMPARACIÓN}

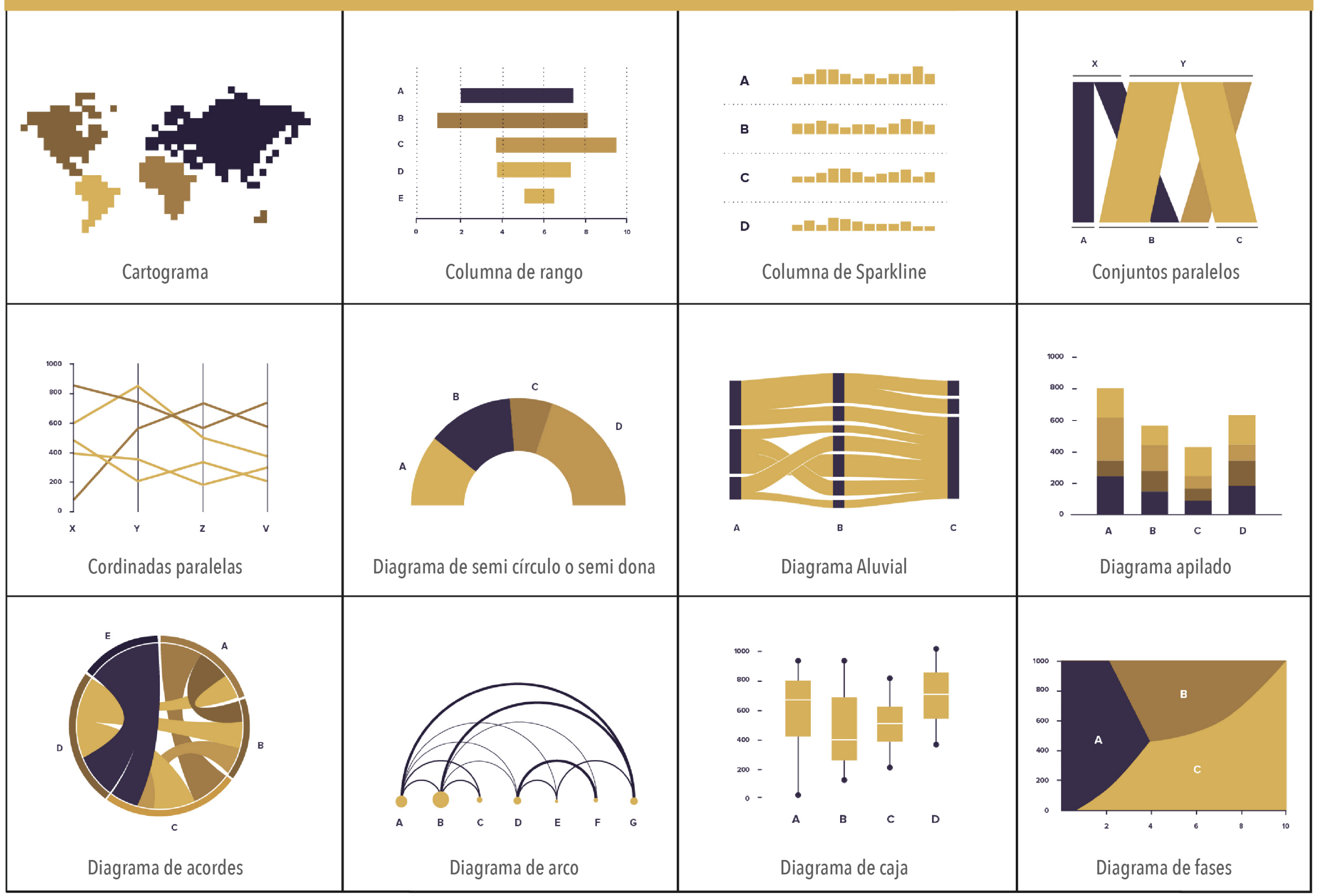




\section{FIGURAS VISUALES DEL MÉTODO DE COMPARACIÓN}

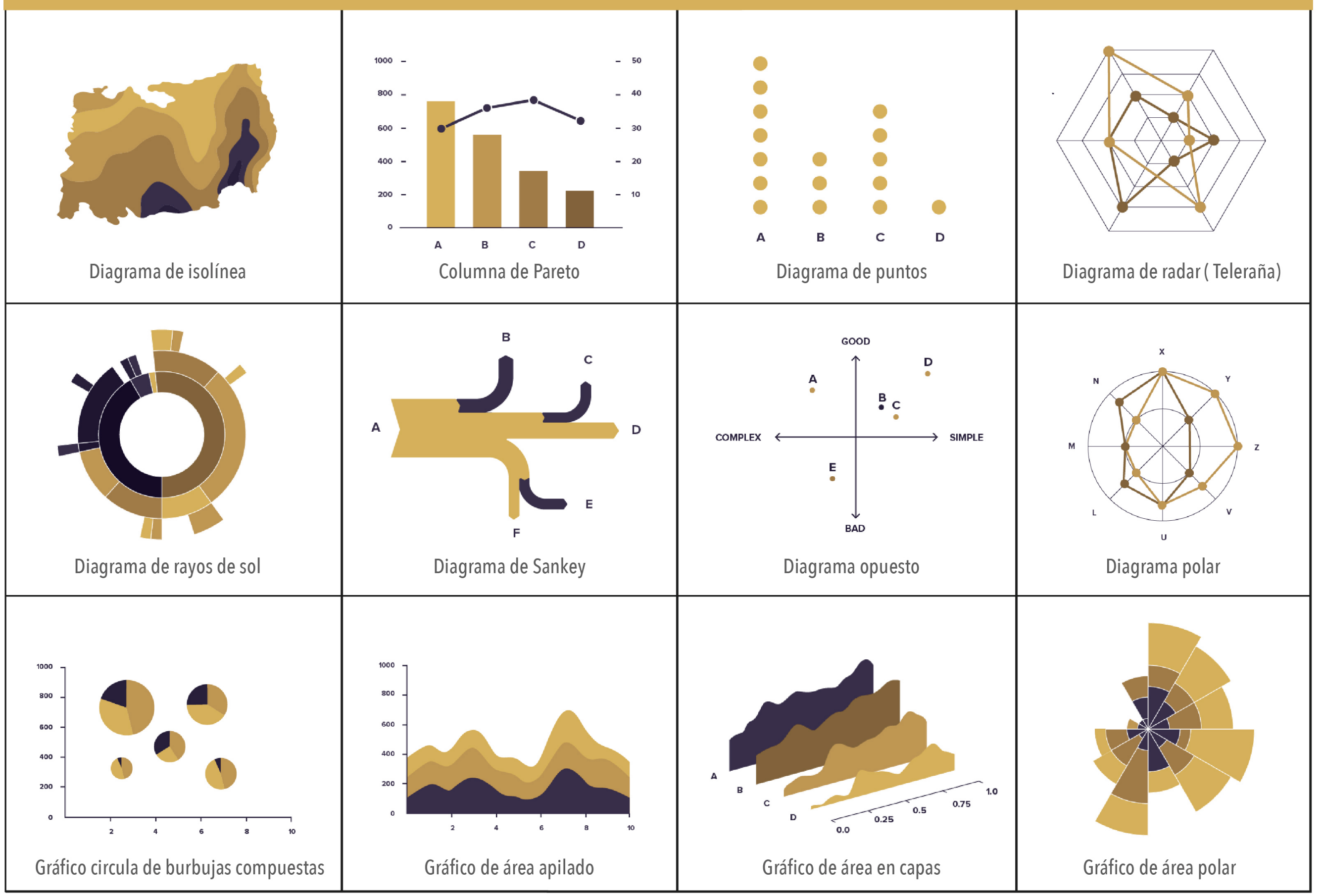




\section{FIGURAS VISUALES DEL MÉTODO DE COMPARACIÓN}

\begin{tabular}{|c|c|c|c|}
\hline Gráfico de área proporcional (círculos) & Gráfico de área proporcional (icono) & Gráfico de pendientes & 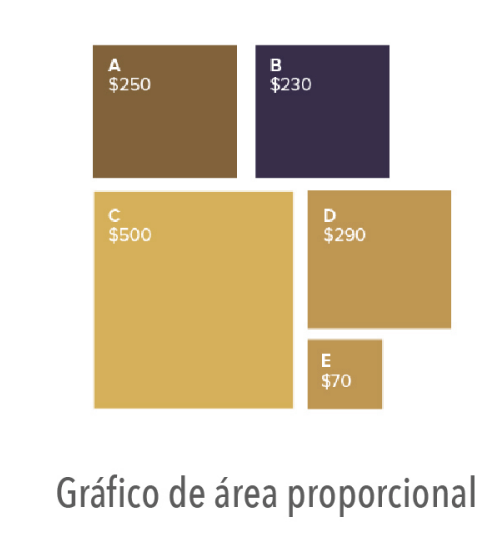 \\
\hline $\begin{array}{l}\text { A } \\
\text { Gráfico de barras (horizontal) }\end{array}$ & 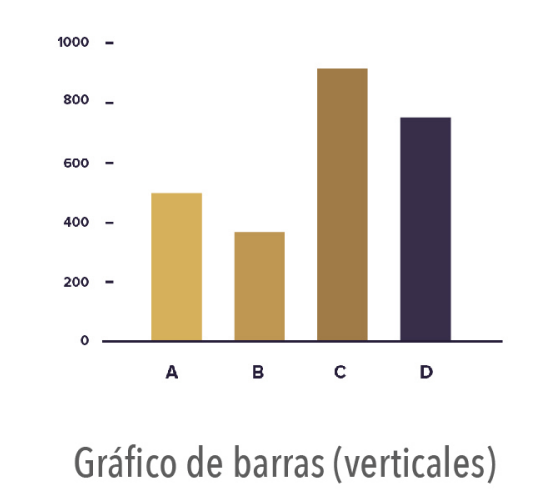 & Gráfico de barras agrupadas & Gráfico de barras curvadas \\
\hline Gráfico de barras del triángulo & Gráfico de barras en un mapa & Gráfico de barras pictorial & Gráfico de barras radiales \\
\hline
\end{tabular}




\section{FIGURAS VISUALES DEL MÉTODO DE COMPARACIÓN}

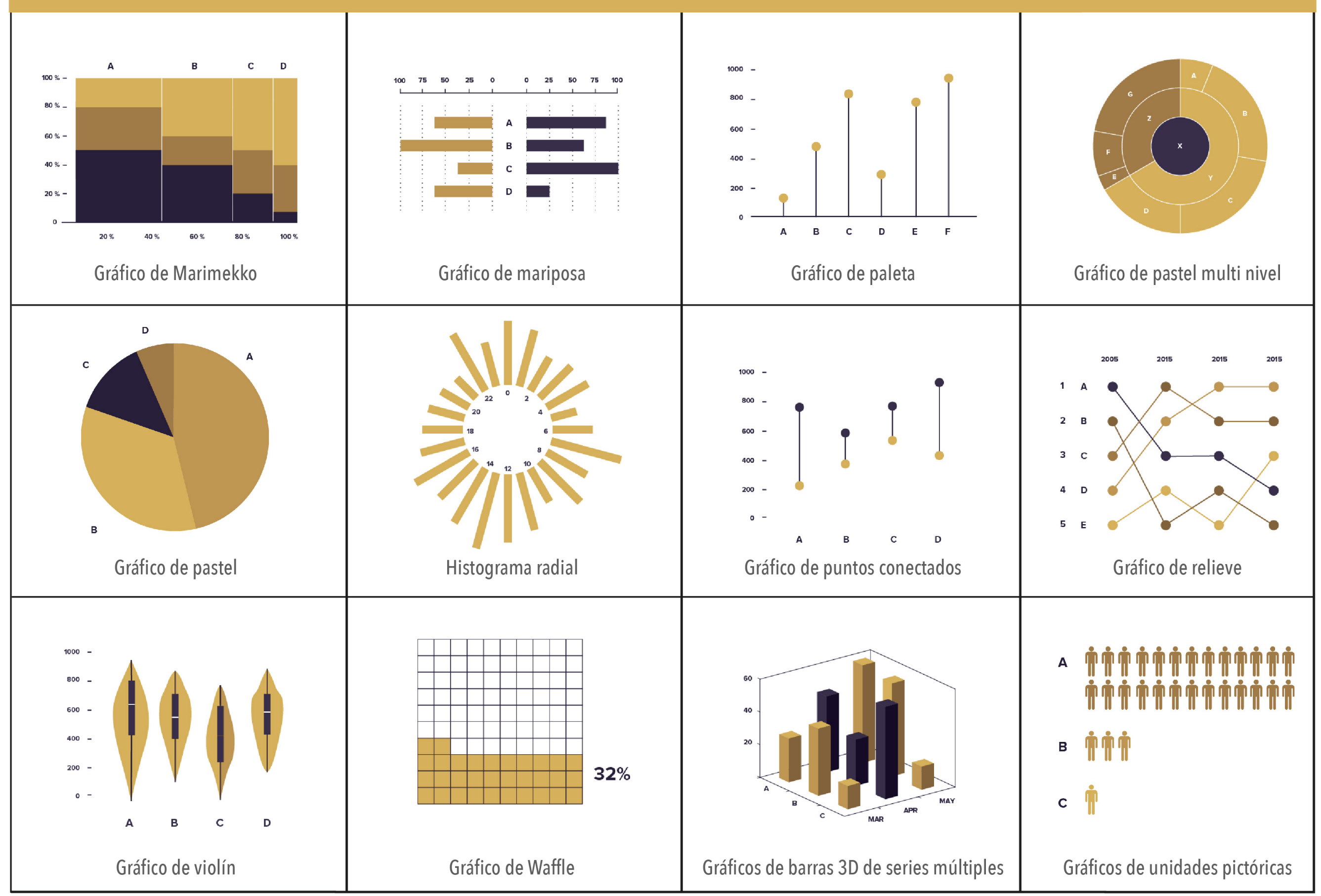




\section{FIGURAS VISUALES DEL MÉTODO DE COMPARACIÓN}

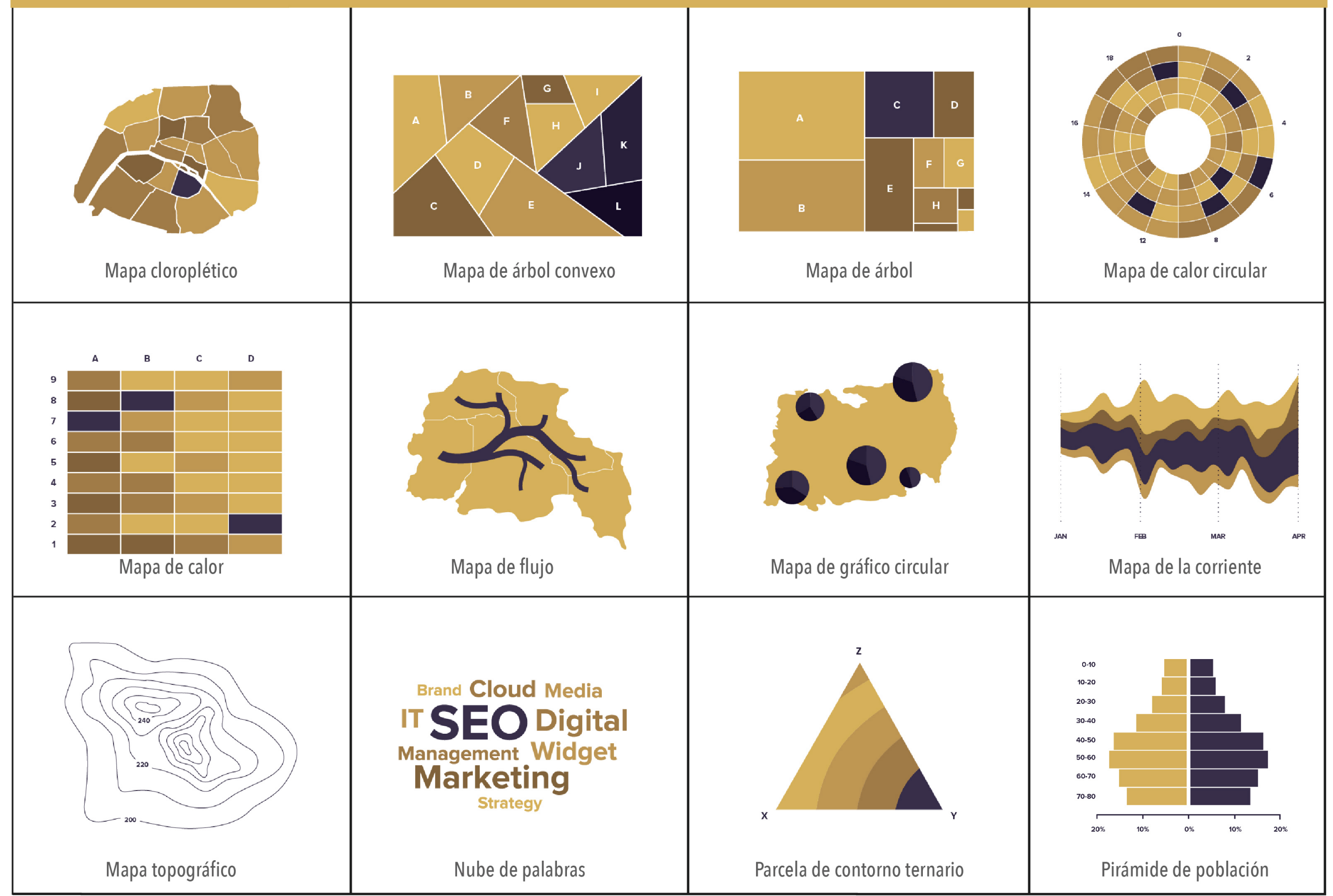




\section{FIGURAS VISUALES DEL MÉTODO DE COMPARACIÓN}

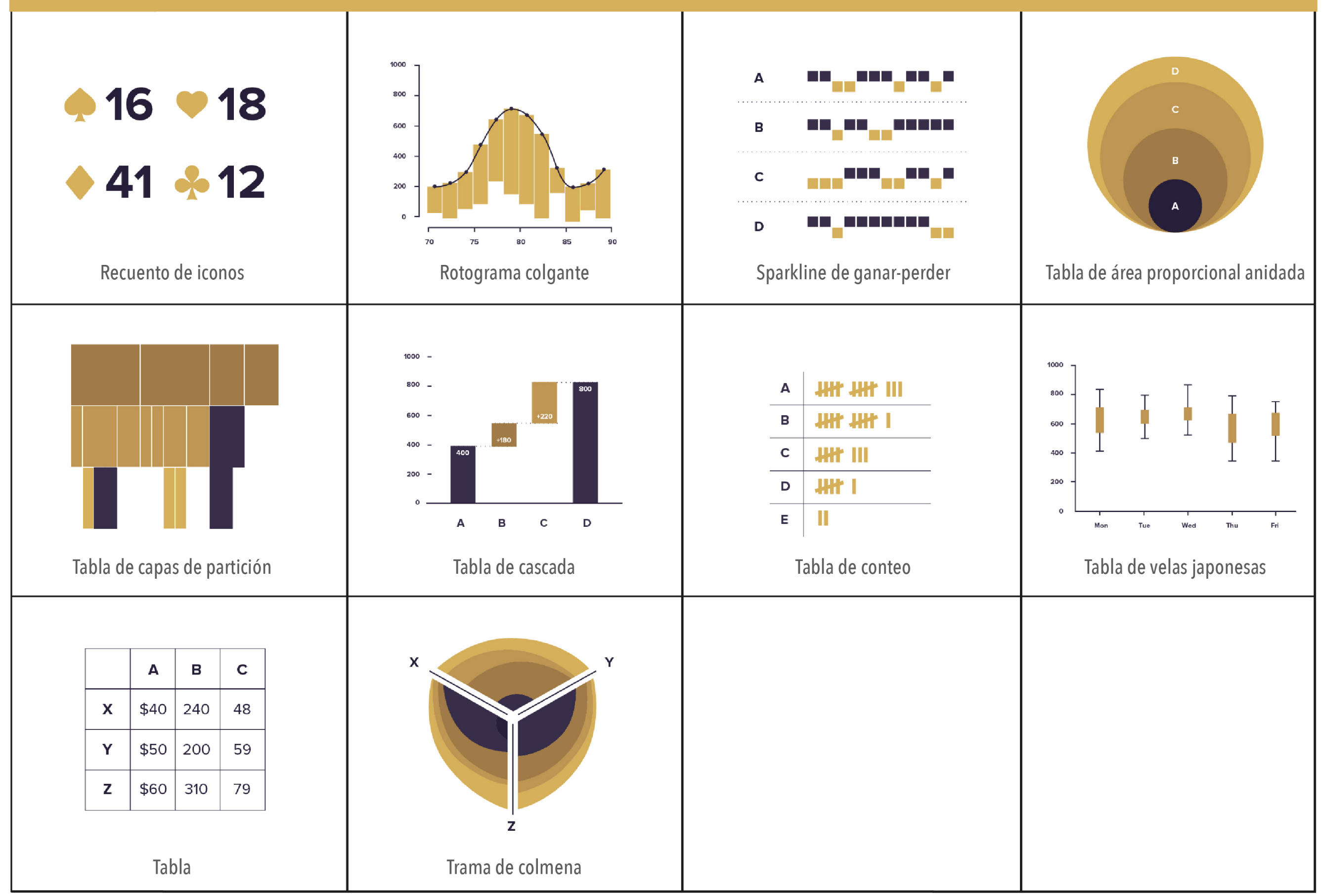





\section{Consentimiento informado}

Proyecto: NOMOLAS: Propuesta de guías de usabilidad para el diseño de interfaces gráficas de sistemas de visualización de información médica.

Nombre del estudio: Evaluación de usabilidad de propuestas editoriales de las guías de usabilidad NOMOLAS con usuarios (lectores) de las mismas.

Lugar y fecha:

\section{Número de registro:}

Justificación y objetivo del estudio: La forma en que se presenta la información es importante para que ésta sea comprendida de la mejor manera posible. Este estudio tiene como propósito elegir la mejor propuesta editorial para implementarla en toda la composición visual del proyecto llamado "NOMOLAS: Propuesta de guías de usabilidad para el diseño de interfaces gráficas de sistemas de visualización de información médica", que es a su vez, trabajo de investigación doctoral.

Procedimientos: Primero, se le explicaran los objetivos y el procedimiento de la sesión; describiendo como se llevará a cabo la prueba. Segundo, le pediremos que siga las instrucciones que le entregue el investigador encargado.

Posibles riesgos y molestias: En investigaciones similares no se han registrado dificultades o riesgos de ningún tipo, por tanto, durante su participación no se prevé ningún riesgo.

Posibles beneficios que recibirá al participar en el estudio: Al final de la prueba se le dará al participante $\$ 50.00$ pesos mexicanos en efectivo.

Participación o retiro: Si después de que Usted haya leído esta información y haya obtenido respuesta a las preguntas que pudiera tener, le vamos a pedir leer y firmar esta carta de consentimiento informado. Sin embargo, Usted puede retirarse en cualquier momento, por cualquier razón y nadie le va a preguntar sobre las razones por las cuales se retira.

Privacidad y confidencialidad: Para garantizar la confidencialidad toda la información será guardada y analizada sin usar los nombres reales de los participantes. Después de ser analizada, la información será guardada por un tiempo razonable y luego destruida.

En caso de dudas o aclaraciones relacionadas con el estudio podrá dirigirse con: Mtra. Mariel García Hernández quien conoce todos los detalles de este estudio. 2224924264 , Correo: mariel.garciahernandez@gmail.com

\section{Participante:}

Nombre:

\section{Quien obtiene el consentimiento:}

Nombre: 



\section{CUESTIONARIO PSSUQ}

Edad: Sexo: M I F Licenciatura: Manejo de llustrator: Si I No

Propuesta de guía: No. de cuestionario:

Este cuestionario es una oportunidad para registrar tus reacciones a la guía de usabilidad. Estas respuestas nos ayudarán a entender qué aspectos hay que mejorar y cuales son con los que no estás satisfechos. Para tener un mejor resultado, piensa en la tarea que se te pidió que realizaras con base a lo que las guías decían mientras contestas estas preguntas.

Instrucciones: Lea cada frase y señala qué tan de acuerdo o en desacuerdo estás y encierra en un circulo un número de la escala. Al terminar, revisaremos juntos el cuestionario para asegurarnos de que entendamos bien la información presentada en este cuestionario.

¡Gracias!

a) La organización de la información proporcionada por las guías me fue clara.

Totalmente en desacuerdo

Totalmente de acuerdo$$
1 \text { - } 1
$$

3

4

45

56

7

b) Fui capaz de completar las tareas que se me indicaron rápidamente con la información proporcionada en las guías.

Totalmente en desacuerdo

$$
12
$$

2

3

4

5

Totalmente de acuerdo

c) La información proporcionada por las guías fue fácil de entender.

Totalmente en desacuerdo
1

2

3

d) La apariencia de las guías es agradable.

Totalmente en desacuerdo

$$
12
$$

3
Totalmente de acuerdo

5

6

7

Totalmente de acuerdo $5 \quad 6$

e) En general estoy satisfecho con el acomodo y presentación visual de la información.

Totalmente en desacuerdo

Totalmente de acuerdo

1

2

3

4

5

6 

Anexo 5. Material para la evaluación FASE 1. Tarea a realizar por el usuario.

\section{LISTA DE CHEQUEO DEL ANÁLISIS DE TAREAS}

Evaluador:

Cuestionario:

Fecha:

Propuesta a evaluar:

\begin{tabular}{|l|l|l|}
\hline Premisa & Si & No \\
\hline El diseñador generó una paleta de cuatro colores. & & \\
\hline $\begin{array}{l}\text { El diseñador relacionó correctamente los lineamientos de } \\
\text { codificación de información en dispositivos médicos y los } \\
\text { aplicó en las secciones de la gráfica de acuerdo a su signi- } \\
\text { ficado. }\end{array}$ & & \\
\hline $\begin{array}{l}\text { El diseñador estableció un buen contraste entre fondo, } \\
\text { figura y texto. }\end{array}$ & & \\
\hline Tiempo en que tardó en leer la página el diseñador. & & \\
\hline Veces en que volvió a consultar la página el diseñador. & & \\
\hline Tiempo en que tardó en completar la tarea el diseñador. & & \\
\hline
\end{tabular}

Anexo 6. Material para la evaluación FASE 1. Enunciados del análisis de tareas

\section{ANÁLISIS DE TAREAS}

1. Abre el archivo de Illustrator llamado "EVA 1" que se encuentra en el escritorio.

2. Modifica la figura de acuerdo a los lineamientos de color presentados en las guías.

3. Al terminar de modificar la figura, guarda el archivo con el comando "Archivo/Guardar". 

Anexo 7. Material para la evaluación FASE 1. Captura de pantalla del archivo "EVA 1"a modificar como parte del análisis de tareas.

\section{GRAVEDAD DE DAÑO DEL PACIENTE}

De acuerdo con la Organización Mundial de la Salud (OMS), el grado del daño "es la gravedad, la duración y las reper-

cusiones terapéuticas del daño derivado de un incidente". A continuación presentamos una gráfica acerca de el

número de pacientes recibidos en la Clínica Mayo en el año del 2018, con base al grado de daño presentado.

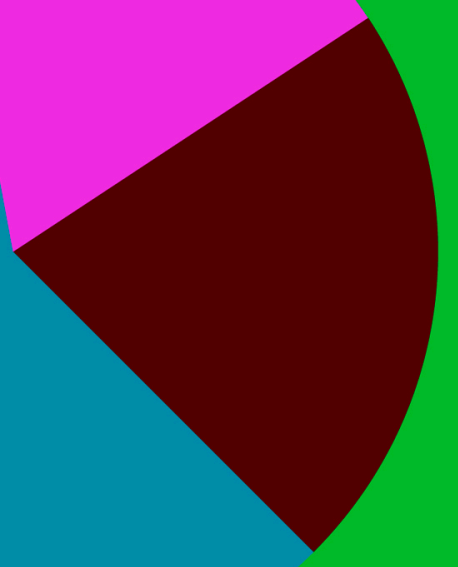

DAÑO LEVE

DAÑO MEDIO

DAÑO GRAVE 

Se recomienda que la elección de color para la interfaz gráfica no se haga mediante gustos personales o juicios del propio diseñador.

Se sugiere elegir el color a usar a partir de las necesidades y objetivo de la interfaz gráfica.

- De acuerdo a lo que establece Wiklund 3 (1995), the Human Engineering Committee of the Association for the Advancement of Medical Instrumentation (AAMI) hace las siguientes sugerencias de uso del color para codificación de información en dispositivos médicos (Figura 22).

\begin{tabular}{|l|l|}
\hline \multicolumn{2}{|c|}{ COLOR } \\
\hline \multirow{2}{*}{ Rojo } & \multicolumn{1}{c|}{ SIGNIFICADO } \\
& Prioridad alta. Advertencia. \\
& Alarma. Emergencia. \\
& Alto. Apagado. \\
Nivel alto. \\
Amarillo & Prioridad Media. \\
& Precaución. \\
& Amenaza potencial. \\
& Nivel medio. \\
Verde & Estado normal. Inicio. \\
& Endendido. Listo. \\
& Nivel estándar. \\
\hline
\end{tabular}

Figura 22. Uso del color para codificación de información en dispositivos médicos. según the Human Engineering Committee of the Association for the Advancement of Medical Instrumentation (AAMI) (1995).

Según Lonsdale \& Lonsdale (2019), es conveniente usar una paleta de color que solo contemple cuatros colores, ya que el exceso de color puede resultar abrumador para el usuario.

Para una alta legibilidad, de acuerdo a Nielsen \& Loranger (2006) debe mantenerse un buen contraste entre el texto, el color y el fondo (ver Figura 23).

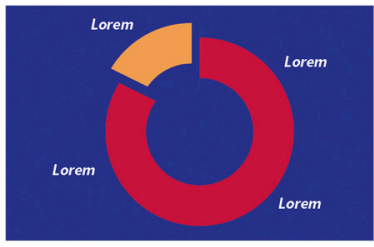

Ejemplo de buen contraste entre los elemento

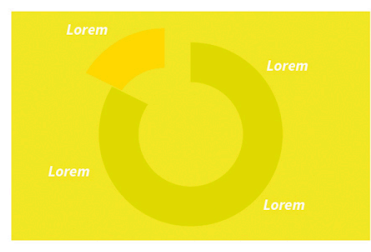

Ejemplo de mal contraste entre los elementos

Figura 23. Es recomendable elegir un buen contraste entre el texto, el color y el fondo.

Es muy importante usar un fondo de color que no generé "ruido visual" en contraste con el color de la tipografía y demás elementos gráficos de la interfaz gráfica. Es decir, se recomienda evitar usar colores que generen un contraste "pesado" a la vista y a la lectura, según los autores anteriores, (Figura 24).

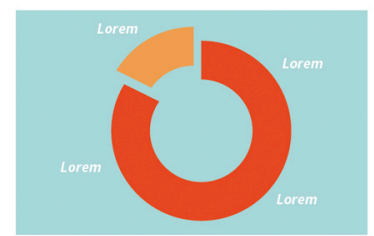

Figura 24. Ejemplo de fondo de color que no generá "ruido" y tiene buen contraste con demás elementos. 

Se recomienda que la elección de color para la interfaz gráfica no se haga mediante gustos personales o juicios del propio diseñador.

Se sugiere elegir el color a usar a partir de las necesidades y objetivo de la interfaz gráfica.

2 De acuerdo a lo que establece Wiklund (1995), the Human Engineering Committee of the Association for the Advancement of Medical Instrumentation (AAMI) hace las siguientes sugerencias de uso del color para codificación de información en dispositivos médicos (Figura 22).

\begin{tabular}{|c|c|}
\hline COLOR & SIGNIFICADO \\
\hline Rojo & $\begin{array}{l}\text { Prioridad alta. Advertencia. } \\
\text { Alarma. Emergencia. } \\
\text { Alto. Apagado. } \\
\text { Nivel alto. }\end{array}$ \\
\hline Amarillo & $\begin{array}{l}\text { Prioridad Media. } \\
\text { Precaución. } \\
\text { Amenaza potencial. } \\
\text { Nivel medio. }\end{array}$ \\
\hline Verde & $\begin{array}{l}\text { Estado normal. Inicio. } \\
\text { Endendido. Listo. } \\
\text { Nivel estándar. }\end{array}$ \\
\hline
\end{tabular}

Figura 22. Uso del color para codificación de información en dispositivos médicos según the Human Engineering Committee of the Association for the

Según Lonsdale \& Lonsdale (2019), es conveniente usar una paleta de color que solo contemple cuatros colores, ya que el exceso de color puede resultar abrumador para el usuario.

5 Para una alta legibilidad, de acuerdo a Nielsen \& Loranger (2006) debe mantenerse un buen contraste entre el texto, el color y el fondo.

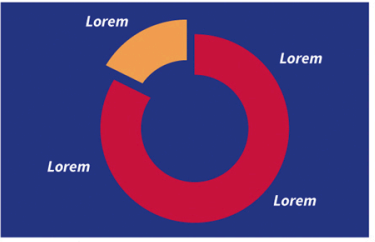

Ejemplo de buen contraste entre los elementos

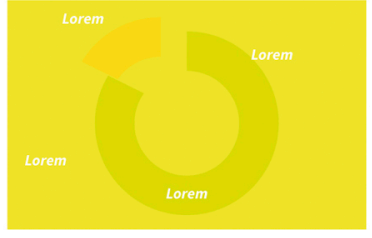

Ejemplo de mal contraste entre los elementos

Figura 23. Es recomendable elegir un buen contraste entre el texto, el color y el fondo. 

Anexo 10. Material de resultados de la evaluación de la propuesta editorial " $A$ ": consentimiento informado, lista de chequedo de análisis de tareas y cuestionario PSSUQ. 
Anexo 10.1. USUARIO 1: Material de resultados de la evaluación de la propuesta editorial "A": consentimiento informado, lista de chequedo de análisis de tareas y cuestionario PSSUQ. 


\section{Consentimiento informado}

Proyecto: NOMOLAS: Propuesta de guias de usabilidad para el diseño de interfaces gráficas de sistemas de visualización de información médica.

Nombre del estudio: Evaluación de usabilidad de propuestas editoriales de las guías de usabilidad NOMOLAS con usuarios (lectores) de las mismas.

Lugar y fecha: UAM Azcapotralco 23 oct. 2019

Número de registro:

Justificación y objetivo del estudio: La forma en que se presenta la información es importante para que ésta sea comprendida de la mejor manera posible. Este estudio tiene como propósito elegir la mejor propuesta editorial para implementarla en toda la composición visual del proyecto llamado "NOMOLAS: Propuesta de guías de usabilidad para el diseño de interfaces gráficas de sistemas de visualización de información médica", que es a su vez, trabajo de investigación doctoral.

Procedimientos: Primero, se le explicaran los objetivos y el procedimiento de la sesión; describiendo como se llevará a cabo la prueba. Segundo, le pediremos que siga las instrucciones que le entregue el investigador encargado.

Posibles riesgos y molestias: En investigaciones similares no se han registrado dificultades o riesgos de ningún tipo, por tanto, durante su participación no se prevé ningún riesgo.

Posibles beneficios que recibirá al participar en el estudio: Al final de la prueba se le dará al participante $\$ 50.00$ pesos mexicanos en efectivo.

Participación o retiro: Si después de que Usted haya leido esta información y haya obtenido respuesta a las preguntas que pudiera tener, le vamos a pedir leer y firmar esta carta de consentimiento informado. Sin embargo, Usted puede retirarse en cualquier momento, por cualquier razón y nadie le va a preguntar sobre las razones por las cuales se retira.

Privacidad y confidencialidad: Para garantizar la confidencialidad toda la información será guardada y analizada sin usar los nombres reales de los participantes. Después de ser analizada, la información será guardada por un tiempo razonable y luego destruida.

En caso de dudas o aclaraciones relacionadas con el estudio podrá dirigirse con: Mtra. Mariel García Hernández quien conoce todos los detalles de este estudio. 22249242 64, Correo: mariel.garciahernandez@gmail.com

Participante:

Nombre: Gloria Takagu Conscelos

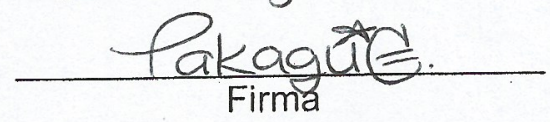

Quien obtiene el consentimiento:

Nombre: Uavel Garcia Hemändec

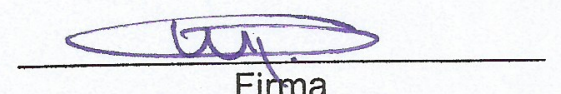




\section{CUESTIONARIOPSSUQ}

Edad:25 Sexo: M / Picenciatura: Diseño de la comunicaciēn gréficamanejo de llustrator: sí I No Propuesta de guía: No. de cuestionario: 1

Este cuestionario es una oportunidad para registrar tus reacciones a la guia de usabilidad. Estas respuestas nos ayudarán a entender qué aspectos hay que mejorar y cuales son con los que no estás satisfechos. Para tener un mejor resultado, piensa en la tarea que se te pidió que realizaras con base a lo que las guias decian mientras contestas estas preguntas.

Instrucciones: Lea cada frase y señala qué tan de acuerdo o en desacuerdo estás y encierra en un circulo un número de la escala. Al terminar, revisaremos juntos el cuestionario para asegurarnos de que entendamos bien la información presentada en este cuestionario.

\section{¡Gracias!}

a) La organización de la información proporcionada por las guías me fue clara.

Totalmente en desacuerdo

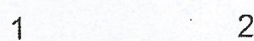

2

3

4

5

Totalmente de acuerdo

(7)

b) Fui capaz de completar las tareas que se me indicaron rápidamente con la información proporcionada en las guías.

Totalmente en desacuerdo

1

2

3

4

5

Totalmente de acuerdo

$+3$

c) La información proporcionada por las guías fue fácil de entender.

Totalmente en desacuerdo

1

2

3

4

5

Totalmente de acuerdo

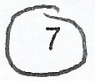

d) La apariencia de las guias es agradable.

Totalmente en desacuerdo

1

2

3

4

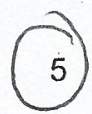

Totalmente de acuerdo

6

7

e) En general estoy satisfecho con el acomodo y presentación visual de la información.

Totalmente en desacuerdo

1

2

3

4

5

Totalmente de acuerdo 
LISTA DE CHEQUEO DEL ANÁLISIS DE TAREAS

Evaluador: Manel Cuestionario: Fecha: $23 \cdot 10 \cdot 19$

Propuesta a evaluar:

\begin{tabular}{|l|c|c|}
\hline Premisa & Si & No \\
\hline El diseñador generó una paleta de cuatro colores. & & \\
\hline $\begin{array}{l}\text { El diseñador relacionó correctamente los lineamientos de } \\
\text { codificación de información en dispositivos médicos y los } \\
\text { aplicó en las secciones de la gráfica de acuerdo a su signi- } \\
\text { ficado. }\end{array}$ & & \\
\hline $\begin{array}{l}\text { El diseñador estableció un buen contraste entre fondo, } \\
\text { figura y texto. }\end{array}$ & & \\
\hline Tiempo en que tardó en leer la página el diseñador. & 56 & \\
\hline Veces en que volvió a consultar la página el diseñador. & 1 & $5: 48: 19$ \\
\hline Tiempo en que tardó en completar la tarea el diseñador. & \\
\hline
\end{tabular}


Anexo 10.2. USUARIO 2: Material de resultados de la evaluación de la propuesta editorial "A": consentimiento informado, lista de chequedo de análisis de tareas y cuestionario PSSUQ. 


\section{Consentimiento informado}

Proyecto: NOMOLAS: Propuesta de guías de usabilidad para el diseño de interfaces gráficas de sistemas de visualización de información médica.

Nombre del estudio: Evaluación de usabilidad de propuestas editoriales de las guías de usabilidad NOMOLAS con usuarios (lectores) de las mismas.

Lugar y fecha:

Número de registro:

02

Justificación y objetivo del estudio: La forma en que se presenta la información es importante para que ésta sea comprendida de la mejor manera posible. Este estudio tiene como propósito elegir la mejor propuesta editorial para implementarla en toda la composición visual del proyecto llamado "NOMOLAS: Propuesta de guías de usabilidad para el diseño de interfaces gráficas de sistemas de visualización de información médica", que es a su vez, trabajo de investigación doctoral.

Procedimientos: Primero, se le explicaran los objetivos y el procedimiento de la sesión; describiendo como se llevará a cabo la prueba. Segundo, le pediremos que siga las instrucciones que le entregue el investigador encargado.

Posibles riesgos y molestias: En investigaciones similares no se han registrado dificultades 0 riesgos de ningún tipo, por tanto, durante su participación no se prevé ningún riesgo.

Posibles beneficios que recibirá al participar en el estudio: Al final de la prueba se le dará al participante $\$ 50.00$ pesos mexicanos en efectivo.

Participación o retiro: Si después de que Usted haya leído esta información y haya obtenido respuesta a las preguntas que pudiera tener, le vamos a pedir leer y firmar esta carta de consentimiento informado. Sin embargo, Usted puede retirarse en cualquier momento, por cualquier razón y nadie le va a preguntar sobre las razones por las cuales se retira.

Privacidad y confidencialidad: Para garantizar la confidencialidad toda la información será guardada y analizada sin usar los nombres reales de los participantes. Después de ser analizada, la información será guardada por un tiempo razonable y luego destruida.

En caso de dudas o aclaraciones relacionadas con el estudio podrá dirigirse con: Mtra. Mariel García Hernández quien conoce todos los detalles de este estudio. 2224924264 , Correo: mariel.garciahernandez@gmail.com

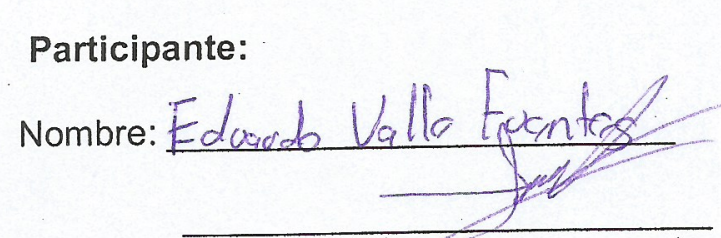

Firma
Quien obtiene el consentimiento:

Nombre: Uamel Garcia Hemānder

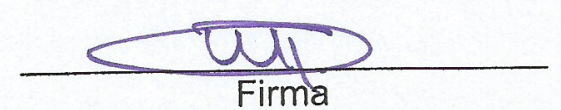




\title{
CUESTIONARIO PSSUQ
}

Edad:26 sexo: M I F Licenciatura: Diseño de la comunicacióng Manejo de llustrator: si I No Propuesta de guía: No. de cuestionario: 2

Este cuestionario es una oportunidad para registrar tus reacciones a la guia de usabilidad. Estas respuestas nos ayudarán a entender qué aspectos hay que mejorar y cuales son con los que no estás satisfechos. Para tener un mejor resultado, piensa en la tarea que se te pidió que realizaras con base a lo que las guías decian mientras contestas estas preguntas.

Instrucciones: Lea cada frase y señala qué tan de acuerdo o en desacuerdo estás y encierra en un circulo un número de la escala. Al terminar, revisaremos juntos el cuestionario para asegurarnos de que entendamos bien la información presentada en este cuestionario.

¡Gracias!

a) La organización de la información proporcionada por las guías me fue clara.

Totalmente en desacuerdo

$$
1 \quad 2
$$

2

3

4

(5)

Totalmente de acuerdo 7

b) Fui capaz de completar las tareas que se me indicaron rápidamente con la información proporcionada en las guías.

Totalmente en desacuerdo$$
12
$$

2

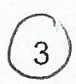

4

5

Totalmente de acuerdo

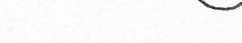

c) La información proporcionada por las guías fue fácil de entender.

Totalmente en desacuerdo

1

2

3

4

5

Totalmente de acuerdo

7

d) La apariencia de las guías es agradable.

Totalmente en desacuerdo

$$
1
$$

2

3

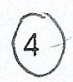

5

Totalmente de acuerdo

e) En general estoy satisfecho con el acomodo y presentación visual de la información.

Totalmente en desacuerdo

1 2

3

\begin{abstract}
4
\end{abstract}

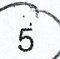

Totalmente de acuerdo

6 


\section{LISTA DE CHEQUEO DEL ANÁLISIS DE TAREAS}

Evaluador: Manlel_Cuestionario:__ Fecha: $23 \cdot 0.19$ Propuesta a evaluar: $A$

\begin{tabular}{|l|l|l|}
\hline Premisa & Si & No \\
\hline El diseñador generó una paleta de cuatro colores. & & \\
\hline $\begin{array}{l}\text { El diseñador relacionó correctamente los lineamientos de } \\
\text { codificación de información en dispositivos médicos y los } \\
\text { aplicó en las secciones de la gráfica de acuerdo a su signi- } \\
\text { ficado. }\end{array}$ & & \\
\hline $\begin{array}{l}\text { El diseñador estableció un buen contraste entre fondo, } \\
\text { figura y texto. }\end{array}$ & & \\
\hline Tiempo en que tardó en leer la página el diseñador. & 50 & seg. \\
\hline Veces en que volvió a consultar la página el diseñador. & $3: 37.85$ \\
\hline Tiempo en que tardó en completar la tarea el diseñador.
\end{tabular}


Anexo 10.3. USUARIO 3: Material de resultados de la evaluación de la propuesta editorial "A": consentimiento informado, lista de chequedo de análisis de tareas y cuestionario PSSUQ. 


\section{Consentimiento informado}

Proyecto: NOMOLAS: Propuesta de guias de usabilidad para el diseño de interfaces gráficas de sistemas de visualización de información médica.

Nombre del estudio: Evaluación de usabilidad de propuestas editoriales de las guías de usabilidad NOMOLAS con usuarios (lectores) de las mismas.

Lugar y fecha: UAM Azcapotzal co 23 octubre. 2019

Número de registro:

Justificación y objetivo del estudio: La forma en que se presenta la información es importante para que ésta sea comprendida de la mejor manera posible. Este estudio tiene como propósito elegir la mejor propuesta editorial para implementarla en toda la composición visual del proyecto llamado "NOMOLAS: Propuesta de guías de usabilidad para el diseño de interfaces gráficas de sistemas de visualización de información médica", que es a su vez, trabajo de investigación doctoral.

Procedimientos: Primero, se le explicaran los objetivos y el procedimiento de la sesión; describiendo como se llevará a cabo la prueba. Segundo, le pediremos que siga. las instrucciones que le entregue el investigador encargado.

Posibles riesgos y molestias: En investigaciones similares no se han registrado dificultades o riesgos de ningún tipo, por tanto, durante su participación no se prevé ningún riesgo.

Posibles beneficios que recibirá al participar en el estudio: Al final de la prueba se le dará al participante $\$ 50.00$ pesos mexicanos en efectivo.

Participación o retiro: Si después de que Usted haya leido esta información y haya obtenido respuesta a las preguntas que pudiera tener, le vamos a pedir leer y firmar esta carta de consentimiento informado. Sin embargo, Usted puede retirarse en cualquier momento, por cualquier razón y nadie le va a preguntar sobre las razones por las cuales se retira.

Privacidad y confidencialidad: Para garantizar la confidencialidad toda la información será guardada y analizada sin usar los nombres reales de los participantes. Después de ser analizada, la información será guardada por un tiempo razonable y luego destruida.

En caso de dudas o aclaraciones relacionadas con el estudio podrá dirigirse con: Mtra. Mariel García Hernández quien conoce todos los detalles de este estudio. 2224924264 , Correo: mariel.garciahernandez@gmail.com

\section{Participante:}

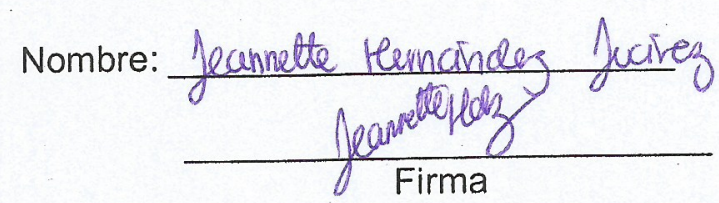

Quien obtiene el consentimiento:

Nombre: Ulanel Garia Hemànder

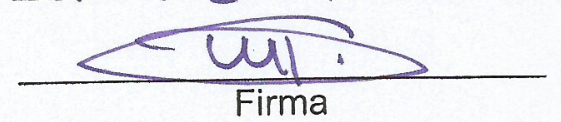




\section{CUESTIONARIO PSSUQ}

Edad:22 Sexo: M I F Licenciatura: Diseñ a la Comanicación Grätica Manejo de llustrator: (si) I No Propuesta de guía: No. de cuestionario:

Este cuestionario es una oportunidad para registrar tus reacciones a la guia de usabilidad. Estas respuestas nos ayudarán a entender qué aspectos hay que mejorar y cuales son con los que no estás satisfechos. Para tener un mejor resultado, piensa en la tarea que se te pidió que realizaras con base a lo que las guías decian mientras contestas estas preguntas.

Instrucciones: Lea cada frase y señala qué tan de acuerdo o en desacuerdo estás y encierra en un circulo un número de la escala. Al terminar, revisaremos juntos el cuestionario para asegurarnos de que entendamos bien la información presentada en este cuestionario.

\section{¡Gracias!}

a) La organización de la información proporcionada por las guías me fue clara.

Totalmente en desacuerdo

$$
1 \quad 2
$$

3

4

5

Totalmente de acuerdo

6 (7)

b) Fui capaz de completar las tareas que se me indicaron rápidamente con la información proporcionada en las guías.

Totalmente en desacuerdo

1

3

4

5

Totalmente de acuerdo

2

c) La información proporcionada por las guías fue fácil de entender.

Totalmente en desacuerdo

1

2

3

4

5

Totalmente de acuerdo

3

d) La apariencia de las guías es agradable.

Totalmente en desacuerdo

1

23

3

4

5

Totalmente de acuerdo

e) En general estoy satisfecho con el acomodo y presentación visual de la información.

Totalmente en desacuerdo

5 


\section{LISTA DE CHEQUEO DEL ANÁLISIS DE TAREAS}

Evaluador: Manel Cuestionario: 3 Fecha: $23.04 \cdot 19$ Propuesta a evaluar: A

\begin{tabular}{|l|c|l|}
\hline Premisa & Si & No \\
\hline El diseñador generó una paleta de cuatro colores. & & \\
\hline $\begin{array}{l}\text { El diseñador relacionó correctamente los lineamientos de } \\
\text { codificación de información en dispositivos médicos y los } \\
\text { aplicó en las secciones de la gráfica de acuerdo a su signi- } \\
\text { ficado. }\end{array}$ & $\checkmark$ & \\
\hline $\begin{array}{l}\text { El diseñador estableció un buẹn contraste entre fondo, } \\
\text { figura y texto. }\end{array}$ & 55 & \\
\hline Tiempo en que tardó en leer la página el diseñador. & & \\
\hline Veces en que volvió a consultar la página el diseñador. & $2: 03: 60$ \\
\hline Tiempo en que tardó en completar la tarea el diseñador. &
\end{tabular}


Anexo 10.4. USUARIO 4: Material de resultados de la evaluación de la propuesta editorial "A": consentimiento informado, lista de chequedo de análisis de tareas y cuestionario PSSUQ. 


\section{Consentimiento informado}

Proyecto: NOMOLAS: Propuesta de guias de usabilidad para el diseño de interfaces gráficas de sistemas de visualización de información médica.

Nombre del estudio: Evaluación de usabilidad de propuestas editoriales de las guías de usabilidad NOMOLAS con usuarios (lectores) de las mismas.

Lugar y fecha: UAM ACC

Número de registro:

04

Justificación y objetivo del estudio: La forma en que se presenta la información es importante para que ésta sea comprendida de la mejor manera posible. Este estudio tiene como propósito elegir la mejor propuesta editorial para implementarla en toda la composición visual del proyecto llamado "NOMOLAS: Propuesta de guías de usabilidad para el diseño de interfaces gráficas de sistemas de visualización de información médica", que es a su vez, trabajo de investigación doctoral.

Procedimientos: Primero, se le explicaran los objetivos y el procedimiento de la sesión; describiendo como se llevará a cabo la prueba. Segundo, le pediremos que siga. las instrucciones que le entregue el investigador encargado.

Posibles riesgos y molestias: En investigaciones similares no se han registrado dificultades o riesgos de ningún tipo, por tanto, durante su participación no se prevé ningún riesgo.

Posibles beneficios que recibirá al participar en el estudio: Al final de la prueba se le dará al participante $\$ 50.00$ pesos mexicanos en efectivo.

Participación o retiro: Si después de que Usted haya leído esta información y haya obtenido respuesta a las preguntas que pudiera tener, le vamos a pedir leer y firmar esta carta de consentimiento informado. Sin embargo, Usted puede retirarse en cualquier momento, por cualquier razón y nadie le va a preguntar sobre las razones por las cuales se retira.

Privacidad y confidencialidad: Para garantizar la confidencialidad toda la información será guardada y analizada sin usar los nombres reales de los participantes. Después de ser analizada, la información será guardada por un tiempo razonable y luego destruida.

En caso de dudas o aclaraciones relacionadas con el estudio podrá dirigirse con: Mtra. Mariel García Hernández quien conoce todos los detalles de este estudio. 2224924264 , Correo: mariel.garciahernandez@gmail.com

\section{Participante:}

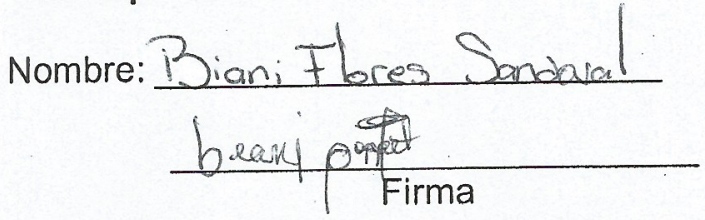

Quien obtiene el consentimiento:

Nombre: Uarel Garéia Hernainder

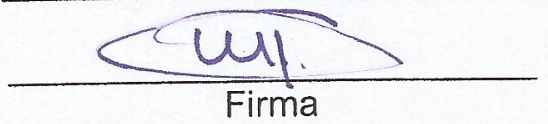




\section{CUESTIONARIO PSSUQ}

Edad:23 Sexo: M / (e) Licenciatura: Diseño de la Conunicaciómanejo de llustrator: Si / No Propuesta de guía: No. de cuestionario: 4

Este cuestionario es una oportunidad para registrar tus reacciones a la guia de usabilidad. Estas respuestas nos ayudarán a entender qué aspectos hay que mejorar y cuales son con los que no estás satisfechos. Para tener un mejor resultado, piensa en la tarea que se te pidió que realizaras con base a lo que las guías decian mientras contestas estas preguntas.

Instrucciones: Lea cada frase y señala qué tan de acuerdo o en desacuerdo estás y encierra en un circulo un número de la escala. Al terminar, revisaremos juntos el cuestionario para asegurarnos de que entendamos bien la información presentada en este cuestionario.

¡Gracias!

a) La organización de la información proporcionada por las guías me fue clara.

Totalmente en desacuerdo

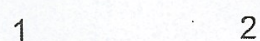
2 3

4

5 Totalmente de acuerdo

4

b) Fui capaz de completar las tareas que se me indicaron rápidamente con la información proporcionada en las guías.

Totalmente en desacuerdo
1
2

3

4

Totalmente de acuerdo

c) La información proporcionada por las guías fue fácil de entender.

Totalmente en desacuerdo

1

2

3

4

5
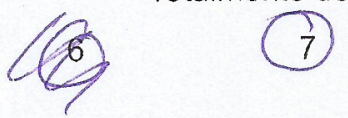

d) La apariencia de las guías es agradable.

Totalmente en desacuerdo

$$
12
$$

2

3

4

5

Totalmente de acuerdo

6

Totalmente de acuerdo

6

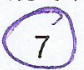

e) En general estoy satisfecho con el acomodo y presentación visual de la información.

Totalmente en desacuerdo

1

2

3

4

5

Totalmente de acuerdo

\section{6}

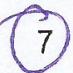




\section{LISTA DE CHEQUEO DEL ANÁLISIS DE TAREAS}

Evaluador: Wariel Cuestionario: 4 Fecha: $23 \cdot 10 \cdot 19$ Propuesta a evaluar: A

\begin{tabular}{|l|c|c|}
\hline Premisa & Si & No \\
\hline El diseñador generó una paleta de cuatro colores. & & \\
\hline $\begin{array}{l}\text { El diseñador relacionó correctamente los lineamientos de } \\
\text { codificación de información en dispositivos médicos y los } \\
\text { aplicó en las secciones de la gráfica de acuerdo a su signi- } \\
\text { ficado. }\end{array}$ & & \\
\hline $\begin{array}{l}\text { El diseñador estableció un buen contraste entre fondo, } \\
\text { figura y texto. }\end{array}$ & & \\
\hline Tiempo en que tardó en leer la página el diseñador. & 55 & \\
\hline Veces en que volvió a consultar la página el diseñador. & $3: 03: 05$ & \\
\hline Tiempo en que tardó en completar la tarea el diseñador. & & \\
\hline
\end{tabular}


Anexo 10.5. USUARIO 5: Material de resultados de la evaluación de la propuesta editorial "A": consentimiento informado, lista de chequedo de análisis de tareas y cuestionario PSSUQ. 


\section{Consentimiento informado}

Proyecto: NOMOLAS: Propuesta de guías de usabilidad para el diseño de interfaces gráficas de sistemas de visualización de información médica.

Nombre del estudio: Evaluación de usabilidad de propuestas editoriales de las guías de usabilidad NOMOLAS con usuarios (lectores) de las mismas.

Lugary fecha: \AM ACC CDMX

Número de registro:

05

Justificación y objetivo del estudio: La forma en que se presenta la información es importante para que ésta sea comprendida de la mejor manera posible. Este estudio tiene como propósito elegir la mejor propuesta editorial para implementarla en toda la composición visual del proyecto llamado "NOMOLAS: Propuesta de guias de usabilidad para el diseño de interfaces gráficas de sistemas de visualización de información médica", que es a su vez, trabajo de investigación doctoral.

Procedimientos: Primero, se le explicaran los objetivos y el procedimiento de la sesión; describiendo como se llevará a cabo la prueba. Segundo, le pediremos que siga las instrucciones que le entregue el investigador encargado.

Posibles riesgos y molestias: En investigaciones similares no se han registrado dificultades o riesgos de ningún tipo, por tanto, durante su participación no se prevé ningún riesgo.

Posibles beneficios que recibirá al participar en el estudio: Al final de la prueba se le dará al participante $\$ 50.00$ pesos mexicanos en efectivo.

Participación o retiro: Si después de que Usted haya leído esta información y haya obtenido respuesta a las preguntas que pudiera tener, le vamos a pedir leer y firmar esta carta de consentimiento informado. Sin embargo, Usted puede retirarse en cualquier momento, por cualquier razón y nadie le va a preguntar sobre las razones por las cuales se retira.

Privacidad y confidencialidad: Para garantizar la confidencialidad toda la información será guardada y analizada sin usar los nombres reales de los participantes. Después de ser analizada, la información será guardada por un tiempo razonable y luego destruida.

En caso de dudas o aclaraciones relacionadas con el estudio podrá dirigirse con: Mtra. Mariel García Hernández quien conoce todos los detalles de este estudio. 22249242 64, Correo: mariel.garciahernandez@gmail.com

Participante:

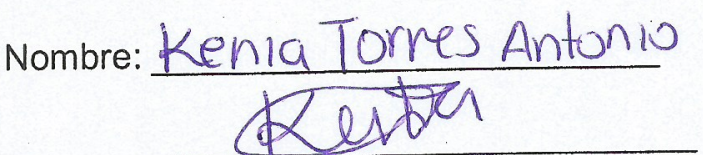

Firma
Quien obtiene el consentimiento:

Nombre: Unanel Garcia Hernänder

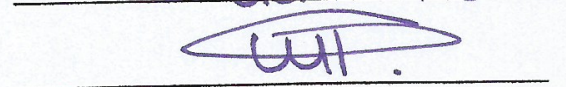

Firma 


\section{CUESTIONARIO PSSUQ}

Edad:20 Sexo: M I F Licenciatura: Diseño Comunicación Grátic Manejo de llustrator: SK I No Propuesta de guía: A No. de cuestionario: 115

Este cuestionario es una oportunidad para registrar tus reacciones a la guia de usabilidad. Estas respuestas nos ayudarán a entender qué aspectos hay que mejorar y cuales son con los que no estás satisfechos. Para tener un mejor resultado, piensa en la tarea que se te pidió que realizaras con base a lo que las guias decian mientras contestas estas preguntas.

Instrucciones: Lea cada frase y señala qué tan de acuerdo o en desacuerdo estás y encierra en un circulo un número de la escala. Al terminar, revisaremos juntos el cuestionario para asegurarnos de que entendamos bien la información presentada en este cuestionario.

¡Gracias!

a) La organización de la información proporcionada por las guías me fue clara.

Totalmente en desacuerdo

1

2

3

4

5

Totalmente de acuerdo

.

6

b) Fui capaz de completar las tareas que se me indicaron rápidamente con la información proporcionada en las guías.

Totalmente en desacuerdo

1

2

3

4

Totalmente de acuerdo

c) La información proporcionada por las guías fue fácil de entender.

Totalmente en desacuerdo

1

2

3

4

5

Totalmente de acuerdo

2

d) La apariencia de las guias es agradable.

Totalmente en desacuerdo

1

2

3

4

5

Totalmente de acuerdo

e) En general estoy satisfecho con el acomodo y presentación visual de la información.

Totalmente en desacuerdo

1

2

3

4

5

Totalmente de acuerdo . 
LISTA DE CHEQUEO DEL ANÁLISIS DE TAREAS

Evaluador: Mariel_Cuestionario: 5

Fecha: $23 \cdot 0.19$ Propuesta a evaluar: $A$

\begin{tabular}{|l|c|c|}
\hline Premisa & Si & No \\
\hline El diseñador generó una paleta de cuatro colores. & $\checkmark$ & \\
\hline $\begin{array}{l}\text { El diseñador relacionó correctamente los lineamientos de } \\
\text { codificación de información en dispositivos médicos y los } \\
\text { aplicó en las secciones de la gráfica de acuerdo a su signi- } \\
\text { ficado. }\end{array}$ & & \\
\hline $\begin{array}{l}\text { El diseñador estableció un buen contraste entre fondo, } \\
\text { figura y texto. }\end{array}$ & $1: 00: 02$ \\
\hline Tiempo en que tardó en leer la página el diseñador. & $11(2)$ & \\
\hline Veces en que volvió a consultar la página el diseñador. & $4: 39$ & \\
\hline Tiempo en que tardó en completar la tarea el diseñador. & \\
\hline
\end{tabular}


Anexo 10.6. USUARIO 6: Material de resultados de la evaluación de la propuesta editorial "A": consentimiento informado, lista de chequedo de análisis de tareas y cuestionario PSSUQ. 


\section{Consentimiento informado}

Proyecto: NOMOLAS: Propuesta de guías de usabilidad para el diseño de interfaces gráficas de sistemas de visualización de información médica.

Nombre del estudio: Evaluación de usabilidad de propuestas editoriales de las guías de usabilidad NOMOLAS con usuarios (lectores) de las mismas.

Lugary fecha: UAM ACC CDMX

Número de registro:

06

Justificación y objetivo del estudio: La forma en que se presenta la información es importante para que ésta sea comprendida de la mejor manera posible. Este estudio tiene como propósito elegir la mejor propuesta editorial para implementarla en toda la composición visual del proyecto llamado "NOMOLAS: Propuesta de guías de usabilidad para el diseño de interfaces gráficas de sistemas de visualización de información médica", que es a su vez, trabajo de investigación doctoral.

Procedimientos: Primero, se le explicaran los objetivos y el procedimiento de la sesión; describiendo como se llevará a cabo la prueba. Segundo, le pediremos que siga las instrucciones que le entregue el investigador encargado.

Posibles riesgos y molestias: En investigaciones similares no se han registrado dificultades o riesgos de ningún tipo, por tanto, durante su participación no se prevé ningún riesgo.

Posibles beneficios que recibirá al participar en el estudio: Al final de la prueba se le dará al participante $\$ 50.00$ pesos mexicanos en efectivo.

Participación o retiro: Si después de que Usted haya leído esta información y haya obtenido respuesta a las preguntas que pudiera tener, le vamos a pedir leer y firmar esta carta de consentimiento informado. Sin embargo, Usted puede retirarse en cualquier momento, por cualquier razón y nadie le va a preguntar sobre las razones por las cuales se retira.

Privacidad y confidencialidad: Para garantizar la confidencialidad toda la información será guardada y analizada sin usar los nombres reales de los participantes. Después de ser analizada, la información será guardada por un tiempo razonable y luego destruida.

En caso de dudas o aclaraciones relacionadas con el estudio podrá dirigirse con: Mtra. Mariel García Hernández quien conoce todos los detalles de este estudio. 2224924264 , Correo: mariel.garciahernandez@gmail.com

Participante:

Nombre: Alade Victoria Villegos Macias

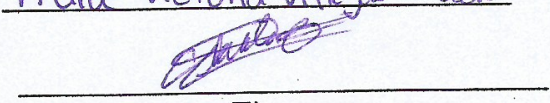

Firma

\section{Quien obtiene el consentimiento:}

Nombre: Wariel Gareta Hernöuder

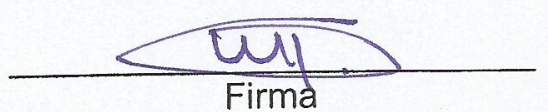




\section{CUESTIONARIO PSSUQ}

Edad: 21 Sexo: M \& Licenciatura: $D C G$ Manejo de llustrator: 8i I No Propuesta de guía: A No. de cuestionario: 6

Este cuestionario es una oportunidad para registrar tus reacciones a la guia de usabilidad. Estas respuestas nos ayudarán a entender qué aspectos hay que mejorar y cuales son con los que no estás satisfechos. Para tener un mejor resultado, piensa en la tarea que se te pidió que realizaras con base a lo que las guías decian mientras contestas estas preguntas.

Instrucciones: Lea çada frase y señala qué tan de acuerdo o en desacuerdo estás y encierra en un circulo un número de la escala. Al terminar, revisaremos juntos el cuestionario para asegurarnos de que entendamos bien la información presentada en este cuestionario.

¡Gracias!

a) La organización de la información proporcionada por las guías me fue clara.

Totalmente en desacuerdo$$
12
$$

2

3

4

5

Totalmente de acuerdo

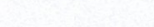

6 7

b) Fui capaz de completar las tareas que se me indicaron rápidamente con la información proporcionada: en las guías.

Totalmente en desacuerdo

$$
1.2
$$

3

(4)

5

Totalmente de acuerdo

7

c) La información proporcionada por las guias fue fácil de entender.

Totalmente en desacuerdo

1

2

3

4

5

Totalmente de acuerdo

2

d) La apariencia de las guías es agradable.

Totalmente en desacuerdo$$
1
$$

2

3

4

5

Totalmente de acuerdo

\section{7}

e) En general estoy satisfecho con el acomodo y presentación visual de la información.

Totalmente en desacuerdo

1

2

3

4

5

Totalmente de acuerdo

1 .

.

4


Evaluador: Wariel Cuestionario: 6 Fecha: $23-10 \cdot 19$ Propuesta a evaluar: $A$

\begin{tabular}{|l|c|c|}
\hline Premisa & Si & No \\
\hline El diseñador generó una paleta de cuatro colores. & & \\
\hline $\begin{array}{l}\text { El diseñador relacionó correctamente los lineamientos de } \\
\text { codificación de información en dispositivos médicos y los } \\
\text { aplicó en las secciones de la gráfica de acuerdo a su signi- } \\
\text { ficado. }\end{array}$ & & \\
\hline $\begin{array}{l}\text { El diseñador estableció un buen contraste entre fondo, } \\
\text { figura y texto. }\end{array}$ & 36 seg & \\
\hline Tiempo en que tardó en leer la página el diseñador. & - & $6: 22: 86$ \\
\hline Veces en que volvió a consultar la página el diseñador. & \\
\hline Tiempo en que tardó en completar la tarea el diseñador. & \\
\hline
\end{tabular}


Anexo 10.7. USUARIO 7: Material de resultados de la evaluación de la propuesta editorial "A": consentimiento informado, lista de chequedo de análisis de tareas y cuestionario PSSUQ. 


\section{Consentimiento informado}

Proyecto: NOMOLAS: Propuesta de guías de usabilidad para el diseño de interfaces gráficas de sistemas de visualización de información médica.

Nombre del estudio: Evaluación de usabilidad de propuestas editoriales de las guías de usabilidad NOMOLAS con usuarios (lectores) de las mismas.

Lugary fecha: UAM ACC CDMX

Número de registro:

Justificación y objetivo del estudio: La forma en que se presenta la información es importante para que ésta sea comprendida de la mejor manera posible. Este estudio tiene como propósito elegir la mejor propuesta editorial para implementarla en toda la composición visual del proyecto llamado "NOMOLAS: Propuesta de guías de usabilidad para el diseño de interfaces gráficas de sistemas de visualización de información médica", que es a su vez, trabajo de investigación doctoral.

Procedimientos: Primero, se le explicaran los objetivos y el procedimiento de la sesión; describiendo como se llevará a cabo la prueba. Segundo, le pediremos que siga las instrucciones que le entregue el investigador encargado.

Posibles riesgos y molestias: En investigaciones similares no se han registrado dificultades o riesgos de ningún tipo, por tanto, durante su participación no se prevé ningún riesgo.

Posibles beneficios que recibirá al participar en el estudio: Al final de la prueba se le dará al participante $\$ 50.00$ pesos mexicanos en efectivo.

Participación o retiro: Si después de que Usted haya leído esta información y haya obtenido respuesta a las preguntas que pudiera tener, le vamos a pedir leer y firmar esta carta de consentimiento informado. Sin embargo, Usted puede retirarse en cualquier momento, por cualquier razón y nadie le va a preguntar sobre las razones por las cuales se retira.

Privacidad y confidencialidad: Para garantizar la confidencialidad toda la información será guardada y analizada sin usar los nombres reales de los participantes. Después de ser analizada, la información será guardada por un tiempo razonable y luego destruida.

En caso de dudas o aclaraciones relacionadas con el estudio podrá dirigirse con: Mtra. Mariel García Hernández quien conoce todos los detalles de este estudio. 2224924264 , Correo: mariel.garciahernandez@gmail.com

\section{Participante:}

Nombre: Sanora Rubio de va Rosa

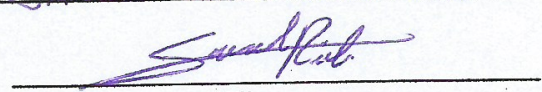

Firma

\section{Quien obtiene el consentimiento:}

Nombre: Uarlel Gartia Hemiòudez

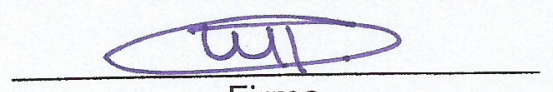

Firma 


\section{CUESTIONARIO PSSUQ}

Edad: 22 Sexo: M / F Licenciatura: Diseño oe ea Gomunicacion Mánejo de llustrator: (Si) I No Propuesta de guía: A No. de cuestionario: 7

Este cuestionario es una oportunidad para registrar tus reacciones a la guia de usabilidad. Estas respuestas nos ayudarán a entender qué aspectos hay que mejorar y cuales son con los que no estás satisfechos. Para tener un mejor resultado, piensa en la tarea que se te pidió que realizaras con base a lo que las guías decian mientras contestas estas preguntas.

Instrucciones: Lea cada frase y señala qué tan de acuerdo o en desacuerdo estás y encierra en un circulo un número de la escala. Al terminar, revisaremos juntos el cuestionario para asegurarnos de que entendamos bien la información presentada en este cuestionario.

¡Gracias!

a) La organización de la información proporcionada por las guías me fue clara.

Totalmente en desacuerdo

$$
1 \quad 2
$$

2

3

4

5

Totalmente de acuerdo

b) Fui capaz de completar las tareas que se me indicaron rápidamente con la información proporcionada en las guías.

Totalmente en desacuerdo

$1-2$

3

4

5

Totalmente de acuerdo

6

(7)

c) La información proporcionada por las guias fue fácil de entender.

Totalmente en desacuerdo$$
1
$$

3

4

5

Totalmente de acuerdo

6

(7)

d) La apariencia de las guías es agradable.

Totalmente en desacuerdo

$$
12
$$

2

3

4

5

Totalmente de acuerdo

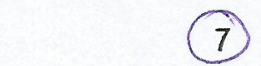

e) En general estoy satisfecho con el acomodo y presentación visual de la información.

Totalmente en desacuerdo 


\section{LISTA DE CHEQUEO DEL ANÁLISIS DE TAREAS}

Evaluador: Wariel Cuestionario: 7 Fecha: $23 \cdot 10 \cdot 19$ Propuesta a evaluar: A

\begin{tabular}{|l|c|c|}
\hline Premisa & Si & No \\
\hline El diseñador generó una paleta de cuatro colores. & & \\
\hline $\begin{array}{l}\text { El diseñador relacionó correctamente los lineamientos de } \\
\text { codificación de información en dispositivos médicos y los } \\
\text { aplicó en las secciones de la gráfica de acuerdo a su signi- } \\
\text { ficado. }\end{array}$ & & \\
\hline $\begin{array}{l}\text { El diseñador estableció un buen contraste entre fondo, } \\
\text { figura y texto. }\end{array}$ & $1: 14: 88 \mathrm{~min} \mathrm{C8}$ \\
\hline \begin{tabular}{l} 
Tiempo en que tardó en leer la página el diseñador. \\
\hline Veces en que volvió a consultar la página el diseñador.
\end{tabular} & $2: 14.60 \mathrm{O}$ \\
\hline Tiempo en que tardó en completar la tarea el diseñador. & $2: 14: 64 \mathrm{~min}$ \\
\hline
\end{tabular}


Anexo 10.8. USUARIO 8: Material de resultados de la evaluación de la propuesta editorial "A": consentimiento informado, lista de chequedo de análisis de tareas y cuestionario PSSUQ. 


\section{Consentimiento informado}

Proyecto: NOMOLAS: Propuesta de guías de usabilidad para el diseño de interfaces gráficas de sistemas de visualización de información médica.

Nombre del estudio: Evaluación de usabilidad de propuestas editoriales de las guías de usabilidad NOMOLAS con usuarios (lectores) de las mismas.

Lugar y fecha: UAM AeC CDMX

Número de registro:

08

Justificación y objetivo del estudio: La forma en que se presenta la información es importante para que ésta sea comprendida de la mejor manera posible. Este estudio tiene como propósito elegir la mejor propuesta editorial para implementarla en toda la composición visual del proyecto llamado "NOMOLAS: Propuesta de guías de usabilidad para el diseño de interfaces gráficas de sistemas de visualización de información médica", que es a su vez, trabajo de investigación doctoral.

Procedimientos: Primero, se le explicaran los objetivos y el procedimiento de la sesión; describiendo como se llevará a cabo la prueba. Segundo, le pediremos que siga. las instrucciones que le entregue el investigador encargado.

Posibles riesgos y molestias: En investigaciones similares no se han registrado dificultades o riesgos de ningún tipo, por tanto, durante su participación no se prevé ningún riesgo.

Posibles beneficios que recibirá al participar en el estudio: Al final de la prueba se le dará al participante $\$ 50.00$ pesos mexicanos en efectivo.

Participación o retiro: Si después de que Usted haya leído esta información y haya obtenido respuesta a las preguntas que pudiera tener, le vamos a pedir leer y firmar esta carta de consentimiento informado. Sin embargo, Usted puede retirarse en cualquier momento, por cualquier razón y nadie le va a preguntar sobre las razones por las cuales se retira.

Privacidad y confidencialidad: Para garantizar la confidencialidad toda la información será guardada y analizada sin usar los nombres reales de los participantes. Después de ser analizada, la información será guardada por un tiempo razonable y luego destruida.

En caso de dudas o aclaraciones relacionadas con el estudio podrá dirigirse con: Mtra. Mariel García Hernández quien conoce todos los detalles de este estudio. 2224924264 , Correo: mariel.garciahernandez@gmail.com

Participante:

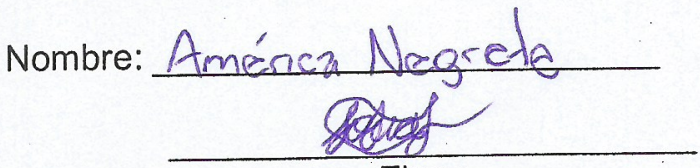

Firma
Quien obtiene el consentimiento:

Nombre: Warel Garcia Hekuouder

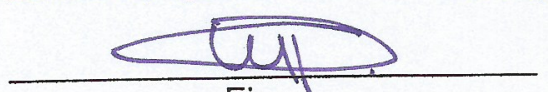

Firma 


\section{CUESTIONARIO PSSUQ}

Edad: Sexo: M / F Licenciatura:

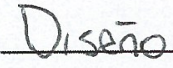

de 1

Propuesta de guía:

No. de cuestionario: grafich

Este cuestionario es una oportunidad para registrar tus reacciones a la guia de usabilidad. Estas respuestas nos ayudarán a entender qué aspectos hay que mejorar y cuales son con los que no estás satisfechos. Para tener un mejor resultado, piensa en la tarea que se te pidió que realizaras con base a lo que las guías decían mientras contestas estas preguntas.

Instrucciones: Lea cada frase y señala qué tan de acuerdo o en desacuerdo estás y encierra en un circulo un número de la escala. Al terminar, revisaremos juntos el cuestionario para asegurarnos de que entendamos bien la información presentada en este cuestionario.

\section{¡Gracias!}

a) La organización de la información proporcionada por las guías me fue clara.

Totalmente en desacuerdo

$$
1 \quad 2
$$

2

Totalmente de acuerdo
3
4
5
4
62

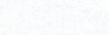

b) Fui capaz de completar las tareas que se me indicaron rápidamente con la información proporcionada en las guías.

Totalmente en desacuerdo

$$
12
$$

2

3

4

5

Totalmente de acuerdo

2

c) La información proporcionada por las guias fue fácil de entender.

Totalmente en desacuerdo$$
1
$$

2

3

4

5

Totalmente de acuerdo

(1)

es agradable.

d) La apariencia de las guias es agradable.

Totalmente en desacuerdo

$$
12
$$

2

3

4

5

Totalmente de acuerdo

e) En general estoy satisfecho con el acomodo y presentación visual de la información. Totalmente en desacuerdo

5

Totalmente de acuerdo

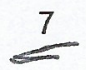




\section{LISTA DE CHEQUEO DEL ANÁLISIS DE TAREAS}

Evaluador: Uanel cuestionario: 8 Fecha: $8^{23 \cdot 10 \cdot 19}$ Propuesta a evaluar: A

\begin{tabular}{|l|l|l|}
\hline Premisa & Si & No \\
\hline El diseñador generó una paleta de cuatro colores. & & \\
\hline $\begin{array}{l}\text { El diseñador relacionó correctamente los lineamientos de } \\
\text { codificación de información en dispositivos médicos y los } \\
\text { aplicó en las secciones de la gráfica de acuerdo a su signi- } \\
\text { ficado. }\end{array}$ & & \\
\hline $\begin{array}{l}\text { El diseñador estableció un buen contraste entre fondo, } \\
\text { figura y texto. }\end{array}$ & & \\
\hline Tiempo en que tardó en leer la página el diseñador. & $53 \mathrm{seg}$. & \\
\hline Veces en que volvió a consultar la página el diseñador. & 1 \\
\hline Tiempo en que tardó en completar la tarea el diseñador. & $28350.5 \mathrm{~min}$ \\
\hline
\end{tabular}


Anexo 10.9. USUARIO 9: Material de resultados de la evaluación de la propuesta editorial "A": consentimiento informado, lista de chequedo de análisis de tareas y cuestionario PSSUQ. 


\section{Consentimiento informado}

Proyecto: NOMOLAS: Propuesta de guias de usabilidad para el diseño de interfaces gráficas de sistemas de visualización de información médica.

Nombre del estudio: Evaluación de usabilidad de propuestas editoriales de las guias de usabilidad NOMOLAS con usuarios (lectores) de las mismas.

Lugar y fecha: LAM AZC CDMX

Número de registro:

09

Justificación y objetivo del estudio: La forma en que se presenta la información es importante para que ésta sea comprendida de la mejor manera posible. Este estudio tiene como propósito elegir la mejor propuesta editorial para implementarla en toda la composición visual del proyecto llamado "NOMOLAS: Propuesta de guías de usabilidad para el diseño de interfaces gráficas de sistemas de visualización de información médica", que es a su vez, trabajo de investigación doctoral.

Procedimientos: Primero, se le explicaran los objetivos y el procedimiento de la sesión; describiendo como se llevará a cabo la prueba. Segundo, le pediremos que siga las instrucciones que le entregue el investigador encargado.

Posibles riesgos y molestias: En investigaciones similares no se han registrado dificultades o riesgos de ningún tipo, por tanto, durante su participación no se prevé ningún riesgo.

Posibles beneficios que recibirá al participar en el estudio: Al final de la prueba se le dará al participante $\$ 50.00$ pesos mexicanos en efectivo.

Participación o retiro: Si después de que Usted haya leído esta información y haya obtenido respuesta a las preguntas que pudiera tener, le vamos a pedir leer y firmar esta carta de consentimiento informado. Sin embargo, Usted puede retirarse en cualquier momento, por cualquier razón y nadie le va a preguntar sobre las razones por las cuales se retira.

Privacidad y confidencialidad: Para garantizar la confidencialidad toda la información será guardada y analizada sin usar los nombres reales de los participantes. Después de ser analizada, la información será guardada por un tiempo razonable y luego destruida.

En caso de dudas o aclaraciones relacionadas con el estudio podrá dirigirse con: Mtra. Mariel Garcia Hernández quien conoce todos los detalles de este estudio. 2224924264 , Correo: mariel.garciahernandez@gmail.com

\section{Participante:}

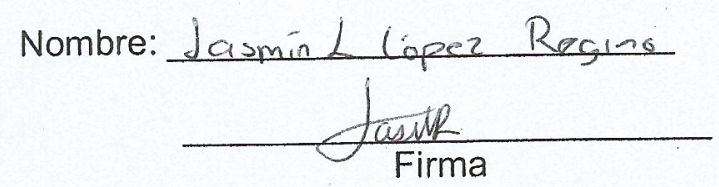

Quien obtiene el consentimiento:

Nombre: Warrel Eareia Heunänder

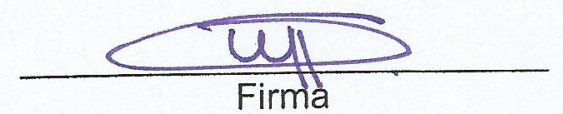




\section{CUESTIONARIO PSSUQ}

Edad: 22 Sexo: M / F Licenciatura:D15.Com Grafica_ Manejo de llustrator: (Si)/ No

Propuesta de guía: $A$

No. de cuestionario:

Este cuestionario es una oportunidad para registrar tus reacciones a la guia de usabilidad. Estas respuestas nos ayudarán a entender qué aspectos hay que mejorar y cuales son con los que no estás satisfechos. Para tener un mejor resultado, piensa en la tarea que se te pidió que realizaras con base a lo que las guías decian mientras contestas estas preguntas.

Instrucciones: Lea cada frase y señala quẻ tan de acuerdo o en desacuerdo estás y encierra en un circulo un número de la escala. Al terminar, revisaremos juntos el cuestionario para asegurarnos de que entendamos bien la información presentada en este cuestionario.

¡Gracias!

a) La organización de la información proporcionada por las guias me fue clara.

Totalmente en desacuerdo

$$
1 \quad 2
$$

2

3

4

5

Totalmente de acuerdo<smiles>c1ccccc1</smiles>

7

b) Fui capaz de completar las tareas que se me indicaron rápidamente con la información proporcionada en las guías.

Totalmente en desacuerdo

$$
1
$$

2

3

4

5

Totalmente de acuerdo

7

c) La información proporcionada por las guías fue fácil de entender.

Totalmente en desacuerdo

1

2

3

4

5

Totalmente de acuerdo

6

(7)

d) La apariencia de las guías es agradable.

Totalmente en desacuerdo

$$
1
$$

2

3

4

5

Totalmente de acuerdo

6

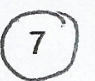

e) En general estoy satisfecho con el acomodo y presentación visual de la información.

Totalmente en desacuerdo 


\section{LISTA DE CHEQUEO DEL ANÁLISIS DE TAREAS}

Evaluador: Uanel Cuestionario: 9 Fecha: $23 \cdot 10 \cdot 19$ Propuesta a evaluar: $A$

\begin{tabular}{|l|c|c|}
\hline Premisa & Si & No \\
\hline El diseñador generó una paleta de cuatro colores. & & \\
\hline $\begin{array}{l}\text { El diseñador relacionó correctamente los lineamientos de } \\
\text { codificación de información en dispositivos médicos y los } \\
\text { aplicó en las secciones de la gráfica de acuerdo a su signi- } \\
\text { ficado. }\end{array}$ & & \\
\hline $\begin{array}{l}\text { El diseñador estableció un buen contraste entre fondo, } \\
\text { figura y texto. }\end{array}$ & 37 sey & \\
\hline Tiempo en que tardó en leer la página el diseñador. & 111 & \\
\hline Veces en que volvió a consultar la página el diseñador. & 3778 & \\
\hline Tiempo en que tardó en completar la tarea el diseñador. & & \\
\hline
\end{tabular}


Anexo 10.10. USUARIO 10: Material de resultados de la evaluación de la propuesta editorial "A": consentimiento informado, lista de chequedo de análisis de tareas y cuestionario PSSUQ. 


\section{Consentimiento informado}

Proyecto: NOMOLAS: Propuesta de guias de usabilidad para el diseño de interfaces gráficas de sistemas de visualización de información médica.

Nombre del estudio: Evaluación de usabilidad de propuestas editoriales de las guias de usabilidad NOMOLAS con usuarios (lectores) de las mismas.

Lugar y fecha: UAMACC ODMX

Número de registro:

10

Justificación y objetivo del estudio: La forma en que se presenta la información es importante para que ésta sea comprendida de la mejor manera posible. Este estudio tiene como propósito elegir la mejor propuesta editorial para implementarla en toda la composición visual del proyecto llamado "NOMOLAS: Propuesta de guías de usabilidad para el diseño de interfaces gráficas de sistemas de visualización de información médica", que es a su vez, trabajo de investigación doctoral.

Procedimientos: Primero, se le explicaran los objetivos y el procedimiento de la sesión; describiendo como se llevará a cabo la prueba. Segundo, le pediremos que siga las instrucciones que le entregue el investigador encargado.

Posibles riesgos y molestias: En investigaciones similares no se han registrado dificultades o riesgos de ningún tipo, por tanto, durante su participación no se prevé ningún riesgo.

Posibles beneficios que recibirá al participar en el estudio: Al final de la prueba se le dará al participante $\$ 50.00$ pesos mexicanos en efectivo.

Participación o retiro: Si después de que Usted haya leído esta información y haya obtenido respuesta a las preguntas que pudiera tener, le vamos a pedir leer y firmar esta carta de consentimiento informado. Sin embargo, Usted puede retirarse en cualquier momento, por cualquier razón y nadie le va a preguntar sobre las razones por las cuales se retira.

Privacidad y confidencialidad: Para garantizar la confidencialidad toda la información será guardada y analizada sin usar los nombres reales de los participantes. Después de ser analizada, la información será guardada por un tiempo razonable y luego destruida.

En caso de dudas o aclaraciones relacionadas con el estudio podrá dirigirse con: Mtra. Mariel García Hernández quien conoce todos los detalles de este estudio. 2224924264 , Correo: mariel.garciahernandez@gmail.com

\section{Participante:}

Nombre: Mavio Alberto Agurlar lskes

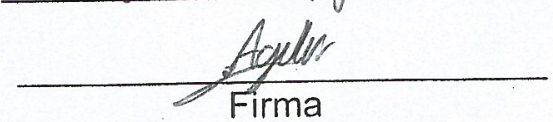

Quien obtiene el consentimiento:

Nombre: Uarlel Garēa Heruōude

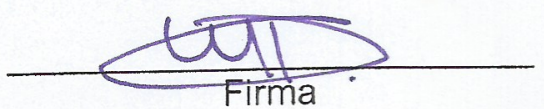




\section{CUESTIONARIO PSSUQ}

Edad:20 sexo: M I F Licenciatura: Diseño de la Coumunícriconle Manejo de llustrator: si I No Propuesta de guía: A No. de cuestionario: 10

Este cuestionario es una oportunidad para registrar tus reacciones a la guía de usabilidad. Estas respuestas nos ayudarán a entender qué aspectos hay que mejorar y cuales son con los que no estás satisfechos. Para tener un mejor resultado, piensa en la tarea que se te pidió que realizaras con base a lo que las guías decían mientras contestas estas preguntas.

Instrucciones: Lea cada frase y señala qué tan de acuerdo o en desacuerdo estás y encierra en un circulo un número de la escala. Al terminar, revisaremos juntos el cuestionario para asegurarnos de que entendamos bien la información presentada en este cuestionario.

¡Gracias!

a) La organización de la información proporcionada por las guías me fue clara.

Totalmente en desacuerdo

$$
1 \quad 2
$$

3

4

5

Totalmente de acuerdo

.

b) Fui capaz de completar las tareas que se me indicaron rápidamente con la información proporcionada:en las guías.

Totalmente en desacuerdo

1

2

3

4

5

Totalmente de acuerdo

(2)

c) La información proporcionada por las guias fue fácil de entender.

Totalmente en desacuerdo

1

2

3

4

5

Totalmente de acuerdo

as

d) La apariencia de las guias es agradable.

Totalmente en desacuerdo

12

23

34

5

Totalmente de acuerdo

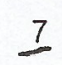

e) En general estoy satisfecho con el acomodo y presentación visual de la información.

Totalmente en desacuerdo 
Evaluador: Waliel_Cuestionario: 10 Fecha: $23 \cdot 10^{-19}$ Propuesta a evaluar: $A$

\begin{tabular}{|l|c|c|}
\hline Premisa & Si & No \\
\hline El diseñador generó una paleta de cuatro colores. & & \\
\hline $\begin{array}{l}\text { El diseñador relacionó correctamente los lineamientos de } \\
\text { codificación de información en dispositivos médicos y los } \\
\text { aplicó en las secciones de la gráfica de acuerdo a su signi- } \\
\text { ficado. }\end{array}$ & & \\
\hline $\begin{array}{l}\text { El diseñador estableció un buen contraste entre fondo, } \\
\text { figura y texto. }\end{array}$ & $40.98 \mathrm{seg}$ \\
\hline Tiempo en que tardó en leer la página el diseñador. & - & $1: 58 \mathrm{~min}$ \\
\hline Veces en que volvió a consultar la página el diseñador. & \\
\hline Tiempo en que tardó en completar la tarea el diseñador. & & \\
\hline
\end{tabular}


Anexo 10.11. USUARIO 11: Material de resultados de la evaluación de la propuesta editorial "A": consentimiento informado, lista de chequedo de análisis de tareas y cuestionario PSSUQ. 


\section{Consentimiento informado}

Proyecto: NOMOLAS: Propuesta de guias de usabilidad para el diseño de interfaces gráficas de sistemas de visualización de información médica.

Nombre del estudio: Evaluación de usabilidad de propuestas editoriales de las guías de usabilidad NOMOLAS con usuarios (lectores) de las mismas.

Lugar y fecha: 24 de oct. 2019 cholula, pue.

Número de registro:

11

Justificación y objetivo del estudio: La forma en que se presenta la información es importante para que ésta sea comprendida de la mejor manera posible. Este estudio tiene como propósito elegir la mejor propuesta editorial para implementarla en toda la composición visual del proyecto llamado "NOMOLAS: Propuesta de guias de usabilidad para el diseño de interfaces gráficas de sistemas de visualización de información médica", que es a su vez, trabajo de investigación doctoral.

Procedimientos: Primero, se le explicaran los objetivos y el procedimiento de la sesión; describiendo como se llevará a cabo la prueba. Segundo, le pediremos que siga las instrucciones que le entregue el investigador encargado.

Posibles riesgos y molestias: En investigaciones similares no se han registrado dificultades o riesgos de ningún tipo, por tanto, durante su participación no se prevé ningún riesgo.

Posibles beneficios que recibirá al participar en el estudio: Al final de la prueba se le dará al participante $\$ 50.00$ pesos mexicanos en efectivo.

Participación o retiro: Si después de que Usted haya leido esta información y haya obtenido respuesta a las preguntas que pudiera tener, le vamos a pedir leer y firmar esta carta de consentimiento informado. Sin embargo, Usted puede retirarse en cualquier momento, por cualquier razón y nadie le va a preguntar sobre las razones por las cuales se retira.

Privacidad y confidencialidad: Para garantizar la confidencialidad toda la información será guardada y analizada sin usar los nombres reales de los participantes. Después de ser analizada, la información será guardada por un tiempo razonable y luego destruida.

En caso de dudas o aclaraciones relacionadas con el estudio podrá dirigirse con: Mtra. Mariel García Hernández quien conoce todos los detalles de este estudio. 2224924264 , Correo: mariel.garciahernandez@gmail.com

\section{Participante:}

Nombre: Irán Carolina Leal

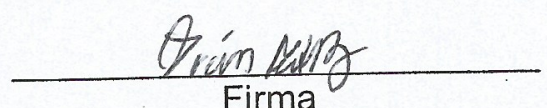

Quien obtiene el consentimiento:

Nombre: Wahel Earria Helnänder

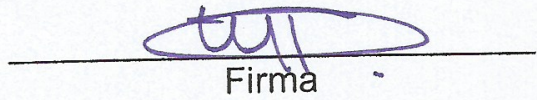




\section{CUESTIONARIO PSSUQ}

Edad:20 Sexo: M I (F) Licenciatura: Diseño de In formación Visual Manejo de llustrator:Si I No Propuesta de guía:

No. de cuestionario: 11

Este cuestionario es una oportunidad para registrar tus reacciones a la guía de usabilidad. Estas respuestas nos ayudarán a entender qué aspectos hay que mejorar y cuales son con los que no estás satisfechos. Para tener un mejor resultado, piensa en la tarea que se te pidió que realizaras con base a lo que las guias decian mientras contestas estas preguntas.

Instrucciones: Lea cada frase y señala qué tan de acuerdo o en desacuerdo estás y encierra en un circulo un número de la escala. Al terminar, revisaremos juntos el cuestionario para asegurarnos de que entendamos bien la información presentada en este cuestionario.

¡Gracias!

a) La organización de la información proporcionada por las guías me fue clara.

Totalmente en desacuerdo

$1 \quad 2$

2.3

34

45

6

Totalmente de acuerdo

(7)

b) Fui capaz de completar las tareas que se me indicaron rápidamente con la información proporcionada en las guías.

Totalmente en desacuerdo

1

2

3

4

5

Totalmente de acuerdo

3

c) La información proporcionada por las guías fue fácil de entender.

Totalmente en desacuerdo

1

2

3

4

5

Totalmente de acuerdo

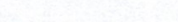

d) La apariencia de las guías es agradable.

Totalmente en desacuerdo

1

2

3

4

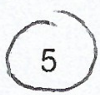

Totalmente de acuerdo

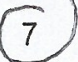

e) En general estoy satisfecho con el acomodo y presentación visual de la información.

Totalmente en desacuerdo

1

2

3

4

5

Totalmente de acuerdo 


\section{LISTA DE CHEQUEO DEL ANÁLISIS DE TAREAS}

Evaluador: Wavel_Cuestionario:_ 11 Fecha:24.0Ct Propuesta a evaluar: A

\begin{tabular}{|l|l|l|}
\hline Premisa & Si & No \\
\hline El diseñador generó una paleta de cuatro colores. & & $\times$ \\
\hline $\begin{array}{l}\text { El diseñador relacionó correctamente los lineamientos de } \\
\text { codificación de información en dispositivos médicos y los } \\
\text { aplicó en las secciones de la gráfica de acuerdo a su signi- } \\
\text { ficado. }\end{array}$ & & \\
\hline $\begin{array}{l}\text { El diseñador estableció un buen contraste entre fondo, } \\
\text { figura y texto. }\end{array}$ & & \\
\hline $\begin{array}{l}\text { Tiempo en que tardó en leer la página el diseñador. } \\
\text { Veces en que volvió a consultar la página el diseñador. }\end{array}$ & $1 / 1(3)$ & \\
\hline Tiempo en que tardó en completar la tarea el diseñador. & $5173 !$ & \\
\hline
\end{tabular}


Anexo 10.12. USUARIO 12: Material de resultados de la evaluación de la propuesta editorial "A": consentimiento informado, lista de chequedo de análisis de tareas y cuestionario PSSUQ. 


\section{Consentimiento informado}

Proyecto: NOMOLAS: Propuesta de guías de usabilidad para el diseño de interfaces gráficas de sistemas de visualización de información médica.

Nombre del estudio: Evaluación de usabilidad de propuestas editoriales de las guias de usabilidad NOMOLAS con usuarios (lectores) de las mismas.

Lugar y fecha:
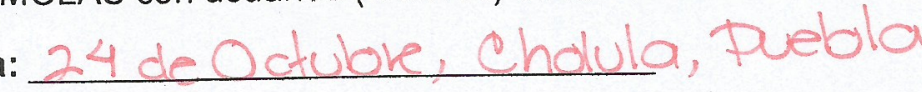

Número de registro:

12.

Justificación y objetivo del estudio: La forma en que se presenta la información es importante para que ésta sea comprendida de la mejor manera posible. Este estudio tiene como propósito elegir la mejor propuesta editorial para implementarla en toda la composición visual del proyecto llamado "NOMOLAS: Propuesta de guías de usabilidad para el diseño de interfaces gráficas de sistemas de visualización de información médica", que es a su vez, trabajo de investigación doctoral.

Procedimientos: Primero, se le explicaran los objetivos y el procedimiento de la sesión; describiendo como se llevará a cabo la prueba. Segundo, le pediremos que siga las instrucciones que le entregue el investigador encargado.

Posibles riesgos y molestias: En investigaciones similares no se han registrado dificultades o riesgos de ningún tipo, por tanto, durante su participación no se prevé ningún riesgo.

Posibles beneficios que recibirá al participar en el estudio: Al final de la prueba se le dará al participante $\$ 50.00$ pesos mexicanos en efectivo.

Participación o retiro: Si después de que Usted haya leido esta información y haya obtenido respuesta a las preguntas que pudiera tener, le vamos a pedir leer y firmar esta carta de consentimiento informado. Sin embargo, Usted puede retirarse en cualquier momento, por cualquier razón y nadie le va a preguntar sobre las razones por las cuales se retira.

Privacidad y confidencialidad: Para garantizar la confidencialidad toda la información será guardada y analizada sin usar los nombres reales de los participantes. Después de ser analizada, la información será guardada por un tiempo razonable y luego destruida.

En caso de dudas o aclaraciones relacionadas con el estudio podrá dirigirse con: Mtra. Mariel García Hernández quien conoce todos los detalles de este estudio. 2224924264 , Correo: mariel.garciahernandez@gmail.com

Participante:

Quien obtiene el consentimiento:

Nombre: Mavia de Jejus Quiñonanombre: Warrel Garéa Hemandez

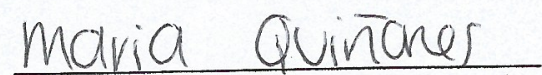

\& R. Firma

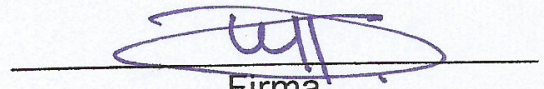

Firma 


\section{CUESTIONARIO PSSUQ}

Edad:20 Sexo: M / F Licenciatura:

Manejo de llustrator: Si / No

Propuesta de guía:

No. de cuestionario: 12

Este cuestionario es una oportunidad para registrar tus reacciones a la guia de usabilidad. Estas respuestas nos ayudarán a entender qué aspectos hay que mejorar y cuales son con los que no estás satisfechos. Para tener un mejor resultado, piensa en la tarea que se te pidió que realizaras con base a lo que las guías decian mientras contestas estas preguntas.

Instrucciones: Lea cada frase y señala qué tan de acuerdo o en desacuerdo estás y encierra en un circulo un número de la escala. Al terminar, revisaremos juntos el cuestionario para asegurarnos de que entendamos bien la información presentada en este cuestionario.

\section{¡Gracias!}

a) La organización de la información proporcionada por las guías me fue clara.

Totalmente en desacuerdo

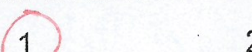

2

3

4

5

Totalmente de acuerdo

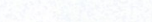

6

7

b) Fui capaz de completar las tareas que se me indicaron rápidamente con la información proporcionada en las guías.

Totalmente en desacuerdo
1
(2)
3
4
5
7

Totalmente de acuerdo

c) La información proporcionada por las guías fue fácil de entender.

Totalmente en desacuerdo

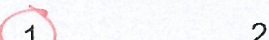

2

3

4

5

Totalmente de acuerdo

6

7

d) La apariencia de las guías es agradable.

Totalmente en desacuerdo

1

(2) 3

34

45

Totalmente de acuerdo

$6 \quad 7$

e) En general estoy satisfecho con el acomodo y presentación visual de la información.

Totalmente en desacuerdo

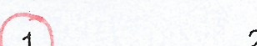

(1)

2

3

4

5

Totalmente de acuerdo 


\section{LISTA DE CHEQUEO DEL ANÁLISIS DE TAREAS}

Evaluador: Uhariel Cuestionario: 12 Fecha: $24 \cdot 0 \mathrm{ct} .19$ Propuesta a evaluar: A

\begin{tabular}{|l|c|l|}
\hline Premisa & Si & No \\
\hline El diseñador generó una paleta de cuatro colores. & $\checkmark$ & \\
\hline $\begin{array}{l}\text { El diseñador relacionó correctamente los lineamientos de } \\
\text { codificación de información en dispositivos médicos y los } \\
\text { aplicó en las secciones de la gráfica de acuerdo a su signi- } \\
\text { ficado. }\end{array}$ & & \\
\hline $\begin{array}{l}\text { El diseñador estableció un buen contraste entre fondo, } \\
\text { figura y texto. }\end{array}$ & 47.79 seg \\
\hline $\begin{array}{l}\text { Tiempo en que tardó en leer la página el diseñador. } \\
\text { Veces en que volvió a consultar la página el diseñador. }\end{array}$ & $0.58 .91 \mathrm{~min}$ \\
\hline Tiempo en que tardó en completar la tarea el diseñador. & 0.58 & \\
\hline
\end{tabular}


Anexo 10.13. USUARIO 13: Material de resultados de la evaluación de la propuesta editorial "A": consentimiento informado, lista de chequedo de análisis de tareas y cuestionario PSSUQ. 


\section{Consentimiento informado}

Proyecto: NOMOLAS: Propuesta de guias de usabilidad para el diseño de interfaces gráficas de sistemas de visualización de información médica.

Nombre del estudio: Evaluación de usabilidad de propuestas editoriales de las guias de usabilidad NOMOLAS con usuarios (lectores) de las mismas.

Lugar y fecha:
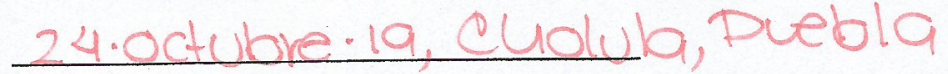

Número de registro:

13

Justificación y objetivo del estudio: La forma en que se presenta la información es importante para que ésta sea comprendida de la mejor manera posible. Este estudio tiene como propósito elegir la mejor propuesta editorial para implementarla en toda la composición visual del proyecto llamado "NOMOLAS: Propuesta de guías de usabilidad para el diseño de interfaces gráficas de sistemas de visualización de información médica", que es a su vez, trabajo de investigación doctoral.

Procedimientos: Primero, se le explicaran los objetivos y el procedimiento de la sesión; describiendo como se llevará a cabo la prueba. Segundo, le pediremos que siga las instrucciones que le entregue el investigador encargado.

Posibles riesgos y molestias: En investigaciones similares no se han registrado dificultades o riesgos de ningún tipo, por tanto, durante su participación no se prevé ningún riesgo.

Posibles beneficios que recibirá al participar en el estudio: Al final de la prueba se le dará al participante $\$ 50.00$ pesos mexicanos en efectivo.

Participación o retiro: Si después de que Usted haya leído esta información y haya obtenido respuesta a las preguntas que pudiera tener, le vamos a pedir leer y firmar esta carta de consentimiento informado. Sin embargo, Usted puede retirarse en cualquier momento, por cualquier razón y nadie le va a preguntar sobre las razones por las cuales se retira.

Privacidad y confidencialidad: Para garantizar la confidencialidad toda la información será guardada y analizada sin usar los nombres reales de los participantes. Después de ser analizada, la información será guardada por un tiempo razonable y luego destruida.

En caso de dudas o aclaraciones relacionadas con el estudio podrá dirigirse con: Mtra. Mariel García Hernández quien conoce todos los detalles de este estudio. 2224924264 , Correo: mariel.garciahernandez@gmail.com

\section{Participante:}

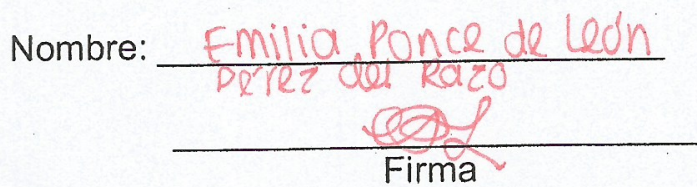

\section{Quien obtiene el consentimiento:}

Nombre: Ulanel Garcia Hernóncler

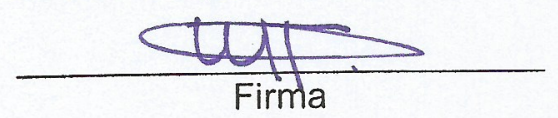




\section{CUESTIONARIO PSSUQ}

Edad: 19 Sexo: M I F Licenciatura: Diseño de Información Vifual Manejo de llustrator: Si I No Propuesta de guía: A No. de cuestionario: 13

Este cuestionario es una oportunidad para registrar tus reacciones a la guía de usabilidad. Estas respuestas nos ayudarán a entender qué aspectos hay que mejorar y cuales son con los que no estás satisfechos. Para tener un mejor resultado, piensa en la tarea que se te pidió que realizaras con base a lo que las guías decian mientras contestas estas preguntas.

Instrucciones: Lea cada frase y señala qué tan de acuerdo o en desacuerdo estás y encierra en un circulo un número de la escala. Al terminar, revisaremos juntos el cuestionario para asegurarnos de que entendamos bien la información presentada en este cuestionario.

¡Gracias!

a) La organización de la información proporcionada por las guías me fue clara.

Totalmente en desacuerdo

$$
1 \quad 2
$$

2

3

4

5

Totalmente de acuerdo

b) Fui capaz de completar las tareas que se me indicaron rápidamente con la información proporcionada:en las guías.

Totalmente en desacuerdo

1

2

3

4

5

Totalmente de acuerdo

c) La información proporcionada por las guías fue fácil de entender.

Totalmente en desacuerdo

1

2

3

4

5

Totalmente de acuerdo

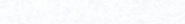

67

d) La apariencia de las guías es agradable.

Totalmente en desacuerdo

1

2

3

4

5

Totalmente de acuerdo

6

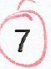

e) En general estoy satisfecho con el acomodo y presentación visual de la información.

Totalmente en desacuerdo

Totalmente de acuerdo

1




\section{LISTA DE CHEQUEO DEL ANÁLISIS DE TAREAS}

Evaluador: Uavel_Cuestionario: 13 Fecha: $24 \cdot 10 \cdot 19$ Propuesta a evaluar: A

\begin{tabular}{|l|l|l|}
\hline Premisa & Si & No \\
\hline El diseñador generó una paleta de cuatro colores. & $\checkmark$ & \\
\hline $\begin{array}{l}\text { El diseñador relacionó correctamente los lineamientos de } \\
\text { codificación de información en dispositivos médicos y los } \\
\text { aplicó en las secciones de la gráfica de acuerdo a su signi- } \\
\text { ficado. }\end{array}$ & & \\
\hline $\begin{array}{l}\text { El diseñador estableció un buen contraste entre fondo, } \\
\text { figura y texto. }\end{array}$ & & \\
\hline $\begin{array}{l}\text { Tiempo en que tardó en leer la página el diseñador. } \\
\text { Veces en que volvió a consultar la página el diseñador. }\end{array}$ & $111(3) 9 \mathrm{seg}$ \\
\hline Tiempo en que tardó en completar la tarea el diseñador. & $2: 36.29 \mathrm{~min}$ \\
\hline
\end{tabular}


Anexo 10.14. USUARIO 14: Material de resultados de la evaluación de la propuesta editorial "A": consentimiento informado, lista de chequedo de análisis de tareas y cuestionario PSSUQ. 


\section{Consentimiento informado}

Proyecto: NOMOLAS: Propuesta de guias de usabilidad para el diseño de interfaces gráficas de sistemas de visualización de información médica.

Nombre del estudio: Evaluación de usabilidad de propuestas editoriales de las guías de usabilidad NOMOLAS con usuarios (lectores) de las mismas.

Lugar y fecha: _ MAt 24 de Octube del 2019

Número de registro: $\quad 14$

Justificación y objetivo del estudio: La forma en que se presenta la información es importante para que ésta sea comprendida de la mejor manera posible. Este estudio tiene como propósito elegir la mejor propuesta editorial para implementarla en toda la composición visual del proyecto llamado "NOMOLAS: Propuesta de guías de usabilidad para el diseño de interfaces gráficas de sistemas de visualización de información médica", que es a su vez, trabajo de investigación doctoral.

Procedimientos: Primero, se le explicaran los objetivos y el procedimiento de la sesión; describiendo como se llevará a cabo la prueba. Segundo, le pediremos que siga. las instrucciones que le entregue el investigador encargado.

Posibles riesgos y molestias: En investigaciones similares no se han registrado dificultades o riesgos de ningún tipo, por tanto, durante su participación no se prevé ningún riesgo.

Posibles beneficios que recibirá al participar en el estudio: Al final de la prueba se le dará al participante $\$ 50.00$ pesos mexicanos en efectivo.

Participación o retiro: Si después de que Usted haya leído esta información y haya obtenido respuesta a las preguntas que pudiera tener, le vamos a pedir leer y firmar esta carta de consentimiento informado. Sin embargo, Usted puede retirarse en cualquier momento, por cualquier razón y nadie le va a preguntar sobre las razones por las cuales se retira.

Privacidad y confidencialidad: Para garantizar la confidencialidad toda la información será guardada y analizada sin usar los nombres reales de los participantes. Después de ser analizada, la información será guardada por un tiempo razonable y luego destruida.

En caso de dudas o aclaraciones relacionadas con el estudio podrá dirigirse con: Mtra. Mariel García Hernández quien conoce todos los detalles de este estudio. 2224924264 , Correo: mariel.garciahernandez@gmail.com

Participante:

Quien obtiene el consentimiento:

Nombre: Ana Ceelia Barrena leo Nombre: Uarlel Garcia Heruouder
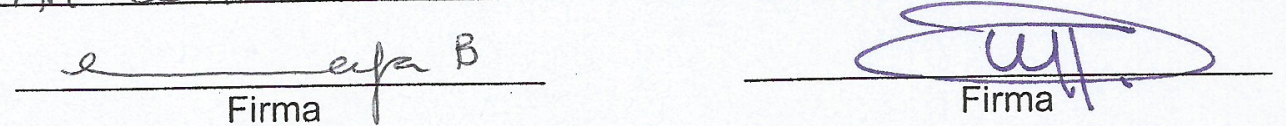


\section{CUESTIONARIO PSSUQ}

Edad: 19 sexo: M I F Licenciatura: Diseño de lnfo Vsud Manejo de llustrator Si I No Propuesta de guía:A No. de cuestionario: 14

Este cuestionario es una oportunidad para registrar tus reacciones a la guia de usabilidad. Estas respuestas nos ayudarán a entender qué aspectos hay que mejorar y cuales son con los que no estás satisfechos. Para tener un mejor resultado, piensa en la tarea que se te pidió que realizaras con base a lo que las guias decian mientras contestas estas preguntas.

Instrucciones: Lea cada frase y señala qué tan de acuerdo o en desacuerdo estás y encierra en un circulo un número de la escala. Al terminar, revisaremos juntos el cuestionario para asegurarnos de que entendamos bien la información presentada en este cuestionario.

¡Gracias!

a) La organización de la información proporcionada por las guías me fue clara.

Totalmente en desacuerdo

$$
12
$$

34

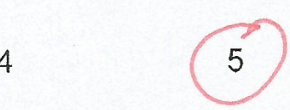

Totalmente de acuerdo 6

b) Fui capaz de completar las tareas que se me indicaron rápidamente con la información proporcionada en las guías.

Totalmente en desacuerdo

1

2

3

4

5

Totalmente de acuerdo

c) La información proporcionada por las guías fue fácil de entender.

Totalmente en desacuerdo

1

2
3

4

d) La apariencia de las guías es agradable.

Totalmente en desacuerdo

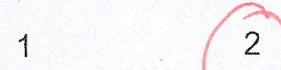

1

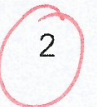

3

4

e) En general estoy satisfecho con el acomodo y presentación visual de la información. Totalmente en desacuerdo

1

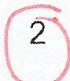

Totalmente de acuerdo

6
Totalmente de acuerdo

7
Totalmente de acuerdo

7 


\section{LISTA DE CHEQUEO DEL ANÁLISIS DE TAREAS}

Evaluador: Uane Cuestionario: 14 Fecha: $24 \cdot 0 \mathrm{ct} \cdot 19$ Propuesta a evaluar: A

\begin{tabular}{|l|c|l|}
\hline Premisa & Si & No \\
\hline El diseñador generó una paleta de cuatro colores. & & \\
\hline $\begin{array}{l}\text { El diseñador relacionó correctamente los lineamientos de } \\
\text { codificación de información en dispositivos médicos y los } \\
\text { aplicó en las secciones de la gráfica de acuerdo a su signi- } \\
\text { ficado. }\end{array}$ & & \\
\hline $\begin{array}{l}\text { El diseñador estableció un buen contraste entre fondo, } \\
\text { figura y texto. }\end{array}$ & & \\
\hline Tiempo en que tardó en leer la página el diseñador. & $22.03 \mathrm{seg}$ \\
\hline Veces en que volvió a consultar la página el diseñador. & 1 \\
\hline Tiempo en que tardó en completar la tarea el diseñador. & $1.44 .58 \mathrm{~min}$ \\
\hline
\end{tabular}


Anexo 10.15. USUARIO 15: Material de resultados de la evaluación de la propuesta editorial "A": consentimiento informado, lista de chequedo de análisis de tareas y cuestionario PSSUQ. 


\section{Consentimiento informado}

Proyecto: NOMOLAS: Propuesta de guias de usabilidad para el diseño de interfaces gráficas de sistemas de visualización de información médica.

Nombre del estudio: Evaluación de usabilidad de propuestas editoriales de las guías de usabilidad NOMOLAS con usuarios (lectores) de las mismas.

Lugar y fecha:

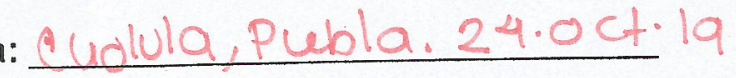

Número de registro:

15

Justificación y objetivo del estudio: La forma en que se presenta la información es importante para que ésta sea comprendida de la mejor manera posible. Este estudio tiene como propósito elegir la mejor propuesta editorial para implementarla en toda la composición visual del proyecto llamado "NOMOLAS: Propuesta de guías de usabilidad para el diseño de interfaces gráficas de sistemas de visualización de información médica", que es a su vez, trabajo de investigación doctoral.

Procedimientos: Primero, se le explicaran los objetivos y el procedimiento de la sesión; describiendo como se llevará a cabo la prueba. Segundo, le pediremos que siga. las instrucciones que le entregue el investigador encargado.

Posibles riesgos y molestias: En investigaciones similares no se han registrado dificultades o riesgos de ningún tipo, por tanto, durante su participación no se prevé ningún riesgo.

Posibles beneficios que recibirá al participar en el estudio: Al final de la prueba se le dará al participante $\$ 50.00$ pesos mexicanos en efectivo.

Participación o retiro: Si después de que Usted haya leido esta información y haya obtenido respuesta a las preguntas que pudiera tener, le vamos a pedir leer y firmar esta carta de consentimiento informado. Sin embargo, Usted puede retirarse en cualquier momento, por cualquier razón y nadie le va a preguntar sobre las razones por las cuales se retira.

Privacidad y confidencialidad: Para garantizar la confidencialidad toda la información será guardada y analizada sin usar los nombres reales de los participantes. Después de ser analizada, la información será guardada por un tiempo razonable y luego destruida.

En caso de dudas o aclaraciones relacionadas con el estudio podrá dirigirse con: Mtra. Mariel García Hernández quien conoce todos los detalles de este estudio. 2224924264 , Correo: mariel.garciahernandez@gmail.com

Participante:

Nombre:

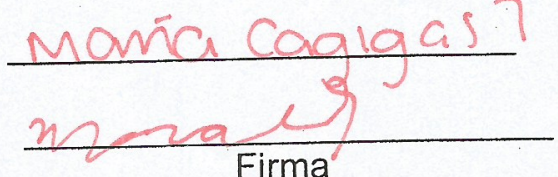

Quien obtiene el consentimiento:

Nombre: Wariel Garcia Hernāndec

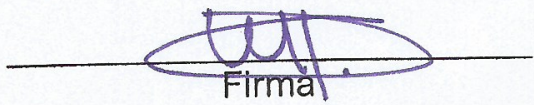




\section{CUESTIONARIO PSSUQ}

Edad:19 Sexo: M / F Licenciatura:Disefnedein formoclónManejo de llustrator: Si / No Propuesta de guía: A No. de cuestionario: 15

Este cuestionario es una oportunidad para registrar tus reacciones a la guia de usabilidad. Estas respuestas nos ayudarán a entender qué aspectos hay que mejorar y cuales son con los que no estás satisfechos. Para tener un mejor resultado, piensa en la tarea que se te pidió que realizaras con base a lo que las guías decian mientras contestas estas preguntas.

Instrucciones: Lea cada frase y señala qué tan de acuerdo o en desacuerdo estás y encierra en un circulo un número de la escala. Al terminar, revisaremos juntos el cuestionario para asegurarnos de que entendamos bien la información presentada en este cuestionario.

¡Gracias!

a) La organización de la información proporcionada por las guías me fue clara.

Totalmente en desacuerdo

$$
12
$$

2

3

4

5

Totalmente de acuerdo

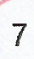

b) Fui capaz de completar las tareas que se me indicaron rápidamente con la información proporcionada en las guías.

Totalmente en desacuerdo

$$
12
$$

2

3

4

5

Totalmente de acuerdo

c) La información proporcionada por las guías fue fácil de entender.

Totalmente en desacuerdo

1

2
4

d) La apariencia de las guías es agradable.

Totalmente en desacuerdo

12
3

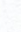

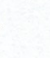

Totalmente de acuerdo

6

Totalmente de acuerdo 7

e) En general estoy satisfecho con el acomodo y presentación visual de la información.

Totalmente en desacuerdo

1

2

3

4

5

Totalmente de acuerdo 


\section{LISTA DE CHEQUEO DEL ANÁLISIS DE TAREAS}

Evaluador: Warel_Cuestionario: 15 Fecha:24.0ct.19 Propuesta a evaluar: A

\begin{tabular}{|l|c|c|}
\hline Premisa & Si & No \\
\hline El diseñador generó una paleta de cuatro colores. & $\checkmark$ & \\
\hline $\begin{array}{l}\text { El diseñador relacionó correctamente los lineamientos de } \\
\text { codificación de información en dispositivos médicos y los } \\
\text { aplicó en las secciones de la gráfica de acuerdo a su signi- } \\
\text { ficado. }\end{array}$ & $\sqrt{ }$ & \\
\hline $\begin{array}{l}\text { El diseñador estableció un buen contraste entre fondo, } \\
\text { figura y texto. }\end{array}$ & $1 \mathrm{~S} \cdot 11 \mathrm{seg}$ \\
\hline Tiempo en que tardó en leer la página el diseñador. & $2 \mathrm{~min}$ \\
\hline Veces en que volvió a consultar la página el diseñador. & \\
\hline Tiempo en que tardó en completar la tarea el diseñador. & & \\
\hline
\end{tabular}



Anexo 10.16. USUARIO 16: Material de resultados de la evaluación de la propuesta editorial "B": consentimiento informado, lista de chequedo de análisis de tareas y cuestionario PSSUQ. 


\section{Consentimiento informado}

Proyecto: NOMOLAS: Propuesta de guías de usabilidad para el diseño de interfaces gráficas de sistemas de visualización de información médica.

Nombre del estudio: Evaluación de usabilidad de propuestas editoriales de las guías de usabilidad NOMOLAS con usuarios (lectores) de las mismas.

Lugar y fecha: Cuolula, Puebla.

Número de registro:

16

Justificación y objetivo del estudio: La forma en que se presenta la información es importante para que ésta sea comprendida de la mejor manera posible. Este estudio tiene como propósito elegir la mejor propuesta editorial para implementarla en toda la composición visual del proyecto llamado "NOMOLAS: Propuesta de guías de usabilidad para el diseño de interfaces gráficas de sistemas de visualización de información médica", que es a su vez, trabajo de investigación doctoral.

Procedimientos: Primero, se le explicaran los objetivos y el procedimiento de la sesión; describiendo como se llevará a cabo la prueba. Segundo, le pediremos que siga. las instrucciones que le entregue el investigador encargado.

Posibles riesgos y molestias: En investigaciones similares no se han registrado dificultades 0 riesgos de ningún tipo, por tanto, durante su participación no se prevé ningún riesgo.

Posibles beneficios que recibirá al participar en el estudio: Al final de la prueba se le dará al participante $\$ 50.00$ pesos mexicanos en efectivo.

Participación o retiro: Si después de que Usted haya leído esta información y haya obtenido respuesta a las preguntas que pudiera tener, le vamos a pedir leer y firmar esta carta de consentimiento informado. Sin embargo, Usted puede retirarse en cualquier momento, por cualquier razón y nadie le va a preguntar sobre las razones por las cuales se retira.

Privacidad y confidencialidad: Para garantizar la confidencialidad toda la información será guardada y analizada sin usar los nombres reales de los participantes. Después de ser analizada, la información será guardada por un tiempo razonable y luego destruida.

En caso de dudas o aclaraciones relacionadas con el estudio podrá dirigirse con: Mtra. Mariel García Hernández quien conoce todos los detalles de este estudio. 2224924264 , Correo: mariel.garciahernandez@gmail.com

\section{Participante:}

Nombre: Paola lbarra Alwarzz

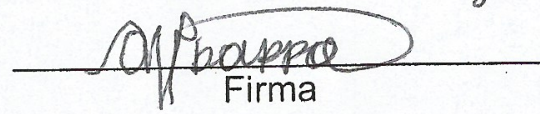

\section{Quien obtiene el consentimiento:}

Nombre: Uarel Garia Hevidudec

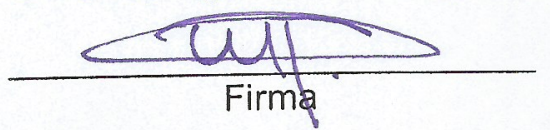




\section{CUESTIONARIO PSSUQ}

Edad: 19 sexo: M IF Licenciatura: D Beño de infoim. Manejo de llustrator: Si I No Propuesta de guía: $B$ No. de cuestionario: 16

Este cuestionario es una oportunidad para registrar tus reacciones a la guía de usabilidad. Estas respuestas nos ayudarán a entender qué aspectos hay que mejorar y cuales son con los que no estás satisfechos. Para tener un mejor resultado, piensa en la tarea que se te pidió que realizaras con base a lo que las guías decian mientras contestas estas preguntas.

Instrucciones: Lea cada frase y señala qué tan de acuerdo o en desacuerdo estás y encierra en un circulo un número de la escala. Al terminar, revisaremos juntos el cuestionario para asegurarnos de que entendamos bien la información presentada en este cuestionario.

¡Gracias!

a) La organización de la información proporcionada por las guías me fue clara.

Totalmente en desacuerdo

1

2

3

4

5

6

Totalmente de acuerdo

.

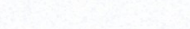

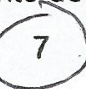

b) Fui capaz de completar las tareas que se me indicaron rápidamente con la información proporcionada en las guías.

Totalmente en desacuerdo

1

2

3

4

5

Totalmente de acuerdo

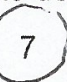

c) La información proporcionada por las guías fue fácil de entender.

Totalmente en desacuerdo

1

2

3

4

5

Totalmente de acuerdo

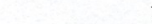

d) La apariencia de las guías es agradable.

Totalmente en desacuerdo

1

2

3

4

5

Totalmente de acuerdo

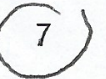

e) En general estoy satisfecho con el acomodo y presentación visual de la información.

Totalmente en desacuerdo

1

2

3

4

5

Totalmente de acuerdo

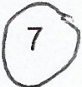


Evaluador: Ulanel Cuestionario: 16 Fecha: $28.00+19$

\begin{tabular}{|l|c|l|}
\hline Premisa & Si & No \\
\hline El diseñador generó una paleta de cuatro colores. & $V$ & \\
\hline $\begin{array}{l}\text { El diseñador relacionó correctamente los lineamientos de } \\
\text { codificación de información en dispositivos médicos y los } \\
\text { aplicó en las secciones de la gráfica de acuerdo a su signi- } \\
\text { ficado. }\end{array}$ & $\checkmark$ & \\
\hline $\begin{array}{l}\text { El diseñador estableció un buen contraste entre fondo, } \\
\text { figura y texto. }\end{array}$ & & \\
\hline Tiempo en que tardó en leer la página el diseñador. & $48.68 \mathrm{seg}$ \\
\hline Veces en que volvió a consultar la página el diseñador. & $2: 03.08$ \\
\hline Tiempo en que tardó en completar la tarea el diseñador. & 2 & \\
\hline
\end{tabular}


Anexo 10.17. USUARIO 17: Material de resultados de la evaluación de la propuesta editorial "B": consentimiento informado, lista de chequedo de análisis de tareas y cuestionario PSSUQ. 


\section{Consentimiento informado}

Proyecto: NOMOLAS: Propuesta de guias de usabilidad para el diseño de interfaces gráficas de sistemas de visualización de información médica.

Nombre del estudio: Evaluación de usabilidad de propuestas editoriales de las guías de usabilidad NOMOLAS con usuarios (lectores) de las mismas.

Lugar y fecha:Cuolula, Puebla. 2 a oct.la

Número de registro:

17

Justificación y objetivo del estudio: La forma en que se presenta la información es importante para que ésta sea comprendida de la mejor manera posible. Este estudio tiene como propósito elegir la mejor propuesta editorial para implementarla en toda la composición visual del proyecto llamado "NOMOLAS: Propuesta de guías de usabilidad para el diseño de interfaces gráficas de sistemas de visualización de información médica", que es a su vez, trabajo de investigación doctoral.

Procedimientos: Primero, se le explicaran los objetivos y el procedimiento de la sesión; describiendo como se llevará a cabo la prueba. Segundo, le pediremos que siga las instrucciones que le entregue el investigador encargado.

Posibles riesgos y molestias: En investigaciones similares no se han registrado dificultades o riesgos de ningún tipo, por tanto, durante su participación no se prevé ningún riesgo.

Posibles beneficios que recibirá al participar en el estudio: Al final de la prueba se le dará al participante $\$ 50.00$ pesos mexicanos en efectivo.

Participación o retiro: Si después de que Usted haya leido esta información y haya obtenido respuesta a las preguntas que pudiera tener, le vamos a pedir leer y firmar esta carta de consentimiento informado. Sin embargo, Usted puede retirarse en cualquier momento, por cualquier razón y nadie le va a preguntar sobre las razones por las cuales se retira.

Privacidad y confidencialidad: Para garantizar la confidencialidad toda la información será guardada y analizada sin usar los nombres reales de los participantes. Después de ser analizada, la información será guardada por un tiempo razonable y luego destruida.

En caso de dudas o aclaraciones relacionadas con el estudio podrá dirigirse con: Mtra. Mariel García Hernández quien conoce todos los detalles de este estudio. 22249242 64, Correo: mariel.garciahernandez@gmail.com

Participante:

Nombre: Sofía Ramitez Garzón

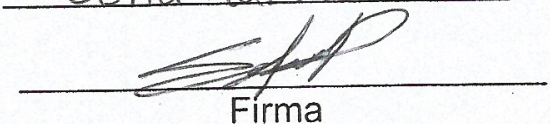

Quien obtiene el consentimiento:

Nombre: Marel García Heruöuder

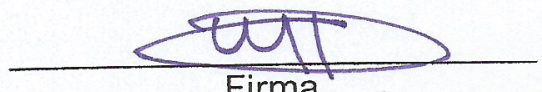




\section{CUESTIONARIO PSSUQ}

Edad: 19 sexo: M I (F) Licenciatura: Diseño de Informoldón Visual manejo de llustrator: (si) I No Propuesta de guía: B No. de cuestionario: 17

Este cuestionario es una oportunidad para registrar tus reacciones a la guía de usabilidad. Estas respuestas nos ayudarán a entender qué aspectos hay que mejorar y cuales son con los que no estás satisfechos. Para tener un mejor resultado, piensa en la tarea que se te pidió que realizaras con base a lo que las guías decian mientras contestas estas preguntas.

Instrucciones: Lea cada frase y señala qué tan de acuerdo o en desacuerdo estás y encierra en un circulo un número de la escala. Al terminar, revisaremos juntos el cuestionario para asegurarnos de que entendamos bien la información presentada en este cuestionario.

\section{¡Gracias!}

a) La organización de la información proporcionada por las guías me fue clara.

Totalmente en desacuerdo

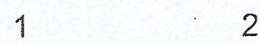

2

3

4

5

Totalmente de acuerdo

6

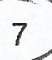

b) Fui capaz de completar las tareas que se me indicaron rápidamente con la información proporcionada en las guías.

Totalmente en desacuerdo

12

3

4

5

Totalmente de acuerdo

6

c) La información proporcionada por las guías fue fácil de entender.

Totalmente en desacuerdo

1

2

3

4

5

Totalmente-de acuerdo

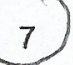

d) La apariencia de las guías es agradable.

Totalmente en desacuerdo

1

2

3

4

5

Totalmente de acuerdo

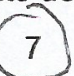

e) En general estoy satisfecho con el acomodo y presentación visual de la información.

Totalmente en desacuerdo

1

2

3

4

5

Totalmente de acuerdo

6 


\section{LISTA DE CHEQUEO DEL ANÁLISIS DE TAREAS}

Evaluador: Mharcel Cuestionario: 17 Fecha: $28.0 \mathrm{ct} .19$ Propuesta a evaluar: $B$

\begin{tabular}{|l|l|l|}
\hline Premisa & Si & No \\
\hline El diseñador generó una paleta de cuatro colores. & & $\times$ \\
\hline $\begin{array}{l}\text { El diseñador relacionó correctamente los lineamientos de } \\
\text { codificación de información en dispositivos médicos y los } \\
\text { aplicó en las secciones de la gráfica de acuerdo a su signi- } \\
\text { ficado. }\end{array}$ & X & \\
\hline $\begin{array}{l}\text { El diseñador estableció un buen contraste entre fondo, } \\
\text { figura y texto. }\end{array}$ & - & \\
\hline $\begin{array}{l}\text { Tiempo en que tardó en leer la página el diseñador. } \\
\text { Veces en que volvió a consultar la página el diseñador. }\end{array}$ & $2.25 .48 \mathrm{~min}$ \\
\hline Tiempo en que tardó en completar la tarea el diseñador.
\end{tabular}


Anexo 10.18. USUARIO 18: Material de resultados de la evaluación de la propuesta editorial "B": consentimiento informado, lista de chequedo de análisis de tareas y cuestionario PSSUQ. 


\section{Consentimiento informado}

Proyecto: NOMOLAS: Propuesta de guías de usabilidad para el diseño de interfaces gráficas de sistemas de visualización de información médica.

Nombre del estudio: Evaluación de usabilidad de propuestas editoriales de las guías de usabilidad NOMOLAS con usuarios (lectores) de las mismas.

Lugar y fecha: 4. Uomeuble 19 , Puebla, Ouebla.

Número de registro:

18

Justificación y objetivo del estudio: La forma en que se presenta la información es importante para que ésta sea comprendida de la mejor manera posible. Este estudio tiene como propósito elegir la mejor propuesta editorial para implementarla en toda la composición visual del proyecto Ilamado "NOMOLAS: Propuesta de guías de usabilidad para el diseño de interfaces gráficas de sistemas de visualización de información médica", que es a su vez, trabajo de investigación doctoral.

Procedimientos: Primero, se le explicaran los objetivos y el procedimiento de la sesión; describiendo como se llevará a cabo la prueba. Segundo, le pediremos que siga las instrucciones que le entregue el investigador encargado.

Posibles riesgos y molestias: En investigaciones similares no se han registrado dificultades o riesgos de ningún tipo, por tanto, durante su participación no se prevé ningún riesgo.

Posibles beneficios que recibirá al participar en el estudio: Al final de la prueba se le dará al participante $\$ 50.00$ pesos mexicanos en efectivo.

Participación o retiro: Si después de que Usted haya leído esta información y haya obtenido respuesta a las preguntas que pudiera tener, le vamos a pedir leer y firmar esta carta de consentimiento informado. Sin embargo, Usted puede retirarse en cualquier momento, por cualquier razón y nadie le va a preguntar sobre las razones por las cuales se retira.

Privacidad y confidencialidad: Para garantizar la confidencialidad toda la información será guardada y analizada sin usar los nombres reales de los participantes. Después de ser analizada, la información será guardada por un tiempo razonable y luego destruida.

En caso de dudas o aclaraciones relacionadas con el estudio podrá dirigirse con: Mtra. Mariel García Hernández quien conoce todos los detalles de este estudio. 2224924264 , Correo: mariel.garciahernandez@gmail.com

\section{Participante:}

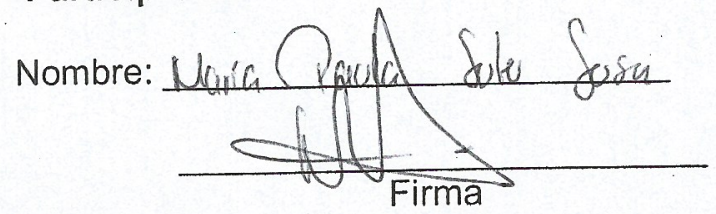

Quien obtiene el consentimiento:

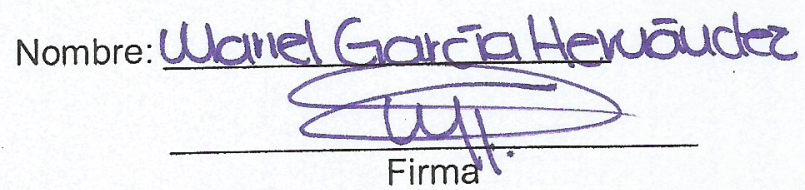




\section{CUESTIONARIO PSSUQ} Edad: 22 Sexo: M, Licenciatura: Difñ Grifice y Digital Manejo de llustrator: \& 1 No
Propuesta de guía: B No. de cuestionario: 18

Este cuestionario es una oportunidad para registrar tus reacciones a la guia de usabilidad. Estas respuestas nos ayudarán a entender qué aspectos hay que mejorar y cuales son con los que no estás satisfechos. Para tener un mejor resultado, piensa en la tarea que se te pidió que realizaras con base a lo que las guías decian mientras contestas estas preguntas.

Instrucciones: Lea cada frase y señala qué tan de acuerdo o en desacuerdo estás y encierra en un circulo un número de la escala. Al terminar, revisaremos juntos el cuestionario para asegurarnos de que entendamos bien la información presentada en este cuestionario.

¡Gracias!

a) La organización de la información proporcionada por las guías me fue clara.

Totalmente en desacuerdo

$$
1 \quad 2
$$
2
3

4

5

Totalmente de acuerdo

b) Fui capaz de completar las tareas que se me indicaron rápidamente con la información proporcionada en las guías.

Totalmente en desacuerdo

1

2

3

4

5

Totalmente de acuerdo

c) La información proporcionada por las guias fue fácil de entender.

Totalmente en desacuerdo

$$
1
$$

2

3

4

5

Totalmente de acuerdo

d) La apariencia de las guías es agradable.

Totalmente en desacuerdo

$$
1 \quad 2
$$
2
3

4

5

Totalmente de acuerdo

e) En general estoy satisfecho con el acomodo y presentación visual de la información.

Totalmente en desacuerdo 


\section{LISTA DE CHEQUEO DEL ANÁLISIS DE TAREAS}

Evaluador: Wanel Cuestionario: 18 Fecha: $4.499^{\circ}$ Propuesta a evaluar: B

\begin{tabular}{|l|c|c|}
\hline Premisa & Si & No \\
\hline El diseñador generó una paleta de cuatro colores. & $\checkmark$ & \\
\hline $\begin{array}{l}\text { El diseñador relacionó correctamente los lineamientos de } \\
\text { codificación de información en dispositivos médicos y los } \\
\text { aplicó en las secciones de la gráfica de acuerdo a su signi- } \\
\text { ficado. }\end{array}$ & $\checkmark$ & $1: 02: 47 \mathrm{mih}$ \\
\hline $\begin{array}{l}\text { El diseñador estableció un buen contraste entre fondo, } \\
\text { figura y texto. }\end{array}$ & $-4: 25 \cdot 53$ \\
\hline Tiempo en que tardó en leer la página el diseñador. & - & \\
\hline Veces en que volvió a consultar la página el diseñador. & \\
\hline Tiempo en que tardó en completar la tarea el diseñador. & \\
\hline
\end{tabular}


Anexo 10.19. USUARIO 19: Material de resultados de la evaluación de la propuesta editorial "B": consentimiento informado, lista de chequedo de análisis de tareas y cuestionario PSSUQ. 


\section{Consentimiento informado}

Proyecto: NOMOLAS: Propuesta de guías de usabilidad para el diseño de interfaces gráficas de sistemas de visualización de información médica.

Nombre del estudio: Evaluación de usabilidad de propuestas editoriales de las guias de usabilidad NOMOLAS con usuarios (lectores) de las mismas.

Lugar y fecha: Puebla, Pue. 4. UOv-19

Número de registro:

19

Justificación y objetivo del estudio: La forma en que se presenta la información es importante para que ésta sea comprendida de la mejor manera posible. Este estudio tiene como propósito elegir la mejor propuesta editorial para implementarla en toda la composición visual del proyecto llamado "NOMOLAS: Propuesta de guías de usabilidad para el diseño de interfaces gráficas de sistemas de visualización de información médica", que es a su vez, trabajo de investigación doctoral.

Procedimientos: Primero, se le explicaran los objetivos y el procedimiento de la sesión; describiendo como se llevará a cabo la prueba. Segundo, le pediremos que siga las instrucciones que le entregue el investigador encargado.

Posibles riesgos y molestias: En investigaciones similares no se han registrado dificultades o riesgos de ningún tipo, por tanto, durante su participación no se prevé ningún riesgo.

Posibles beneficios que recibirá al participar en el estudio: Al final de la prueba se le dará al participante $\$ 50.00$ pesos mexicanos en efectivo.

Participación o retiro: Si después de que Usted haya leido esta información y haya obtenido respuesta a las preguntas que pudiera tener, le vamos a pedir leer y firmar esta carta de consentimiento informado. Sin embargo, Usted puede retirarse en cualquier momento, por cualquier razón y nadie le va a preguntar sobre las razones por las cuales se retira.

Privacidad y confidencialidad: Para garantizar la confidencialidad toda la información será guardada y analizada sin usar los nombres reales de los participantes. Después de ser analizada, la información será guardada por un tiempo razonable y luego destruida.

En caso de dudas o aclaraciones relacionadas con el estudio podrá dirigirse con: Mtra. Mariel García Hernández quien conoce todos los detalles de este estudio. 2224924264 , Correo: mariel.garciahernandez@gmail.com

\section{Participante:}

Nombre: María José Ramírez Arrieta:

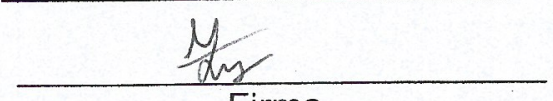

Firma
Quien obtiene el consentimiento:

Nombre: Marlel Garcia Hemōuder

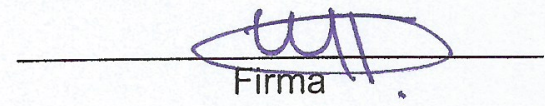




\section{CUESTIONARIO PSSUQ}

Edad:22 Sexo: M / X Licenciatura: Diseño gráfico y digital Manejo de llustrator: \$ 1 No Propuesta de guía: $B$ No. de cuestionario: 19

Este cuestionario es una oportunidad para registrar tus reacciones a la guia de usabilidad. Estas respuestas nos ayudarán a entender qué aspectos hay que mejorar y cuales son con los que no estás satisfechos. Para tener un mejor resultado, piensa en la tarea que se te pidió que realizaras con base a lo que las guías decian mientras contestas estas preguntas.

Instrucciones: Lea cada frase y señala qué tan de acuerdo o en desacuerdo estás y encierra en un circulo un número de la escala. Al terminar, revisaremos juntos el cuestionario para asegurarnos de que entendamos bien la información presentada en este cuestionario.

|Gracias!

a) La organización de la información proporcionada por las guías me fue clara.

Totalmente en desacuerdo

1.2
2
3

4

5

Totalmente de acuerdo

7

b) Fui capaz de completar las tareas que se me indicaron rápidamente con la información proporcionada en las guías.

Totalmente en desacuerdo

1

2

3

4

Totalmente de acuerdo

-

c) La información proporcionada por las guías fue fácil de entender.

Totalmente en desacuerdo

1

2

3

4

5

Totalmente de acuerdo

astable.

d) La apariencia de las guias es agradable.

Totalmente en desacuerdo

12

23

34

45

Totalmente de acuerdo

ॠ 7

Totalmente en desacuerdo

1

2

3

4

5

Totalmente de acuerdo

\section{6}




\section{LISTA DE CHEQUEO DEL ANÁLISIS DE TAREAS}

Evaluador: Uaviel Cuestionario: 19 Fecha: $4 \cdot 11 \cdot 19$ Propuesta a evaluar: B

\begin{tabular}{|l|c|c|}
\hline Premisa & Si & No \\
\hline El diseñador generó una paleta de cuatro colores. & $\checkmark$ & \\
\hline $\begin{array}{l}\text { El diseñador relacionó correctamente los lineamientos de } \\
\text { codificación de información en dispositivos médicos y los } \\
\text { aplicó en las secciones de la gráfica de acuerdo a su signi- } \\
\text { ficado. }\end{array}$ & $\checkmark$ & \\
\hline $\begin{array}{l}\text { El diseñador estableció un buen contraste entre fondo, } \\
\text { figura y texto. }\end{array}$ & $1.24 .53 \mathrm{culu}$ \\
\hline Tiempo en que tardó en leer la página el diseñador. & 1 & $2: 29.99 \mathrm{mil}$ \\
\hline Veces en que volvió a consultar la página el diseñador. & \\
\hline Tiempo en que tardó en completar la tarea el diseñador. & & \\
\hline
\end{tabular}


Anexo 10.20. USUARIO 20: Material de resultados de la evaluación de la propuesta editorial "B": consentimiento informado, lista de chequedo de análisis de tareas y cuestionario PSSUQ. 


\section{Consentimiento informado}

Proyecto: NOMOLAS: Propuesta de guías de usabilidad para el diseño de interfaces gráficas de sistemas de visualización de información médica.

Nombre del estudio: Evaluación de usabilidad de propuestas editoriales de las guías de usabilidad NOMOLAS con usuarios (lectores) de las mismas.

Lugar y fecha: Puebla, Pue. 4 - UOu' iq

Número de registro:

Justificación y objetivo del estudio: La forma en que se presenta la información es importante para que ésta sea comprendida de la mejor manera posible. Este estudio tiene como propósito elegir la mejor propuesta editorial para implementarla en toda la composición visual del proyecto llamado "NOMOLAS: Propuesta de guías de usabilidad para el diseño de interfaces gráficas de sistemas de visualización de información médica", que es a su vez, trabajo de investigación doctoral.

Procedimientos: Primero, se le explicaran los objetivos y el procedimiento de la sesión; describiendo como se llevará a cabo la prueba. Segundo, le pediremos que siga. las instrucciones que le entregue el investigador encargado.

Posibles riesgos y molestias: En investigaciones similares no se han registrado dificultades o riesgos de ningún tipo, por tanto, durante su participación no se prevé ningún riesgo.

Posibles beneficios que recibirá al participar en el estudio: Al final de la prueba se le dará al participante $\$ 50.00$ pesos mexicanos en efectivo.

Participación o retiro: Si después de que Usted haya leido esta información y haya obtenido respuesta a las preguntas que pudiera tener, le vamos a pedir leer y firmar esta carta de consentimiento informado. Sin embargo, Usted puede retirarse en cualquier momento, por cualquier razón y nadie le va a preguntar sobre las razones por las cuales se retira.

Privacidad y confidencialidad: Para garantizar la confidencialidad toda la información será guardada y analizada sin usar los nombres reales de los participantes. Después de ser analizada, la información será guardada por un tiempo razonable y luego destruida.

En caso de dudas o aclaraciones relacionadas con el estudio podrá dirigirse con: Mtra. Mariel Garcia Hernández quien conoce todos los detalles de este estudio. 2224924264 , Correo: mariel.garciahernandez@gmail.com

Participante:

Quien obtiene el consentimiento:

Nombre: Cnstiadasué Castello Castro Nombre: Uanel Garcia Heviöudec
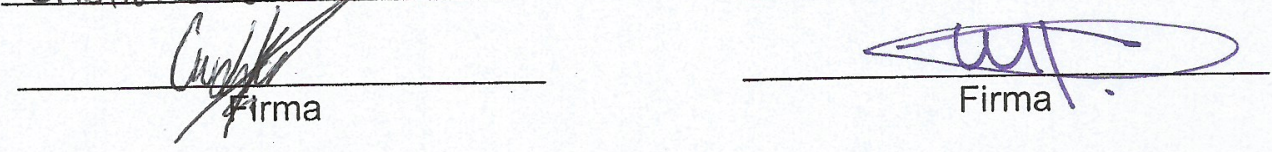


\section{CUESTIONARIO PSSUQ}

Edad:22 Sexo: M I F Licenciatura: DiseñográGio y digital Manejo de llustrator: Si I No Propuesta de guía: $B \quad$ No. de cuestionario: 20

Este cuestionario es una oportunidad para registrar tus reacciones a la guía de usabilidad. Estas respuestas nos ayudarán a entender qué aspectos hay que mejorar y cuales son con los que no estás satisfechos. Para tener un mejor resultado, piensa en la tarea que se te pidió que realizaras con base a lo que las guías decian mientras contestas estas preguntas.

Instrucciones: Lea cada frase y señala qué tan de acuerdo o en desacuerdo estás y encierra en un circulo un número de la escala. Al terminar, revisaremos juntos el cuestionario para asegurarnos de que entendamos bien la información presentada en este cuestionario.

¡Gracias!

a) La organización de la información proporcionada por las guías me fue clara.

Totalmente en desacuerdo

12

2

3

4

5

Totalmente de acuerdo<smiles>C1CCCCCC1</smiles>

b) Ful capaz de completar las tareas que se me indicaron rápidamente con la información proporcionada. en las guías.

Totalmente en desacuerdo

1

2

3

4

5

Totalmente de acuerdo

7

c) La información proporcionada por las guías fue fácil de entender.

Totalmente en desacuerdo

1

2

3

4

5

Totalmente de acuerdo

d) La apariencia de las guias es agradable.

Totalmente en desacuerdo

$$
1 \quad 2
$$

2

3

4

5

Totalmente de acuerdo

e) En general estoy satisfecho con el acomodo y presentación visual de la información.

Totalmente en desacuerdo

1

2

3

4

5

Totalmente de acuerdo

6 
Evaluador: Uanel Cuestionario: 20 Fecha: $4 \cdot 11 \cdot 19$ Propuesta a evaluar: B

\begin{tabular}{|l|c|c|}
\hline Premisa & Si & No \\
\hline El diseñador generó una paleta de cuatro colores. & & \\
\hline $\begin{array}{l}\text { El diseñador relacionó correctamente los lineamientos de } \\
\text { codificación de información en dispositivos médicos y los } \\
\text { aplicó en las secciones de la gráfica de acuerdo a su signi- } \\
\text { ficado. }\end{array}$ & $x$ \\
\hline $\begin{array}{l}\text { El diseñador estableció un buen contraste entre fondo, } \\
\text { figura y texto. }\end{array}$ & 3.39 seg \\
\hline $\begin{array}{l}\text { Tiempo en que tardó en leer la página el diseñador. } \\
\text { Veces en que volvió a consultar la página el diseñador. }\end{array}$ & 1 \\
\hline Tiempo en que tardó en completar la tarea el diseñador. & 3.37 .43 \\
\hline
\end{tabular}


Anexo 10.21. USUARIO 21: Material de resultados de la evaluación de la propuesta editorial "B": consentimiento informado, lista de chequedo de análisis de tareas y cuestionario PSSUQ. 


\section{Consentimiento informado}

Proyecto: NOMOLAS: Propuesta de guías de usabilidad para el diseño de interfaces gráficas de sistemas de visualización de información médica.

Nombre del estudio: Evaluación de usabilidad de propuestas editoriales de las guías de usabilidad NOMOLAS con usuarios (lectores) de las mismas.

Lugar y fecha: Puebla, Pue. 4. Mov.19

Número de registro:

21

Justificación y objetivo del estudio: La forma en que se presenta la información es importante para que ésta sea comprendida de la mejor manera posible. Este estudio tiene como propósito elegir la mejor propuesta editorial para implementarla en toda la composición visual del proyecto Ilamado "NOMOLAS: Propuesta de guías de usabilidad para el diseño de interfaces gráficas de sistemas de visualización de información médica", que es a su vez, trabajo de investigación doctoral.

Procedimientos: Primero, se le explicaran los objetivos y el procedimiento de la sesión; describiendo como se llevará a cabo la prueba. Segundo, le pediremos que siga las instrucciones que le entregue el investigador encargado.

Posibles riesgos y molestias: En investigaciones similares no se han registrado dificultades o riesgos de ningún tipo, por tanto, durante su participación no se prevé ningún riesgo.

Posibles beneficios que recibirá al participar en el estudio: Al final de la prueba se le dará al participante $\$ 50.00$ pesos mexicanos en efectivo.

Participación o retiro: Si después de que Usted haya leído esta información y haya obtenido respuesta a las preguntas que pudiera tener, le vamos a pedir leer y firmar esta carta de consentimiento informado. Sin embargo, Usted puede retirarse en cualquier momento, por cualquier razón y nadie le va a preguntar sobre las razones por las cuales se retira.

Privacidad y confidencialidad: Para garantizar la confidencialidad toda la información será guardada y analizada sin usar los nombres reales de los participantes. Después de ser analizada, la información será guardada por un tiempo razonable y luego destruida.

En caso de dudas o aclaraciones relacionadas con el estudio podirá dirigirse con: Mtra. Mariel García Hernández quien conoce todos los detalles de este estudio. 22249242 64, Correo: mariel.garciahernandez@gmail.com

Participante:

Quien obtiene el consentimiento:

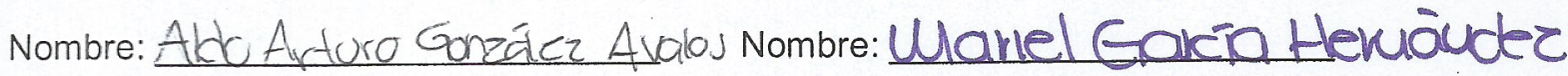
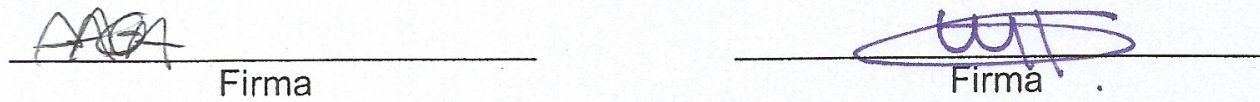


\section{CUESTIONARIO PSSUQ}

Edad:22 Sexo:M I F Licenciatura: Diseño gráfico y digitalmanejo de llustrator: Si I No Propuesta de guía: B No. de cuestionario: 21

Este cuestionario es una oportunidad para registrar tus reacciones a la guia de usabilidad. Estas respuestas nos ayudarán a entender qué aspectos hay que mejorar y cuales son con los que no estás satisfechos. Para tener un mejor resultado, piensa en la tarea que se te pidió que realizaras con base a lo que las guías decían mientras contestas estas preguntas.

Instrucciones: Lea cada frase y señala qué tan de acuerdo o en desacuerdo estás y encierra en un circulo un número de la escala. Al terminar, revisaremos juntos el cuestionario para asegurarnos de que entendamos bien la información presentada en este cuestionario.

¡Gracias!

a) La organización de la información proporcionada por las guías me fue clara.

Totalmente en desacuerdo

1

2

3

4

5

Totalmente de acuerdo

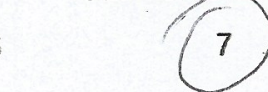

b) Fui capaz de completar las tareas que se me indicaron rápidamente con la información proporcionada en las guías.

Totalmente en desacuerdo

1

2

3

4

5

Totalmente de acuerdo

c) La información proporcionada por las guias fue fácil de entender.

Totalmente en desacuerdo

1

2

3

4

5

Totalmente de acuerdo

d) La apariencia de las guías es agradable.

Totalmente en desacuerdo

1

2

3

4

5

Totalmente de acuerdo

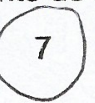

e) En general estoy satisfecho con el acomodo y presentación visual de la información.

Totalmente en desacuerdo

1

4

5

Totalmente de acuerdo

6

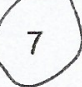




\section{LISTA DE CHEQUEO DEL ANÁLISIS DE TAREAS}

Evaluador: Uarel Cuestionario: 21 Fecha: $21.11 \cdot 19$ Propuesta a evaluar: B

\begin{tabular}{|l|c|c|}
\hline Premisa & Si & No \\
\hline El diseñador generó una paleta de cuatro colores. & $\checkmark$ & \\
\hline $\begin{array}{l}\text { El diseñador relacionó correctamente los lineamientos de } \\
\text { codificación de información en dispositivos médicos y los } \\
\text { aplicó en las secciones de la gráfica de acuerdo a su signi- } \\
\text { ficado. }\end{array}$ & $\checkmark$ & \\
\hline $\begin{array}{l}\text { El diseñador estableció un buen contraste entre fondo, } \\
\text { figura y texto. }\end{array}$ & $1.05 .50 \mathrm{~min}$ \\
\hline $\begin{array}{l}\text { Tiempo en que tardó en leer la página el diseñador. } \\
\text { Veces en que volvió a consultar la página el diseñador. }\end{array}$ & $2.55 .01 \mathrm{~min}$ \\
\hline Tiempo en que tardó en completar la tarea el diseñador. & & \\
\hline
\end{tabular}


Anexo 10.22. USUARIO 22: Material de resultados de la evaluación de la propuesta editorial "B": consentimiento informado, lista de chequedo de análisis de tareas y cuestionario PSSUQ. 


\section{CUESTIONARIO PSSUQ}

Edad:21 Sexo: M I (E) Licenciatura: Deseño grafice y digital Manejo de llustrator: (Si) I No Propuesta de guía: $B$ No. de cuestionario: 22

Este cuestionario es una oportunidad para registrar tus reacciones a la guia de usabilidad. Estas respuestas nos ayudarán a entender qué aspectos hay que mejorar y cuales son con los que no estás satisfechos. Para tener un mejor resultado, piensa en la tarea que se te pidió que realizaras con base a lo que las guias decian mientras contestas estas preguntas.

Instrucciones: Lea cada frase y señala qué tan de acuerdo o en desacuerdo estás y encierra en un circulo un número de la escala. Al terminar, revisaremos juntos el cuestionario para asegurarnos de que entendamos bien la información presentada en este cuestionario.

¡Gracias!

a) La organización de la información proporcionada por las guías me fue clara.

Totalmente en desacuerdo

$$
1 \quad 2
$$

2

3

4

5

Totalmente de acuerdo<smiles>c1ccccc1</smiles>

7

b) Fui capaz de completar las tareas que se me indicaron rápidamente con la información proporcionada en las guías.

Totalmente en desacuerdo$$
12
$$

3

4

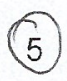

Totalmente de acuerdo

2

c) La información proporcionada por las guías fue fácil de entender.

Tntalmente en desacuerdo

1

2

3

4

5

Totalmente de acuerdo

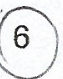

7

d) La apariencia de las guías es agradable.

Totalmente en desacuerdo

1

23

4

5

Totalmente de acuerdo

7

e) En general estoy satisfecho con el acomodo y presentación visual de la información.

Totalmente en desacuerdo

1

2

3

4

5

Totalmente de acuerdo 
LISTA DE CHEQUEO DEL ANÁLISIS DE TAREAS

Evaluador: Mariel Cuestionario: 22 Fecha: $4 \cdot 40$ V.19 Propuesta a evaluar:

B

\begin{tabular}{|l|c|l|}
\hline Premisa & Si & No \\
\hline El diseñador generó una paleta de cuatro colores. & & \\
\hline $\begin{array}{l}\text { El diseñador relacionó correctamente los lineamientos de } \\
\text { codificación de información en dispositivos médicos y los } \\
\text { aplicó en las secciones de la gráfica de acuerdo a su signi- } \\
\text { ficado. }\end{array}$ & & \\
\hline $\begin{array}{l}\text { El diseñador estableció un buen contraste entre fondo, } \\
\text { figura y texto. }\end{array}$ & $1.09 .56 \mathrm{culv}$ \\
\hline $\begin{array}{l}\text { Tiempo en que tardó en leer la página el diseñador. } \\
\text { Veces en que volvió a consultar la página el diseñador. }\end{array}$ & 1 & $2: 34.59$ \\
\hline Tiempo en que tardó en completar la tarea el diseñador. & 2.06 \\
\hline
\end{tabular}




\section{Consentimiento informado}

Proyecto: NOMOLAS: Propuesta de guías de usabilidad para el diseño de interfaces gráficas de sistemas de visualización de información médica.

Nombre del estudio: Evaluación de usabilidad de propuestas editoriales de las guías de usabilidad NOMOLAS con usuarios (lectores) de las mismas.

Lugary fecha: Puebla, Puebla. $4 \cdot 40 u \cdot 19$

Número de registro:

22

Justificación y objetivo del estudio: La forma en que se presenta la información es importante para que ésta sea comprendida de la mejor manera posible. Este estudio tiene como propósito elegir la mejor propuesta editorial para implementarla en toda la composición visual del proyecto llamado "NOMOLAS: Propuesta de guías de usabilidad para el diseño de interfaces gráficas de sistemas de visualización de información médica", que es a su vez, trabajo de investigación doctoral.

Procedimientos: Primero, se le explicaran los objetivos y el procedimiento de la sesión; describiendo como se llevará a cabo la prueba. Segundo, le pediremos que siga las instrucciones que le entregue el investigador encargado.

Posibles riesgos y molestias: En investigaciones similares no se han registrado dificultades o riesgos de ningún tipo, por tanto, durante su participación no se prevé ningún riesgo.

Posibles beneficios que recibirá al participar en el estudio: Al final de la prueba se le dará al participante $\$ 50.00$ pesos mexicanos en efectivo.

Participación o retiro: Si después de que Usted haya leido esta información y haya obtenido respuesta a las preguntas que pudiera tener, le vamos a pedir leer y firmar esta carta de consentimiento informado. Sin embargo, Usted puede retirarse en cualquier momento, por cualquier razón y nadie le va a preguntar sobre las razones por las cuales se retira.

Privacidad y confidencialidad: Para garantizar la confidencialidad toda la información será guardada y analizada sin usar los nombres reales de los participantes. Después de ser analizada, la información será guardada por un tiempo razonable y luego destruida.

En caso de dudas o aclaraciones relacionadas con el estudio podrá dirigirse con: Mtra. Mariel García Hernández quien conoce todos los detalles de este estudio. 22249242 64, Correo: mariel.garciahernandez@gmail.com

Participante:

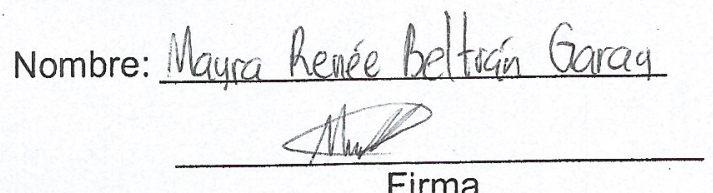

$$
\text { Firma }
$$

\section{Quien obtiene el consentimiento:}

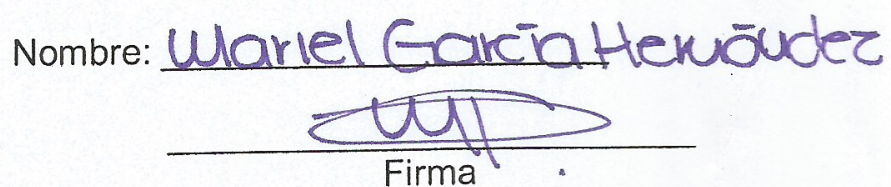


Anexo 10.23. USUARIO 23: Material de resultados de la evaluación de la propuesta editorial "B": consentimiento informado, lista de chequedo de análisis de tareas y cuestionario PSSUQ. 


\section{Consentimiento informado}

Proyecto: NOMOLAS: Propuesta de guias de usabilidad para el diseño de interfaces gráficas de sistemas de visualización de información médica.

Nombre del estudio: Evaluación de usabilidad de propuestas editoriales de las guías de usabilidad NOMOLAS con usuarios (lectores) de las mismas.

Lugar y fecha: Puebla, Pue. 40 Uovieubre - 19

Número de registro:

23

Justificación y objetivo del estudio: La forma en que se presenta la información es importante para que ésta sea comprendida de la mejor manera posible. Este estudio tiene como propósito elegir la mejor propuesta editorial para implementarla en toda la composición visual del proyecto llamado "NOMOLAS: Propuesta de guías de usabilidad para el diseño de interfaces gráficas de sistemas de visualización de información médica", que es a su vez, trabajo de investigación doctoral.

Procedimientos: Primero, se le explicaran los objetivos y el procedimiento de la sesión; describiendo como se llevará a cabo la prueba. Segundo, le pediremos que siga. las instrucciones que le entregue el investigador encargado.

Posibles riesgos y molestias: En investigaciones similares no se han registrado dificultades 0 riesgos de ningún tipo, por tanto, durante su participación no se prevé ningún riesgo.

Posibles beneficios que recibirá al participar en el estudio: Al final de la prueba se le dará al participante $\$ 50.00$ pesos mexicanos en efectivo.

Participación o retiro: Si después de que Usted haya leído esta información y haya obtenido respuesta a las preguntas que pudiera tener, le vamos a pedir leer y firmar esta carta de consentimiento informado. Sin embargo, Usted puede retirarse en cualquier momento, por cualquier razón y nadie le va a preguntar sobre las razones por las cuales se retira.

Privacidad y confidencialidad: Para garantizar la confidencialidad toda la información será guardada y analizada sin usar los nombres reales de los participantes. Después de ser analizada, la información será guardada por un tiempo razonable y luego destruida.

En caso de dudas o aclaraciones relacionadas con el estudio podrá dirigirse con: Mtra. Mariel García Hernández quien conoce todos los detalles de este estudio. 22249242 64, Correo: mariel.garciahernandez@gmail.com

Participante:

Nombre: MICHEL A. HUERTA TORRES

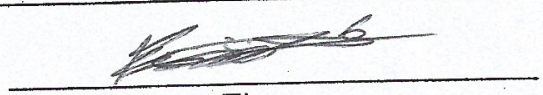

Firma

\section{Quien obtiene el consentimiento:}

Nombre: Mlarrel GareTa Heruãder

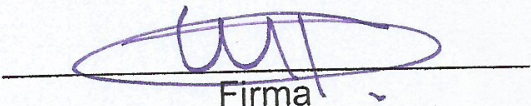




\section{CUESTIONARIO PSSUQ}

Edad:24 Sexo:M I F Licenciatura: DISEÑO GRAFICo Y DIGITAL Manejo de Ilustrator: Si I No Propuesta de guía: $B$ No. de cuestionario: 23

Este cuestionario es una oportunidad para registrar tus reacciones a la guia de usabilidad. Estas respuestas nos ayudarán a entender qué aspectos hay que mejorar y cuales son con los que no estás satisfechos. Para tener un mejor resultado, piensa en la tarea que se te pidió que realizaras con base a lo que las guías decian mientras contestas estas preguntas.

Instrucciones: Lea cada frase y señala qué tan de acuerdo o en desacuerdo estás y encierra en un circulo un número de la escala. Al terminar, revisaremos juntos el cuestionario para asegurarnos de que entendamos bien la información presentada en este cuestionario.

¡Gracias!

a) La organización de la información proporcionada por las guías me fue clara.

Totalmente en desacuerdo

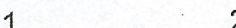

2

3

4

5

Totalmente de acuerdo

$$
1
$$

(2.

6 (7)

b) Fui capaz de completar las tareas que se me indicaron rápidamente con la información proporcionada en las guías.

Totalmente en desacuerdo

1

2

3

4

5

Totalmente de acuerdo

c) La información proporcionada por las guías fue fácil de entender.

Totalmente en desacuerdo

1

2

3

4

5

Totalmente de acuerdo

-

(n)

6

(7)

d) La apariencia de las guías es agradable.

Totalmente en desacuerdo

1

2

3

4

5

Totalmente de acuerdo

\section{7}

e) En general estoy satisfecho con el acomodo y presentación visual de la información. Totalmente en desacuerdo

1 


\section{LISTA DE CHEQUEO DEL ANÁLISIS DE TAREAS}

Evaluador: Uariel cuestionario: 23 Fecha: $4 \cdot 11 \cdot 19$ Propuesta a evaluar:

B

\begin{tabular}{|l|c|l|}
\hline Premisa & Si & No \\
\hline El diseñador generó una paleta de cuatro colores. & $\checkmark$ & \\
\hline $\begin{array}{l}\text { El diseñador relacionó correctamente los lineamientos de } \\
\text { codificación de información en dispositivos médicos y los } \\
\text { aplicó en las secciones de la gráfica de acuerdo a su signi- } \\
\text { ficado. }\end{array}$ & $\checkmark$ & \\
\hline $\begin{array}{l}\text { El diseñador estableció un buen contraste entre fondo, } \\
\text { figura y texto. }\end{array}$ & $\checkmark .18 .40$ \$ 14 \\
\hline Tiempo en que tardó en leer la página el diseñador. & - \\
\hline Veces en que volvió a consultar la página el diseñador. & $1: 37.12$ \\
\hline Tiempo en que tardó en completar la tarea el diseñador. & \\
\hline
\end{tabular}


Anexo 10.24. USUARIO 24: Material de resultados de la evaluación de la propuesta editorial "B": consentimiento informado, lista de chequedo de análisis de tareas y cuestionario PSSUQ. 


\section{Consentimiento informado}

Proyecto: NOMOLAS: Propuesta de guías de usabilidad para el diseño de interfaces gráficas de sistemas de visualización de información médica.

Nombre del estudio: Evaluación de usabilidad de propuestas editoriales de las guias de usabilidad NOMOLAS con usuarios (lectores) de las mismas.

Lugar y fecha: Puenca 4 /Novembre 12019

Número de registro: $\quad 24$

Justificación y objetivo del estudio: La forma en que se presenta la información es importante para que ésta sea comprendida de la mejor manera posible. Este estudio tiene como propósito elegir la mejor propuesta editorial para implementarla en toda la composición visual del proyecto llamado "NOMOLAS: Propuesta de guías de usabilidad para el diseño de interfaces gráficas de sistemas de visualización de información médica", que es a su vez, trabajo de investigación doctoral.

Procedimientos: Primero, se le explicaran los objetivos y el procedimiento de la sesión; describiendo como se llevará a cabo la prueba. Segundo, le pediremos que siga las instrucciones que le entregue el investigador encargado.

Posibles riesgos y molestias: En investigaciones similares no se han registrado dificultades o riesgos de ningún tipo, por tanto, durante su participación no se prevé ningún riesgo.

Posibles beneficios que recibirá al participar en el estudio: Al final de la prueba se le dará al participante $\$ 50.00$ pesos mexicanos en efectivo.

Participación o retiro: Si después de que Usted haya leído esta información y haya obtenido respuesta a las preguntas que pudiera tener, le vamos a pedir leer y firmar esta carta de consentimiento informado. Sin embargo, Usted puede retirarse en cualquier momento, por cualquier razón y nadie le va a preguntar sobre las razones por las cuales se retira.

Privacidad y confidencialidad: Para garantizar la confidencialidad toda la información será guardada y analizada sin usar los nombres reales de los participantes. Después de ser analizada, la información será guardada por un tiempo razonable y luego destruida.

En caso de dudas o aclaraciones relacionadas con el estudio podrá dirigirse con: Mtra. Mariel Garcia Hernández quien conoce todos los detalles de este estudio. 2224924264 , Correo: mariel.garciahernandez@gmail.com

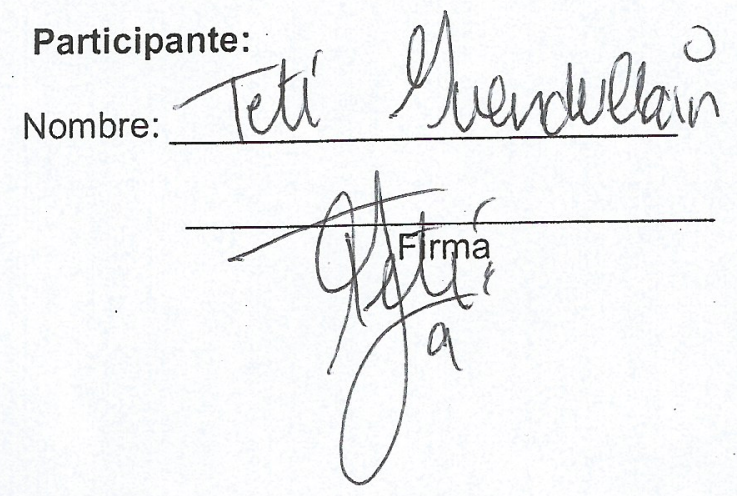

Quien obtiene el consentimiento:

Nombre: Marlel Garcia Herciōuder

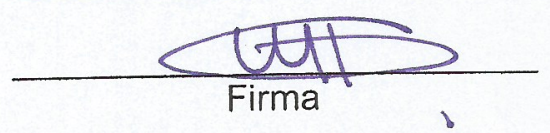




\section{CUESTIONARIO PSSUQ}

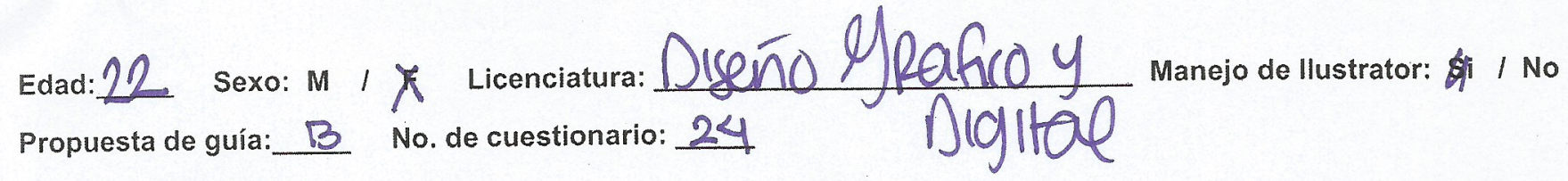

Este cuestionario es una oportunidad para registrar tus reacciones a la guía de usabilidad. Estas respuestas nos ayudarán a entender qué aspectos hay que mejorar y cuales son con los que no estás satisfechos. Para tener un mejor resultado, piensa en la tarea que se te pidió que realizaras con base a lo que las guías decian mientras contestas estas preguntas.

Instrucciones: Lea cada frase y señala qué tan de acuerdo o en desacuerdo estás y encierra en un circulo un número de la escala. Al terminar, revisaremos juntos el cuestionario para asegurarnos de que entendamos bien la información presentada en este cuestionario.

¡Gracias!

a) La organización de la información proporcionada por las guías me fue clara.

Totalmente en desacuerdo

Totalmente de acuerdo
1
2
3
4
5
$(6)$

7

b) Fui capaz de completar las tareas que se me indicaron rápidamente con la información proporcionada en las guías.

Totalmente en desacuerdo

$$
12
$$
2
3

4

5

Totalmente de acuerdo

c) La información proporcionada por las guías fue fácil de entender.

Totalmente en desacuerdo

2

3

4

5

Totalmente de acuerdo

1

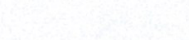

d) La apariencia de las guías es agradable.

Totalmente en desacuerdo

12

2

3

4

5

Totalmente de acuerdo

7

e) En general estoy satisfecho con el acomodo y presentación visual de la información.

Totalmente en desacuerdo 
Evaluador: Wariel_Cuestionario: 24 Fecha: $\underline{4 \cdot 11 \cdot 19}$ Propuesta a evaluar: $B$

\begin{tabular}{|l|c|l|}
\hline Premisa & Si & No \\
\hline El diseñador generó una paleta de cuatro colores. & & \\
\hline $\begin{array}{l}\text { El diseñador relacionó correctamente los lineamientos de } \\
\text { codificación de información en dispositivos médicos y los } \\
\text { aplicó en las secciones de la gráfica de acuerdo a su signi- } \\
\text { ficado. }\end{array}$ & $1: 31.88 \mathrm{~min}$ \\
\hline $\begin{array}{l}\text { El diseñador estableció un buen contraste entre fondo, } \\
\text { figura y texto. }\end{array}$ & 1 & \\
\hline Tiempo en que tardó en leer la página el diseñador. & $3: 25.12 \mathrm{~min}$ \\
\hline Veces en que volvió a consultar la página el diseñador.
\end{tabular}


Anexo 10.25. USUARIO 25: Material de resultados de la evaluación de la propuesta editorial "B": consentimiento informado, lista de chequedo de análisis de tareas y cuestionario PSSUQ. 


\section{Consentimiento informado}

Proyecto: NOMOLAS: Propuesta de guías de usabilidad para el diseño de interfaces gráficas de sistemas de visualización de información médica.

Nombre del estudio: Evaluación de usabilidad de propuestas editoriales de las guias de usabilidad NOMOLAS con usuarios (lectores) de las mismas.

Lugar y fecha: Puebla, Puebla. $4 \cdot 40 \mathrm{~V} \cdot 19$

Número de registro:

25

Justificación y objetivo del estudio: La forma en que se presenta la información es importante para que ésta sea comprendida de la mejor manera posible. Este estudio tiene como propósito elegir la mejor propuesta editorial para implementarla en toda la composición visual del proyecto llamado "NOMOLAS: Propuesta de guías de usabilidad para el diseño de interfaces gráficas de sistemas de visualización de información médica", que es a su vez, trabajo de investigación doctoral.

Procedimientos: Primero, se le explicaran los objetivos y el procedimiento de la sesión; describiendo como se llevará a cabo la prueba. Segundo, le pediremos que siga las instrucciones que le entregue el investigador encargado.

Posibles riesgos y molestias: En investigaciones similares no se han registrado dificultades o riesgos de ningún tipo, por tanto, durante su participación no se prevé ningún riesgo.

Posibles beneficios que recibirá al participar en el estudio: Al final de la prueba se le dará al participante $\$ 50.00$ pesos mexicanos en efectivo.

Participación o retiro: Si después de que Usted haya leido esta información y haya obtenido respuesta a las preguntas que pudiera tener, le vamos a pedir leer y firmar esta carta de consentimiento informado. Sin embargo, Usted puede retirarse en cualquier momento, por cualquier razón y nadie le va a preguntar sobre las razones por las cuales se retira.

Privacidad y confidencialidad: Para garantizar la confidencialidad toda la información será guardada y analizada sin usar los nombres reales de los participantes. Después de ser analizada, la información será guardada por un tiempo razonable y luego destruida.

En caso de dudas o aclaraciones relacionadas con el estudio podrá dirigirse con: Mtra. Mariel García Hernández quien conoce todos los detalles de este estudio. 2224924264 , Correo: mariel.garciahernandez@gmail.com

Participante:

Quien obtiene el consentimiento:

Nombre: hosemary Susana Fgaredo Ĺpen Nombre: Uavel Garéra Hexöludez
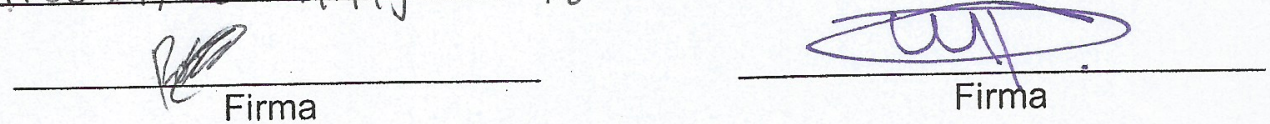

Firma 


\section{CUESTIONARIO PSSUQ}

Edad:21 sexo: M I ( L Licenciatura: Diseño Gráfico y Digital manejo de llustrator: (Si I No Propuesta de guía: $B$ No. de cuestionario: 25

Este cuestionario es una oportunidad para registrar tus reacciones a la guía de usabilidad. Estas respuestas nos ayudarán a entender qué aspectos hay que mejorar y cuales son con los que no estás satisfechos. Para tener un mejor resultado, piensa en la tarea que se te pidió que realizaras con base a lo que las guías decian mientras contestas estas preguntas.

Instrucciones: Lea cada frase y señala qué tan de acuerdo o en desacuerdo estás y encierra en un circulo un número de la escala. Al terminar, revisaremos juntos el cuestionario para asegurarnos de que entendamos bien la información presentada en este cuestionario.

¡Gracias!

a) La organización de la información proporcionada por las guías me fue clara.

Totalmente en desacuerdo
1
2
3
4
5

Totalmente de acuerdo

7

b) Fui capaz de completar las tareas que se me indicaron rápidamente con la información proporcionada en las guías.

Totalmente en desacuerdo

$$
1
$$

\section{2}

3

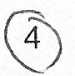

5

Totalmente de acuerdo

c) La información proporcionada por las guías fue fácil de entender.

Totalmente en desacuerdo

1 2

3

4

5

Totalmente de acuerdo

(6)

7

d) La apariencia de las guías es agradable.

Totalmente en desacuerdo$$
1
$$

3

4

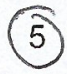

Totalmente de acuerdo

6

7

e) En general estoy satisfecho con el acomodo y presentación visual de la información.

Totalmente en desacuerdo

1

2

3

4

5

Totalmente de acuerdo 


\section{LISTA DE CHEQUEO DEL ANÁLISIS DE TAREAS}

Evaluador: Wanel Cuestionario: 25 Fecha: $4000 \mathrm{~V} \cdot 19$ Propuesta a evaluar: B

\begin{tabular}{|l|c|c|}
\hline Premisa & Si & No \\
\hline El diseñador generó una paleta de cuatro colores. & $\checkmark$ & \\
\hline $\begin{array}{l}\text { El diseñador relacionó correctamente los lineamientos de } \\
\text { codificación de información en dispositivos médicos y los } \\
\text { aplicó en las secciones de la gráfica de acuerdo a su signi- } \\
\text { ficado. }\end{array}$ & $\checkmark$ & \\
\hline $\begin{array}{l}\text { El diseñador estableció un buen contraste entre fondo, } \\
\text { figura y texto. }\end{array}$ & $1: 32.39 \mathrm{~min}$ \\
\hline \begin{tabular}{l} 
Tiempo en que tardó en leer la página el diseñador. \\
\hline Veces en que volvió a consultar la página el diseñador.
\end{tabular} & $11(2)$ \\
\hline Tiempo en que tardó en completar la tarea el diseñador. & $3: 48.75 \mathrm{~min}$ \\
\hline
\end{tabular}


Anexo 10.26. USUARIO 26: Material de resultados de la evaluación de la propuesta editorial "B": consentimiento informado, lista de chequedo de análisis de tareas y cuestionario PSSUQ. 


\section{Consentimiento informado}

Proyecto: NOMOLAS: Propuesta de guias de usabilidad para el diseño de interfaces gráficas de sistemas de visualización de información médica.

Nombre del estudio: Evaluación de usabilidad de propuestas editoriales de las guías de usabilidad NOMOLAS con usuarios (lectores) de las mismas.

Lugar y fecha: Duebla, Puebla. 4. 4OU. 19

Número de registro:

26

Justificación y objetivo del estudio: La forma en que se presenta la información es importante para que ésta sea comprendida de la mejor manera posible. Este estudio tiene como propósito elegir la mejor propuesta editorial para implementarla en toda la composición visual del proyecto llamado "NOMOLAS: Propuesta de guias de usabilidad para el diseño de interfaces gráficas de sistemas de visualización de información médica", que es a su vez, trabajo de investigación doctoral.

Procedimientos: Primero, se le explicaran los objetivos y el procedimiento de la sesión; describiendo como se llevará a cabo la prueba. Segundo, le pediremos que siga las instrucciones que le entregue el investigador encargado.

Posibles riesgos y molestias: En investigaciones similares no se han registrado dificultades o riesgos de ningún tipo, por tanto, durante su participación no se prevé ningún riesgo.

Posibles beneficios que recibirá al participar en el estudio: Al final de la prueba se le dará al participante $\$ 50.00$ pesos mexicanos en efectivo.

Participación o retiro: Si después de que Usted haya leido esta información y haya obtenido respuesta a las preguntas que pudiera tener, le vamos a pedir leer y firmar esta carta de consentimiento informado. Sin embargo, Usted puede retirarse en cualquier momento, por cualquier razón y nadie le va a preguntar sobre las razones por las cuales se retira.

Privacidad y confidencialidad: Para garantizar la confidencialidad toda la información será guardada y analizada sin usar los nombres reales de los participantes. Después de ser analizada, la información será guardada por un tiempo razonable y luego destruida.

En caso de dudas o aclaraciones relacionadas con el estudio podrá dirigirse con: Mtra. Mariel García Hernández quien conoce todos los detalles de este estudio. 2224924264 , Correo: mariel.garciahernandez@gmail.com

\section{Participante:}

Nombre: Aime Estrada Zorrilla

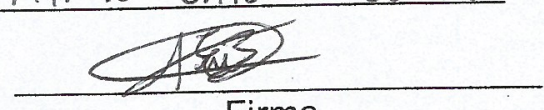

Firma
Quien obtiene el consentimiento:

Nombre: Uanel Gakia Hemöuder

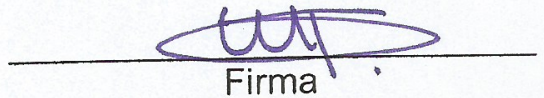




\section{CUESTIONARIO PSSUQ}

Edad:23 Sexo: M $\{$ Licenciatura: Dijeño Gráfico y Digital Manejo de llustrator: Sfi I No Propuesta de guía: $B$ No. de cuestionario: 26

Este cuestionario es una oportunidad para registrar tus reacciones a la guia de usabilidad. Estas respuestas nos ayudarán a entender qué aspectos hay que mejorar y cuales son con los que no estás satisfechos. Para tener un mejor resultado, piensa en la tarea que se te pidió que realizaras con base a lo que las guías decian mientras contestas estas preguntas.

Instrucciones: Lea cada frase y señala qué tan de acuerdo o en desacuerdo estás y encierra en un circulo un número de la escala. Al terminar, revisaremos juntos el cuestionario para asegurarnos de que entendamos bien la información presentada en este cuestionario.

¡Gracias!

a) La organización de la información proporcionada por las guías me fue clara.

Totalmente en desacuerdo

$1 \cdot 2$ 2 3

4

5 Totalmente de acuerdo 6 $x$

b) Fui capaz de completar las tareas que se me indicaron rápidamente con la información proporcionada en las guías.

Totalmente en desacuerdo

1

3

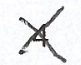

5 Totalmente de acuerdo $2+3$

c) La información proporcionada por las guías fue fácil de entender.

Totalmente en desacuerdo

1 2 3 4 5 Totalmente de acuerdo (n)

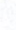

4.20

d) La apariencia de las guías es agradable.

Totalmente en desacuerdo

$$
1
$$

2

3

4

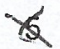
Totalmente de acuerdo 7

e) En general estoy satisfecho con el acomodo y presentación visual de la infớmación. Totalmente en desacuerdo 
Evaluador: Wanel_Cuestionario: 26 Fecha: 1.11 .19 Propuesta a evaluar: $B$

\begin{tabular}{|c|c|c|}
\hline Premisa & Si & No \\
\hline El diseñador generó una paleta de cuatro colores. & 1 & \\
\hline $\begin{array}{l}\text { El diseñador relacionó correctamente los lineamientos de } \\
\text { codificación de información en dispositivos médicos y los } \\
\text { aplicó en las secciones de la gráfica de acuerdo a su signi- } \\
\text { ficado. }\end{array}$ & $\checkmark$ & \\
\hline $\begin{array}{l}\text { El diseñador estableció un buen contraste entre fondo, } \\
\text { figura y texto. }\end{array}$ & $\gamma$ & \\
\hline Tiempo en que tardó en leer la página el diseñador. & $1: 09.65$ & wily \\
\hline Veces en que volvió a consultar la página el diseñador. & $(1)$ & \\
\hline Tiempo en que tardó en completar la tarea el diseñador. & $1: 45.70 r$ & in \\
\hline
\end{tabular}


Anexo 10.27. USUARIO 27: Material de resultados de la evaluación de la propuesta editorial "B": consentimiento informado, lista de chequedo de análisis de tareas y cuestionario PSSUQ. 


\section{Consentimiento informado}

Proyecto: NOMOLAS: Propuesta de guías de usabilidad para el diseño de interfaces gráficas de sistemas de visualización de información médica.

Nombre del estudio: Evaluación de usabilidad de propuestas editoriales de las guías de usabilidad NOMOLAS con usuarios (lectores) de las mismas.

Lugar y fecha: Duebla, Puebla.40 Uoveubre 19

Número de registro:

27

Justificación y objetivo del estudio: La forma en que se presenta la información es importante para que ésta sea comprendida de la mejor manera posible. Este estudio tiene como propósito elegir la mejor propuesta editorial para implementarla en toda la composición visual del proyecto llamado "NOMOLAS: Propuesta de guías de usabilidad para el diseño de interfaces gráficas de sistemas de visualización de información médica", que es a su vez, trabajo de investigación doctoral.

Procedimientos: Primero, se le explicaran los objetivos y el procedimiento de la sesión; describiendo como se llevará a cabo la prueba. Segundo, le pediremos que siga las instrucciones que le entregue el investigador encargado.

Posibles riesgos y molestias: En investigaciones similares no se han registrado dificultades o riesgos de ningún tipo, por tanto, durante su participación no se prevé ningún riesgo.

Posibles beneficios que recibirá al participar en el estudio: Al final de la prueba se le dará al participante $\$ 50.00$ pesos mexicanos en efectivo.

Participación o retiro: Si después de que Usted haya leído esta información y haya obtenido respuesta a las preguntas que pudiera tener, le vamos a pedir leer y firmar esta carta de consentimiento informado. Sin embargo, Usted puede retirarse en cualquier momento, por cualquier razón y nadie le va a preguntar sobre las razones por las cuales se retira.

Privacidad y confidencialidad: Para garantizar la confidencialidad toda la información será guardada y analizada sin usar los nombres reales de los participantes. Después de ser analizada, la información será guardada por un tiempo razonable y luego destruida.

En caso de dudas o aclaraciones relacionadas con el estudio podrá dirigirse con: Mtra. Mariel García Hernández quien conoce todos los detalles de este estudio. 2224924264 , Correo: mariel.garciahernandez@gmail.com

\section{Participante:}

Nombre: Renata Campos Escalante

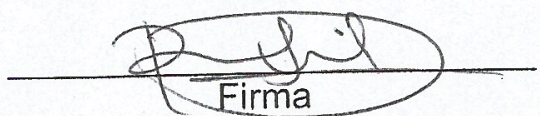

Quien obtiene el consentimiento:

Nombre: Uarlel Gareia tenóuder

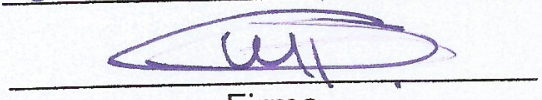

Firma 


\section{CUESTIONARIO PSSUQ}

Edad:21 Sexo: M If Licenciatura: Diseño Gráfico \& Digital Manejo de llustrator: Sí I No Propuesta de guía: $B$ No. de cuestionario: 27

Este cuestionario es una oportunidad para registrar tus reacciones a la guia de usabilidad. Estas respuestas nos ayudarán a entender qué aspectos hay que mejorar y cuales son con los que no estás satisfechos. Para tener un mejor resultado, piensa en la tarea que se te pidió que realizaras con base a lo que las guías decian mientras contestas estas preguntas.

Instrucciones: Lea cada frase y señala qué tan de acuerdo o en desacuerdo estás y encierra en un circulo un número de la escala. Al terminar, revisaremos juntos el cuestionario para asegurarnos de que entendamos bien la información presentada en este cuestionario.

¡Gracias!

a) La organización de la información proporcionada por las guías me fue clara.

Totalmente en desacuerdo

$$
1 \quad 2
$$

3

4

5

Totalmente de acuerdo

$4 \cdot 2 \cdot 5$

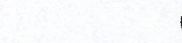

$6 \quad 7$

b) Fui capaz de completar las tareas que se me indicaron rápidamente con la información proporcionada en las guías.

Totalmente en desacuerdo

1

3

4

5

Totalmente de acuerdo

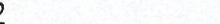

c) La información proporcionada por las guías fue fácil de entender.

Totalmente en desacuerdo

1

2

3

4

5

Totalmente de acuerdo

6

7

d) La apariencia de las guías es agradable.

Totalmente en desacuerdo

$$
12
$$

3

4

5

Totalmente de acuerdo

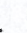

$6 \quad \underline{7}$

e) En general estoy satisfecho con el acomodo y presentación visual de la información. Totalmente en desacuerdo

1 2

3

4

5

Totalmente de acuerdo 


\section{LISTA DE CHEQUEO DEL ANÁLISIS DE TAREAS}

Evaluador: manel Cuestionario: 27 Fecha: $4 \cdot 11$ '19 Propuesta a evaluar: $B$

\begin{tabular}{|l|c|c|}
\hline Premisa & Si & No \\
\hline El diseñador generó una paleta de cuatro colores. & $\checkmark$ & \\
\hline $\begin{array}{l}\text { El diseñador relacionó correctamente los lineamientos de } \\
\text { codificación de información en dispositivos médicos y los } \\
\text { aplicó en las secciones de la gráfica de acuerdo a su signi- } \\
\text { ficado. }\end{array}$ & 1 & \\
\hline $\begin{array}{l}\text { El diseñador estableció un buen contraste entre fondo, } \\
\text { figura y texto. }\end{array}$ & $1: 01.25 \mathrm{Seg}$ \\
\hline Tiempo en que tardó en leer la página el diseñador. & $11.23 .92 \mathrm{~min}$ \\
\hline Veces en que volvió a consultar la página el diseñador. & $(11)$ & \\
\hline Tiempo en que tardó en completar la tarea el diseñador. & & \\
\hline
\end{tabular}


Anexo 10.28. USUARIO 28: Material de resultados de la evaluación de la propuesta editorial "B": consentimiento informado, lista de chequedo de análisis de tareas y cuestionario PSSUQ. 


\section{Consentimiento informado}

Proyecto: NOMOLAS: Propuesta de guías de usabilidad para el diseño de interfaces gráficas de sistemas de visualización de información médica.

Nombre del estudio: Evaluación de usabilidad de propuestas editoriales de las guias de usabilidad NOMOLAS con usuarios (lectores) de las mismas.

Lugary fecha: Puebla, Pue. 4. UOU.19

Número de registro:

28

Justificación y objetivo del estudio: La forma en que se presenta la información es importante para que ésta sea comprendida de la mejor manera posible. Este estudio tiene como propósito elegir la mejor propuesta editorial para implementarla en toda la composición visual del proyecto llamado "NOMOLAS: Propuesta de guías de usabilidad para el diseño de interfaces gráficas de sistemas de visualización de información médica", que es a su vez, trabajo de investigación doctoral.

Procedimientos: Primero, se le explicaran los objetivos y el procedimiento de la sesión; describiendo como se llevará a cabo la prueba. Segundo, le pediremos que siga las instrucciones que le entregue el investigador encargado.

Posibles riesgos y molestias: En investigaciones similares no se han registrado dificultades o riesgos de ningún tipo, por tanto, durante su participación no se prevé ningún riesgo.

Posibles beneficios que recibirá al participar en el estudio: Al final de la prueba se le dará al participante $\$ 50.00$ pesos mexicanos en efectivo.

Participación o retiro: Si después de que Usted haya leido esta información y haya obtenido respuesta a las preguntas que pudiera tener, le vamos a pedir leer y firmar esta carta de consentimiento informado. Sin embargo, Usted puede retirarse en cualquier momento, por cualquier razón y nadie le va a preguntar sobre las razones por las cuales se retira.

Privacidad y confidencialidad: Para garantizar la confidencialidad toda la información será guardada y analizada sin usar los nombres reales de los participantes. Después de ser analizada, la información será guardada por un tiempo razonable y luego destruida.

En caso de dudas o aclaraciones relacionadas con el estudio podrá dirigirse con: Mtra. Mariel García Hernández quien conoce todos los detalles de este estudio. 2224924264 , Correo: mariel.garciahernandez@gmail.com

Participante:

Nombre: Ma. Monilsewat Manturo S.

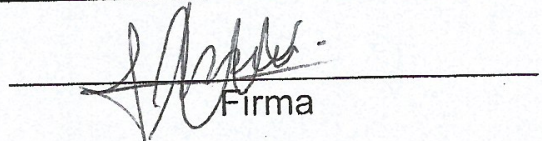

Quien obtiene el consentimiento:

Nombre:Uanel Gavía Hewionder

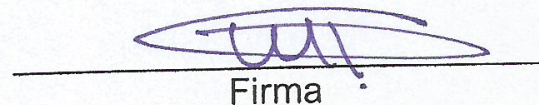




\section{CUESTIONARIO PSSUQ}

Edad:22 Sexo: M IF Licenciatura: Diseño Gráfico y Digilal. Manejo de llustrator. Si I No Propuesta de guía: 3 No. de cuestionario: 28

Este cuestionario es una oportunidad para registrar tus reacciones a la guía de usabilidad. Estas respuestas nos ayudarán a entender qué aspectos hay que mejorar y cuales son con los que no estás satisfechos. Para tener un mejor resultado, piensa en la tarea que se te pidió que realizaras con base a lo que las guías decían mientras contestas estas preguntas.

Instrucciones: Lea cada frase y señala qué tan de acuerdo o en desacuerdo estás y encierra en un circulo un número de la escala. Al terminar, revisaremos juntos el cuestionario para asegurarnos de que entendamos bien la información presentada en este cuestionario.

\section{¡Gracias!}

a) La organización de la información proporcionada por las guías me fue clara.

Totalmente en desacuerdo$$
1 \text {. }
$$

2

3

4

5

Totalmente de acuerdo

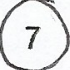

b) Fui capaz de completar las tareas que se me indicaron rápidamente con la información proporcionada en las guías.

Totalmente en desacuerdo

$$
12
$$

3

4

5

Totalmente de acuerdo

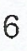

7

c) La información proporcionada por las guias fue fácil de entender.

Totalmente en desacuerdo

1

2

3

4

5

Totalmente de acuerdo

6

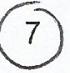

d) La apariencia de las guías es agradable.

Totalmente en desacuerdo

1

2

3

4

5

Totalmente de acuerdo

7

e) En general estoy satisfecho con el acomodo y presentación visual de la información.

Totalmente en desacuerdo

Totalmente de acuerdo

1

2

3

4

$\dot{5}$

6 
LISTA DE CHEQUEO DEL ANÁLISIS DE TAREAS

Evaluador: Wanel Cuestionario: 28 Fecha: $4 \cdot 40 \mathrm{~V} \cdot 19$ Propuesta a evaluar: $B$

\begin{tabular}{|l|c|c|}
\hline Premisa & Si & No \\
\hline El diseñador generó una paleta de cuatro colores. & $\checkmark$ & \\
\hline $\begin{array}{l}\text { El diseñador relacionó correctamente los lineamientos de } \\
\text { codificación de información en dispositivos médicos y los } \\
\text { aplicó en las secciones de la gráfica de acuerdo a su signi- } \\
\text { ficado. }\end{array}$ & & \\
\hline $\begin{array}{l}\text { El diseñador estableció un buen contraste entre fondo, } \\
\text { figura y texto. }\end{array}$ & $1: 18.25 \mathrm{~min}$ \\
\hline \begin{tabular}{l} 
Tiempo en que tardó en leer la página el diseñador. \\
\hline Veces en que volvió a consultar la página el diseñador.
\end{tabular} & $2: 20 \mathrm{mill}$ \\
\hline Tiempo en que tardó en completar la tarea el diseñador. & 20 \\
\hline
\end{tabular}


Anexo 10.29. USUARIO 29: Material de resultados de la evaluación de la propuesta editorial "B": consentimiento informado, lista de chequedo de análisis de tareas y cuestionario PSSUQ. 


\section{Consentimiento informado}

Proyecto: NOMOLAS: Propuesta de guías de usabilidad para el diseño de interfaces gráficas de sistemas de visualización de información médica.

Nombre del estudio: Evaluación de usabilidad de propuestas editoriales de las guías de usabilidad NOMOLAS con usuarios (lectores) de las mismas.

Lugar y fecha: Puebla, Puebla. 4. 4ovieubre. 19

Número de registro:

29

Justificación y objetivo del estudio: La forma en que se presenta la información es importante para que ésta sea comprendida de la mejor manera posible. Este estudio tiene como propósito elegir la mejor propuesta editorial para implementarla en toda la composición visual del proyecto llamado "NOMOLAS: Propuesta de guías de usabilidad para el diseño de interfaces gráficas de sistemas de visualización de información médica", que es a su vez, trabajo de investigación doctoral.

Procedimientos: Primero, se le explicaran los objetivos y el procedimiento de la sesión; describiendo como se llevará a cabo la prueba. Segundo, le pediremos que siga las instrucciones que le entregue el investigador encargado.

Posibles riesgos y molestias: En investigaciones similares no se han registrado dificultades o riesgos de ningún tipo, por tanto, durante su participación no se prevé ningủn riesgo.

Posibles beneficios que recibirá al participar en el estudio: Al final de la prueba se le dará al participante $\$ 50.00$ pesos mexicanos en efectivo.

Participación o retiro: Si después de que Usted haya leído esta información y haya obtenido respuesta a las preguntas que pudiera tener, le vamos a pedir leer y firmar esta carta de consentimiento informado. Sin embargo, Usted puede retirarse en cualquier momento, por cualquier razón y nadie le va a preguntar sobre las razones por las cuales se retira.

Privacidad y confidencialidad: Para garantizar la confidencialidad toda la información será guardada y analizada sin usar los nombres reales de los participantes. Después de ser analizada, la información será guardada por un tiempo razonable y luego destruida.

En caso de dudas o aclaraciones relacionadas con el estudio podrá dirigirse con: Mtra. Mariel García Hernández quien conoce todos los detalles de este estudio. 2224924264 , Correo: mariel.garciahernandez@gmail.com

\section{Participante:}

Nombre: Azalea tlernander.

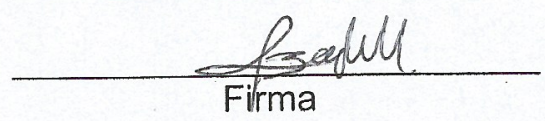

Quien obtiene el consentimiento:

Nombre: Marrel Garcia Heriöudec

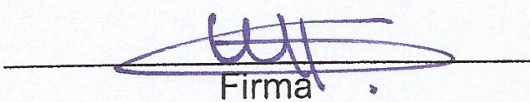




\section{CUESTIONARIO PSSUQ}

Edad:21 Sexo: M /(F) Licenciatura: Discño Grúfico Manejo de llustrator: (Si) / No Propuesta de guía: 3 No. de cuestionario: 29

Este cuestionario es una oportunidad para registrar tus reacciones a la guía de usabilidad. Estas respuestas nos ayudarán a entender qué aspectos hay que mejorar y cuales son con los que no estás satisfechos. Para tener un mejor resultado, piensa en la tarea que se te pidió que realizaras con base a lo que las guías decian mientras contestas estas preguntas.

Instrucciones: Lea cada frase y señala qué tan de acuerdo o en desacuerdo estás y encierra en un circulo un número de la escala. Al terminar, revisaremos juntos el cuestionario para asegurarnos de que entendamos bien la información presentada en este cuestionario.

¡Gracias!

a) La organización de la información proporcionada por las guías me fue clara.

Totalmente en desacuerdo

1

2

3

4

5

Totalmente de acuerdo

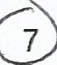

b) Ful capaz de completar las tareas que se me indicaron rápidamente con la información proporcionada en las guías.

Totalmente en desacuerdo

1

2

3

4

5

Totalmente de acuerdo

c) La información proporcionada por las guías fue fácil de entender.

Totalmente en desacuerdo

1

2

3

4

5

Totalmente de acuerdo

d) La apariencia de las guías es agradable.

Totalmente en desacuerdo

1

2

3

4

5

Totalmente de acuerdo

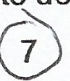

e) En general estoy satisfecho con el acomodo y presentación visual de la infởmación.

Totalmente en desacuerdo

1

2

3

4

5

Totalmente de acuerdo 


\section{LISTA DE CHEQUEO DEL ANÁLISIS DE TAREAS}

Evaluador: Wahel Cuestionario: 29 Fecha: $4 \cdot 40 v \cdot 19$ Propuesta a evaluar: B

\begin{tabular}{|c|c|c|}
\hline Premisa & $\mathrm{Si}$ & No \\
\hline El diseñador generó una paleta de cuatro colores. & $\checkmark$ & \\
\hline $\begin{array}{l}\text { El diseñador relacionó correctamente los lineamientos de } \\
\text { codificación de información en dispositivos médicos y los } \\
\text { aplicó en las secciones de la gráfica de acuerdo a su signi- } \\
\text { ficado. }\end{array}$ & / & \\
\hline $\begin{array}{l}\text { El diseñador estableció un buen contraste entre fondo, } \\
\text { figura y texto. }\end{array}$ & $\checkmark$ & \\
\hline Tiempo en que tardó en leer la página el diseñador. & \multicolumn{2}{|c|}{$1: 05.43$ unin } \\
\hline Veces en que volvió a consultar la página el diseñador. & \multicolumn{2}{|l|}{-} \\
\hline Tiempo en que tardó en completar la tarea el diseñador. & \multicolumn{2}{|c|}{2.38 .52 un } \\
\hline
\end{tabular}


Anexo 10.30. USUARIO 30: Material de resultados de la evaluación de la propuesta editorial "B": consentimiento informado, lista de chequedo de análisis de tareas y cuestionario PSSUQ. 


\section{Consentimiento informado}

Proyecto: NOMOLAS: Propuesta de guías de usabilidad para el diseño de interfaces gráficas de sistemas de visualización de información médica.

Nombre del estudio: Evaluación de usabilidad de propuestas editoriales de las guías de usabilidad NOMOLAS con usuarios (lectores) de las mismas.

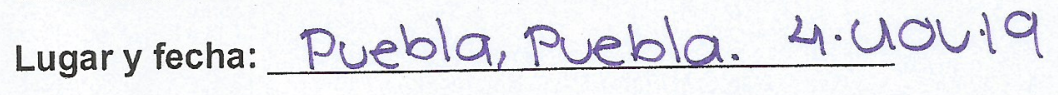

Número de registro: 30

Justificación y objetivo del estudio: La forma en que se presenta la información es importante para que ésta sea comprendida de la mejor manera posible. Este estudio tiene como propósito elegir la mejor propuesta editorial para implementarla en toda la composición visual del proyecto llamado "NOMOLAS: Propuesta de guías de usabilidad para el diseño de interfaces gráficas de sistemas de visualización de información médica", que es a su vez, trabajo de investigación doctoral.

Procedimientos: Primero, se le explicaran los objetivos y el procedimiento de la sesión; describiendo como se llevará a cabo la prueba. Segundo, le pediremos que siga las instrucciones que le entregue el investigador encargado.

Posibles riesgos y molestias: En investigaciones similares no se han registrado dificultades o riesgos de ningún tipo, por tanto, durante su participación no se prevé ningún riesgo.

Posibles beneficios que recibirá al participar en el estudio: Al final de la prueba se le dará al participante $\$ 50.00$ pesos mexicanos en efectivo.

Participación o retiro: Si después de que Usted haya leído esta información y haya obtenido respuesta a las preguntas que pudiera tener, le vamos a pedir leer y firmar esta carta de consentimiento informado. Sin embargo, Usted puede retirarse en cualquier momento, por cualquier razón y nadie le va a preguntar sobre las razones por las cuales se retira.

Privacidad y confidencialidad: Para garantizar la confidencialidad toda la información será guardada y analizada sin usar los nombres reales de los participantes. Después de ser analizada, la información será guardada por un tiempo razonable y luego destruida.

En caso de dudas o aclaraciones relacionadas con el estudio podrá dirigirse con: Mtra. Mariel García Hernández quien conoce todos los detalles de este estudio. 2224924264 , Correo: mariel.garciahernandez@gmail.com

Participante:

Nombre: $\frac{\text { Michelle Pérez Ramirez }}{\text { AmantletDD }}$
Quien obtiene el consentimiento:

Nombre: Uahel Garcia Hewoudec

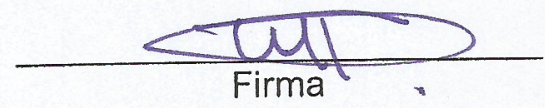




\section{CUESTIONARIO PSSUQ}

Edad: 20 Sexo: M / F Licenciatura: Diseño gráfico y digital Manejo de llustrator: (Si) I No Propuesta de guía: $B$ No. de cuestionario: 30

Este cuestionario es una oportunidad para registrar tus reacciones a la guia de usabilidad. Estas respuestas nos ayudarán a entender qué aspectos hay que mejorar y cuales son con los que no estás satisfechos. Para tener un mejor resultado, piensa en la tarea que se te pidió que realizaras con base a lo que las guías decian mientras contestas estas preguntas.

Instrucciones: Lea cada frase y señala qué tan de acuerdo o en desacuerdo estás y encierra en un circulo un número de la escala. Al terminar, revisaremos juntos el cuestionario para asegurarnos de que entendamos bien la información presentada en este cuestionario.

¡Gracias!

a) La organización de la información proporcionada por las guías me fue clara.

Totalmente en desacuerdo

1 2

3

4

5

Totalmente de acuerdo

b) Fui capaz de completar las tareas que se me indicaron rápidamente con la información proporcionada en las guías.

Totalmente en desacuerdo

12

3

4

5

Totalmente de acuerdo

c) La información proporcionada por las guías fue fácil de entender.

Totalmente en desacuerdo

1

3

4

5

Totalmente de acuerdo

d) La apariencia de las guías es agradable.

Totalmente en desacuerdo

1 2 3

4

5

Totalmente de acuerdo

(7)

e) En general estoy satisfecho con el acomodo y presentación visual de la información.

Totalmente en desacuerdo

Totalmente de acuerdo

1

2

3

4

5

6 


\section{LISTA DE CHEQUEO DEL ANÁLISIS DE TAREAS}

Evaluador: Uamel Cuestionario: 30 Fecha: $4 \cdot 11 \cdot 19$ Propuesta a evaluar:

B

\begin{tabular}{|l|l|l|}
\hline Premisa & Si & No \\
\hline El diseñador generó una paleta de cuatro colores. & & \\
\hline $\begin{array}{l}\text { El diseñador relacionó correctamente los lineamientos de } \\
\text { codificación de información en dispositivos médicos y los } \\
\text { aplicó en las secciones de la gráfica de acuerdo a su signi- } \\
\text { ficado. }\end{array}$ & $1: 52.09 \mathrm{~min}$ \\
\hline $\begin{array}{l}\text { El diseñador estableció un buen contraste entre fondo, } \\
\text { figura y texto. }\end{array}$ & & \\
\hline Tiempo en que tardó en leer la página el diseñador. & $2: 43.09 \mathrm{u}$. & \\
\hline Veces en que volvió a consultar la página el diseñador. & \\
\hline Tiempo en que tardó en completar la tarea el diseñador. & & \\
\hline
\end{tabular}



Anexo 11. Material para la evaluación de la FASE 2. 
Anexo 11.1. Material para de la evaluación FASE 2. Pieza publicitaria para redes sociales buscando la promoción del workshop.

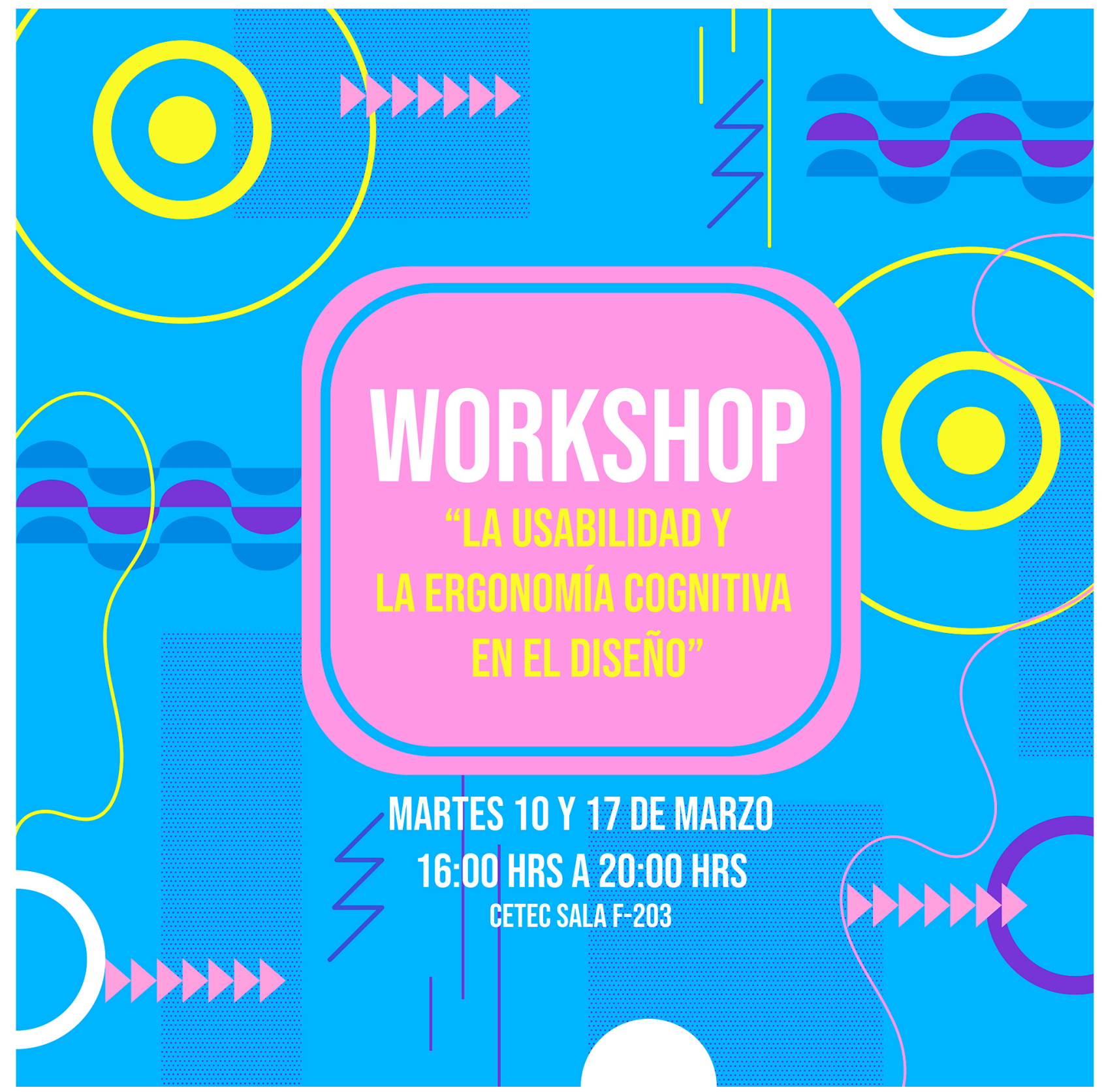


Anexo 11.2. Material para de la evaluación FASE 2. Captura de pantalla del formulario en la plataforma "Google Forms" para el workshop.

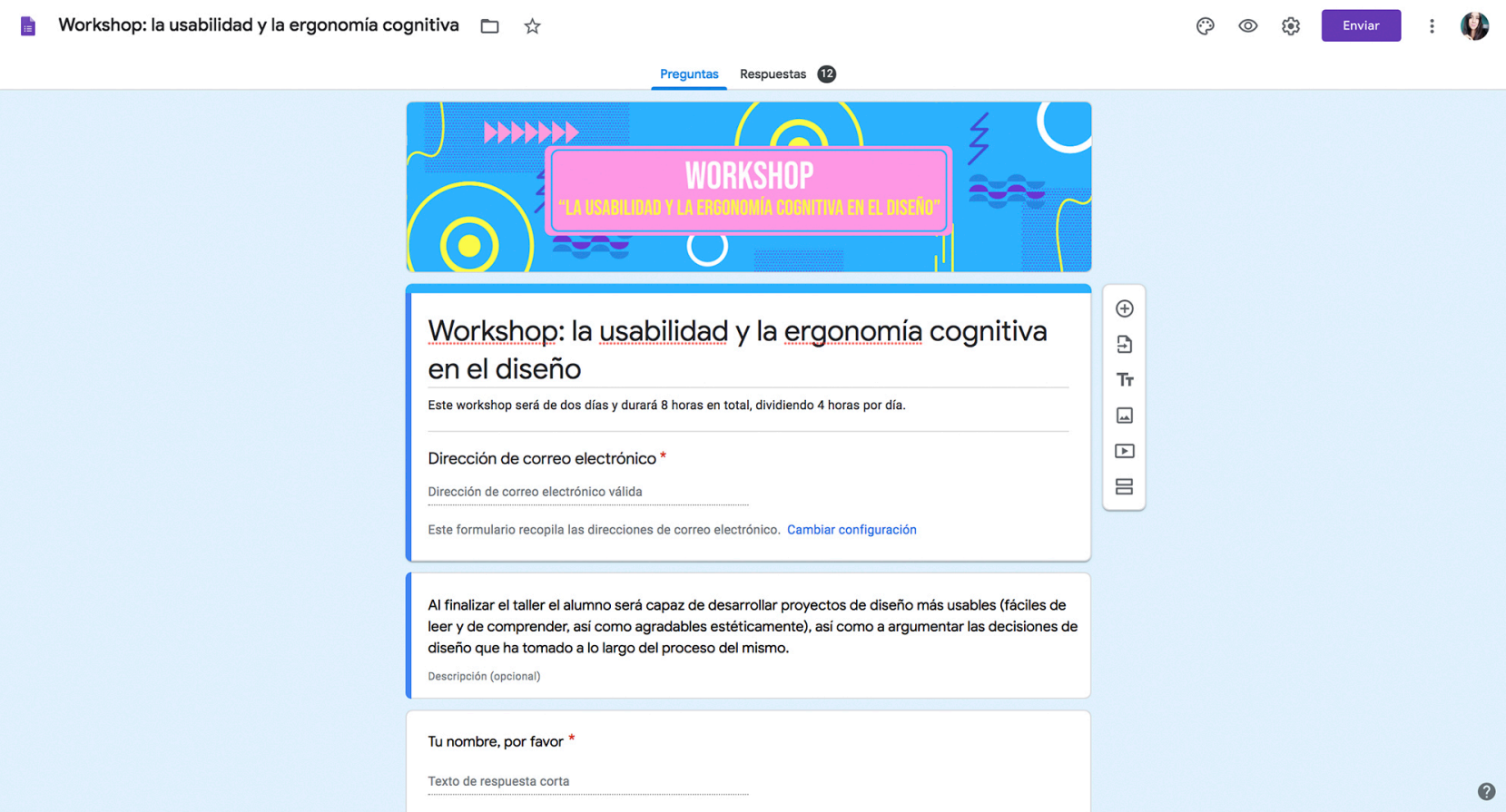


Anexo 11.3. Material para de la evaluación FASE 2. Láminas de la presentación usada durante el workshop.
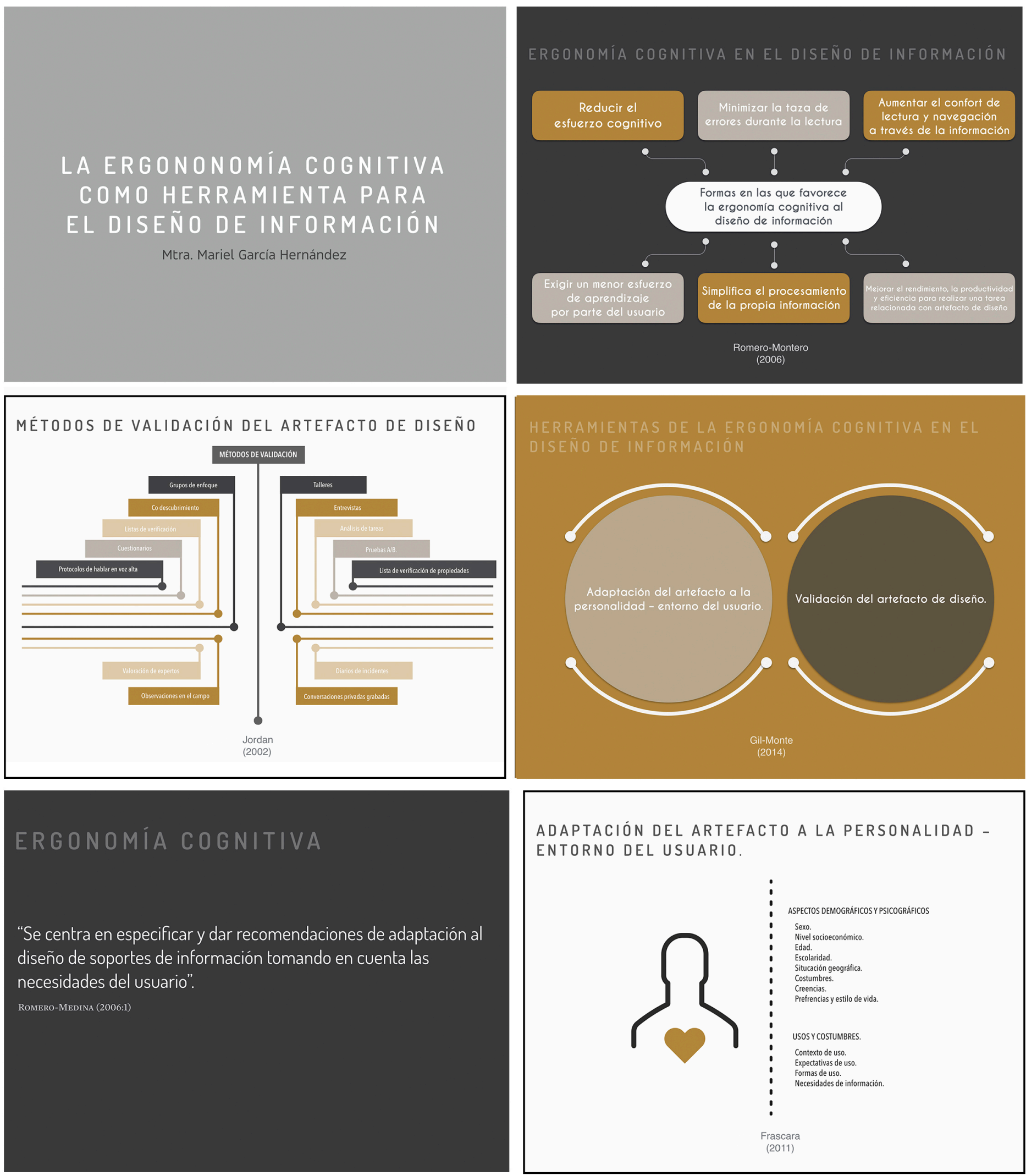

ADAPTACIÓN DEL ARTEFACTO A LA PERSONALIDAD ENTORNO DEL USUARIO

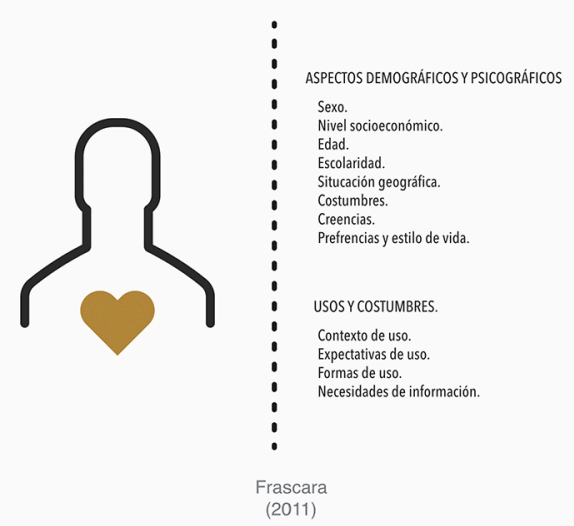


Anexo 11.4. Material para la evaluación de la FASE 2. Lámina de la presentación con la tarea a realizar de la herramienta Análisis de Tareas.

\section{ACTIVIDAD}

Objetivo: Re diseñar el historial clínico de un paciente con diabetes tomando como base las guías NOMOLAS.

\section{Instrucciones:}

1) Reunirse en parejas.

2) Identificar la información con la que se va a trabajar.

3) Llenar el lienzo el apartado de “USUARIO” del LEAN CANVAS DECISIONES DE DISEÑO.

4] Desarrollar tres bocetos a lápiz.

5) Digitalizar el boceto ganador.

6] Comenzar a llenar los demás apartados del LEAN CANVAS DECISIONES DE DISEÑO.

7) Desarrollar el historial clínico de un paciente con diabetes con base a las guias.

8) Al finalizar el historial clinico enviar al correo mariel.garciahernandez@gmail.com

9) Contestar el cuestionario PSSUQ que se les entregará. 
Anexo 11.5. Material para de la evaluación FASE 2. Fotos como evidencia de la impartición del workshop.
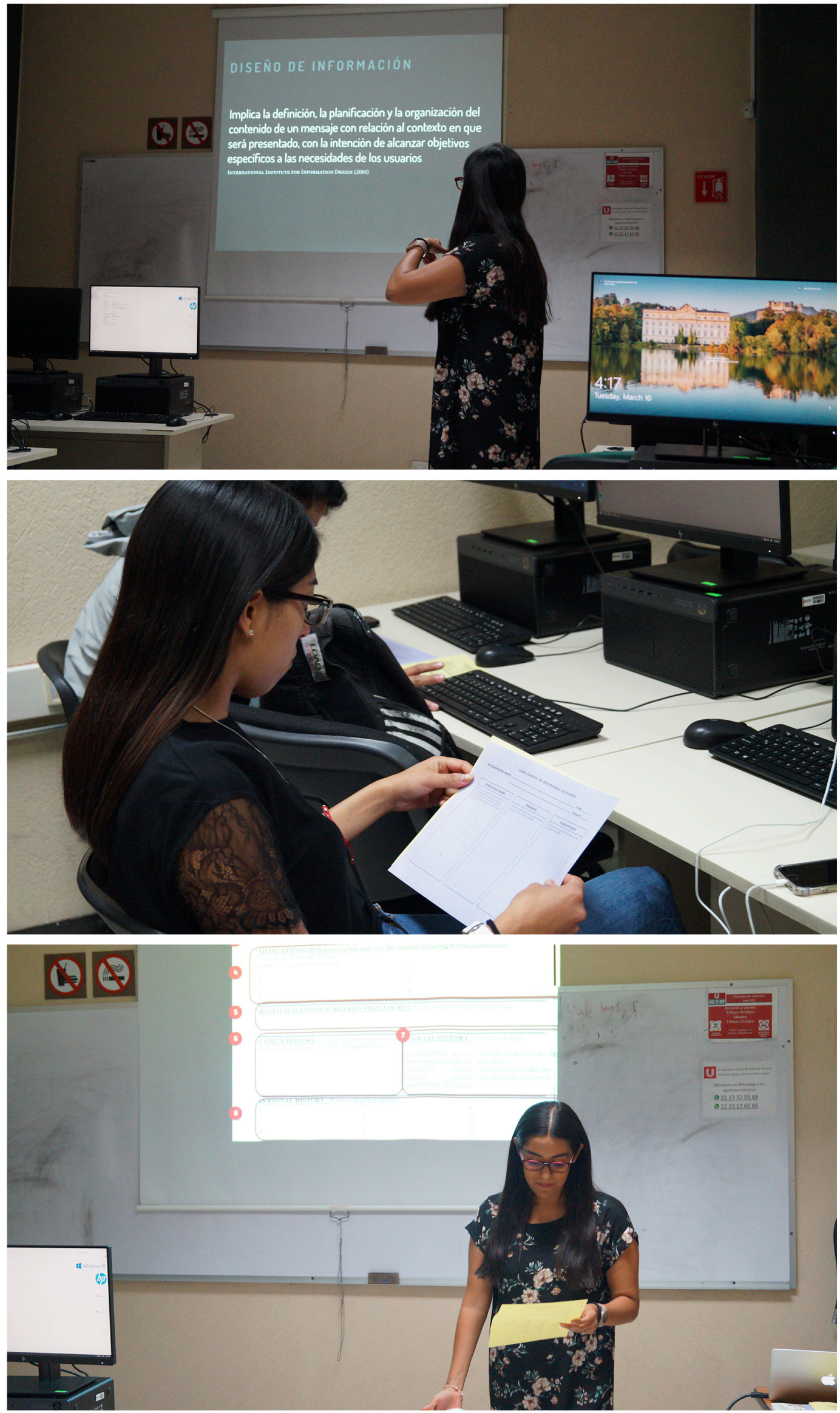
Anexo 11.6. Material para de la evaluación FASE 2. Lean Canvas de decisiones de diseño.

\section{LEAN CANVAS DE DECISIONES DE DISEÑO}

INTEGRANTES DEL EQUIPO:

Fecha:

Equipo \#:

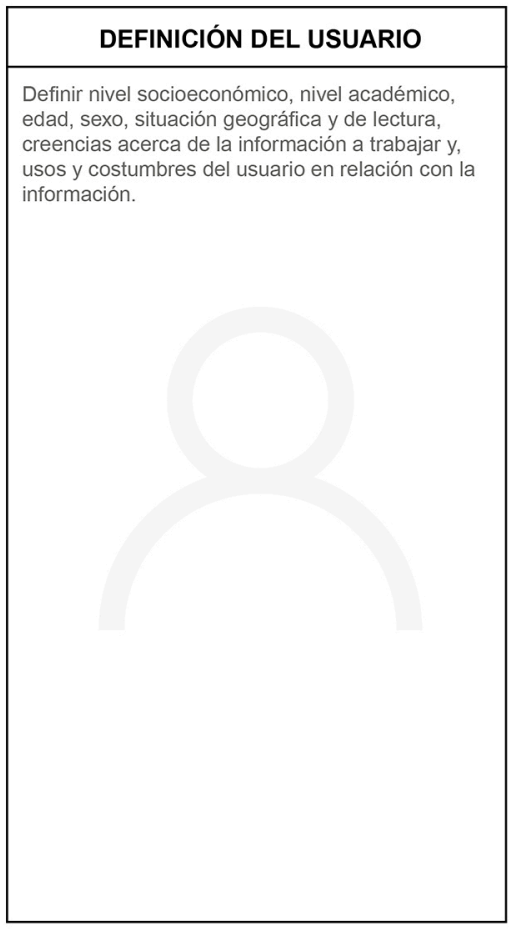

TIPOGRAFÍA

Señalar tipografía usada para el cuerpo del texto, títulos, subtítulos, leyendas y etiquetas.

\section{PALETA DE COLOR}

Señalar los colores usados en la paleta de color (indicar código RGB). 


\begin{tabular}{|c|c|c|}
\hline $\begin{array}{l}\quad \text { LISTA DE CHEQUEO DEL ANÁLISIS DE TAREAS } \\
\text { Evaluador: } \\
\text { SECCIÓN DE LAS GUÍAS NOMOLAS }\end{array}$ & \multirow[b]{2}{*}{ Si } & \multirow[b]{2}{*}{ No } \\
\hline USUARIO & & \\
\hline El diseñador definió el nivel socioeconómico. & & \\
\hline El diseñador definió el nivel académico. & & \\
\hline El diseñador definió edad. & & \\
\hline El diseñador definió sexo. & & \\
\hline El diseñador definió situación geográfica. & & \\
\hline El diseñador definió situación de lectura. & & \\
\hline El diseñador definió creencias sobre la información. & & \\
\hline El diseñador definió usos y costumbres presentadas alrededor de la información. & & \\
\hline ESTRUCTURA DE LA INFORMACIÓN & Si & No \\
\hline El diseñador utilizó una retícula para generar la composición de su gráfica. & & \\
\hline La información presentada de manera visual tiene congruencia y presenta jerarquía en relación al contenido. & & \\
\hline La navegación de lectura se hace de izquierda a derecha y en forma de zig-zag. & & \\
\hline TIPOGRAFÍA & Si & No \\
\hline El diseñador utilizó alguna de las fuentes sugeridas en las guías. & & \\
\hline El diseñador utilizó un espacio interlineal de 1.5 & & \\
\hline El diseñador evitó la aparición de "viudas" en la composición. & & \\
\hline El diseñador evitó la aparición de "ríos" en la composición. & & \\
\hline El diseñador utilizó la variante negrita para hacer énfasis en palabras clave. & & \\
\hline El diseñador utilizó la variante cursiva para hacer referencia a palabras en idioma extranjero. & & \\
\hline El diseñador utilizó un puntaje de carácter para el cuerpo de texto de no menor a 8 puntos. & & \\
\hline El diseñador utilizó para los títulos tipografías sans serif. & & \\
\hline Los títulos están alienados a la izquierda o centrados. & & \\
\hline Los títulos están en variante negrita y en un puntaje mayor al del cuerpo de texto. & & \\
\hline El cuerpo de texto está alienado a la izquierda. & & \\
\hline El texto y el fondo de la interfaz tienen un buen contraste. & & \\
\hline El diseñador combinó tipografías serif y sans serif en la composición de la pieza de diseño. & & \\
\hline COLOR & Si & No \\
\hline El diseñador utilizó cuatro colores dentro de la composición. & & \\
\hline El diseñador cuidó el buen contraste entre figura, fondo y texto en la pieza de diseño. & & \\
\hline El diseñador tomó en consideración el uso de contraste de color entre fondo y texto. & & \\
\hline El diseñador evitó el uso de degradados. & & \\
\hline El diseñador utilizó el mismo color para representar un mismo tipo de dato. & & \\
\hline El diseñador creo codificaciones de información a través del color. & & \\
\hline ELEMENTOS GRÁFICOS & Si & No \\
\hline Todos los elementos conserven un mismo estilo gráfico. & & \\
\hline El diseñador implementó imágenes que tienen la misma orientación & & \\
\hline El diseñador evitó el uso de emojis. & & \\
\hline El diseñador usó etiquetas o leyendas debajo de los elementos gráficos que necesitaban algún tipo de aclaración. & & \\
\hline $\begin{array}{l}\text { El diseñador usó bullets point, listas numéricas y flechas para enfatizar información que pertenecía a una misma } \\
\text { categoría. }\end{array}$ & & \\
\hline El diseñador evitó el uso de elementos o información innecesarios, extraños, decorativos o irre & & \\
\hline
\end{tabular}


Anexo 11.8. Material para de la evaluación FASE 2. Cuestionario PSSUQ.

\section{CUESTIONARIO PSSUQ}

Edad:

Sexo: M / F Licenciatura:

Manejo de llustrator: Si / No

Este cuestionario es una oportunidad para registrar tus reacciones a la guía de usabilidad. Estas respuestas nos ayudarán a entender que aspectos hay que mejorar y cuales son con los que no estás satisfechos. Para tener un mejor resultado, piensa en la tarea que se te pidió que realizaras con base a lo que las guías decían mientras contestas estas preguntas.

Instrucciones: Lea cada frase y señala qué tan de acuerdo o en desacuerdo estás y encierra en un circulo un número de la escala. Al terminar, revisaremos juntos con usted el cuestionario para asegurarnos de que entendamos bien la información presentada en este cuestionario.

\section{¡Gracias!}

a) La organización de la información proporcionada por las guías me fue clara.

Totalmente en desacuerdo

Totalmente de acuerdo

1

3

4

5

7

b) Fui capaz de completar la tarea que se me indicó rápidamente con la información proporcionada en las guías.

Totalmente en desacuerdo

Totalmente de acuerdo

$$
1
$$

2

3

4

5

6

7

c) La información proporcionada por las guías fue fácil de entender.

Totalmente de desacuerdo

1

$$
2
$$

3

4

5

Totalmente de acuerdo

d) La apariencia de las guías es agradable.

Totalmente en desacuerdo

$$
1
$$

2

3

4

5

Totalmente de acuerdo

e) En general estoy satisfecho con el acomodo y presentación visual de la información.

Totalmente en desacuerdo

Totalmente de acuerdo

1

2

3

4

5

6

7 
Anexo 11.9. Material para de la evaluación FASE 2. Guías de usabilidad para del desarrollo de interfaces gráficas de visualizaciones de información médica. 

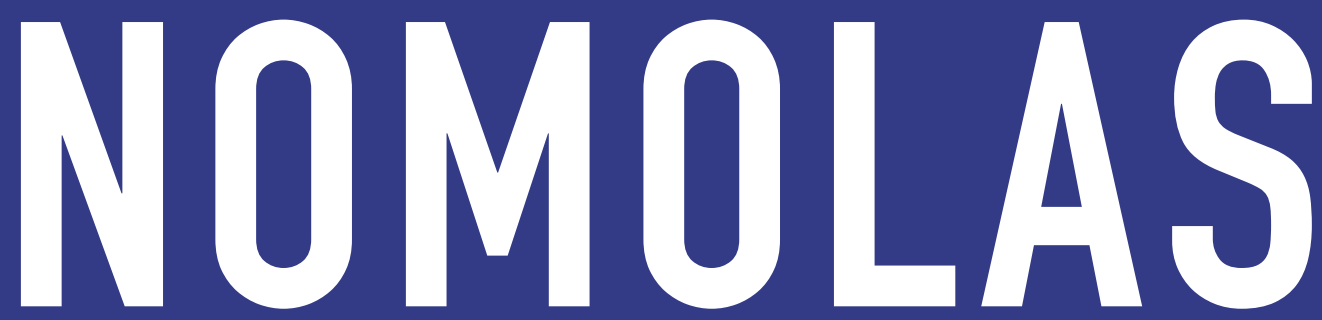

Gúas de usabilindad para el diseño de interfaces graficas de sistemas de visualización de información médica 



\section{INTRODUCCIÓN}

La problemática principal de este trabajo de investigación da como resultado una propuesta de guías que permitan al diseñador desarrollar interfaces gráficas de sistemas de visualización de información médica que aseguren usabilidad de estos para su usuario.

Dicha problemática tiene su origen, de acuerdo a lo que plantea Few (2004), en que la mayoría de los sistemas de visualización de información son difíciles de desarrollar de una forma ra de los siste clara, ya que suen estar llension de información son dificiles de doc propensos a erros $y$, por ende, pú pecto al conocimiento que se está intentando transmitir o proyectar a través de éstos. Las o lector.

El uso de tipografías ilegibles, de elementos visuales usados con un objetivo ornamental y no como un potenciador cognitivo, colores que generan mal contraste entre sí, información desordenada y mal estructurada compromete de manera grave el objetivo de comunicación de la interfaz gráfica (consultar la sección de anexo para ver ejemplos).

Las guías que se exponen a continuación como producto de este trabajo de investigación están divididas de la siguiente manera:

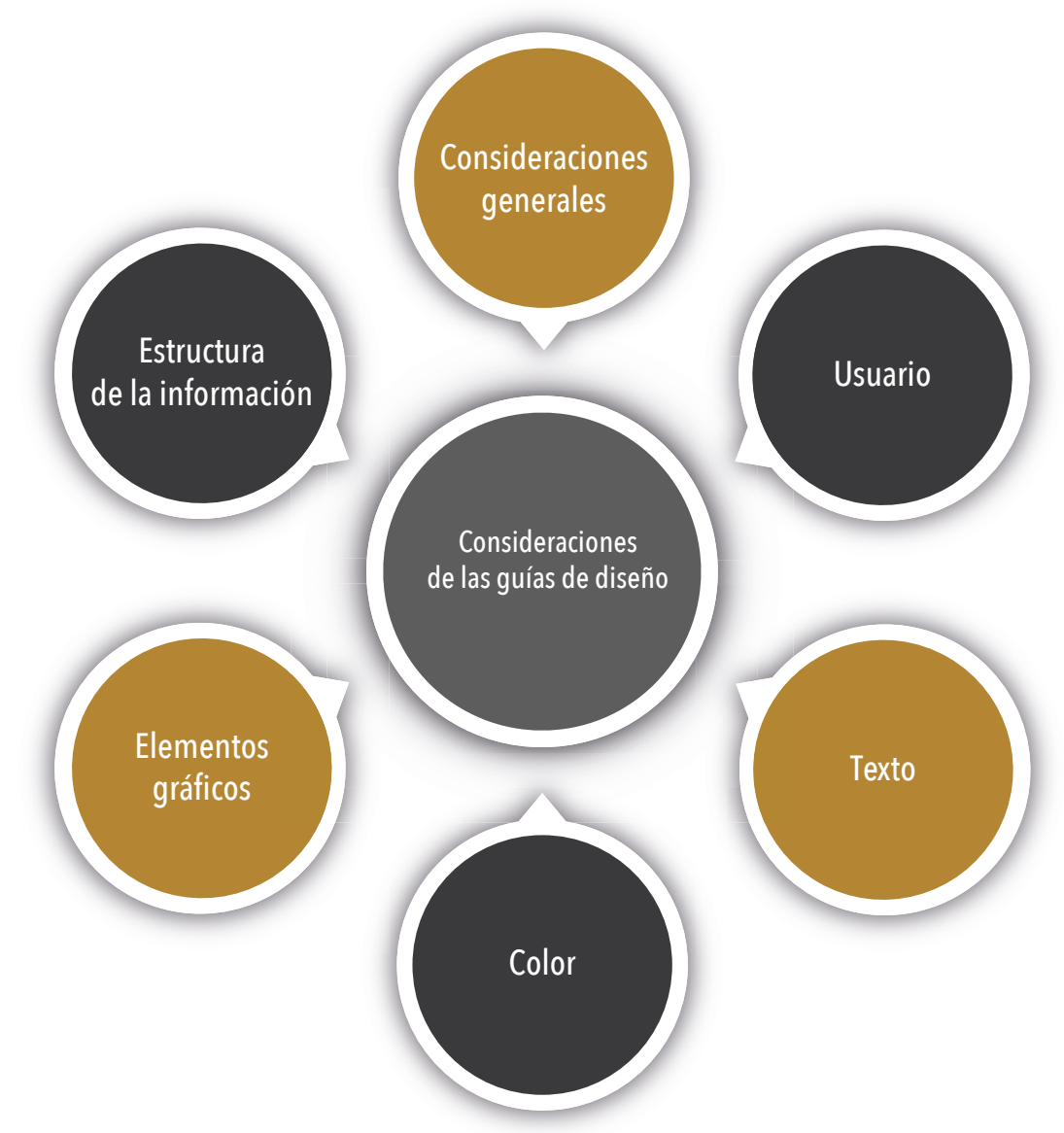




\section{ÍNDICE}

5 Consideraciones generales

9 Usuario

13 Estructura de la información

21 Texto

33 Color

41 Elementos gráficos

49 Figuras en la visualización de información

81 Referencias 


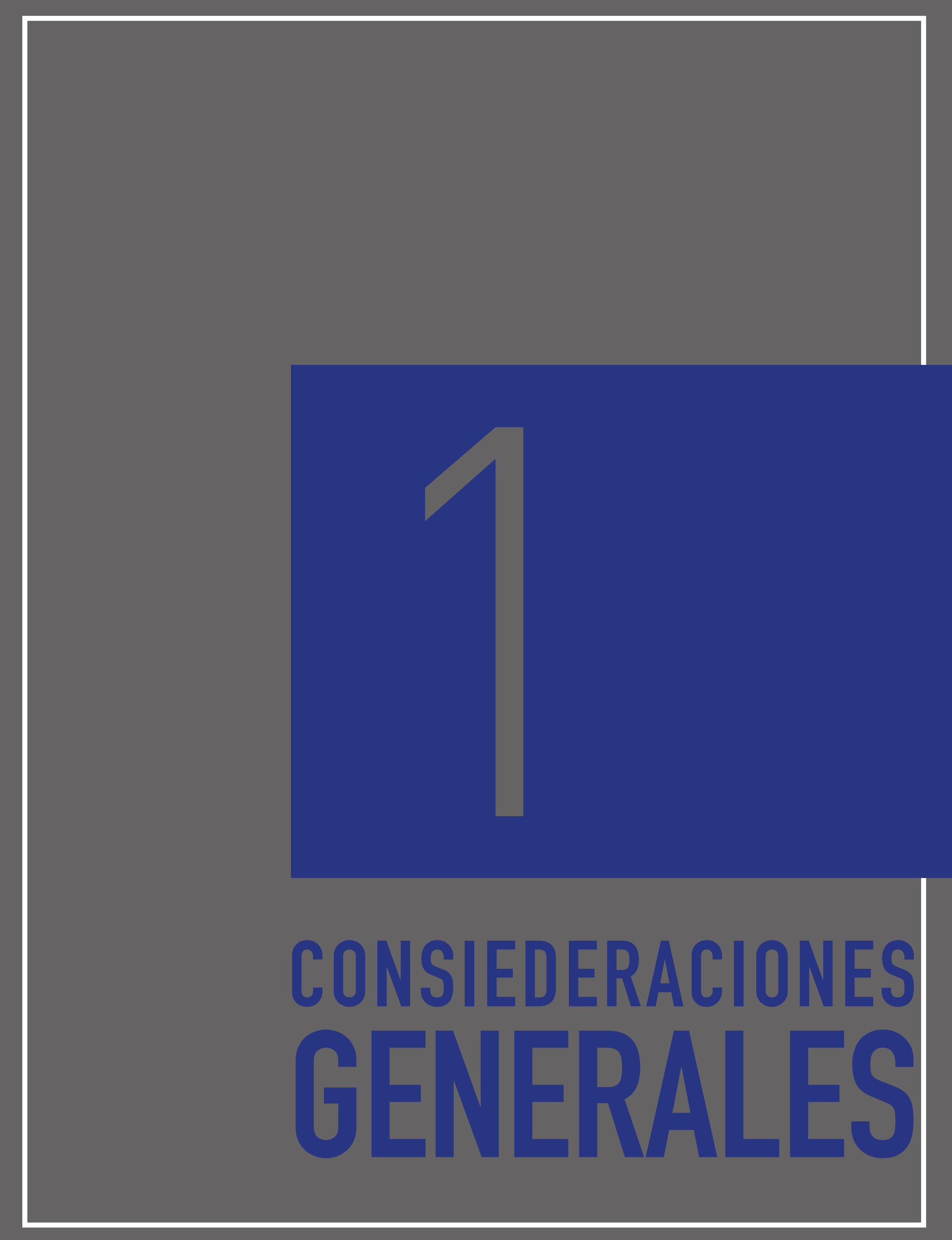


1 Agrupación de información. Cada uno de los elementos que se utilicen en la interfaz gráfica deben agruparse de manera significativa, ya que el usuario logrará su comprensión si éstos le son presentados de una manera agrupada, de acuerdo a las Leyes de la Gestalt. De esta forma, el lector podrá recordar y comprender la información de una mejor manera.

2 Recordatorios o texto de apoyo. Se recomienda auxiliarse de señales visuales que ayuden al usuario a recordar la clase de información con la que están interactuando o que aporten un poco de contexto previo a dicha información.

3 Uso de elementos familiares. Es recomendable que la forma en que se visualiza la información en una interfaz gráfica se base en el conocimiento que el usuario pueda tener con respecto a los símbolos, imágenes o elementos gráficos utilizados. De esta manera, se le aporta un valor más significativo a la información y refuerza la transmisión del propio conocimiento que se está tratando de proyectar. Debe utilizarse un diseño simple y directo con una riqueza de datos, reduciendo la necesidad de inferencias, haciendo comparaciones claras y explícitas en la información de ser el caso.

\section{4}

Uso de elementos gráficos limitados. Aunque un sistema de visualización de información tiene como fin hacer que la información que se presenta sea más accesible y rápida de interpretar para el usuario, se recomienda que el uso de elementos gráficos en cada sección de cualquier sistema de visualización sea limitado, así se evitará que el usuario haga esfuerzos cognitivos extras para determinar la razón de ser de cada uno de los elementos gráficos utilizados en el sistema. Cualquier elemento gráfico que no aporte significado o no favorezca el procesamiento y la comprensión de información debe omitirse. Deben minimizarse los patrones de distracción, colores predominantes, sombreado, 3D, cuadrículas innecesarias, etc.

\section{5}

Jerarquía. Aunque un sistema de visualización de información tiene como fin hacer que la información. Es importante ordenar la información de modo en que ésta resulte más relevante para el objetivo de comunicación, se sugiere que vaya primero u ocupe el foco visual de la interfaz gráfica, ya que esto afectará la forma en que los usuarios la información. El objetivo es priorizar la información en orden de importancia para el usuario.

6 Consistencia. Se debe presentar de una forma coherente la información que se va a incluir en el sistema de información, ya que así el usuario la encontrará más fácil de comprender. La calidad y simplicidad de la información se debe garantizar manteniendo símbolos, colores, texto y métricas consistentes, seleccionando cuidadosamente los elementos visuales para ayudar a y métricas consistentes, seleccionando cuidadosamente los elementos visuales para ayudar a
aclarar el significado de los datos, auxiliarse de títulos claros para cada sección o bloque de información y, del uso anotaciones sobre cómo interpretar la visualización. 
7 Énfasis. Es muy importante generar énfasis visual en la información que sea de suma relevancia para el objetivo de comunicación de la interfaz gráfica. El diseñador se puede auxiliar desde un acomodo en la retícula que resalte dicha información hasta el uso de colores, elementos visuales o algún tipo de juego gráfico que aluda a este fin. Esto favorecerá a la memoria icónica para el procesamiento y comprensión de información que le es presentada al lector o usuario. 8 Simplicidad. El sistema de visualización de información debe presentar de una manera sencilla y accesible la información con la que se está trabajando. Es decir, que este sistema no reque

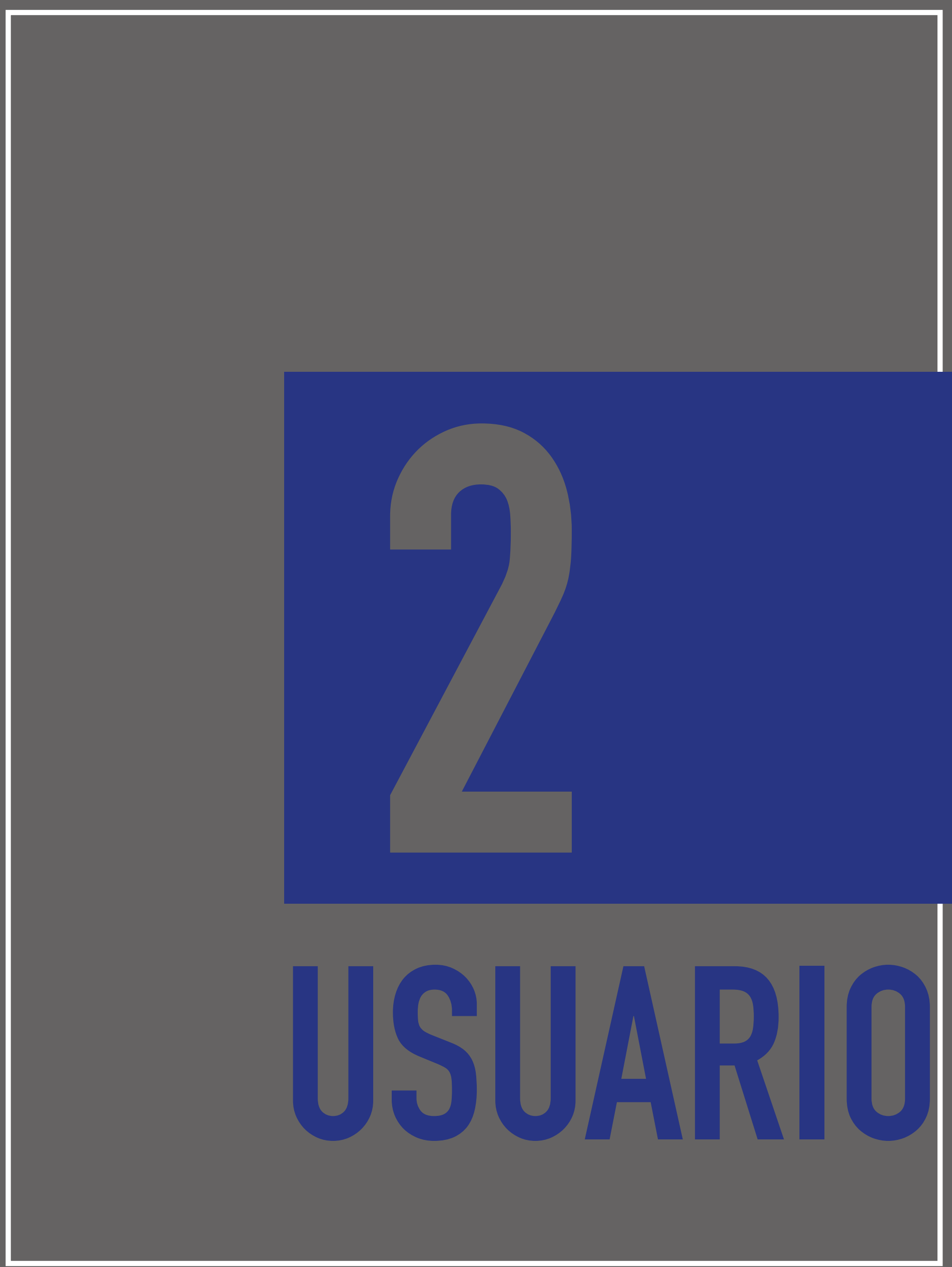


2 De acuerdo a Frascara (2000) se recomienda segmentar y definir al usuario de la siguiente manera:

1. Nivel socioeconómico: Este punto hace referencia al nivel jerárquico que ocupa el usuario de acuerdo a su bienestar económico y social.

2. Nivel de escolaridad o académicos: Hace referencia al grado de estudios máximo alcanzado por el usuario.

3. Edad: Rango de tiempo que ha vivido el usuario.

4. Sexo: Características biológicas y fisiológicas que clasifican al usuario como femenino o masculino.

5. Situación geográfica: Este punto se refiere al lugar de residencia del usuario.

6. Situación de lectura: Hace referencia al medio por donde el usuario interactuará con la información, tomando en cuenta que puede ser a través de un medio impreso o digital.

\section{Creencias sobre la información que se le va a presentar.}

8. Usos y costumbres: Este rubro hace referencia a la manera en que se relaciona el usuario con la información que se trabajará en la interfaz gráfica.

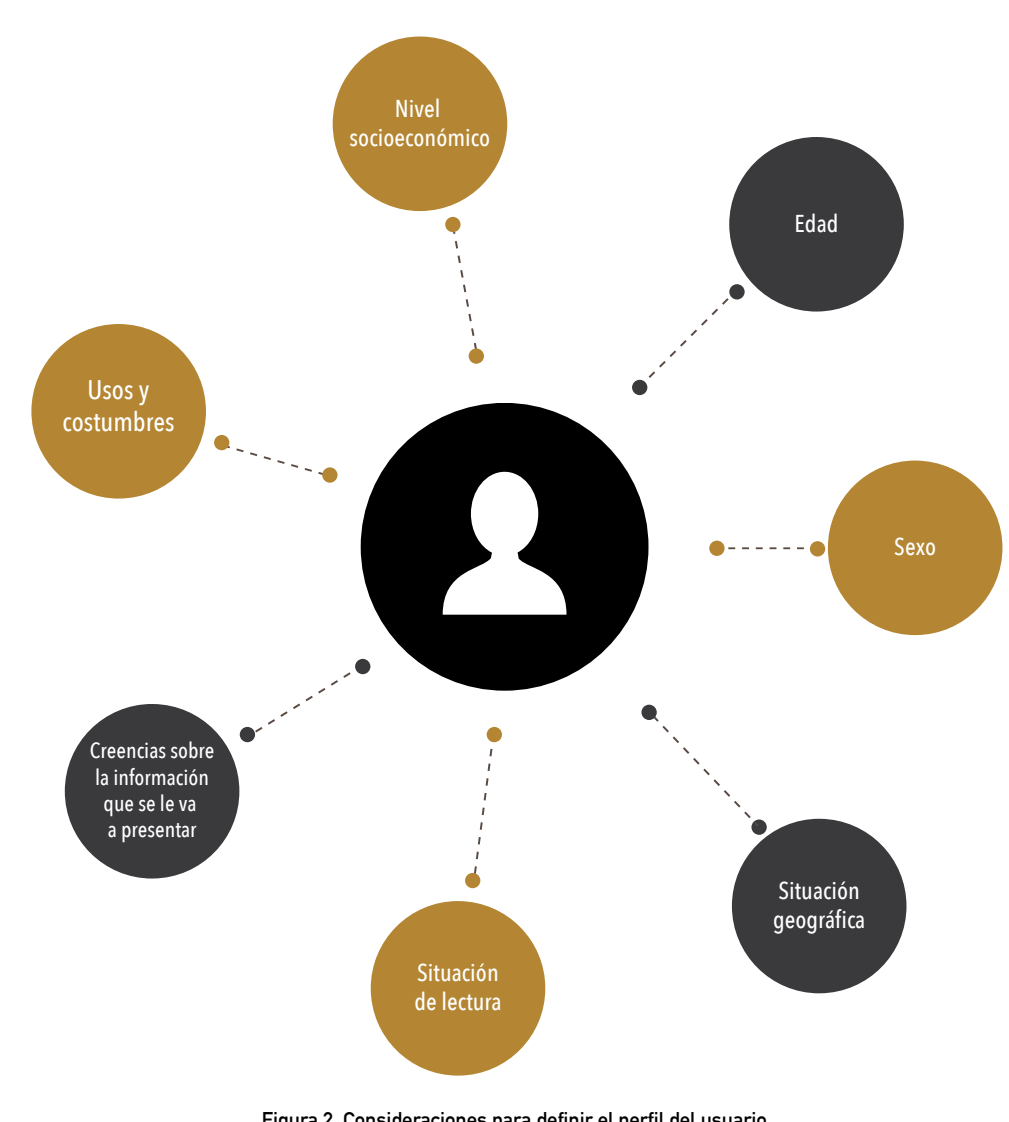

Figura 2. Consideraciones para definir e l perfil del usuario 
3 Ya definiendo los puntos anteriores, se sugiere tener esto siempre presente a la hora de tomar

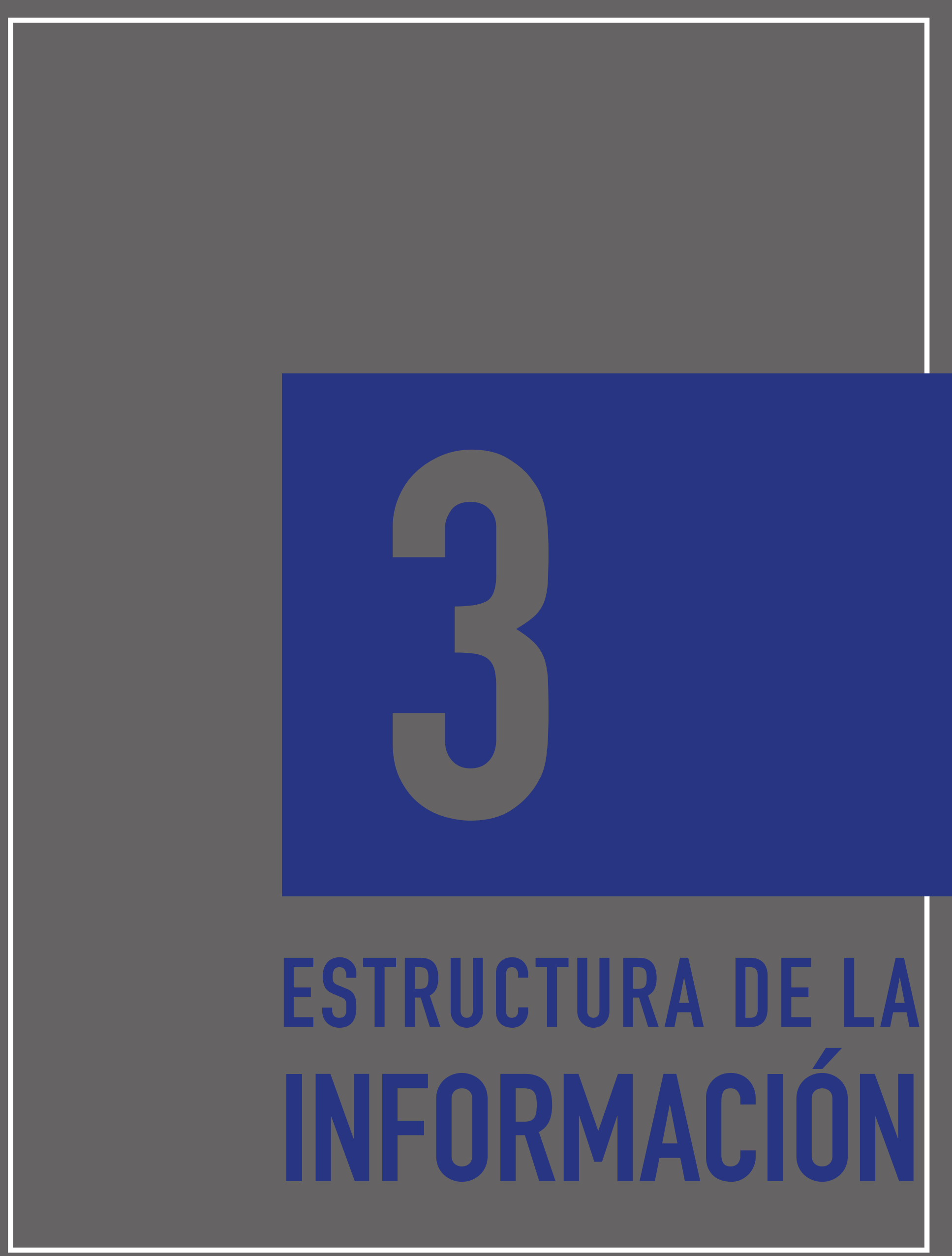


1 Es primordial leer y relacionarse con la información que se va a trabajar. Sí hubiera dudas es recomendable hondar en el tema, según lo establece Cairo (2011).

2 De acuerdo al autor anterior, es importante que se estructure la información de una forma en que haya congruencia y secuencia entre términos y conceptos.

3 La estructura en sí de la propia información que se está trabajando en el sistema de visualización de información debe mostrar una jerarquía clara y bien planificada que ayude al lector a identificar dicho orden, acorde a lo que Lonsdale \& Lonsdale (2019) señalan. $4 \begin{aligned} & \text { Para ayudar al usuario a procesar la información dentro de cuadros complejos, debe existir } \\ & \text { una jerarquía visual clara en la que se resalten los elementos importantes, se eliminen las }\end{aligned}$ distracciones y se establezca el orden visual, según Cairo (2011).

5 Se sugiere, de acuerdo a lo que analizan Nielsen \& Loranger (2016), un diseño en el cual la navegación se haga de izquierda a derecha y en forma de zigzag, ya que esto responde a la forma natural en que nuestros ojos leen la información.

Todos los elementos gráficos que se utilizan, deben apoyar a la estructuración jerárquica de información, así como también, deben ser consistentes visualmente hablando entre ellos, según argumenta Cairo (2011).

7 El texto y las imágenes que se encuentren relacionados entre sí bajo términos de concepto se recomienda que se coloquen muy juntos en términos de proximidad perceptiva (y con la ayuda de guías visuales, si corresponde) para dirigir el ojo desde el texto a las imágenes y la espalda, y facilitar la integración de la información, de acuerdo a lo que establecen Lonsdale \& Lonsdale (2019). Es recomendable el uso de retículas para estructurar todos los elementos que contenga el
sistema de visualización de información. Las retículas más usadas en el diseño de interfaces gráficas son las siguientes (ver en la próxima página): 
Retícula de manuscrito. Este tipo de retícula se usa generalmente para bloques de texto largos. Está compuesta por márgenes amplios que enmarcan un rectángulo en donde se vaciará la información. Los títulos, pies y número de página se encuentran dentro de los marcadores que se localizan fuera de los márgenes, así como lo muestra la siguiente figura.

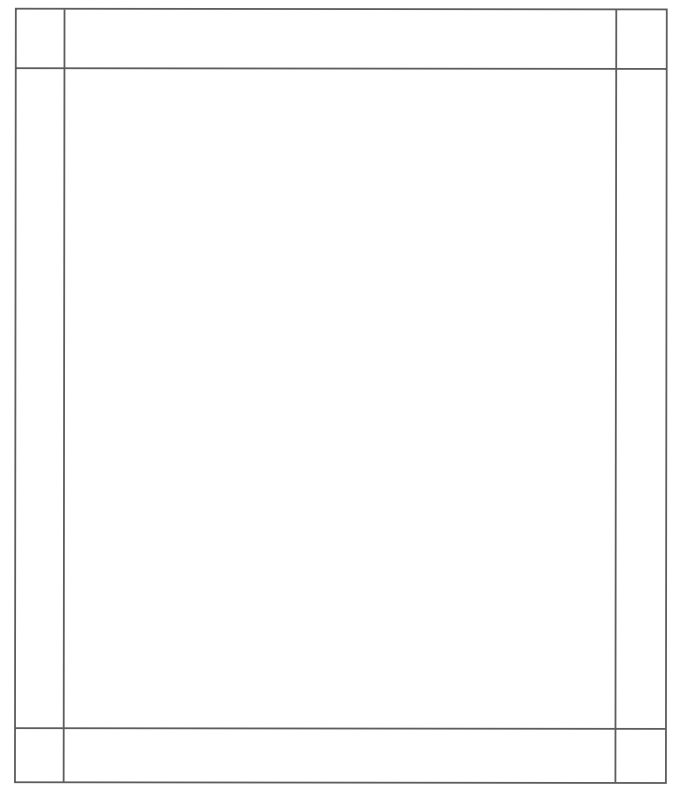

Figura 3. Reticula de manuscrito

Retícula de columna. Esta retícula resulta ser bastante flexible en cuanto al acomodo de la información. El número de columnas va a depender de la cantidad de información que se esté manejando, es decir, entre más información mayor número de columnas.

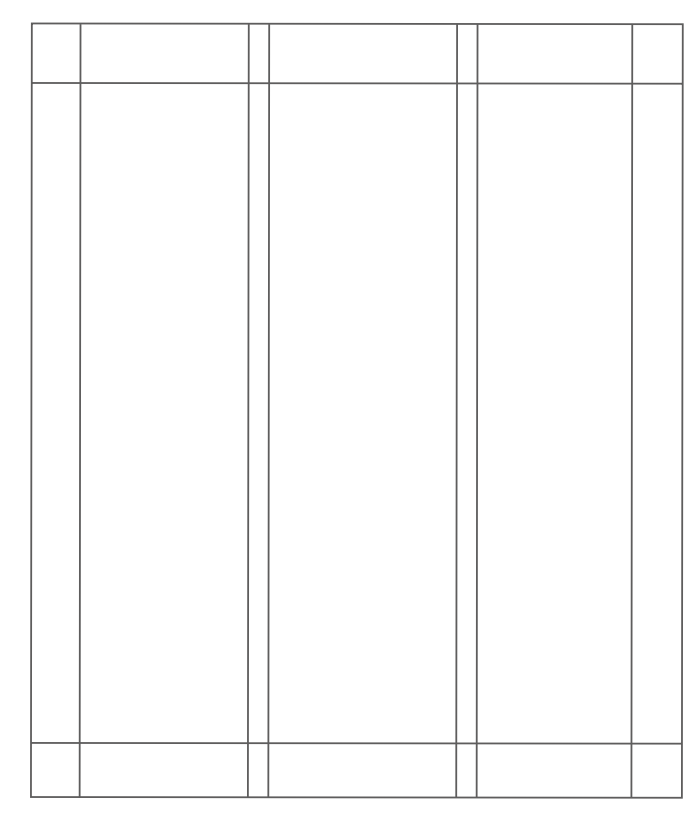

Retícula modular. Este sistema reticular está compuesto por módulos del mismo tamaño. Se puede diagramar con base al número de módulos que se tengan sobre el lienzo, ya que a través de estos se puede crear zonas espaciales ${ }^{2}$ para insertar imágenes y texto. Entre más módulos tenga la retícula más flexible será para el acomodo de la información, sin embargo, esto aumentará el nivel de complejidad para mantener la estética de la interfaz.

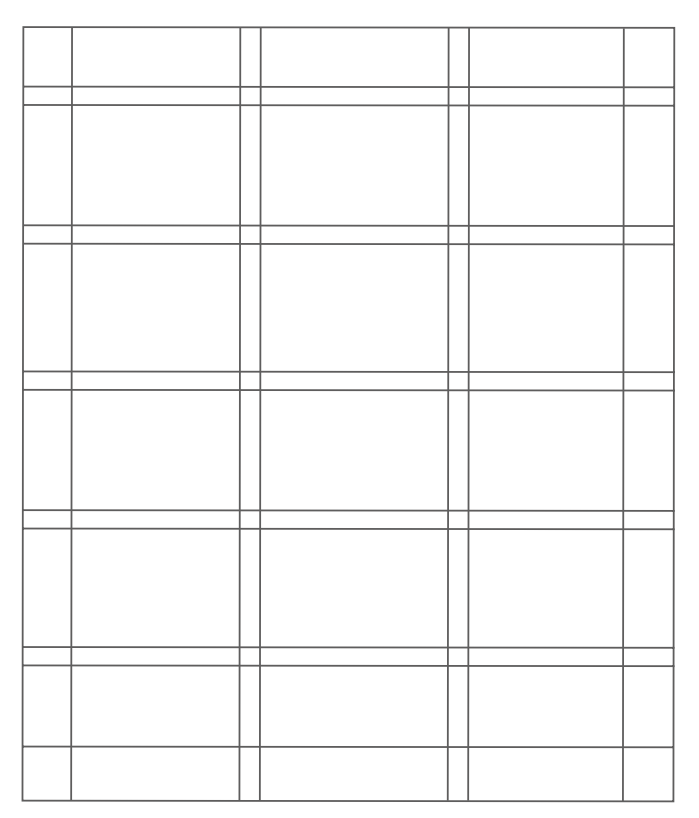

Figura 5. Reticula modular

Retícula jerarquíca. Este tipo de retícula, al contrario de las anteriores, no se rige a través de módulos, columnas o márgenes. Esta retícula se adapta al contenido y no éste a ella. Este sistema reticular se establece a través de los niveles de jerarquía de la propia información.

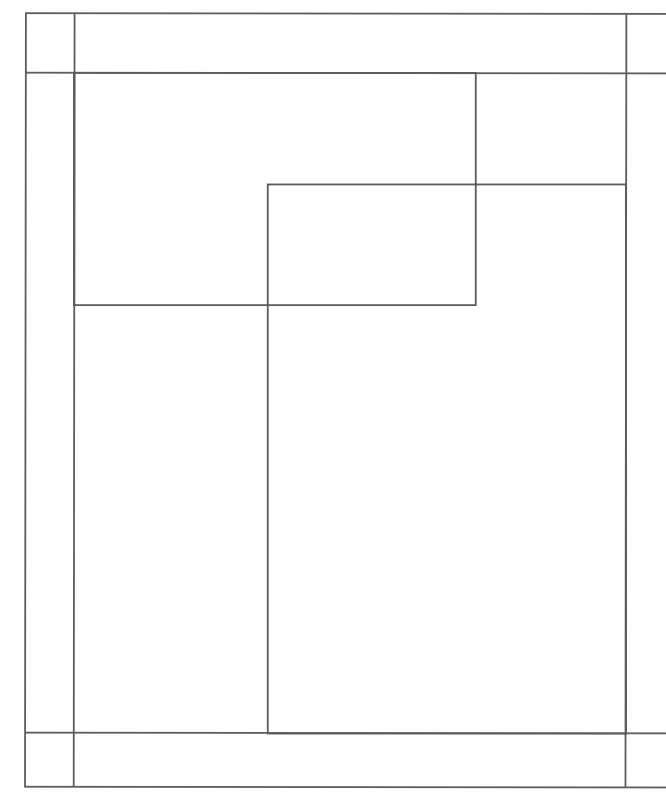

Figura 6. Reticula jerarquica 
Al ser estas guías que se enfocan en el desarrollo de sistemas de visualización médica es importante mencionar los datos médicos y sus diversas clasificaciones basándose en el caso de estudio de esta investigación que es la diabetes. Los datos médicos que se pueden trabajar respecto a esta patología son los siguientes:

Historial clínico. El historial clínico es un compendio de información que alude a datos de identificación y evolución del propio paciente. En éste se asienta la evolución de la patología. Dentro de este bloque de información, de acuerdo a Castro \& Gámez, (2002), se encuentran a su vez los siguientes datos:

\section{Datos de identificación.}

a. Número de historia clínica.

a. Nombre y apellido clinica.

b. Nombre apellido del paciente.

c. Fecha de nacimiento del paciente.
d. Género del paciente.

d. Genero del paciente.

e. Edad del paciente.

. Domicilio particular del paciente

g. Número telefónico de contacto.

h. Peso del paciente.

i. Altura del paciente.

. Signos vitales del paciente (temperatura, presión, pulso, frecuencia respiratoria, nivel de glucosa).

2. Datos relativos al centro de salud o del doctor tratante.

a. Nombre de la unidad o centro de salud donde ingresa el paciente.

b. Nombre del doctor a cargo del caso clínico.

d. Persona facultativa a cargo del ingreso del paciente.

\section{Datos referidos al proceso de ingreso.}

a. Fecha de admisión del paciente.

a. Fecha de admisión del paciente.

c. Diagnóstico principal.

d. Procedimientos quirúrgicos u obstétricos que ha tenido el paciente.

e. Otros procedimientos significativos que haya tenido el paciente.

\section{Datos referidos a antecedentes clínicos.}

a. Antecedentes familiares de enfermedades (diabetes, hipertensión, cáncer, enfermedades del corazón, etc).

b. Si el paciente tiene hijos y, en caso de ser afirmativo, cuáles son las edades de éstos.

c. Historial social, tales como cuál es su trabajo, su jornada laboral, dónde vive, cuál es el ambiente emocional en el que el paciente habita. d. Hábitos del paciente. Si hace ejercicio y con qué frecuencia realiza esta actividad, si fuma, se droga y toma, y la periodicidad con la que desarrolla o desarrolló estas actividades. Si se droga (o drogaba), que estupefaciente usa o usó. Patrón de sueño, a qué hora duerme y más o Alergis a medicamentos y alin

\section{Datos referentes a la historia de la enfermedad actual.}

a. Fecha de diagnostico de diabetes.

b. Nombre del médico que trata actualmente la diabetes del paciente. c. Dirección del médico que trata actualmente la diabetes del paciente. d. Fecha de última revisión de parte del médico tratante por diabetes. e. Si el paciente está siguiendo una dieta en especial.

. Consumo aproximado de calorías al día.

g. Si el paciente está tomando insulina.

i. Unidades de insulina.

iii. Hora en que se inyecta la dosis de insulina.

h. Si el paciente ha sufrido un coma diabético, fecha de éste y frecuen-

Si el paciente se ha realizado análisis de glucosa en la orina. En caso de ser afirmativo, mencionar las últimas dos fechas de éstos.

j. Si el paciente ha tenido alguno de estos padecimientos:

i. Infecciones dentales.

ii. Trastornos en la visión.

iii. Problemas en el corazón.

v. Presión alta.

v. Problemas en los riñones o en las vías urinarias.

vi. Alguna enfermedad recurrente o prolongada. En caso de ser afirmativo, mencionar cuál.

k. Niveles de glucosa.

i. En ayunas.

ii. Después de la comida.

iii. Antes de la cena.

l. Sí se le ha realizado un electrocardiograma. En caso de ser afirmativo, establecer la fecha.

$m$. Si se le ha realizado una radiografía de tórax. En caso de ser afirmativo, indicar la fecha.

6. Datos bioquímicos relacionados con el control de la diabetes.

a. Triglicéridos $(\mathrm{mg} / \mathrm{dL})$.

b. Glucosa (mg/D).

. Hemoglobina glucosilada (HbA1c).

. Colesterol total $(\mathrm{mg} / \mathrm{dL})$

e. Colesterol de alta densidad (mg/dL).

. Colesterol de baja intensidad (mg/dL).

g. Colesterol de muy baja intensidad (mg/dL).

h. Índice de riesgo coronario.

i. Examen de orina.

i. Color.

ii. Aspecto.

iii. Gravedad específica.

iv. $\mathrm{Ph}$

v. Sedimiento

vi. Proteínas $(\mathrm{mg} / \mathrm{dL})$

vii. Glusoca $(g / d L)$.

viii. Hemoglobina.

ix. Bilirubina.

$x$. Cetonas.

xi. Urobilinor

xi. Urobilinogeno $(\mathrm{mg} / \mathrm{dL})$

xii. Esterasa Leucocitaria (Leu/uL).

xiii. Nitritos. 


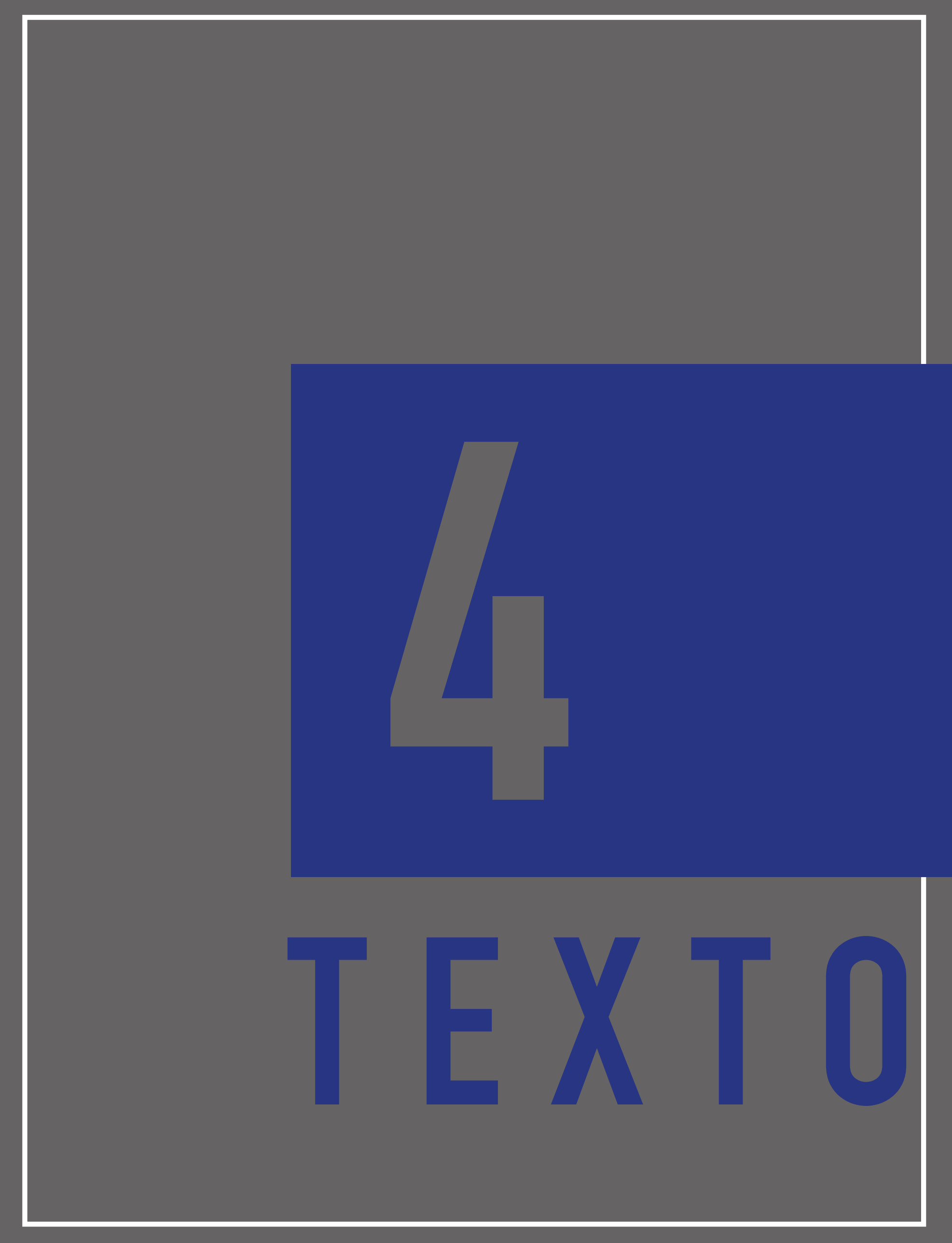




\section{ELECCIÓNTIPOGRÁFICA}

1 Según a Nielsen \& Loranger (2006), la tipografía debe elegirse de manera apropiada para su función, es decir, para transmitir el mensaje de manera efectiva.

2 El tipo de letra seleccionada deben coincidir con el tema de la información que se trabajará. 3

Las fuentes tipográficas, según determina Nielsen \& Loranger (2006) son las siguientes:

\begin{tabular}{|c|c|c|}
\hline FUENTE TIPOGRÁFICA & LEGIBILIDAD & CARÁCTER/TONO \\
\hline Arial & $\begin{array}{l}\text { Es una tipografía legible. Se recomienda } \\
\text { usar en puntajes superiores a } 10 \text { puntos. }\end{array}$ & $\begin{array}{l}\text { Moderna, básica y sin adornos. } \\
\text { Suele gustar a los usuarios de } \\
\text { todas las edades. }\end{array}$ \\
\hline Georgia & $\begin{array}{l}\text { La mejor fuente serif diseñada para la } \\
\text { lectura online. Generalmente buena en } \\
\text { tamaños de letra } 10 \text { o más. }\end{array}$ & $\begin{array}{l}\text { De aspecto tradicional, pero más } \\
\text { moderna y legible que Times } \\
\text { New Roman. }\end{array}$ \\
\hline Times New Roman & $\begin{array}{l}\text { Tiene buen rendimiento en materiales } \\
\text { impresos, ya que en la pantalla, la legibili } \\
\text { dad disminuye en pequeños puntajes. } \\
\text { Se sugiere su uso a partir de } 12 \text { puntos. }\end{array}$ & $\begin{array}{l}\text { Es una tipografía que no es } \\
\text { prefererida por la mayoría de los } \\
\text { usuarios. Tiene un aspecto } \\
\text { profesional. }\end{array}$ \\
\hline Trebuchet MS & $\begin{array}{l}\text { Es una tipografía legible. Se recomienda } \\
\text { usar en puntajes superiores a } 10 \text { puntos. }\end{array}$ & $\begin{array}{l}\text { Tiene un aspecto moderno, } \\
\text { sencillo y vanguardista. }\end{array}$ \\
\hline Verdana & $\begin{array}{l}\text { La tipografía con mayor legibilidad. } \\
\text { Recomendada para usarla en cuerpo de } \\
\text { texto. }\end{array}$ & $\begin{array}{l}\text { De aspecto simple, moderno y } \\
\text { profesional. Alta preferencia por } \\
\text { parte del usuario. }\end{array}$ \\
\hline
\end{tabular}

Figurr 7. Tipografaías recomennadas por Nielesen \& Loranger 20006

1 No es recomendable los tipos de letra con características inusuales (Nielsen \& Loranger, de distracción durante el recorrido de la lectura

\section{Hamburguosa Bambuttututesa}


5

El tamaño del tipo, el espacio interlineal y la longitud de la línea se deben coordinar y elegir juntos.

6 Según lo que sugiere Götz (1988:58), "el espacio interlineal debe ser por lo menos uno y medio más grande que la altura de $x$, es decir, 1.5".

\section{Aturatidex Conej0}

Así mismo, la autora sugiere que se le de la importancia a este elemento tipográfico, ya que interviene en la legibilidad del texto y del mismo contenido en sí.

7 Siguiendo con las recomendaciones de la autora, el ancho normal de una línea debe tener alrededor de 50 caracteres.

8 Lonsdale \& Lonsdale (2019), hacen las siguientes recomendaciones acerca de la tipografía y su uso:

a. Debe evitarse dejar una sola palabra en un renglón dentro de una caja de texto. A esto se le llama viuda.

$$
\begin{aligned}
& \text { Lorem ipsum dolor sit amet, consectetuer adipiscing elit. Aenean com } \\
& \text { modo ligula eget dolor. Aenean massa. Cum sociis natoque penatibus } \\
& \text { etmagnis dis parturient montes, nascetur ridiculus mus. Donec quam }
\end{aligned}
$$
et magnis dis

Figura 10. Fjemplo de una "viuda" en una caja de texto

b. La variante "negrita" debe usarse sobre la variante "cursiva" para enfatizar el texto. La variante cursiva debe reservarse para situaciones en las que se utiliza una palabra extranjera o para títulos cortos.

Muy lejos, más allá de las montañas)de palabras, alejados de los países
de las vocales y las consonantes, viven los textos simulados. Un riachuelo llamado Pons fluye por su pueblo y los abastece con las normas necesarias. c. La variante "negrita" se puede usar para enfatizar información, y como una técnica para engrosar los caracteres cuando estos deben imprimirse o vers en un fondo oscuro $y / 0$ de color.

d. Se debe evitar utilizar la variante "cursiva" para grandes bloques de texto, ya que esta atrasa la lectura.

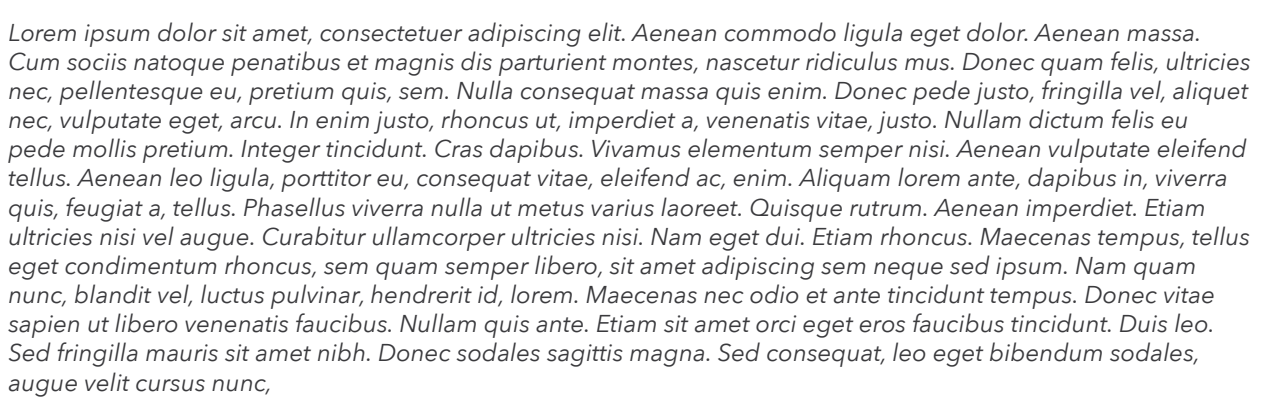

Figura 12 El uso de la

e. Se recomienda usar la variante "negrita" para aumentar la legibilidad en un fondo de color o sombreado.

f. La variante "negrita" no debe usarse para una gran cantidad de texto porque al resaltar todo, no se enfatizará nada del contenido a un nivel cognitivo.

\section{Lorem ipsum dolor sit amet, consectetuer adipiscing elit. Aenean commodo ligula eget dolor. Aenean massa.} vel, aliquet nec, vulputate egel, arcu. In enim justo, rhoncus ut, imperdiet a, venenatis vitae, justo. Nullam dictum eleifend tellus. Aenean leo ligula, porttitor eu, consequat vitae, eleifend ac, enim. Aliquam lorem ante, dapibus

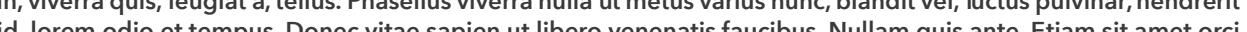
eget e ros faucibus tincidunt. Duis leo. Sed fringilla mauris sit a met nibh. Donec sodales sagitis magna. Sed

Figura 13. El luso de la variable "negrita" en todo el texto no logra enfatizar nada del contenido a un nivel cognitivo.

g. Se debe evitar la variante "subrayado" porque agrega bastante ruido y compromete la legibilidad del texto y de la información en sí.

h. No se deben usar diferentes tipos de letra para enfatizar el contenido en sí, no solo porque hace que la lectura sea más ardua, sino también porque altera la estética.

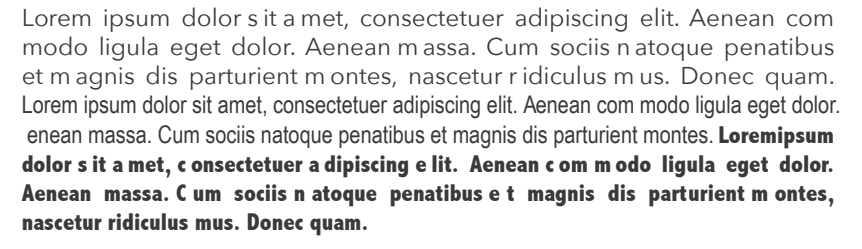

Figura 14. Ejemplo del mal uso de diversas variantes tipograficas en un bloque de texto. 
Según lineamientos que proponen Nielsen \& Loranger (2016) la lectura es más agradable y confortable para el usuario cuando se emplean tipografías serif 3 .

\section{Hamburguesa Hamburguesa}

Figura 15. Ejemplos de tipografía sans serify serit.

10 El puntaje mínimo recomendado para las cajas de texto es de 11 pts. y para las anotaciones o dato complementarios como fuentes de referencia es 8 pts, de acuerdo a Lonsdale \& Londsdale (2019).

11 Nielsen \& Loranger (2016) argumentan que el puntaje se debe elegir dependiendo del usuario al que la interfaz va dirigida, por lo cual se presentan las siguientes sugerencias de acuerdo al usuario:

\begin{tabular}{|l|c|}
\hline \multicolumn{1}{|c|}{ AUDIENCIA } & PUNTAJE \\
\hline Audiencia general & $0 \cdot 12$ \\
Personas mayores y personas con discapacidad visual. & $12 \cdot 14$ \\
Niños pequeños y otros lectores principiantes. & $12 \cdot 14$ \\
Adolescentes y adultos jovvenes & $10-12$ \\
\hline
\end{tabular}

Figura 16. Tamaño de puntaje recomendado de acuerdo a la audiencia por Nielse \& Loranger (2006).

12 La tipografía no debe ser demasiada fina o condensada en su forma, según plantean Lonsdale \& Lonsdale (2019).

\section{Figura 17. La tipografaín no debe ser demasiado fina ni condestan}

14

Los mismos autores recomiendan utilizar notas al pie para aclarar puntos en especiales del texto que se está leyendo.

\section{TÍTULOS}

15 Los títulos deben ser uno de los elementos más dominantes en la interfaz gráfica y deben presentar rápidamente el propósito del contenido y el enfoque del mensaje. El contraste entre el título, los subtítulos y el texto narrativo debe ser claro en términos de
diferencias de tamaño y las características del tipo de letra. 17 De acuerdo a lo que plantea Götz, (1988:56), las tipografías sans serif son utilizadas para los

18 Es recomendable no usar más de tres niveles de jerarquía en cuanto a texto, el nivel de mayor jerarquía puede distinguirse usando un puntaje de letra mayor con la variable "negritas" centrado en el lienzo, de acuerdo a lo que argumentan Nielsen \& Loranger (2006).

19 De acuerdo a Lonsdale \& Lonsdale (2019), los títulos pueden estar centrados o alineados a la izquierda, mientras que los encabezados deben alinearse a la izquierda.

20 Es recomendable que los títulos puedan ser usados en la variante "negrita" o un par de puntajes más grandes que el texto principal, según los mismos autores.

\section{TíTULO}

Subtitulo

Muy lejos, más allá de las montañas de palabras, alejados de los países de las vocales y las consonantes, viven los textos simulados. Viven aislados en casas de letras, en la costa de la semántica, un gran océano de lenguas. Un riachuelo llamado Pons fluye por su pueblo y los abastece con las normas necesarias.

$$
\text { Figura 18. Contraste de peso tipgoráfico entre el titulo, subtitulo y el texto. }
$$

\section{ETIQUETASYLEYENDAS}

21 Lonsdale \& Lonsdale (2019), hacen las siguientes recomendaciones sobre el uso de etiquetas y leyendas:

a. Las etiquetas se deben utilizar para proporcionar información detallada sobre los datos y se deben excluir si son redundantes o si el gráico se ve desordenado. 
b. Se sugiere que los textos de apoyo (etiquetas, leyendas, etc.) deben colocarse para ayudar al usuario a interpretar el gráfico, no para distraer o confundir.

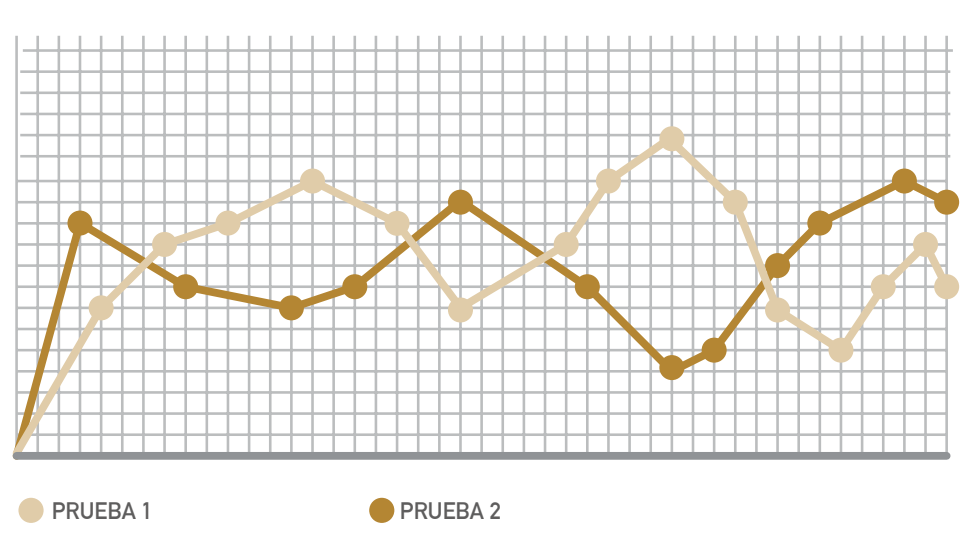

Figura 19. Uso de etiquetas para ayudar a lu suario a identificary y distinguri información.

c. Las etiquetas deben usarse con datos segmentados, con una amplia gama de datos y con áreas de datos (especialmente cuando se usa el volumen para representar el tamaño).

d. Se recomienda evitar usar etiquetas horizontales que se extiendan más allá de la tabla.

e. Las etiquetas no se deben usar cuando la tarea es solo para comprender tendencias generales o para comparar un elemento de datos con otro.

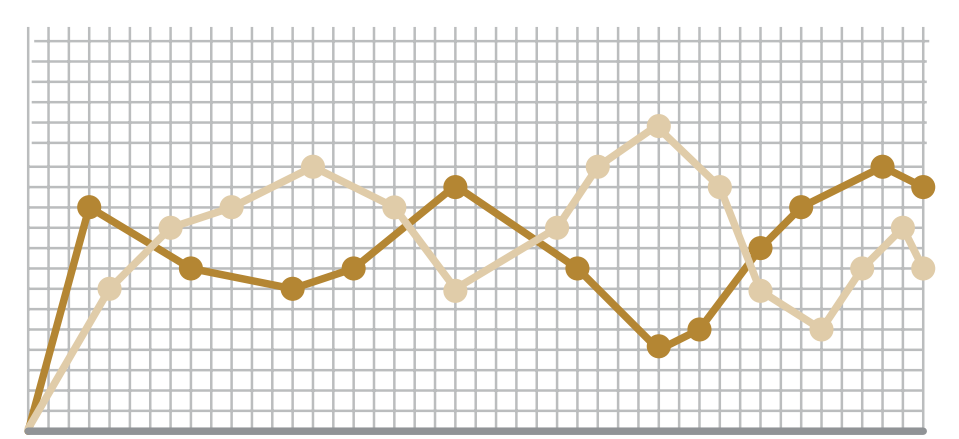

- Lorem issum dolor sit amet, consecteterer adipising elit. Aenean commodo ligula eget dolor. Aenean massa

Figura 20. Se debe evitar el uso de etiquetas que se extiendan más allá de la tabla.

f. Las etiquetas deben ser concisas y se debe tener cuidado de no usar grandes bloques de texto (especialmente debajo de una línea en un gráfico).

g. Las leyendas deben escribirse para que el cuadro se explique por sí mismo.

h. Una buena opción es incorporar las leyendas alrededor o dentro de la tabla, de tal forma en que no parezca un ente separado de la interfaz.

i. Es recomendable que las leyendas tengan el mismo orden que los elementos de contenido correspondientes en el gráfico. j. Los símbolos auto explicativos podrían usarse en ciertos contextos en lugar de una leyenda, pero todas las abreviaturas y símbolos deben estar claramente definidos.

k. Es conveniente utilizar verbos y adjetivos en una leyenda para sugerir o dejar claro cuál es la categoría general del mensaje que se usará en el gráfico.

I. El utilizar una leyenda y el área de datos como conjunto ayuda al usuario a completar la tarea más rápido

Continuando con las recomendaciones de los autores, Lonsdale \& Lonsdale (2019) plantean lo siguiente en cuanto al rendmiento visual del texto:

a. El texto y el color del fondo de la interfaz gráfica deben tener un buen contraste para ser legibles. Los fondos inadecuados, como los fondos de varios colores o degradados, deben evitarse para el texto.

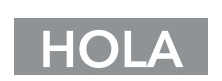

\section{$\mathbf{x}$}

HOLA

$\checkmark$

\section{$\boldsymbol{x}$}

Figura 21. Ejemplos de buen y mal contraste entre el texto ye color de fondo de la intertaz

b. Grandes cantidades de texto deben dejarse alineadas en lugar de centralizadas. La justificación centralizada debe limitarse a cantidades muy pequeñas de texto o texto / encabezados.

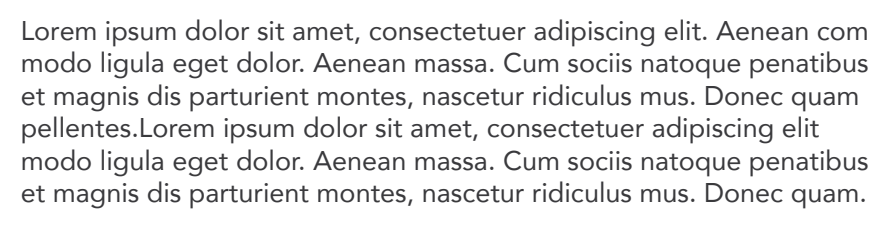

Lorem ipsum dolor sit amet, consectetuer a dipiscing elit. Aenean elitjadolien cjejd com
et magnis dis adf departurient

Grandes cantidades alineadas a la izquierda

Figura 22. Ejemplos de justificaciones de contenido apartir de la cantidad de texto.

c. Se deben evitar las mayúsculas siempre que se requiera una lectura rápida del contenido del texto.

d. El interletrado no debe ser demasiado ancho ni demasiado estrecho, ya que esto interrumpe el flujo normal de lectura. 
e. El espacio interlineal debe ser aproximadamente 2 puntos más alto que el tamaño del tipo para una lectura cómoda.

f. Se deben evitar los espacios amplios entre las palabras del texto, así como también el texto totalmente justificado, ya que generan un fenómeno visual llamado "ríos", (espacios blancos verticales que parecen rios que corren por la página) los cuales interrumpen la le

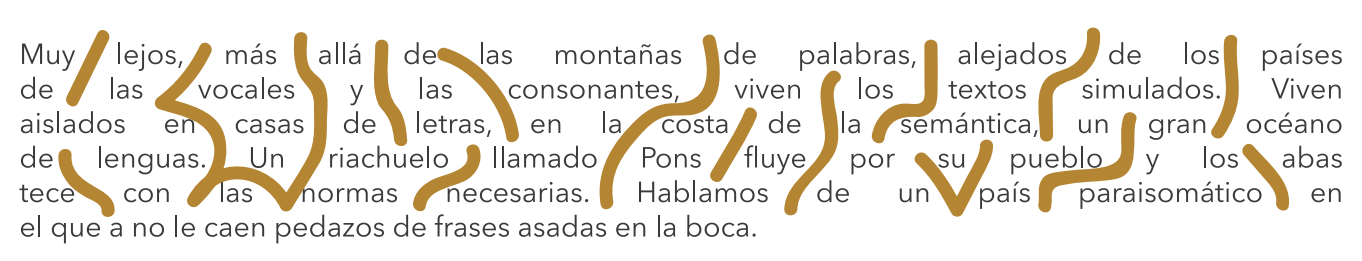

Figura 24. Ejemplo de "rios" en el texto

g. Se recomienda alinear los textos al lado izquierdo y usar líneas cortas para evitar los ríos en el acomodo del texto.

h. Los párrafos largos deben indicarse con una sangría moderada de 1 a 4 ems, o separados por un espacio de una línea. Los párrafos cortos, sin embargo, no deben estar separados por un espacio de una línea.

i. Se debe crear una paleta de fuentes para establecer qué tipos de letra funcionan juntos y qué tamaños, pesos y tipos de letra se utilizarán en las diferentes partes de la interfaz gráfica.

j. Los tamaños de la tipografía deben ser apropiados para el tamaño del gráfico y el área del mismo, si es que se llegan a utilizar.

k. Tanto las fuentes serif (con patín) como sans serif (sin patín) se pueden usar en combinación para crear una jerarquía visual y mantener la legibilidad. Por ejemplo, el uso de un tipo de letra sans serif para los encabezados y un tipo de letra serif para el text del párrafo crea un contraste y ayuda al usuario a navegar por los datos e identificar qué texto debe recibir atención primero.

\section{TíTULO}

Muy lejos, más allá de las montañas de palabras, alejados de los países de las vocales las consonantes, viven los textos simulados. Viven aislados en casas de letras, en la
costa de la semántica, un gran océano de lenguas. Un riachuelo llamado Pons fluyc por su pueblo y los abastece con las normas necesarias. Hablamos de un país parais mático en el que a uno le caen pedazos de frases asadas en la boca.

Figura 25. Ejemplo de jerarquúa tipográfica a traveśs de tuentes serify sans serif.

1. Otra forma de crear jerarquía a través de la tipografía es utilizando diferentes pesos de una misma tipografía.

m. Es una buena opción utilizar información numérica (numeración) y textual importante a la interfaz gráfica para aumentar la precisión. n. Los gráficos y el texto deben tener un formato consistente.

o. La tipografía no debe llamar más la atención de cualquier figura o diagrama que se encuentre en la interfaz gráfica.

p. La variación de tamaño también se puede utilizar para enfatizar información importante y captar la atención del usuario.

q. Se sugiere que el estilo de escritura debe ser simple, independientemente de se serif o sans serif.

r. Es recomendable usar mayúsculas y minúsculas en lugar de mayúsculas para el texto narrativo.

s. Para secuencias de palabras cortas (por ejemplo, títulos, etiquetas, palabras clave), es posible utilizar todas las mayúsculas.

t. A pesar de que el texto es importante en una interfaz gráfica, los principales entes actores deben de ser las figuras de visualización de información. 


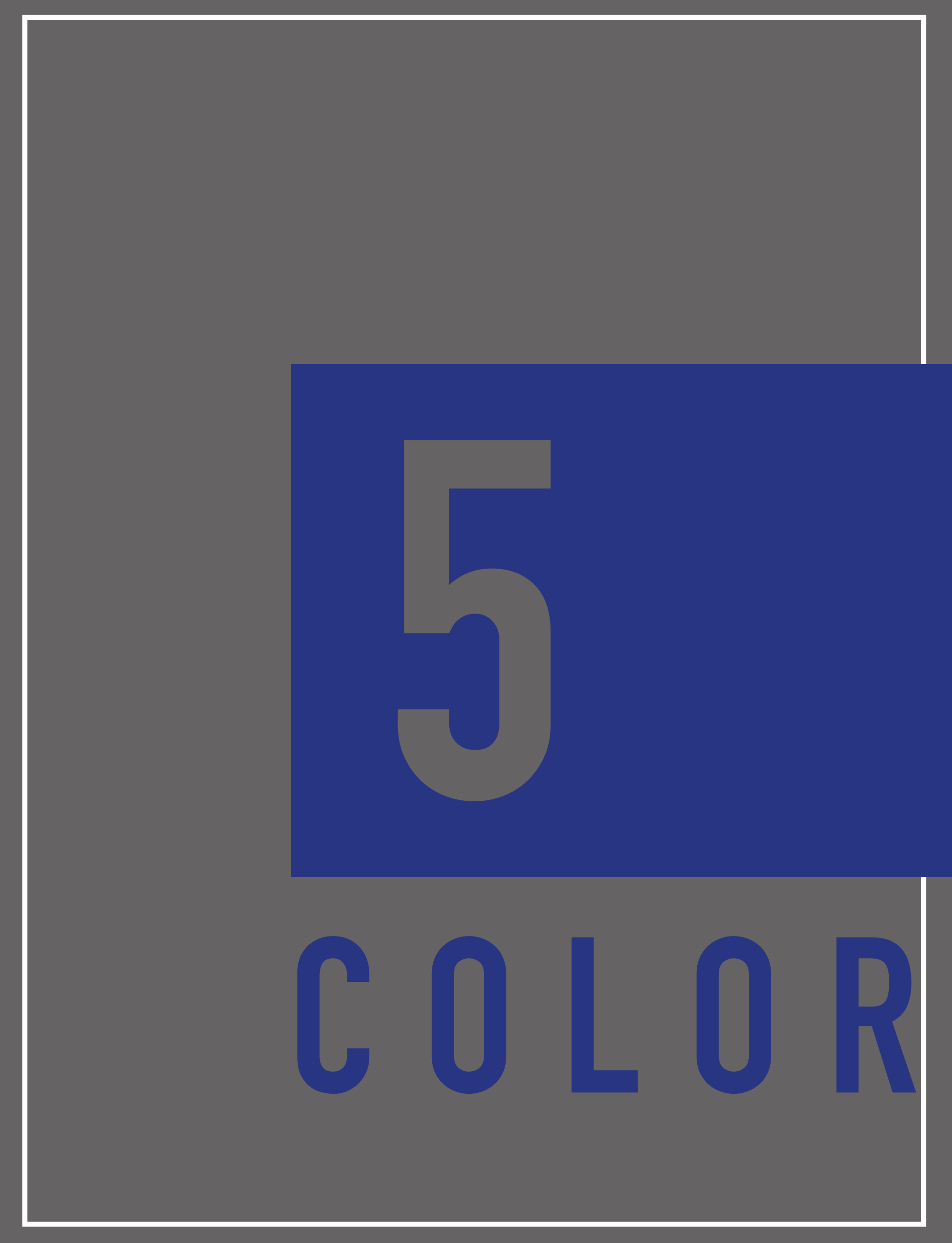


Se recomienda que la elección de color para la interfaz gráfica no se haga mediante gustos personales o juicios del propio diseñador.

2

Se sugiere elegir el color a usar a partir de las necesidades y objetivo de la interfaz gráfica.

2 De acuerdo a lo que establece Wiklund (1995) en the Human Engineering Committee of the Association for the Advancement of Medical Instrumentation (AAMI) se hacen las the Association for the Advancement of Medical Instrumentation (AAMI) se hacen las
siguientes sugerencias de uso del color para codificación de información en dispositivos médicos (Figura 22).

\begin{tabular}{|l|l|}
\hline \multicolumn{1}{|c|}{ COLOR } & \multicolumn{1}{|c|}{ SIGNIFICADO } \\
\hline Rojo & Prioridad alta. Advertencia. Alarma. Emergencia. Alto. Apagado. Nivel alto. \\
Amarillo & Prioridad Media. Precaución. Amenaza potencial. Nivel medio. \\
Verde & Estado normal. Inicio. Endendido. Listo. Nivel estándar. \\
\hline
\end{tabular}

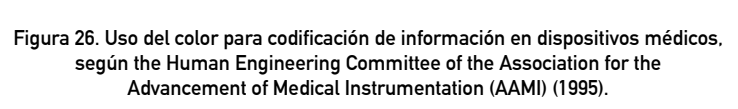
Según Lonsdale \& Lonsdale (2019), es conveniente usar una paleta de color que solo con-
temple cuatros colores, ya que el exceso de color puede resultar abrumador para el usuario. Para una alta legibilidad, de acuerdo a Nielsen \& Loranger (2006) debe mantenerse un buen
contraste entre el texto, el color y el fondo.

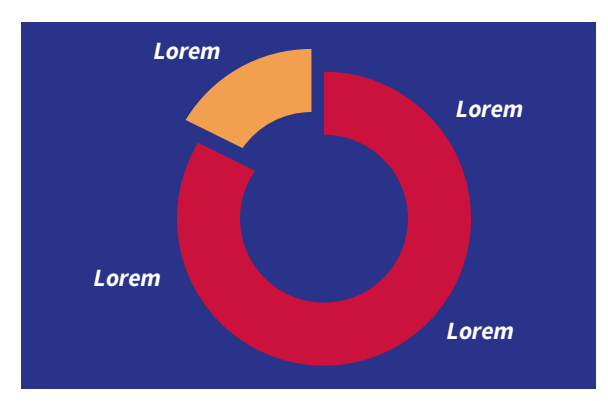


6 Por otra parte Götz, (1988:16), propone una relación entre algunos colores y su significado.

\begin{tabular}{|c|c|}
\hline COLOR & SIGNIFICADO \\
\hline Rojo & $\begin{array}{l}\text { Activo. Poderoso. Agresivo. Fuerte. Atractivo. } \\
\text { Dominante. Vigorazante. }\end{array}$ \\
\hline Rosa & Cuidado. Sensible. Dulce. \\
\hline Violeta & $\begin{array}{l}\text { Mistico. Sensual. Delicado. Encantadora. } \\
\text { Solitario. Inhibido. Turbio }\end{array}$ \\
\hline Azul & $\begin{array}{l}\text { Controlado. Misterioso. Harmonioso. Frío. } \\
\text { Profundo. Racional. Sensible. Intelectual. } \\
\text { Abstinencia. Agresivo. }\end{array}$ \\
\hline Verde & $\begin{array}{l}\text { Refrescante. Harmonioso. Calma. Gentill. } \\
\text { Cercano a la naturaleza. Conciliador. }\end{array}$ \\
\hline Amarillo & $\begin{array}{l}\text { Colorido. Extrovertido. Vivido. Lleno de alegria.a } \\
\text { Superficial. Joven. Alegre. Luz. }\end{array}$ \\
\hline Naranja & $\begin{array}{l}\text { Directo. Juguetón. Cálido.VVigoroso. Directo. } \\
\text { Vivo. Comunicativo. Posesivo. Intimo. }\end{array}$ \\
\hline
\end{tabular}

Figur 28. Colores y sus significados. según 6özz 1988:16

7 Es muy importante usar un fondo de color que no generé "ruido visual" en contraste con el color de la tipografía y demás elementos gráficos de la interfaz gráfica. Es decir, se recomienda evitar usar colores que generen un contraste "pesado" a la vista y a la lectura, según los autores anteriores.

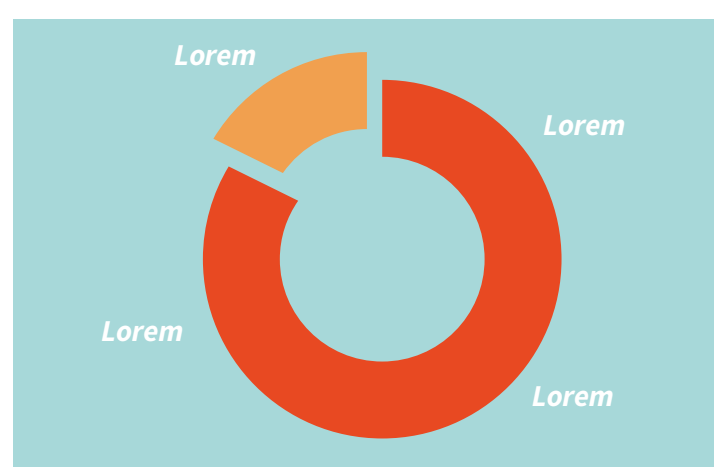

Figura 29. Fiemplo de fondo de color gue no generá "ruido" y tiene buen contraste con demás elementos

8 Según Nielsen \& Loranger (2006), la mejor combinación de colores para generar un buen contraste es el texto en color negro sobre fondo blanco o texto azul sobre fondo blanco. Estos mismos autores establecen la siguiente relación entre el contraste del color del texto
con el color fondo y el nivel de legibilidad de estos mismos elementos:

\begin{tabular}{|c|c|}
\hline COMBINACIÓN DE COLORES & NIVEL DE LEGIBLIDDAD \\
\hline Texto de color negro y fondo blanco & $\begin{array}{l}\text { Alto: Mayor valor de contraste. Diferenciación de los } \\
\text { elementos altamente perceptible. }\end{array}$ \\
\hline Texto de color azul y fondo blanco & $\begin{array}{l}\text { Alto: Mayor valor de contraste. Siempre y cuando se } \\
\text { use azul oscuro. }\end{array}$ \\
\hline Texto de color blanco y fondo gris & $\begin{array}{l}\text { Medio: Diferenciación de los elementos de un nivel } \\
\text { alto a medio, dependiendo de la saturación del gris. }\end{array}$ \\
\hline Texto de color blanco y fondo azul & $\begin{array}{l}\text { Bajo: Dificil de leer, ya que se percibe que el fondo } \\
\text { oscuro sobrepasa visualmente el texto blanco. }\end{array}$ \\
\hline Texto de color gris y fondo blanco & $\begin{array}{l}\text { Bajo: Bajo valor de contraste. Diferenciación de los } \\
\text { elementos casi inperceptible. }\end{array}$ \\
\hline Texto de color blanco y fondo gris & $\begin{array}{l}\text { Bajo: Bajo valor de contraste. Diferenciación de los } \\
\text { elementos casi inperceptible. }\end{array}$ \\
\hline Texto de color blanco y fondo azul & $\begin{array}{l}\text { Bajo: El contraste que generarlos colores hacen que la } \\
\text { lectura resulte cansada para el ojo. }\end{array}$ \\
\hline Texto de color gris y fondo blanco & $\begin{array}{l}\text { Bajo: El contraste que generarlos colores hacen que la } \\
\text { lectura resulte cansada para el ojo. }\end{array}$ \\
\hline
\end{tabular}

Figurr 30. Nivel de legibilidada de difierentes combinaciones de colores por Nielsen \& Loranger r200e)

10 El color se puede utilizar para centrar la atención del usuario y garantizar que todo el texto sea claro, legible y que se pueda leer rápidamente, de acuerdo a lo que plantean Lonsdale \& Lonsdale (2019).

11 De acuerdo a los mismos autores, el color se puede usar para ayudar a organizar fragmentos de información que compartan características en común. Por ejemplo, usar un color en especial para los títulos, otro para elementos gráficos, etc.

\section{TÍTULO \\ Subtitulo}

Muy lejos, más allá de las montañas de palabras, a lejados de los países de las vocales y las consonantes, viven los textos simulados. Viven aislados en casas de letras, en la costa de la abastece con las normas necesarias. Hablamos de un país paraisomático en el que a uno le caen pedazos de frases asadas en la boca.

Subtítulo

Muy lejos, más allá de las montañas de palabras, alejados de los países de las vocales y las
consonantes, viven los textos simulados. Viven aislados en casas de letras, en la costa de la semántica, un gran océano de lenguas. Un riachuelo llamado Pons fluye por su pueblo y los 
12 Lonsdale \& Londsdale (20019), señalan las siguientes recomendaciones sobre color:

a. Resulta esencial usar el color para enfatizar palabras, resaltar los encabezados, señalar relaciones dentro de un documento, mostrar niveles jerárquicos y proporcionar estructura y organización en un documento.

b. Se deben usar colores en contrastes claros, donde se recomienda un contraste del $70 \%$ entre un objeto y su fondo.

c. Los colores que se usen como fondo, se sugiere que estos deben proporcionar suficiente contraste con los objetos que estén sobre éste.

d. Se sugiere para comprobar rápidamente el contraste entre los valores, el diseño debe imprimirse en escala de grises o el monitor debe cambiarse a escala de grises. Si esto demuestra que los diferentes elementos visuales se mezclan, entonces los colores deben ajustarse para crear un buen contraste.

e. Se deben evitar los efectos de gradiente de color, ya que estos efectos dificultan la lectura del contenido de la interfaz gráica.

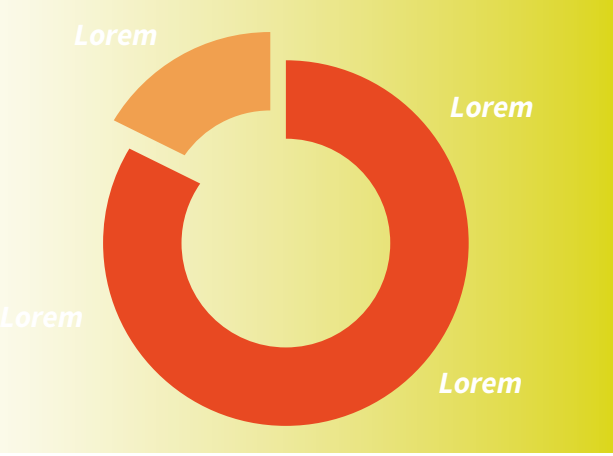

Figura 32. Eiemplo del mal uso del efecte de gradiente como fonde

f. Se sugiere no utilizar los colores brillantes, altamente saturados (primarios ${ }^{5}$ ), ya que son visualmente demasiado molestos y pueden crear problemas de legibilidad.

g. El texto coloreado, los bordes coloreados, los fondos coloreados o los patrones coloreados no se deben utilizar únicamente para la decoración.

h. Para las tareas de búsqueda e identificación, se recomienda usar una codificación de colores, ya que éstas funcionan mejor que la variación en la forma y el tamaño.

i. Para información categórica, se deben usar colores que sean complementarios en el círculo cromático 6 .

j. Se recomienda para datos continuos, utilizar saturación u oscuridad de los mismos colores.

k. Deben evitarse los colores adyacentes entre sí en el círculo cromático, ya que producen poco contraste cuando se usan juntos. Si se elije esta combinación, en- tonces su brillo debe ser lo suficientemente diferente para crear un contraste claro.

l. Los colores deben mantenerse uniformes en todos los gráficos de todos los elementos de la interfaz gráfica.

m. La codificación de colores se puede utilizar en gráficos para ayudar a los usuarios a interpretar los datos.

n. Resulta conveniente usar colores suaves en gráficos, en lugar de los colores del adyacentes en el círculo cromático (que tienen un alto contraste).
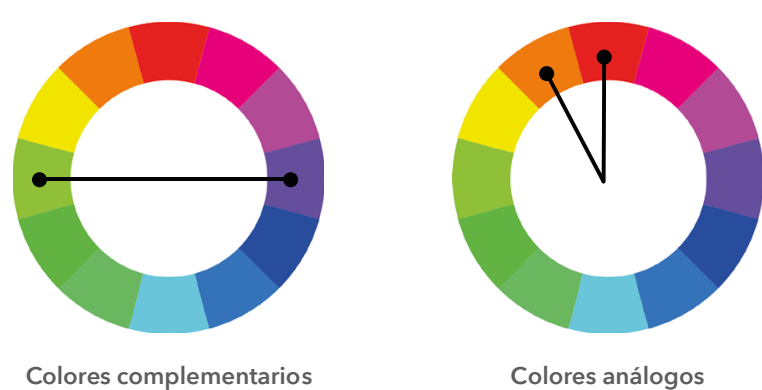

Colores análogos

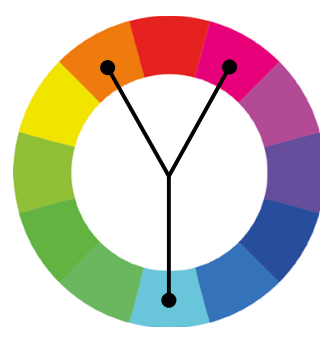

Colores adyacentes

Figura 33. Circulo cromatitco, colores complementariss, an

ñ. El contraste entre los colores se debe usar para la legibilidad, y diferentes valore dentro del mismo color también se pueden usar para definir capas de atención.

o. No se deben usar múltiples colores para representar el mismo tipo de datos (por ejemplo, diferentes colores para cada gráfico de barras en la misma categoría.

p. Se recomienda usar un tono más oscuro o más claro, o un color diferente, para enfatizar un punto específico o un valor de datos dentro de la interfaz gráicas.

q. El gris debería usarse para información contextual y de segundo nivel, así come para elementos estructurales como las líneas de cuadrícula.

r. El rojo no debe usarse para números positivos en un gráfico de barras, ya que está fuertemente asociado con la pérdida, pero se puede usar efectivamente para valores negativos. 


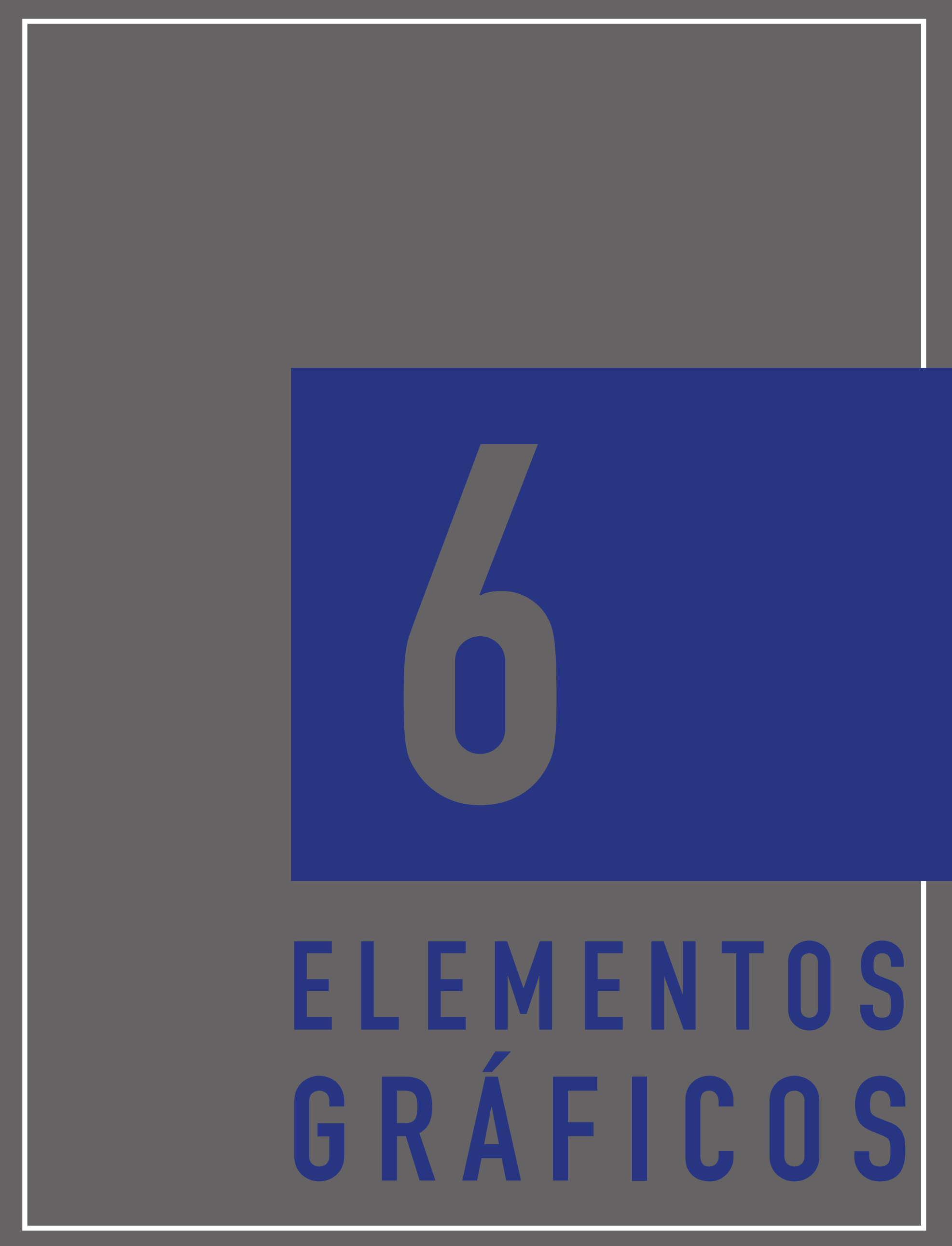


1 Resulta importante definir los elementos gráficos que se utilizarán en la pieza de diseño desde el principio del proceso de diseño.

2 Dentro de una interfaz gráfica se recomienda que todos los elementos conserven un mismo estilo gráfico.

3 Todos los elementos visuales deben usarse de manera efectiva y organizarse adecuadamente dentro de la estructura del sistema de visualización de información.

4 La carga cognitiva en la interfaz gráica que se está trabajando, de acuerdo a Lonsdale \& Lonsdale (2019) debe reducirse, se recomienda minimizar la cantidad de información que se transmite a través de gráficos, así como también se sugiere el uso de colores significativos, símbolos, líneas o barras de etiquetado directo.

5 Los elementos gráficos que se utilicen dentro de la interfaz gráfica deben aportar denotaciones relacionadas directamente con el objetivo de comunicación, de acuerdo a los autores ciones relacion
anteriores.

6 Todos los elementos gráficos que se utilizan, deben apoyar a la estructuración jerárquica de información, así como también, deben ser consistentes visualmente hablando entre ellos, según argumenta Cairo (2011)

7 Es importante implementar imágenes que tengan la misma orientación (horizontal o vertiEs importante implementar imágenes que tengan la misma orientación (horizontal o verti-
cal), dependiendo de la retícula del lienzo de trabajo sobre el cual se este diagramando, de tal manera que se facilita el acomodo de los elementos que forman parte del contenido de la interfaz gráfica, de acuerdo a lo que establecen Lonsdale \& Lonsdale (2019).

8 Las imágenes que sean usadas dentro de la interfaz gráfica deben responder a términos del objetivo de comunicación y la temática del mismo.

Wiklund (1995), sugiere utilizar pictogramas, ya que estos albergan significados universales en una imagen simple. 
10 Para generar claridad, Lonsdale \& Lonsdale (2019), recomiendan usar como contenedor un círculo para el uso de pictogramas.

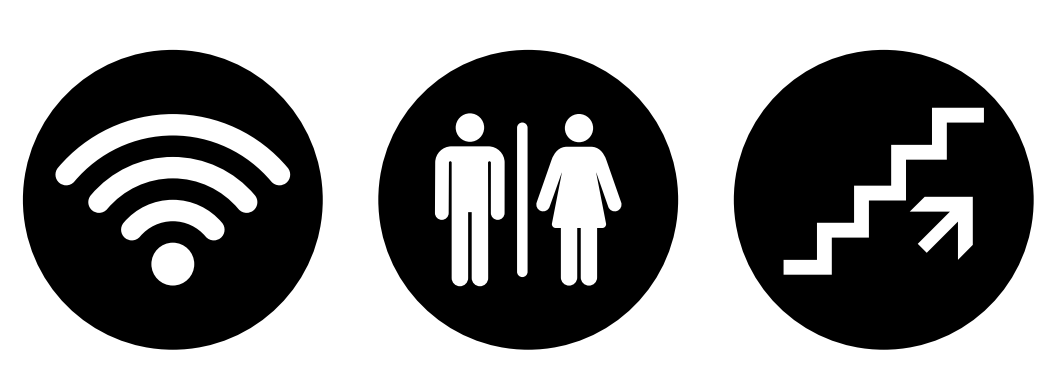

Figura 32. Uso de pictogramas parr englobar connotaciones de conceptos.

11 No es conveniente el uso de emojis ${ }^{8}$ otro tipo de elemento gráfico que tenga un significado amplio a su interpretación, según lo plantean Krajil Novak, Smailović, sluban, \& Mozetič (2015).

12 Lonsdale \& Lonsdale (2019), establecen que una manera efectiva de guiar al usuario a través de la lectura de la pieza de diseño es a través de flechas y líneas que puedan generar un recorrido visual.

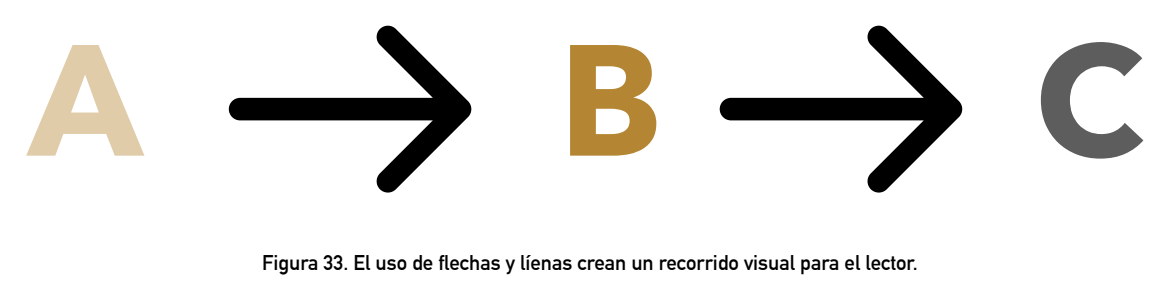

13 Resulta importante el uso de etiquetas o leyendas debajo de los elementos gráficos que necesiten algún tipo de aclaración, nota o título, establece los mismos autores.

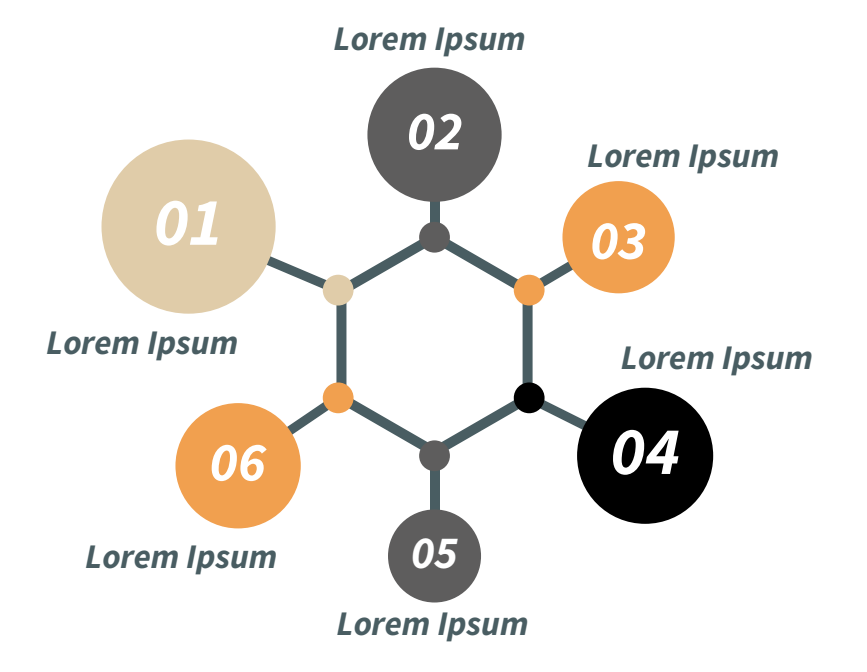

4 Es beneficioso para el diseño de la interfaz gráfica que los elementos visuales no distraigan al usuario del contenido que se le está presentando, según señalan Nielsen \& Loranger (2006).

15 De acuerdo a lo que sugieren los autores anteriores, los elementos gráficos del sistema de visualización deben respetar y usar la paleta de colores con la que se está trabajando. Ya que al usar colores que no estén dentro de ésta puede generar incongruencias visuales y de contenido dentro de la interfaz gráfica.

16 Según Lonsdale \& Lonsdale (2019) el uso de recuadros en blanco dentro de una interfaz gráfica de un sistema de visualización de información médica es recomendable para anotaciones textuales largas sobre un tópico en particular, por ejemplo, motivos de ingreso del paciente a la clínica o hospital.

17 Se sugiere, de acuerdo a los autores anteriores, el uso de bullets point, listas numéricas y flechas para enfatizar información que pertenezca a una misma categoría, la cual sea secuencial.

$\begin{array}{ll}\text { 1) Manzana. } & \text { - Gato. } \\ \text { 2) Pera. } & \text { - Piedra. } \\ \text { 3) Melón. } & \text { - Muñeca. } \\ \text { 4) Kiwi. } & \text { - Contenedor. } \\ \text { 5) Fresa. } & \text { Mariposa. } \\ \text { Ejemplo de lista númerica } & \text { Ejemplo de lista con bullet points }\end{array}$

Figura 35. Ejemplo de uso de etiquetas para hacer actaraciones sobre los elementos graficos presenntados

18 Los elementos que no tengan mucha relevancia dentro de la pieza de diseño, pero sigan siendo necesarios, se recomienda usar una tonalidad de gris o una opacidad de color equivalente al 40\%, de acuerdo a Lonsdale \& Lonsdale (2019).

19 El espacio en blanco es un buen elemento que se puede usar de manera efectiva para llamar la atención sobre el gráfico o para generar "aire" en donde hay una tensión visual por el exceso de contenido. No se recomienda el uso de degradados ni texturas en las secciones que conforman a las fi-
guras en la visualización de información, en su lugar, se sugiere el uso de plastas de colores, acorde a lo que establece Cairo (2011).

21 La relación de aspecto (altura y anchura relativas) y la densidad de datos (tamaño del gráfico) según señala Tufte (2001). 
22 Sí se llegará a requerir de usar un fondo en algún tipo de figura dentro de la interfaz gráfica, se sugiere que los elementos de fondo no deben se agrupen o fusionen con los elementos de contenido, de acuerdo con Cairo (2011).

23 Se sugiere, según a lo que Tufte (2001) indica el uso de puntos y las líneas, ya que son una buena opción para facilitar la comparación entre valores individuales en puntos específicos en el tiempo de datos.

Los elementos o información innecesarios, extraños, decorativos o irrelevantes en una figura de visualización de información deben eliminarse, mientras se mantiene el significado

25 Es importante usar informes estadísticos, según establece Cairo (2011) a través de figuras de visualización de información en lugar de informes solo narrativos, de esta mane la carga cognitiva de la información y se mejora la usabilidad de la interfaz gráfica.

26 Es de suma importancia el uso de figuras de visualización de información para condensa datos cuantitativos y cualitativos dentro del sistema de visualización de información médica. El criterio a seguir para la elección de las figuras de visualización de información es el siguiente:

1. ¿Qué necesita averiguar el usuario (en términos de información)?

2. ¿A qué categoría o método de codificación de información pertenece esta necesidad?

3. ¿Oué fiaura de visualización de información cubre esta necesidad?

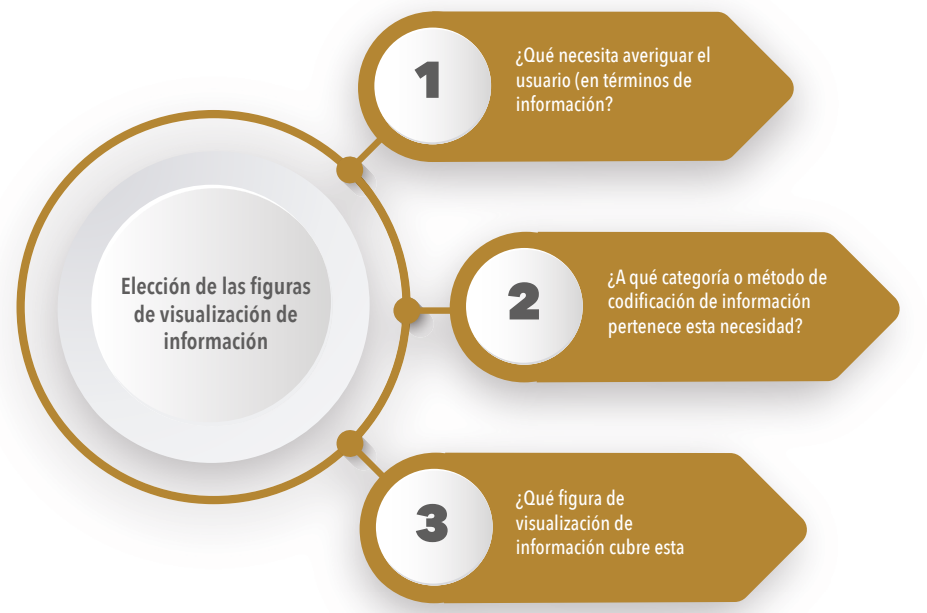

Existen diversas categorías que se clasifican de acuerdo a la función de la representación de la información con la que se está trabajando. Dichas categorías o métodos de codificación de información son las siguientes:

1. Comparación: Este método busca generar contaste entre conjuntos de datos. A través de está técnica se busca establecer una comparación visual entre las características o atributos de dichos conjuntos de datos.

2. Visualización de conceptos: Es la representación de uno o varios conceptos a través de gráfico.

3. Correlación o de patrones: Es la proporcionalidad entre atributos o características de uno o varios datos entre sí. Se centra en revelar formas o patrones en los datos para darle significado.

4. Distribución: Esta técnica busca distribuir un determinado dato en un lugar determinado por alguna característica o valor en especial.

5. Datos geográficos: Este método de visualización de información se encarga de representar datos que guardan relación con atributos de índole geográfica, ubicando a éstos en un lugar y espacio determinado.

6. Parte del todo: Es la representación de un conjunto de datos que forman parte de un todo.

7. Tendencia a través del tiempo: Esta técnica de visualización de información se ocupa de la representación de la evolución o perspectiva de un fenómeno a través del tiempo.

8. Jerarquía: Este método muestra la relación de cómo las entidades se pueden clasificar y ordenar dependiendo de su grado de importancia y pueden clasificar y ordenar dependiendo de su

9. Procesos y métodos: Esta técnica en la visualización de información ayuda a explicar como están hechos ciertos procesos o métodos, as como los pasos que están involucrados en éstos.

10. Funcionamiento de las cosas: Este método tiene como objetivo ilustrar el funcionamiento de algún objeto o sistema.

11. Movimiento o flujo: Herramienta que se encarga de mostrar el movimiento físico, proceso de transferencia o el flujo de conceptos abstractos través de un gráfico o figura visual. 

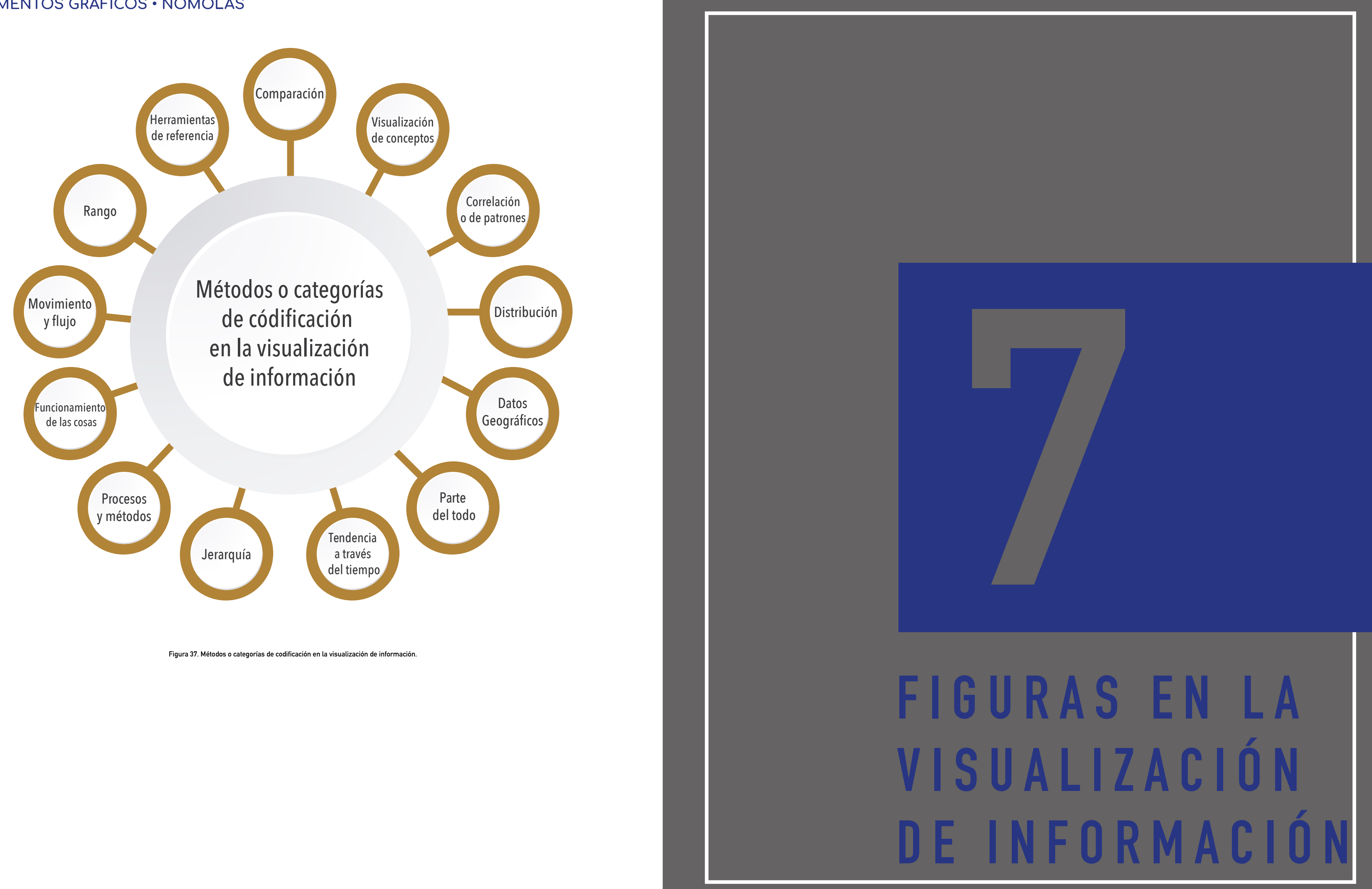


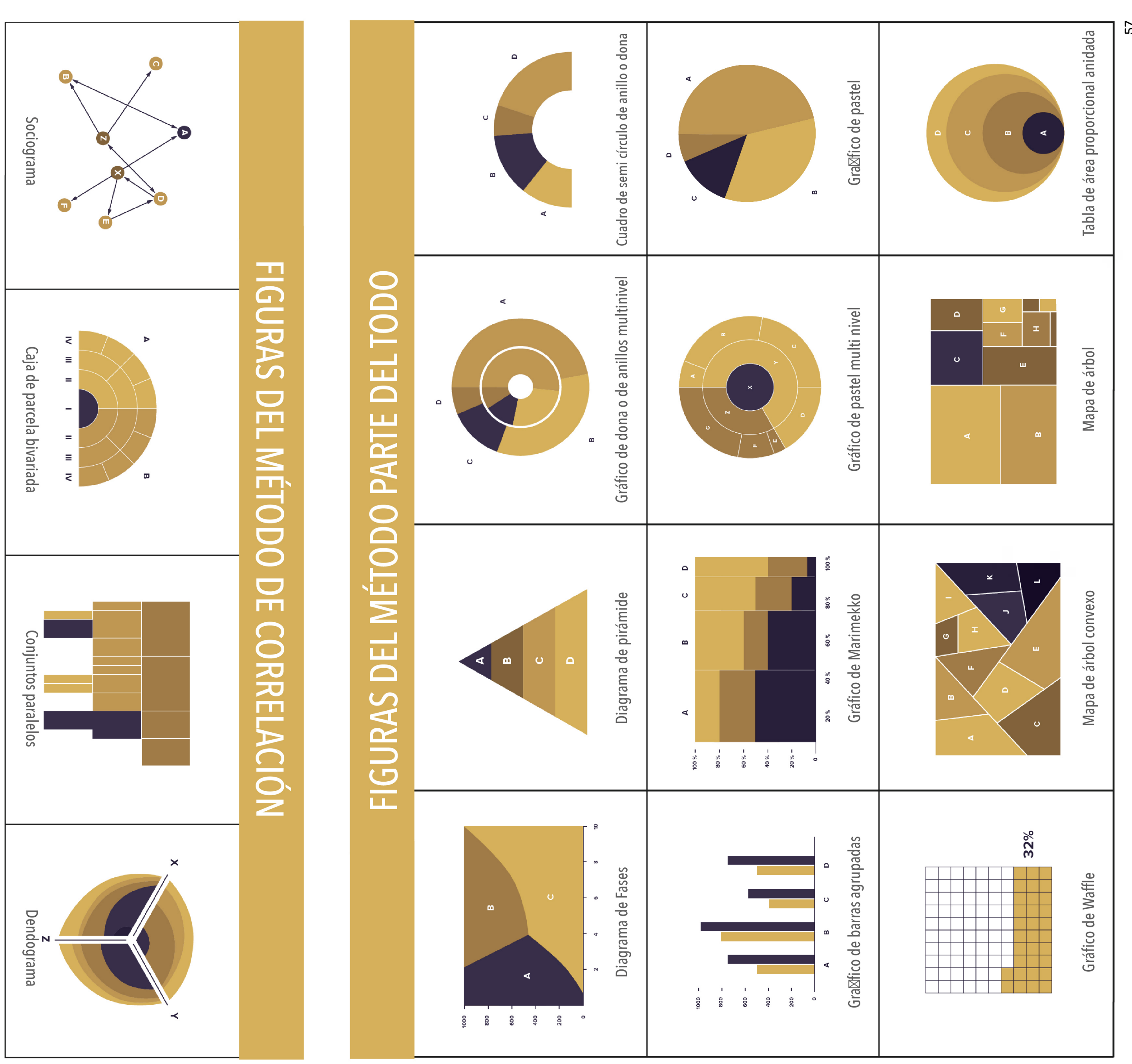




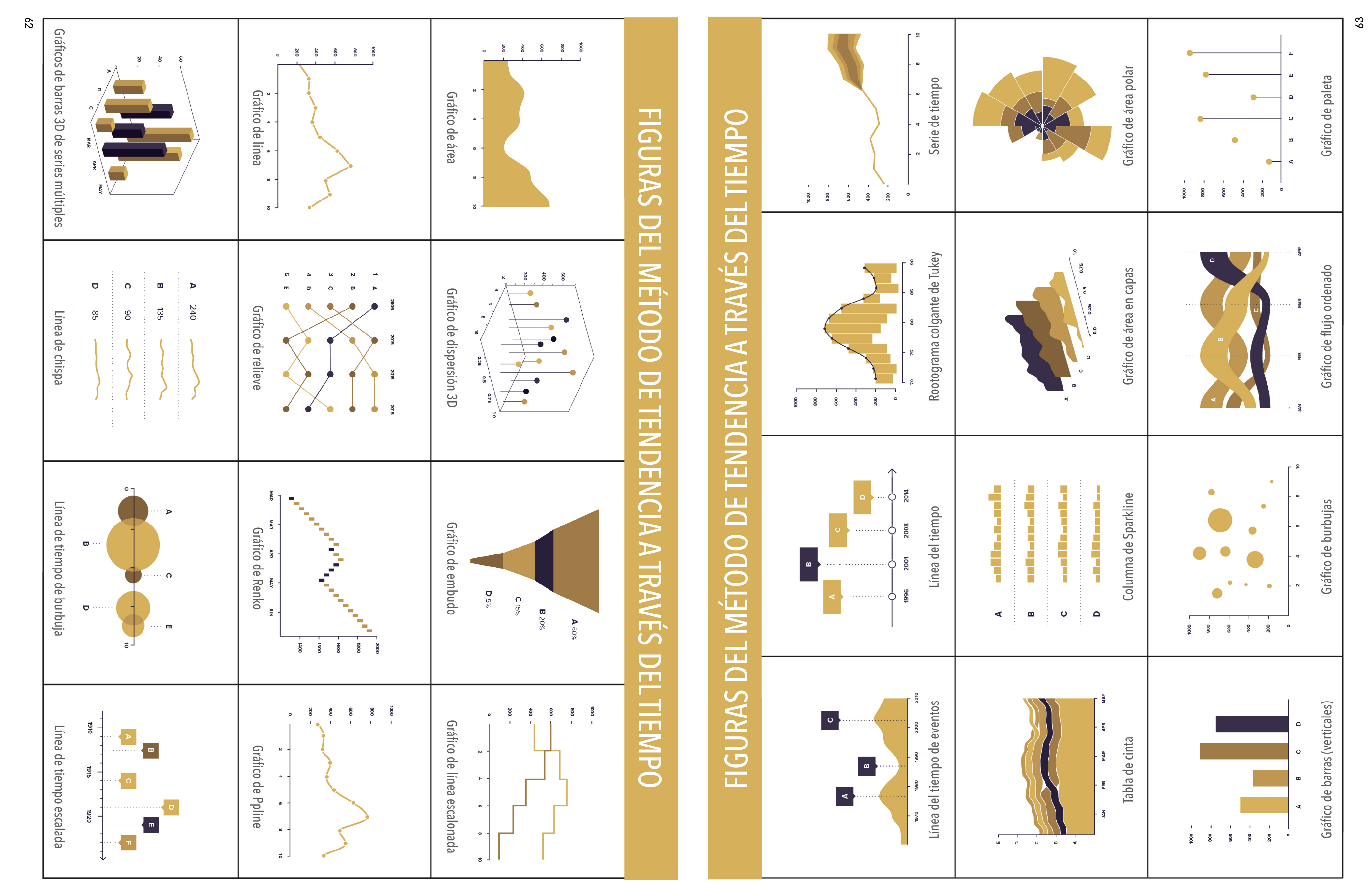




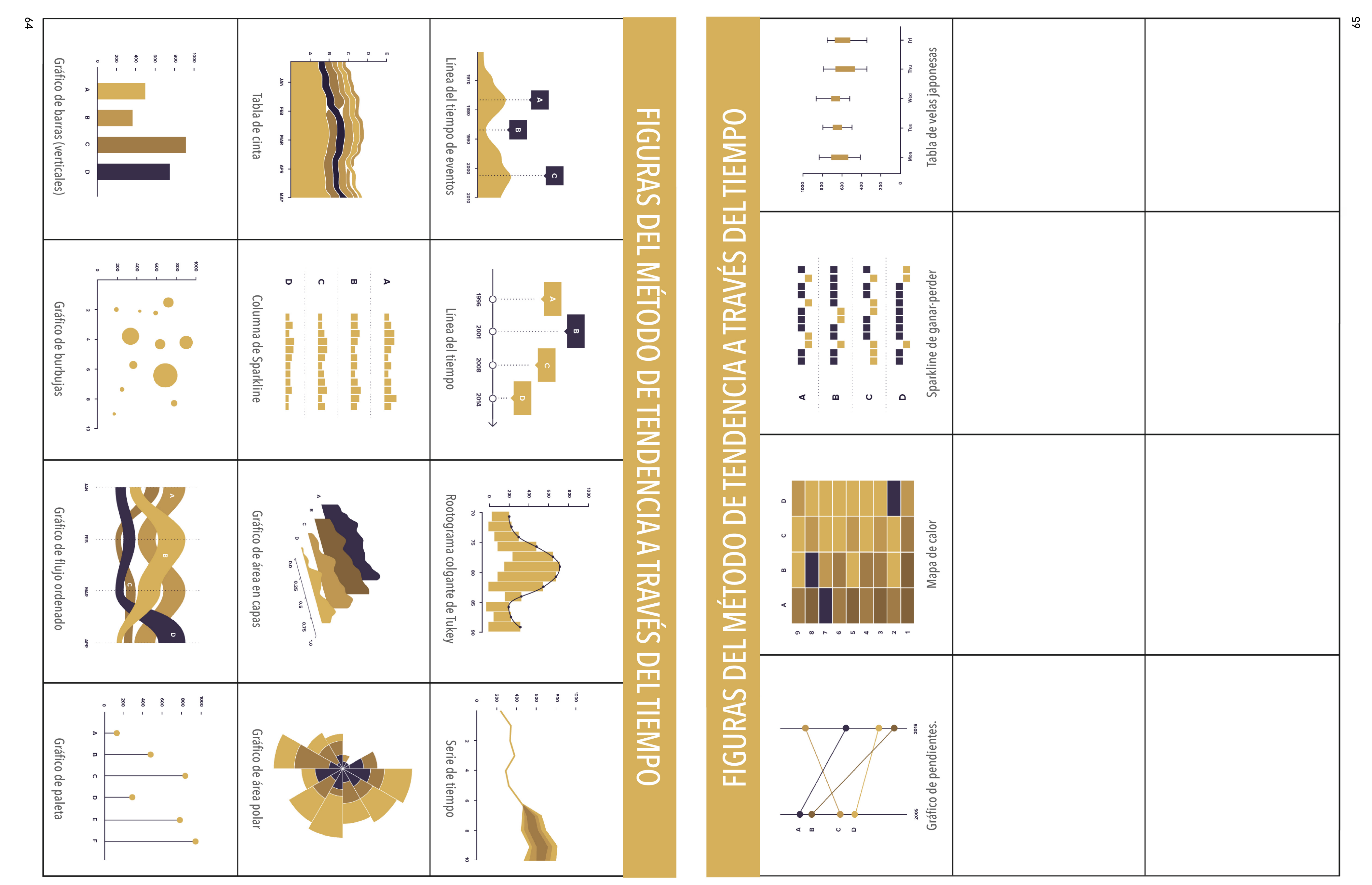




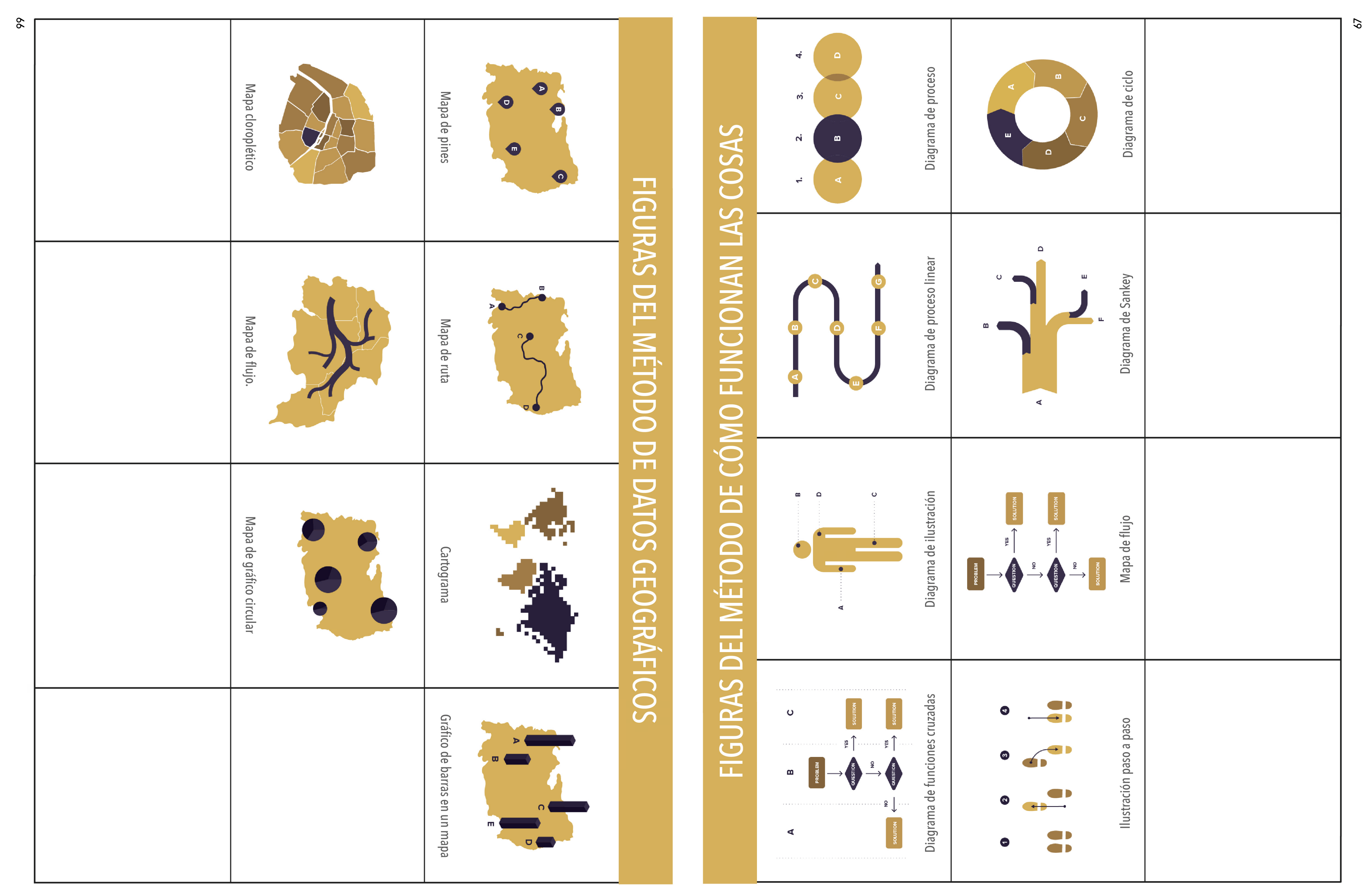




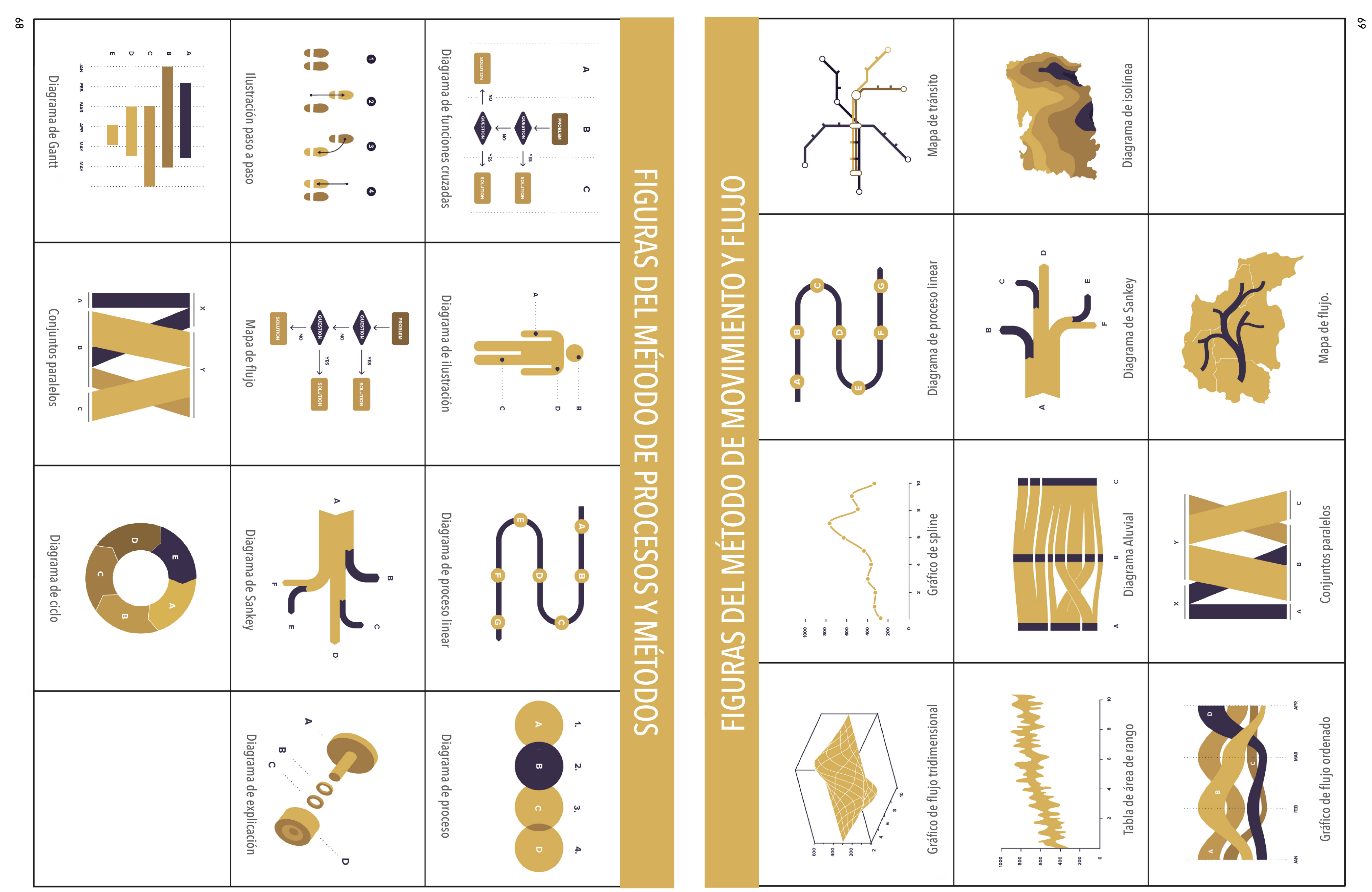




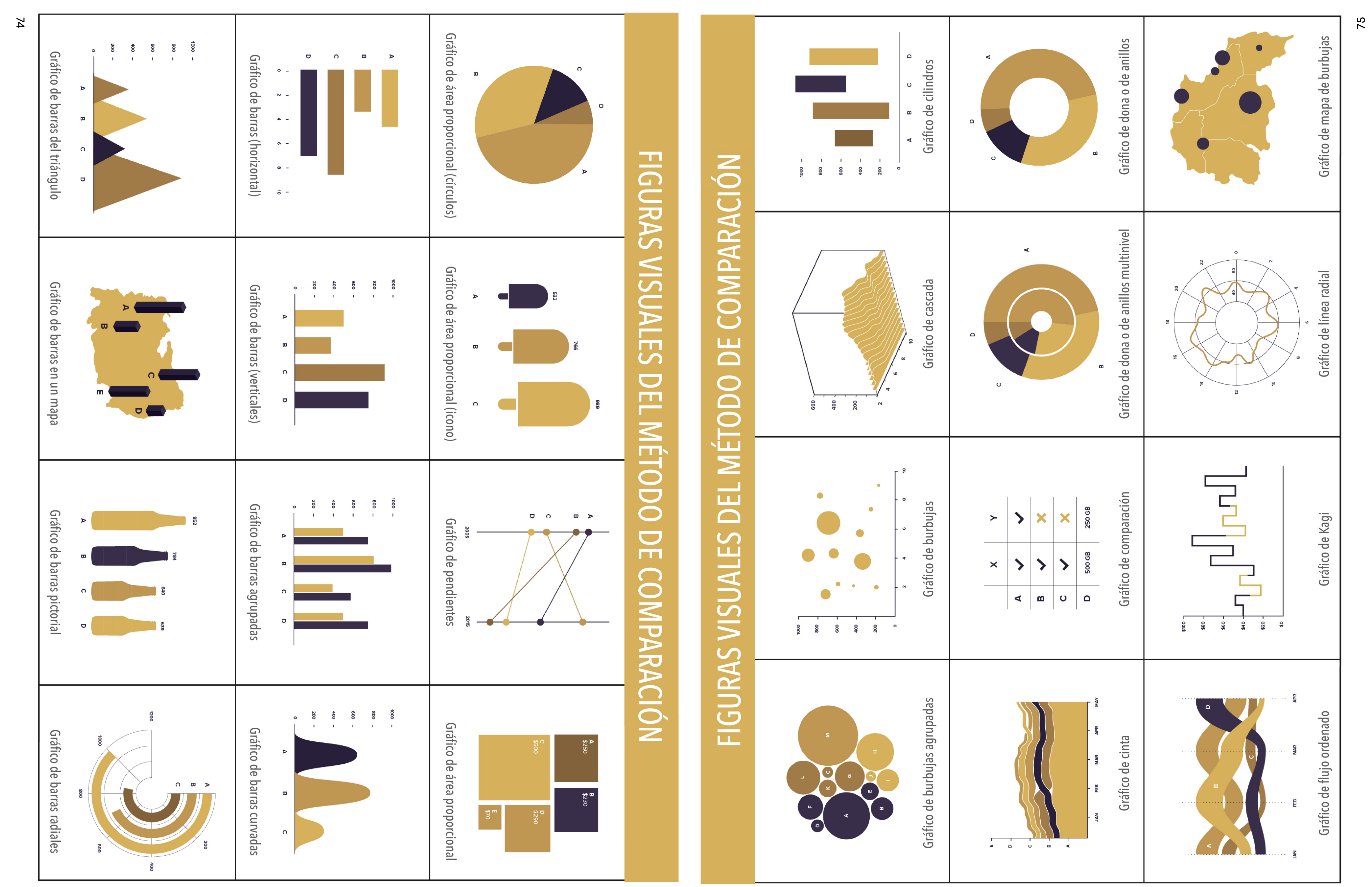




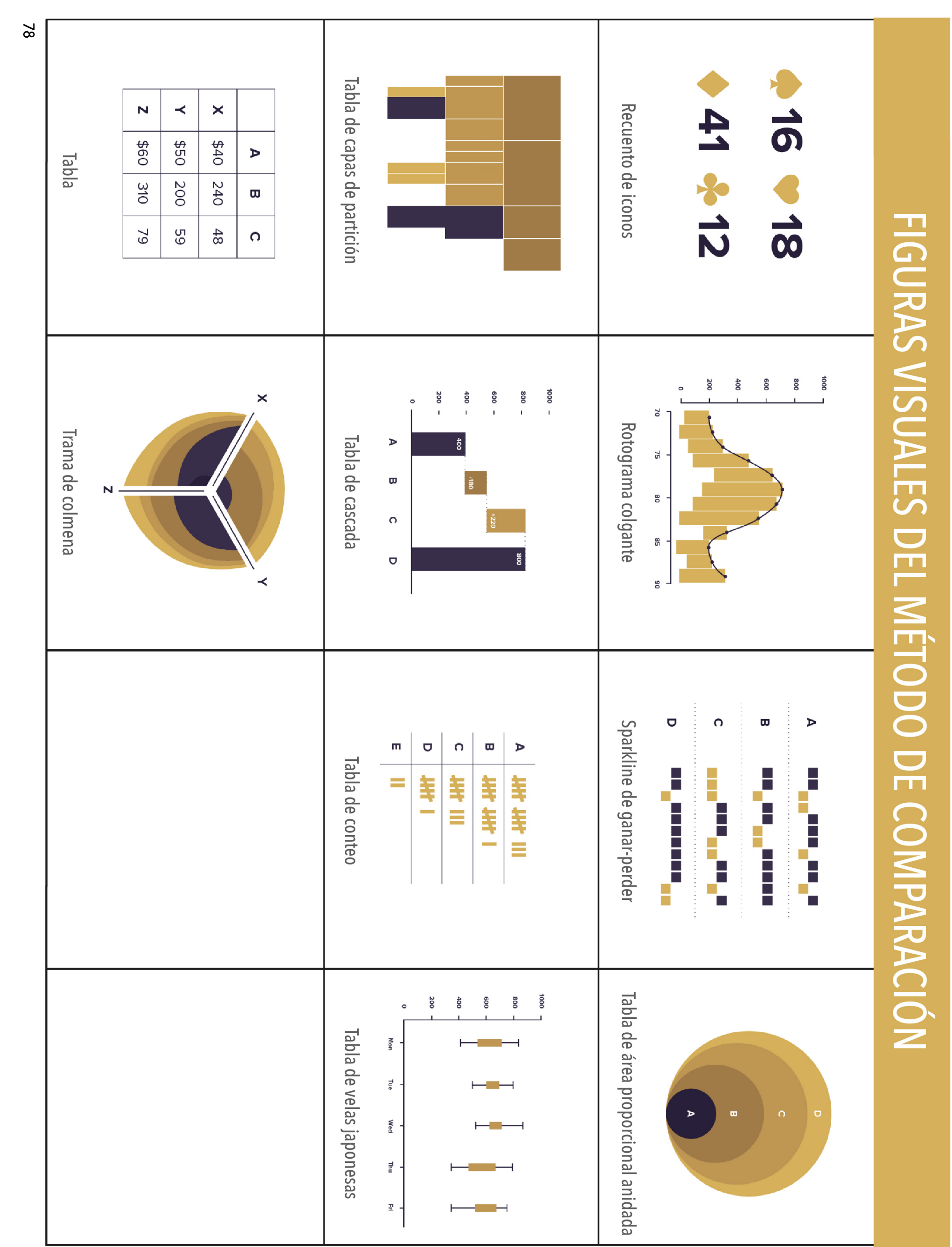




\title{
REFERENCIAS
}

Cairo, A. (2011). The Functional Art- An Introduction to Information Graphics and Visualization. (L. G. Prado, Ed.). Madrid: Alamut.

Castro, I., \& Gámez, M. (2002). 2.2. Historia clínica. In M. C. G. Planas (Ed.), Farmacia Hospitalaria (Tercera Ed, Pp. 295-305). Barcelona: Hospitalitaria, Fundación Española de Farmacia.

Few, S. (2004). Perceptual Edge Common Mistakes in Data Presentation Common Mistakes in Data Presentation Start with a Clear Message, 1-5. Retrieved from https://moodle. chatham.edu/pluginfile.php/712404/mod_resource/content/1/Common Mistakes in Data Presentation.pdf

Götz, V. (1988). Color \& Type for the screen. Suiza: RotoVision SA.

Krajil Novak, P., Smailović, J., Sluban, B., \& Mozetič, I. (2015). Sentiment of emojis. PloS ONE, 10(12).

Lonsdale and Lonsdale. (2019). Design2Inform: Information visualisation guidelines [Report 02]. Gov UK.

Nielsen, J., \& Loranger, H. (2006). Priorityzing Web Usability. California: New Riders.

Rodrigues, D., Prada, M., Gaspar, R., Garrido, M. V., \& Lopes, D. (2017). Lisbon Emoji and Emoticon Database (LEED): Norms for emoji and emoticons in seven evaluative dimensions. Behavior Research Methods, 50(1), 392.

Tufte, E. (2001). The visual display of quantitative information (Segunda Ed). Cheshire: Graphic Press.

Wiklund, M. (1995). Medical Device and Equipment Design: Usability engineering and ergo-

\author{
mics. Florida: Taylor \& Francis Group.
}



Anexo 11.10. Material a re diseñar: Hoja de ingreso de paciente con diabetes. 


\section{Denver Endocrinology, Diabetes \& Thyroid Center, P.C. \\ 799 E Hampden Ave, Suite 525, Englewood, CO 80113 \\ Phone: 303-321-2644 Fax: 303-321-2446 \\ Website: www.denverendocenter.com}

Patient Name

Today's Date

Date of Birth

Primary Care Provider

Occupation

Referring Physician(if not PCP)

Phone

Other Care Providers Phone

Main Concern(s)/Reason for visit today

ALLERGIES (Please include type of reaction to each allergy listed)

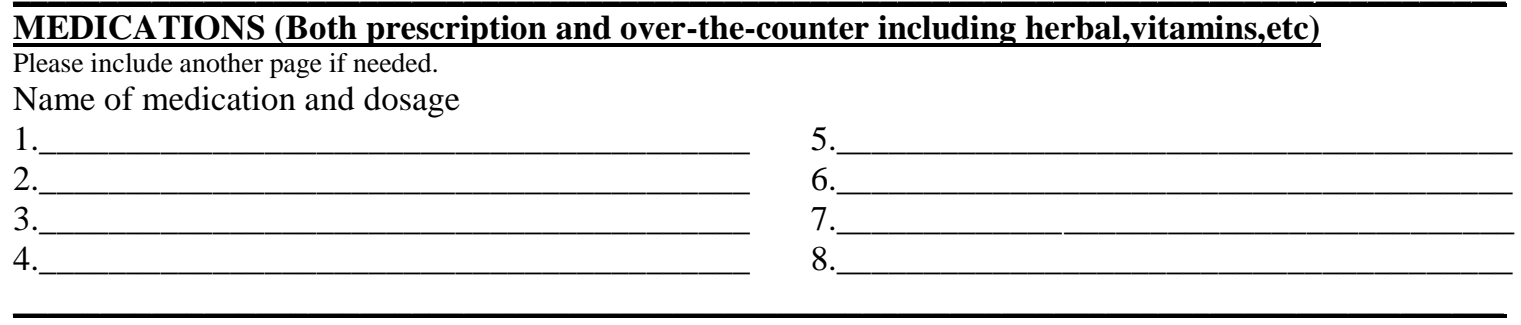

HOSPITALIZATIONS/SURGERIES/PROCEDURES (Please include exact date or at least year)

FAMILY HISTORY (List any health problems of your mother, father, siblings, children or grandparents only)

\section{SOCIAL HISTORY (Circle all that apply)}

Current smoker yes/no number of cigarettes per day Previous smoker yes/no date quit: Alcohol use yes/no number of drinks per day Exercise yes/no number of days in a week duration/type of exercise

PERSONAL HISTORY_(Previous health problems)

1.

2.

3.

4.
5.

6.

7.

8.
9.

10 .

11.

12.

REVIEW OF SYSTEM (Circle current problems/symptoms you are experiencing now in past 1 month)

\begin{tabular}{|c|c|c|c|}
\hline 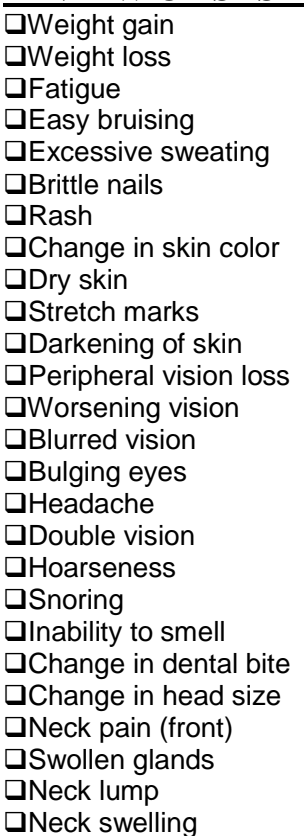 & 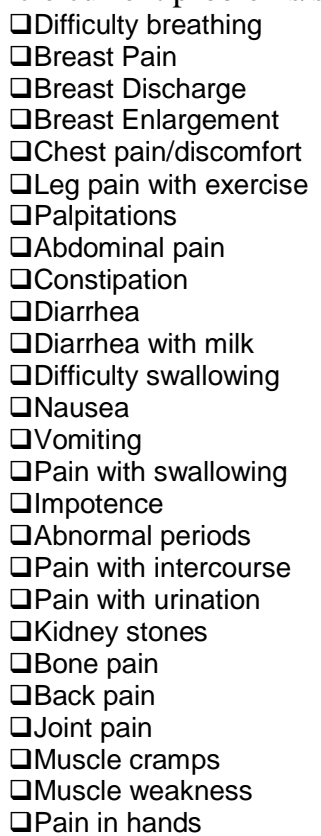 & 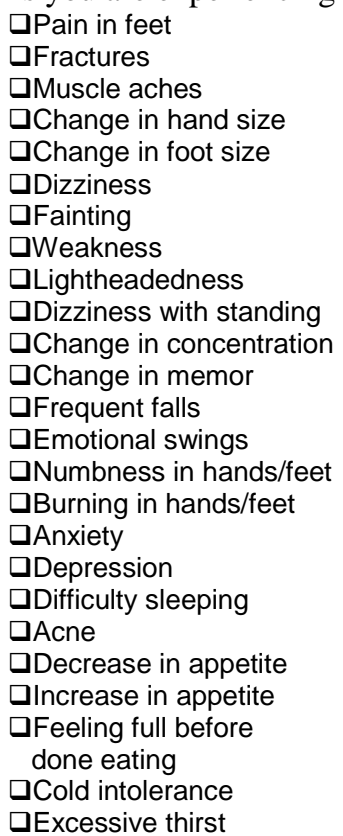 & 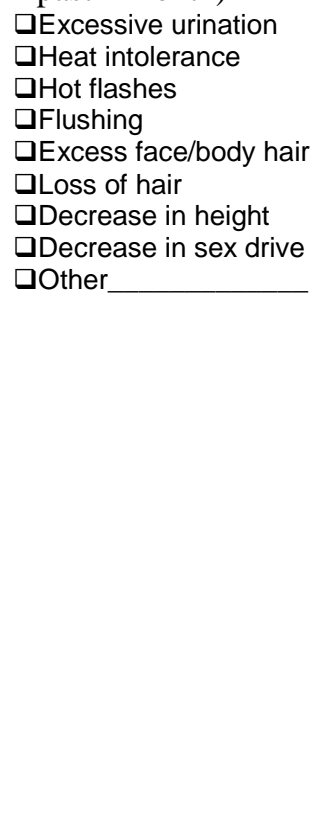 \\
\hline
\end{tabular}

Version Date: Oct 2012 
Anexo 11.11. Material de resultados para la evaluación de la FASE 2. 
Anexo 11.11.1. USUARIO 1. Material de resultados para la evaluación de la FASE 2. Lean Canvas de Decisiones de Diseño. Bocetaje. Propuesta de interfaz gráfica. Cuestionario PSSUQ contestado. Lista de chequeo de Análisis de Tareas contestada. 


\section{LEAN CANVAS DE DECISIONES DE DISEÑO}

integrantes del equipo: Cistion Joséé Castillo Castro

Fecha: $10-03-2020$ Equipo \#:
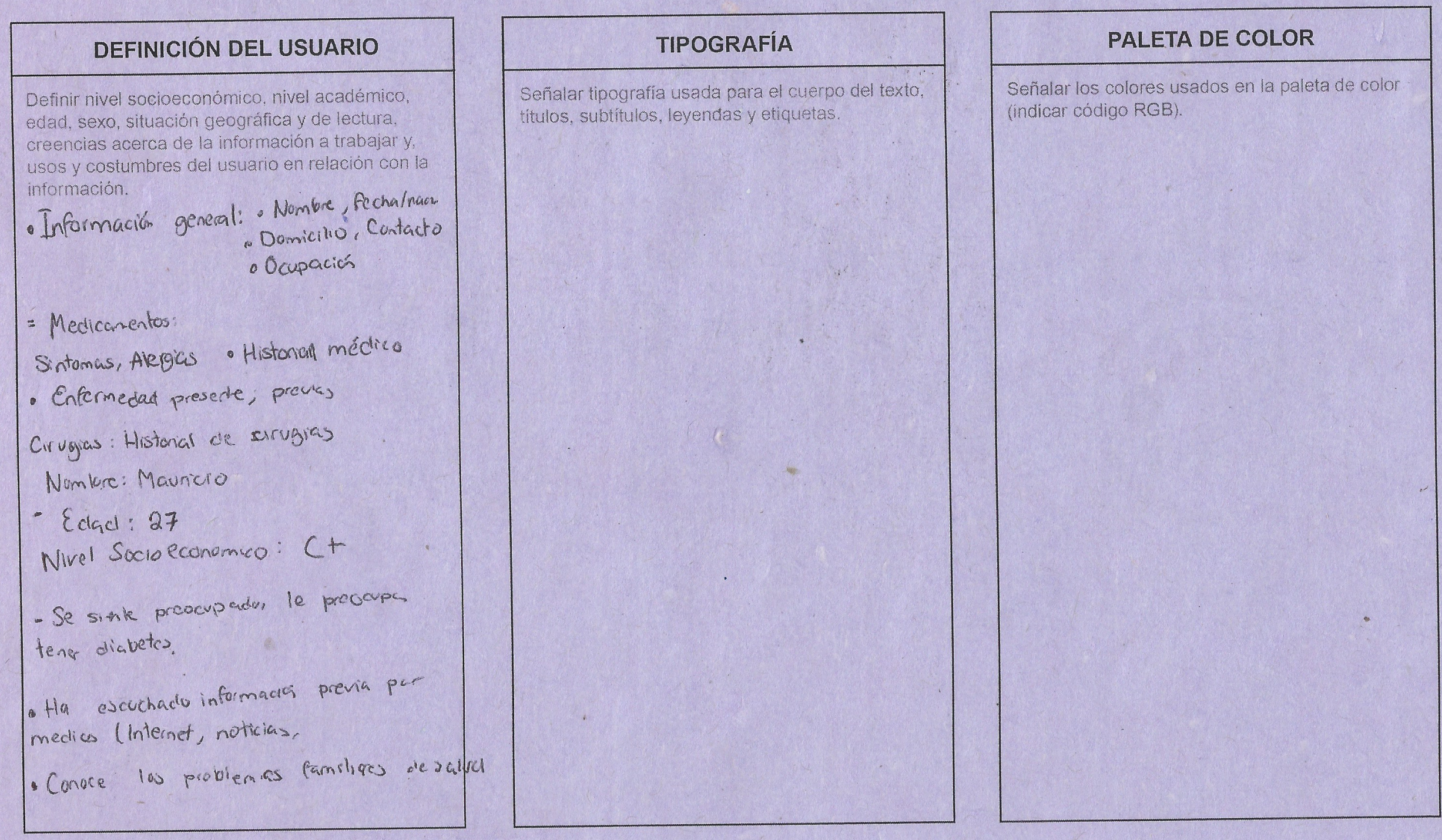

- Quere información rápida y mix effurenlé de leer 
DENVER ENDOCRINOLOGy DIABETES \& THYROID CENTER

Personal Info

NA ME

DATE

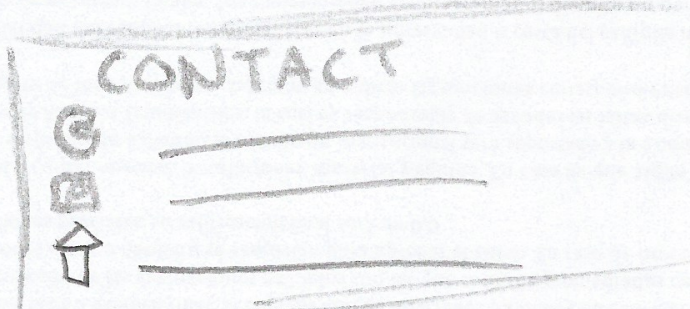

(8) Medications

(ii) Allergies

(5) HOSPITALIZATIONS/SURGERIE

(8) Social activities

B. REVIEW OF SYSTEM 
DENVER DIABETES \& THYROID CENTER

NAME

MEDiCATIONS

INFO:

SYSTEM

0

0

o

SYSTEM SCORE AND MEDICATION' / SOW TOWS
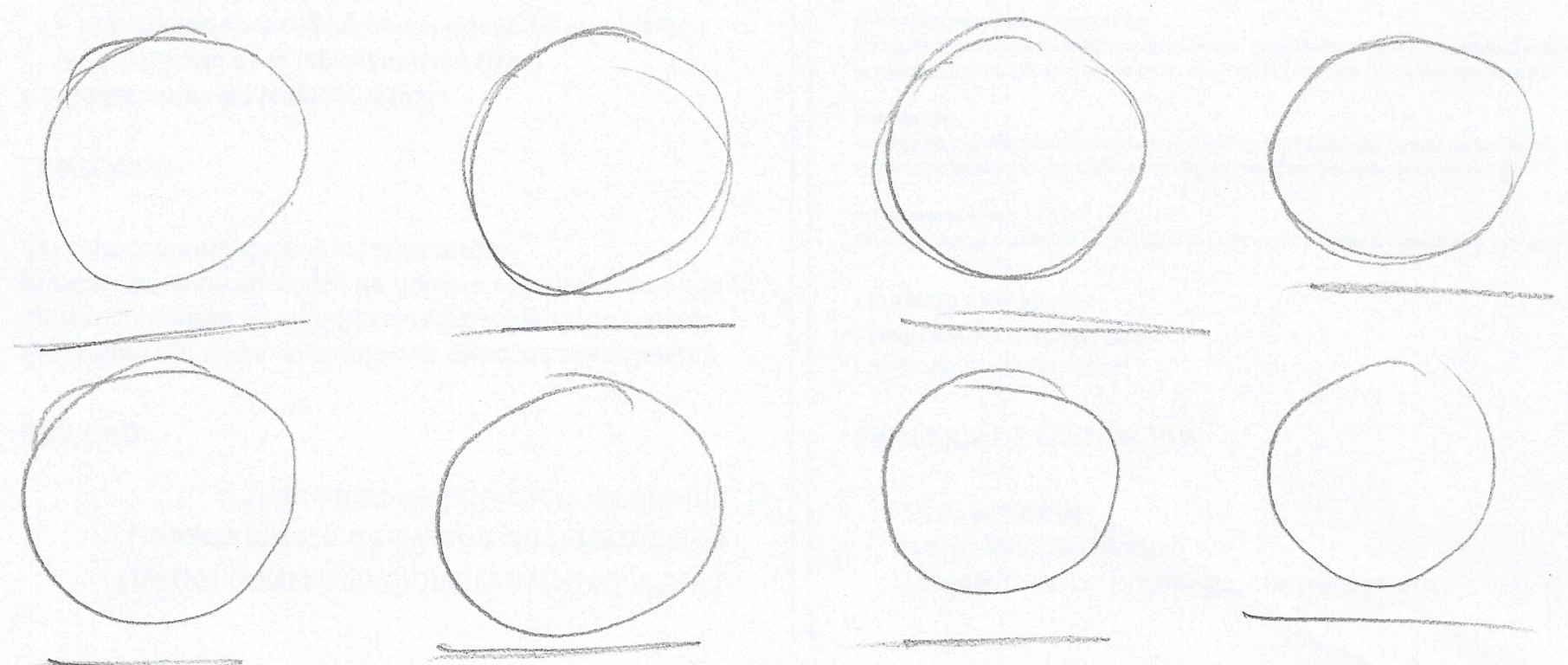


\section{Denver Endocrinology, Diabetes \& Thyroid Center, P.C.}

799 E Hampden Ave, Suite 525, Englewood, CO 80113

Phone: 303-321-2644 Fax: 303-321-2446

Website: www.denverendocenter.com

Today's Date

\section{Personal information}

Patient Name

Date of Birth

Primary Care Provider

Phone

Occupation

\section{Medications}

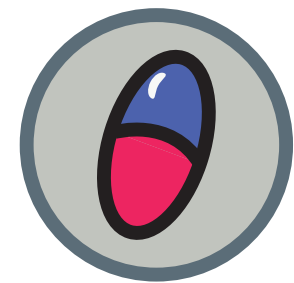

2.

4.

8

8.

\section{Social history}

Member 1.

Member 2.

Member 3.

Member 4.

Member 5.

Member 6.

Family history

Member 7.
1.
3.
4.
5.
6.
7.
8.

5.

\section{Hospitalizations/Surgeries}

\section{Personal history (previous health problems)}

1.$$
2 .
$$

3

4.

5.

6

7

8.
1.

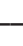

9.
10.
11.
12.
13.
14.
15.
16.

17.
18.
19.
20.
21.
22.
23.
24.

Review of system (Mark the little square)

$\otimes$ Weight gain

$\otimes$ Weight loss

$\triangle$ Fatigue

$\nabla$ Easy bruising

$\otimes$ Difficulty breathing

$\triangle$ Breast Pain

$\triangle$ Breast Discharge

$\triangle$ Breast Enlargement

$\triangle$ Pain in feet

$\triangle$ Fractures

$\otimes$ Muscle aches

$\otimes$ Change in hand size

$\triangle$ Excessive urination

$\nabla$ Heat intolerance

$\nabla$ Hot flashes

$\triangle$ Flushing

$\triangle$ Excessive sweating

$\otimes$ Brittle nails

$\otimes$ Rash

$\otimes$ Change in skin color

$\otimes$ Dry skin $\nabla$ Stretch marks

$\bigotimes$ Darkening of skin

$\triangle$ Peripheral vision loss

$\nabla$ Worsening vision

$\triangle$ Blurred vision

$\triangle$ Bulging eyes

$\nabla$ Headache

$\nabla$ Double vision

$\otimes$ Hoarseness

$\nabla$ Snoring

$\nabla$ Inability to smell

$\nabla$ Change in dental bite

$\nabla$ Change in head size

$\nabla$ Neck pain (front)

$\nabla$ Swollen glands

$\nabla$ Neck lump

$\otimes$ Neck swelling

$\otimes$ Diarrhea

$\triangle$ Diarrhea with milk

$\bigotimes$ Difficulty swallowing

$\nabla$ Nausea

$\triangle$ Vomiting

$\triangle$ Pain with swallowing $\nabla$ Change in foot size

$\triangle$ Dizziness

$\nabla$ Fainting

$\nabla$ Weakness

$\nabla$ Light headedness

$\triangle$ Dizziness with standing

$\nabla$ Change in concentration

$\nabla$ Change in memor

$\triangle$ Frequent falls

$\triangle$ Emotional swings

$\nabla$ Numbness in hands/feet

$\otimes$ Burning in hands/feet

\section{$\triangle$ Anxiety}

$\triangle$ Depression

$\otimes$ Difficulty sleeping

$\triangle$ Acne

$\nabla$ Decrease in appetite

$\triangle$ Increase in appetite

$\nabla$ Feeling full before done eating

$\nabla$ Cold intolerance 


\section{CUESTIONARIOPSSUQ}

Edad:_23_Sexo:M I F Licenciatura:_Diseño gráfico y digital___ Manejo de llustrator.SSi No

Este cuestionario es una oportunidad para registrar tus reacciones a la guía de usabilidad. Estas respuestas nos ayudarán a entender que aspectos hay que mejorar y cuales son con los que no estás satisfechos. Para tener un mejor resultado, piensa en la tarea que se te pidió que realizaras con base a lo que las guías decían mientras contestas estas preguntas.

Instrucciones: Lea cada frase y señala qué tan de acuerdo o en desacuerdo estás y encierra en un circulo un número de la escala. Al terminar, revisaremos juntos con usted el cuestionario para asegurarnos de que entendamos bien la información presentada en este cuestionario.

\section{¡Gracias!}

a) La organización de la información proporcionada por las guías me fue clara.

Totalmente en desacuerdo

1

2

3

4

5

6

Totalmente de acuerdo

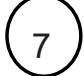

b) Fui capaz de completar la tarea que se me indicó rápidamente con la información proporcionada en las guías.

Totalmente en desacuerdo

12

3

(4)

5

Totalmente de acuerdo

3

4

c) La información proporcionada por las guías fue fácil de entender.

Totalmente de desacuerdo

1

2

3

4

5

Totalmente de acuerdo

riencia de las guías es agradable.

d) La apariencia de las guia
Totalmente en desacuerdo

12

23

3

5

Totalmente de acuerdo

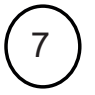

e) En general estoy satisfecho con el acomodo y presentación visual de la información.

Totalmente en desacuerdo

Totalmente de acuerdo

1 2

3

4

(5)

6 


\begin{tabular}{|c|c|c|}
\hline 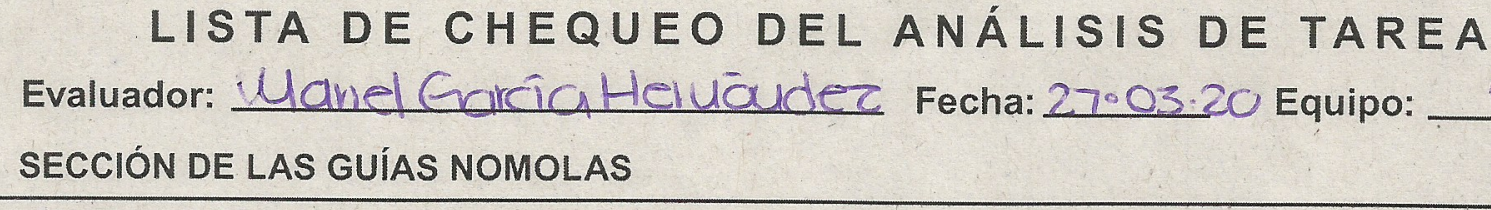 & & \\
\hline USUARIO & $\mathrm{Si}$ & No \\
\hline El diseñador definió el nivel socioeconómico. & 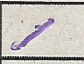 & \\
\hline El diseñador definió el nivel académico. & 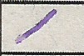 & \\
\hline El diseñador definió edad. & $\gamma$ & \\
\hline El diseñador definió sexo. & $<$ & \\
\hline El diseñador definió situación geográfica. & & $<$ \\
\hline El diseñador definió situación de lectura. & $\angle$ & \\
\hline El diseñador definió creencias sobre la información. & 2 & \\
\hline El diseñador definió usos y costumbres presentadas alrededor de la información. & $\angle$ & \\
\hline ESTRUCTURA DE LA INFORMACIÓN & Si & No \\
\hline El diseñador utilizó una retícula para generar la composición de su gráfica. & 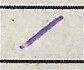 & \\
\hline La información presentada de manera visual tiene congruencia y presenta jerarquia en relación al contenido. & Z & \\
\hline La navegación de lectura se hace de izquierda a derecha y en forma de zig-zag. & 7 & \\
\hline TIPOGRAFIA & $\mathrm{Si}$ & No \\
\hline El diseñador utilizó alguna de las fuentes sugeridas en las guias. & $\alpha$ & \\
\hline El diseñador utilizó un espacio interlineal de 1.5 & 1 & \\
\hline El diseñador evitó la aparición de "viudas" en la composición. & 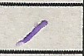 & \\
\hline El diseñador evitó la aparición de "ríos" en la composición. & 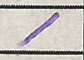 & \\
\hline El diseñador utilizó la variante negrita para hacer énfasis en palabras clave. & & 2 \\
\hline El diseñador utilizó la variante cursiva para hacer referencia a palabras en idioma extranjero. & & 2 \\
\hline El diseñador utilizó un puntaje de carácter para el cuerpo de texto de no menor a 8 puntos. & 7 & \\
\hline El diseñador utilizó para los titulos tipografias sans serif. & 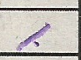 & \\
\hline Los titulos están alienados a la izquierda o centrados. & $\angle$ & \\
\hline Los titulos están en variante negrita y en un puntaje mayor al del cuerpo de texto. & & $\angle$ \\
\hline El cuerpo de texto está alienado a la izquierda. & 2 & \\
\hline El texto y el fondo de la interfaz tienen un buen contraste. & $\angle$ & \\
\hline El diseñador combinó tipografias serif y sans serif en la composición de la pieza de diseño. & & 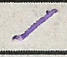 \\
\hline COLOR & Si & No \\
\hline El diseñador utilizó cuatro colores dentro de la composición. & & C. \\
\hline El diseñador cuidó el buen contraste entre figura, fondo y texto en la pieza de diseño. & 1 & \\
\hline El diseñador tomó en consideración el uso de contraste de color entre fondo y texto. & $\angle$ & \\
\hline El diseñador evitó el uso de degradados. & $\angle$ & \\
\hline El diseñador utilizó el mismo color para representar un mismo tipo de dato. & 2 & \\
\hline El diseñador creo codificaciones de información a través del color. & $\angle$ & \\
\hline ELEMENTOS GRÁFICOS & Si & No \\
\hline Todos los elementos conserven un mismo estilo gráfico. & 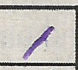 & (15) \\
\hline El diseñador implementó imágenes que tienen la misma orientación & 8 & \\
\hline El diseñador evitó el uso de emojis. & $\not$ & \\
\hline El diseñador usó etiquetas o leyendas debajo de los elementos gráficos que necesitaban algún tipo de aclaración. & l & \\
\hline $\begin{array}{l}\text { El diseñador usó bullets point, listas numéricas y flechas para enfatizar información que pertenecia a una misma } \\
\text { categoria. }\end{array}$ & 7 & \\
\hline El diseñador evitó el uso de elementos o información innecesarios, extraños, decorativos o irrelevantes. & 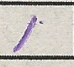 & \\
\hline
\end{tabular}


Anexo 11.11.2. USUARIO 2. Material de resultados para la evaluación de la FASE 2. Lean Canvas de Decisiones de Diseño. Bocetaje. Propuesta de interfaz gráfica. Cuestionario PSSUQ contestado. Lista de chequeo de Análisis de Tareas contestada. 


\section{LEAN CANVAS DE DECISIONES DE DISEÑO}

INTEGRANTES DEL EQUIPO:

Fecha: 1) Whese 2000

Equipo \#:
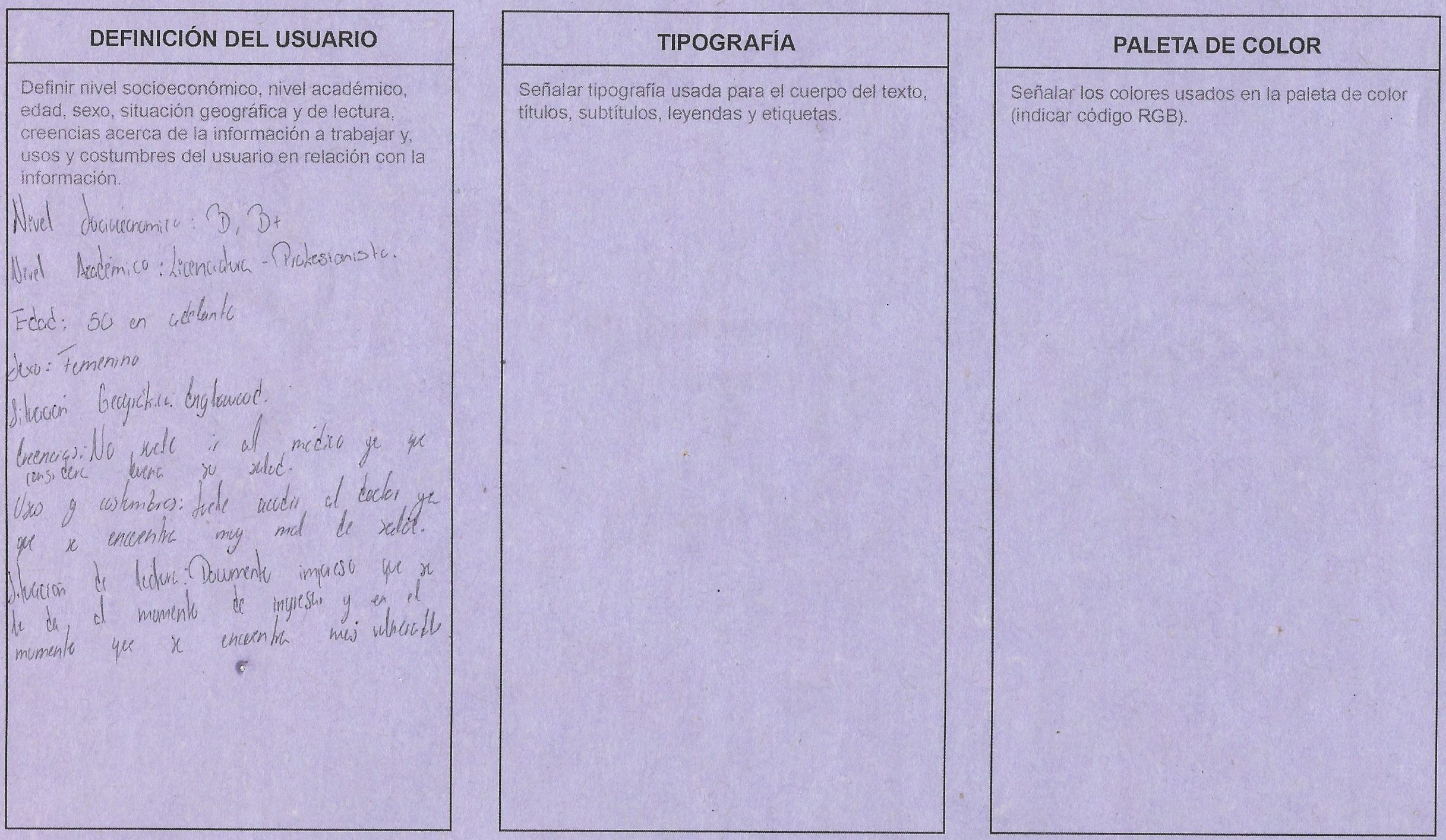
Denver endoorindegy lenter

Persenal Intarmatien.

Name.

Medications.
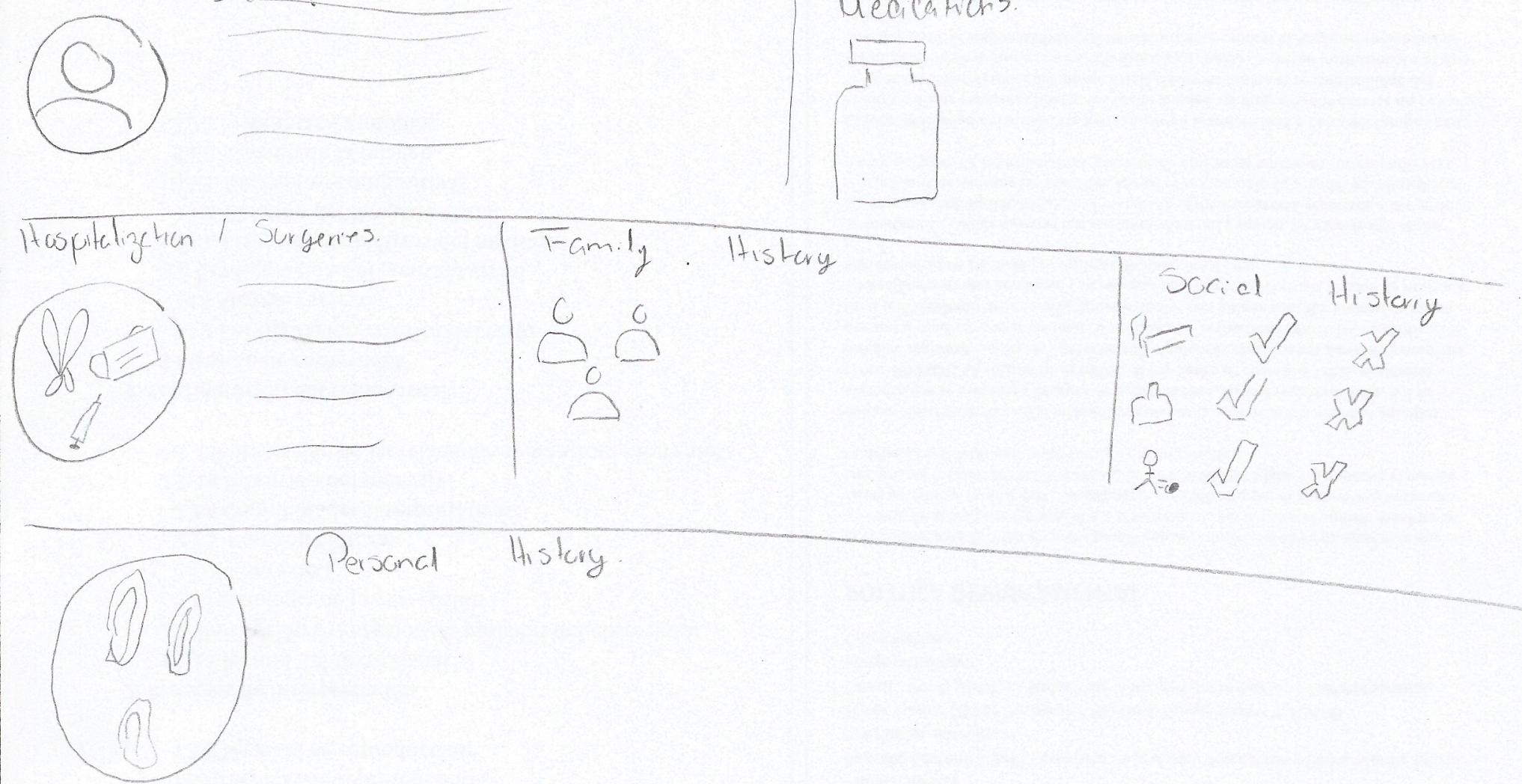

Persanal Histary.

Revew ot System.

$(8$

0

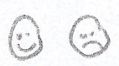

(2)

(1) 9

(2) $(5)$

(C)

(C)

$(\Theta$ 


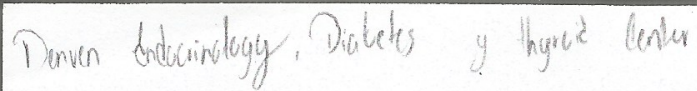

Stated It

Pahent Vame

Date Bith

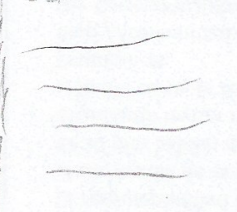

Medications

Hention o lypes (neme and dakge)

(co)
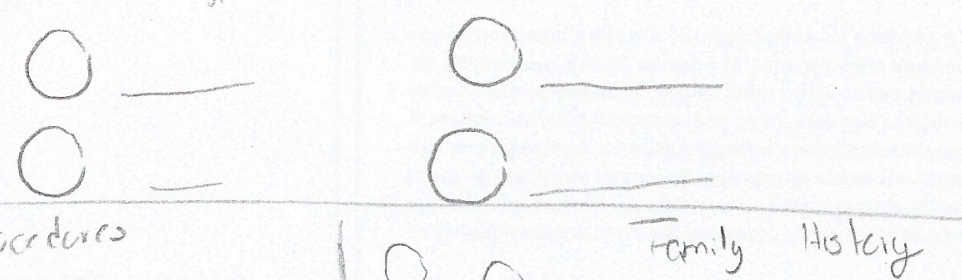

(ba)

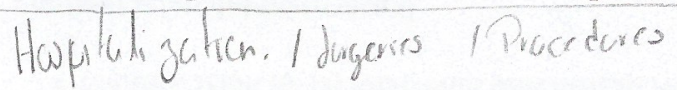

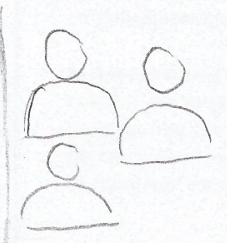

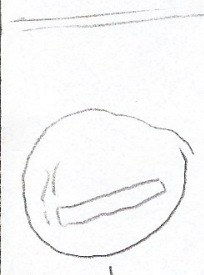

smoker

紧

How many? Haw Hang?

Sacid History

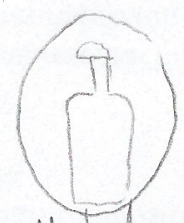

Alconal.

V 8

Hew Meny?

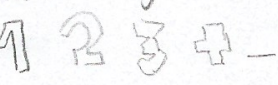

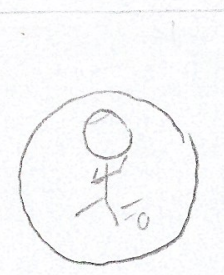

Personal

Exercise

$\sqrt{ } \times$

(4)

Fomily Histery<smiles>CC1CC1C(C)(C)C1CCCCC1</smiles>

$: \bar{I}$
$: \bar{I}$
$: \bar{I}$
$: \bar{I}$
$: \bar{I}$
$: \bar{I}$
$: \square$
$: \square$
$: \square$

Revicu ot System. 
Denver Endocrinology, Diabetes \& Thyrod Center, P.C.

799 E Hampden Av, Suite 525, Englewood, CO 80113

Phone: 303-321-2644 Fax: 303-321-2446

Website: www.denverendocenter.com

Today's Date:

Patient Name:

Date of Birth:

Occupation:

Primary Care Provider:

Referring Physician (If not PCP):

Other Care Providers:

Phone:

Phone:

Main Concern/Reason for visit today:

Phone:

Allergies (Please included type of reaction to each allergy listed):

\section{Social History}

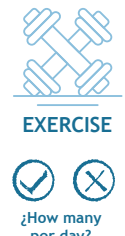

per day?

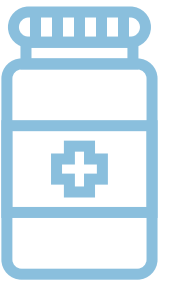

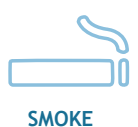

$\theta \otimes$ ¿How many

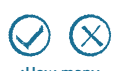
¿How many per day?

\section{Medications}

1.
2.
3.
4.
5.

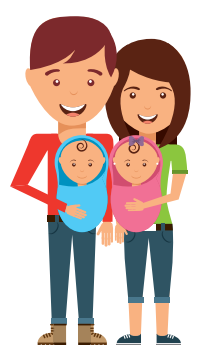

Family History

(List any health problems of your mother, father, siblings, children or grandparents only)

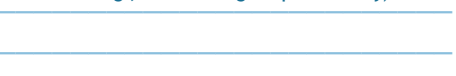

(1)

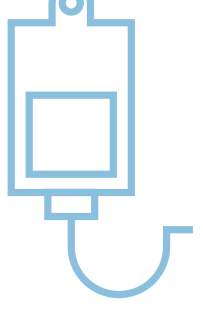

Hospitalizations

(Please include exact date or a least year)

\section{Personal History (Previus heath problems}

\section{Review of System}

\footnotetext{
Weight Gain

Weight Loss

-Fatigue

Easy Bruising

- Excessive Sweating

- Brittle Nails

- Rash

- Change in skin color

- Dry Skyn

- Stretch marks

- Darkening of Skin

- Peripheral vision loss

- Worsening vision
}

- Bulging eyes

- Headache

- Double vision

- Hoarseness

- Snoring

- Inability to smell

- Change in dental bite

- Change in head size

- Neck pain

- Swollen glands

- Neck lump

- Neck swelling

- Difficulty breathing

- Breast pain
- Breast discharge
Chest pain
- Leg pain with exercise
- Palpitations
- Abdominal pain
Constipation
- Diarrhea
- Diarrhea with milk
- Difficulty swallowing
- Vausea
- Painiting with swallowing

- Impotence

- Abnormal periods

- Pain with intercourse

- Pain with urination

- Kidney stones

- Bone pain

- Back pain

- Joint pain

- Muscle cramps

- Muscle weakness

- Pain in hands

- Pain in feet

- Fractures
- Muscle aches

- Change in hand size

- Change in foot size

- Dizziness

- Fainting

- Weakness

- Lightheadedness

- Frequent fails

- Emotional swings

- Anxiety

- Depression

- Acne

- Decrease in appetite 


\section{Selección Tipográfica}

Para los textos utilicé Trebuchet MS en sus diferentes variantes, ya que leyendo el Nomolas, es una tipografía escogida para esté tipo de documentos, además de que se adecua perfectamente a los distintos puntajes usados y a pesar de la paleta de color, considero que sigue siendo legible y amigable a la vista.

\section{Paleta de color.}

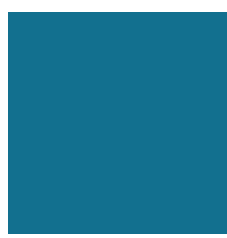

$\mathrm{R}=0$

$\mathrm{G}=112$

$B=143$

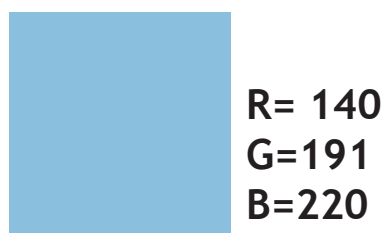

$R=255$

$\mathrm{G}=255$

$B=255$

Escogí está paleta de color porqué considero que es amigable con documentos de hospitales, ya que no se ve tan cargado, no molesta a la vista, es legible y no es agresivo para comunicar mensajes. 


\section{CUESTIONARIOPSSUQ}

\section{Edad:23 Sexo: M I Licenciatura:_Diseño Gráfico Y Digital Manejo de llustrator: I No}

Este cuestionario es una oportunidad para registrar tus reacciones a la guía de usabilidad. Estas respuestas nos ayudarán a entender que aspectos hay que mejorar y cuales son con los que no estás satisfechos. Para tener un mejor resultado, piensa en la tarea que se te pidió que realizaras con base a lo que las guías decían mientras contestas estas preguntas.

Instrucciones: Lea cada frase y señala qué tan de acuerdo o en desacuerdo estás y encierra en un circulo un número de la escala. Al terminar, revisaremos juntos con usted el cuestionario para asegurarnos de que entendamos bien la información presentada en este cuestionario.

\section{¡Gracias!}

a) La organización de la información proporcionada por las guías me fue clara.

Totalmente en desacuerdo

Totalmente de acuerdo

1

2

3

4

5

7

b) Fui capaz de completar la tarea que se me indicó rápidamente con la información proporcionada en las guías.

Totalmente en desacuerdo

Totalmente de acuerdo

$$
1
$$

2

3

4

5

7

c) La información proporcionada por las guías fue fácil de entender.

Totalmente de desacuerdo

1

2

3

4

5

Totalmente de acuerdo

7

d) La apariencia de las guías es agradable.

Totalmente en desacuerdo

Totalmente de acuerdo

1

2

3

4

5

7

e) En general estoy satisfecho con el acomodo y presentación visual de la información.

Totalmente en desacuerdo

Totalmente de acuerdo

1

2

3

4

5 


\section{LISTA DE CHEQUEO DEL ANÁLISIS DE TAREAS}

\section{Evaluador: Wariel Garéa Hevioucher Fecha: 27.03.20 Equipo: 2}

\section{SECCIÓN DE LAS GUÍAS NOMOLAS}

\section{USUARIO}

El diseñador definió el nivel socioeconómico.

El diseñador definió el nivel académico.

El diseñador definió edad.

El diseñador definió sexo.

El diseñador definió situación geográfica.

El diseñador definió situación de lectura.

El diseñador definió creencias sobre la información.

El diseñador definió usos y costumbres presentadas alrededor de la información.

\section{ESTRUCTURA DE LA INFORMACIÓN}

El diseñador utilizó una retícula para generar la composición de su gráfica

La información presentada de manera visual tiene congruencia y presenta jerarquia en relación al contenido.

La navegación de lectura se hace de izquierda a derecha y en forma de zig-zag.

\section{TIPOGRAFÍA}

El diseñador utilizó alguna de las fuentes sugeridas en las guias.

El diseñador utilizó un espacio interlineal de 1.5

El diseñador evitó la aparición de "viudas" en la composición.

El diseñador evitó la aparición de "ríos" en la composición.

El diseñador utilizó la variante negrita para hacer énfasis en palabras clave.

El diseñador utilizó la variante cursiva para hacer referencia a palabras en idioma extranjero.

El diseñador utilizó un puntaje de carácter para el cuerpo de texto de no menor a 8 puntos.

El diseñador utilizó para los títulos tipografías sans serif.

Los titulos están alienados a la izquierda o centrados.

Los titulos están en variante negrita y en un puntaje mayor al del cuerpo de texto.

El cuerpo de texto está alienado a la izquierda.

El texto y el fondo de la interfaz tienen un buen contraste.

El diseñador combinó tipografias serif y sans serif en la composición de la pieza de diseño.

\section{COLOR}

El diseñador utilizó cuatro colores dentro de la composición.

El diseñador cuidó el buen contraste entre figura, fondo y texto en la pieza de diseño. :

El diseñador tomó en consideración el uso de contraste de color entre fondo y texto.

El diseñador evitó el uso de degradados.

El diseñador utilizó el mismo color para representar un mismo tipo de dato.

El diseñador creo codificaciones de información a través del color

\section{ELEMENTOS GRÁFICOS}

Todos los elementos conserven un mismo estilo gráfico.

El diseñador implementó imágenes que tienen la misma orientación

El diseñador evitó el uso de emojis.

El diseñador usó etiquetas o leyendas debajo de los elementos gráficos que necesitaban algún tipo de aclaración. El diseñador usó bullets point, listas numéricas y flechas para enfatizar información que pertenecia a una misma categoria.

El diseñador evitó el uso de elementos o información innecesarios, extraños, decorativos o irrelevantes. 
Anexo 11.11.3. USUARIO 3. Material de resultados para la evaluación de la FASE 2. Lean Canvas de Decisiones de Diseño. Bocetaje. Propuesta de interfaz gráfica. Cuestionario PSSUQ contestado. Lista de chequeo de Análisis de Tareas contestada. 


\begin{tabular}{|l|}
\hline \multicolumn{1}{|c|}{ DEFINICIÓN DEL USUARIO } \\
\hline Definir nivel socioeconómico, nivel académico, \\
edad, sexo, situación geográfica y de lectura, \\
creencias acerca de la información a trabajar y, \\
usos y costumbres del usuario en relación con la \\
información. \\
Edad: 30 a 50 años. NSE: Medio Alto. \\
Sexo: Tendencia a ser más hombres que \\
mujeres. Radican en la ciudad de Engle- \\
wood, Colorado. Al ser una ciudad \\
pequeña es probable que no haya muchas \\
clínicas para tratar este padecimiento, por \\
lo que el usuario se siente muy estresado y \\
ansioso por su salud. El usuario se ha \\
sentido mal durante algunas semanas, \\
pero no logra descifrar lo que le está \\
pasando. Quiere obtener respuestas \\
rápidas y que se le atienda de una manera \\
discreta. Es probable que viva con su \\
familia pero en muchos de los casos \\
suelen mantener en secreto este tipo de \\
padecimientos por miedo a que les \\
tengan lástima. Consulta normalmente la \\
información del padecimiento en internet \\
o redes sociales, así que vive en un estado \\
de "mal información". El ir a la clínica ha \\
sido su último recuerdo ante esa "mal \\
información". \\
\end{tabular}

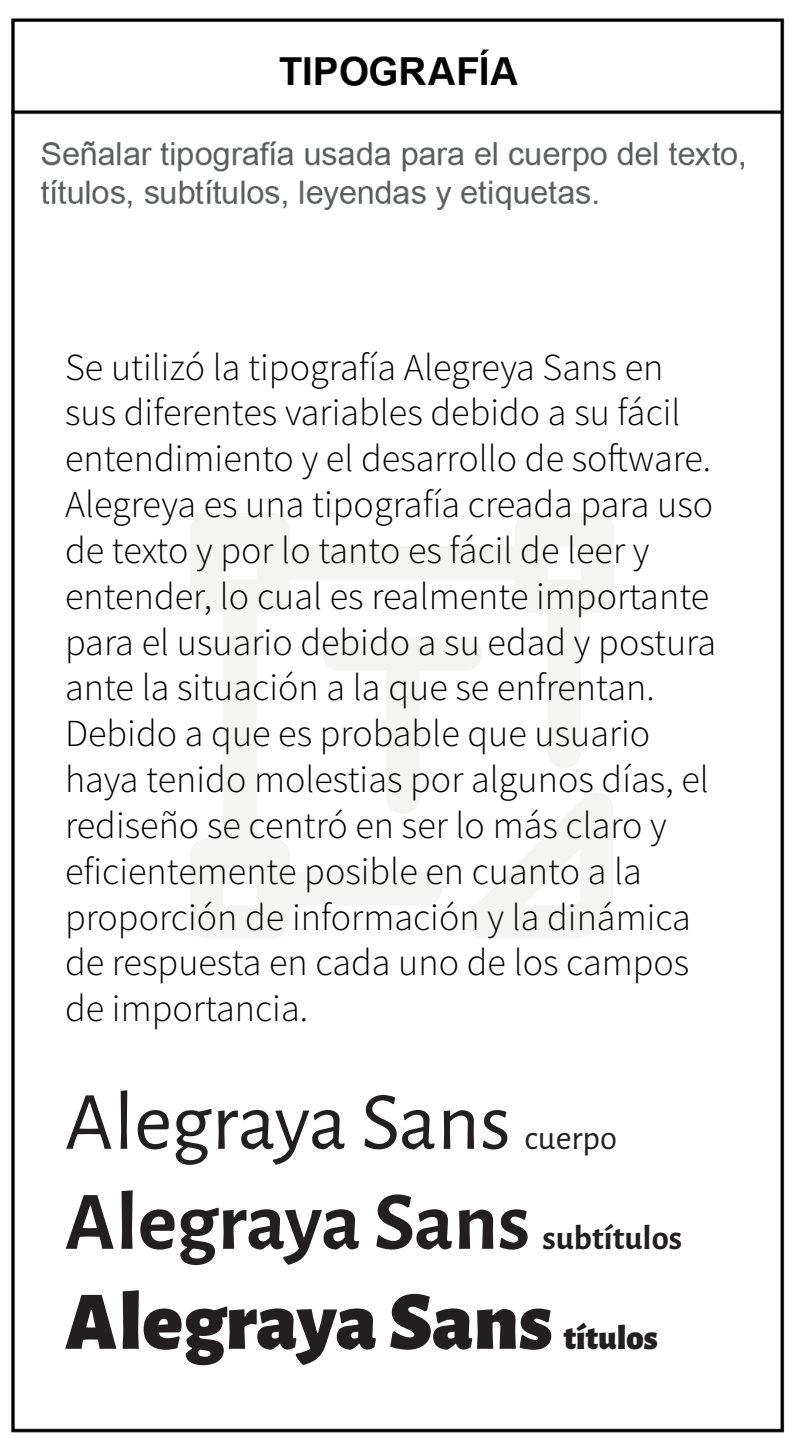

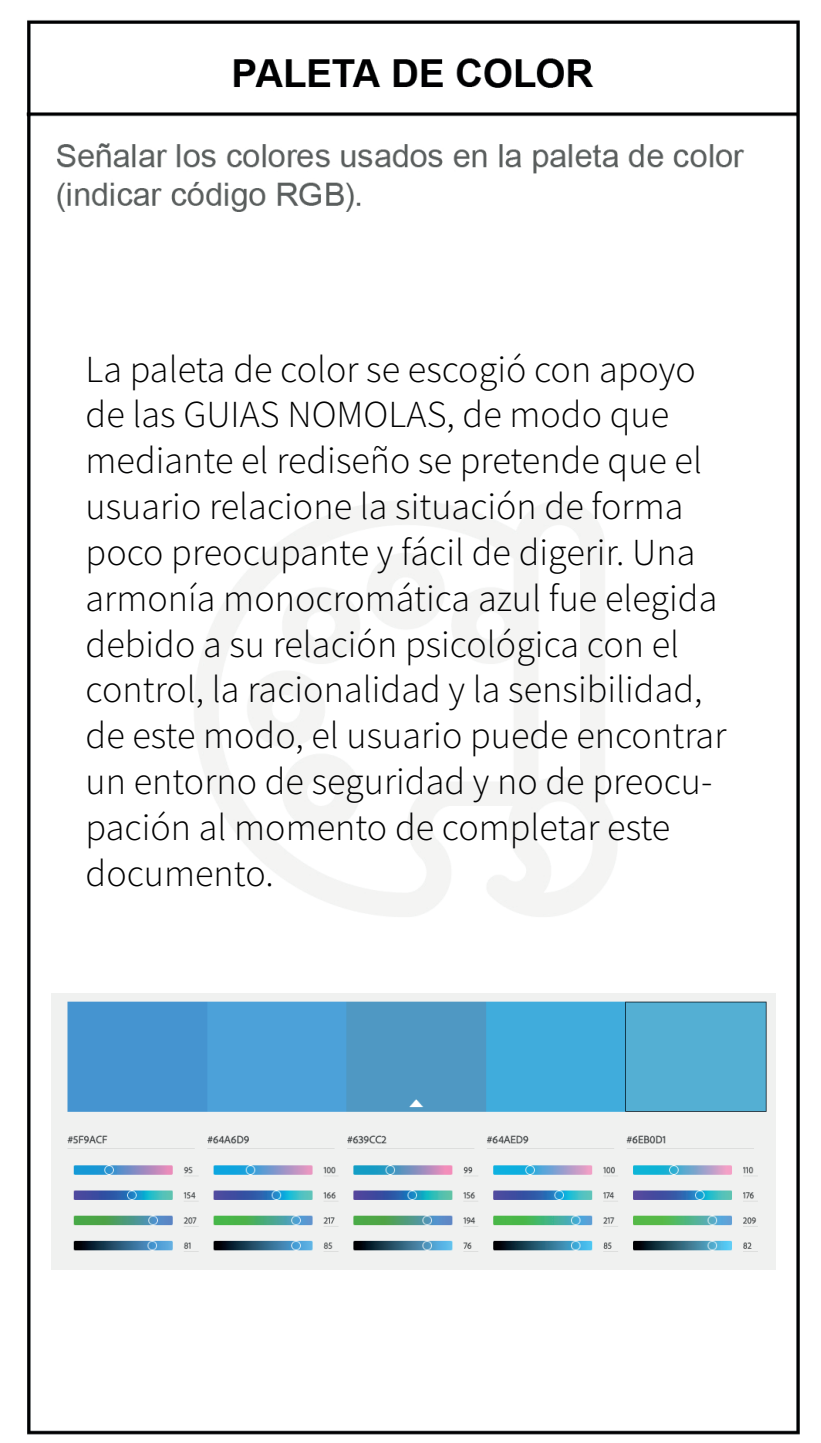


Denver endocrindogy

Diabetes \& thyroid enter pe into
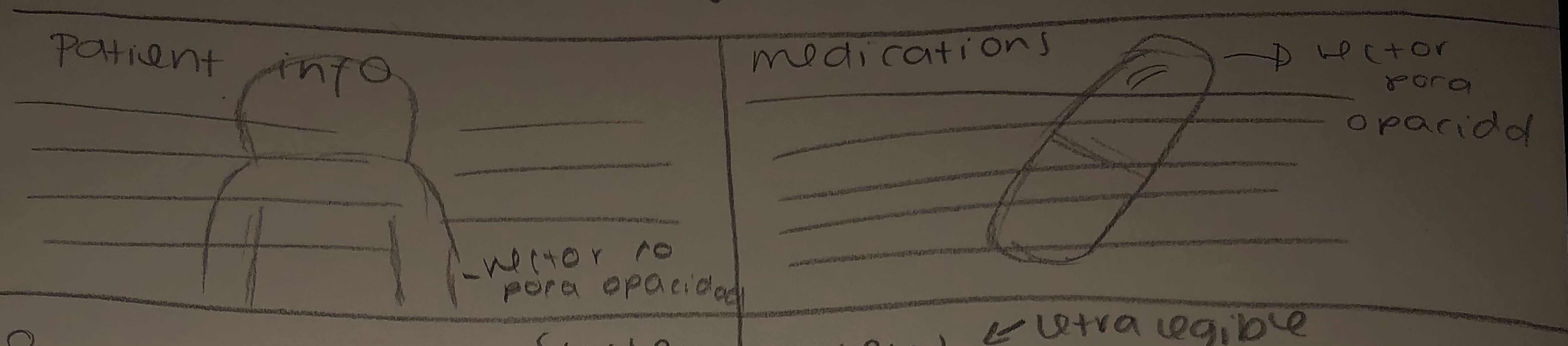

0

system review tetra legible

0

o

$0 \longrightarrow 0$

0

0

0

0

0

0

0

0

O

$0 \longdiv { - 2 }$

0

0

0

0

Hopitalization

procedure bate

social History

6

6

o.

ב

ye, no how many? -

yer no ne of days

family History

4

2

5

1

personal History

2

5

3

6

4

4 
Denver endocrinology, Diabetes \& thyroid center P.C,

patient name Date of birth
Today date occupation phone phone

All orgies r 1. name Medications

2.

5. name Dosage color 2

3.

4.

6

7 .

\begin{tabular}{l} 
Hospitalizations/surgaves \\
$\begin{array}{c}\text { Procedure date or year } \\
\text { Date }\end{array}$ \\
\hline
\end{tabular}

Social History

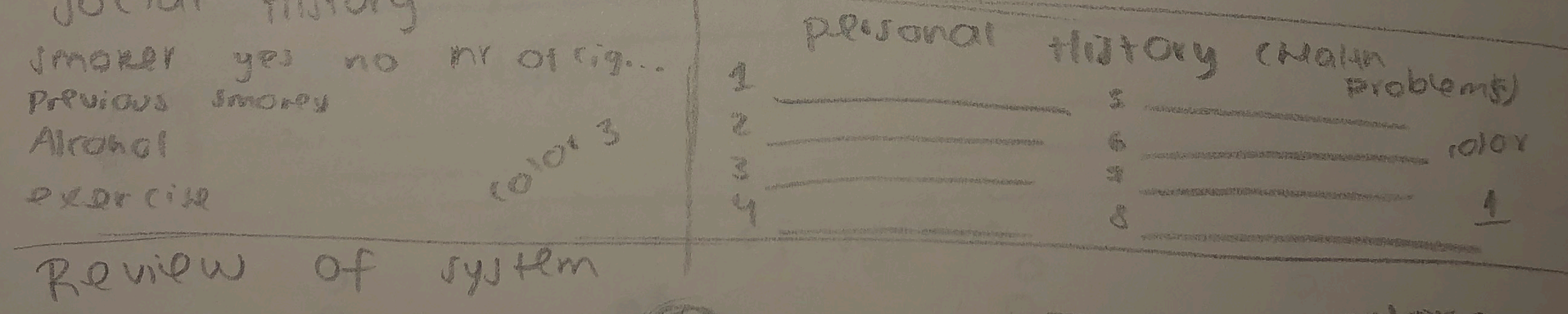

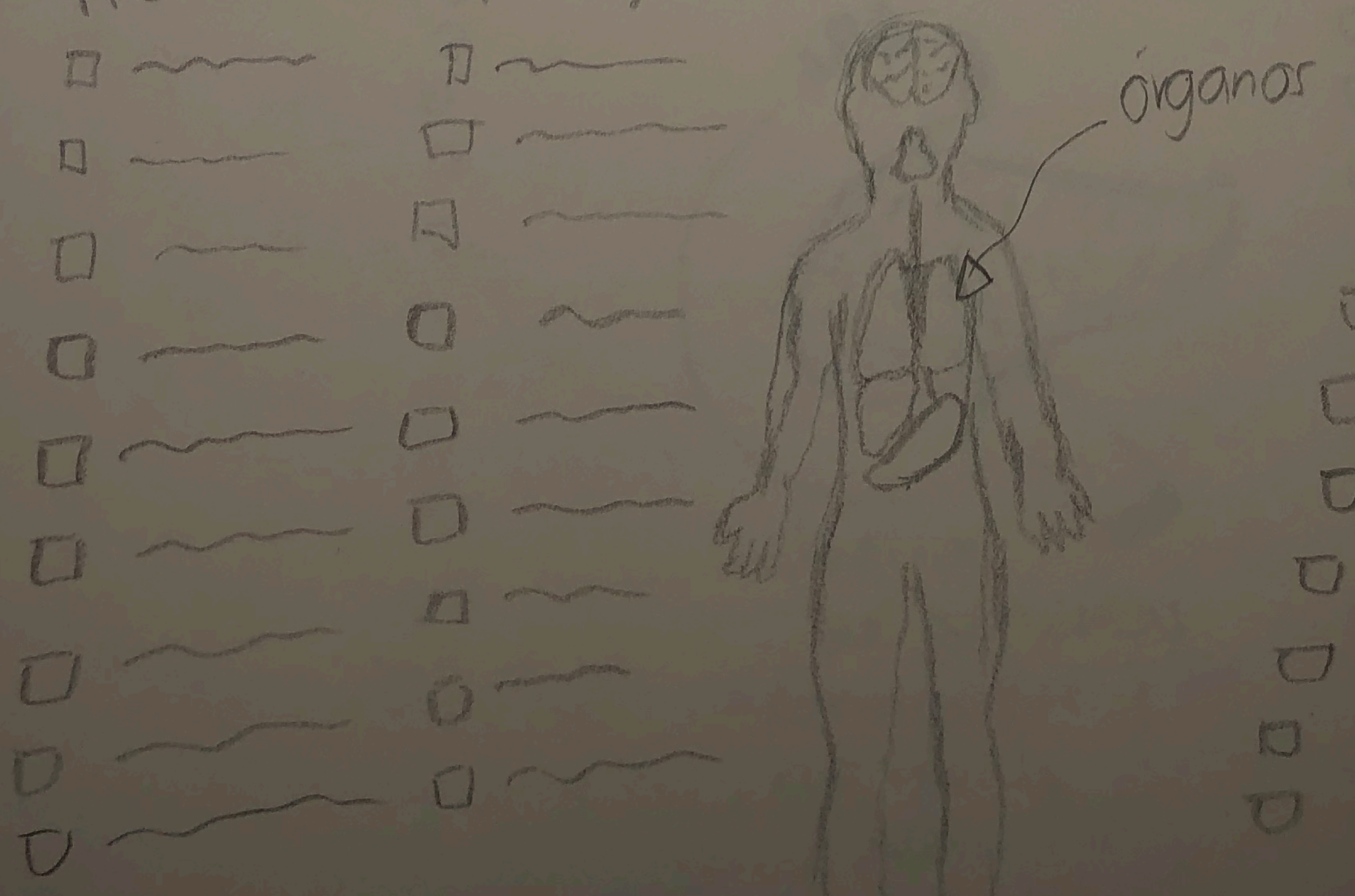
color? 


\section{Denver Endocrinology, Diabetes \& Thyroid Center, P.C.}

799 E Hampden Ave, Suite 525, Englewood, CO 80113

Phone: 303-321-2644

Fax: 303-321-2446

Website: www.denverendocenter.com

Primary Care Provider:

Phone:

Referring Physician(if not PCP):

Phone:

Other Care Providers:

Phone:

ALLERGIES (Please include type

of reaction to each allergy listed):

\section{Medications}

(Both prescription and over-the-counter including herbal,vitamins,etc) Please include another page if needed.

1.Name:

2.Name:

3.Name:

4.Name:

\section{Hospitalizations/surgeries/procedures}

(Please include exact date or at least year).
Dosage:

Dosage:

Dosage:

Dosage:

Family history (List any health problems of your mother, father, siblings, children or grandparents only).
Social history (Circle all that apply).

Current smoker yes/no number of cigarettes per day:

Previous smoker yes/no date quit:

Alcohol use yes/no number of drinks per day:

Exercise yes/no number of days in a week:

Weight gain

Weight loss

Fatigue

Easy bruising

Excessive sweating

Brittle nails

Rash

Change in skin color

Dry skin

Stretch marks

Darkening of skin

Peripheral vision loss

Worsening vision

Blurred vision

Bulging eyes

Headache

Double vision

Hoarseness

Snoring
Inability to smell

Change in dental bite

Change in head size

Neck pain (front)

Swollen glands

Neck lump

Neck swelling

Difficulty breathing

Breast Pain

Breast Discharge

Breast Enlargement

Chest pain/discomfort

Leg pain with exercise

Palpitations

Abdominal pain

Constipation

Diarrhea

Diarrhea with milk

Difficulty swallowing
Heat intolerance

Hot flashes

Flushing

\section{Review of system}

(Circle current problems/symptoms you are experiencing now in past 1 month)

Cold intolerance

Excessive thirst

Excessive urination

Personal history (Previous health problems).

Decrease in

sex drive

Other

Lightheadedness

Dizziness with standing

Change in concentration

Change in memor

Frequent falls

Emotional swings

Numbness in hands/feet

Burning in hands/feet

Anxiety

Depression

Difficulty sleeping

Acne

Decrease in appetite

Increase in appetite

Feeling full before done eating
Nausea

Vomiting

Pain with swallowing Impotence

Abnormal periods

Pain with intercourse

Pain with urination

Kidney stones

Bone pain

Back pain

Joint pain

Muscle cramps

Muscle weakness

Muscle aches

Pain in hands

Pain in feet

Fractures

Change in hand size

Change in foot size 


\section{CUESTIONARIOPSSUQ}

Edad: 21 Sexo: M I (F) Licenciatura: Diseño de infromación visual Manejo de llustrator: (Si) I No

Este cuestionario es una oportunidad para registrar tus reacciones a la guía de usabilidad. Estas respuestas nos ayudarán a entender que aspectos hay que mejorar y cuales son con los que no estás satisfechos. Para tener un mejor resultado, piensa en la tarea que se te pidió que realizaras con base a lo que las guías decían mientras contestas estas preguntas.

Instrucciones: Lea cada frase y señala qué tan de acuerdo o en desacuerdo estás y encierra en un circulo un número de la escala. Al terminar, revisaremos juntos con usted el cuestionario para asegurarnos de que entendamos bien la información presentada en este cuestionario.

\section{¡Gracias!}

a) La organización de la información proporcionada por las guías me fue clara.

Totalmente en desacuerdo

Totalmente de acuerdo$$
1
$$

2

3

4

5

6

(7)

b) Fui capaz de completar la tarea que se me indicó rápidamente con la información proporcionada en las guías.

Totalmente en desacuerdo

$$
1
$$

3

4

(5)

6

Totalmente de acuerdo

c) La información proporcionada por las guías fue fácil de entender.

Totalmente de desacuerdo$$
1
$$

2

3

4

5

Totalmente de acuerdo

d) La apariencia de las guías es agradable.

Totalmente en desacuerdo

$$
12
$$

2

3

4

5

Totalmente de acuerdo

(6)

7

e) En general estoy satisfecho con el acomodo y presentación visual de la información.

Totalmente en desacuerdo

Totalmente de acuerdo

1

2

3

4

5

6

(7) 


\section{LISTA DE CHEQUEO DEL ANÁLISIS DE TAREAS. \\ Evaluador: Wanel Garća Heluauder Fecha: 27.03 .20 Equipo: 3}

\section{SECCIÓN DE LAS GUÍAS NOMOLAS}

\section{USUARIO}

El diseñador definió el nivel socioeconómico.

El diseñador definió el nivel académico.

El diseñador definió edad.

El diseñador definió sexo.

El diseñador definió situación geográfica.

El diseñador definió situación de lectura.

El diseñador definió creencias sobre la información.

El diseñador definió usos y costumbres presentadas alrededor de la información.

\section{ESTRUCTURA DE LA INFORMACIÓN}

El diseñador utilizó una retícula para generar la composición de su gráfica.

La información presentada de manera visual tiene congruencia y presenta jerarquia en relación al contenido. La navegación de lectura se hace de izquierda a derecha y en forma de zig-zag.

\section{TIPOGRAFÍA}

El diseñador utilizó alguna de las fuentes sugeridas en las guias

El diseñador utilizó un espacio interlineal de 1.5

El diseñador evitó la aparición de "viudas" en la composición.

El diseñador evitó la aparición de "rios" en la composición.

El diseñador utilizó la variante negrita para hacer énfasis en palabras clave.

El diseñador utilizó la variante cursiva para hacer referencia a palabras en idioma extranjero

El diseñador utilizó un puntaje de carácter para el cuerpo de texto de no menor a 8 puntos.

El diseñador utilizó para los títulos tipografias sans serif.

Los títulos están alienados a la izquierda o centrados.

Los títulos están en variante negrita y en un puntaje mayor al del cuerpo de texto.

El cuerpo de texto está alienado a la izquierda

El texto y el fondo de la interfaz tienen un buen contraste.

El diseñador combinó tipografias serif y sans serif en la composición de la pieza de diseño COLOR

El diseñador utilizó cuatro colores dentro de la composición.

El diseñador cuidó el buen contraste entre figura, fondo y texto en la pieza de diseño.

El diseñador tomó en consideración el uso de contraste de color entre fondo y texto.

El diseñador evitó el uso de degradados.

El diseñador utilizó el mismo color para representar un mismo tipo de dato.

El diseñador creo codificaciones de información a través del color.

\section{ELEMENTOS GRÁFICOS}

Todos los elementos conserven un mismo estilo gráfico.

El diseñador implementó imágenes que tienen la misma orientación

El diseñador evitó el uso de emojis.

El diseñador usó etiquetas o leyendas debajo de los elementos gráficos que necesitaban algún tipo de aclaración El diseñador usó bullets point, listas numéricas y flechas para enfatizar información que pertenecia a una misma categoría.

El diseñador evitó el uso de elementos o información innecesarios, extraños, decorativos o irrelevantes.
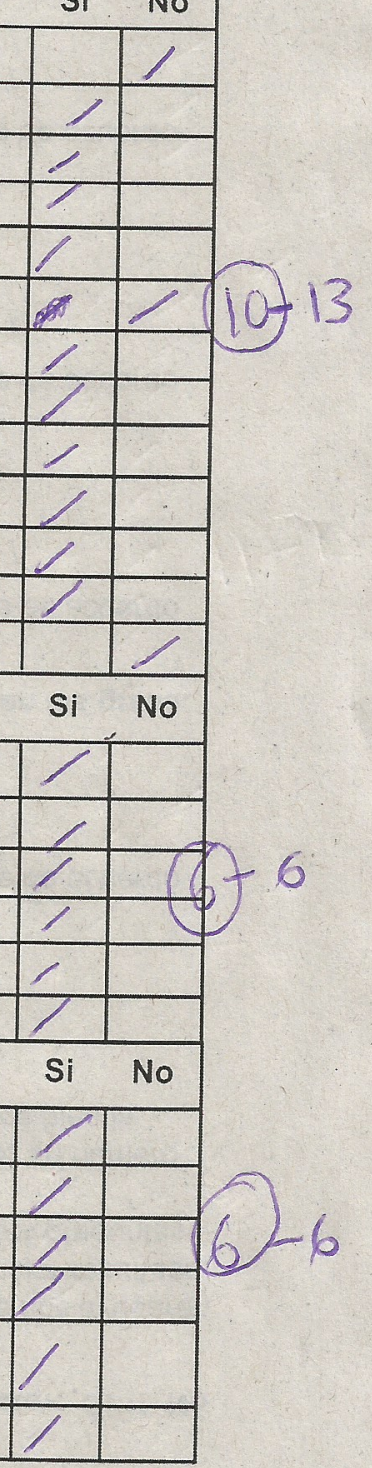
Anexo 11.11.4. USUARIO 4. Material de resultados para la evaluación de la FASE 2. Lean Canvas de Decisiones de Diseño. Bocetaje. Propuesta de interfaz gráfica. Cuestionario PSSUQ contestado. Lista de chequeo de Análisis de Tareas contestada. 
LEAN CANVAS DE DECISIONES DE DISEÑO

INTEGRANTES DEL EQUIPO: Jetto Garcia Castillo

Fecha: $25 / 03 / 20$

Equipo \#:

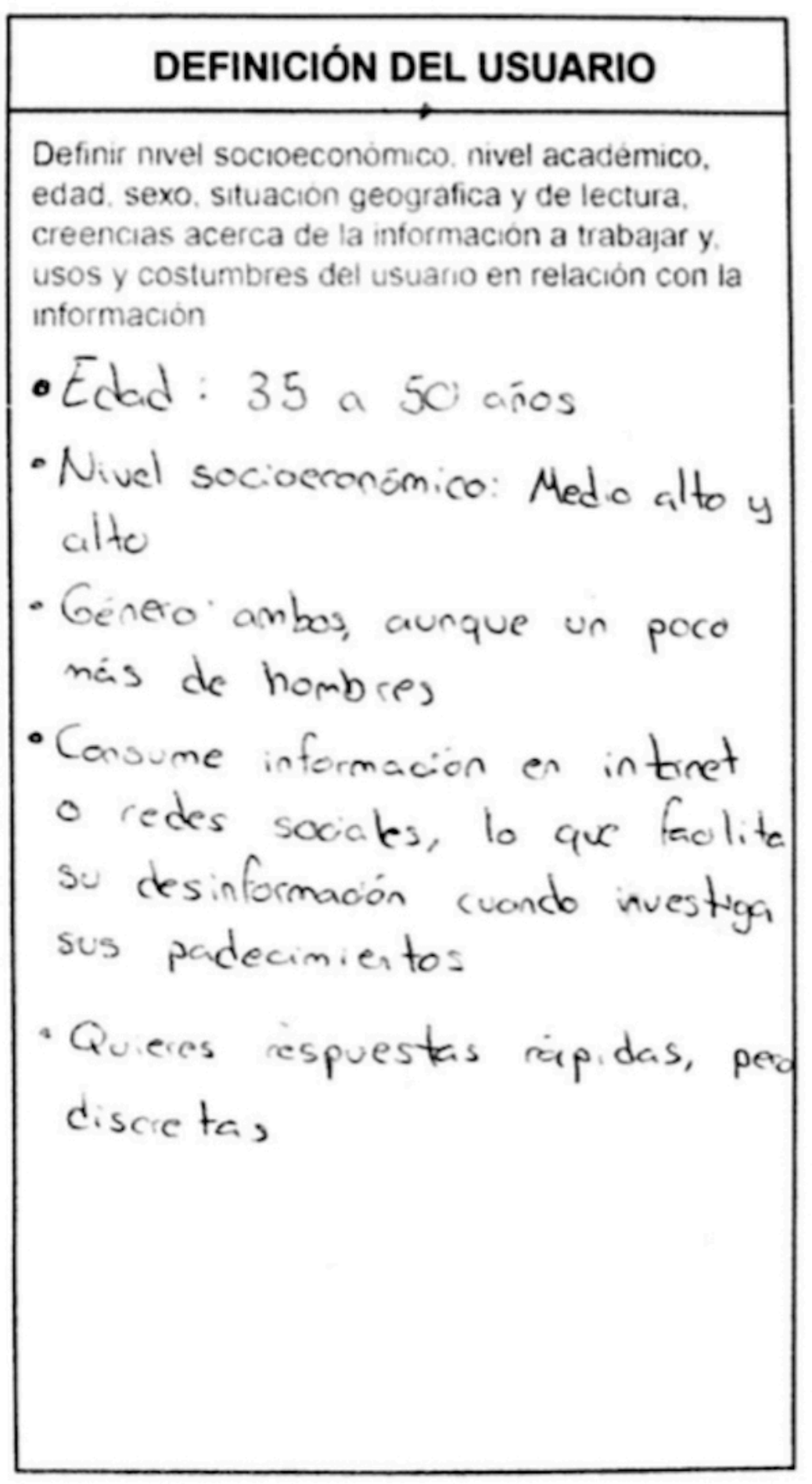

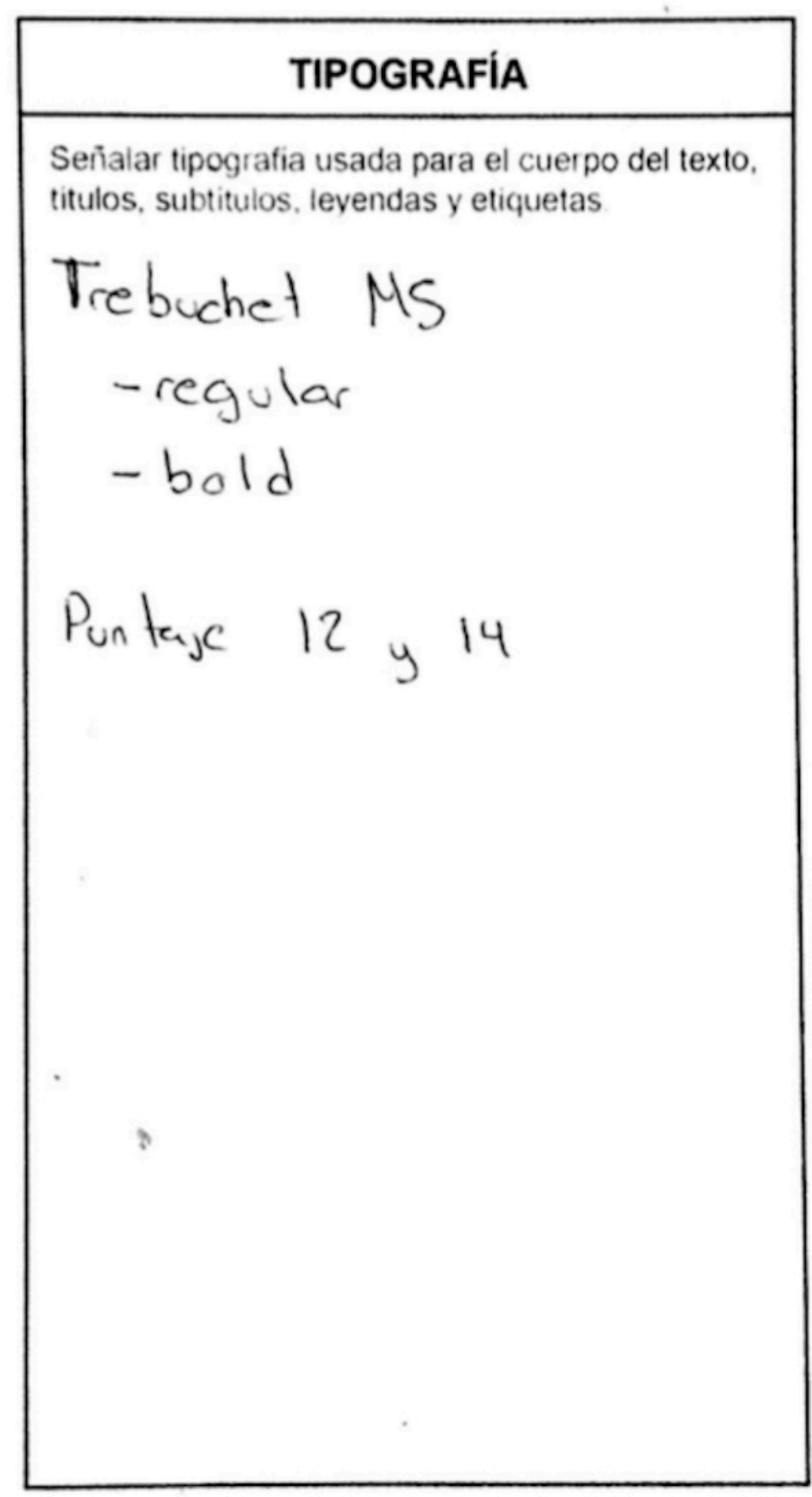

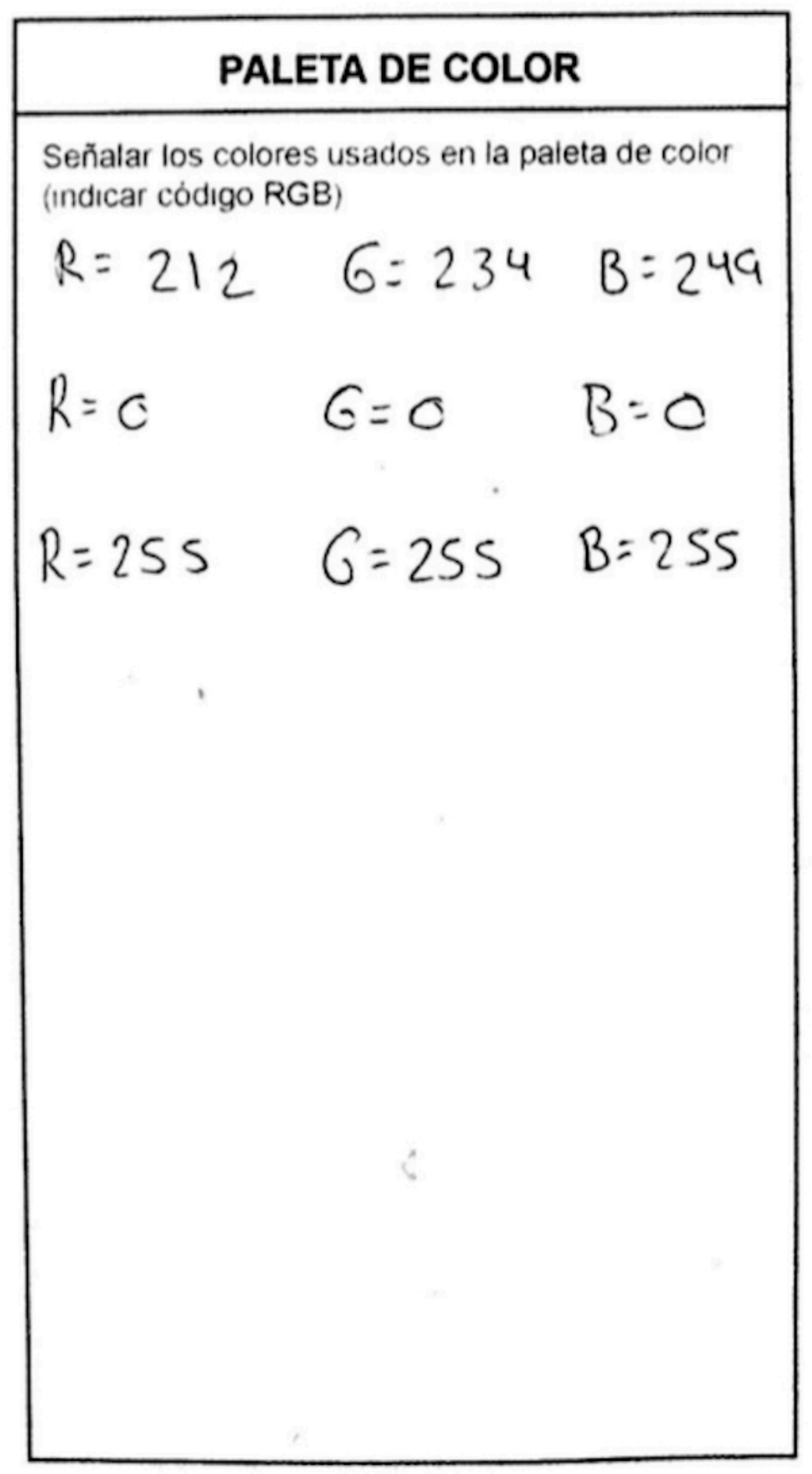




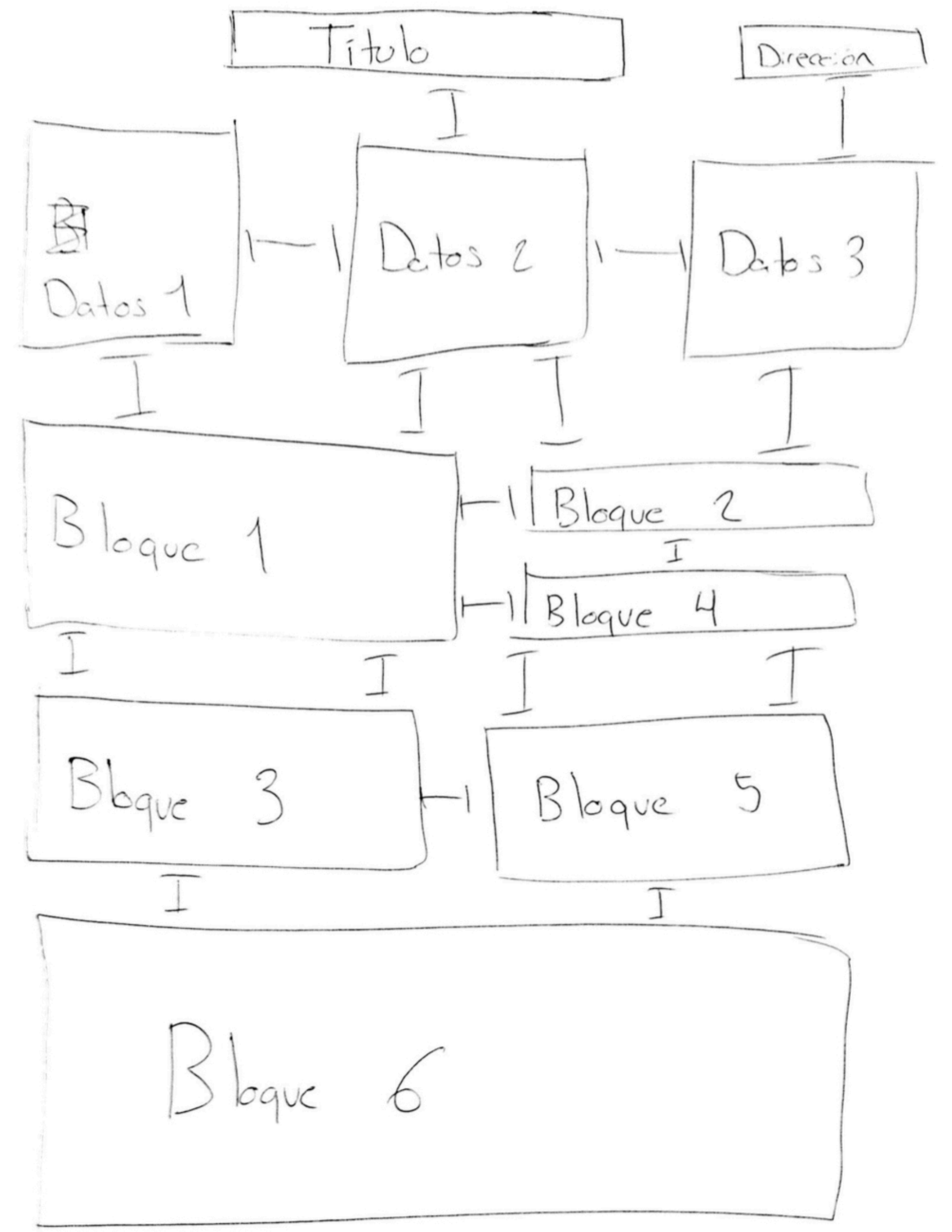




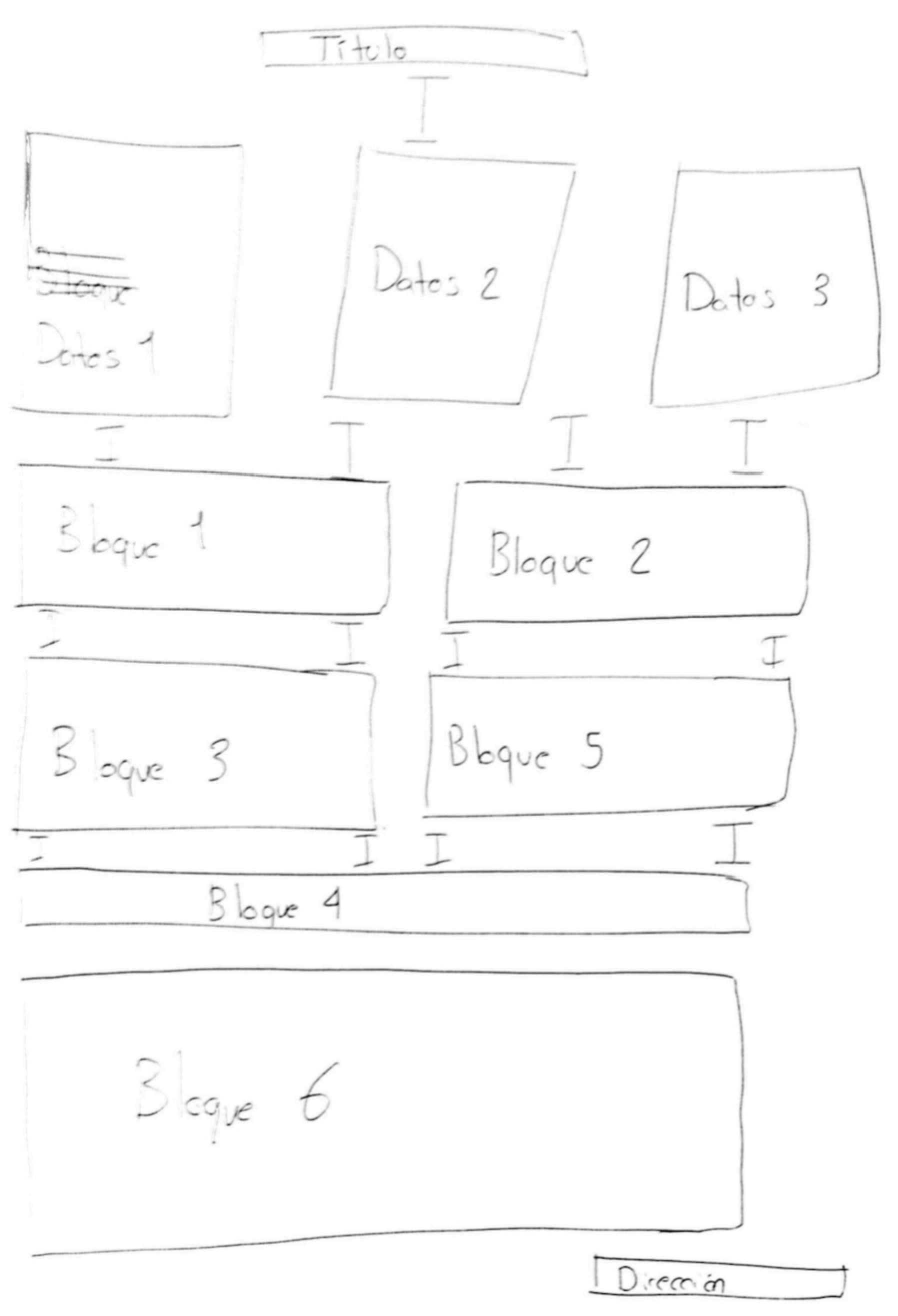




\section{Denver Endocrinology, Diabetes \& Thyroid Center, PC.}

Patient Name

Date of Birth

Primary Care Provider

Referring Physician (if not PCP)

Other Care Providers
Today's Date

Occupation

Phone

Phone

Phone

Main Concern(s)/Reasons for visit today

Allergies (please include type of reaction to each allergy listed)

Medications (Both prescription and over-the-counter including herbal, vitamins, etc.) Please, include another page if needed

1.

3.

5.

Hospitalizations/Surgeries/Procedures please include exact date or at least year

Family History (List any health problems of your mother, father, siblings, children, or grandparents only)

2.

4.

6.

Social History (Circle all that apply)

Current smoker yes/no

*Number of cigarretes per day

Previous smoker yes/no

*Date quit

Alcohol use yes/no

*Number of drinks per day

Exercise yes/no

*Number of days in a week duration/ type of exercise

Personal History (Previous problems) 
Review of system (Circle current problems/symptoms you aare experiencing now in past 1 month)

$\square$ Weight gain

Weight loss

Fatigue

Easy bruising

Excessive sweating

Brittle nails

Rash

Change in skin color

Dry skin

Stretch marks

Darkening of skin

Peripheral vision loss

Worsening vision

Blurred vision

Bulging eyes

Headache

Double vision

Hoarseness

Snoring

$\square$ Inability to smell

Change in dental bite

Change in head size

Neck pain (front)

Swollen glands

Neck lump

Neck swelling

Difficulty breathing

Breast pain

Breast discharge

Breast Enlargement
Chest pain

Leg pain with exercise

$\square$ Palpitations

Abdominal pain

$\square$ Constipation

Diarrhea

Diarrhea with milk

Difficulty swallowing

Nausea

Vomiting

Pain with swallowing

Impotence

Abnormal periods

Pain with intercourse

Pain with urination

Kidney stones

Bone pain

Back pain

Joint pain

Muscle cramps

$\square$ Muscle weakness

Pain in hands

Pain in feets

Fractures

Muscle aches

Change in hand size

Change in foot size

Dizziness

Fainting

Weakness
Lightheadedness

Dizziness with standing

Change concentration

$\square$ Change in memor

$\square$ Frequent falls

$\square$ Emotional swings

$\square$ Numbness in hands/feet

$\square$ Burning in hands/feets

$\square$ Anxiety

Depression

Difficulty sleeping

Acne

Decrease in appetite

$\square$ Increase in appetite

$\square$ Felling full before eat

Cold intolerance

$\square$ Excessive thirst

$\square$ Excessve urination

Heat intolerance

Hot flashes

Flushing

Excess face/body hair

$\square$ Loss hair

Decrease in height

Decrease in sex drive

Other

799 E Hampden Ave, Suite 525, Englewood, CO 80113 www.denverendocenter.com 


\section{CUESTIONARIO PSSUQ}

Edad: 21 Sexo: M I F Licenciatura: Diseio de icformicein Manojo de llustrator: ISI I No

Este cuestionario es una oportunidad para registrar tus reacciones a la guia de usabilidad. Estas respuestas nos ayudaran a entender que aspectos hay que mejorar y cuales son con los que no estas satisfechos. Para tener un mejor resultado. piensa en la tarea que se te pidio que realizaras con base a lo que las guias decian mientras contestas estas preguntas

Instrucciones: Lea cada frase y señala qué tan de acuerdo o en desacuerdo estás y encierra en un circulo un número de la escala. Al terminar, revisaremos juntos con usted el cuestionario para asegurarnos de que entendamos bien la información presentada en este cuestionario.

¡Gracias!

a) La organización de la información proporcionada por las guias me fue clara.

Totaimente en desacuerdo
2
3
4
5

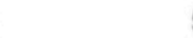
6
17

Totalmente de acuerdo

b) Fui capaz de completar la tarea que se me indicó rápidamente con la información proporcionada en las guias.

Totalmente en desacuerdo<smiles>[3H]</smiles>

2
3

c) La información proporcionada por las guias fue fácil de entender.

Totalmente de desacuerdo$$
2
$$

4

d) La apariencia de las guias es agradable.

Totalmente en desacuerdo

1

2
3
4
Totalmente de acuerdo

5

6

Totalmente de acuerdo

5

6

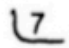

e) En general estoy satisfecho con el acomodo y presentación visual de la información. Totalmente en desacuerdo 


\section{LISTA DE CHEQUEO DEL ANÁLISIS DE TAREAS \\ Evaluador: Wanel Gareta Hewäder Fecha: 27.03.20 Equipo:}

\section{SECCIÓN DE LAS GUÍAS NOMOLAS}

USUARIO

El diseñador definió el nivel socioeconómico.

El diseñador definió el nivel académico.

El diseñador definió edad.

El diseñador definió sexo

El diseñador definió situación geográfica.

El diseñador definió situación de lectura.

El diseñador definió creencias sobre la información

El diseñador definió usos y costumbres presentadas alrededor de la información

\section{ESTRUCTURA DE LA INFORMACIÓN}

El diseñador utilizó una retícula para generar la composición de su gráfica.

La información presentada de manera visual tiene congruencia y presenta jerarquía en relación al contenido.

La navegación de lectura se hace de izquierda a derecha y en forma de zig-zag.

TIPOGRAFÍA

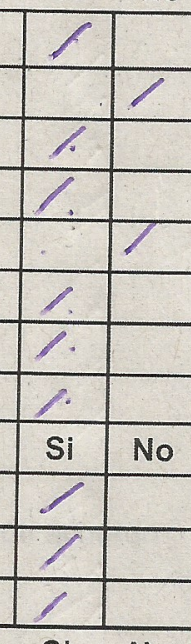

El diseñador utilizó alguna de las fuentes sugeridas en las guias.

El diseñador utilizó un espacio interlineal de 1.5

"El diseñador evitó la aparición de "viudas" en la composición.

El diseñador evitó la aparición de "ríos" en la composición.

El diseñador utilizó la variante negrita para hacer énfasis en palabras clave.

El diseñador utilizó la variante cursiva para hacer referencia a palabras en idioma extranjero.

El diseñador utilizó un puntaje de carácter para el cuerpo de texto de no menor a 8 puntos.

El diseñador utilizó para los títulos tipografias sans serif.

Los títulos están alienados a la izquierda o centrados.

Los títulos están en variante negrita y en un puntaje mayor al del cuerpo de texto.

El cuerpo de texto está alienado a la izquierda.

El texto y el fondo de la interfaz tienen un buen contraste.

El diseñador combinó tipografias serif y sans serif en la composición de la pieza de diseño

COLOR

El diseñador utilizó cuatro colores dentro de la composición.

El diseñador cuidó el buen contraste entre figura, fondo y texto en la pieza de diseño.

El diseñador tomó en consideración el uso de contraste de color entre fondo y texto.

El diseñador evitó el uso de degradados.

El diseñador utilizó el mismo color para representar un mismo tipo de dato.

El diseñador creo codificaciones de información a través del color.

\section{ELEMENTOS GRÁFICOS}

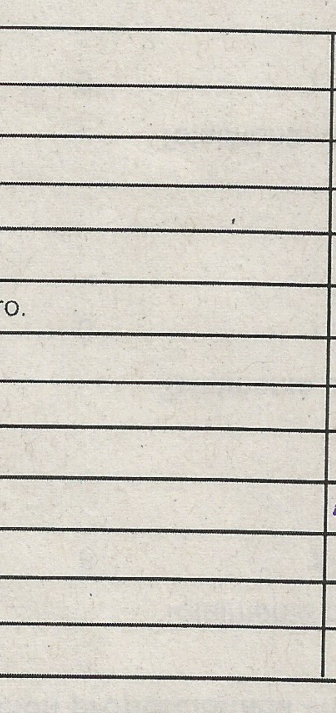

Todos los elementos conserven un mismo estilo gráfico.

El diseñador implementó imágenes que tienen la misma orientación

El diseñador evitó el uso de emojis.

El diseñador usó etiquetas o leyendas debajo de los elementos gráficos que necesitaban algún tipo de aclaración.

El diseñador usó bullets point, listas numéricas y flechas para enfatizar información que pertenecia a una misma categoría.

El diseñador evitó el uso de elementos o información innecesarios, extraños, decorativos o irrelevantes.

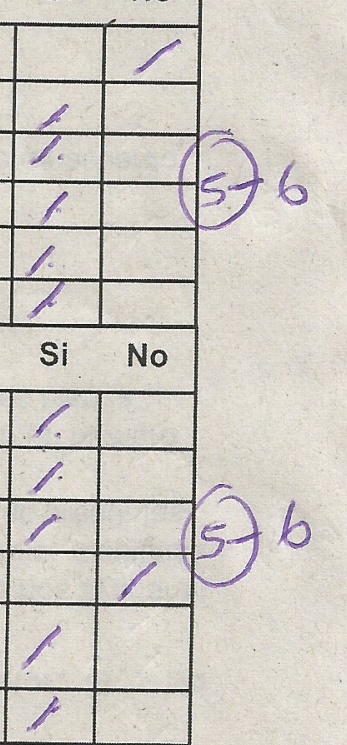


Anexo 11.11.5. USUARIO 5. Material de resultados para la evaluación de la FASE 2. Lean Canvas de Decisiones de Diseño. Bocetaje. Propuesta de interfaz gráfica. Cuestionario PSSUQ contestado. Lista de chequeo de Análisis de Tareas contestada. 


\section{LEAN CANVAS DE DECISIONES DE DISEÑO}

INTEGRANTES DEL EQUIPO:

Irán Carolina Leal

Fecha:

Equipo \#:

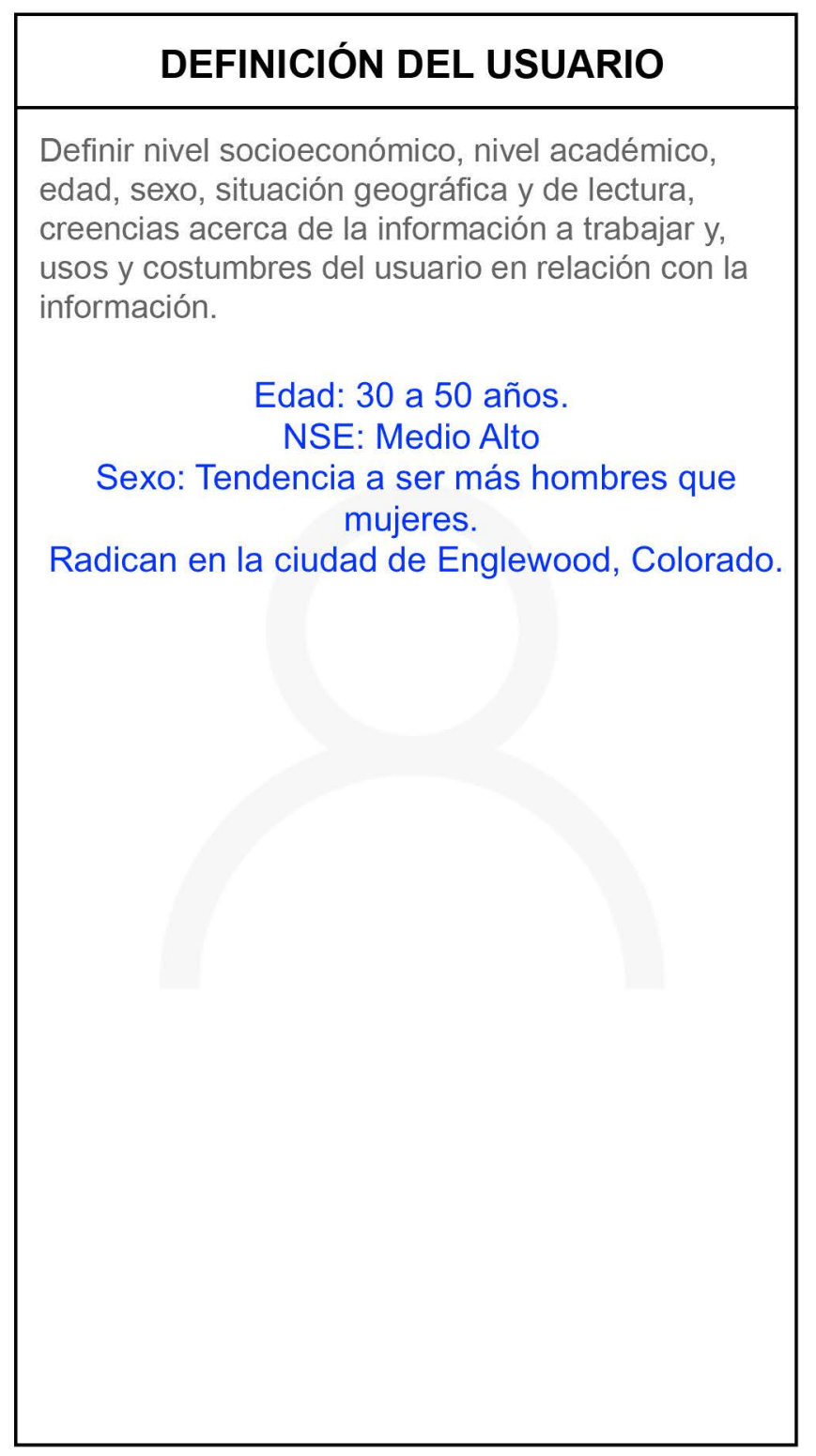

\begin{tabular}{|c|}
\hline TIPOGRAFÍA \\
\hline $\begin{array}{c}\text { Señalar tipografía usada para el cuerpo del texto, } \\
\text { títulos, subtítulos, leyendas y etiquetas. } \\
\text { Fira Sans-bold } \\
\text { para título y subtítulo }\end{array}$ \\
Verdana- Regular \\
para cuerpo de texto \\
Fira Sans book \\
para etiquetas \\
\\
\end{tabular}

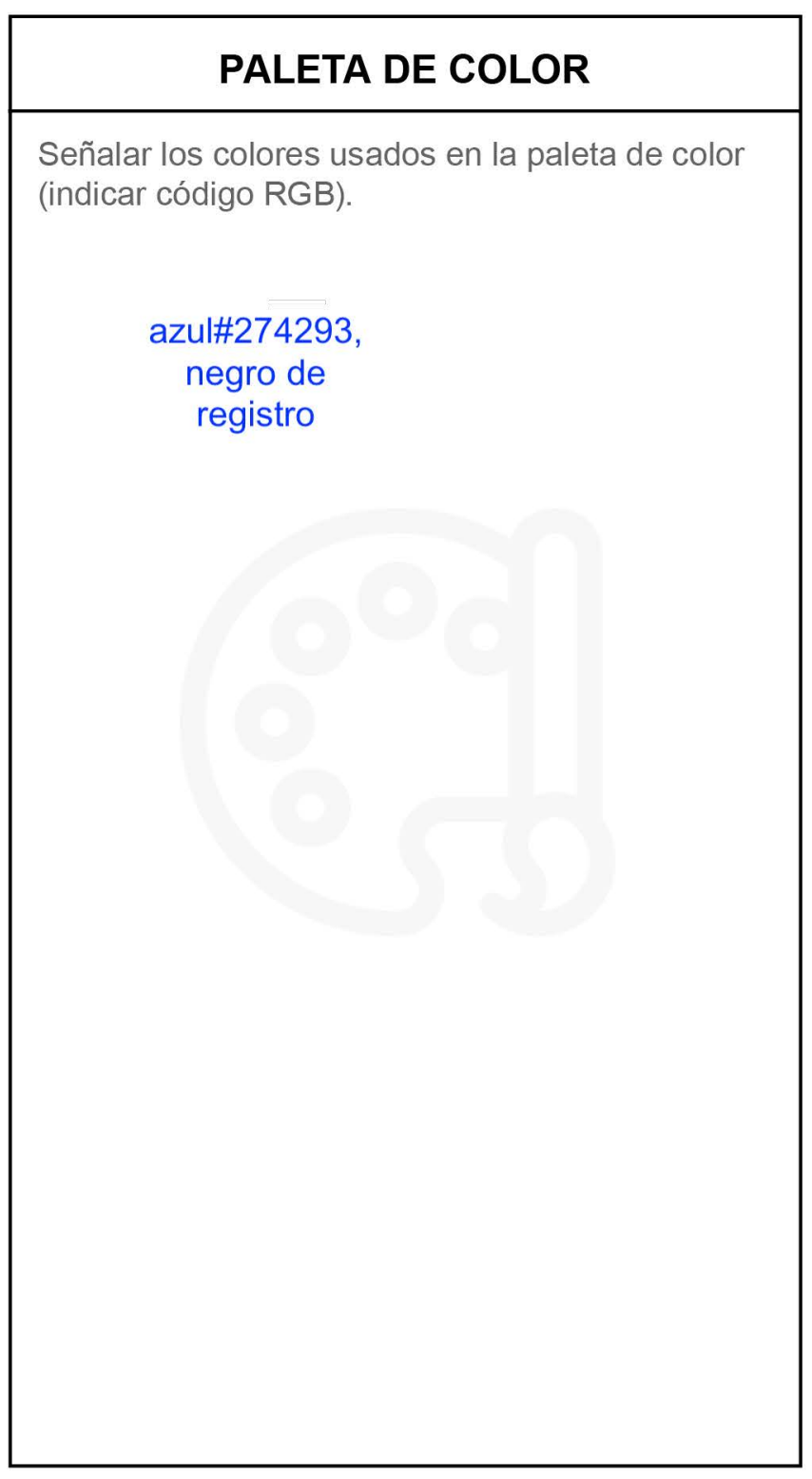




\section{INSTITUTION TITLE}

(1) subtitle

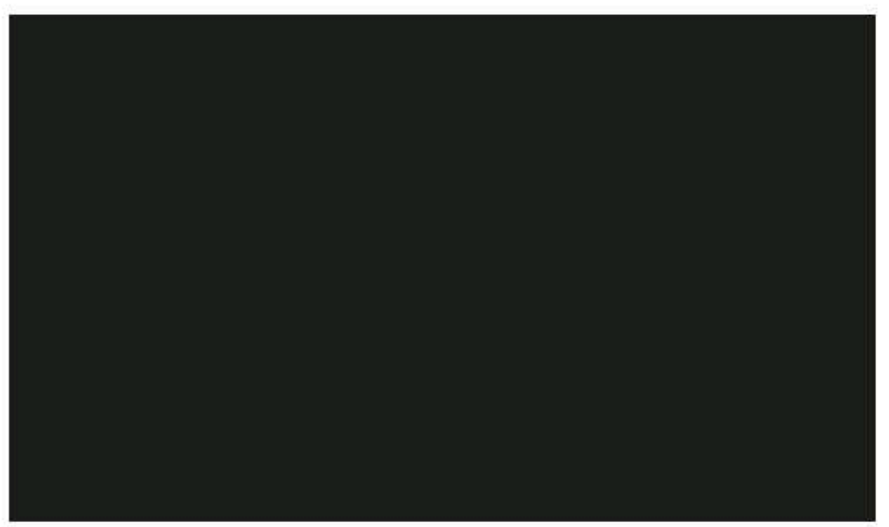

(2) SubtitLe

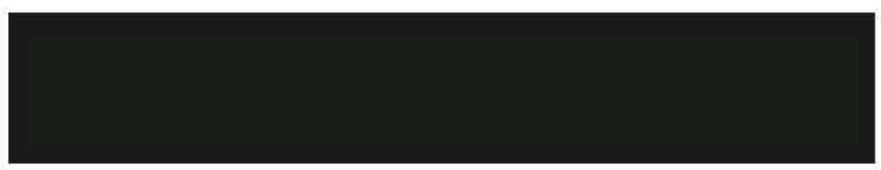

(3) REVIEW OF SYSTEM

\section{(4) SUBtitle}

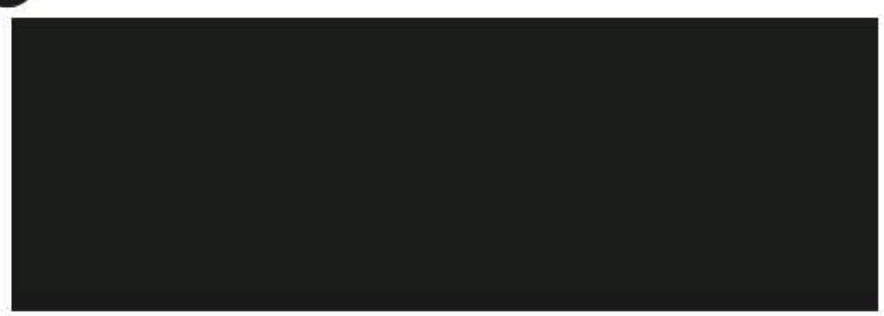

(5) SUbtitLe

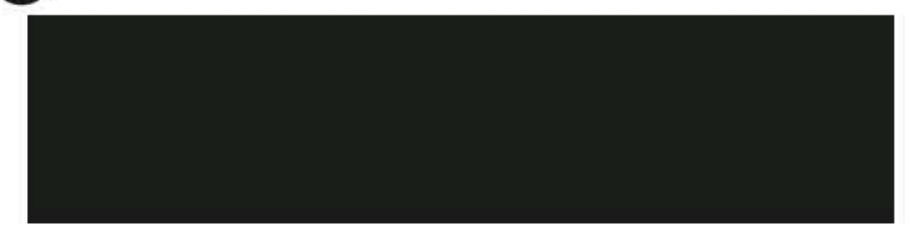

(6) SUBtitLe

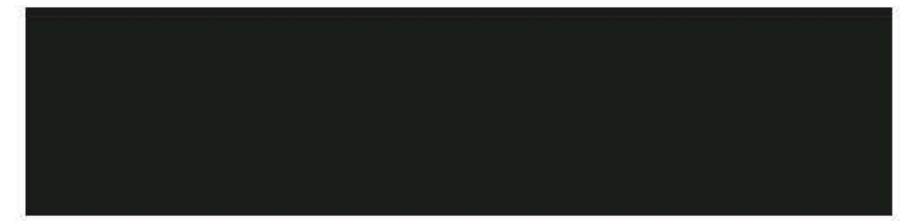

(7) Subtitle

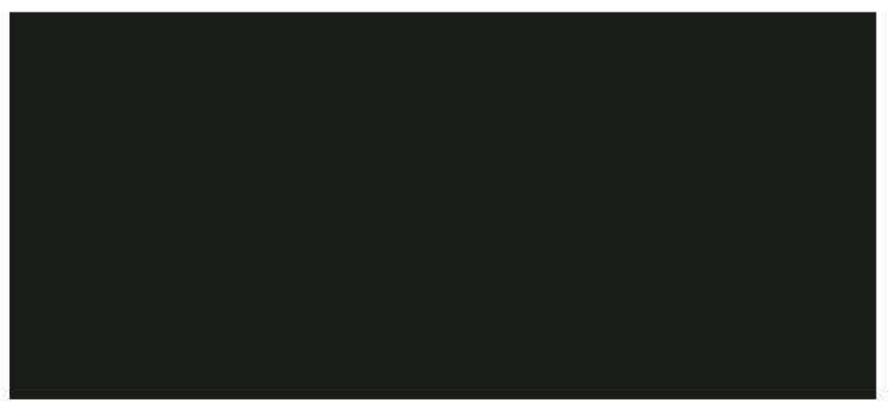

(8) SubTitLe

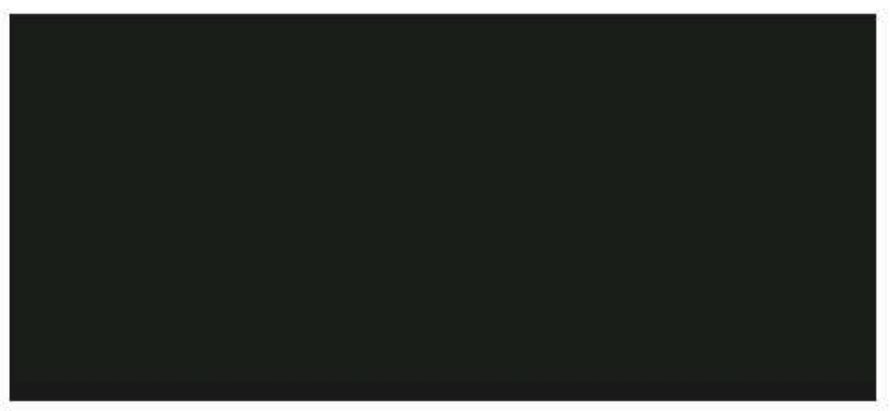




\section{TITLE INSTITUTION}

INFORMATION'S INSTITUTION

\section{SUBTITLE}

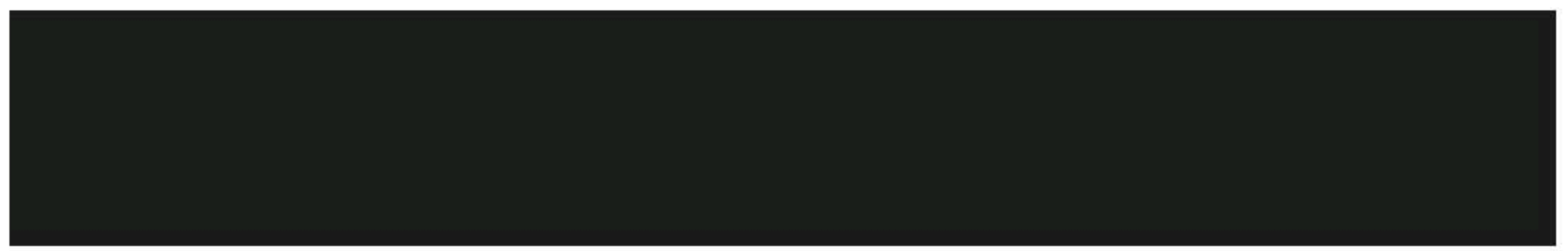

\section{SUBTITLE}

\section{SUBTITLE}

\section{SUBTITLE}

\section{SUBTITLE}

\section{SUBTITLE}

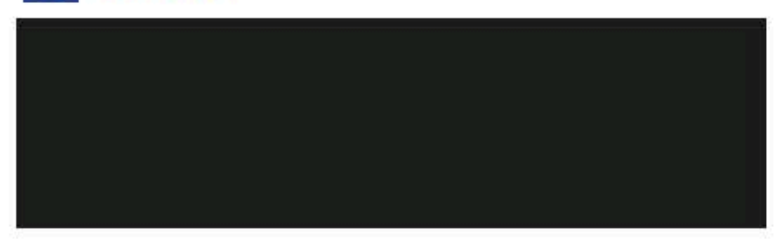

7 SUBTITLE

\section{SUBTITLE}

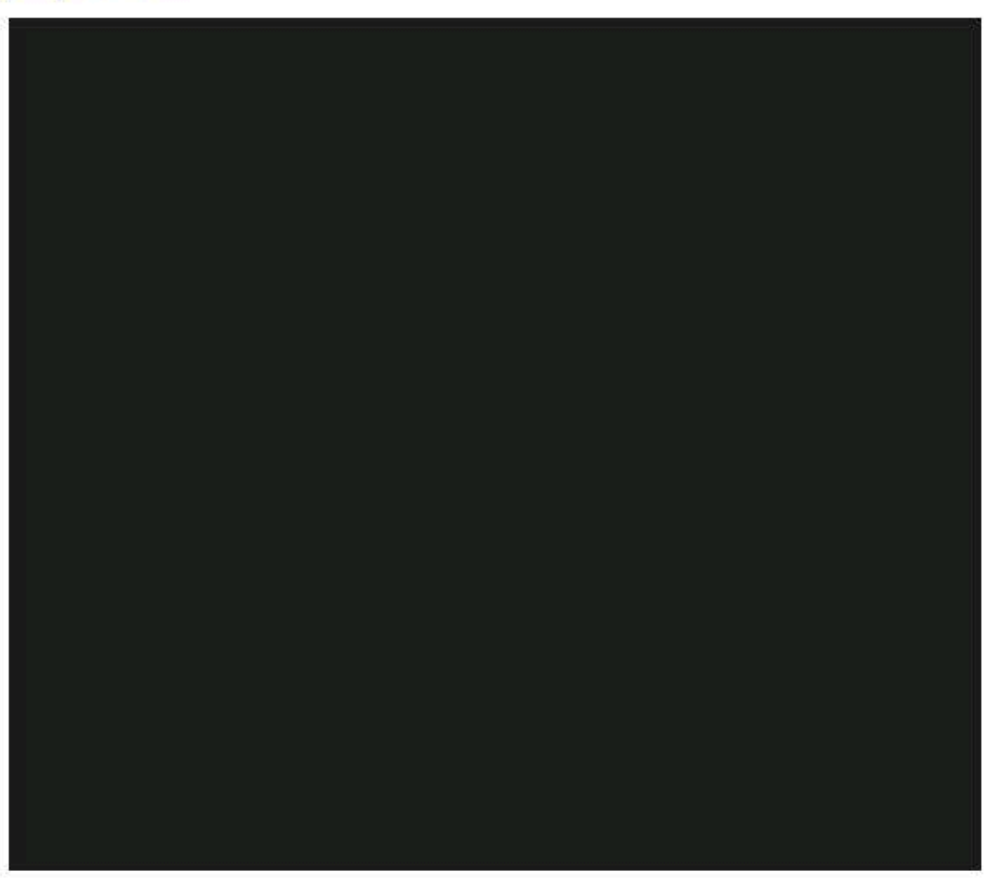




\section{INSTITUTION TITLE}

INFORMATION'S INSTITUTION

\section{SUBTITLE}

\section{SUBTITLE}

\section{SUBTITLE}

\section{SUBTITLE}

\section{SUBTITLE}

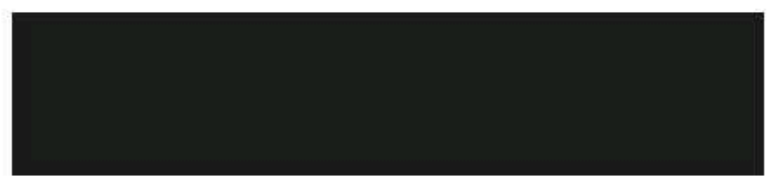

SUBTITLE
SUBTITLE

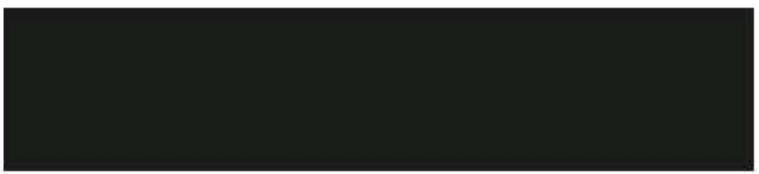

SUBTITLE
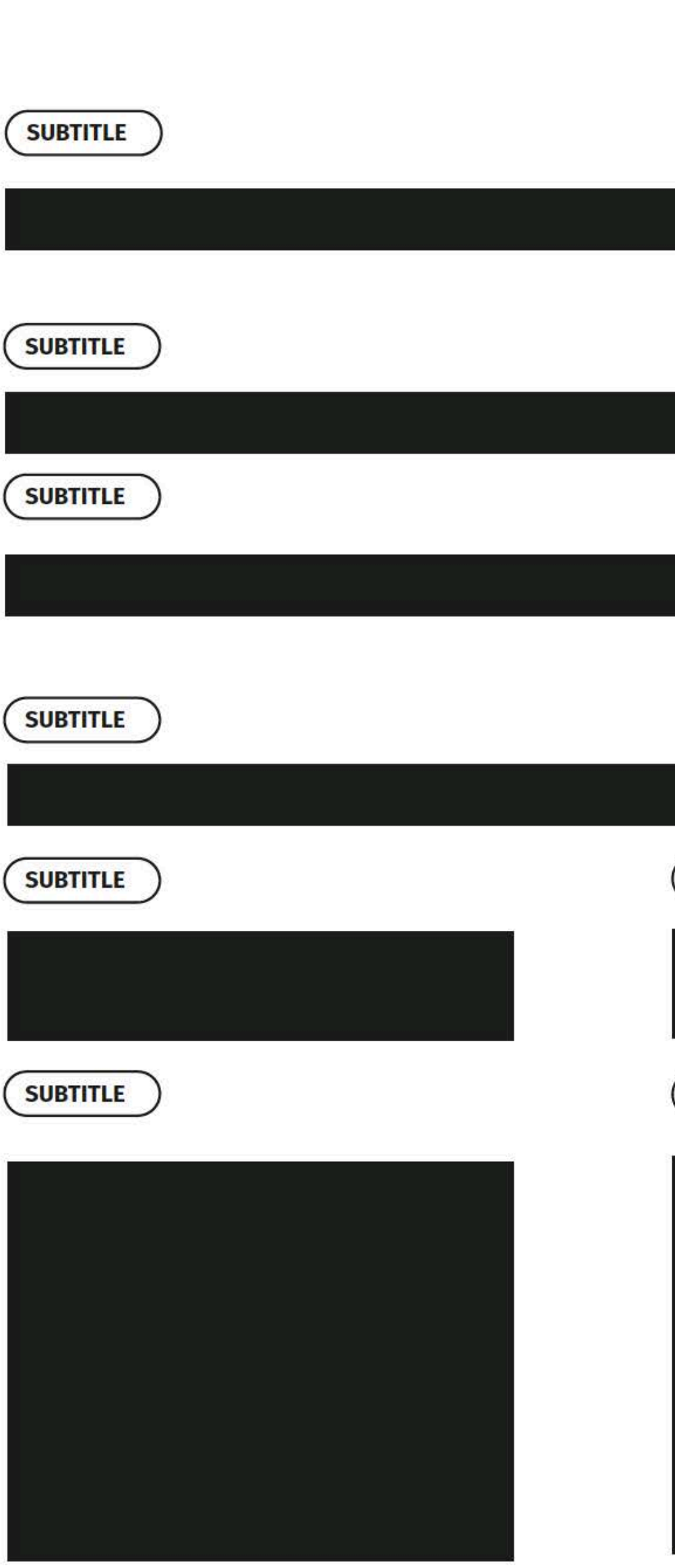


Today's Date: $\quad / l^{\text {month }}$ year

\section{PERSONAL INFORMATION}

Patient Name:

Date of Birth:

Occupation:

Primary Care Providente:

- - - - - - - - - - - - - - - - - - C-- - - - - - -

Referring Physician(if not PCP):

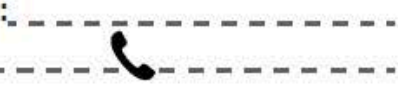

Other Care Providers:

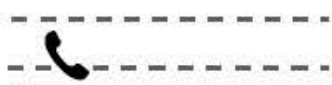

Main Concern(s)/Reason for visit today:

\section{ALLERGIES}

(Please include type of reaction to each allergy listed).

\section{REVIEW OF SYSTEM}

(Circle $\bigcirc$ current problems/symptoms you are experiencing now in past 1 month).

Weight gain

Weight loss

Fatigue

Easy bruising

Difficulty breathing

Breast Pain

Breast Discharge

Breast Enlargement

Pain in feet

Fractures

Muscle aches

Change in hand size

Excessive urination

Heat intolerance

Hot flashes

Flushing

Excessive sweating Brittle nails Rash

Change in skin color Dry skin

Stretch marks

Darkening of skin

Peripheral vision loss

Worsening vision

Blurred vision

Bulging eyes

Headache

Double vision
Hoarseness Snoring

Inability to smell

Change in dental bite

Change in head size

Neck pain (front)

Swollen glands

Neck lump

Neck swelling

Chest pain/discomfort

Leg pain with exercise

Palpitations

Abdominal pain

Constipation

Diarrhea

Diarrhea with milk

Difficulty swallowing Nausea Vomiting

Pain with swallowing Impotence

Abnormal periods

Pain with intercourse

Pain with urination

Kidney stones

Bone pain

Back pain

Joint pain

Muscle cramps
Muscle weakness Pain in hands

Change in foot size

Dizziness

Fainting

Weakness

Lightheadedness

Dizziness with standing

Change in concentration

Change in memor

Frequent falls

Emotional swings

Numbness in hands/feet

Burning in hands/feet Anxiety

Depression

Difficulty sleeping Acne

Decrease in appetite

Increase in appetite

Feeling full before done eating

Cold intolerance

Excessive thirst

Excess face/body hair Loss of hair

Decrease in height

Decrease in sex drive

Other:
$(4)$

MEDICATIONS

(Both prescription and over-the-counter including herbal,vitamins,etc)

-Please include another page if needed.

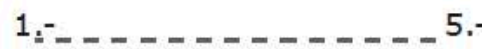

2:-

6.-

3.-

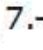

4:-

8.

5

HOSPITALIZATIONS/SURGERIES/PROCEDURES

(Please include exact date or at least year).
6

FAMILY HISTORY

(List any health problems of your mother, father, siblings, children or grandparents only). 


\section{CUESTIONARIO PSSUQ}

Edad: 20 Sexo: M /F Licenciatura: Diseño de la Información visual Manejo de llustrator:Si $/$ No

Este cuestionario es una oportunidad para registrar tus reacciones a la guía de usabilidad. Estas respuestas nos ayudarán a entender que aspectos hay que mejorar y cuales son con los que no estás satisfechos. Para tener un mejor resultado, piensa en la tarea que se te pidió que realizaras con base a lo que las guías decían mientras contestas estas preguntas.

Instrucciones: Lea cada frase y señala qué tan de acuerdo o en desacuerdo estás y encierra en un circulo un número de la escala. Al terminar, revisaremos juntos con usted el cuestionario para asegurarnos de que entendamos bien la información presentada en este cuestionario.

\section{¡Gracias!}

a) La organización de la información proporcionada por las guías me fue clara.

Totalmente en desacuerdo

Totalmente de acuerdo$$
1
$$

2

3

4

5

6

7

b) Fui capaz de completar la tarea que se me indicó rápidamente con la información proporcionada en las guías.

Totalmente en desacuerdo

Totalmente de acuerdo

12

3

4

5

6

7

c) La información proporcionada por las guías fue fácil de entender.

Totalmente de desacuerdo

1

2

3

4

5

Totalmente de acuerdo

d) La apariencia de las guías es agradable.

Totalmente en desacuerdo

Totalmente de acuerdo

$$
1
$$

2

3

4

5

6

7

e) En general estoy satisfecho con el acomodo y presentación visual de la información.

Totalmente en desacuerdo

Totalmente de acuerdo

1

2
3
4

5
6 


\begin{tabular}{|c|c|c|}
\hline 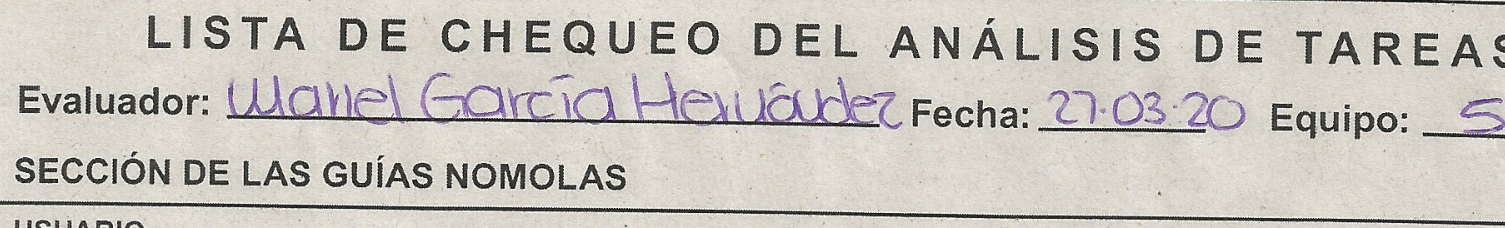 & & - \\
\hline USUARIO & $\mathrm{Si}$ & No \\
\hline El diseñador definió el nivel socioeconómico. & 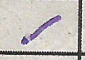 & \\
\hline El diseñador definió el nivel académico. & & $\angle$ \\
\hline El diseñador definió edad. & 8 & \\
\hline El diseñador definió sexo. & 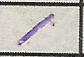 & \\
\hline El diseñador definió situación geográfica. & 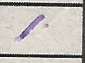 & \\
\hline El diseñador definió situación de lectura. & & 8 \\
\hline El diseñador definió creencias sobre la información. & & 8 \\
\hline El diseñador definió usos y costumbres presentadas alrededor de la información. & & 1 \\
\hline ESTRUCTURA DE LA INFORMACIÓN & $\mathrm{Si}$ & No \\
\hline El diseñador utilizó una reticula para generar la composición de su gráfica. & 1 & \\
\hline La información presentada de manera visual tiene congruencia y presenta jerarquia en relación al contenido. & 1 & \\
\hline La navegación de lectura se hace de izquierda a derecha y en forma de zig-zag. & 1 & \\
\hline TIPOGRAFÍA & $\mathrm{Si}$ & No \\
\hline El diseñador utilizó alguna de las fuentes sugeridas en las guias. & & $\gamma$ \\
\hline El diseñador utilizó un espacio interlineal de 1.5 & 1 & \\
\hline El diseñador evitó la aparición de "viudas". en la composición. & 1 & \\
\hline El diseñador evitó la aparición de "rios" en la composición. & 7 & \\
\hline El diseñador utilizó la variante negrita para hacer énfasis en palabras clave. & 1 & \\
\hline El diseñador utilizó la variante cursiva para hacer referencia a palabras en idioma extranjero. & 1 & \\
\hline El diseñador utilizó un puntaje de carácter para el cuerpo de texto de no menor a 8 puntos. & 8 & \\
\hline El diseñador utilizó para los titulos tipografias sans serif. & 1 & \\
\hline Los títulos están alienados a la izquierda o centrados: & 7 & \\
\hline Los titulos están en variante negrita y en un puntaje mayor al del cuerpo de texto. & 1 & \\
\hline $\begin{array}{l}\text { El cuerpo de texto está alienado a la izquierda. } \\
\text { El texto y el fondo de la interfaz tienen un buen contraste. }\end{array}$ & $\frac{1}{1}$ & \\
\hline $\begin{array}{l}\text { El texto y el fondo de la interfaz tienen un buen contraste. } \\
\text { El diseñador combinó tipografias serif y sans serif en la composición de la pieza de diseño. }\end{array}$ & $M$ & 7 \\
\hline El diseñador combinó tipografias serif y sans serif en la composición de la pieza de diseño. & Si & No \\
\hline El diseñador utilizó cuatro colores dentro de la composición. & 1 & \\
\hline $\begin{array}{l}\text { El diseñador utilizó cuatro colores dentro de la composición. } \\
\text { El diseñador cuidó el buen contraste entre figura, fondo y texto en la pieza de diseño. }\end{array}$ & 1 & \\
\hline El diseñador tomó en consideración el uso de contraste de color entre fondo y texto. & 1 & \\
\hline El diseñador evitó el uso de degradados. & 1 & \\
\hline El diseñador utilizó el mismo color para representar un mismo tipo de dato. & 7 & \\
\hline El diseñador creo codificaciones de información a través del color. & 7 & \\
\hline $\begin{array}{l}\text { Todos los elementos conserven un mismo estilo gráfico. } \\
\text { El diseñador implementó imágenes que tienen la misma orientación }\end{array}$ & $\frac{1}{t}$ & \\
\hline $\begin{array}{l}\text { El diseñador implementó imágenes que tienen la misma orientación } \\
\text { El diseñador evitó el uso de emojis. }\end{array}$ & 1 & \\
\hline $\begin{array}{l}\text { El diseñador evitó el uso de emojis. } \\
\text { El diseñador usó etiquetas o leyendas debajo de los elementos gráficos que necesitaban algún tipo de aclaración. }\end{array}$ & 1 & \\
\hline $\begin{array}{l}\text { El diseñador usó etiquetas o leyendas debajo de los elementos gráficos que necesitaban algún tipo de aclaración. } \\
\text { El diseñador usó bullets point, listas numéricas y flechas para enfatizar información que pertenecia a una misma } \\
\text { categoria. }\end{array}$ & I & \\
\hline El diseñador evitó el uso de elementos o información innecesarios, extraños, decorativos o irrelevantes. & 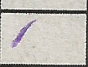 & \\
\hline
\end{tabular}


